Florida International University

FIU Digital Commons

FIU Electronic Theses and Dissertations

University Graduate School

11-13-2009

\title{
Aerodynamic Load Characteristics Evaluation and Tri-Axial Performance Testing on Fiber Reinforced Polymer Connections and Metal Fasteners to Promote Hurricane Damage Mitigation
}

Iván R. Canino-Vazquez

Florida International University, ivan.canino@hotmail.com

DOI: $10.25148 /$ etd.FI09120825

Follow this and additional works at: https://digitalcommons.fiu.edu/etd

\section{Recommended Citation}

Canino-Vazquez, Iván R., "Aerodynamic Load Characteristics Evaluation and Tri-Axial Performance Testing on Fiber Reinforced

Polymer Connections and Metal Fasteners to Promote Hurricane Damage Mitigation" (2009). FIU Electronic Theses and Dissertations. 128.

https://digitalcommons.fiu.edu/etd/128

This work is brought to you for free and open access by the University Graduate School at FIU Digital Commons. It has been accepted for inclusion in FIU Electronic Theses and Dissertations by an authorized administrator of FIU Digital Commons. For more information, please contact dcc@fiu.edu. 


\title{
FLORIDA INTERNATIONAL UNIVERSITY
}

Miami, Florida

\begin{abstract}
AERODYNAMIC LOAD CHARACTERISTICS EVALUATION AND TRI-AXIAL PERFORMANCE TESTING ON FIBER REINFORCED POLYMER CONNECTIONS AND METAL FASTENERS TO PROMOTE HURRICANE DAMAGE MITIGATION
\end{abstract}

A dissertation submitted in partial fulfillment of the

requirements for the degree of

DOCTOR OF PHILOSOPHY

in

CIVIL ENGINEERING

by

Iván R. Canino-Vazquez 
To: Dean Amir Mirmiran

College of Engineering and Computing

This dissertation, written by Iván R. Canino-Vazquez, and entitled Aerodynamic Load Characteristics Evaluation and Tri-Axial Performance Testing on Fiber Reinforced Polymer Connections and Metal Fasteners to Promote Hurricane Damage Mitigation, having been approved in respect to style and intellectual content, is referred to you for judgment.

We have read this dissertation and recommend that it be approved.

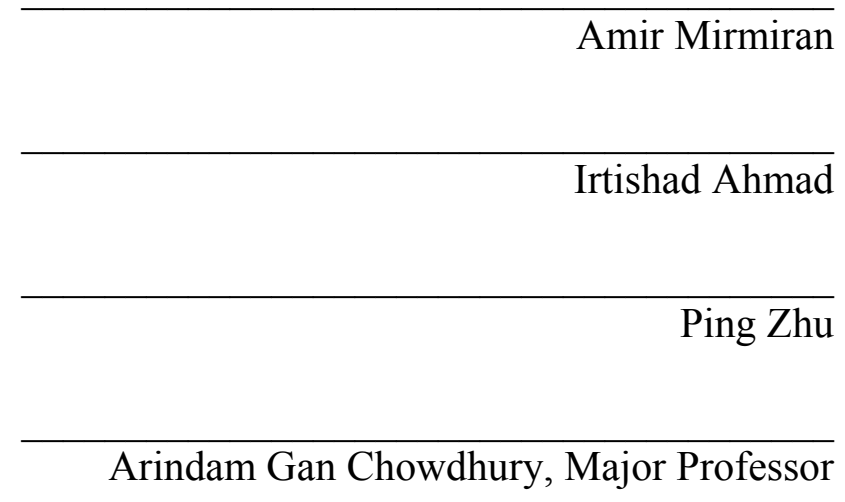

Date of Defense: November 13, 2009

The dissertation of Iván R. Canino-Vazquez is approved.

Dean Amir Mirmiran
College of Engineering and Computing

Florida International University, 2009 
(C) Copyright 2009 by Iván R. Canino-Vazquez

All rights reserved. 


\section{DEDICATION}

I dedicate this dissertation to my Wife for her support, love and understanding, to my Bella (this is for you), to my father for always believing in me and to Dr. Arindam Gan Chowdhury for his continuous tutelage and guidance.

I would also like to dedicate this research to all peoples affected by tropical cyclone damage. Hopefully, this work can help the construction industry mitigate residential damages caused by such an extreme weather phenomenon. 


\section{ACKNOWLEDGMENTS}

Firstly, I would like to express my gratitude to Dr. Arindam Gan Chowdhury for his extensive mentoring throughout my studies. Working under his supervision was truly a privilege. I would also like to thank Dr. Emil Simiu, Dr. Amir Mirmiran and Dr. Nakin Suksuwang for their input and expertise and Dr. Irtishad Ahmad and Dr. Ping Zhu for their committee responsibilities.

I would like to thank the entire Wall of Wind team, especially Jimmy Erwin, Roy Liu, Walter Conklin, Ryan Perez and Steven Hungler for their help, advice, friendship and support. Also, I would like to acknowledge Zak Lata, Sheikh Saad Ahmed, Cetin Canbek, Brandon Mintz and Edgar Polo for their help in this study. 


\begin{abstract}
OF THE DISSERTATION
AERODYNAMIC LOAD CHARACTERISTICS EVALUATION AND TRI-AXIAL PERFORMANCE TESTING ON FIBER REINFORCED POLYMER CONNECTIONS AND METAL FASTENERS TO PROMOTE HURRICANE DAMAGE MITIGATION by
\end{abstract}

Iván R. Canino-Vazquez

Florida International University, 2009

Miami, Florida

Professor Arindam Gan Chowdhury, Major Professor

Damages during extreme wind events highlight the weaknesses of mechanical fasteners at the roof-to-wall connections in residential timber frame buildings. The allowable capacity of the metal fasteners is based on results of unidirectional component testing that do not simulate realistic tri-axial aerodynamic loading effects. The first objective of this research was to simulate hurricane effects and study hurricane-structure interaction at full-scale, facilitating better understanding of the combined impacts of wind, rain, and debris on inter-component connections at spatial and temporal scales. The second objective was to evaluate the performance of a non-intrusive roof-to-wall connection system using fiber reinforced polymer (FRP) materials and compare its load capacity to the capacity of an existing metal fastener under simulated aerodynamic loads.

The Wall of Wind (WoW) testing performed using FRP connections on a onestory gable-roof timber structure instrumented with a variety of sensors, was used to create a database on aerodynamic and aero-hydrodynamic loading on roof-to-wall connections tested under several parameters: angles of attack, wind-turbulence content, 
internal pressure conditions, with and without effects of rain. Based on the aerodynamic loading results obtained from WoW tests, sets of three force components (tri-axial mean loads) were combined into a series of resultant mean forces, which were used to test the FRP and metal connections in the structures laboratory up to failure. A new component testing system and test protocol were developed for testing fasteners under simulated triaxial loading as opposed to uni-axial loading. The tri-axial and uni-axial test results were compared for hurricane clips. Also, comparison was made between tri-axial load capacity of FRP and metal connections.

The research findings demonstrate that the FRP connection is a viable option for use in timber roof-to-wall connection system. Findings also confirm that current testing methods of mechanical fasteners tend to overestimate the actual load capacities of a connector. Additionally, the research also contributes to the development a new testing protocol for fasteners using tri-axial simultaneous loads based on the aerodynamic database obtained from the WoW testing. 


\section{TABLE OF CONTENTS}

CHAPTER

PAGE

1. Introduction

1.1. Tropical Cyclone Activities

1.2. Damages in Residential Buildings 2

1.3. Research Objectives 4

1.4. Outline of Research Work 6

1.5. Layout of Report

2. Timber Connection Systems 9

2.1. Residential Construction Connection Systems 9

2.1.1. Wind-Load Induced Failures 9

2.1.2. Failures of Inter-Component Connections 12

2.1.3. Current Practice for Roof-to-Wall Connections 14

2.2. Past Research on Roof-to-Wall Connections 15

$\begin{array}{ll}\text { 2.2.1. Toe Nailed Connection Systems } & 17\end{array}$

2.2.1.1. Up-Lift Loading 18

2.2.1.2. Lateral Loading $\quad 19$

2.2.1.3. Combined Up-Lift and Lateral Loading 20

2.2.2. Mechanical Connection Systems (Hurricane Clips) 23

2.2.2.1. Up-lift Loading 23

2.2.2.2. Lateral Loading 25

2.2.2.3. Combined Up-Lift and Lateral Loading 32

3. Full-Scale Wall of Wind Testing 37

3.1. Overview of Current Testing Methods $\quad 37$

3.1.1. Wind Tunnels $\quad 37$

3.1.2. Wind Effects on Full-Scale Buildings 39

3.1.3. Full-Scale Laboratory Testing of Components and Structures $\quad 40$

3.2. The Wall of Wind Laboratory 41

3.2.1. Background 42

3.2.2. Application of WoW Testing 45

3.2.3. WoW Testing Methodology 45

3.2.4. Description of the WoW Facility 47

3.2.4.1. Simulation of Tropical Cyclone Characteristics $\quad 50$

3.2.4.2. WoW Instrumentation 56

3.2.4.3. WoW Research Goals $\quad 56$

3.3. Summary 57

4. Initial Development of Fiber Reinforced Polymer Connections 58

4.1. Introduction $\quad 58$

4.2. Rationale for a Non-Intrusive Connection System 59

4.3. Past Work on FRP-Timber Interaction 59 
4.4. FRP Tie Roof-to-Wall Connection Development Tests 62

4.4.1. Test Specimen and Setup 62

4.4.2. FRP Tie Connection Testing and Results: Uplift Loading 64

4.4.3. FRP Tie Connection Testing and Results: Lateral Loading $\quad 71$

4.5. Full-Scale Testing 73

4.5.1. Test Setup and Specimen Preparation 73

4.5.2. Test Observations and Results $\quad 80$

$\begin{array}{ll}\text { 4.6. Conclusions } & 97\end{array}$

5. Wall of Wind Testing of the FRP Roof-to-Wall Connections 99

5.1. Introduction $\quad 99$

5.2. Rationale for Testing GFRP Connection at the WoW 99

5.3. Test Specimen and Setup $\quad 100$

5.4. Test Specimen Instrumentation 105

5.4.1. Load Cell Loads Transferred to the GFRP Connection 108

5.5. WoW Testing Protocol for GFRP Roof-to-Wall Connections 110

5.5.1. Phase I Test Protocol 110

5.5.2. Phase II Test Protocol 111

5.5.3. Phase III Test Protocol 112

5.5.4. Phase IV Test Protocol 113

5.5.5. Phase V Test Protocol 114

5.6. WoW Test Results for GFRP Roof-to-Wall Connections 115

5.6.1. Load Cell Results from Phase I Testing 118

5.6.2. Load Cell Results from Phase II Testing 124

5.6.3. Load Cell Results from Phase III Testing 130

5.6.4. Load Cell Results from Phase IV Testing 136

5.6.5. Load Cell Results from Phase V Testing 142

5.6.6. Bar Graphs with Mean Results of All Conditions in Load Cell $1 \quad 148$

5.6.7. Bar Graphs with Mean Results of All Conditions in Load Cell 2

5.6.8. Bar Graphs with Mean Results of All Conditions in Load Cell $3 \quad 156$

5.6.9. Bar Graphs with Mean Results of All Conditions in Load Cell 4

5.6.10. Bar Graphs with Mean Results of All Conditions in Load Cell 5

164

5.6.11. Bar Graphs with Mean Results of All Conditions in Load Cell 6

5.6.12. Scatter Plots of Mean Fx, Fy and Fz in Load Cell 1

5.6.13. Scatter Plots of Mean Fx, Fy and Fz in Load Cell 2

5.6.14. Scatter Plots of Mean Fx, Fy and Fz in Load Cell 3

5.6.15. Scatter Plots of Mean Fx, Fy and Fz in Load Cell 4

5.6.16. Scatter Plots of Mean Fx, Fy and Fz in Load Cell 5

5.6.17. Scatter Plots of Mean Fx, Fy and Fz in Load Cell 6 
5.6.18. Strain Time Histories

5.6.19. Horizontal Displacement (Parallel to the Side Walls) Time Histories

5.6.20. Horizontal Deflection (Perpendicular to the Side Walls) Time Histories

5.6.21. Vertical Deflection Time Histories

5.6.22. Internal Pressure Time Histories

6. Tri-Axial Component Testing of the GFRP Connections to Failure 196

6.1. Introduction

6.2. Rationale for Tri-Axial Testing of GFRP Connection 197

6.3. Test Specimen, Setup and Instrumentation 198

6.4. SCL Testing Protocol of Tri-Axial Component Specimens 200

6.4.1. SCL Tri-Axial Test Cases 201

6.5. SCL Tri-Axial Tests Results 208

6.6. Tri-Axial Component Specimens Failure Modes 213

6.7. Unidirectional Tests on Metal and GFRP Connections 224

6.8. Test Observations and Discussion 229

7. Summary, Conclusions and Future Work 235

7.1. Summary of Research Activities and Findings 235

7.2. Initial GFRP Connection Development 236

7.3. Wall of Wind (WoW) Tropical Storm Simulator Experiments 237

7.4. Laboratory Tri-Axial Loading Experiments 241

7.5. Project Contributions 243

7.6. Future Work Recommendations 245

$\begin{array}{ll}\text { REFERENCES } & 247\end{array}$

$\begin{array}{ll}\text { VITA } & 254\end{array}$ 
Table 1.1: Comparison of Tropical Cyclones Losses (Dantin, 20007)

Table 3.1: Wind Characteristics of 2-fan WoW and Comparison with Real Hurricane (Gan Chowdhury et al., 2009)

Table 3.2: Wind characteristics of Full-Scale WoW (Huang et al., 2008)

Table 4.1: Schematics and Types of FRP Connections Tested in Stage II (Canbek, 2009)

Table 4.2: Summarized FRP Tests Results (Canbek, 2009)

Table 4.3: Cost Analysis for Configuration A with GFRP and CFRP (Canbek, 2009) 71

Table 4.4: Sensor List (Canbek, 2009)

Table 5.1: Uni-Axial Component Tests of 3" x 1" GFRP used in WoW Tests (Canbek, 2008)

Table 6.1: Specimen Locations for Connection \#1 202

Table 6.2: Specimen Locations for Connection \#2 203

Table 6.3: Specimen Locations for Connection \#3 204

Table 6.4: Specimen Locations for Connection \#4 205

Table 6.5: Specimen Locations for Connection \#5 206

Table 6.6: Specimen Locations for Connection \#6 207

$\begin{array}{ll}\text { Table 6.7: Tri-Axial Test Results AOA } 0^{\circ} & 208\end{array}$

Table 6.8: Tri-Axial Test Results AOA 30 209

Table 6.9: Tri-Axial Test Results AOA 45 ${ }^{\circ} \quad 210$

Table 6.10: Tri-Axial Test Results AOA 60 ${ }^{\circ} \quad 211$

Table 6.11: Tri-Axial Test Results AOA 90 ${ }^{\circ}$ 
Table 6.12: Measured Test Results and Sample Statistics of the Load capacity of Metal Clip Connectors Tested in Up-Lift

Table 6.13: Metal Clip Connection Tests Results for L1 or Parallel to the Side Walls Direction

Table 6.14: GFRP Tests Results for Up-Lift (Canbek, 2009)

Table 6.15: GFRP Connection Tested for L1 or Parallel to the Side Walls (Canbek, 2009)

Table 6.16: Component Tri-Axial Tests Configuration 233

Table 6.17: Tri-Axial Tests Example 234 


\section{LIST OF FIGURES}

FIGURE

PAGE

Figure 1.1: Formation Dynamics (Left) and Tropical Cyclones Winds (Right) 1

Figure 2.1: Wind Dynamics around a Building $\quad 10$

Figure 2.2: Conical Vortices (Texas Tech University on the Right) 11

Figure 2.3: High Negative Pressure Peaks Generate Roofs Suction or Uplift Loads

Figure 2.4: Wind Loads and Modes of Failures a-d (Simpson Strong Tie) 12

Figure 2.5: Complete Roof Failure (Coastal Contractor, 2009) 13

Figure 2.6: Notice of approval (MDC, 2004) 14

Figure 2.7: (a) Vertical and Horizontal Actuators; (b) Toe-Nail Failure (NIST, 2003) 18

Figure 2.8: Failure of Toe-Nail Connection with a Lateral Load (NIST, 2003) 20

Figure 2.9: Displacements Applied To Specimen with Toe-Nail

$\begin{array}{ll}\text { Connections (NIST, 2003) } & 21\end{array}$

Figure 2.10: Loads Applied To Specimen with Toe-Nail Connections (NIST, 2003) 21

Figure 2.11: Failure of Toe-Nailed Connection with Combined Load (NIST, 2003) 22

Figure 2.12: Typical Failure Modes of Roof-To-Wall Connections for NIST (NIST, 2003)

Figure 2.13: Comparison of Responses with Toe-Nailed Connections and Hurricane Clips (NIST, 2003) 24

Figure 2.14: Outer Truss Failure Due to Overturning Moment (NIST, 2003) 26

Figure 2.15: Comparison of Responses of the Inner Trusses (NIST, 2003) 26

Figure 2.16: Comparison of Responses of the Outer Trusses (NIST, 2003) 27

Figure 2.17: Roof-To-Wall Connection Test Set-Up (NAHB, 2002) 28 
Figure 2.18: Vertical Tension Applied Using a Strap, Hydraulic Actuator and Clevis (NAHB, 2002)

Figure 2.19: Truss Plate Separation (NAHB, 2002) 29

Figure 2.20: Truss Slip and Rotation (NAHB, 2002) 30

Figure 2.21: Hurricane Clip Buckling (NAHB, 2002) 30

Figure 2.22: Hurricane Clip Tension Failure (NAHB, 2002) 31

Figure 2.23: Hurricane Clip Tension Failure (NAHB, 2002) 31

Figure 2.24: Displacements Applied to the Specimen with Hurricane Clips (NIST, 2003) 34

Figure 2.25: Loads Applied to the Specimen with Hurricane Clips (NIST, 2003) 34

Figure 2.26: Failure of Hurricane Clip Connection with Combined Load (NIST, 2003) 35

Figure 2.27: Comparison of Responses of Inner Trusses (NIST, 2003) 36

Figure 2.28: Comparison of Responses of Outer Trusses (NIST, 2003) 36

Figure 3.1: Wind Tunnel Tests on Scaled Models 38

Figure 3.2: Wind Effects on Full-Scale Buildings, a) Field Studies of Wind Loads on Buildings (Texas Tech U.), b) Full-Scale Building Testing using Pressure Bags (U. of Western Ontario)

Figure 3.3: Full-Scale Testing of Individual Structural Components in Laboratories

Figure 3.4: FIU-IHRC Full-Scale Testing Simulator 42

Figure 3.5: Debris Simulation Testing with Air-Cannon 44

$\begin{array}{ll}\text { Figure 3.6: Vortex-Suppression Systems } & 47\end{array}$

$\begin{array}{ll}\text { Figure 3.7: Water-Tight Soffits } & 47\end{array}$

Figure 3.8: 2-Fan WoW 48

Figure 3.9: Metal Roof Edge Fascia Testing 49 
Figure 3.10: Performance Testing of FPL Structures, (A) Three Transformers and PVC/PE U-Guard, (B) Single Transformer and Capacitor Bank, (C) Cutoff Cobra Head and Open Bottom Luminaries

Figure 3.11: Wind-Structure Interaction for Building Structures

Figure 3.12: Horizontal Airfoils for Vertical Fluctuations in the Flow

Figure 3.13: Small-Scale Model Configuration (Liu, 2008)

Figure 3.14: Water monitoring and collection setup. (a) Complete setup with camera and plastic ceiling, (b) the SWB test specimen from bird's view and (c) leaked water through the roof layer and (d) water collection - (Bitsuamlak, 2009)

Figure 4.1: The contoured double-cantilevered beam specimen (Davalos et al., 2000)

Figure 4.2: Views of Test Specimen (Canbek, 2009)

Figure 4.3: A Typical Specimen before Testing (Canbek, 2009)

Figure 4.4: Schematics and Application of FRP Tie Configuration I (Canbek, 2009)

Figure 4.5: Configuration A with CFRP (Left) and GFRP (Right)

Before Testing (Canbek, 2009)

Figure 4.6: Failure of Configurations A with CFRP (Left) and GFRP (Right)

(Canbek, 2009)

Figure 4.7: Configuration B with CFRP (Left) and GFRP (Right) Before Testing (Canbek, 2009)

Figure 4.8: Two Modes of Failure Observed in Configuration B (Canbek, 2009)

Figure 4.9: Configuration C with CFRP (Left) and GFRP (Right) Before Testing (Canbek, 2009)

Figure 4.10: Failure of Configurations $\mathrm{C}$ with CFRP (Left) and GFRP (Right) (Canbek, 2009)

Figure 4.11: Results of FRP Tie Connection Development Stage II (Canbek, 2009) 70

Figure 4.12: Views of Specimen Tested For Lateral Loading (Canbek, 2009) 
Figure 4.13: Specimen Used For Lateral Loading Tests (Canbek, 2009) 72

Figure 4.14: Application of Load in Lateral Loading Test (Canbek, 2009) 72

Figure 4.15: Typical Mode of Failure under Lateral Loading (Canbek, 2009) 72

Figure 4.16: The Full-Scale Test Specimen without Sheathing (Canbek, 2009) 73

Figure 4.17: Front View of Test Specimen (Canbek, 2009) 74

Figure 4.18: Side View of Test Specimen (Canbek, 2009) 74

Figure 4.19: (1) Strap Holding the Stud and the Lower Top Plate Together; and

(2) U- Shaped Metal Plates Holding the Upper and Lower Top

Plates Together (Canbek, 2009)

Figure 4.20: Full-Scale Test Specimen and the Loading Frame without Sheathing and Instrumentation (Canbek, 2009)

Figure 4.21: Placement of Load Cell between the Loading Frame and Steel Plate (Canbek, 2009)

Figure 4.22: Jack with the Load Distribution Channel Mounted On Top (Canbek, 2009)

Figure 4.23: Schematic Representation of Sensor Locations (Canbek, 2009)

Figure 4.24: Schematics of Full-Scale Test Specimen with Sensors in Place (Canbek, 2009)

Figure 4.25: Load Applied From Each Jack (Canbek, 2009)

Figure 4.26: Load Applied To Each Quadrant of the Roof (Canbek, 2009)

Figure 4.27: Total Load Applied on the Specimen (Canbek, 2009)

Figure 4.28: The Loads Applied At Each Cylinder at Initial Failure Load (Canbek, 2009)

Figure 4.29: The Numbering of FRP Tie Connections (Canbek, 2009)

Figure 4.30: Initiation of Failure in FRP Tie Connections 13 and 14 at 20,716 lbs (Canbek, 2009) 
Figure 4.31: Complete Failure of FRP Tie Connections 13 and 14 at 23,659 lbs (Canbek, 2009)

Figure 4.32: Failure of FRP Tie Connections 11 and 12 (Canbek, 2009) 84

Figure 4.33: Failure of FRP Tie Connections 19 and 20 (Canbek, 2009) 84

Figure 4.34: Failure of FRP Tie Connections 7 and 8 and Separation of Timber Fibers (Canbek, 2009)

Figure 4.35: The Loads at Pairs of FRP Tie Connections at Initiation of Failure (Canbek, 2009)

Figure 4.36: Load-Displacement for FRP Tie Connections 1 and 2 (Canbek, 2009) 86

Figure 4.37: Load-Displacement for FRP Tie Connections 3 and 4 (Canbek, 2009) 87

Figure 4.38: Load-Displacement for FRP Tie Connections 5 and 6 (Canbek, 2009) 87

Figure 4.39: Load-Displacement for FRP Tie Connections 7 and 8 (Canbek, 2009) 88

Figure 4.40: Load-Displacement for FRP Tie Connections 9 and 10 (Canbek, 2009) 88

Figure 4.41: Load-Displacement for FRP Tie Connections 11 and 12 (Canbek, 2009) 89

Figure 4.42: Load-Displacement for FRP Tie Connections 13 and 14 (Canbek, 2009) 89

Figure 4.43: Load-Displacement for FRP Tie Connections 15 and 16 (Canbek, 2009) 90

Figure 4.44: Load-Displacement for FRP Tie Connections 17 and 18 (Canbek, 2009) 90

Figure 4.45: Load-Displacement for FRP Tie Connections 19 and 20 (Canbek, 2009) 91

Figure 4.46: Total Load-Displacements on the North Side of the Truss vs.

Total Load (Canbek, 2009)

Figure 4.47: Total Load-Displacements on the South Side of the Truss vs.

Total Load (Canbek, 2009)

Figure 4.48: Total Load-Displacements at the Center of the Bottom Chord of the Truss (Canbek, 2009)

Figure 4.49: Stress-Strain for FRP Tie Connections 1 and 2 (Canbek, 2009)

Figure 4.50: Stress-Strain for FRP Tie Connections 9 and 10 (Canbek, 2009) 
Figure 4.51: Stress-Strain for FRP Tie Connections 11 and 12 (Canbek, 2009)

Figure 4.52: Stress-Strain for FRP Tie Connections 19 and 20 (Canbek, 2009)

Figure 4.53: Strain Values of FRP Tie Connections Located at the Corners of the Truss (Canbek, 2009)

Figure 4.54: Total Load-Strain for FRP Tie Connections Located at the Corners (Canbek, 2009)

Figure 5.1: Wall of Wind Test Specimen

Figure 5.2: Floor Membrane

Figure 5.3: Wall with Door \& Window

Figure 5.4: Metal Clips at the Stud to Top \& Bottom Plate

Figure 5.5: Roof Trusses

Figure 5.6: Mitered Top-Plate \& GFRP Connection

Figure 5.7: Typical 3 x 1 inch GFRP

Figure 5.8: Roof \& Bottom structure Aluminum Plate Connection

Figure 5.9: Vented Soffit

Figure 5.10: Roof Flashing

Figure 5.11: WoW Test Specimen Instrumentation; and Connection Numbers

Figure 5.12: Typical Connection Instruments

Figure 5.13: Load Cell \& LVDT

Figure 5.14: String Potentiometers

Figure 5.15: Strain Gauges

Figure 5.16: Compact Rios

Figure 5.17: Load Cell and Truss Connection Points Eccentricities

Figure 5.18: Wind AOA of 0 Degrees 
Figure 5.19: Wind AOA of 90 Degrees

Figure 5.20: Wind AOA of 45 Degrees

Figure 5.21: Wind AOA of 30 Degrees

Figure 5.22: Wind AOA of 60 Degrees

Figure 5.23: Enclosed 0

Figure 5.24: Partially Enclosed One Window Removed $90^{\circ}$

Figure 5.25: Enclosed \& Wind Driven Rain $0^{\circ}$

Figure 5.26: Partially Enclosed Two Windows Removed $45^{\circ}$

Figure 5.27: Partially Enclosed One Window \& Door Removed $0^{\circ}$

Figure 6.1: GFRP Specimen

Figure 6.2: Metal Fastener Specimen

Figure 6.3: Load Cell Figure

Figure 6.4a: SCL Test System

Figure 6.4b: Tri-Axial System, X, Y \& Z Directional Illustration

Figure 6.5: GRFP Connector Case 1

Figure 6.6: Metal Connector Case 1

Figure 6.7: GRFP Connector Case 2

Figure 6.8: Metal Connector Case 2

Figure 6.9: GRFP Connector Case 3

Figure 6.10: Metal Connector Case 3

Figure 6.11: GRFP Connector Case 4

Figure 6.12: Metal Connector Case 4 
Figure 6.13: GRFP Connector Case 5

Figure 6.14: Metal Connector Case 5

Figure 6.15: GRFP Connector Case 6

Figure 6.16: Metal Connector Case 6

Figure 6.17: GRFP Connector Case 7

Figure 6.18: Metal Connector Case 7

Figure 6.19: GRFP Connector Case 8

Figure 6.20: Metal Connector Case 8

Figure 6.21: GFRP Connector Case 9

Figure 6.22: Metal Connector Case 9

Figure 6.23: GRFP Connector Case 10

Figure 6.24: Metal Connector Case 10

Figure 6.25: GRFP Connector Case 11

Figure 6.26: Metal Connector Case 11

Figure 6.27: GRFP Connector Case 12

Figure 6.28: Metal Connector Case 12

Figure 6.29: GRFP Connector Case 13

Figure 6.30: Metal Connector Case 13

Figure 6.31: GRFP Connector Case 14

Figure 6.32: Metal Connector Case 14

Figure 6.33: GRFP Connector Case 15

Figure 6.34: Metal Connector Case 15

Figure 6.35: GRFP Connector Case 16 
Figure 6.36: Metal Connector Case 16

Figure 6.37: GRFP Connector Case 17

Figure 6.38: Metal Connector Case 17

Figure 6.39: GRFP Connector Case 18

Figure 6.40: Metal Connector Case 18

Figure 6.41: GFRP Connector Case 19

Figure 6.42: Metal Connector Case 19

Figure 6.43: GRFP Connector Case 20

Figure 6.44: Metal Connector Case 20

Figure 6.45: GFRP Connector Case 21

Figure 6.46: GRFP Connector Case 21

Figure 6.47: Metal Connector Case 22

Figure 6.48: Metal Connector Case 22

Figure 6.49: GFRP Connector Case 23

Figure 6.50: GRFP Connector Case 23

Figure 6.51: Metal Clip Connection Tested in Up-Lift

Figure 6.52: Metal Clip Connection Tests Set-Up in the L1or Parallel to the Side Walls Direction

Figure 6.53: GFRP Connection Tested for Up-Lift (Canbek, 2009)

Figure 6.54: GFRP Connection Tested for L1 or Parallel to the Side Walls (Canbek, 2009) 


\section{LIST OF GRAPHS}

GRAPH

PAGE

Graph 5.1: Load Cell 1 Fx $0^{\circ}$

118

Graph 5.2: Load Cell 1 Fy $0^{\circ}$

118

Graph 5.3: Load Cell 1 Fz $0^{\circ}$

118

Graph 5.4: Load Cell $1 \mathrm{Mx} 0^{\circ}$

118

Graph 5.5: Load Cell 1 My $0^{\circ}$

118

Graph 5.6: Load Cell $1 \mathrm{Mz} 0^{\circ}$

118

Graph 5.7: Load Cell 2 Fx $0^{\circ}$

119

Graph 5.8: Load Cell 2 Fy $0^{\circ}$

119

Graph 5.9: Load Cell 2 Fz $0^{\circ}$

119

Graph 5.10: Load Cell 2 Mx $0^{\circ}$

119

Graph 5.11: Load Cell 2 My $0^{\circ}$

119

Graph 5.12: Load Cell $2 \mathrm{Mz} 0^{\circ}$

119

Graph 5.13: Load Cell 3 Fx $0^{\circ}$

120

Graph 5.14: Load Cell 3 Fy $0^{\circ}$

120

Graph 5.15: Load Cell 3 Fz $0^{\circ}$

120

Graph 5.16: Load Cell 3 Mx $0^{\circ}$

120

Graph 5.17: Load Cell 3 My $0^{\circ}$

120

Graph 5.18: Load Cell $3 \mathrm{Mz} 0^{\circ}$

120

Graph 5.19: Load Cell 4 Fx $0^{\circ}$

121

Graph 5.20: Load Cell 4 Fy $0^{\circ}$

121

Graph 5.21: Load Cell 4 Fz $0^{\circ}$

121 
Graph 5.22: Load Cell $4 \mathrm{Mx} 0^{\circ}$

Graph 5.23: Load Cell 4 My $0^{\circ}$

121

Graph 5.24: Load Cell 4 Mz $0^{\circ}$

121

Graph 5.25: Load Cell 5 Fx $0^{\circ}$

122

Graph 5.26: Load Cell 5 Fy $0^{\circ}$

122

Graph 5.27: Load Cell 5 Fz $0^{\circ}$

122

Graph 5.28: Load Cell $5 \mathrm{Mx} 0^{\circ}$

122

Graph 5.29: Load Cell 5 My $0^{\circ}$

122

Graph 5.30: Load Cell $5 \mathrm{Mz} 0^{\circ}$

122

Graph 5.31: Load Cell 6 Fx $0^{\circ}$

123

Graph 5.32: Load Cell 6 Fy $0^{\circ}$

123

Graph 5.33: Load Cell 6 Fz $0^{\circ}$

123

Graph 5.34: Load Cell $6 \mathrm{Mx} 0^{\circ}$

123

Graph 5.35: Load Cell 6 My $0^{\circ}$

123

Graph 5.36: Load Cell $6 \mathrm{Mz} 0^{\circ}$

123

Graph 5.37: Load Cell 1 Fx 90

124

Graph 5.38: Load Cell 1 Fy 90

124

Graph 5.39: Load Cell 1 Fz 90

124

Graph 5.40: Load Cell $1 \mathrm{Mx} 90^{\circ}$

124

Graph 5.41: Load Cell 1 My 90

124

Graph 5.42: Load Cell $1 \mathrm{Mz} 90^{\circ}$

124

Graph 5.43: Load Cell 2 Fx 90

125

Graph 5.44: Load Cell 2 Fy 90 
Graph 5.68: Load Cell 6 Fy 90 
Graph 5.91: Load Cell 4 Fx $45^{\circ}$ 
Graph 5.114: Load Cell $1 \mathrm{Mz} 30^{\circ}$

Graph 5.115: Load Cell 2 Fx 30

137

Graph 5.116: Load Cell 2 Fy 30

137

Graph 5.117: Load Cell 2 Fz 30

137

Graph 5.118: Load Cell $2 \mathrm{Mx} 30^{\circ}$

137

Graph 5.119: Load Cell 2 My 30

137

Graph 5.120: Load Cell $2 \mathrm{Mz} 30^{\circ}$

137

Graph 5.121: Load Cell 3 Fx 30

138

Graph 5.122: Load Cell 3 Fy 30

138

Graph 5.123: Load Cell 3 Fz 30

138

Graph 5.124: Load Cell 3 Mx 30

138

Graph 5.125: Load Cell 3 My 30

138

Graph 5.126: Load Cell 3 Mz 30

138

Graph 5.127: Load Cell 4 Fx 30

139

Graph 5.128: Load Cell 4 Fy 30

139

Graph 5.129: Load Cell 4 Fz 30

139

Graph 5.130: Load Cell $4 \mathrm{Mx} 30^{\circ}$

139

Graph 5.131: Load Cell 4 My 30

139

Graph 5.132: Load Cell $4 \mathrm{Mz} 30^{\circ}$

139

Graph 5.133: Load Cell 5 Fx 30

140

Graph 5.134: Load Cell 5 Fy 30

140

Graph 5.135: Load Cell 5 Fz 30

140

Graph 5.136: Load Cell $5 \mathrm{Mx} \mathrm{30^{ \circ }}$

140 
Graph 5.137: Load Cell 5 My 30

Graph 5.138: Load Cell $5 \mathrm{Mz} 30^{\circ}$

140

Graph 5.139: Load Cell 6 Fx 30

141

Graph 5.140: Load Cell 6 Fy 30

141

Graph 5.141: Load Cell 6 Fz 30

141

Graph 5.142: Load Cell $6 \mathrm{Mx} 30^{\circ}$

141

Graph 5.143: Load Cell 6 My 30

141

Graph 5.144: Load Cell $6 \mathrm{Mz} 30^{\circ}$

141

Graph 5.145: Load Cell 1 Fx 60

142

Graph 5.146: Load Cell 1 Fy 60

142

Graph 5.147: Load Cell 1 Fz 60

142

Graph 5.148: Load Cell $1 \mathrm{Mx} 60^{\circ}$

142

Graph 5.149: Load Cell 1 My 60

142

Graph 5.150: Load Cell $1 \mathrm{Mz} 60^{\circ}$

142

Graph 5.151: Load Cell 2 Fx 60

143

Graph 5.152: Load Cell 2 Fy 60

143

Graph 5.153: Load Cell 2 Fz 60

143

Graph 5.154: Load Cell $2 \mathrm{Mx} 60^{\circ}$

143

Graph 5.155: Load Cell 2 My 60

143

Graph 5.156: Load Cell $2 \mathrm{Mz} 60^{\circ}$

143

Graph 5.157: Load Cell 3 Fx 60

144

Graph 5.158: Load Cell 3 Fy 60

144

Graph 5.159: Load Cell 3 Fz 60

144

xxviii 
Graph 5.160: Load Cell 3 Mx 60

Graph 5.161: Load Cell 3 My 60

144

Graph 5.162: Load Cell $3 \mathrm{Mz} 60^{\circ}$

144

Graph 5.163: Load Cell 4 Fx $60^{\circ}$

145

Graph 5.164: Load Cell 4 Fy $60^{\circ}$

145

Graph 5.165: Load Cell $4 \mathrm{Fz} 60^{\circ}$

145

Graph 5.166: Load Cell 4 Mx 60

145

Graph 5.167: Load Cell 4 My 60 145

Graph 5.168: Load Cell $4 \mathrm{Mz} 60^{\circ}$

145

Graph 5.169: Load Cell 5 Fx $60^{\circ}$

146

Graph 5.170: Load Cell 5 Fy $60^{\circ}$

146

Graph 5.171: Load Cell $5 \mathrm{Fz} 60^{\circ}$

146

Graph 5.172: Load Cell 5 Mx $60^{\circ}$

146

Graph 5.173: Load Cell 5 My $60^{\circ}$

146

Graph 5.174: Load Cell 5 Mz 60 146

Graph 5.175: Load Cell 6 Fx $60^{\circ}$ 147

Graph 5.176: Load Cell 6 Fy $60^{\circ}$ 147

Graph 5.177: Load Cell 6 Fz $60^{\circ}$ 147

Graph 5.178: Load Cell 6 Mx $60^{\circ}$ 147

Graph 5.179: Load Cell 6 My 60 147

Graph 5.180: Load Cell $6 \mathrm{Mz} 60^{\circ}$

147

Graph 5.181: Load Cell 1 All Angles and Conditions Fx_FT 148

Graph 5.182: Load Cell 1 All Angles and Conditions Fy_FT 148 
Graph 5.183: Load Cell 1 All Angles and Conditions Fz_FT

Graph 5.184: Load Cell 1 All Angles and Conditions Fx_QP

149

Graph 5.185: Load Cell 1 All Angles and Conditions Fy_QP

Graph 5.186: Load Cell 1 All Angles and Conditions Fz_QP

149

Graph 5.187: Load Cell 1 All Angles and Conditions Mx_FT

Graph 5.188: Load Cell 1 All Angles and Conditions My_FT

150

Graph 5.189: Load Cell 1 All Angles and Conditions Mz_FT

150

Graph 5.190: Load Cell 1 All Angles and Conditions Mx_QP

Graph 5.191: Load Cell 1 All Angles and Conditions My_QP

151

Graph 5.192: Load Cell 1 All Angles and Conditions Mz_QP

Graph 5.193: Load Cell 2 All Angles and Conditions Fx_FT

152

Graph 5.194: Load Cell 2 All Angles and Conditions Fy_FT

152

Graph 5.195: Load Cell 2 All Angles and Conditions Fz_FT

152

Graph 5.196: Load Cell 2 All Angles and Conditions Fx_QP

153

Graph 5.197: Load Cell 2 All Angles and Conditions Fy_QP

153

Graph 5.198: Load Cell 2 All Angles and Conditions Fz_QP

153

Graph 5.199: Load Cell 2 All Angles and Conditions Mx_FT

154

Graph 5.200: Load Cell 2 All Angles and Conditions My_FT

154

Graph 5.201: Load Cell 2 All Angles and Conditions Mz_FT

154

Graph 5.202: Load Cell 2 All Angles and Conditions Mx_QP 155

Graph 5.203: Load Cell 2 All Angles and Conditions My_QP

155

Graph 5.204: Load Cell 2 All Angles and Conditions Mz_QP 155

Graph 5.205: Load Cell 3 All Angles and Conditions Fx_FT 
Graph 5.206: Load Cell 3 All Angles and Conditions Fy_FT

Graph 5.207: Load Cell 3 All Angles and Conditions Fz_FT 156

Graph 5.208: Load Cell 3 All Angles and Conditions Fx_QP 157

Graph 5.209: Load Cell 3 All Angles and Conditions Fy_QP 157

Graph 5.210: Load Cell 3 All Angles and Conditions Fz_QP 157

Graph 5.211: Load Cell 3 All Angles and Conditions Mx_FT 158

Graph 5.212: Load Cell 3 All Angles and Conditions My_FT 158

Graph 5.213: Load Cell 3 All Angles and Conditions Mz_FT 158

Graph 5.214: Load Cell 3 All Angles and Conditions Mx_QP 159

Graph 5.215: Load Cell 3 All Angles and Conditions My_QP 159

Graph 5.216: Load Cell 3 All Angles and Conditions Mz_QP 159

Graph 5.217: Load Cell 4 All Angles and Conditions Fx_FT 160

Graph 5.218: Load Cell 4 All Angles and Conditions Fy_FT 160

Graph 5.219: Load Cell 4 All Angles and Conditions Fz_FT 160

Graph 5.220: Load Cell 4 All Angles and Conditions Fx_QP 161

Graph 5.221: Load Cell 4 All Angles and Conditions Fy_QP 161

Graph 5.222: Load Cell 4 All Angles and Conditions Fz_QP 161

Graph 5.223: Load Cell 4 All Angles and Conditions Mx_FT 162

Graph 5.224: Load Cell 4 All Angles and Conditions My_FT 162

Graph 5.225: Load Cell 4 All Angles and Conditions Mz_FT 162

Graph 5.226: Load Cell 4 All Angles and Conditions Mx_QP 163

Graph 5.227: Load Cell 4 All Angles and Conditions My_QP 163

Graph 5.228: Load Cell 4 All Angles and Conditions Mz_QP 163 
Graph 5.229: Load Cell 5 All Angles and Conditions Fx_FT

Graph 5.230: Load Cell 5 All Angles and Conditions Fy_FT

164

Graph 5.231: Load Cell 5 All Angles and Conditions Fz_FT

164

Graph 5.232: Load Cell 5 All Angles and Conditions Fx_QP

165

Graph 5.233: Load Cell 5 All Angles and Conditions Fy_QP

165

Graph 5.234: Load Cell 5 All Angles and Conditions Fz_QP

165

Graph 5.235: Load Cell 5 All Angles and Conditions Mx_FT

166

Graph 5.236: Load Cell 5 All Angles and Conditions My_FT

166

Graph 5.237: Load Cell 5 All Angles and Conditions Mz_FT

166

Graph 5.238: Load Cell 5 All Angles and Conditions Mx_QP

Graph 5.239: Load Cell 5 All Angles and Conditions My_QP

167

Graph 5.240: Load Cell 5 All Angles and Conditions Mz_QP 167

Graph 5.241: Load Cell 6 All Angles and Conditions Fx_FT

168

Graph 5.242: Load Cell 6 All Angles and Conditions Fy_FT

168

Graph 5.243: Load Cell 6 All Angles and Conditions Fz_FT

168

Graph 5.232: Load Cell 6 All Angles and Conditions Fx_QP

169

Graph 5.233: Load Cell 6 All Angles and Conditions Fy_QP

Graph 5.234: Load Cell 6 All Angles and Conditions Fz_QP

169

Graph 5.235: Load Cell 6 All Angles and Conditions Mx_FT

170

Graph 5.236: Load Cell 6 All Angles and Conditions My_FT

170

Graph 5.237: Load Cell 6 All Angles and Conditions Mz_FT

170

Graph 5.238: Load Cell 6 All Angles and Conditions Mx_QP

171

Graph 5.239: Load Cell 6 All Angles and Conditions My_QP 
Graph 5.240: Load Cell 6 All Angles and Conditions Mz_QP

Graph 5.241: Mean Forces, Enclosed at Full Throttle

172

Graph 5.242: Mean Forces, Partially Enclosed at Full Throttle

172

Graph 5.243: Mean Forces, Partially Enclosed' at Full Throttle

172

Graph 5.244: Mean Forces, Enclosed with Water at Full Throttle

172

Graph 5.245: Mean Forces, Enclosed at Quasi-Periodical

173

Graph 5.246: Mean Forces, Partially Enclosed at Quasi-Periodical

173

Graph 5.247: Mean Forces, Partially Enclosed' at Quasi-Periodical

173

Graph 5.248: Mean Forces, Enclosed with Water at Quasi-Periodical

173

Graph 5.249: Mean Forces, Enclosed at Full Throttle

174

Graph 5.250: Mean Forces, Partially Enclosed at Full Throttle

174

Graph 5.251: Mean Forces, Partially Enclosed' at Full Throttle

174

Graph 5.252: Mean Forces, Enclosed with Water at Full Throttle

174

Graph 5.253: Mean Forces, Enclosed at Quasi-Periodical

175

Graph 5.254: Mean Forces, Partially Enclosed at Quasi-Periodical

175

Graph 5.255: Mean Forces, Partially Enclosed' at Quasi-Periodical

175

Graph 5.256: Mean Forces, Enclosed with Water at Quasi-Periodical

175

Graph 5.257: Mean Forces, Enclosed at Full Throttle

176

Graph 5.258: Mean Forces, Partially Enclosed at Full Throttle

176

Graph 5.259: Mean Forces, Partially Enclosed' at Full Throttle

176

Graph 5.260: Mean Forces, Enclosed with Water at Full Throttle

176

Graph 5.261: Mean Forces, Enclosed at Quasi-Periodical

Graph 5.262: Mean Forces, Partially Enclosed at Quasi-Periodical

177 
Graph 5.263: Mean Forces, Partially Enclosed' at Quasi-Periodical

Graph 5.264: Mean Forces, Enclosed with Water at Quasi-Periodical

Graph 5.265: Mean Forces, Enclosed at Full Throttle

Graph 5.266: Mean Forces, Partially Enclosed at Full Throttle

Graph 5.267: Mean Forces, Partially Enclosed' at Full Throttle

Graph 5.268: Mean Forces, Enclosed with Water at Full Throttle

Graph 5.269: Mean Forces, Enclosed at Quasi-Periodical

Graph 5.270: Mean Forces, Partially Enclosed at Quasi-Periodical

Graph 5.271: Mean Forces, Partially Enclosed' at Quasi-Periodical

Graph 5.272: Mean Forces, Enclosed with Water at Quasi-Periodical

Graph 5.273: Mean Forces, Enclosed at Full Throttle

Graph 5.274: Mean Forces, Partially Enclosed at Full Throttle

Graph 5.275: Mean Forces, Partially Enclosed' at Full Throttle

Graph 5.276: Mean Forces, Enclosed with Water at Full Throttle

Graph 5.277: Mean Forces, Enclosed at Quasi-Periodical

Graph 5.278: Mean Forces, Partially Enclosed at Quasi-Periodical

Graph 5.279: Mean Forces, Partially Enclosed' at Quasi-Periodical

Graph 5.280: Mean Forces, Enclosed with Water at Quasi-Periodical

Graph 5.281: Mean Forces, Enclosed at Full Throttle

Graph 5.282: Mean Forces, Partially Enclosed at Full Throttle

Graph 5.283: Mean Forces, Partially Enclosed' at Full Throttle

Graph 5.284: Mean Forces, Enclosed with Water at Full Throttle 
Graph 5.286: Mean Forces, Partially Enclosed at Quasi-Periodical 
Graph 5.309: Uplift Load Time Histories for Connection \#5

Graph 5.310: Mean Up-Lift Loads of for Connection \#5

188

Graph 5.311: Internal Pressure: Transducer \#3

189

Graph 5.312: Internal Pressure Transducer \#4

189

Graph 5.313: Internal Pressure: Transducer \#5

189

Graph 5.314: Internal Pressure: Transducers \# 3, 4 \& 5 (E \& PE at FT)

189

Graph 5.315: Mean Internal Pressures: Transducers \# 3, 4 \& 5 (E \& PE at FT)

189 


\section{Introduction}

\subsection{Tropical Cyclone Activities}

Since the early-1990 the North Atlantic Basin has experienced a substantial increase in tropical cyclone activity. Tropical cyclones form in tropical regions where there is warm water (at least 80 degrees Fahrenheit), moist air and converging equatorial winds (see Figure 1.1). Most tropical cyclones begin off the west coast of Africa. Typically, as the thunderstorm moves out over the Atlantic Ocean, it gains strength and becomes a tropical cyclone fueled by the warm seasonal waters; were zones of warm sea surface temperatures, decreased wind shear and areas of low pressure are prevalent. Goldenberg et al. (2001) concluded that the years 1995-2000 saw the highest mean number of major tropical cyclones and mean Net Tropical Cyclone (NTC) activity of any 6 consecutive years in the entire 1944-2000 database.
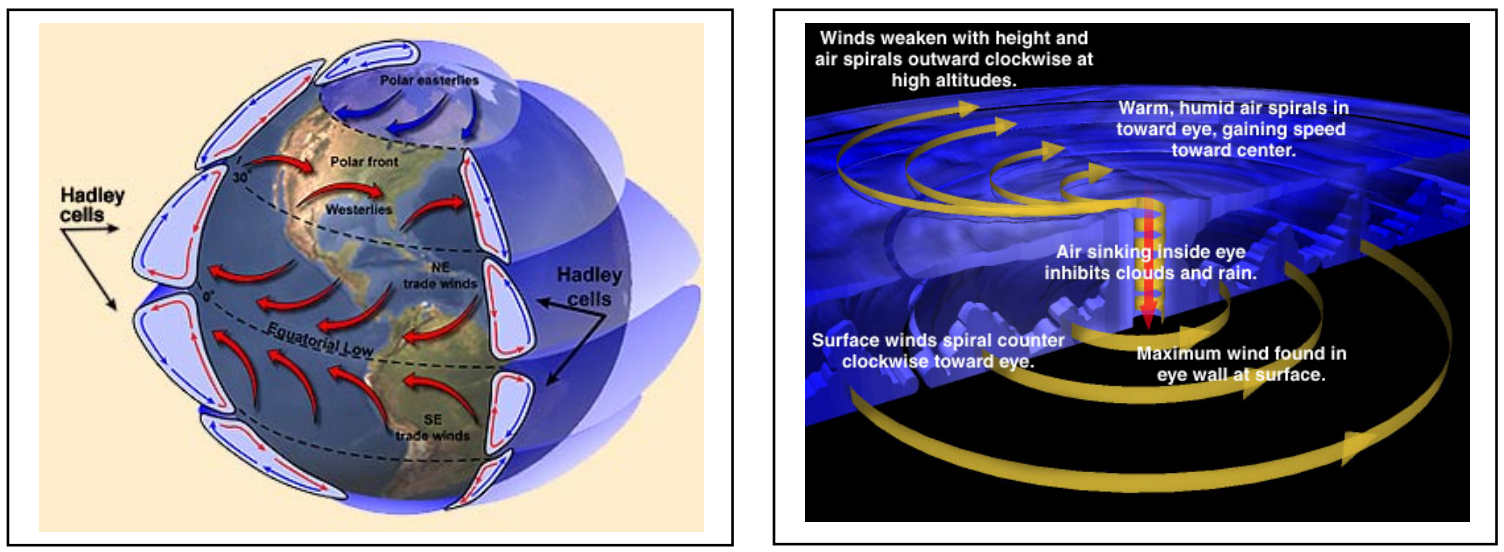

Figure 1.1: Formation Dynamics (Left) and Tropical Cyclones Winds (Right) 
Whether the increase in tropical cyclone activity is a consequence of climate change or a pattern repeated during Earth natural cycles may be debatable. Since the tropical cyclone database was implemented in 1944 and more sophisticated weathermonitoring systems employed today allow meteorologist to account for all weather activities, it is difficult to ascertain the tropical cyclone activity before the 1940's.

It is a fact that the 2004 and 2005 tropical cyclone seasons were extremely active; costing the state of Florida and adjacent states millions of dollars in damages and loss of life. The annual average economic losses due to tropical cyclone activity increased from \$1.3 billion in the years 1949-1989 to $\$ 10.1$ billion from 1990-1995; with the occurrence of tropical cyclones Katrina and Rita, the 2005 season set a new record with losses totaling over $\$ 100$ billion (Lott and Ross, 2006).

The economic impact of wind damage is at the highest point ever recorded. Wind related property damage is the most costly of all natural disasters with the costs doubling every 5-10 years (Davenport 2002). Table 1.1 shows several of the most severe tropical cyclones and the economic impact of each event (Dantin, 2007). Loss of life also increased; 1,450 persons lost their lives between the 2004 and 2005 tropical cyclone seasons.

\subsection{Damages in Residential Buildings}

The residential damages occurring during tropical cyclone activity and the loss of life reflect the obsolete and poor construction practices in tropical cyclone active areas. More importantly, the public's belief in the effectiveness of its built environment and its ability to withstand the brutal forces of nature has been shattered. Damages caused by 


\begin{tabular}{|c|c|c|c|c|}
\hline $\begin{array}{l}\text { Hurricane } \\
\text { (Year) }\end{array}$ & $\begin{array}{l}\text { Damage } \\
\text { (\$Billion) }\end{array}$ & $\begin{array}{l}\text { Hurricane } \\
\text { Category }^{1}\end{array}$ & Main Finding/Recommendation & Reference \\
\hline $\begin{array}{l}\text { Camille } \\
(1969)\end{array}$ & 1.42 & 5 & $\begin{array}{l}\text { - Most common failures were roofs } \\
\text { - "...proper anchorage..." }\end{array}$ & $\begin{array}{c}\text { (Dikkers et al. } \\
1970)\end{array}$ \\
\hline $\begin{array}{l}\text { Alicia } \\
(1983)\end{array}$ & 2.6 & 3 & $\begin{array}{l}\text { - Most structural damage due to loss of roof sheathing } \\
\text { - "Total collapse of timber-framed houses was a com- } \\
\text { mon scene." }\end{array}$ & (Kareem 1985) \\
\hline $\begin{array}{l}\text { Gilbert } \\
(1988)\end{array}$ & 5 & 4 & $\begin{array}{l}\text { - Most of the damage due to anchorage deficiencies } \\
\text { - Continuous load path is needed }\end{array}$ & $\begin{array}{l}\text { (Adams 1989; } \\
\text { Allen 1989) }\end{array}$ \\
\hline $\begin{array}{l}\text { Hugo } \\
\text { (1989) }\end{array}$ & 7 & 4 & $\begin{array}{l}\text { - Roof loss with subsequent collapse of walls } \\
\text { - Most damage was roof and wall cladding failures re- } \\
\text { sulting in extensive rain damage }\end{array}$ & (Sparks 1990) \\
\hline $\begin{array}{l}\text { Andrew } \\
(1992)\end{array}$ & 20 & 5 & $\begin{array}{l}\text { - Excessive negative pressure and/or induced internal } \\
\text { pressure } \\
\text { - Correct methods for load transfer are needed }\end{array}$ & (FEMA 1992) \\
\hline $\begin{array}{c}\text { Iniki } \\
(1992)\end{array}$ & 1.8 & 4 & $\begin{array}{l}\text { - Overload on roof systems due to uplift forces } \\
\text { - Load path must be continuous from the roof to the } \\
\text { foundation }\end{array}$ & (FEMA 1993) \\
\hline $\begin{array}{c}\text { Georges } \\
\text { (1998) }\end{array}$ & 5.9 & 2 & $\begin{array}{l}\text { - Shingle damage resulted in extensive water penetra- } \\
\text { tion and subsequent damage }\end{array}$ & (FEMA 1999) \\
\hline $\begin{array}{l}\text { Charley } \\
(2004)\end{array}$ & 15 & 4 & $\begin{array}{l}\text { - High internal pressure due to window failure was the } \\
\text { major cause of roof loss } \\
\text { - Load path needs to be continuous }\end{array}$ & $\begin{array}{l}\text { (FEMA 2005a } \\
\text { FEMA 2005c) }\end{array}$ \\
\hline $\begin{array}{l}\text { Ivan } \\
(2004)\end{array}$ & 14.2 & 3 & $\begin{array}{l}\text { - Structural damage was due to sheathing loss } \\
\text { - Ensure a complete load path for uplift loads }\end{array}$ & $\begin{array}{l}\text { (FEMA 2005b } \\
\text { FEMA 2005c) }\end{array}$ \\
\hline $\begin{array}{c}\text { Katrina } \\
(2005)\end{array}$ & $>40.6$ & 3 & $\begin{array}{l}\text { - Structural failures limited to roof sheathing loss \& } \\
\text { roof-to-wall connection failure } \\
\text { - A continuous load path must be present }\end{array}$ & (FEMA 2006) \\
\hline
\end{tabular}

Table 1.1: Comparison of Tropical Cyclones Losses (Dantin, 2007)

tropical cyclone Andrew in Florida and Iniki in Hawaii in 1992, demonstrated that tropical cyclone impact mitigation is an imperative area of study (DCCA, 2006). More recently, the impact of hurricanes Katrina and Rita indicated that serious research must be undertaken into hurricane damage mitigation in order to lessen the toll that hurricane and/or tropical cyclones can exact in human lives and property. 
In the United States, it is estimated that wood-frame buildings account for approximately $90 \%$ of all residential buildings ( $\mathrm{Li}, 2005)$; and approximately $50 \%$ of the United States population now lives within 100 miles of a tropical cyclone-prone coastline (Alvarez 2000). These are the zones at most risk for tropical cyclone activity, so the development of structural mitigation techniques and retrofit systems that protect residents against timber-framed home damage and loss of life is of great importance.

\subsection{Research Objectives}

This research work addresses two high priority investment categories for hurricane research: 'Impacts and Interactions' and 'Preparedness and Building Resiliency' as suggested by the National Science Board (NSB, 2007).

Engineered structures are vulnerable to damage from tropical cyclone induced wind, rain, and debris; however the concepts of their combined impacts on a structure are not well understood. Therefore, the first objective of this research is to simulate tropical cyclone effects, in order to study tropical cyclone-structure interaction in a full-scale environment. The use of a full-scale testing environment will enhance the understanding of the combined impacts of wind, rain, and debris on the built environment at spatial and temporal scales. High-resolution surface wind data obtained during tropical cyclones through the Florida Coastal Monitoring Program (FCMP) will establish a baseline for simulating the requisite surface level wind characteristics in the full-scale testing facility.

Damages during extreme wind events highlight the weaknesses inherent in coastal residential building construction and underscore the need for improving their structural performance; such as the weak-link at the roof-to-wall connection. Current codes call for 
the use of code approved metal connectors; commonly referred as hurricane clips or straps in timber frame construction. Thus, second objective of the research is to develop a novel alternative system, cost-effective, light, strong, ductile, and non-intrusive roof-towall connection system. Using high performance fiber composite materials, such as fiber-reinforced polymers (FRP), an alternative to conventional intrusive connections will be developed. The concept and viability of such FRP connection has been developed through component testing using actuator loading (Canbek, 2009). However, the aerodynamic loadings on typical residential buildings needs to be evaluated at full-scale and such results need to be used to develop roof-to-wall connections that will withstand extreme wind loading. The methodology for such development will involve performance based design (PBD); a concept well embraced by the earthquake engineering community. The project will assess the structural and economical feasibility, constructability, and performance of the proposed connection system through detailed experimental investigations, including non-linear effect. The FRP connection system will be applicable for new and existing buildings that are prone to extreme wind events such as tropical cyclones and hurricanes. The FRP connection developed could be an alternative for retrofitting existing buildings that may have wood fiber degradation due to long exposure to moisture or water damage and excessive nail penetration. Older buildings may have degraded timber members that can be further damaged by the addition of more nails into the wood fibers, which will reduce the connection capacity. 


\subsection{Outline of Research Work}

The scope of the research work is described herein. The investigation into the development of a FRP roof-to-wall connection consisted of many phases. The initial phase was an exhausting literature review of previous roof-to-wall connection methods, wood-FRP applications and existing testing methods.

Research on the initial development of FRP roof-to-wall connections have been already performed at the Structures and Construction Laboratory (SCL) (Canbek, 2008). A series of component tests were performed using a universal testing machine (UTM) and compared to the currently used fastening products capacities. Based on the results of component testing a full-scale section of a building was built and incorporated with FRP roof-to-wall connections and tested at the SCL. These tests demonstrated the overall ultimate failure modes of the connections in the structures lab. These results helped in determining the configuration of the FRP connection including the type of FRP, type of epoxy, and shape details.

The current work used the results obtained from initial component level testing (Canbek, 2009) and performed systematic hybrid testing using full-scale aerodynamic and aero-hydrodynamic experiments and additional component level experiments to develop the final design of the FRP connection. The hybridization was based on PBD approach taking into the effects of wind, rain, and internal pressure due to breach of the building envelope.

Wall of Wind (WoW) tests simulated hurricane effects for the purpose of evaluating the performance of the initially developed roof-to-wall connection system and also determining the wind-rain loading effects at full-scale. Tri-degree of freedom load 
cells were used to measure the loads induced by properly simulated hurricane level winds accompanied with wind-driven rain (WDR) on FRP roof-to-wall connections incorporated in a holistic building model. A series of uplift and bi-directional lateral load components were developed by correlating the connection loads and the WoW flow field profiles. These coefficients were evaluated using different angles of wind attack on the structure, under enclosed and partially-enclosed conditions, as well as with wind driven rain effects.

Once obtained, the SCL was used to conduct a series of test that validated the WoW coefficients. At the component level and using the WoW obtained load values, these loads were used in a series of simultaneous tri-directional force component testing completing an entire hybrid system for the ultimate design of the FRP connections. Using the tri-directional force component or 3-dimensional resultant load testing on a connection section, a FRP connection could be directly correlated to aerodynamic and hydro-dynamic loads.

\subsection{Layout of Report}

The report has been divided into the following chapters.

Chapter 1 explains the objectives of this research and the hybrid testing concept used.

Chapter 2 discusses the current metal connection systems used in residential construction and the reports on failures of the roof-to-wall connection during an extreme wind event. Previous testing research and the results regarding their failure modes are presented.

Chapter 3 describes the existing wind testing methods and the new concept of full-scale wind-structure interaction studies using the WoW to test and validate connection systems. 
Chapter 4 describes prior research work on FRP connections and the completed work at FIU on FRP timber connections (Canbek, 2009). The FRP component and full-scale tests of several FRP roof-to-wall connections are presented.

Chapter 5 describes the WoW testing on the FRP connections subjected to tropical cyclone simulations to study the aerodynamic and aero-hydrodynamic effects. The test specimen, instrumentation, their location and WoW testing methodology is outlined. The test results are reported and the connection loads to use at the SCL were developed.

Chapter 6 describes the testing at SCL at component level using the aerodynamic loads obtained from the WoW tests. The specimen, reaction frame, test set-up, test protocol and used instrumentation are presented; and all tests results are reported.

Chapter 7 discusses the final conclusions on the FRP design and suggests recommendations for future research on FRP roof-to-wall connections.

$\underline{\text { Chapter } 8}$ reports all the references used in this dissertation. 


\section{Timber Connection Systems}

\subsection{Residential Construction Connection Systems}

Timber or wood construction has been around before the 1800's. By the 1940's the introduction of mass produced steel nails and light-frame construction led to a revolutionary change in the wood construction industry. As hundreds of thousands of veterans of World War II needed temporary housing, the construction of roof structures was innovated and plywood was introduced to replace planking (Wolfe and McCarthy 1989). These construction methods still dominate the construction practices in residential structures.

As trussed-roof configurations become more and more complex, the necessity to investigate and understand the behavior (i.e. how loads are resisted, transferred, and distributed) of the complete roof system becomes progressively more important (Gupta 2005). There are different ways that a residential structure can fail under the extreme wind loads associated with tropical cyclones and hurricanes. Most people only consider window or garage door shutters when retrofitting their homes as a tropical cyclone approaches. In reality there are other structural considerations that must be addressed in order to increase the resilience of a residential building.

\subsubsection{Wind-Load Induced Failures}

As wind impacts a building, it creates vortices that can overwhelm the structure on different locations (see Figure 2.1). As wind travels around sharp edges, such as wall corners, roof overhangs and roof ridgelines, a separation bubble is formed. The wind 


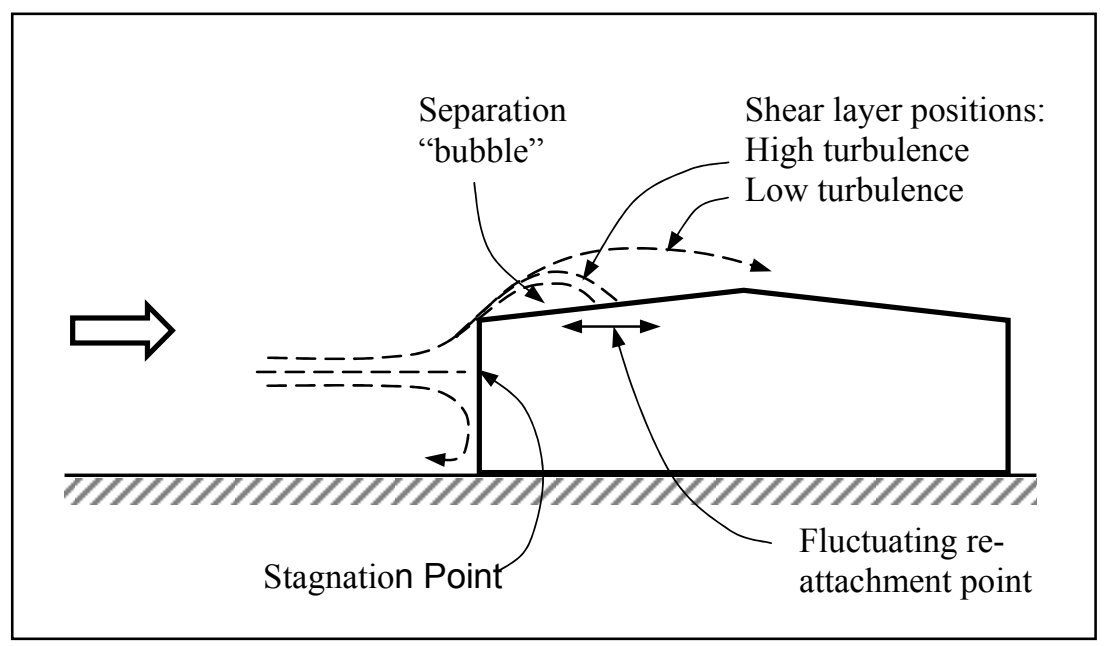

Figure 2.1: Wind Dynamics around a Building

separation bubble is bounded by a free shear layer region of high velocity gradients and high turbulence (Holmes 2001). Conical vortices are formed (see Figure 2.2); as these are shed down wind, high negative pressure peaks are produced which generate suction or uplift loads on roofs up-lift loads on a roof are transferred through the roof elements (e.g., tiles, shingles) to the plywood sheathing to the roof trusses; which could lead to roof detachment if the inter-component connections are improperly designed or installed.

Figure 2.3 illustrates the distribution of forces along a timber building during a high wind event. In a properly designed building the roof loads are transferred through a continuous vertical load path to the foundation.

Besides uplift, the high tropical cyclone winds place loads on a building that creates other modes of structural deformation (Figure 2.4). These are racking that is resisted by the walls and sliding and overturning both resisted by the anchoring system into the concrete (www.SimpsonStrongTie.com). If the structure is not properly 
anchored to foundation, it may lead to sliding or raking of the structure. As demonstrated in tropical cyclone Camille, it is essential that wood-frame buildings have to be properly anchored to their foundations, and the walls, floors and roofs adequately tied together (Dikkers et al. 1970).
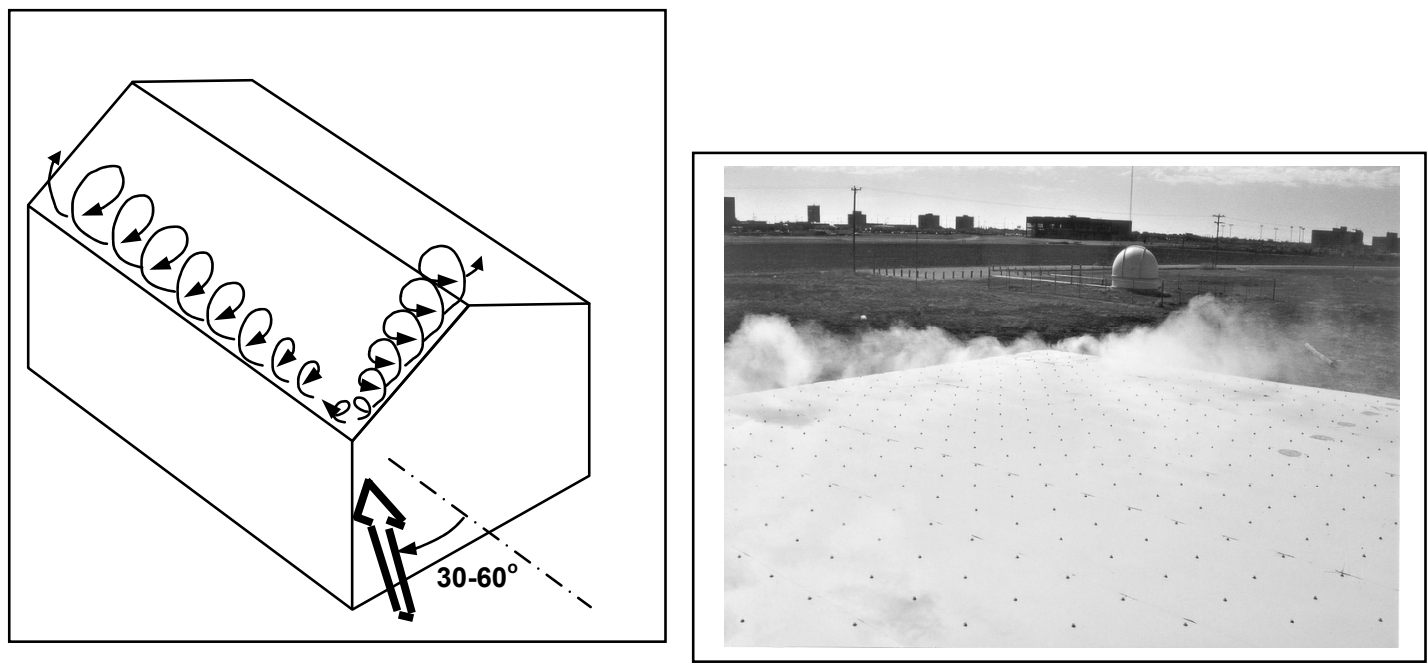

Figure 2.2: Conical Vortices (Texas Tech University on the Right)

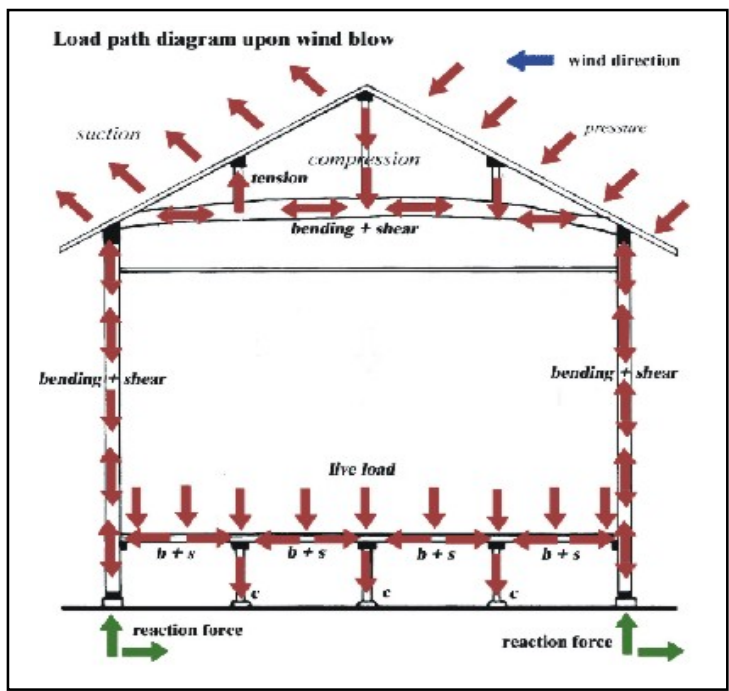

Figure 2.3: High Negative Pressure Peaks Generate Roofs Suction or Uplift Loads 


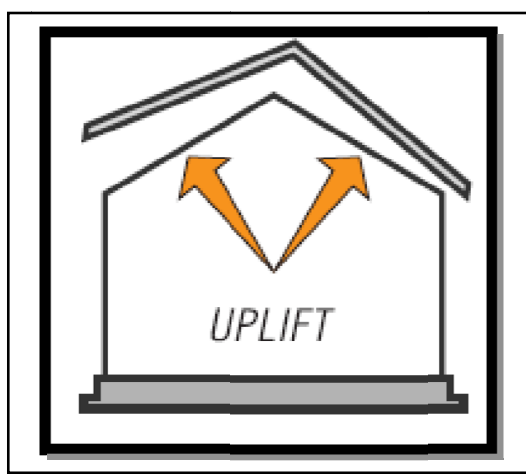

(a) Uplift Failure

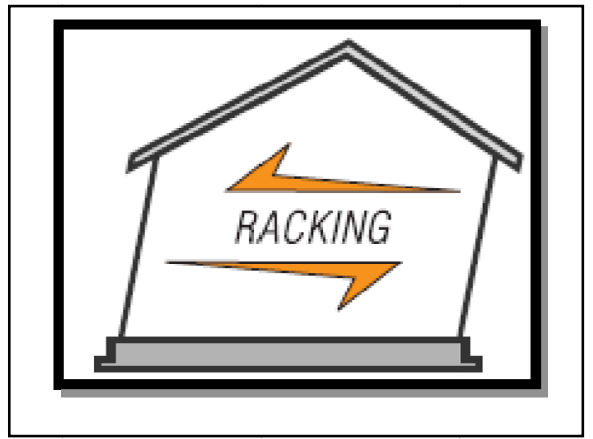

(c) Racking Failure

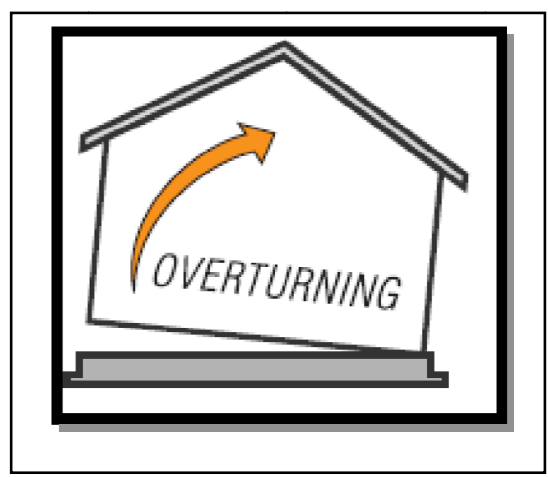

(b) Overturning Failure

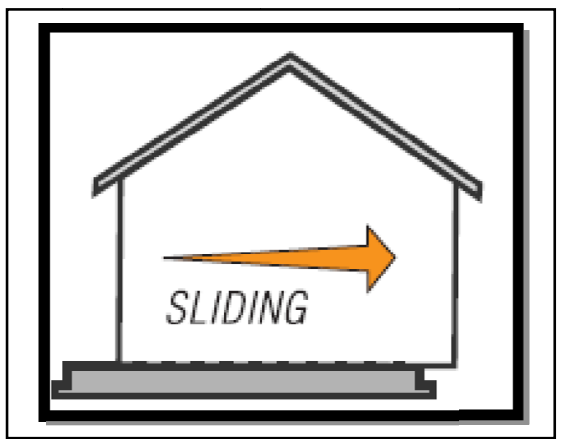

(d) Sliding Failure

Figure 2.4: Wind Loads and Modes of Failures a-d (Simpson Strong Tie)

\subsubsection{Failures of Inter-Component Connections}

Post-disaster building damage surveys (Florida Division of Emergency Management, 2007) indicate that inter-component connections play a major role in the failure of a structure. The majority of residential construction performs well under gravity loads, but often performs poorly under the lateral and uplift loads created by an extreme wind event. In general, poor performance of residential buildings is due to discontinuous load paths (Yancey, 1998). Building structure integrity is compromised when the inter-component connections, such as roof-to-wall connections, wall-to-wall 
connections, wall-to-floor connections, or anchorage-to-foundations fail. Continuous load path and structural integrity are crucial for windstorm resiliency of residential buildings.

Tropical cyclone damage has shown that wood structures tend to suffer little damage when the roof system remains intact under extreme wind loading, while major damage occurs when the roof system is partially or completely damaged (Reed et al. 1997). Post tropical cyclone inspections have noted the entire roofs detaching from buildings in some cases (Figure 2.5). This indicates a serious deficiency in the roof-towall connection systems, most notable in older construction. Thus the roof-to-wall connections play an important role to prevent roof failures and lessen the damages during high winds.

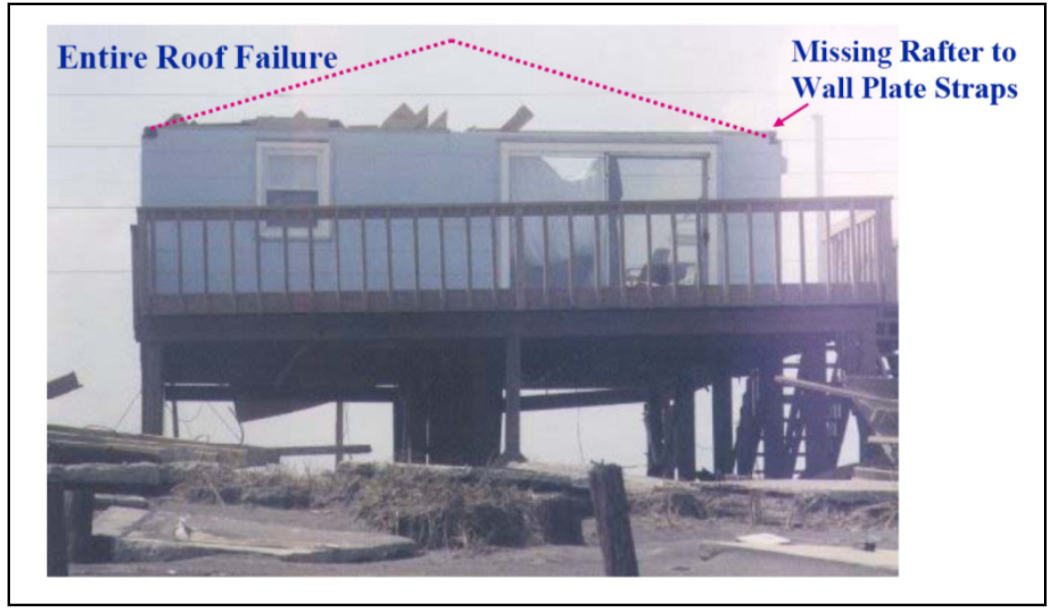

Figure 2.5: Complete Roof Failure (Coastal Contractor, 2009) 


\subsubsection{Current Practice for Roof-to-Wall Connections}

The Florida Building Code (FBC, 2007) has special provisions for buildings in the High Velocity Hurricane Zone (HVHZ) which consists of Miami-Dade and Broward counties in the state of Florida. Due to the strict design and construction practices used in the HVHZ, all metal connectors must be approved and rated by the code compliance authorities for use in buildings. The Notice of Approval (NOA) lets structural designers know the capacity of a specific product to be used in their design (Figure 2.6). FBC-07: 2321.7.2 requires all wood to wood straps to resist a minimum uplift force of 700 pounds with 4-16d nails in each member (FBC, 2007). The nails used may change if the NOA allows it.

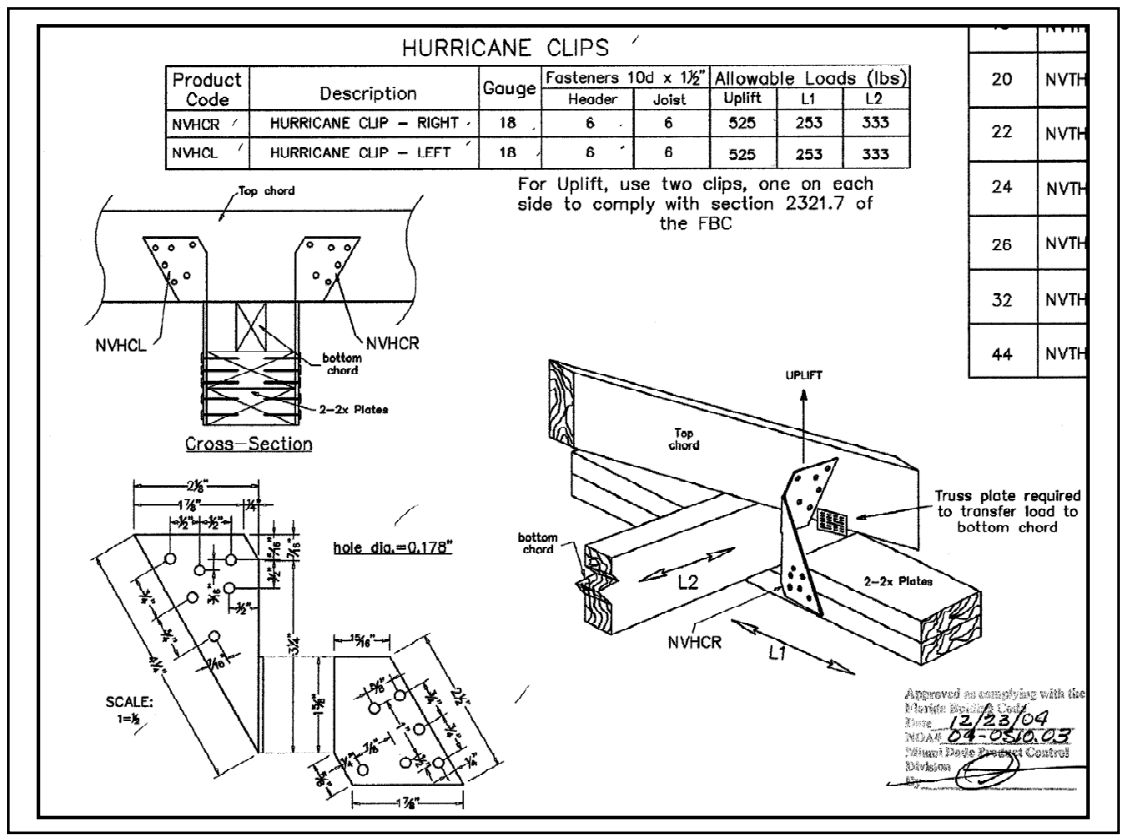

Figure 2.6: Notice of approval (MDC, 2004) 
Although significant improvements in building codes have improved roofing designs, such as the use of ring-shank nails spaced every 6 inches, post tropical cyclone inspections have noted a deficiency in the roof-to-wall connection systems; especially in older constructions. There has been limited research focusing on the load transfer mechanisms resulting from vertical uplift loads (i.e. wind loads) and the distribution of those loads through the roof assembly, especially through the roof-to-wall connections (Mani 1997).

Traditional intrusive roof-to-wall connections, such as toe-nail connections metal plates and hurricane clips connected with nails have several disadvantages. The invasive nature of these connections weakens the connected structural members. Timber structural capacity is decreased through crushing of the wood fibers of the bottom chord of a roof truss by deep and dense pattern of toe-nail penetrations. Holes created from these connections can also make paths for water infiltration. Along coastal areas, metal connections deteriorate rapidly due to the harsh environments. Extreme wind events cause non-linear aerodynamic loading effects which cause splitting and tear out of wood, nail withdrawal, nail bending, and clip buckling (NAHB 2002; Riley and Sadek, 2003). The next section describes past research regarding roof-to-wall connections.

\subsection{Past Research on Roof-to-Wall Connections}

Only limited research has been directed toward the analysis of the response of the inter-component connections and their effect on a complete building system (Polensek and Schimel, 1986, 1988; Groom and Leichti, 1991, 1994). Some of the previous studies performed by Rosowsky et al. (1998) and Reed et al. (1996, 1997), also recognized that 
the behavior of inter-component connections is not well understood and recommended further testing of such connections. The purpose of the analytical studies conducted on different structural components as well as the inter-component connections in an assembled model, is to compare the experimental research and assess the validity of the proposed models and analyses (Riley and Sadek 2003).

Experimental testing of roof-to-wall connections in wood frame buildings was carried out by National Institute of Standards and Technology (NIST) (NISTIR 6938 by Riley and Sadek, 2003). The National Association of Home Builders (NAHB) Research Center, Inc., under sponsorship of the U.S. Department of Housing and Urban Development (HUD), performed research work on roof framing connections in conventional residential construction (NAHB, 2002).

Past studies and experiments reveal that there are several inconsistencies in the design methodologies used for engineering analysis of traditional and hardware-type connections and there are several failure modes that can potentially lead to building safety issues. The study suggested that "further increases in the connection capacity would require clips or straps that connect the trusses directly to the wall studs, and should probably be paired with straps that anchor the studs directly to the foundation" (Riley and Sadek, 2003). The performance of connections tested by NIST was necessary for the development of analytical models of the connections and for complete 3-D numerical models of entire houses (Riley and Sadek, 2003).

Additional research and testing was recommended to predict the response of roofto-wall connection, its performance and their non-linear behavior under combined loads from wind induced dynamic effects (Riley and Sadek, 2003). Riley and Sadek suggested 
testing of different types of connectors and longer wall lengths. Furthermore, they recommended that "component tests of single, directly loaded connections would allow numerous tests with a particular load pattern and connection type, to determine the statistical mean, variance, and uncertainty of the response" (Riley and Sadek, 2003).

For the NAHB project, several research areas were investigated to benchmark the response of conventional and engineered roof connections. Results of the hardware-type connections show a potential than can lead to inaccurate prescriptive connection provisions and design solutions. Testing revealed that primary failure modes for joints with hurricane clips included buckling of the clip, separation of metal truss plate, and truss rotation. The research report emphasized that the current design methods can potentially overestimate the resistance of certain connections and cause safety issues (NAHB, 2002).

Several roof-to-wall connection systems were tested under various past research projects. The testing of the various systems and the results are described below.

\subsubsection{Toe Nailed Connection Systems}

Past research work included toe-nailed connections. The building frame specimen incorporated with these connections was subjected to four types of loading: monotonic up-lift, monotonic lateral load or pushover, combined up-lift and lateral load, and cyclic lateral loading. The loads were generated by vertical and horizontal actuators (Figure 2.7). The experiments investigated behavior of the connections at failure. 


\subsubsection{Up-Lift Loading}

Toe-nailed connection failure mode from up-lift load test at NIST was characterized with nails pulling out of the top plate of the wall, which resulted in separation in the bottom wood fibers of the bottom chord of the roof truss (see Figure 2.7). A constant up-lift deformation of $0.25 \mathrm{in} / \mathrm{min}$ was applied for 360 seconds. After 125 seconds, the actuator load was almost 4,000 pounds ( 8 connections would correspond to 500 pounds per connection), the specimen failed at the connection between the trusses and the top-plate of the wall. According to the test results the measured load of a particular connection failure was not more than 600 pounds. The behavior of the connection was highly non-linear and once the connection reached its ultimate load it lost a significant portion of its resistance.

Several research areas were investigated to benchmark the response of toe-nail roof-to-wall connections by the NAHB (NAHB, 2002). Results from the studies indicate

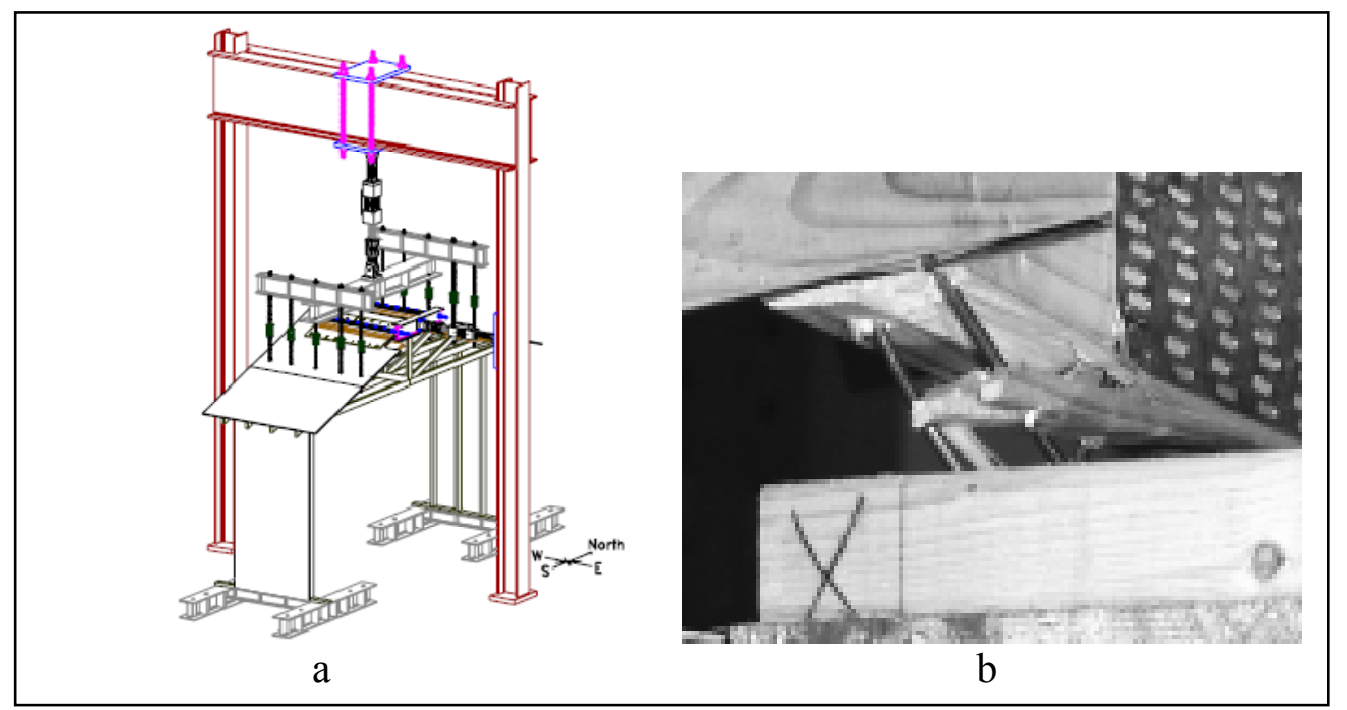

Figure 2.7: (a) Vertical and Horizontal Actuators; (b) Toe-Nail Failure (NIST, 2003) 
several inconsistencies in the design methodologies used for engineering analysis of traditional connections that can potentially lead to inaccurate regulatory connection provisions and design solutions. Testing revealed that primary failure modes for toenailed connections included splitting and tear-out of wood, nail bending, and nailwithdrawal NAHB.

Most toe-nailed connections fail at winds in excess of $90 \mathrm{mph}$ (Cheng, 2004). Cheng's research, "Testing and analysis of the Toe-Nailed Connection in the Residential Roof-to-Wall System", looked into the rafter to top-plate toe-nailed connection. Using an Instron 5581 test machine, over 300 mechanical tests were conducted on three different wood types and two common and box nail types; to statistically determine mean values and variance of the uplift capacity of selected wood types (Cheng, 2004). The study suggested that an amendment to the International Building Code (IBC, 2000) would be a more effective approach to reduce building loss. The author strongly opposed the use of toe-nailed roof-to-wall connections in any type of buildings located in hurricane prone regions and suggested the use of other types of hardware (Chang, 2004).

\subsubsection{Lateral Loading}

The NIST researchers tested specimens using monotonic lateral load to determine the ultimate shear capacity and the pushover response of the toe-nailed connection. A lateral deformation (parallel to the side wall) was applied. The specimen resisted the applied load before it failed at approximately 2,500 pounds ( 8 connections corresponded to $300 \mathrm{lbs} /$ connection) (NIST, 2003). The overturning moments in the connection at one end caused the outer truss to pull free of the top-plate (please see Figure 2.8). The failure 


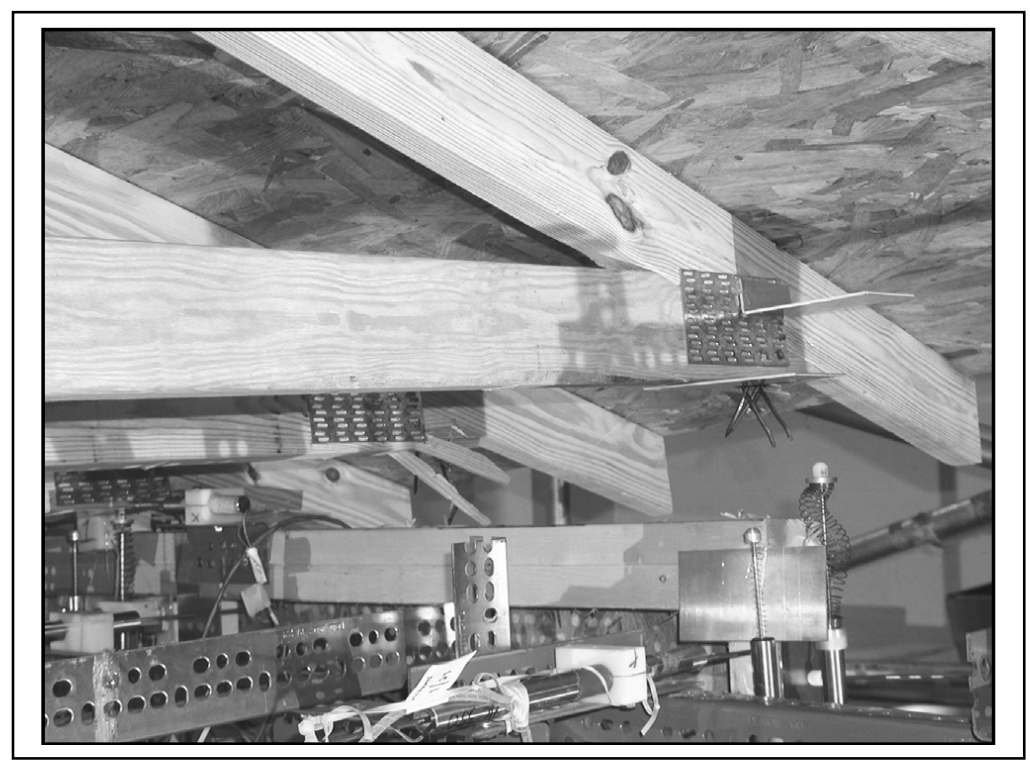

Figure 2.8: Failure of Toe-Nail Connection with a Lateral Load (NIST 2003)

mode was observed to be nail withdrawal from the top-plate, resulting in wood splitting from the bottom chord of an inner truss. The failed outer truss reached an ultimate load of approximately 550 pounds. Results indicated that the connections in shear are rigid, but more flexible in tension (NIST, 2003).

\subsubsection{Combined Up-Lift and Lateral Loading}

NIST researchers tested the specimen in both up-lift and lateral directions to simulate wind effects on a structure, including a lateral load component to simulate pressure on the outside wall (NIST, 2003). A constant up-lift deformation was applied to the roof, simultaneously a lateral displacement was applied to produce a lateral load equal to $29.5 \%$ of the vertical load, but in general the peak lateral loads were about $25 \%$ of the peak vertical loads (Figure 2.9 and 2.10) (NIST, 2003). 


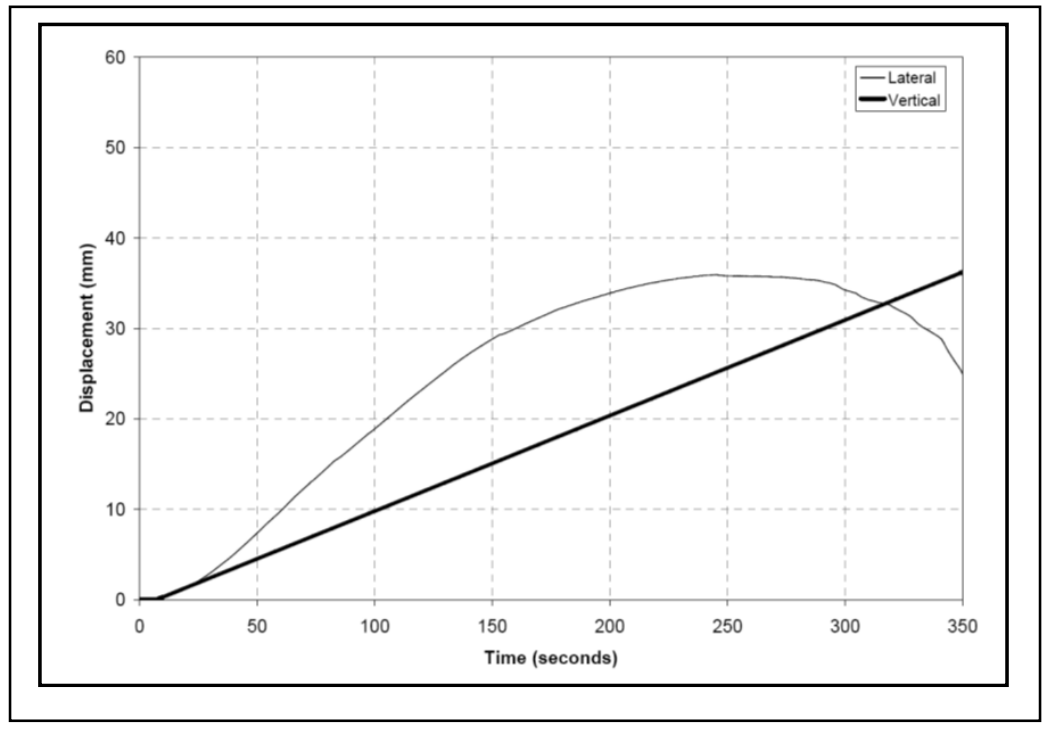

Figure 2.9: Displacements Applied To Specimen with Toe-Nail Connections (NIST, 2003)

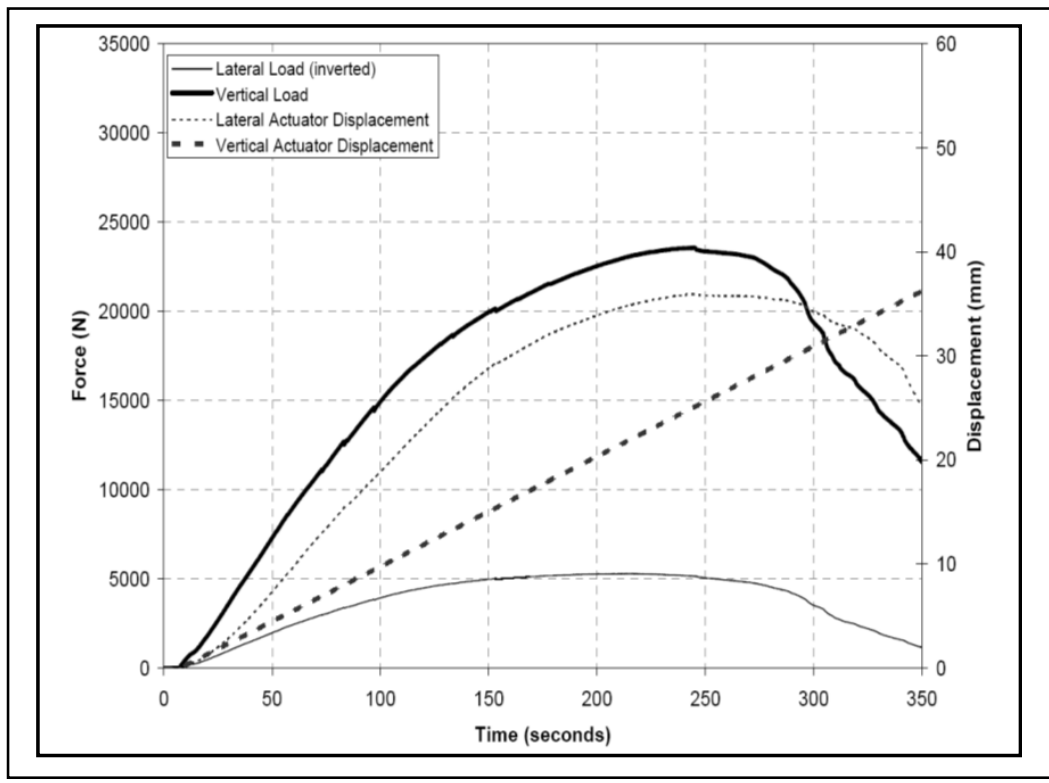

Figure 2.10: Loads Applied To Specimen with Toe-Nail Connections (NIST, 2003) 
Similarly to previous tests, the specimen's stiffness decreased throughout the test, but the resistance continued to increase until connections began to failed (NIST, 2003). The nails in the connection, placed in tension by the overturning moment from the lateral portion of the load, pulled free from the top plate of the wall and resulted in some wood splitting in the top plate of the wall (Figure 2.11). The lateral force did not exceed 140 pounds and the maximum up-lift force in the outer truss was 900 pounds (NIST, 2003). The peak vertical loads carried by the failed connections were larger than those measured in the up-lift test alone.

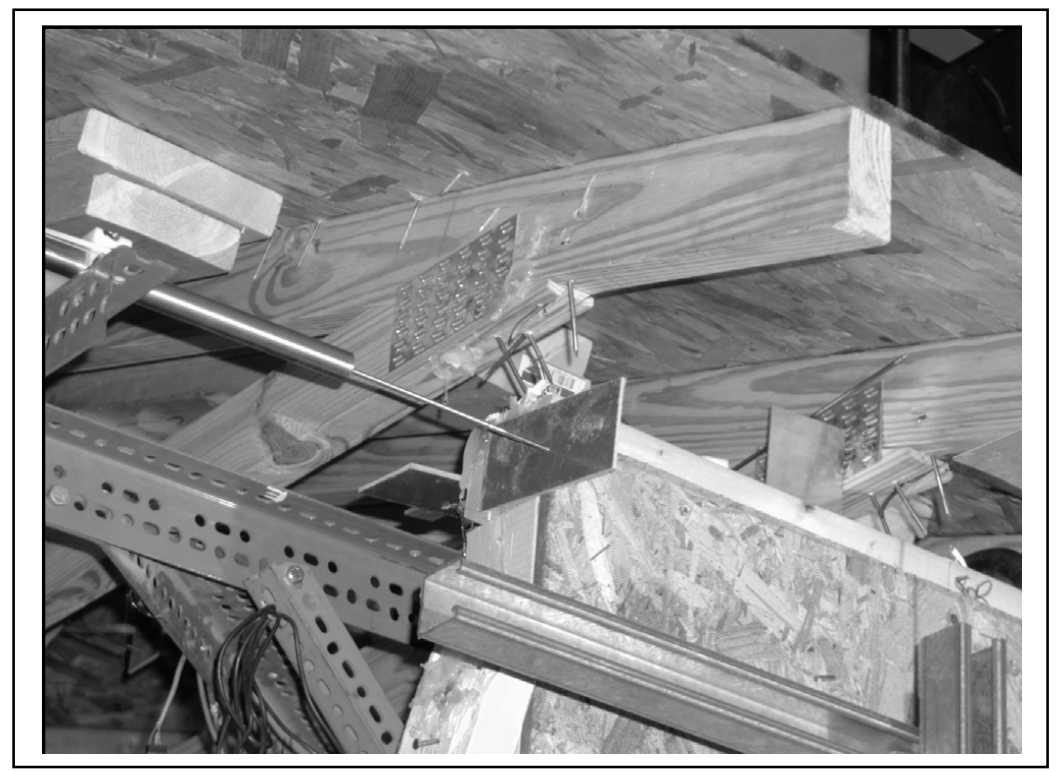

Figure 2.11: Failure of Toe-Nailed Connection with Combined Load (NIST, 2003) 


\subsubsection{Mechanical Connection Systems (Hurricane Clip)}

In past research, mechanical clips were tested under four types of loading:

monotonic up-lift, monotonic lateral load or pushover, combined up-lift and lateral load, and cyclic lateral loading. The experiments investigated behavior of the connections at failure.

\subsubsection{Up-lift Loading}

NIST tested a hurricane clip specimens twice in up-lift. The first test failed when the entire top-plate pulled loose from the wall studs and cladding, with a load of 6,000 pounds ( 8 connections would correspond to $760 \mathrm{lbs} /$ connection). Results indicated that the maximum ultimate load of failure was 1,000 pounds per connection (NIST, 2003). The second test failure was occurred when the hurricane clip remained attached to the upper member of the top-plate and the truss, but the upper member of the top-plate and a portion of lower member separated from the rest of the wall (Figure 2.12). The behavior of the hurricane clip connection was highly non-linear and once the connection reached its ultimate load of 1,070 pounds, it also lost a significant portion of its resistance. The hurricane clip connections showed good ductility, continuing to carry significant, but reduced, load at relatively large levels of deformation (NIST, 2003).

The data obtained at NIST provided the basis for limited analytical models of the connection response. Figure 2.13 shows a comparison of toe-nail and hurricane clip failure. The behavior of both toe-nail and hurricane clip is highly nonlinear. Once the connections reached their ultimate load they lose a significant portion of their resistance (NIST, 2003). Nevertheless, Figure 2.13 clearly shows that hurricane clips have a higher 


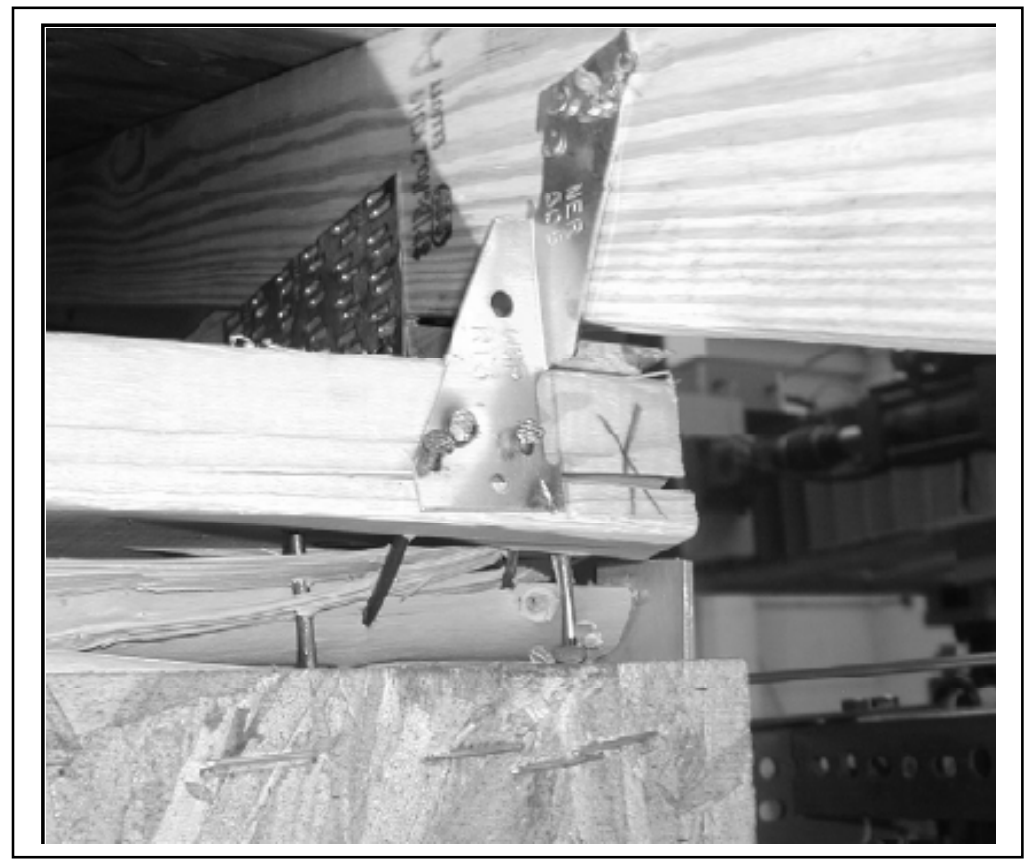

Figure 2.12: Typical Failure Modes of Roof-To-Wall Connections from NIST Tests (NIST, 2003)

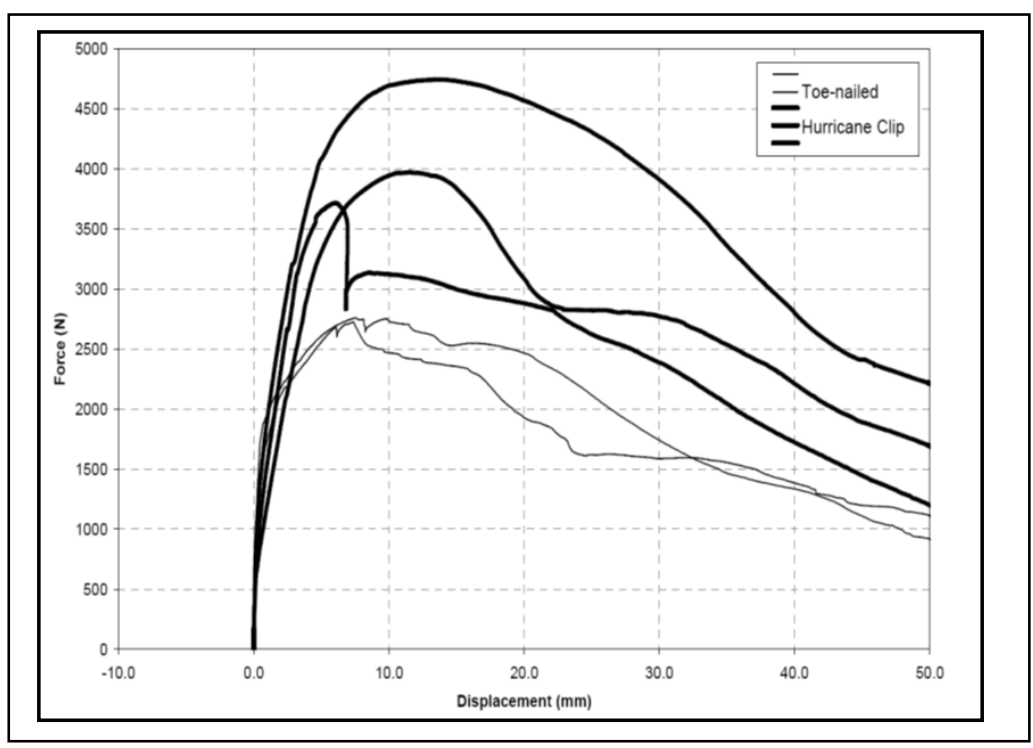

Figure 2.13: Comparison of Responses with Toe-Nailed Connections and Hurricane Clips (NIST, 2003) 
up-lift capacity. Furthermore, in most cases the hurricane clip had a larger deformation at failure than the toe-nail connection; and the residual strength of the hurricane clip connection was usually greater than the toe-nail connection (NIST, 2003). Further research and testing was recommended to fully quantify the response of roof-to-wall connections.

The NAHB researchers did not conduct any up-lift tests on metal connectors only lateral resistance was tested.

\subsubsection{Lateral Loading}

NIST tested a specimen under a monotonic lateral load to determine the ultimate shear capacity and the pushover response of hurricane clip connections. A lateral deformation was applied at a constant rate and a near constant stiffness; the specimen began to fail at 3,500 pounds (NIST, 2003). The outer truss pulled free of the top-plate, due to the tension of the overturning moments; as shown in Figure 2.14. As in the previous toe-nail tests, the failure mode was nail withdraw from the top-plate. The results indicated that the hurricane clip connection was fairly stiff in shear, but weaker in tension. The response of the connections were similar in shear, but the outer connection, which failed first, was clearly carrying greater tension due to the overturning moments (NIST, 2003). The peak vertical load measured in the failed connection was near twice as large as the peak lateral load. It was smaller than the load measured in the hurricane clip during the up-lift loading test. This may be due to the different modes of failure between the two tests. 


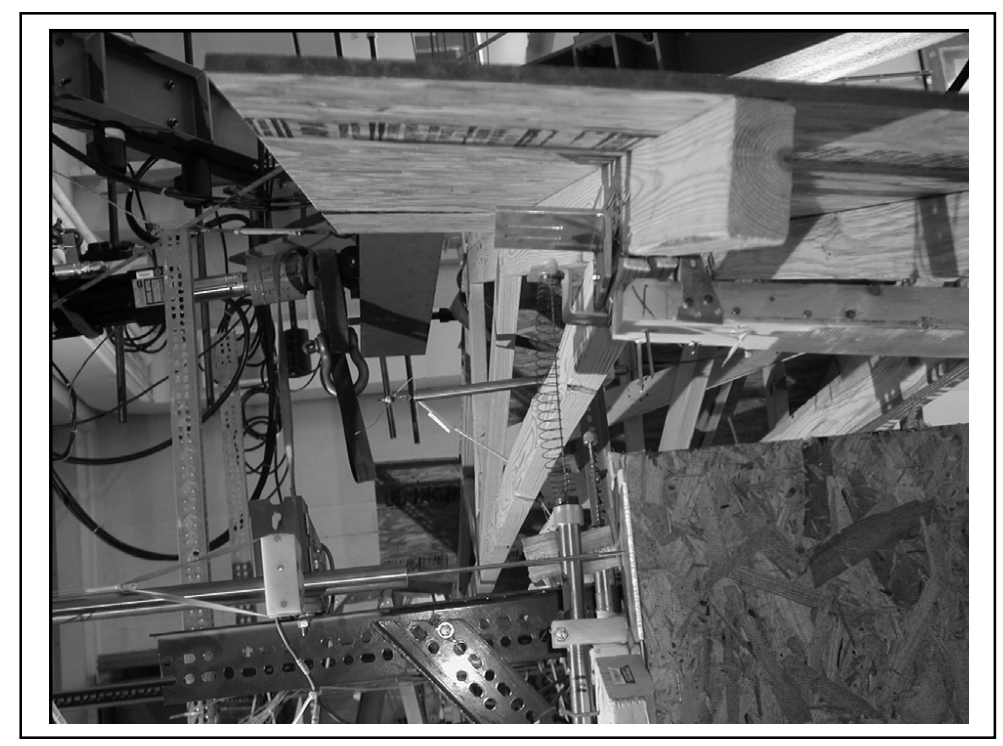

Figure 2.14: Outer Truss Failure Due to Overturning Moment (NIST, 2003)

The behavior of both types of connections (toe-nail and hurricane clip) was highly non-linear, with most deformation occurring in the vertical direction. Figures 2.15 and 2.16 illustrate that the hurricane clip connections had a higher capacity in both shear and

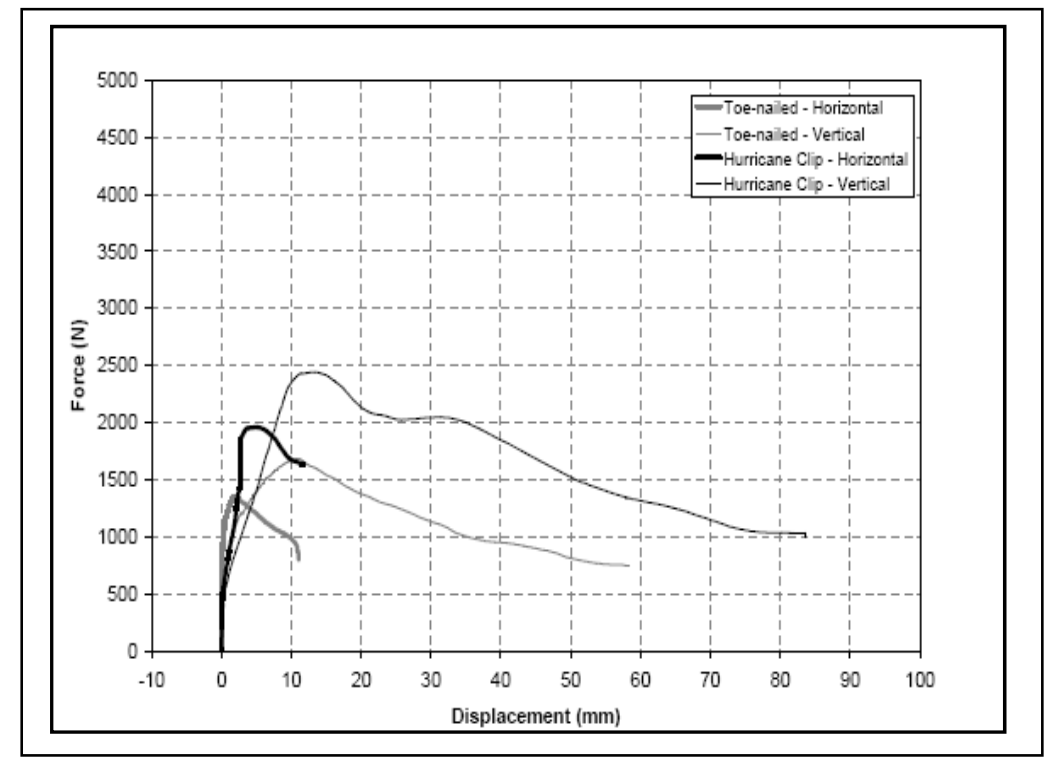

Figure 2.15: Comparison of Responses of the Inner Trusses (NIST, 2003) 


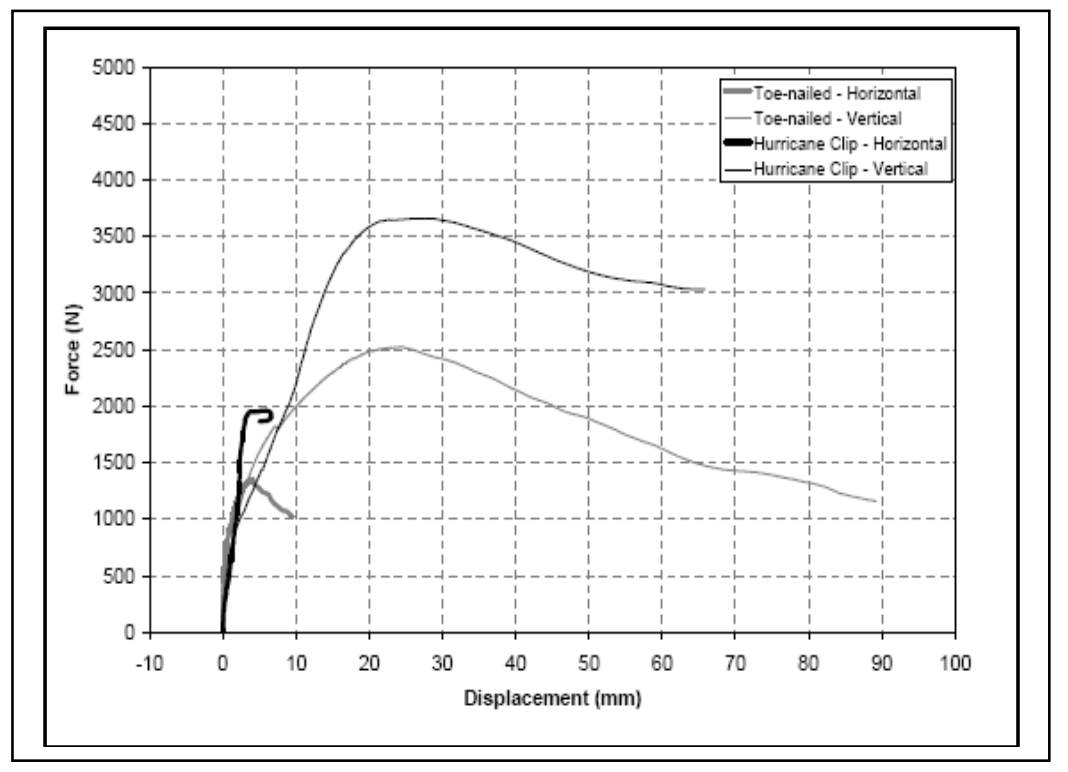

Figure 2.16: Comparison of Responses of the Outer Trusses (NIST, 2003)

up-lift (NIST, 2003). The residual strength of the hurricane clip connection tended to be similar to or greater than the capacity of the toe-nailed connection (NIST, 2003).

The NAHB study measured and compared the lateral (parallel-to-wall) performance of full-scale roof-to-wall connections systems constructed with, among others, metal connector hardware. Based on test results the scope of the minimum prescriptive provisions for roof-to-wall attachment was determined for a building configuration and loading conditions (NAHB, 2002).

The test consisted of laterally loading a 12 feet wide by 20 feet long specimen. The trusses were connected to the top plate using metal connectors on one side (loading side) and rollers on the other (see Figure 2.17). Tension was applied to the roof using a strap attached to a hydraulic actuator using a clevis (see Figure 2.18). 


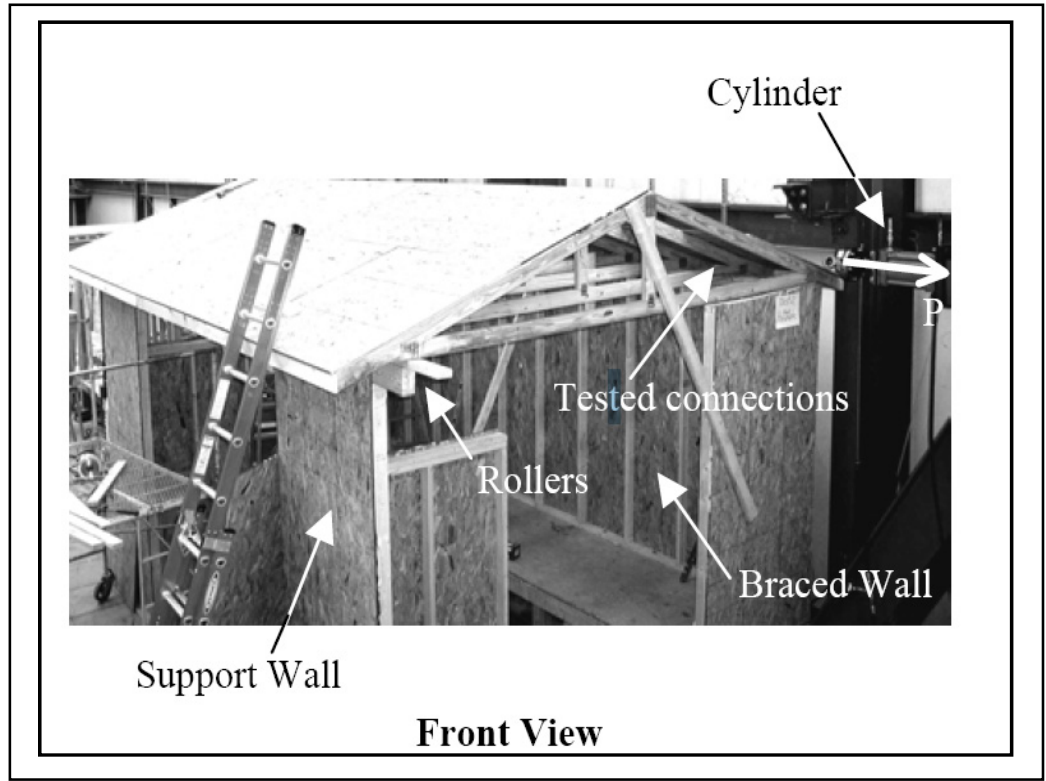

Figure 2.17: Roof-To-Wall Connection Test Set-Up (NAHB, 2002)

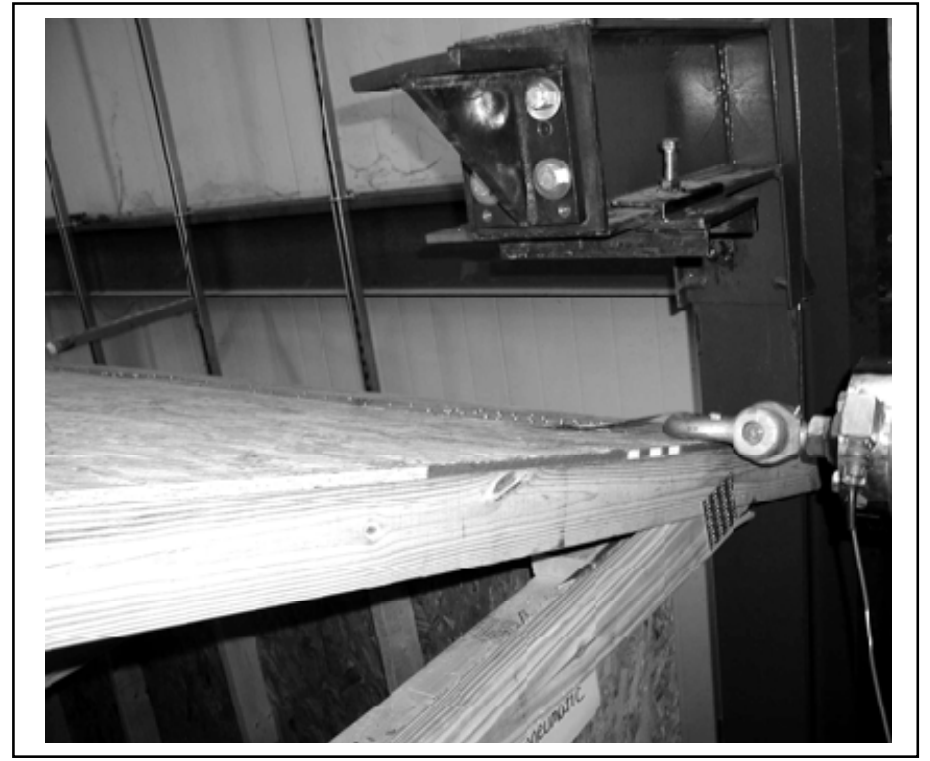

Figure 2.18: Vertical Tension Applied Using a Strap, Hydraulic Actuator and Clevis (NAHB, 2002) 
Although designed primarily to resist roof uplift forces, the hurricane clips increased the peak lateral resistance of the roof-to-wall connections by approximately a factor of two as compared to toe-nails. The NAHB researchers conducted six tests on hurricane clips in up-lift loading. The average peak load was found to be 6,427 pounds or 584 pounds per joint and had a displacement of 1.10 inch at peak load (NAHB, 2002). The modes of failure consisted of truss plate separation, truss slip and rotation, clip buckling, clip tension failure and truss plate separation as shown in Figures 2.19 through 2.23 (NAHB, 2002).

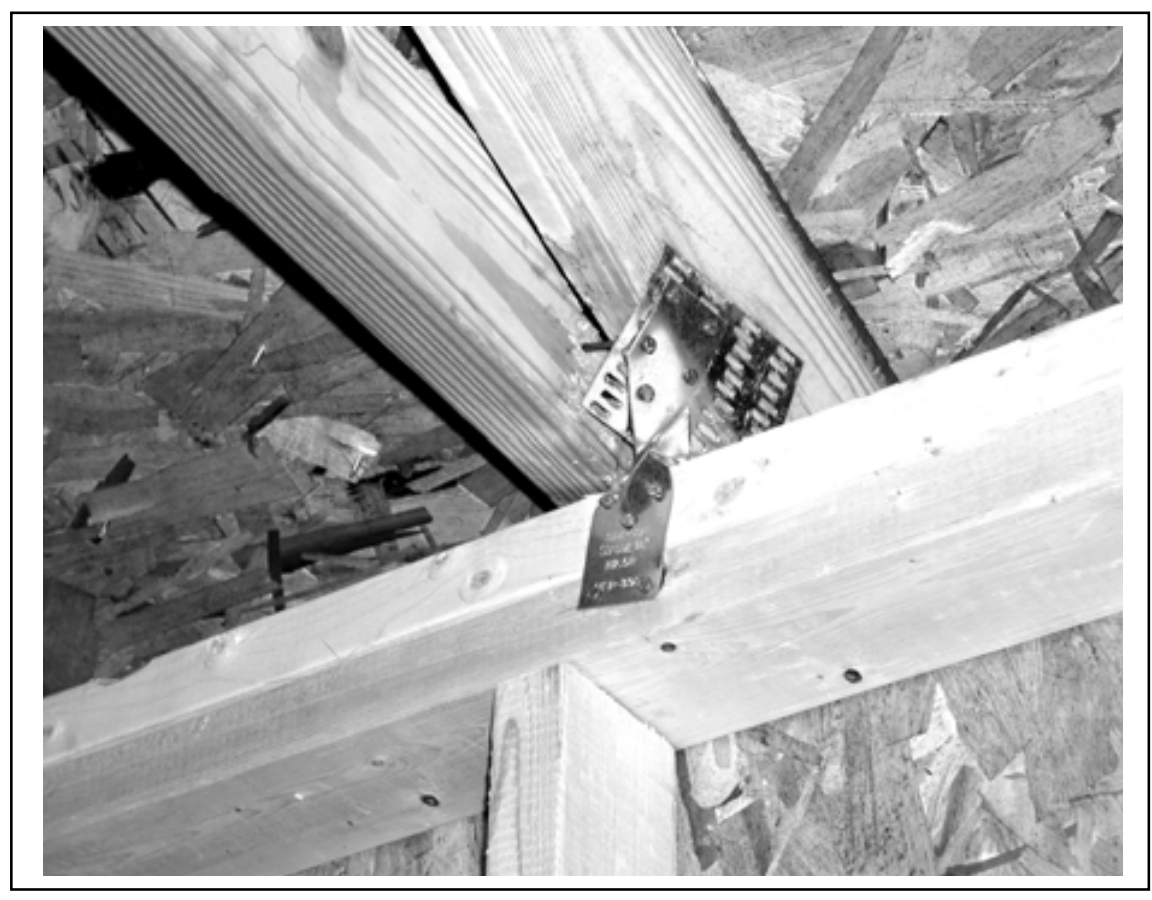

Figure 2.19: Truss Plate Separation (NAHB, 2002) 


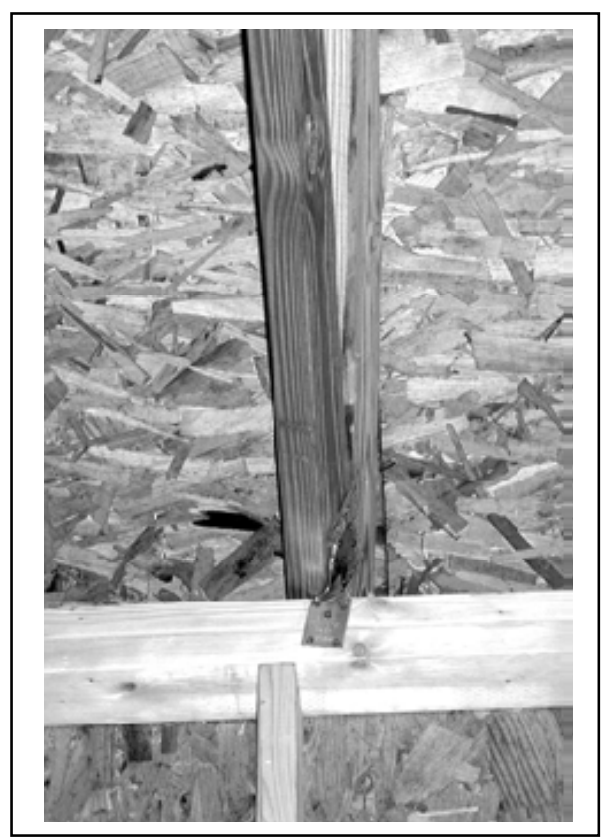

Figure 2.20: Truss Slip and Rotation (NAHB, 2002)

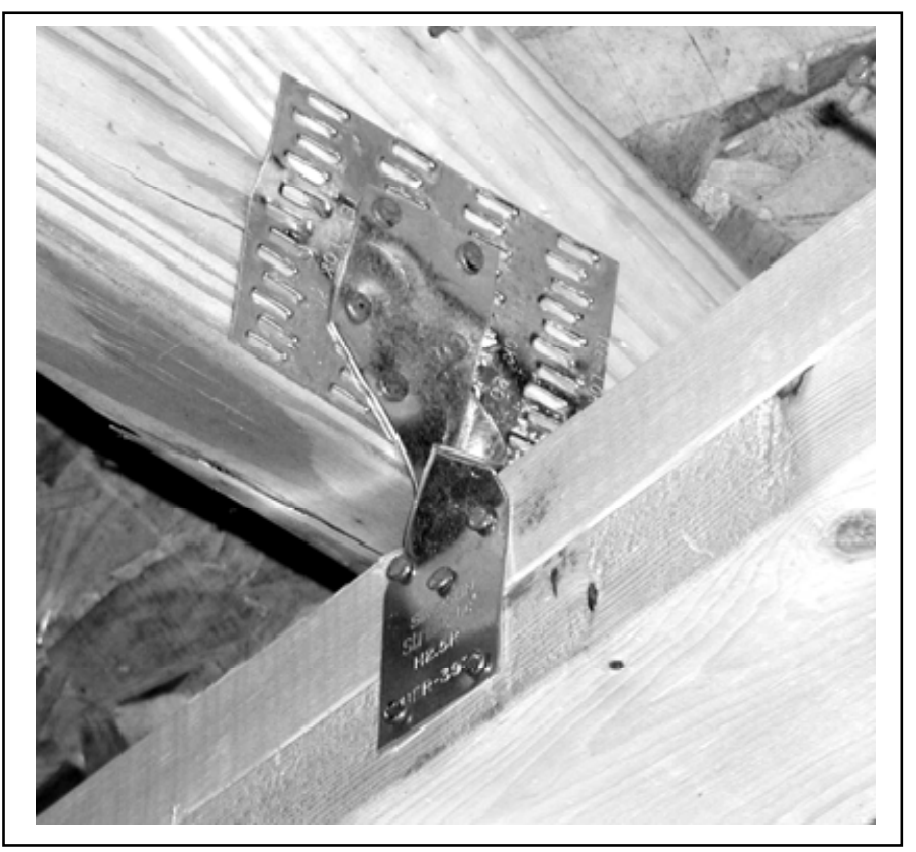

Figure 2.21: Hurricane Clip Buckling (NAHB, 2002) 


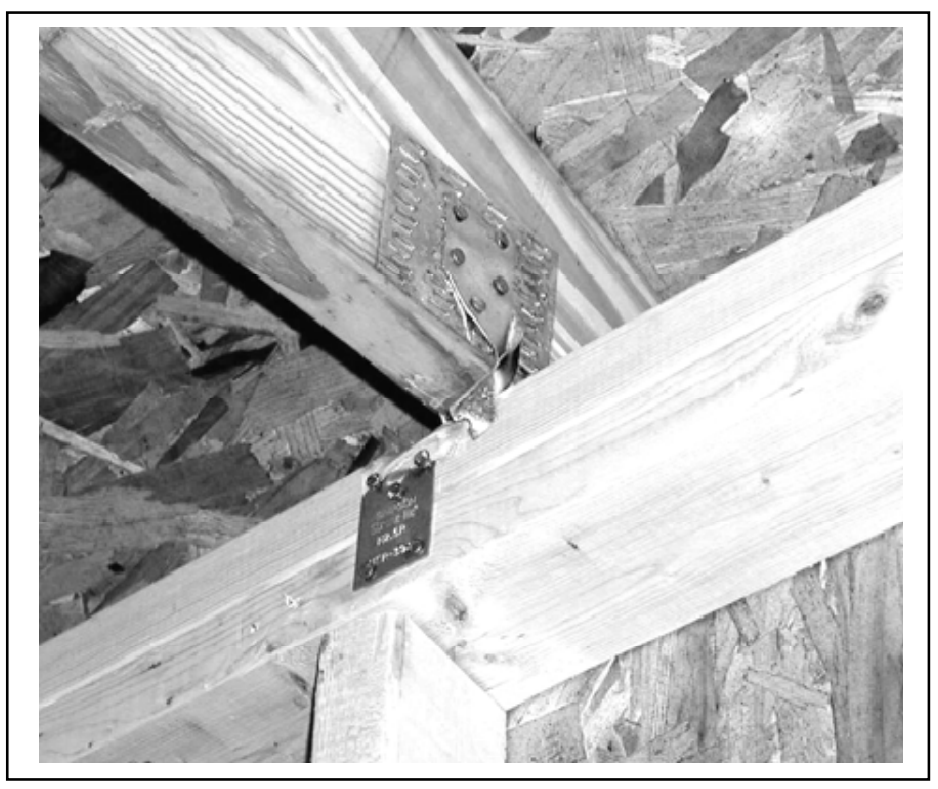

Figure 2.22: Hurricane Clip Tension Failure (NAHB, 2002)

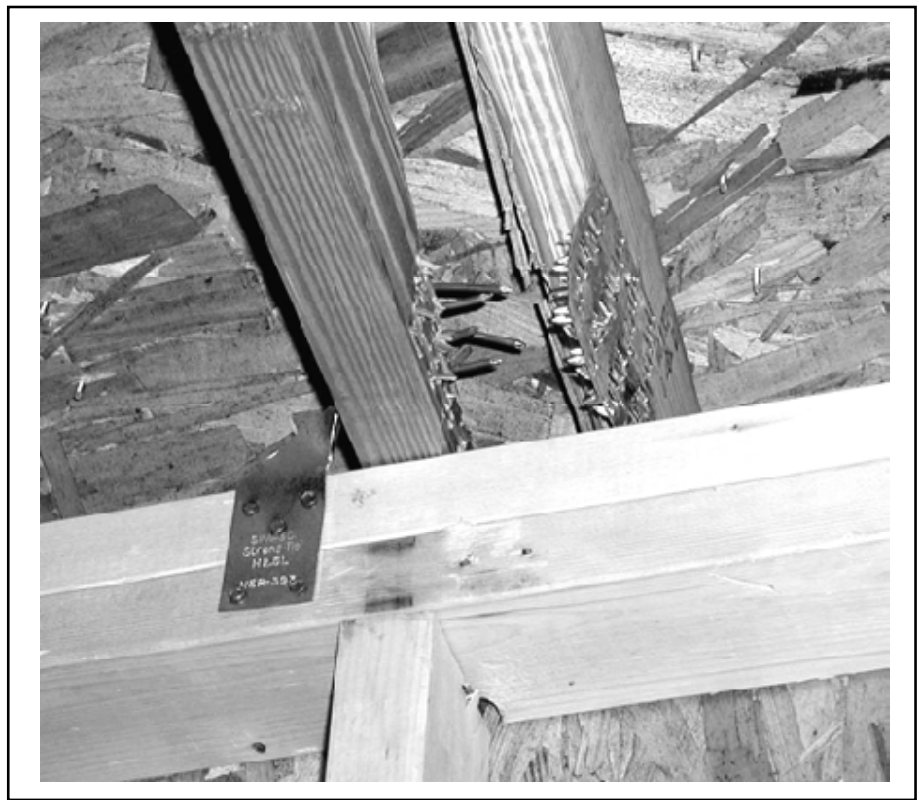

Figure 2.23: Hurricane Clip Tension Failure and Connector Plate Nail Withdrawal (NAHB, 2002) 
In the NAHB test, H2.5 hurricane clips manufactured by Simpson Strong Tie were used. The lateral capacity of a single H2.5 hurricane clip, as provided by the manufacturer, is 130 pounds (Simpson Strong Tie, 1999). By comparing the experimental values and the analytical predictions of the yield theory of the NDS design and capacity limit states, the safety margin was calculated (NDS, 2007). The safety margins of were found to be excessive (NAHB, 2002). The allowable design value specified by the manufacturer is established based on a joint slip limit state. The direct implementation of design methods develop for single dowel connections to light-gage steel hardware connections, which exhibited different response and unique failure modes, resulted in ambiguous design values and an arbitrary design basis with respect to the performance levels of the hardware systems (NAHB, 2002). Based on the limited testing performed in this research, the allowable lateral resistance of hurricane clip H2.5 in the direction parallel to wall could be increased from $130 \mathrm{lb}$ to 260 pounds per clip. The calculated lateral design values expose the inconsistencies in using the joint slip limit state for establishing connection properties (NAHB, 2002).

\subsubsection{Combined Up-Lift and Lateral Loading}

Only NIST conducted tests on a specimen under both up-lift and lateral loads to simulate wind effects on the structure, including a lateral load component to simulate pressure on the outside wall (NIST, 2003). The applied vertical load was measured and a lateral displacement applied to produce a lateral load equal to $29.5 \%$ of the vertical load; in general the peak lateral loads were about $25 \%$ of the peak vertical loads (NIST, 2003). 
The deformation and the loads applied to the hurricane clip test are shown in Figures 2.24 and 2.25. The first connection began to fail at an applied lateral load of 1,900 pounds with a total deflection of $1 / 2$ inch; while the maximum applied vertical load was almost 7,900 pounds and a total vertical deflection of almost 2.5 inches (Figure 2.25) (NIST, 2003). The failure occurred at the connection on the outer truss that was in tension from both the uplift and the overturning moment due to the lateral load (NIST, 2003). The top plate of the wall split, which allowed the hurricane clip to pull free (Figure 2.26). The connection of the inner truss adjacent to the truss that failed first, failed when the nails withdrew from the intact top plate.

The maximum up-lift load was measured in the inner truss hurricane clip, which had a load of more than 1,500 pounds and the lateral load was about 225 pounds (NIST, 2003). The responses of the inner truss connections were quite similar, but the outer truss that failed first, exhibited much less stiffness in both shear and up-lift, and failed at a relatively low load (NIST, 2003). Unexpectedly, the capacity of this connection was slightly bigger than the toe-nail connection and less than other hurricane clip connections. The reduced capacity may have been due to an inherit weakness in the wood of the toplate, or a split in the wood caused by poorly driven nails.

A comparison of the inner and outer truss responses with the two types of connections is illustrated on Figures 2.27 and 2.28 (NIST, 2003). These curves highlight the great variability that can occur in the response of wood frame construction. This could be caused by poor quality of the materials and the quality of workmanship. The wood properties can vary considerably, and are dependent on the wood type, dryness, and density, as well as cracks or other physical defects. The combined strength of the other 


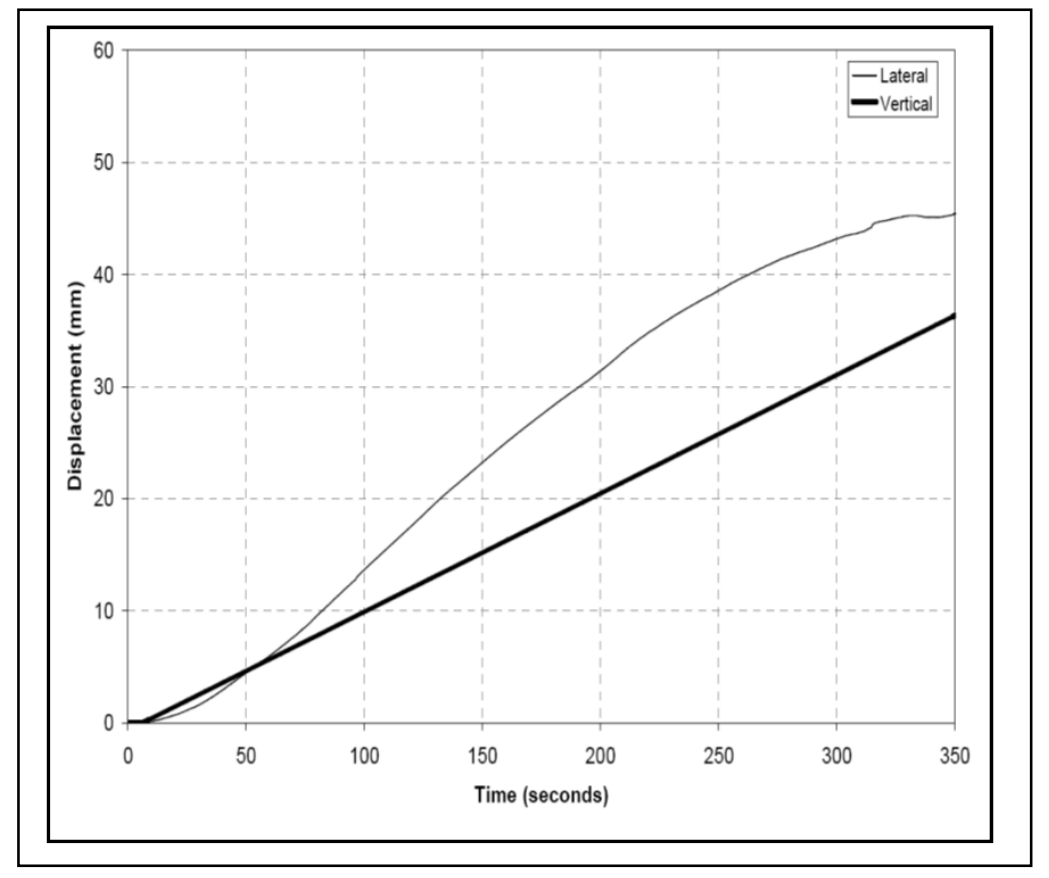

Figure 2.24: Displacements Applied to the Specimen with Hurricane Clips (NIST, 2003)

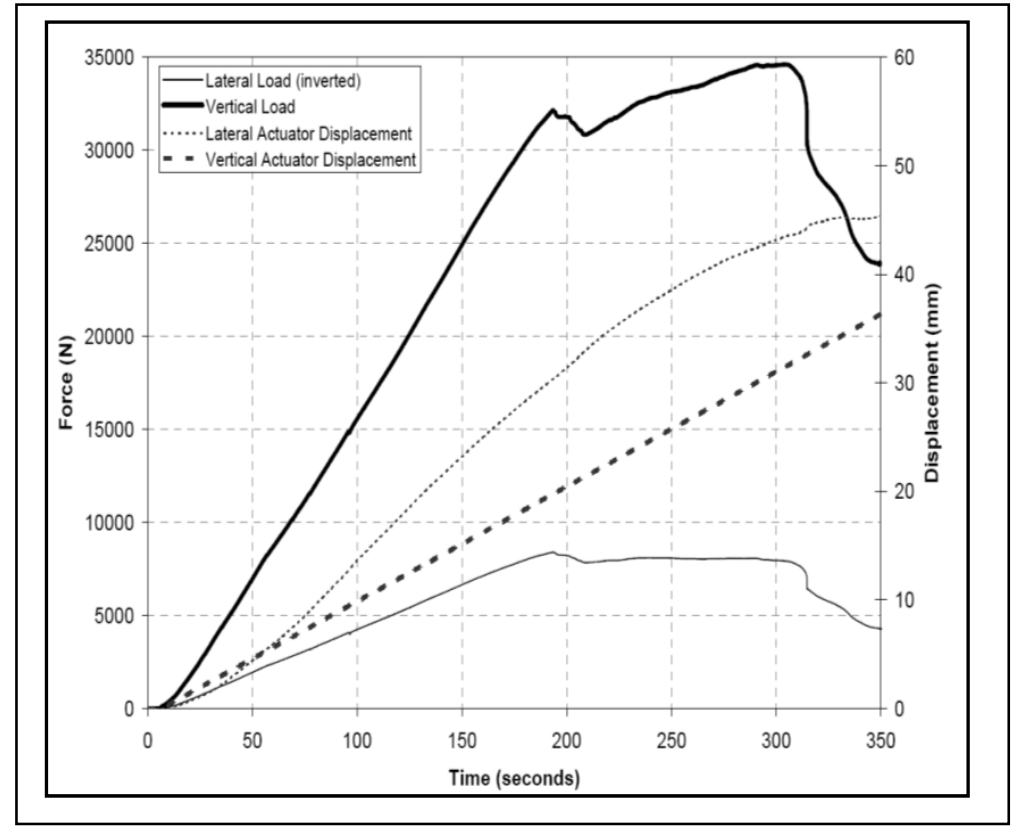

Figure 2.25: Loads Applied to the Specimen with Hurricane Clips (NIST, 2003) 


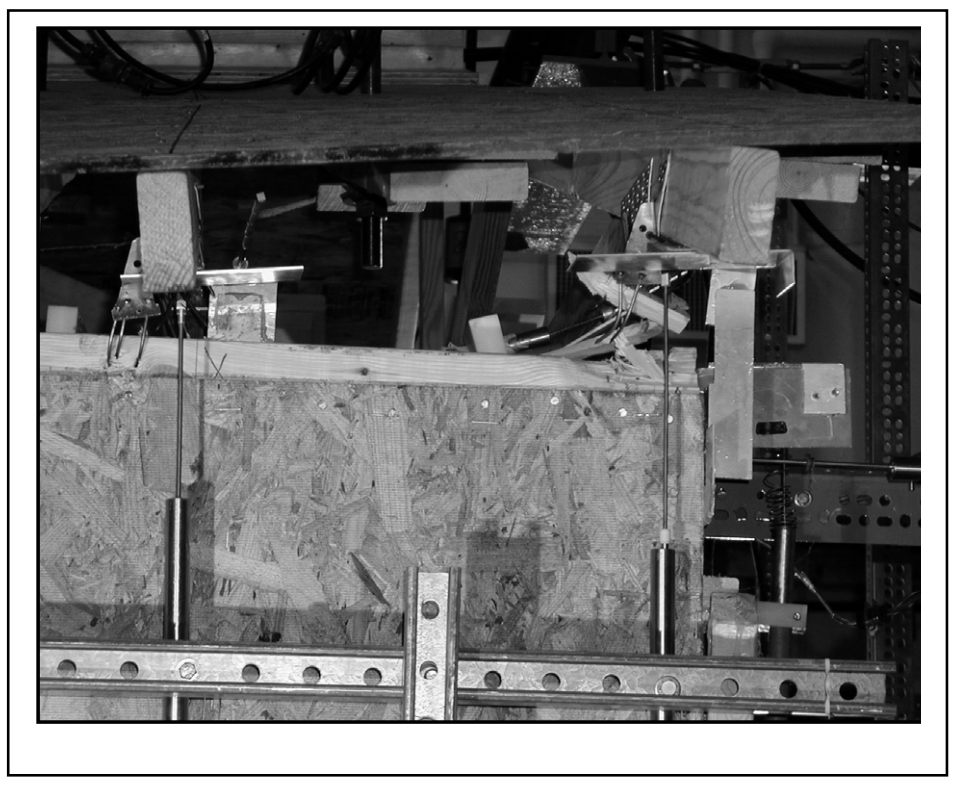

\section{Figure 2.26: Failure of Hurricane Clip Connection with Combined Load (NIST, 2003)}

three hurricane clips on that wall of the specimen allowed the specimen to resist almost $45 \%$ more load than the specimen with toe-nailed connections.

A comparison of the inner and outer truss responses with the two types of connections is illustrated on Figures 2.27 and 2.28 (NIST, 2003). These curves highlight the great variability that can occur in the response of wood frame construction. This could be caused by poor quality of the materials and the quality of workmanship. The wood properties can vary considerably, and are dependent on the wood type, dryness, and density, as well as cracks or other physical defects. The combined strength of the other three hurricane clips on that wall of the specimen allowed the specimen to resist almost $45 \%$ more load than the specimen with toe-nailed connections. 


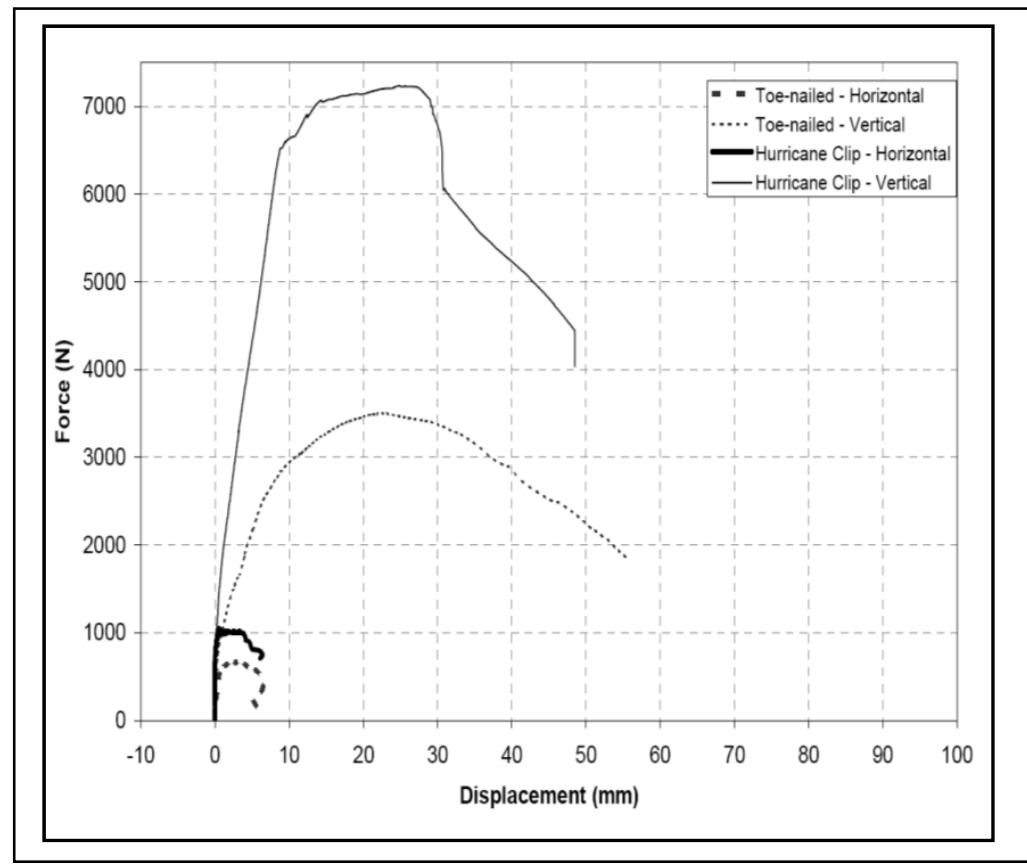

Figure 2.27: Comparison of Responses of Inner Trusses (NIST, 2003)

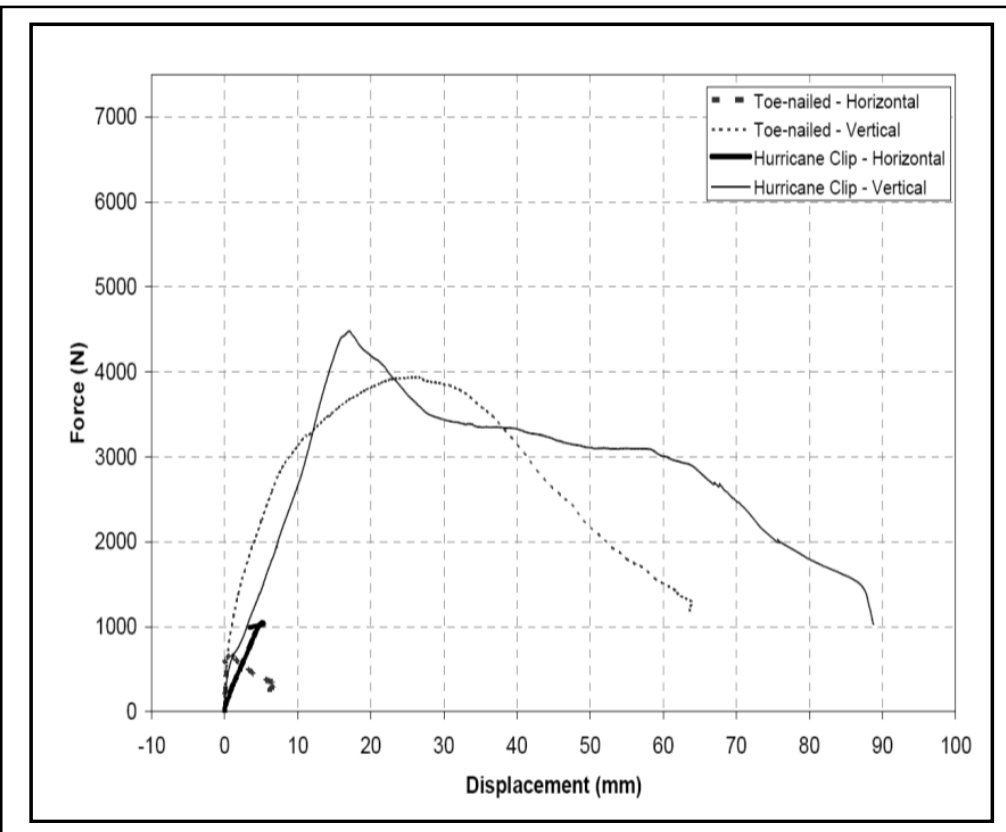

Figure 2.28: Comparison of Responses of Outer Trusses (NIST, 2003) 


\section{Full-Scale Wall of Wind Testing}

\subsection{Overview of Current Testing Methods}

Residential structures are susceptible to damage from tropical cyclone induced

wind, rain, and debris; however, these combined impacts are not well understood (NSB, 2007). In order to understand tropical cyclone wind-induced impacts and interactions, and increase the resiliency and preparedness of our built environment, scientists and engineers attempt to simulate the wind loads on structures. Several experimental methods are available for research and development of engineered structures:

- Wind-tunnel testing of small-scale models

- Full-scale field testing in the natural environment

- Full-scale laboratory testing of components and structures to simulated wind induced forces generated by actuators and pressure chambers

\subsubsection{Wind Tunnels}

Wind tunnel tests provide a wealth of useful data on scaled-models of buildings (see Figure 3.1) in wind flows, to within various degrees of approximation that simulate natural wind flows and their effects (Cermak et al., 1995). Some limitations of wind tunnel testing are due to:

- The use of highly simplified model structures with only the external geometry modeled

- Reynolds number effects 

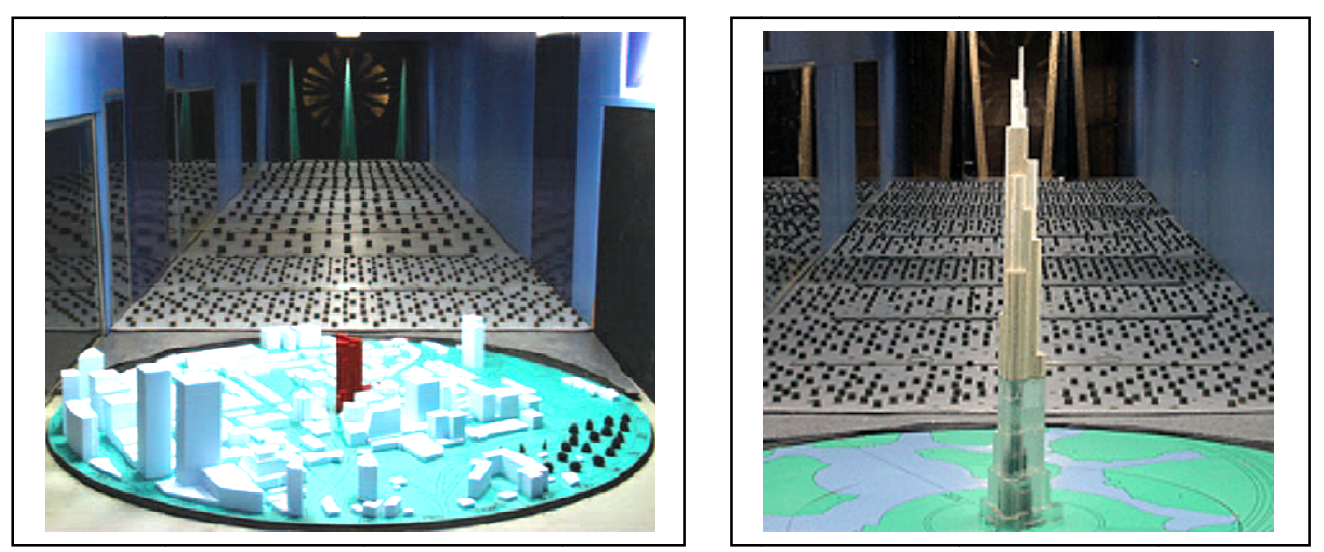

Figure 3.1: Wind Tunnel Tests on Scaled Models

- The general inability of small-scale simulations to help investigate the causes of failure of structural elements or connections or validate material performance

Yet, wind tunnels perform a useful function. They are at the origin of aerodynamics specifications in standards and codes. They have also used for ad-hoc tests.

In order to beneficially employ a wind tunnel one must recognize their limitations, these in turn depend on the test application. One example that wind tunnel tests must take into account is the Reynolds number dependence, which is significant for bodies with rounded shapes. On the other hand the dependence for bodies with sharp edges is less critical. Nevertheless, the inadequate simulation of small-scale turbulence, characteristic of boundary-layer wind tunnels, may affect the magnitude of negative pressures in the separation zones and the reattachment of the flow downwind of separation lines. For certain types of tests, such as some types of trussed frameworks, it is possible with little loss of accuracy to obtain results in uniform-smooth flows (Whitbread, 1980). 
Wind tunnel testing is sometimes thought of as an art, which requires judgment and experience in wind tunnel test development and in interpreting, adjusting, or correcting the obtained test results. Commercial boundary layer wind tunnel testing has been used for more than forty years. In that time there has been a gradual evolution from the rudimentary 1960's testing at Teddington, UK on models of the New York Trade Center's twin towers, to the more elaborate tests conducted in 2002 by two laboratories on models of the same towers. The evolution continues, as the tests elicited controversy, because their respective estimates of the towers' response differed by over $40 \%$ (Federal Building and Fire Safety Investigation of the World Trade Center Disaster, 2005).

\subsubsection{Wind Effects on Full-Scale Buildings}

Effective studies of wind effects on full-scale buildings have been limited (Levitan and Mehta, 1992) (see Figure 3.2). Commonly, the instrumentation, the power sources, and the recording devices fail in severe windstorms; which may lead to gaps of unrecorded data uncertainties on the response. Nevertheless, valuable field studies such as measurements conducted in Gaithersburg (Marshall, 1977), Aylesbury (Eaton and Mayne, 1975), Silsoe (Richardson et al., 1997) and Lubbock (Long et al., 2006) have provided valuable findings and data; these findings are crucial to the validation or otherwise of certain wind tunnel techniques. A major finding of such studies is that Reynolds number effects may cause peak pressures on low-rise buildings to be incorrectly simulated in a wind tunnel.

Some useful wind load data is collected on roofs of residential homes during tropical cyclones through the Florida Coastal Monitoring Program (FCMP) 

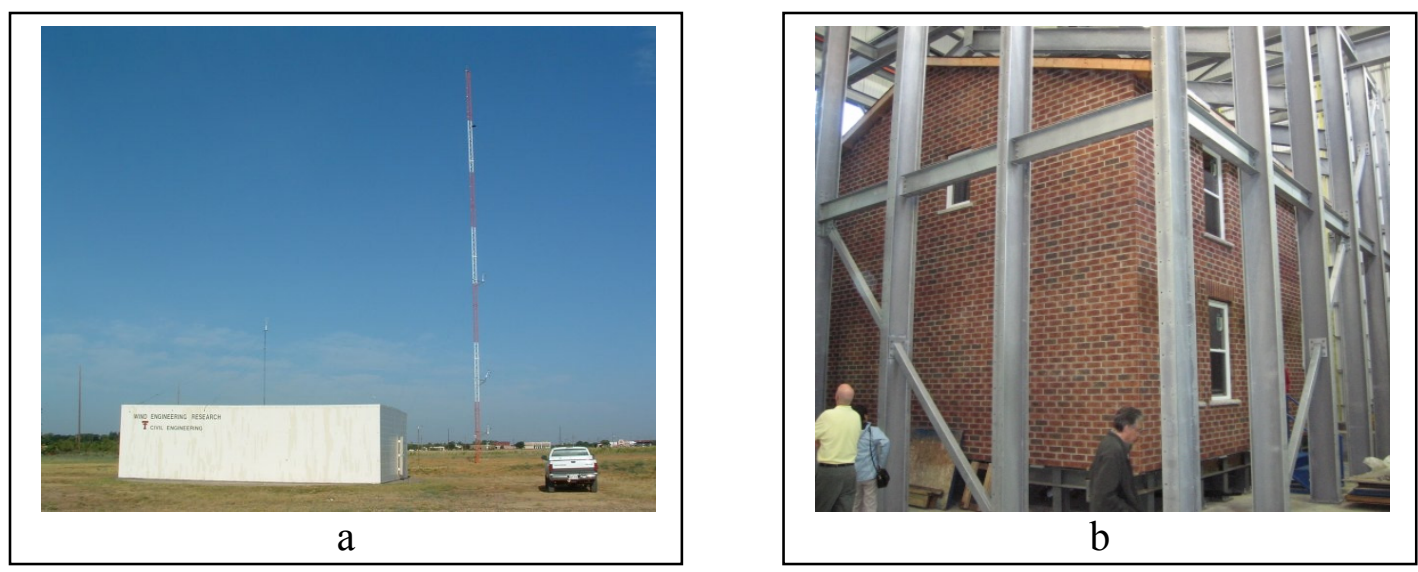

Figure 3.2: Wind Effects on Full-Scale Buildings, a) Field Studies of Wind Loads on Buildings (Texas Tech U.), b) Full-Scale Building Testing using Pressure Bags (U. of Western Ontario)

(http://users.ce.ufl.edu/ fcmp/overview/house.htm). The FCMP data report on actual wind dynamics and wind-structure interaction during an entire wind event. These data gives researchers a baseline to simulate wind effects in various testing facilities.

\subsubsection{Full-Scale Laboratory Testing of Components and Structures}

Most of the current full-scale testing of structural components and connections in structural laboratories are limited to individual components evaluations; such as windows, doors, and shutters (see Figure 3.3). The tests do not reflect the actual physical processes at work in a severe windstorm, owing to the absence of a "holistic building system" approach; i.e., the components are not treated, and cannot be expected to behave as part of the entire building. 


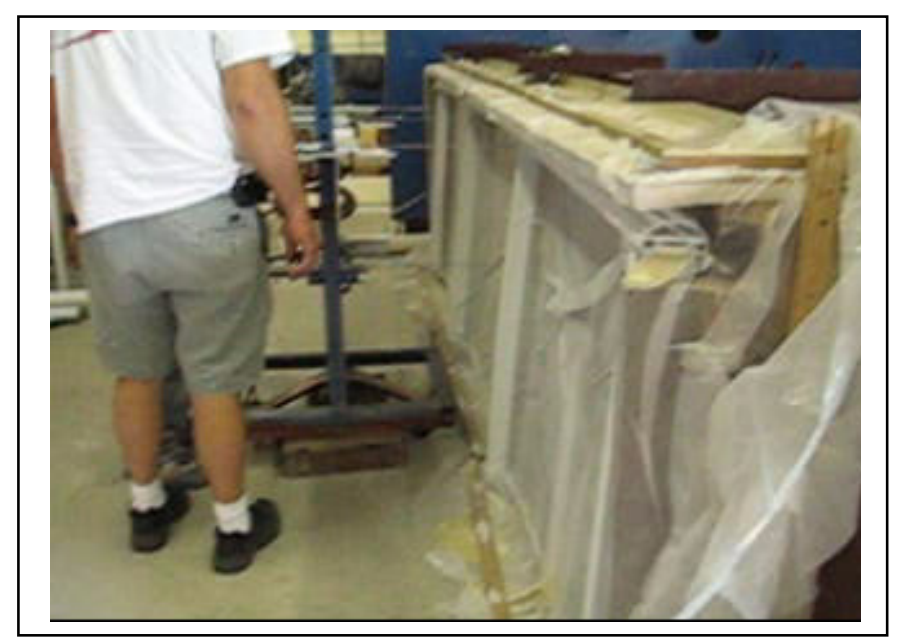

Figure 3.3: Full-Scale Testing of Individual Structural Components in Laboratories

A few of exceptions exist. The Wind Simulator of the University of Florida is one such exception. This mobile system is transported to the test site and used to evaluate the performance of a variety of low-rise structures in Florida (http://news.ufl.edu/2007/08/29/tropical cyclone-wind-machine/). Another exception is the "Three Little Pigs" facility in the University of Western Ontario, (http://www.eng.uwo.ca/research/ttlpp/default.htm), which enables pressures measured in a wind tunnel to be exerted on full-scale models using air bags (see Figure 3.2b).

\subsection{The Wall of Wind Laboratory}

A great deal of valuable information can be developed from existing testing techniques. Nevertheless, the complex wind-structure interactions that occur within a holistic structure during a tropical cyclone can only be determined by full - or large -scale experiments; using flow fields that closely represent those present in a tropical cyclone. Sound design of a structure's components and connections, imperative for damage 
mitigation of new and existing buildings, requires an innovative facility that will closely simulate tropical cyclone effects. This facility has to be capable of performing full- or large-scale experiments and destructive testing to establish the inherent weaknesses of components or connections built with real materials when subjected to various combinations of wind, rain, and debris impacts. The International Hurricane Center (IHRC) at Florida International University (FIU) has developed a full-scale testing simulator with these capabilities (see Figure 3.4).
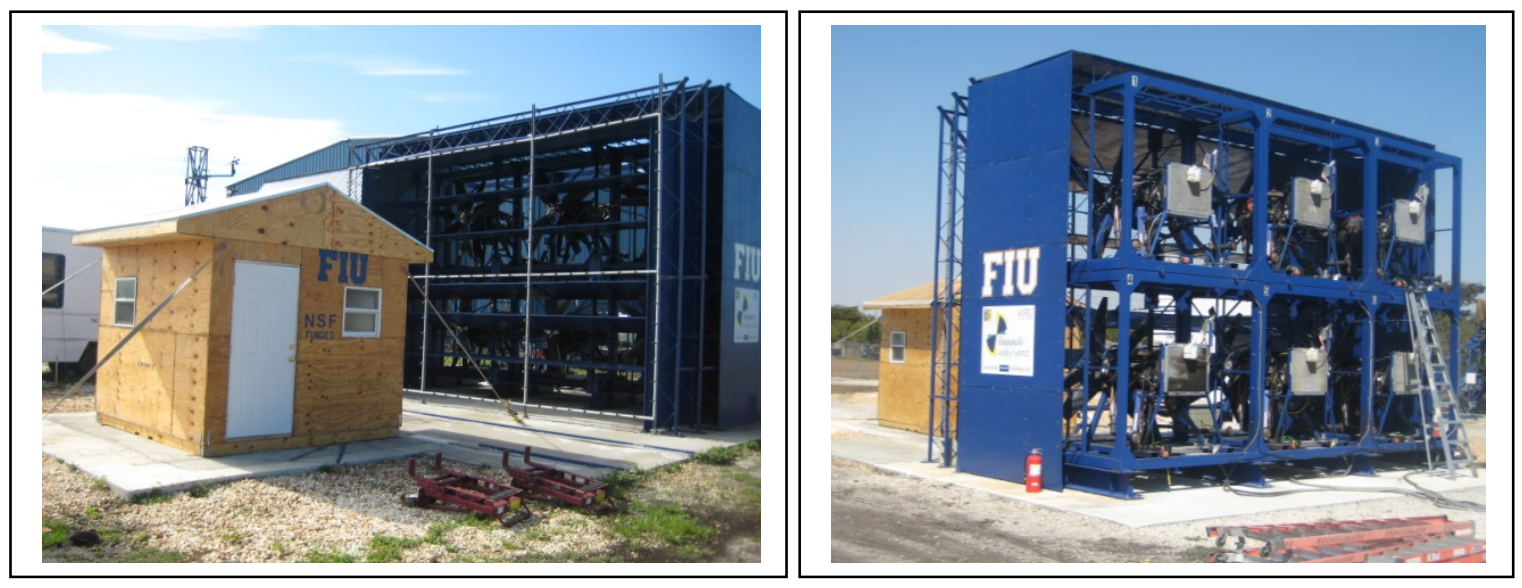

Figure 3.4: FIU-IHRC Full-Scale Testing Simulator

\subsubsection{Background}

In 2003, the wind engineering team at the IHRC, with Dr. Timothy Reinhold's assistance from the Institute for Business and Home Safety (IBHS) began planning the development of a full-scale wind testing facility named the "Wall of Wind" (WoW). The concept had been previously validated at small-scale by Mr. Charles Kennedy and Dr. Reinhold while at Clemson State University (Kennedy, 1999). The WoW facility would be capable of testing full-sized structures such as site-built or manufactured housing to 
failure under a range of wind and wind-rain conditions in a controlled and repeatable environment.

The WoW simulator facilitates structural testing to study the inherent weaknesses of structures subjected to tropical cyclone wind and rain impacts at full- or large-scale conditions. Testing for debris can also be incorporated with the addition of IHRC's aircannons currently operational as debris-propelling devices (see Figure 3.5). Using the WoW full-scale simulator, destructive testing, performance-based engineering, and failure-mode analysis can be studied and innovative mitigation techniques can be developed. The advantages of WoW full-scale testing on structural systems are:

1. WoW provides an environment of controllable, programmable, and repeatable testing. This allows the development and validation of retrofit systems and study new mitigation techniques and their validation without waiting passively for a storm event to validate the mitigation deigns.

2. Aerodynamic effects of tropical cyclone wind loads on structural components are simulated on the full-scale test structure, producing a more realistic dynamic loading pattern on the components.

3. WoW testing simulator enables the study of progressive damage to failure, so that wind characteristics associated with the beginning of specific damage could be determined and facilitate improvement on the prior design through performancebased engineering.

4. WoW enables testing under wind driven rain associated with tropical cyclones, which aids in the study of water infiltration through the specimen interfaces at different stages of weathering. 
5. WoW full-scale testing will allow the building test specimen and its components to be tested with time-dependent effects, non-linear effects, boundary conditions, and material properties.

6. WoW full-scale testing will eliminate difficult scaling issues and allow testing to realistic values of non-dimensional fluid mechanics parameters (Reynolds number, Strouhal number).

7. WoW used in conjunction with debris-propelling devices or air-cannons simulates flying debris under tropical cyclone conditions and studies their impacts on the test specimen.

7.1. Direct impact resistance of the test model components can be evaluated, demonstrating if components or connection systems are damaged or pierced by debris.

7.2. Breach of the building envelope (e.g., roof, soffit, door, vents, garages and windows) changes internal pressures in the building model and may generate different loading conditions on members and connections.

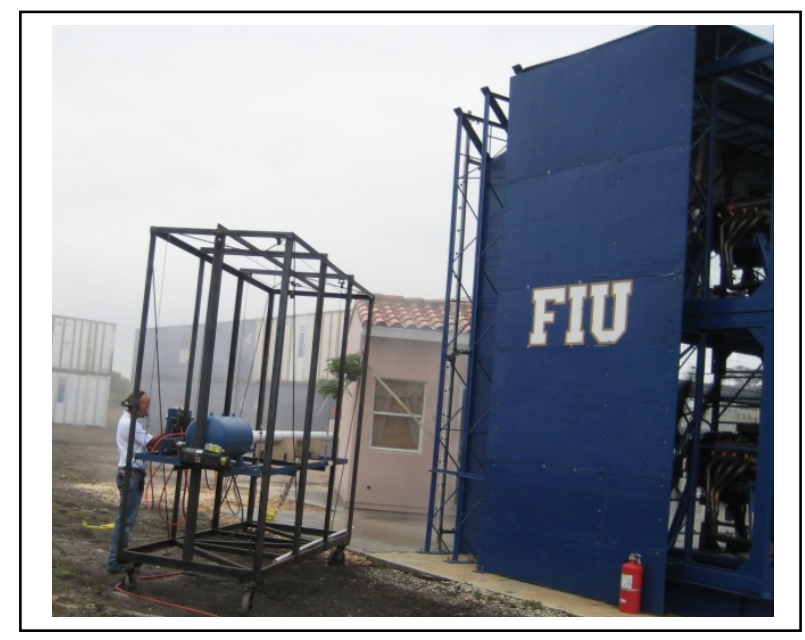

Figure 3.5: Debris Simulation Testing with Air-Cannon 


\subsubsection{Application of WoW Testing}

Full-scale destructive testing has the potential for improving safety during a major wind-event and may lead to the development of mitigation techniques needed in U.S. coastal states, vulnerable to tropical cyclones; and for affected states economy to remain sustainable. Similar to research based on car crash testing, which significantly enhanced automobile safety through the introduction of air bags and other safety features, the

development of wind damage mitigation technology for property loss reduction and human safety through WoW full-scale testing of building models and components until failure, allow the development of effective strengthening systems. Building components such as windows and doors are usually tested separately with air canons and actuators. On the other hand, the WoW allows full-scale destructive testing under wind, rain, and debris to determine the performance of the entire structure.

The WoW full-scale testing simulator can be employed to develop innovative tropical cyclone damage mitigation measures through Performance Based Engineering (PBE). PBE measures design adequacy based on tri-objective system performance, rather than the traditional component ultimate strength approach. In wind design, PBE can address issues of serviceability, safety, and occupant comfort for more variable environmental conditions.

\subsubsection{WoW Testing Methodology}

The basic approach of the WoW testing is to subject a full-scale model of a structure to simulated tropical cyclone effects generated by the WoW. Different combinations of high wind, wind-driven rain, and flying debris are simulated. The 
responses of the structure and its components to these combinations are recorded through instrumentation. Measurements are obtained regarding:

- Aerodynamic pressures

- Member deformations

- Displacements of components and connections (including non-linear effects)

- Volume of rain infiltration into the system

- Damages from debris

The weak-links in the structure are revealed by evaluation of system performance under different combinations of tropical cyclone conditions. This information will lead to four types of design improvements:

1. Aerodynamic modifications to alleviate wind effects; like vortex-suppression systems on sharp edges and corners at and near roof edges and wall corners, which considerably reduce suctions and damages (see Figure 3.6).

2. Development of water-infiltration mitigation measures, such as development of water-tight soffits to reduce rainwater infiltration (see Figure 3.7).

3. Structural strengthening of the members to resist the high wind loading.

4. Development of products such as advanced composite panels to reduce debris impact damages during tropical cyclones. 


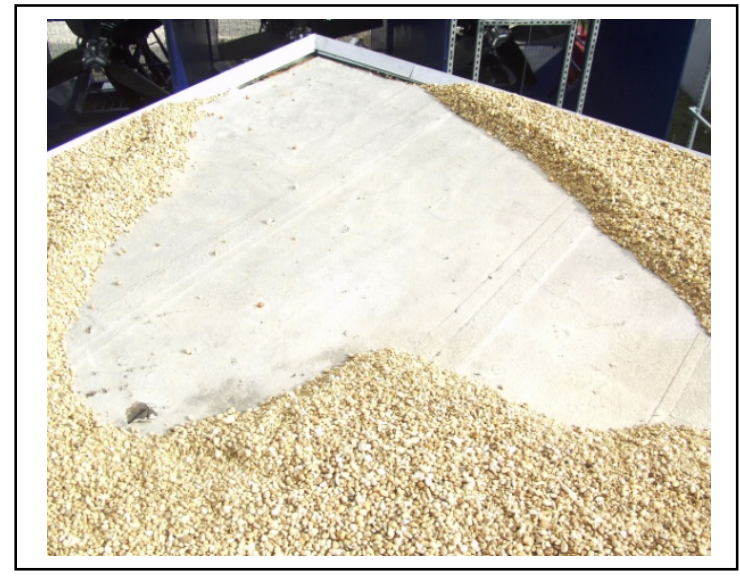

Figure 3.6: Vortex-Suppression Systems

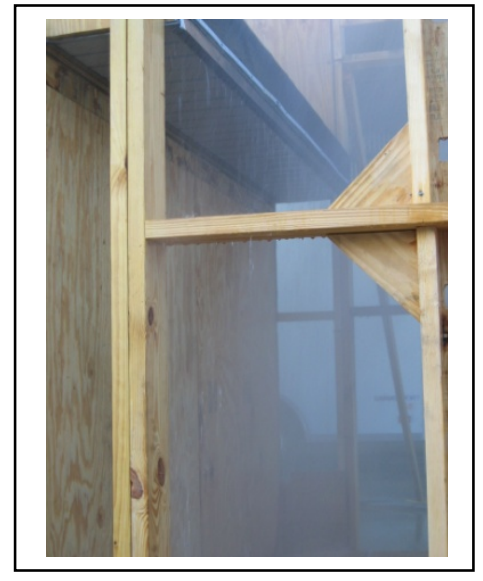

Figure 3.7: Water-Tight Soffits

\subsubsection{Description of the WoW Facility}

The initial development of the WoW concept is marked by the construction of the 2-fan WoW (see Figure 3.8) that generates Category 3 winds and simulates horizontallyflowing rain (Gan Chowdhury et al., 2009). Table 3.1 lists the 2-fan WoW flow

\begin{tabular}{|l|c|c|c|}
\hline & $\begin{array}{c}\text { TI } \\
(\%)\end{array}$ & $\begin{array}{c}L_{u}^{x} \\
(\mathrm{~m})\end{array}$ & $G F(T, t)$ \\
\hline 2-fan WOW flow & 10.6 & 66.2 & $\begin{array}{c}G F(6 \mathrm{~min}, 0.1 \mathrm{sec})=1.28 \\
G F(6 \mathrm{~min}, 3 \mathrm{sec})=1.18\end{array}$ \\
\hline Hurricane Lili (2002)* & 17.8 & $\begin{array}{c}67.0(5 \text {-min segment } \\
\text { length })\end{array}$ & $G F(1 \mathrm{hr}, 3 \mathrm{sec})=1.53$ \\
\hline
\end{tabular}

* Based on 1-hour wind data at 5-meter height of flat open land, which was collected by Florida Coastal Monitoring Program (FCMP).

Table 3.1: Wind Characteristics of 2-fan WoW and Comparison with Real Hurricane (Gan Chowdhury et al., 2009) 


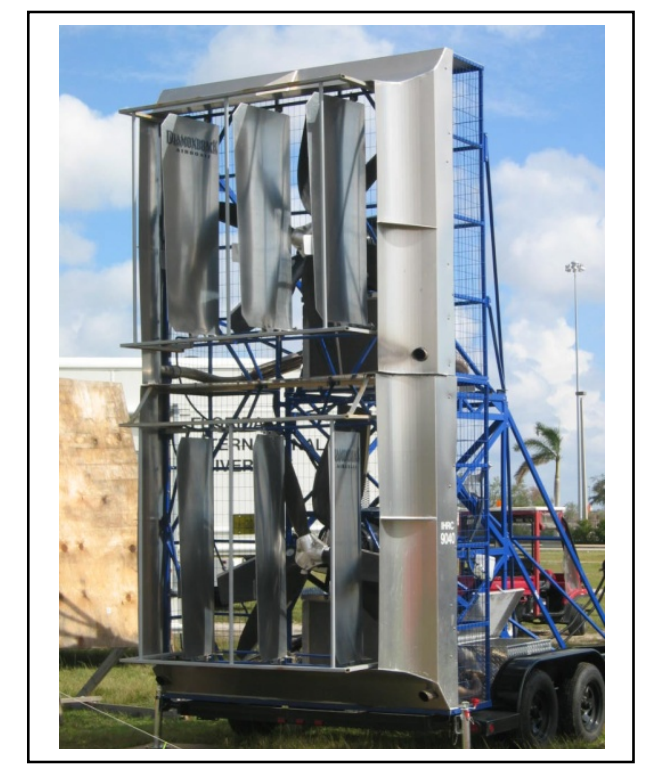

Figure 3.8: 2-Fan WoW

turbulence intensity $(T I)$, longitudinal integral length scale $\left(L_{u}^{x}\right)$ and gust factor $(G F(T, t))$, the latter being defined as:

$$
G F(T, t)=u_{\max }(T, t) / U(T)
$$

Where, $u_{\max }$ is the maximum value of the wind speeds averaged over the intervals of length $t$, and $U$ is the mean wind speed averaged over the time period $T$. Phase I flow characteristics are compared in Table 3.1 with those of Tropical cyclone Lili (2002), measured by the FCMP tower in a flat open field at Lydia, LA (Yu, 2007). The differences are due to the lack of a controllable turbulence generating system for the 2fan WoW. The 2-fan system was employed on the following research

- Metal Roof Edge Fascia Testing (see Figure 3.9)

- Product Testing For Tropical cyclones

- Preliminary Testing On Utilities (see Figure 3.10) 


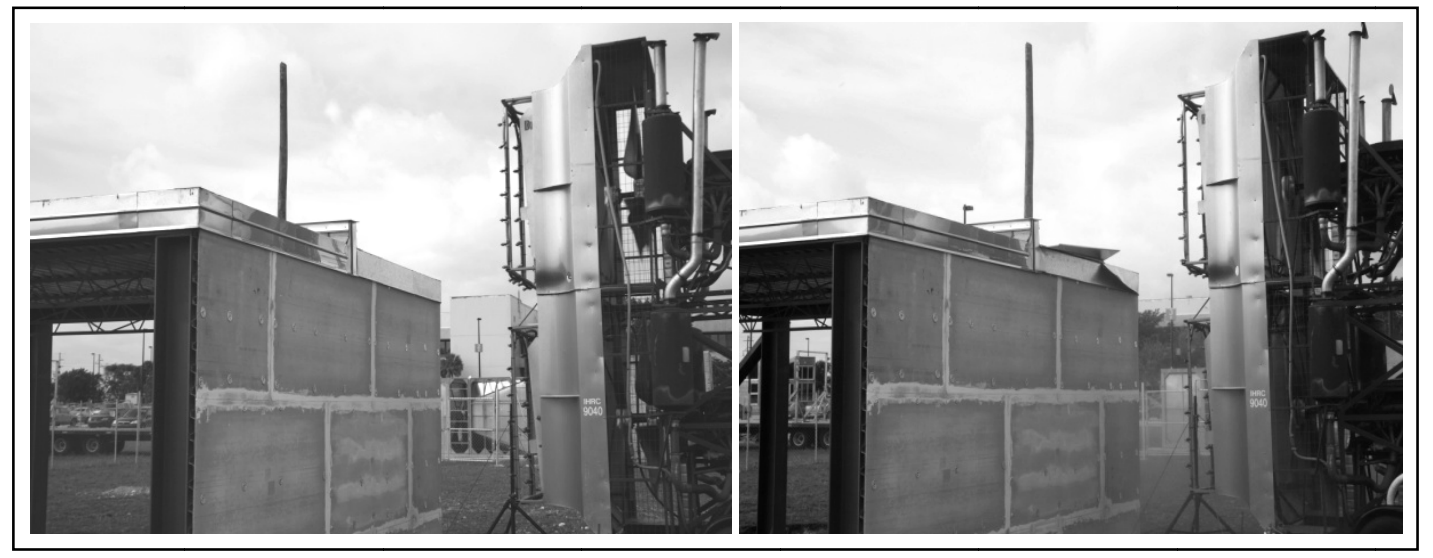

Figure 3.9: Metal Roof Edge Fascia Testing

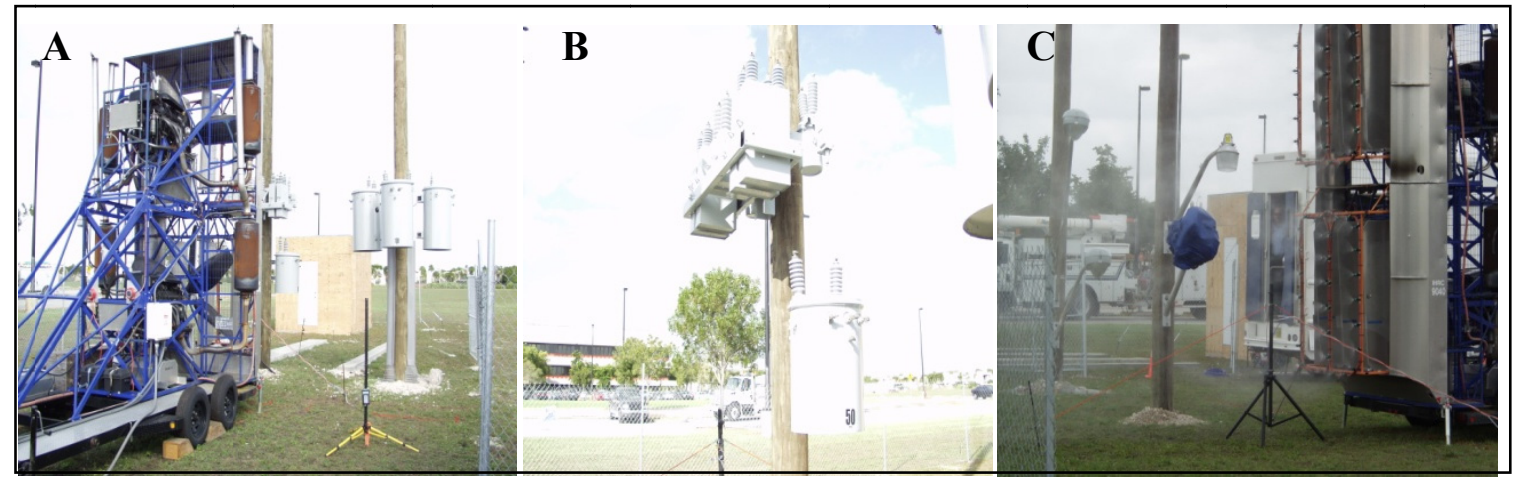

Figure 3.10: Performance Testing of FPL Structures, (A) Three Transformers and PVC/PE U-Guard, (B) Single Transformer and Capacitor Bank, (C) Cutoff Cobra Head and Open Bottom Luminaries

A larger, more powerful 6-fan WoW (see Figure 3.4) is currently in operation on the FIU Engineering campus. The 6-fan system can generate up to $56.5 \mathrm{~m} / \mathrm{s}(126 \mathrm{mph})$ winds, with a wind field large enough to engulf a full-scale low-rise single-story building model with real life components. The 6-fan WoW testing facility is sponsored by RenaissanceRe Holdings Ltd., one of the largest international property catastrophe re- 
insurers. The current research on innovative roof-to-wall connection development has been performed using the 6 -fan WoW system. The flow simulation for the 6-fan WoW is described in the following sections.

\subsubsection{Simulation of Tropical Cyclone Characteristics}

Atmospheric turbulence strongly influences the wind flow around a structure and the aerodynamic loading on the structure (see Figure 3.11). Many researchers, including Kareem and Cermak (1979), Li and Melbourne (1995) and others have been documented the role of wind turbulence in the aerodynamics of bluff bodies, such as buildings. The following are several useful descriptors of atmospheric turbulence (Simiu and Scanlan, 1996):

- $\quad$ Co-spectra, indicates the extent to which wind fluctuations with various frequencies at different points in space are mutually coherent

- $\quad$ Turbulence Intensity, e.g., longitudinal turbulence intensity given by the ratio of the root mean square of the longitudinal ( $x$-direction) wind speed fluctuations $u(z, t)$ to the longitudinal mean wind speed $U(z)$ at elevation $z$

- $\quad$ Integral Turbulence Lengths, i.e., measures of the overall sizes of the eddies associated with the various turbulent fluctuation components

- $\quad$ Turbulence Spectra, (defined by spectral density functions $S_{x}(z, n), S_{y}(z, n)$, $\left.\mathrm{S}_{z}(\mathrm{z}, \mathrm{n})\right)$ used to estimate the frequency content of wind speed fluctuations in the $\mathrm{x}, \mathrm{y}$, and $\mathrm{z}$ directions 


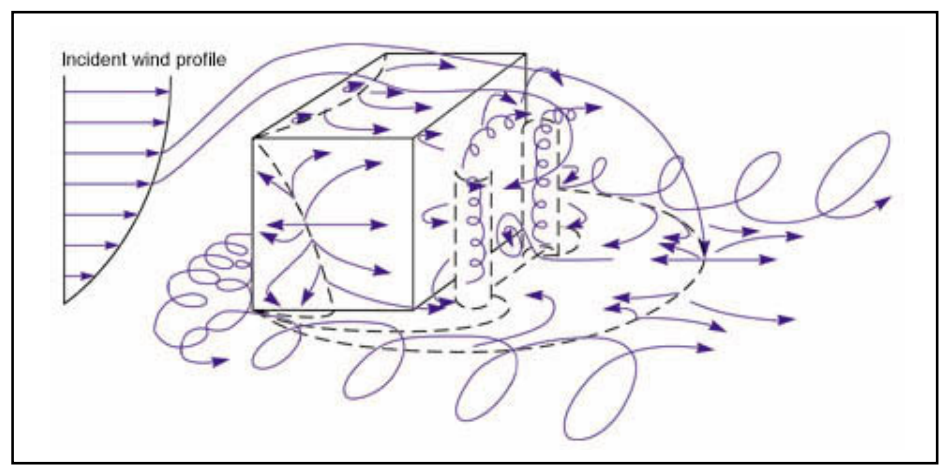

Figure 3.11: Wind-Structure Interaction for Building Structures

The accuracy of the WoW testing and its success in helping to understand windstructure interaction and mitigating tropical cyclone effects will depend on the research aimed at stimulating a wind field that reasonably resembles wind mean and turbulence characteristics for real tropical cyclones.

Transient flow field characteristics have been simulated actively in small-scale laboratory experiments the multiple-fan systems sharp changes in gust magnitudes were successfully simulated. To achieve better simulation of flow features at high frequencies, oscillating vanes were incorporated in the flow by Nishi and Miyagi (1995). Methods already proven for gust and turbulence generation for small scale experiments will be used for the generation of velocity profile, turbulence, and gust effects for the WoW. Rapid variations of the fan engine speed (achieved by servo-control) simulate longitudinal turbulence. Horizontal airfoils enhance the control of vertical fluctuations in the flow through multiple sinusoidal or quasi-sinusoidal control functions (see Figure $3.12)$. 


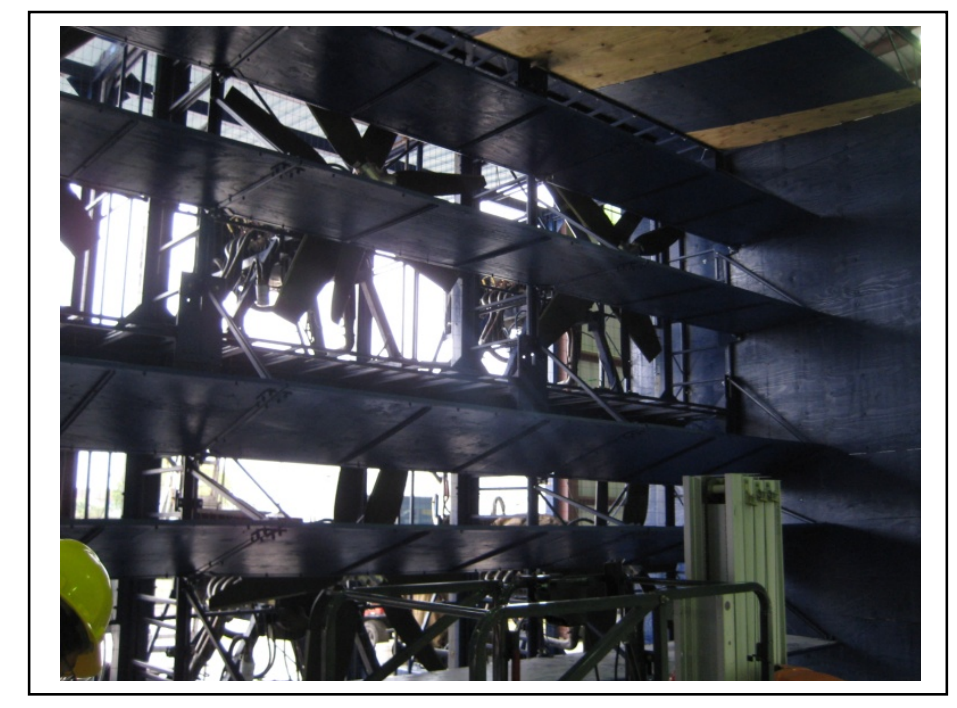

Figure 3.12: Horizontal Airfoils for Vertical Fluctuations in the Flow

As a member of the FCMP, the IHRC research team has invaluable highresolution surface wind data (Masters et al., 2005) collected during tropical cyclones Floyd, Francis, Isabel, Iván, Jeanne and Lili. The FCMP data generated mean wind speed, gust factor, turbulence intensity, integral length scale, and turbulence spectra are used as baseline wind field characteristics to closely simulate tropical cyclone winds in the WoW facility.

In view of the deficiencies of the preliminary 6-fan WoW system an investigation was undertaken using a small-scale (1:8) WoW model to develop the target wind flow generating devices and methods efficiently (see Figure 3.13). The mean and turbulence characteristics of the flow were improved markedly through the application of passive devices and of active controls designed on the basis of analyses of tropical cyclone wind data. The knowledge gained from the small-scale WoW was used to enhance the fullscale WoW wind field parameters (Huang et al., 2008). 


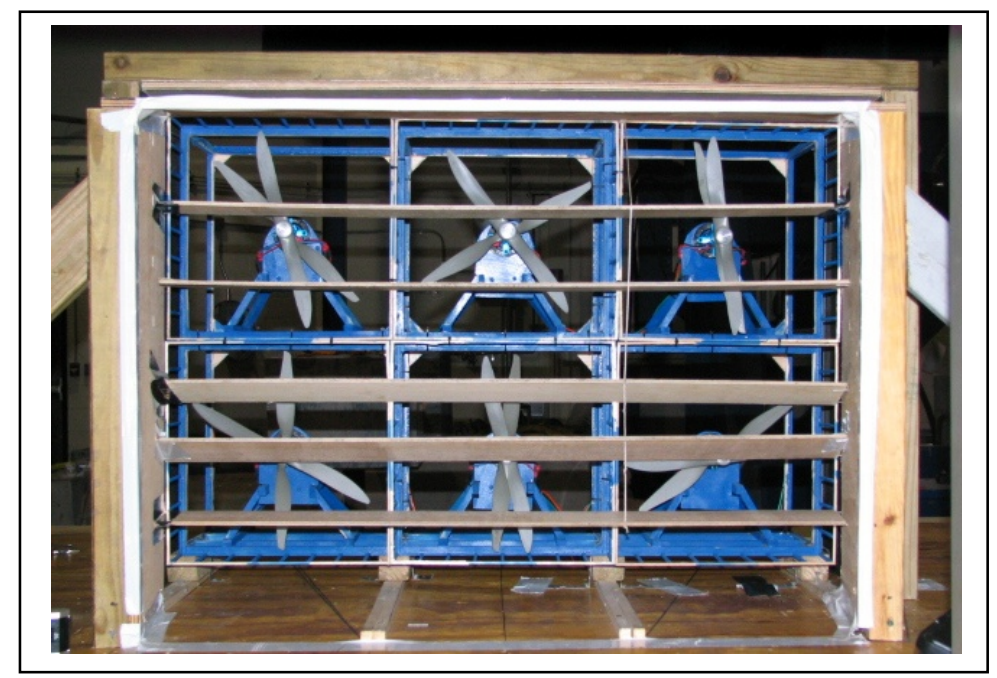

Figure 3.13: Small-Scale Model Configuration (Liu, 2008)

In the revised full-scale WoW configuration, it was possible to generate reasonable mean wind speed profiles and turbulence characteristics closely resembling tropical cyclone conditions (Huang et al., 2009). To produce more severe hurricanes, additional research is currently being performed on redesigning the WoW fan engines, so that high mean rpm be maintained while adequate turbulence generation is achieved.

Just as in the small-scale WoW, the results in full-scale WoW show that the application of fluctuating waveforms can greatly influence and improve the turbulence characteristics. Application of quasi-periodic sums of sinusoidal signals, designed on the basis of real tropical cyclone wind data analyses, succeeded in adding low-frequency quasi-periodic components to the WoW flow and improving the longitudinal power spectral densities, turbulence intensities, integral length scales, and gust factors. The application of quasi-periodic signals also improved the vertical turbulence for the revised full-scale WoW configuration. The wind characteristics of Phase II of the WoW are shown in Table 3.2. 
The WoW has the capability of generating wind-driven rain (WDR) to re-create, as closely as possible; tropical cyclone conditions (Bitsuamlak et al., 2009) (see Figure 3.14). The challenge is to achieve an accurate raindrop size distribution in the flow field. The WoW used with debris-propelling devices provides the capability to simulate the behavior of wind-borne debris generated by tropical cyclones and study their effects on structures. Holmes et al. (2006) present numerical modeling of sphere and square plate trajectories which can be used for debris simulation in the WoW.
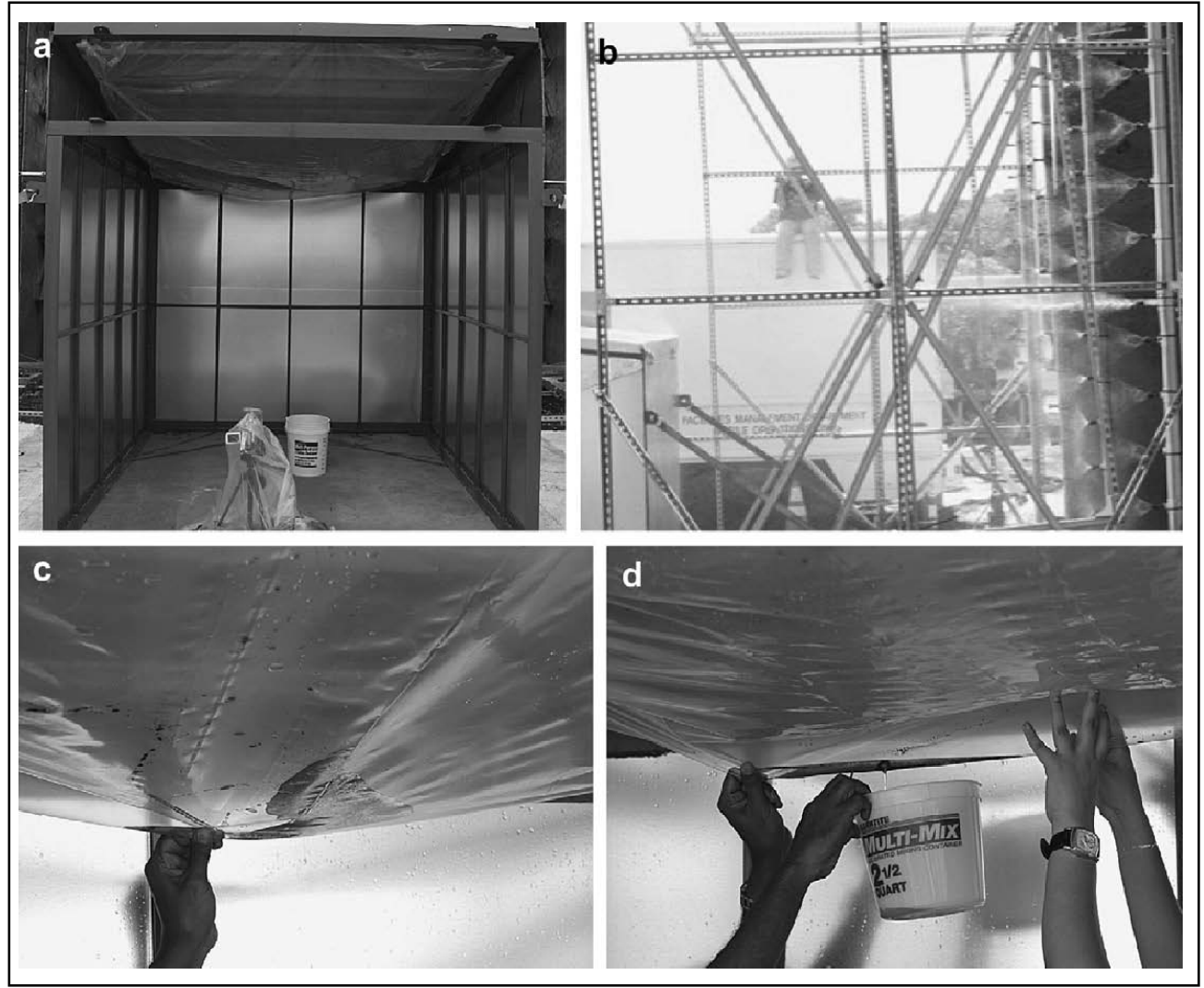

Figure 3.14: Water monitoring and collection setup. (a) Complete setup with camera and plastic ceiling, (b) the SWB test specimen from bird's view and (c) leaked water through the roof layer and (d) water collection - (Bitsuamlak, 2009) 


\begin{tabular}{|c|c|c|c|c|c|}
\hline $\begin{array}{c}\text { Case } \\
\text { (Waveform; mean } \\
\text { rpm) }\end{array}$ & $\begin{array}{l}\text { Wind speed } \\
\qquad(\mathrm{m} / \mathrm{s})\end{array}$ & $\begin{array}{l}\mathrm{TI}_{\mathrm{u}} \\
(\%)\end{array}$ & $\begin{array}{l}\mathrm{TI}_{\mathrm{w}} \\
(\%)\end{array}$ & $\mathrm{GF}(\mathrm{T}, \mathrm{t})$ & $\begin{array}{l}\mathrm{L}_{\mathrm{u}}^{\mathrm{x}} \\
(\mathrm{m})\end{array}$ \\
\hline $\begin{array}{c}\text { Revised WoW } \\
\text { (Flat waveform; } \\
4,000)\end{array}$ & $\begin{array}{c}36.7 \\
\text { (1-min mean } \\
\text { speed) } \\
38.2 \\
\text { (3-sec peak gust) }\end{array}$ & 4.6 & 5.4 & $\begin{array}{c}G F(6 \mathrm{~min}, 3 \mathrm{sec})= \\
1.06 \\
G F(1 \mathrm{~min}, 3 \mathrm{sec})= \\
1.04\end{array}$ & 36.6 \\
\hline $\begin{array}{c}\text { Revised WoW } \\
\text { (W3 sinusoidal } \\
\text { waveform; 3,500) }\end{array}$ & $\begin{array}{c}33.7 \\
\text { (1-min mean } \\
\text { speed) } \\
41.8 \\
\text { (3-sec peak gust) }\end{array}$ & 19.9 & 6.7 & $\begin{array}{c}G F(6 \mathrm{~min}, 3 \mathrm{sec})= \\
1.33 \\
G F(1 \mathrm{~min}, 3 \mathrm{sec})= \\
1.24\end{array}$ & 134.7 \\
\hline $\begin{array}{l}\text { Revised WoW } \\
\text { (W4 quasi- } \\
\text { periodic } \\
\text { waveform; 2,855) }\end{array}$ & $\begin{array}{c}28.8 \\
\text { (1-min mean } \\
\text { speed) } \\
38.3 \\
\text { (3-sec peak gust) }\end{array}$ & 23.8 & 7.1 & $\begin{array}{c}G F(6 \mathrm{~min}, 3 \mathrm{sec})= \\
1.42 \\
G F(1 \mathrm{~min}, 3 \mathrm{sec})= \\
1.33\end{array}$ & 89.9 \\
\hline $\begin{array}{c}\text { Preliminary } \\
\text { WoW } \\
\text { (Flat waveform; } \\
\text { 4,000) }\end{array}$ & $\begin{array}{c}36.3 \\
\text { (1-min mean } \\
\text { speed) } \\
38.5 \\
\text { (3-sec peak gust) }\end{array}$ & 6.0 & - & $\begin{array}{l}G F(6 \mathrm{~min}, 3 \mathrm{sec})=1.09 \\
G F(1 \mathrm{~min}, 3 \mathrm{sec})=1.06\end{array}$ & 59.6 \\
\hline FCMP* & $\begin{array}{c}22.3 \\
\text { (1-min mean } \\
\text { speed) } \\
28.3 \\
\text { (3-sec peak gust) }\end{array}$ & 17.8 & 7.0 & $\begin{array}{c}G F(1 \mathrm{~min}, 3 \mathrm{sec})= \\
1.27 \\
G F(6 \mathrm{~min}, 3 \mathrm{sec})= \\
1.43 \\
G F(1 \mathrm{hr}, 3 \mathrm{sec})=1.59\end{array}$ & 98.7 \\
\hline
\end{tabular}

* Mean results of three observation sites (Iván - 1, Iván - 2, and Lili) at which data were collected by Florida Coastal Monitoring Program (FCMP).

Table 3.2: Wind characteristics of Full-Scale WoW (Huang et al., 2008) 


\subsubsection{WoW Instrumentation}

The WoW test specimens (houses or other structures) are instrumented with strain gages, linear voltage differential transducers (LVDT), string potentiometers (String Pots), load cells, and pressure transducers to gain maximum information about the response characteristics of the different components (see Chapter 5). The displacement sensors measure both absolute and relative motions of the components. Motions are recorded in all 3 directions, $\mathrm{X}, \mathrm{Y}$, and $\mathrm{Z}$. The pressure transducers measure the aerodynamic pressures on the model surface. Water infiltration into the test specimen at different stages of testing will be measured by rain collecting modules mounted inside the building model.

\subsubsection{WoW Research Goals}

Full- or large-scale aerodynamics and destructive testing helps to determine the wind effects and structural behavior leading to failure; thus facilitating design improvements. The 6-fan WoW testing, used in conjunction with structural reliability, factorial experimental design, and other techniques, may allow for better understanding of tropical cyclone-structure interaction and inherent design weaknesses leading to failure, thus facilitating the development of advanced mitigation techniques to enhance resiliency of coastal buildings and infrastructure against windstorms.

Tropical cyclone damage mitigation technologies can be tested on components, but their actual behavior within a building system can in most instances be determined only by testing a full-scale, complete (holistic) system. Using the WoW testing, retrofit 
and mitigation techniques can be validated in a controllable, programmable, and repeatable test environment, such as:

- $\quad$ Mitigation of Roof Damage

- Development of High Performance Materials

- $\quad$ Soffit resistant Materials

- Development of Innovative Roof-to-Wall Connection System.

The current work is based on the use of WoW testing on holistic test specimens to develop a new non-intrusive roof-to-wall connection system.

\subsection{Summary}

Loss due to tropical cyclones is one of the largest and most pervasive risks faced by the U.S. Full-scale aerodynamic and destructive testing of houses and structures using the WoW, developed at the IHRC, will help to change the public's perception of building safety and contribute to the development of a "culture of preparedness." The current research focuses on the development of an innovative inter-component connection system to strengthen houses against extreme wind events through systemic hybrid testing using the full-scale WoW testing facility and the SCL laboratory at FIU. 


\section{Initial Development of Fiber Reinforced Polymer Connections}

\subsection{Introduction}

In an effort to provide the timber construction industry with an alternative roof-towall connection system, researchers at Florida International University (FIU) are developing an innovative FRP connection system (Canbek, 2009). The methodology is to perform hybrid testing at the Structural and Construction Laboratory (SCL) and the Wall of Wind (WoW) facilities. To develop the proof of concept, extensive testing was carried out at the component and full-scale level to determine feasibility of FRP connection as part of the vertical load path system (Canbek, 2009). This chapter summarizes the initial testing of FRP connections at the SCL.

A direct shear test was performed to evaluate the strength of the FRP-timber interface in shear. Next, three phases of component level FRP tie connection tests were conducted using a Universal Testing Machine (UTM). Several FRP tie connection configurations were tested according to the American Standards for Testing of Materials (ASTM) D 1761 standard (ASTM, 2006). The most viable type of FRP connection, in terms of cost-effectiveness, applicability and efficiency was selected for further research and development. The FRP-tie was then incorporated in a full-scale laboratory test specimen to validate and evaluate the in-situ performance of the tie. The uplift forces from an extreme wind event were simulated using hydraulic jacks controlled by an electric pump. 


\subsection{Rationale for a Non-Intrusive Connection System}

The roof-to-wall failures of timber residential structures caused by extreme wind events demonstrate the necessity of a sound roof-to-wall connection system, capable of transferring the wind induced forces through the vertical load path into the foundation. The deficiencies of conventional hurricane clips at the roof-to-wall interface are listed below:

- The connection with metal clips may fail prematurely through nail pull-out at a much lower load than the specified capacities recommended by the manufacturer

- Metal clips can create weak zones in the timber, due to closely spaced nails used for attaching the connector to the timber connection

- Metal clips may make the structure susceptible to water intrusion due to holes created by excessive nail penetrations

- In humid coastal regions harsh environmental conditions may weaken the connection by corroding the metal clips and/or a toe-nailed connection

In order to overcome the above mentioned shortcomings of metal connectors, an innovative connection design was conceived using advanced high-performance fiber composite polymers (FRP).

\subsection{Past Work on FRP-Timber Interaction}

Several studies have aimed at investigating the FRP-timber bonding characteristics and the strengthening of timber members with FRP. Davalos et al. (2000) investigated the Mode I fracture of FRP-timber bond interface using a contoured doublecantilevered beam specimen (see Figure 4.1). The goal was to establish fracture 
toughness data to predict whether de-lamination of FRP will occur under actual service conditions. Results showed that Hydroxyl Methanol Resorcinol (HMR) performed much better than Resorcinol-Formaldehyde (RF) as a coupling agent with higher strength and lower coefficient of variation values in dry conditions. Under wet conditions, the difference in specimens tested with HMR and RF became more apparent.

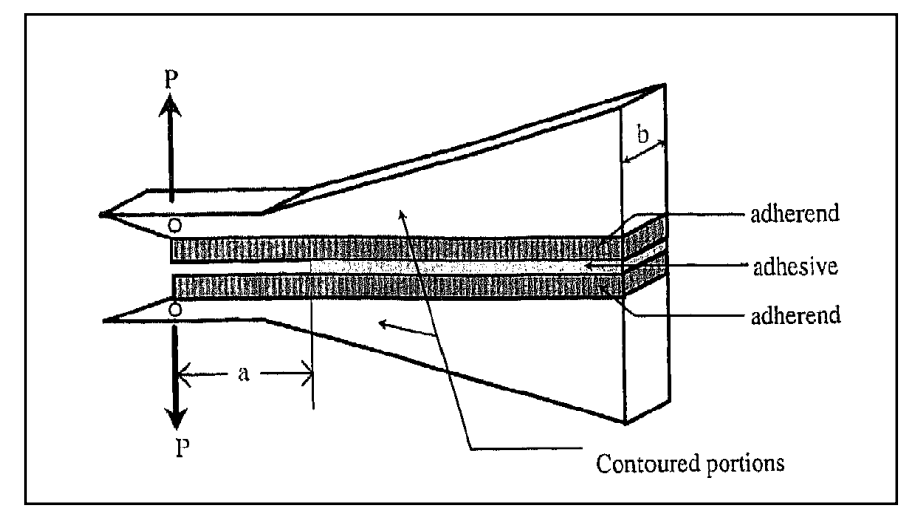

\section{Figure 4.1: The Contoured Double-Cantilevered Beam Specimen (Davalos et al., 2000)}

Jia and Davalos (2004) conducted a study to understand the effect of load ratio on Mode-I fatigue fracture of FRP-timber bonded interfaces. For this study, they used the contoured double cantilevered beam specimen show in Figure 4.1. The adherents used in this study were red maple timber and pultruded Phenolic FRP laminate. The FRP-timber interface was bonded using RF. After processing the results of the experiments, the following three equations were developed by modifying Paris Law: 


$$
\begin{aligned}
& \frac{d a}{d N}=2 \times 10^{-17}\left(\frac{\Delta G}{(1-R)^{0.79}}\right)^{5.54} \\
& \frac{d a}{d N}=2 \times 10^{-15}\left(\Delta G^{0.87} G_{\text {min }}^{0.13}\right)^{5.34} \\
& \frac{d a}{d N}=9 \times 10^{-16}\left(\Delta G^{0.07} G_{\text {mean }}^{0.93}\right)^{5.59}
\end{aligned}
$$

where $a$ is the crack length, $N$ is the number of cycles, $G$ is the energy release rate, as shown in Equation 4.4, $C$ is the compliance, $b$ is the thickness of the specimen, $P$ is the applied load, and $R$ is the load ratio $\left(P_{\min } / P_{\max }\right)$. Stating that any of these equations yields satisfactory results for determining the effect of load ratio on crack propagation, authors recommended Eq. (4.3) for use in engineering applications (Jia and Davalos, 2004).

$$
G_{\min , \max }=\frac{P^{2}{ }_{\min , \max }}{2 b} \frac{d C}{d A}
$$

Tascioglu et al. (2003) studied the durability and shear strength of Eglass/Phenolic composite and treated timber bond interface. The goal of the study was to evaluate the effects of preservatives and pre- and post-treatment applications on FRPtimber bond interface. After conducting the modified ASTM D 905 (ASTM, 2008) and ASTM D 2559 (ASTM, 2004) tests, the authors concluded that preservative treatments and pre- and post-treatment applications have significant negative effects on the FRPtimber bond strength (Tascioglu et al., 2003). 
Triantafillou (1997) investigated the shear strengthening of timber members using FRP. They tested twenty one beams, which were designed to fail in shear, and strengthened them using FRP with varying configurations and coverage areas. The study showed that externally bonded FRP can significantly increase the shear capacity of timber beams, and that the coverage area of FRP may be optimized following the basic principles of mechanics (Triantafillou, 1997).

Plevris and Triantafillou (1995) conducted a research on creep behavior of FRPreinforced timber members. An analytical study was performed to model the timber beams reinforced with carbon FRP (CFRP) in three point bending. It was observed that creep behavior of FRP-reinforced timber beam was dominated by the creep behavior of timber itself. Also, it was noted that FRP would make a significant impact on the creep performance of the timber beam, as it generally decreases the deformations and increases the ultimate strength (Plevris and Triantafillou, 1995).

\subsection{FRP Tie Roof-to-Wall Connection Development Tests}

\subsubsection{Test Specimen and Setup}

Viable FRP roof-to-wall component connections were designed and tested according to specifications of the ASTM D 1761 (ASTM, 2006) (Canbek, 2009). The specimens simulated, as close as possible an actual roof-to-wall connection. Figure 4.2 shows the schematics of the test specimen. They consisted of 2-14 inch long double top plates and a 33 inch long joist (22 inch clear spacing); all members used were 2 x 6 inch No 2 Spruce-Pine-Fir (SPF) lumber. The FRP was attached at two ends of the joist using two-part epoxy according to the manufacturer's specifications. The specimens were 


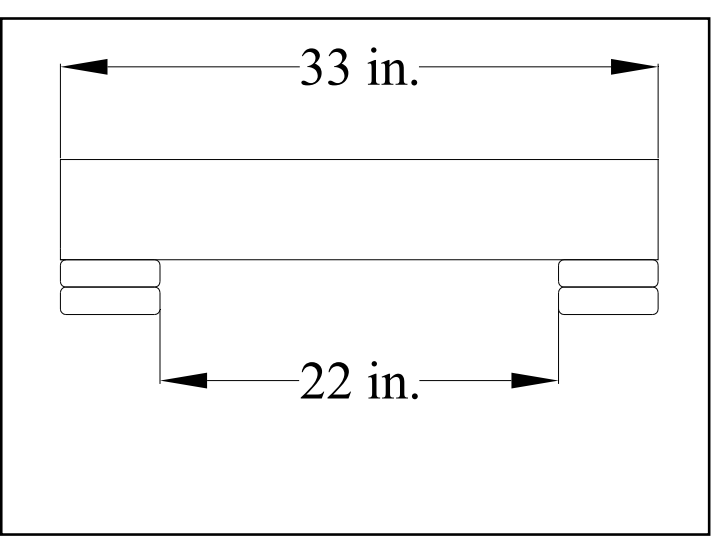

Side View

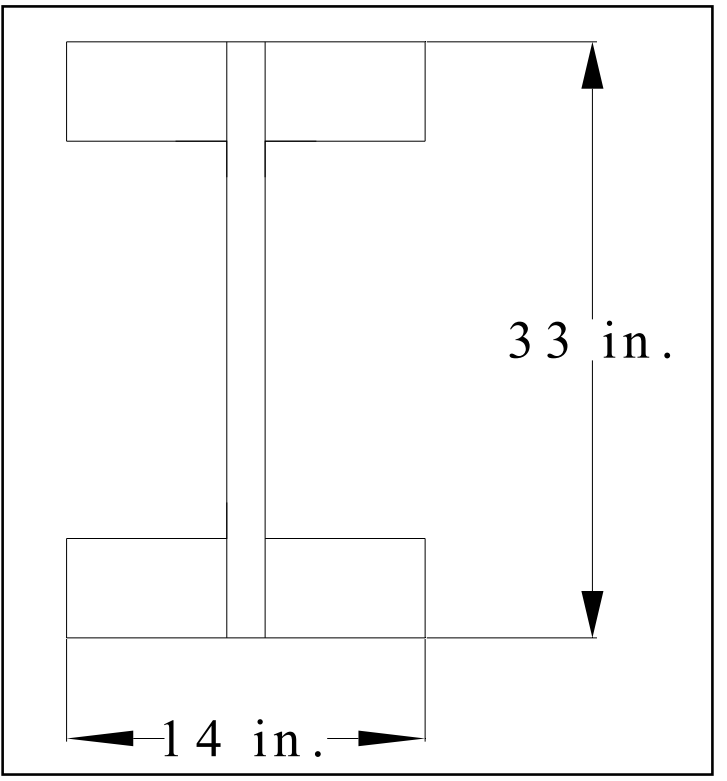

Top View

Figure 4.2: Top and Side Views of Test Specimen (Canbek, 2009)

allowed to cure for at least one week prior to testing. Four types of FRP were used, including unidirectional carbon FRP (CFRP), bidirectional CFRP, unidirectional glass FRP (GFRP) and bidirectional GFRP.

The specimens were tested upside down on a steel frame, as shown in Figure 4.3. The specimens were connected to the frame using either bolts or clamps at the corners of the double top plates. The load was applied at the center on the bottom of the joist, using a Universal Testing Machine (UTM) at a displacement rate of $0.035 \mathrm{inch} /$ minute. A 5 inch long rubber was placed under the crosshead to avoid crushing of the timber under the loading point. As per ASTM 1761 (ASTM, 2006), two dial gages were placed at the two ends of the joist, 1.5 inches from the top plates in order to measure the load at the $1 / 8$ inch deflection (Figure 4.4). 


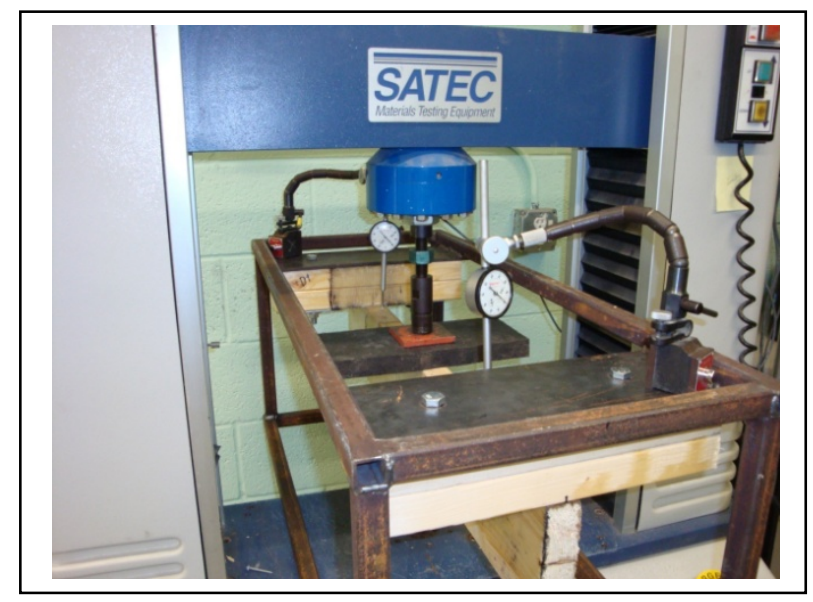

Figure 4.3: A Typical Specimen before Testing (Canbek, 2009)
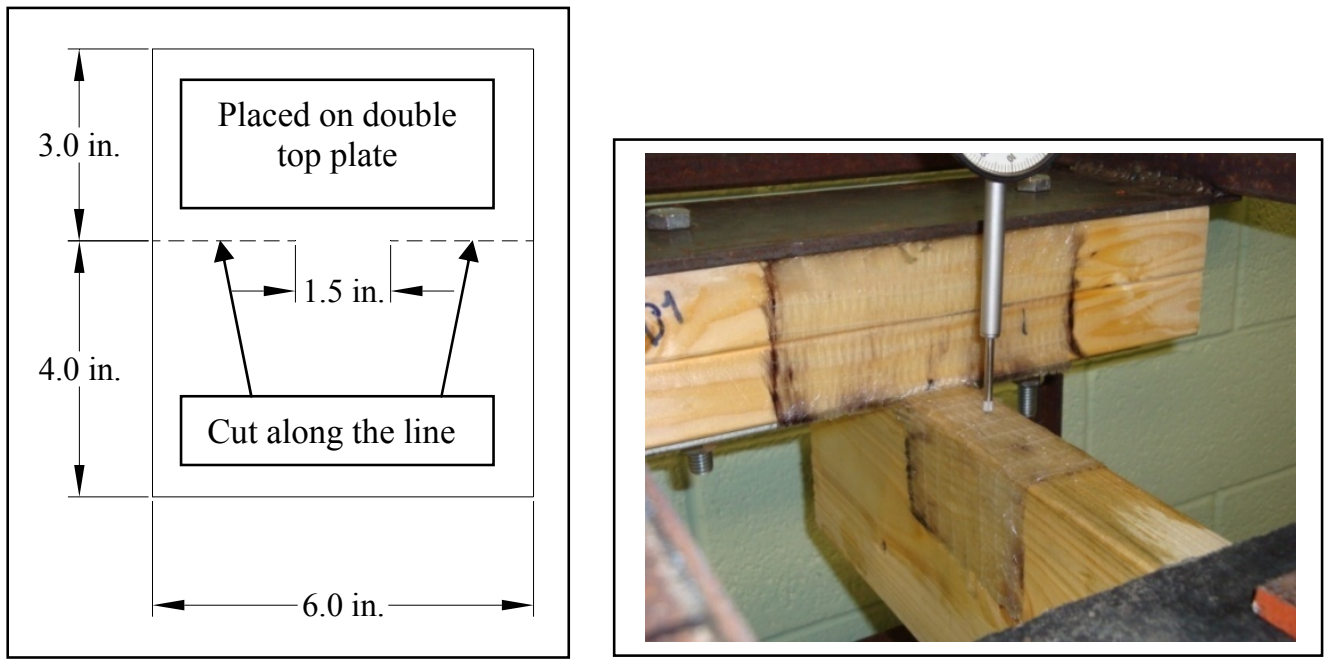

Figure 4.4: Schematics and Application of FRP Tie Configuration I (Canbek, 2009)

\subsubsection{FRP Tie Connection Testing and Results: Uplift Loading}

Three configurations of FRP connections, namely, Configurations A, B, and C were tested (Canbek, 2009). Two types of FRP's were used with each configuration, making six sets of test specimens. Each set consisted of three identical samples to assess repeatability of test results. Configurations details (A, B and C) are listed in Table 4.1. 


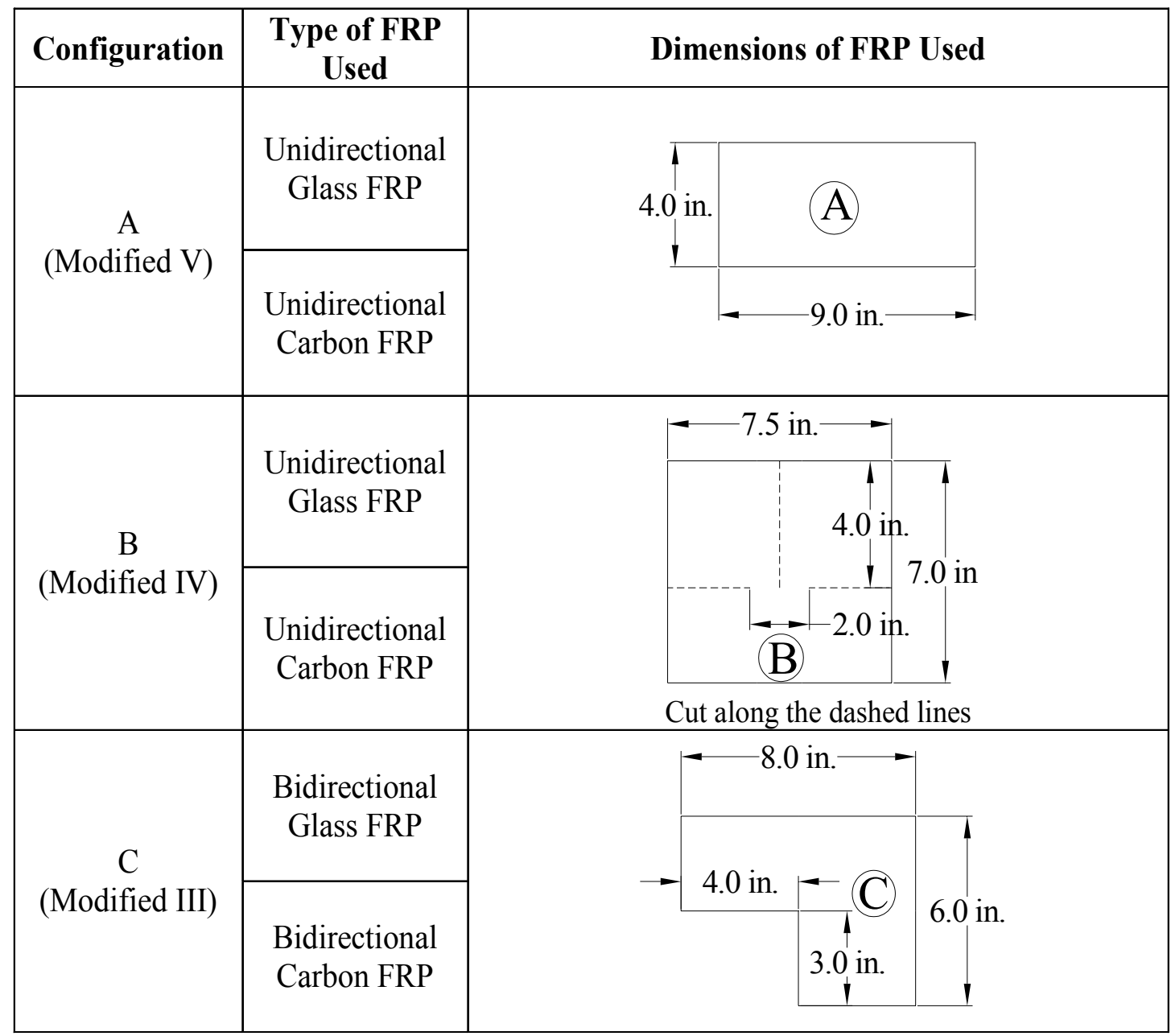

Table 4.1: Schematics and Types of FRP Connections Tested in Stage II (Canbek, 2009)

In Configuration A four $4 \times 9$ inches FRP ties were placed on the top plates and connected to the joist. Each FRP tie was placed, such that half would attach to the top plate and the other half on the joist. The specimens prepared by GFRP and CFRP are shown in Figure 4.5. The modes of failures were very similar for glass and carbon (Canbek, 2009). In all specimens, the FRP peeled off from the top-plate, and in various cases detached some timber fibers (Figure 4.6). The ultimate load for CFRP was approximately 20\% higher than that of GFRP (Canbek, 2009). Furthermore, the 

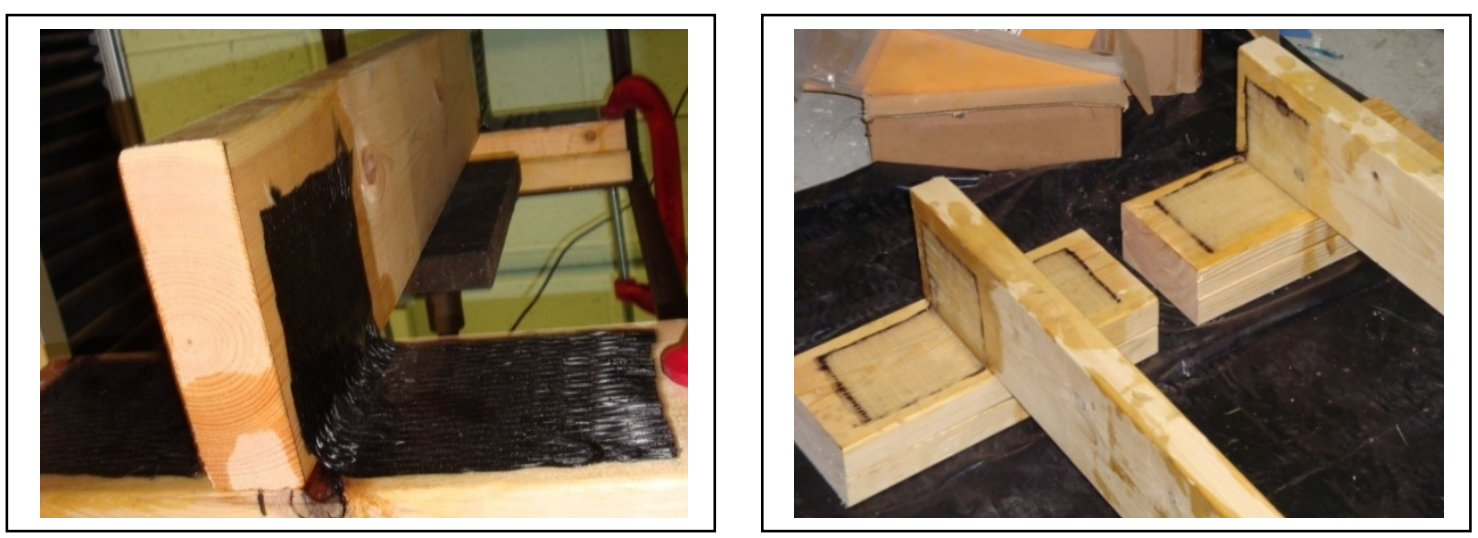

Figure 4.5: Configuration A with CFRP (Left) and GFRP (Right) Before Testing (Canbek, 2009)
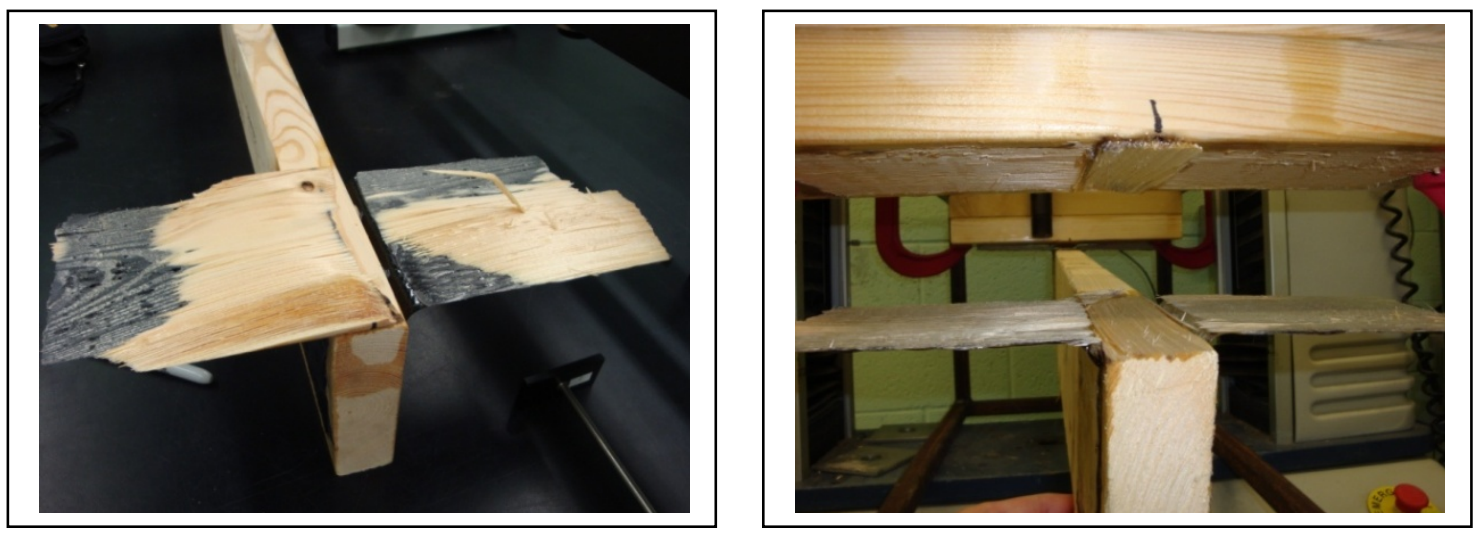

Figure 4.6: Failure of Configurations A with CFRP (Left) and GFRP (Right) (Canbek, 2009)

separation of timber fibers from the top plate was more obvious in the CFRP tie connections (Figure 4.6).

In Configuration B the FRP used for each connection consisted of one FRP tie instead of two and the load transfer width was 1 inch on the joist-top plate interface (Figure 4.7). The FRP was also bonded on the vertical surface of the double top plate. The specimens were prepared with CFRP and GFRP are shown in Figure 4.7. 

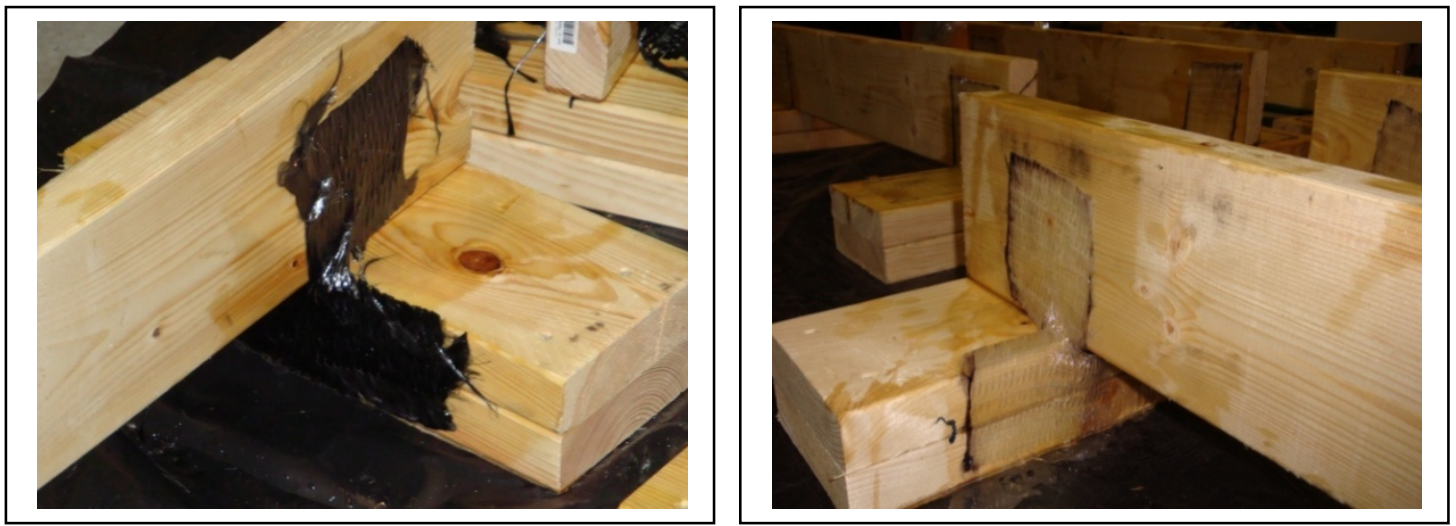

Figure 4.7: Configuration B with CFRP (Left) and GFRP (Right)

Before Testing (Canbek, 2009)

In Configuration B, two different modes of failure were observed as shown in

Figure 4.8. Figure 4.8a shows that the FRP under the load transferring piece peeled off as a block, while in the other specimen the load transferring piece ruptured and a portion of FRP separated from the top plate (Figure $4.8 \mathrm{~b}$ ).

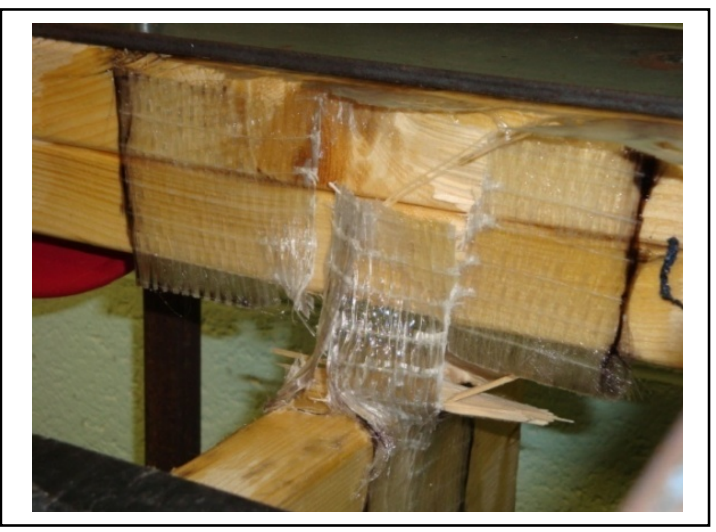

(a)

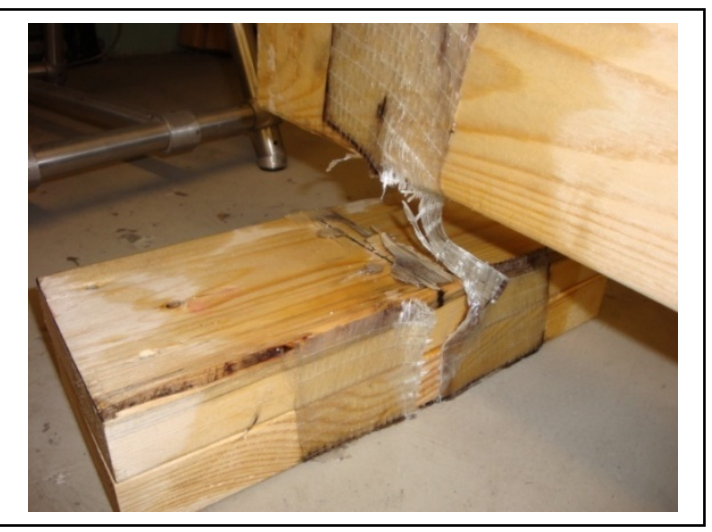

(b)

Figure 4.8: Two Modes of Failure Observed in Configuration B (Canbek, 2009) 
Configuration $\mathrm{C}$ was made using bidirectional GFRP or CFRP to attempt to improve the mode of failure. The FRP was placed on each side of the top plate and at the end of the joist (Figure 4.9). The mode of failure was very similar for both types of FRP. The connection failed as the FRP ruptured along the bent line on the top plate, and subsequently peeled off (Figure 4.10). The results obtained from the experiments are summarized in Table 4.2 and graphed in Figure 4.11.
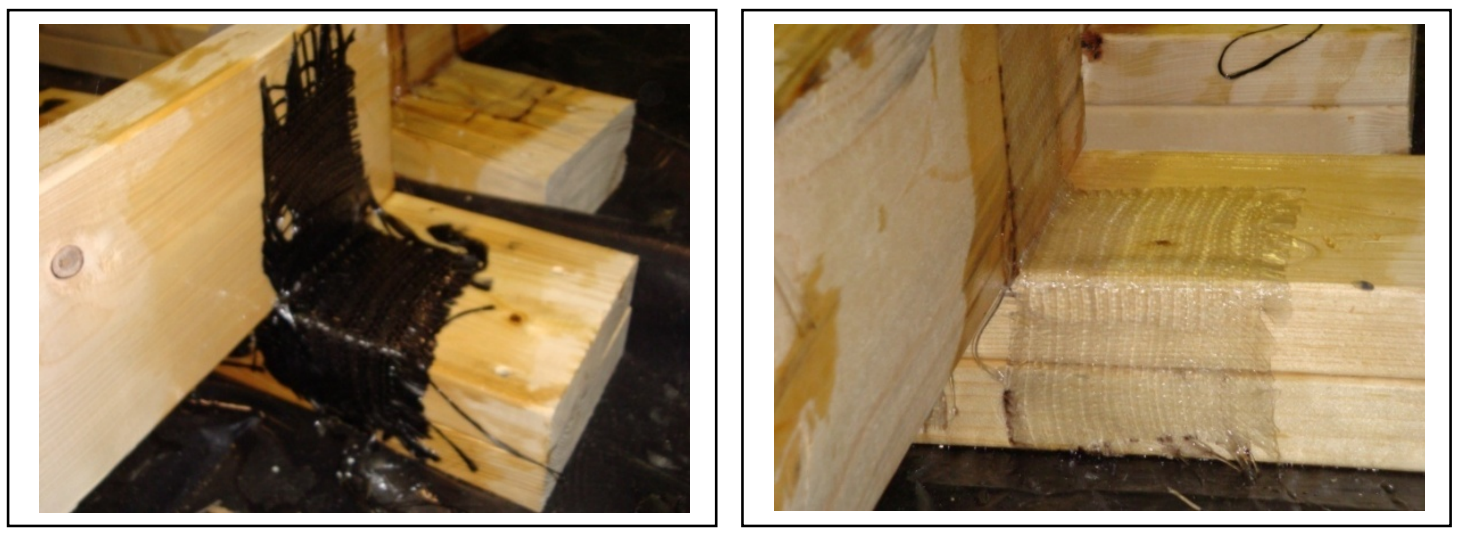

Figure 4.9: Configuration C with CFRP (Left) and GFRP (Right) Before Testing (Canbek, 2009)
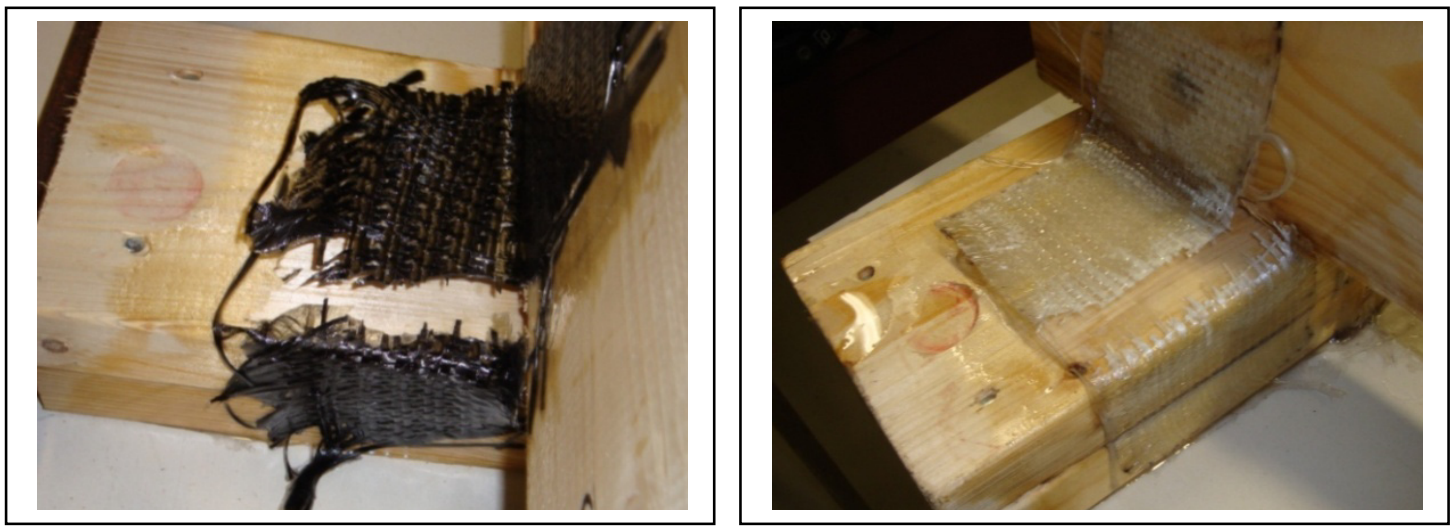

Figure 4.10: Failure of Configurations $C$ with CFRP (Left) and GFRP (Right) (Canbek, 2009) 


\begin{tabular}{|c|c|c|c|c|c|}
\hline Configuration & $\begin{array}{l}\text { FRP } \\
\text { Type }\end{array}$ & $\begin{array}{c}\text { Specimen } \\
\text { No. }\end{array}$ & $\begin{array}{l}\text { Ultimate } \\
\text { Load (lbs) }\end{array}$ & $\begin{array}{l}\text { Average } \\
\text { Ultimate } \\
\text { Load (lbs) }\end{array}$ & $\begin{array}{c}\text { Coefficient } \\
\text { of } \\
\text { Variation }\end{array}$ \\
\hline \multirow{6}{*}{ A } & \multirow{3}{*}{ GFRP } & AG1 & 4,650 & \multirow{3}{*}{4,320} & \multirow{3}{*}{0.089} \\
\hline & & AG2 & 3,900 & & \\
\hline & & AG3 & 4,410 & & \\
\hline & \multirow{3}{*}{ CFRP } & $\mathrm{AC} 1$ & 5,280 & \multirow{3}{*}{5,187} & \multirow{3}{*}{0.022} \\
\hline & & $\mathrm{AC} 2$ & 5,220 & & \\
\hline & & AC3 & 5,060 & & \\
\hline \multirow{6}{*}{ B } & \multirow{3}{*}{ GFRP } & BG1 & 3,000 & \multirow{3}{*}{2,273} & \multirow{3}{*}{0.277} \\
\hline & & BG2 & 1,870 & & \\
\hline & & BG3 & 1,950 & & \\
\hline & \multirow{3}{*}{ CFRP } & $\mathrm{BC} 1$ & 2,530 & \multirow{3}{*}{3,067} & \multirow{3}{*}{0.251} \\
\hline & & $\mathrm{BC} 2$ & 3,950 & & \\
\hline & & $\mathrm{BC} 3$ & 2,720 & & \\
\hline \multirow{6}{*}{ C } & \multirow{3}{*}{ GFRP } & CG1 & 4,070 & \multirow{3}{*}{3,200} & \multirow{3}{*}{0.238} \\
\hline & & CG2 & 2,660 & & \\
\hline & & CG3 & 2,870 & & \\
\hline & \multirow{3}{*}{ CFRP } & $\mathrm{CC} 1$ & 3,880 & \multirow{3}{*}{4,490} & \multirow{3}{*}{0.124} \\
\hline & & $\mathrm{CC} 2$ & 4,620 & & \\
\hline & & $\mathrm{CC} 3$ & 4,970 & & \\
\hline
\end{tabular}

Table 4.2: Summarized FRP Tests Results (Canbek, 2009) 


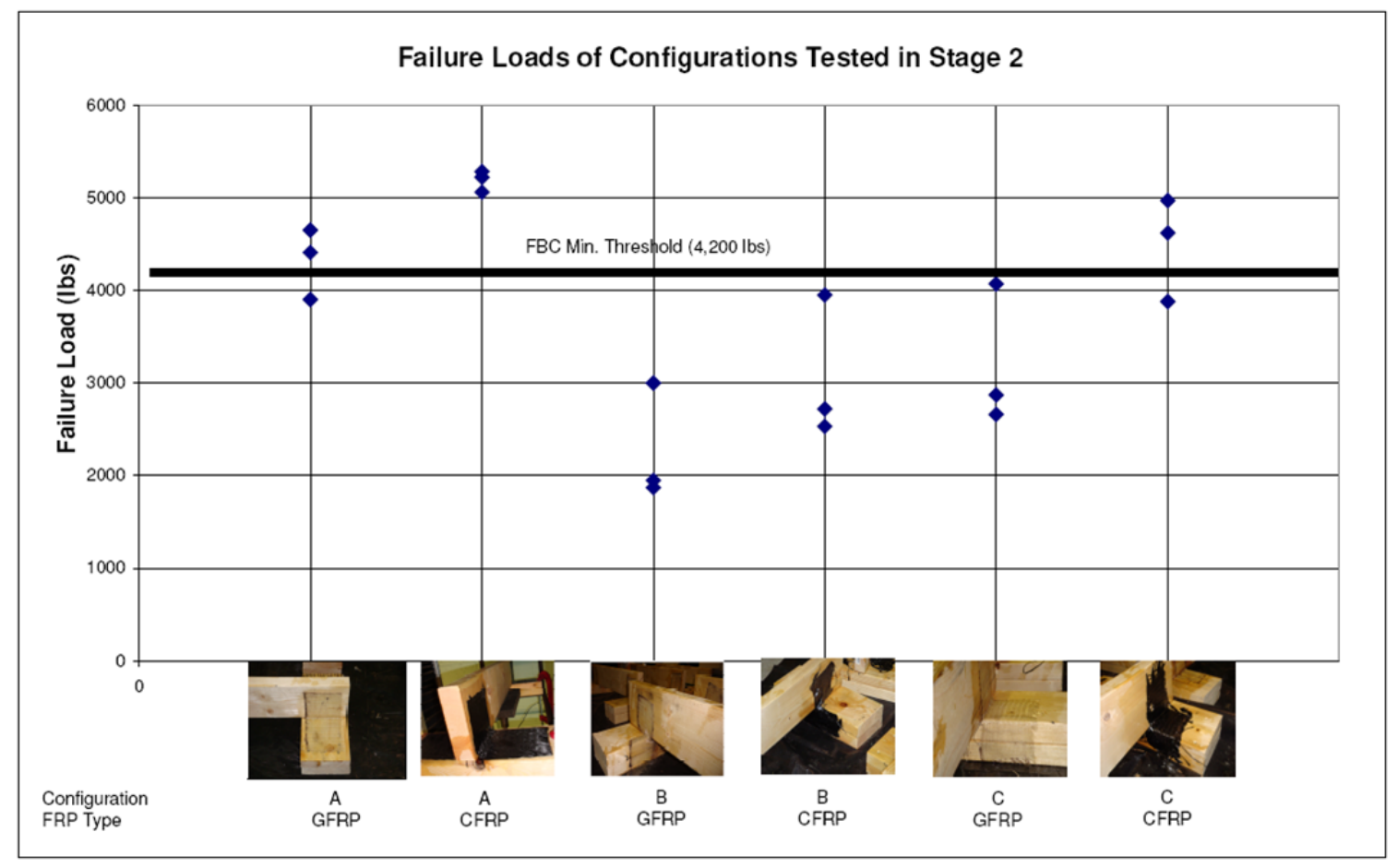

Figure 4.11: Results of FRP Tie Connection Development Stage II (Canbek, 2009)

Compared to other configurations, Configuration A yielded more favorable results. The failure loads obtained with CFRP were 20\% higher (Canbek, 2009). Nevertheless, the price of a CFRP tie connection is approximately 5 times higher than that of a GFRP tie connection. Therefore, Configuration A with GFRP was selected as the best alternative for further development (Canbek, 2009). Table 4.3 gives a cost analysis for Configuration A based on prices obtained from local suppliers of FRP and epoxy materials and manufacturer data sheets for GFRP and CFRP. The resin consumption rate used was not measured during the experiments, but was rather obtained from manufacturer data sheets. 


\begin{tabular}{|c|c|c|c|c|}
\hline $\begin{array}{c}\text { Type of } \\
\text { FRP Used }\end{array}$ & $\begin{array}{c}\text { Price of FRP } \\
\text { without epoxy } \\
\left.\mathbf{( \$ / i n}^{\mathbf{2}}\right)\end{array}$ & $\begin{array}{c}\text { Resin } \\
\text { Consumption } \\
\left.\mathbf{( g a l}^{\text {(gin }} \mathbf{2}\right)\end{array}$ & $\begin{array}{c}\text { Price of Epoxy } \\
\text { for 4 Gallons } \\
\text { Kit (\$) }\end{array}$ & $\begin{array}{c}\text { Cost of a } \\
\text { Single FRP } \\
\text { Tie with } \\
\text { Epoxy (\$) }\end{array}$ \\
\hline GFRP & 0.013 & 0.0001102 & 272.41 & 0.73 \\
\hline CFRP & 0.0123 & 0.0001102 & 272.41 & 4.71 \\
\hline
\end{tabular}

FBC Min. Threshold (4200 lbs)

Table 4.3: Cost Analysis for Configuration A with

GFRP and CFRP (Canbek, 2009)

\subsubsection{FRP Tie Connection Testing and Results: Lateral Loading}

Only Configuration A (GFRP and CFRP) and C (CFRP) met the minimum High Velocity Hurricane Zone (HVHZ) required threshold (700 lbs x 3FS = 2,100 lbs) with 4,200 lbs. Based on the economy of GFRP, Configuration A with GFRP was selected as the most feasible connection for further study (Canbek, 2009). The purpose of the next round of testing was to determine the performance of Configuration A under lateral loads. A testing setup similar to that commonly used by hurricane clip manufacturers was adopted. Two ties were placed at the centerline of the nominal 2 x10 inch Southern Yellow Pine (SYP) timber, as shown in Figures 4.12 and 4.13. The load was applied using an inverted U-shaped timber member (Figure 4.14).

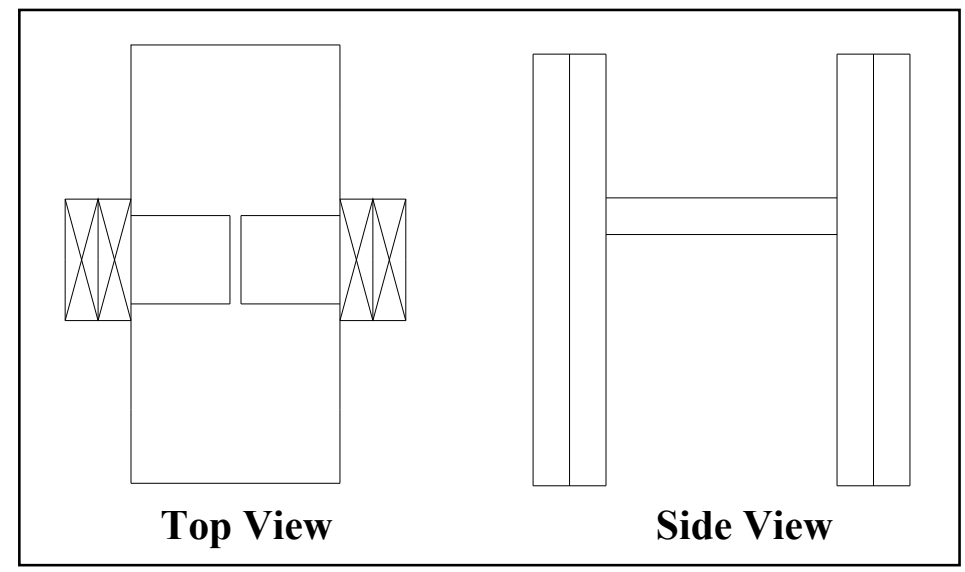

Figure 4.12: Views of Specimen Tested For Lateral Loading (Canbek, 2009) 


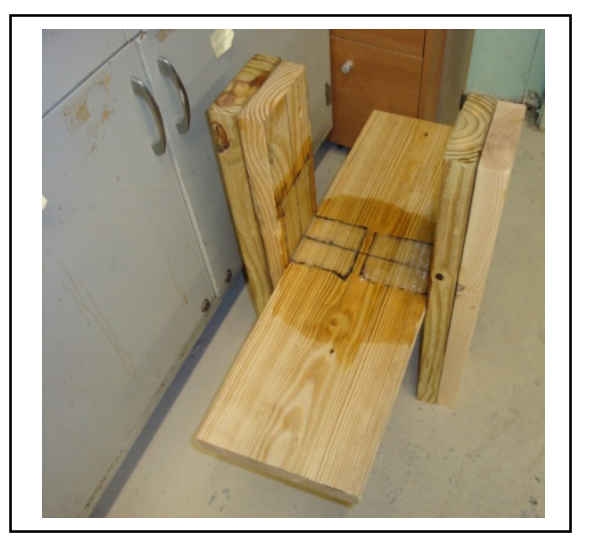

Figure 4.13: Specimen Used For Lateral Loading Tests (Canbek, 2009)

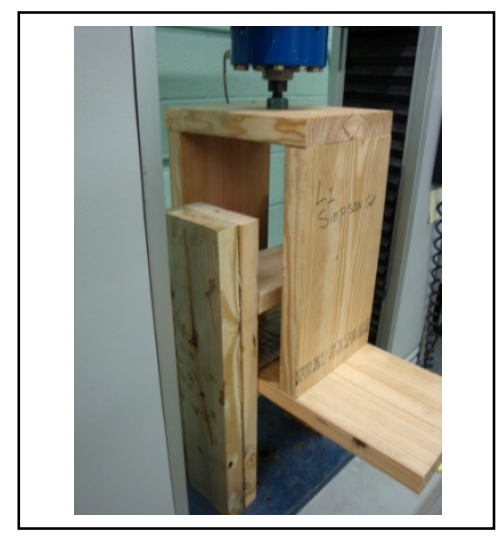

Figure 4.14: Application of Load in Lateral Loading Test (Canbek, 2009)

The average ultimate load for the three specimens was 2,290 lbs, yielding a value of 1,145 lbs per connection in the lateral direction (Canbek, 2009). This value is much higher than the lateral capacity of many hurricane clips available, which can range between 100 to $200 \mathrm{lbs}$ (Canbek, 2009). Figure 4.14 shows that the typical mode of failure for FRP tie connections under lateral loads is peeling off.

Based on the uplift and lateral load carrying capacity, Configuration A with GFRP was selected as the best alternative, in terms of cost and applicability, for validation in the full-scale tests.

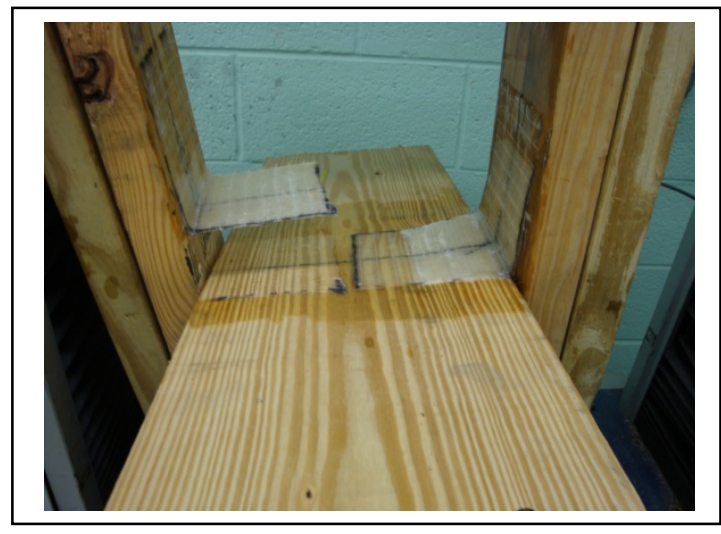

Figure 4.15: Typical Mode of Failure under Lateral Loading (Canbek, 2009) 


\subsection{Full-Scale Testing}

A full-scale specimen was tested to evaluate the in-situ performance of the FRP tie connection developed at the component level under uplift forces.

\subsubsection{Test Setup and Specimen Preparation}

The full scale specimen was built using No. 2 Spruce Pine Fir (SPF) 2 x 6 inch lumber. The specimen consisted of two 8 feet- 3 inch high, 8 feet long shear walls, with a center to center spacing of 17 feet. The shear walls were supported by five fink type trusses, as shown in Figures 4.16 and 4.17. Each shear wall had 9 feet long double top plates, five vertical studs with a center-to-center distance of 2 feet, and a single 8 feet long bottom plate. The double top plate had 6 inches of overhang at the ends, for the placement of FRP tie connection (Figure 4.16, 4.17 and 4.18). The $4 \times 8$ feet sheathing plywood was American Paper Association (APA) -rated and 19/32 inch thick, it was used as sheathing on the outer walls and the roof. The roof sheathing was placed such that the 8 feet sides were parallel to the ridge. The outer walls sheathing were placed vertical along the studs. The sheathing was attached to the roof and the outer walls using $8 \mathrm{~d}-2$ inch long screws, spaced every 6 inches.

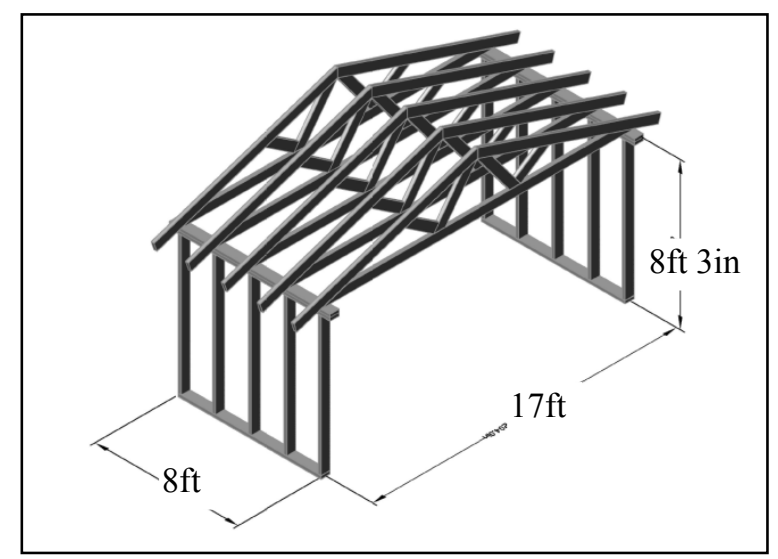

Figure 4.16: The Full-Scale Test Specimen without Sheathing (Canbek, 2009) 


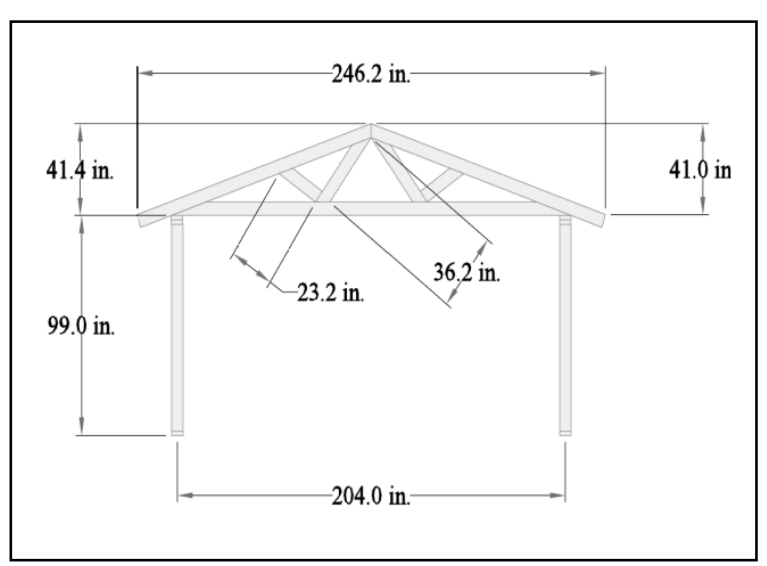

Figure 4.17: Front View of Test Specimen (Canbek, 2009)

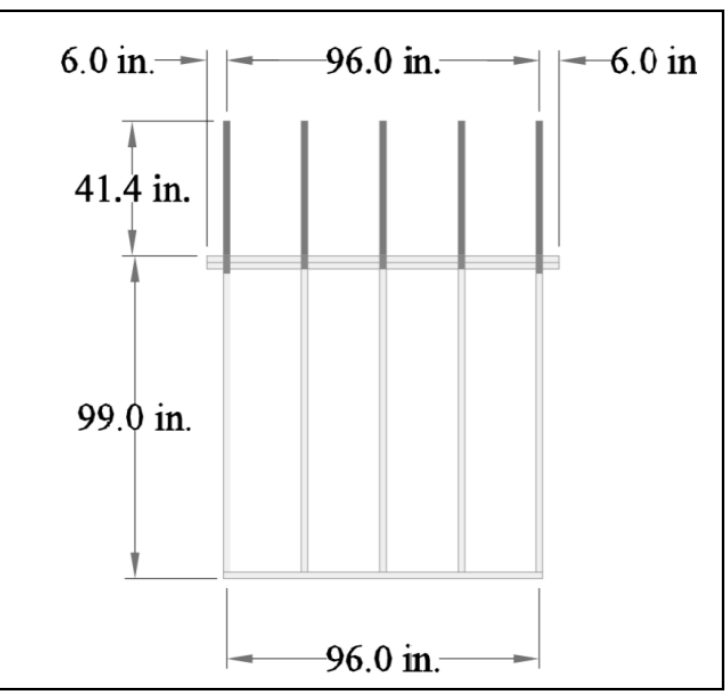

Figure 4.18: Side View of Test Specimen (Canbek, 2009)

The specimen was constructed with parts of the structure intentionally strengthened beyond normal construction practice to ensure that the failure would be localized to the FRP connection. U-shaped metal straps were used at the top and bottom of the shear walls, to connect the plates to the studs using twelve 10d-1.5 inch long nails (Figure 4.19-1). To avoid the possible separation of the double top plates, a metal Ushaped connector, spaced every 24 inches, was installed and nailed using nine 8d-1.5 inch long nails (Figure 4.19-2). Finally, the roof ridge was strengthened using V-shaped metal straps to avoid separation at high loads. The test specimen was affixed to the laboratory tie-downs, using two steel channel sections under the two shear walls, bolted on the bottom plate every 24 inches (Figure 4.20). 


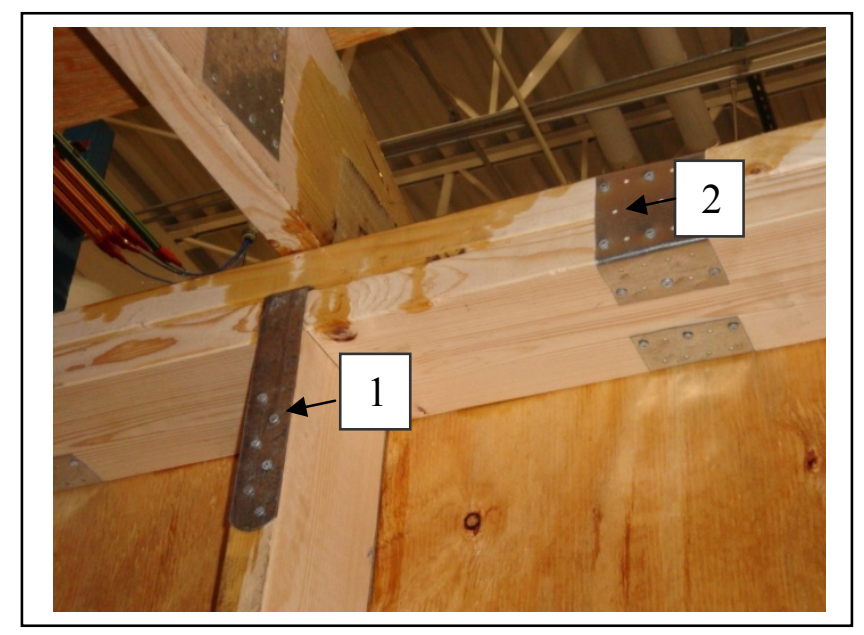

Figure 4.19: (1) Strap Holding the Stud and the Lower Top Plate Together; and (2) U- Shaped Metal Plates Holding the Upper and Lower Top Plates Together (Canbek, 2009)

The load was applied onto the roof using 8 hydraulic jacks connected to a single electric pump equipped with a speed control valve. Four of the jacks were applying force to the north part of the roof and four to the south part of the roof. The spacing between the jacks was 2 feet in east-west direction and 6 feet in north-south direction (Figure 4.20). A steel loading frame was fabricated to mount the hydraulic jacks. The jacks were first bolted to $1 / 2$ inch thick steel plates. Subsequently, the plates were bolted to four 12 inch long 3/4 inch diameter threaded rods. The steel plates of the same size as those on the top were bolted at the bottom. Load cells were placed on the top beam of the loading frame, such that it would be on the same vertical axis with the jack. The jack system was placed on the loading frame through the holes on the top beam, such that the load cells will be sandwiched between the bottom plates and the loading frame (Figure 4.21). In order to distribute the load, 8 feet long channel members were constructed using four $2 \mathrm{x}$ 6 inch dimensional lumbers. Steel angles were screwed to the timber channel, and the 
entire section was connected to the clevis eyes placed on top of the jacks using a bolt (Figure 4.22). This connection system allowed the timber member to rotate freely about a clevis. The FRP tie connections for the full-scale test used Configuration A with GFRP, as described in the previously. The FRP tie connection was applied at the ends of each side of the joists, making for a total of 20 FRP tie connections.

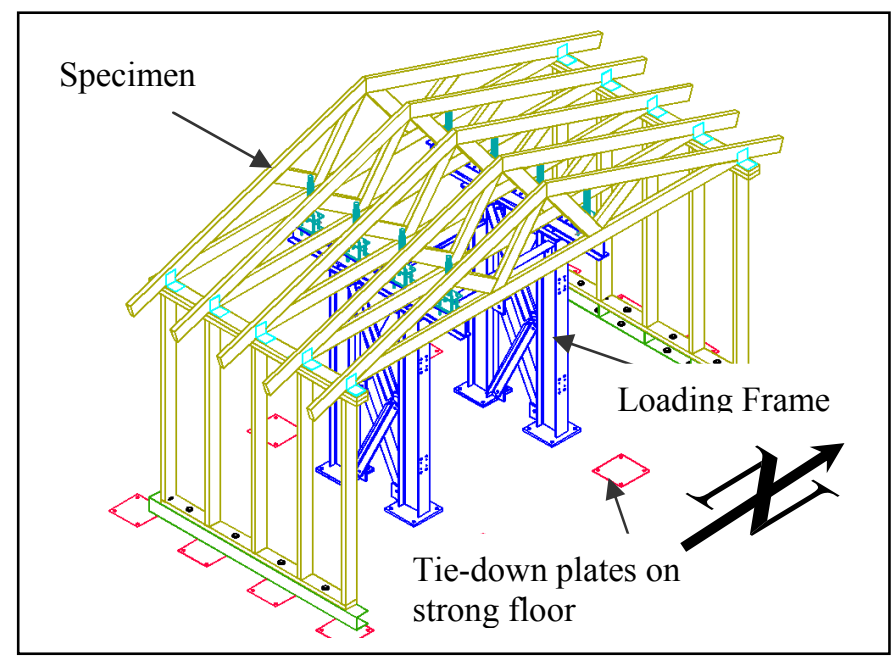

Figure 4.20: Full-Scale Test Specimen and the Loading Frame without Sheathing and Instrumentation (Canbek, 2009)

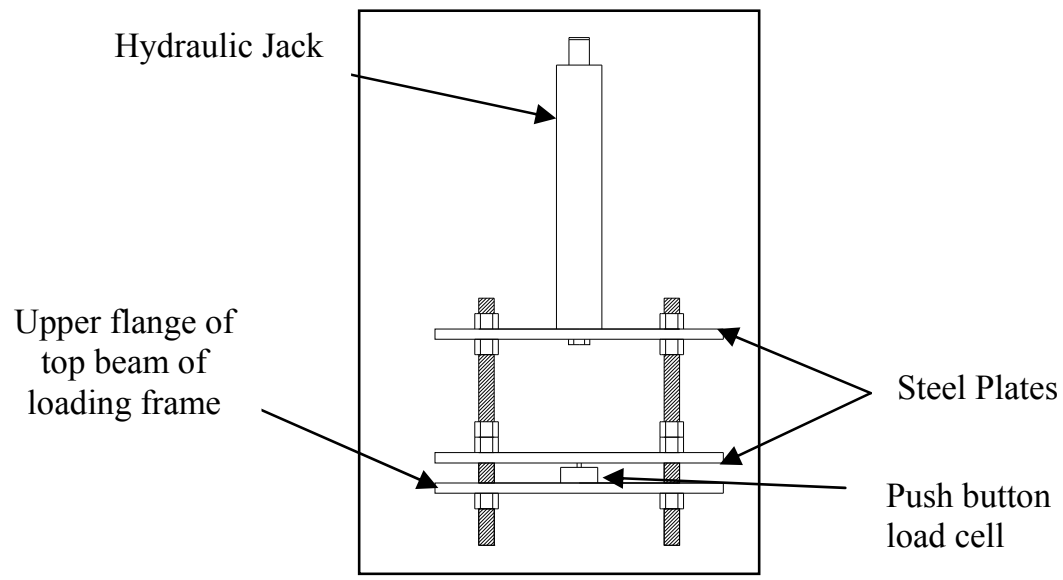

Figure 4.21: Placement of Load Cell between the Loading Frame and Steel Plate (Canbek, 2009) 


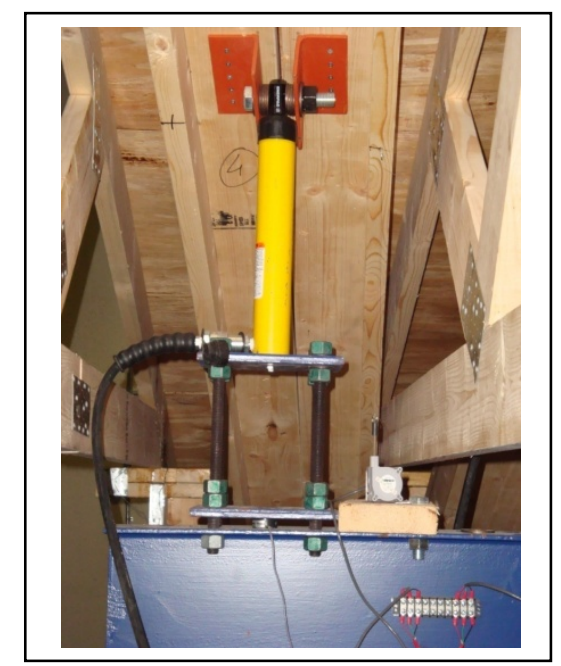

\section{Figure 4.22: Jack with the Load Distribution Channel Mounted On Top (Canbek, 2009)}

The instrumentation for the full-scale specimen consisted of twenty three string pots, eight strain gages and eight load cells. The numbering and schematic representation of sensors are summarized in Table 4.4 and shown in Figure 4.23. The sensors were numbered starting from the load cells, to string pots and finally to strain gages. The numbering sequence started from northeast corner and moved in the clockwise direction. A push-button load cell was placed under the vertical axis of each jack to measure applied load. String pots 9-13 and 27-31 were placed on the outer wall, to measure the displacement of each truss at 1.5 inch away from the wall on the outside. String pots 18 22 were connected to the 8 feet long timber member assembled on the loading frame to measure the displacements at the center of the bottom chord of the truss. String pots 1417 and 23-26 were directly connected to the loading frame to measure the displacements at loading points on the axis of rotation of the timber channel members. Eight $60 \mathrm{~mm}$ strain gages were used to measure the strains centered on the vertical section of the FRP 
tie connections. The strain gages measured the strains of the FRP tie connections located at the four corners of test specimen. Figure 4.24 shows a sketch of the instrumented specimen before testing.

\begin{tabular}{|c|c|c|}
\hline Sensor No. & Sensor Type & Measurement \\
\hline $1,2,3,4$ & Load cells & $\begin{array}{c}\text { Located under the jacks on the north side of the } \\
\text { structure to measure the applied load }\end{array}$ \\
\hline $5,6,7,8$ & Load cells & $\begin{array}{c}\text { Located under the jacks on the south side of the } \\
\text { structure to measure the applied load }\end{array}$ \\
\hline $\begin{array}{c}9,10,11,1 \\
12,13\end{array}$ & String pots & $\begin{array}{c}\text { Connected to the northern outer wall, } 4 \mathrm{ft} \text { above } \\
\text { the ground to measure the displacement of the } \\
\text { truss at a distance of 1.5 in. from top plate }\end{array}$ \\
\hline $\begin{array}{c}14,15,16, \\
17\end{array}$ & String pots & $\begin{array}{c}\text { Connected to the loading frame to measure the } \\
\text { displacements at the loading points on the north } \\
\text { side of the test specimen }\end{array}$ \\
\hline $\begin{array}{c}18,19,20, \\
21,22\end{array}$ & String pots & $\begin{array}{c}\text { Connected to the loading frame to measure the } \\
\text { displacements at the center of the bottom chord } \\
\text { of the trusses }\end{array}$ \\
\hline $\begin{array}{c}23,24,25, \\
26\end{array}$ & String pots & $\begin{array}{c}\text { Connected to the loading frame to measure the } \\
\text { displacements at the loading points on the south } \\
\text { side of the test specimen }\end{array}$ \\
\hline $\begin{array}{c}27,28,29, \\
30,31\end{array}$ & String pots & $\begin{array}{c}\text { Connected to the southern outer wall, } 4 \mathrm{ft} \text { above } \\
\text { the ground to measure the displacement of the } \\
\text { truss at a distance of 1.5 in. from top plate }\end{array}$ \\
\hline $\begin{array}{c}32,33,34, \\
35,36,37, \\
38,39\end{array}$ & Strain gages & $\begin{array}{c}\text { Attached to FRP ties at } 4 \text { corners of the test } \\
\text { specimen to measures the strain on center line of } \\
\text { the vertical leg of the tie placed on the joist }\end{array}$ \\
\hline
\end{tabular}

Table 4.4: Sensor List (Canbek, 2009) 


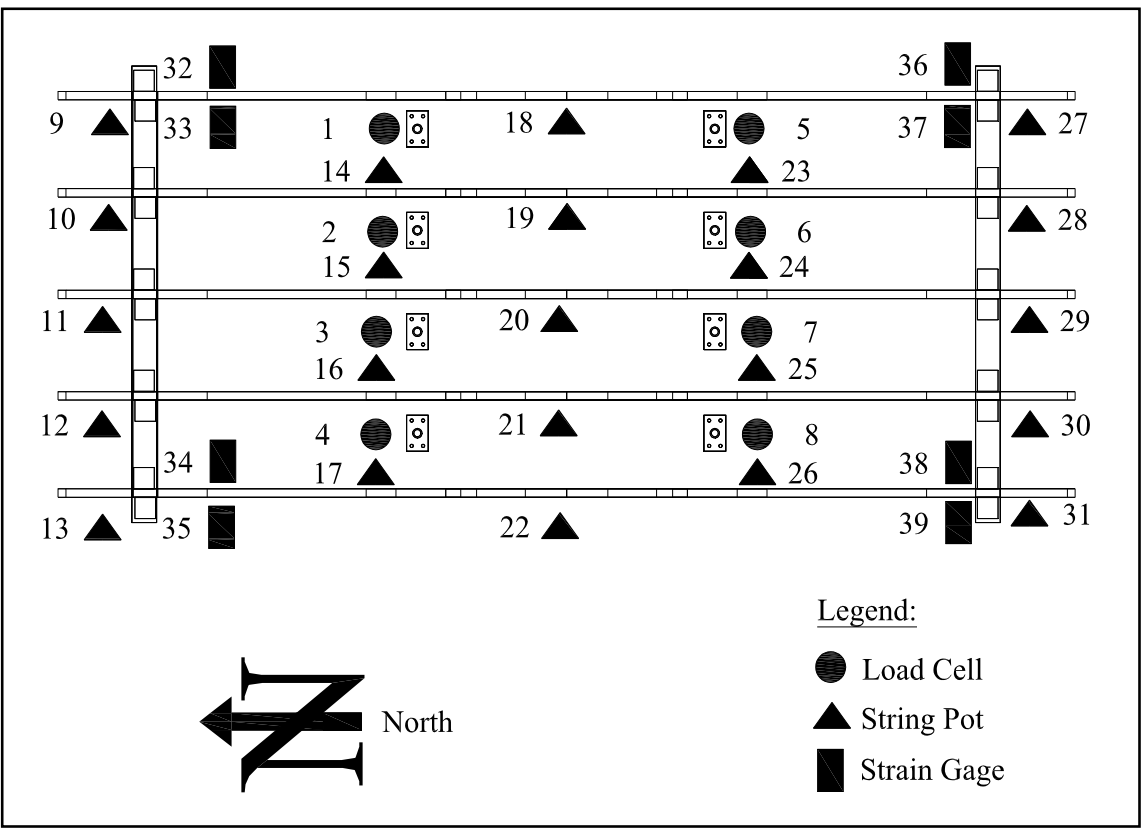

Figure 4.23: Schematic Representation of Sensor Locations (Canbek, 2009)

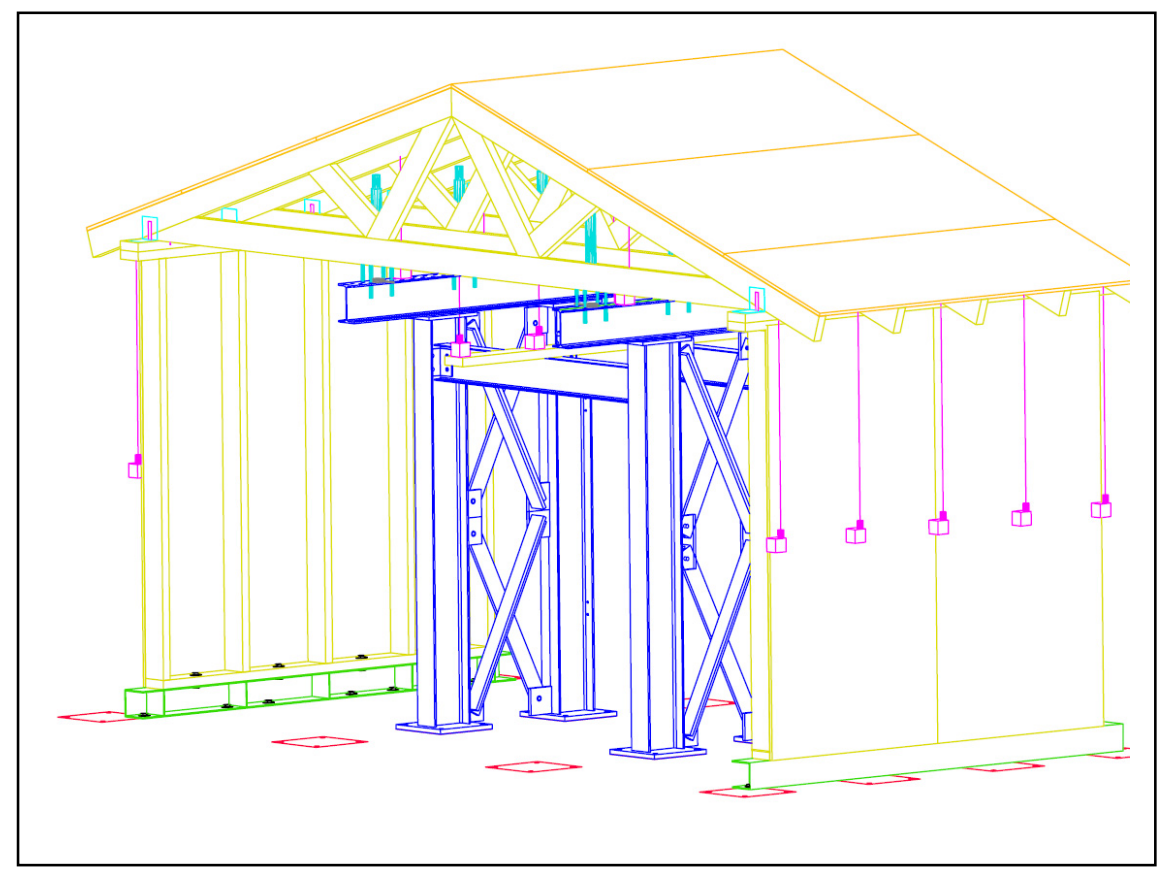

Figure 4.24: Schematics of Full-Scale Test Specimen with Sensors in Place 


\subsubsection{Test Observations and Results}

The loading history for the test specimen is shown in Figures 4.25, 4.26 and 4.27.

Figure 4.25 represents the load applied from each individual jack. Figure 4.26 shows the load applied on each quadrant of the roof. Figure 4.27 shows the total load applied on the specimen. Figure 4.28 compares the loads applied from each jack at the time of failure. In Figures 4.25 and 4.26, the loads applied from each jack were not exactly the same. This may be attributed to the manifold locations, hose lengths, and bends that could alter the ease of flow through the system (Canbek, 2009). The FRP tie connections were numbered as shown in Figure 4.29.

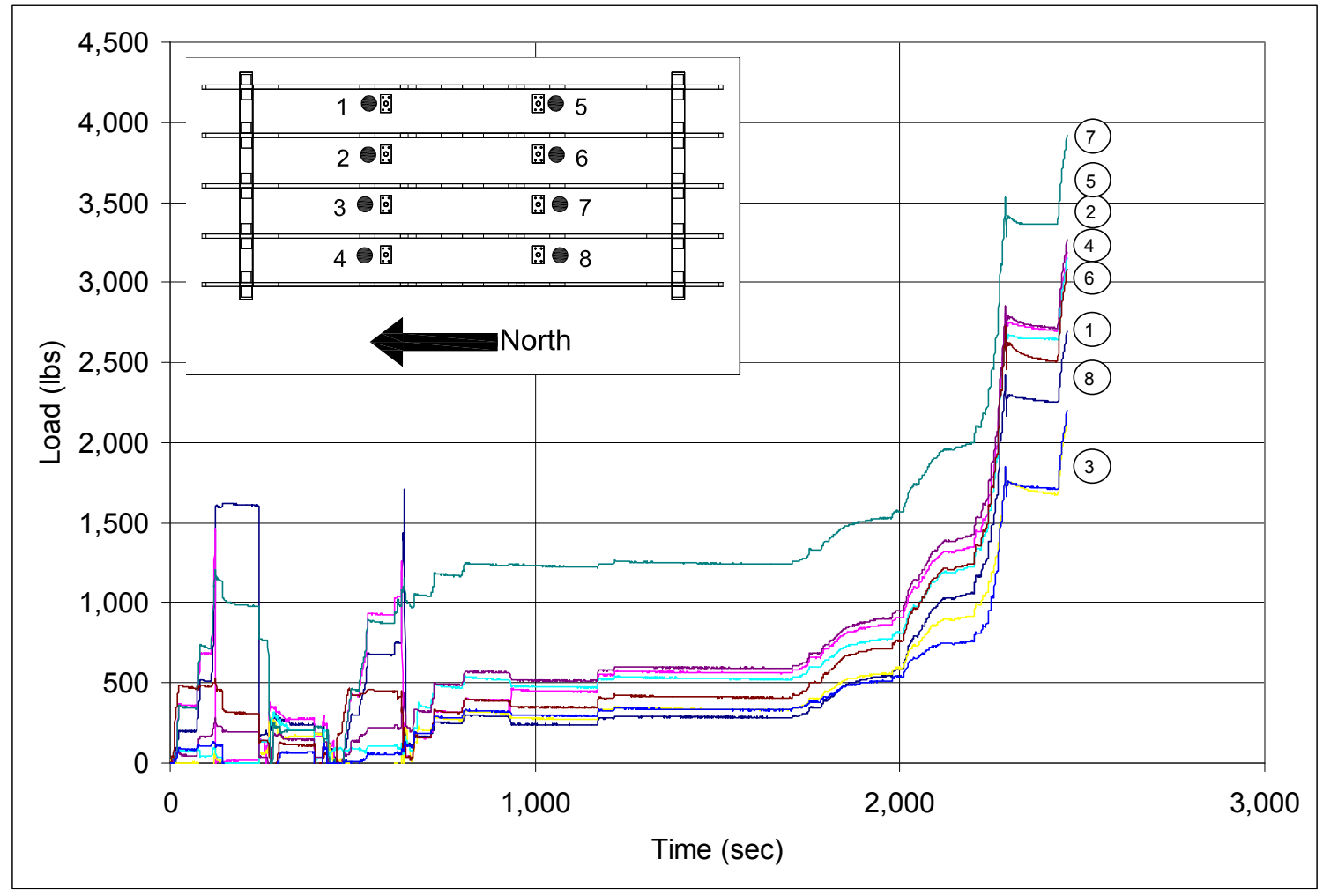

Figure 4.25: Load Applied From Each Jack (Canbek, 2009) 


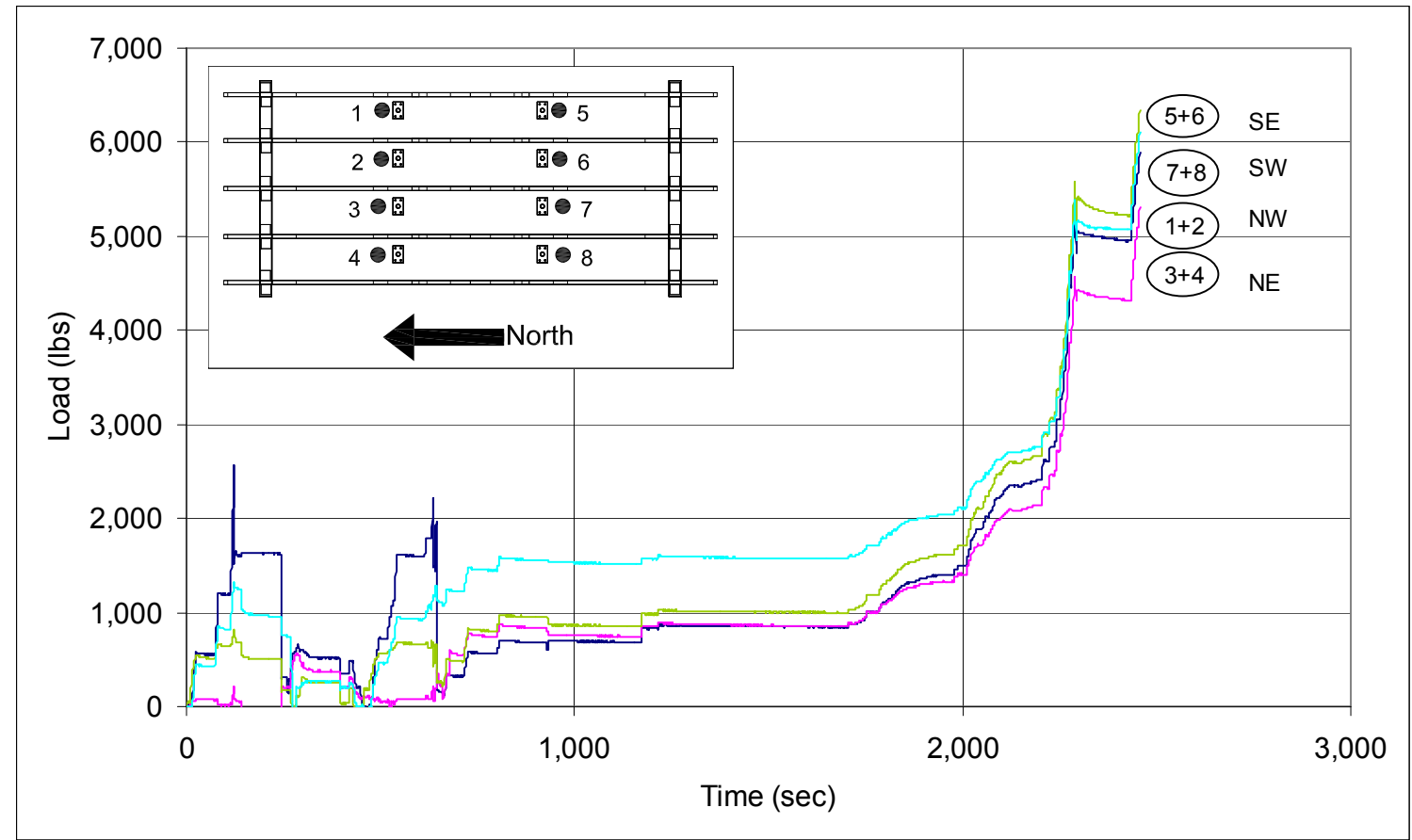

Figure 4.26: Load Applied To Each Quadrant of the Roof (Canbek, 2009)

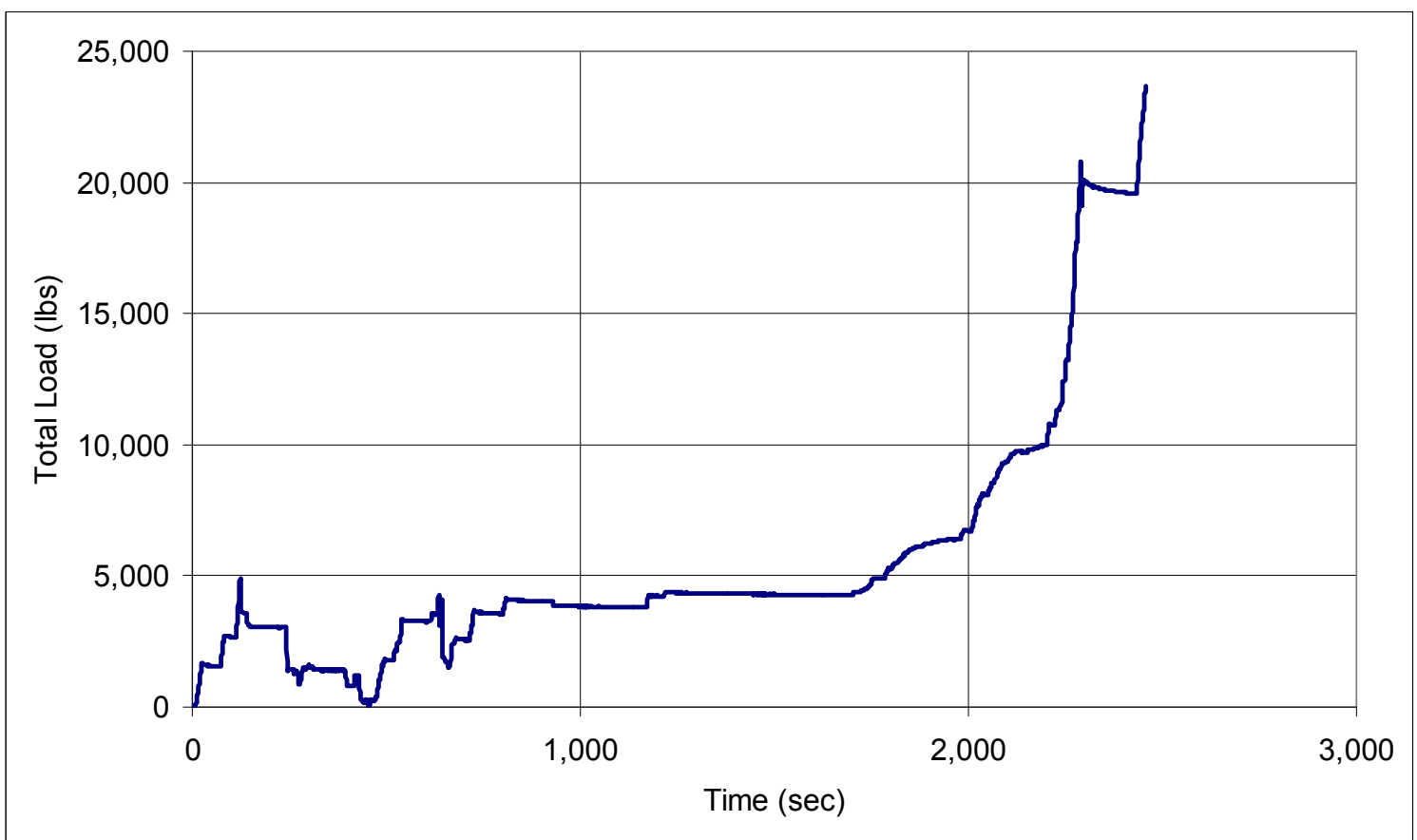

Figure 4.27: Total Load Applied on the Specimen (Canbek, 2009) 


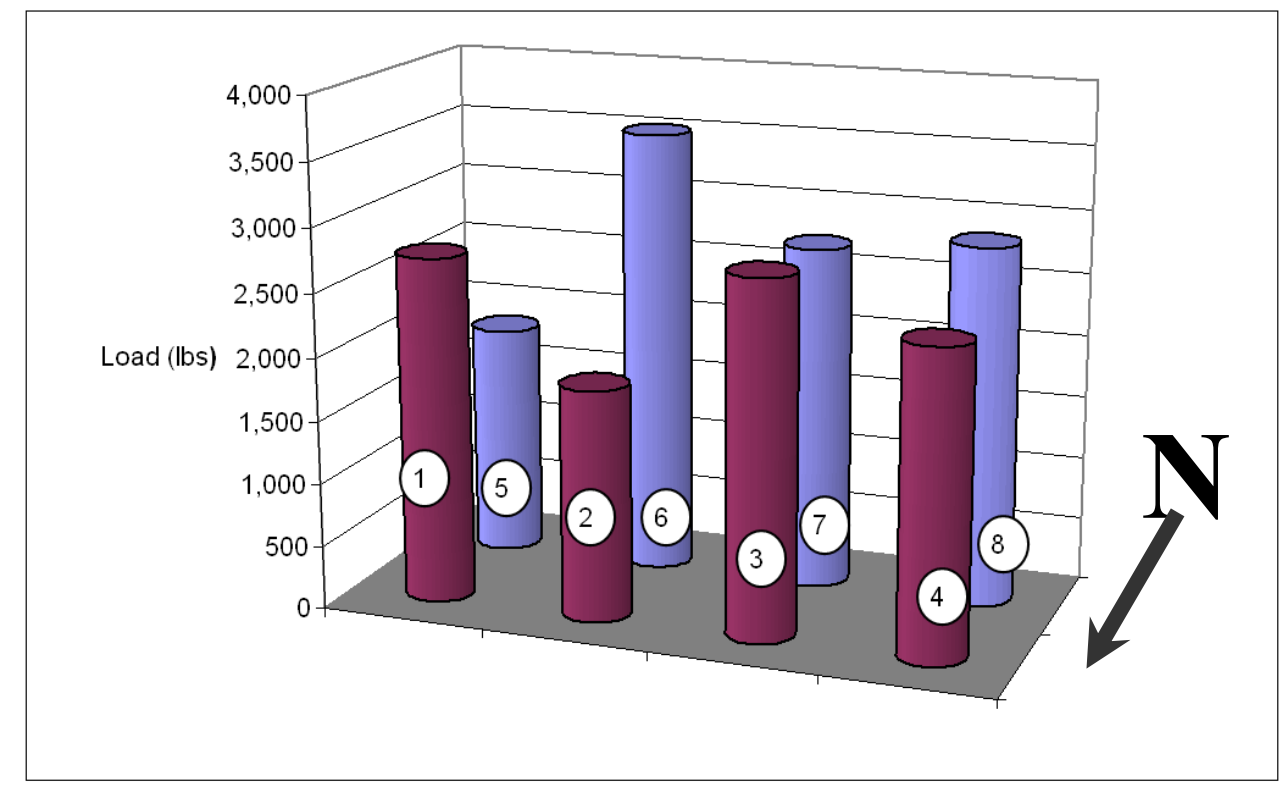

Figure 4.28: The Loads Applied At Each Cylinder at Initial Failure Load (Canbek, 2009)

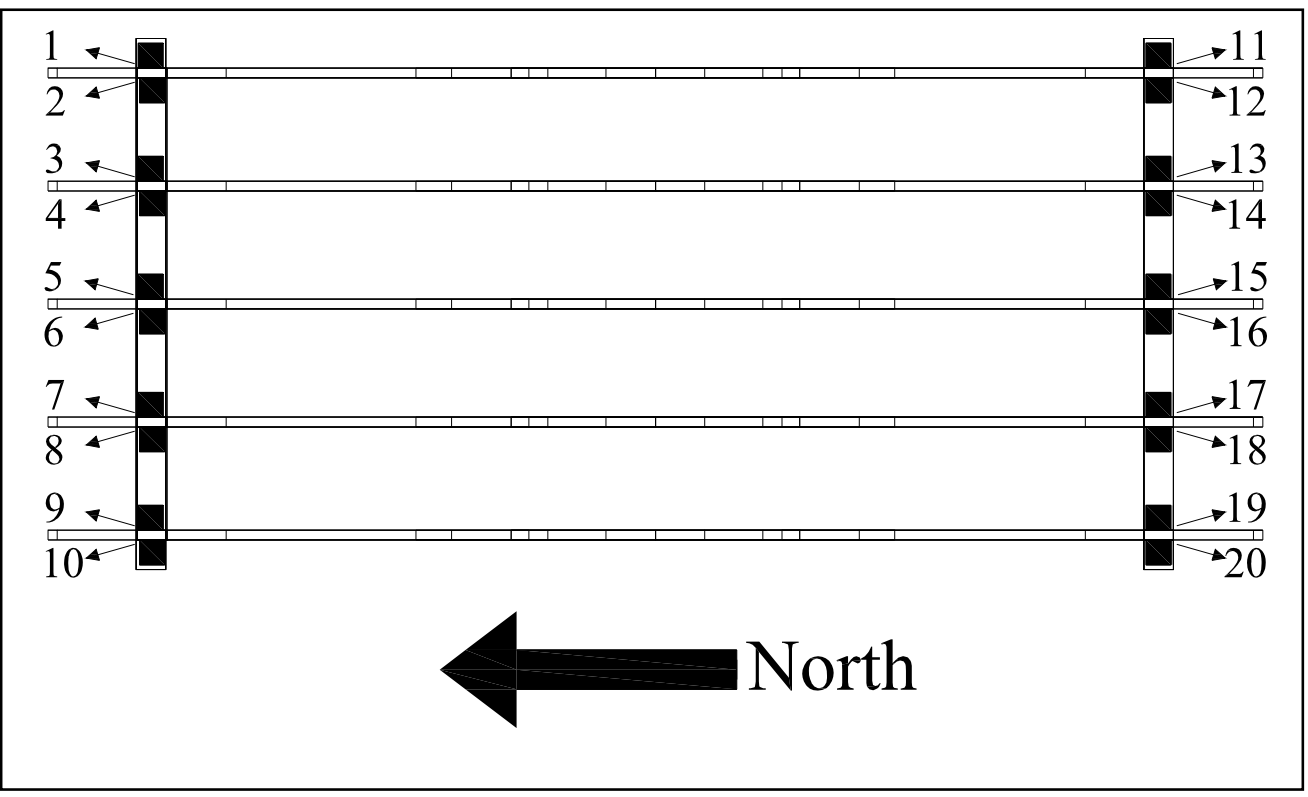

Figure 4.29: The Numbering of FRP Tie Connections (Canbek, 2009) 
The initial failure of FRP tie connections was seen at connections 13 and 14 at a total load of 20,716 lbs. The failure of these two ties started as both began to peel off from the top plate. Although most of the portion of the FRP tie connections 13 and 14 were detached from the top plate, the system was still able to sustain the applied load. When the load was increased to 23,659 lbs, FRP tie connections 7, 8, 11, 12, 19 and 20 failed at the same time, following the complete detachment of FRP tie connections 13 and 14 in a domino pattern. The FRP tie connection 13 detached from the top plate completely, while the FRP tie connection 14 failure was at the interface between the FRP and the truss. The two different modes of failures observed on the two different sides of the same truss suggested that the FRP-timber bond strength in Mode I and Mode II are very close to each other (also observed in the component level tests) (Canbek, 2009). The initiation of failure of FRP tie connections 13 and 14 at 20,716 lbs is shown in Figure 4.30. The complete failure of these two FRP tie connections at 23,659 lbs is shown in Figure 4.31. Failure of FRP tie connections 11 and 12 was very similar to that of FRP tie connections 13 and 14. FRP tie connection 11 remained attached to top plate and its failure took place at the interface between the FRP and the truss. FRP tie connection 12 remained attached to the truss, and peeled off from the top plate completely (Figure 4.32). FRP tie connections 19 and 20 failed as the FRP peeled off from the top plate. At the failure load, some parts of these ties were still attached to the top plate as seen in Figure 4.33. Figure 4.34 shows the FRP tie connections 7 and 8 at the ultimate load. A complete failure was not observed, but considerable peel off of FRP from the top plate along with timber fibers was noted with significant amounts of timber fibers remaining attached to the FRP in the failed ties (Canbek, 2009). 


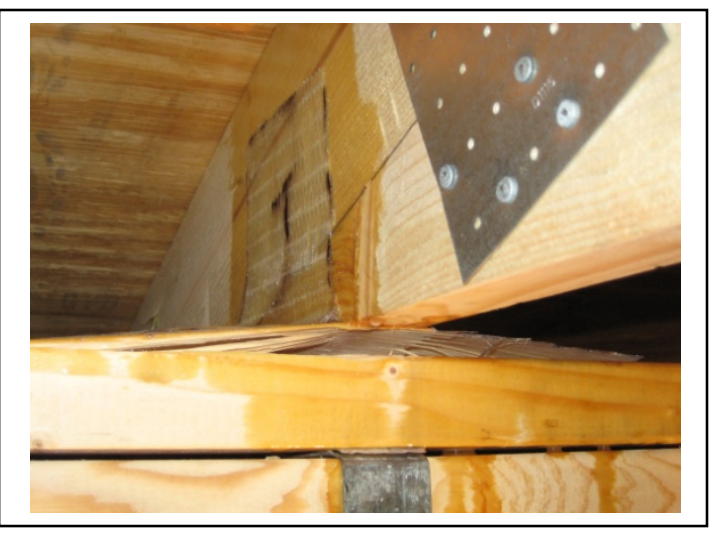

Figure 4.30: Initiation of Failure in FRP Tie Connections 13 and 14 at 20,716 lbs (Canbek, 2009)

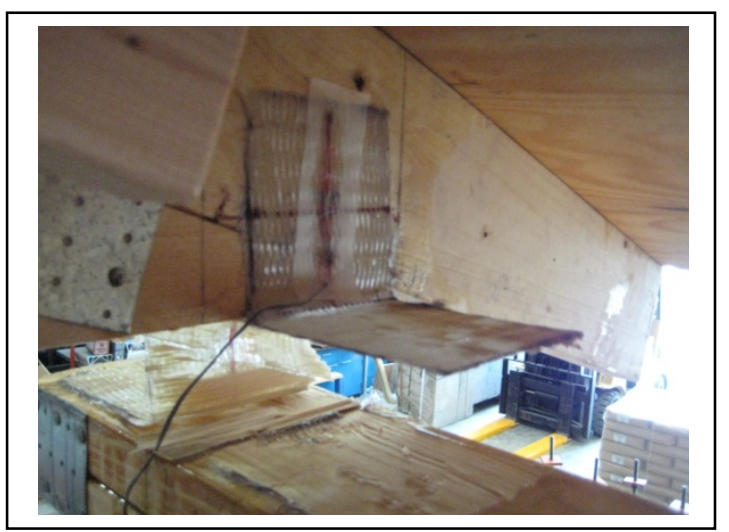

Figure 4.32: Failure of FRP Tie Connections 11 and 12 (Canbek, 2009)

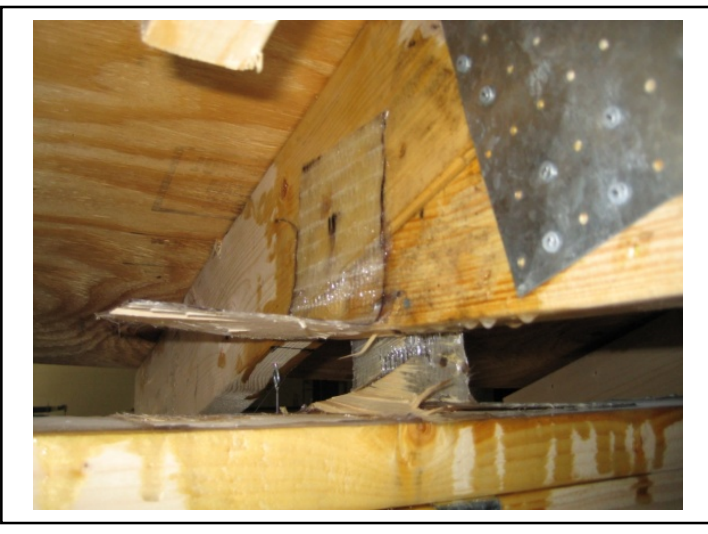

Figure 4.31: Complete Failure of FRP Tie Connections 13 and 14 at 23,659 lbs (Canbek, 2009)

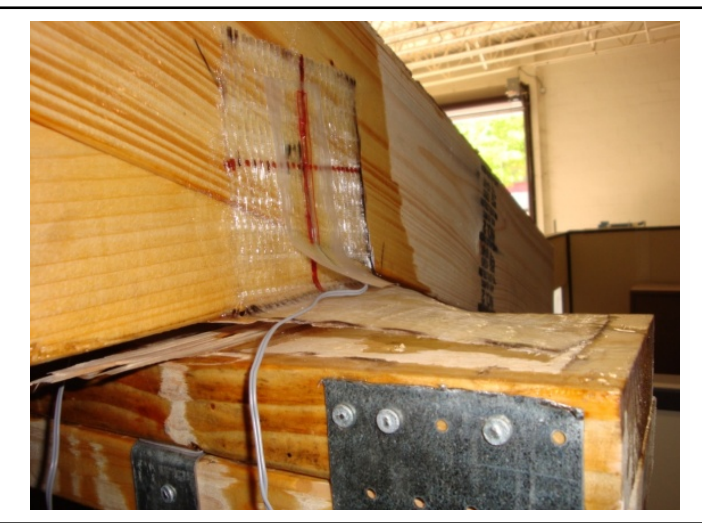

Figure 4.33: Failure of FRP Tie Connections 19 and 20 (Canbek, 2009) 


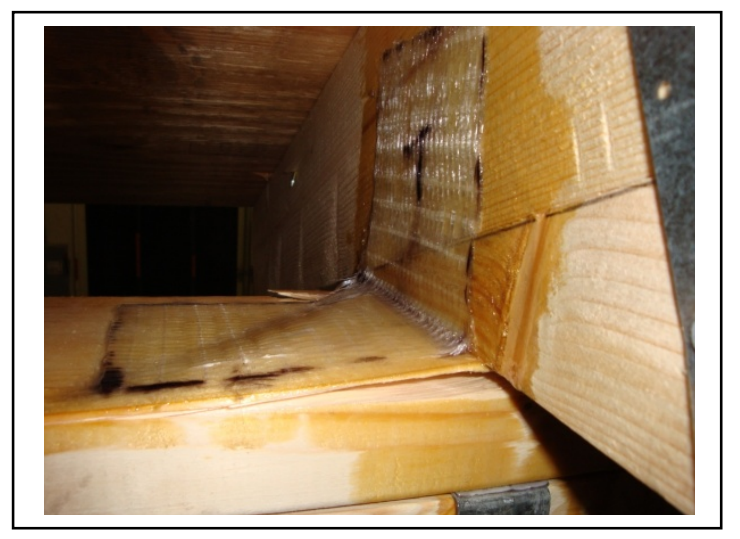

\section{Figure 4.34: Failure of FRP Tie Connections 7 and 8 and Separation of Timber Fibers (Canbek, 2009)}

If it is assumed that loads applied from each jack is transferred to the closest connections, loads at pairs of FRP tie connections are as shown in Figure 4.35. Based on this assumption, the load versus displacement values of string pots located at the outer walls are presented in Figures 4.36-46.

The displacement readings obtained from string pots 9 through 13 on the north side of the trusses are shown in Figure 4.46. Figure 4.47 illustrates the displacement readings obtained from string pots 27 to 31 on the south side of the trusses. The data obtained from string pots 18 to 22 , which were displacements at the center of the bottom chord of the trusses are shown in Figure 4.48. The displacements in these figures are plotted against the total load applied. Upward displacements are considered positive. The three figures collectively suggest that the FRP tie connections provide a rigid and stiff load transfer mechanism from roof to the wall (Canbek, 2009). Results indicate very small displacements at each connection and that the $1 / 8$ inch deflection limit is never reached, this is in full agreement with the component level tests (Canbek, 2009). 


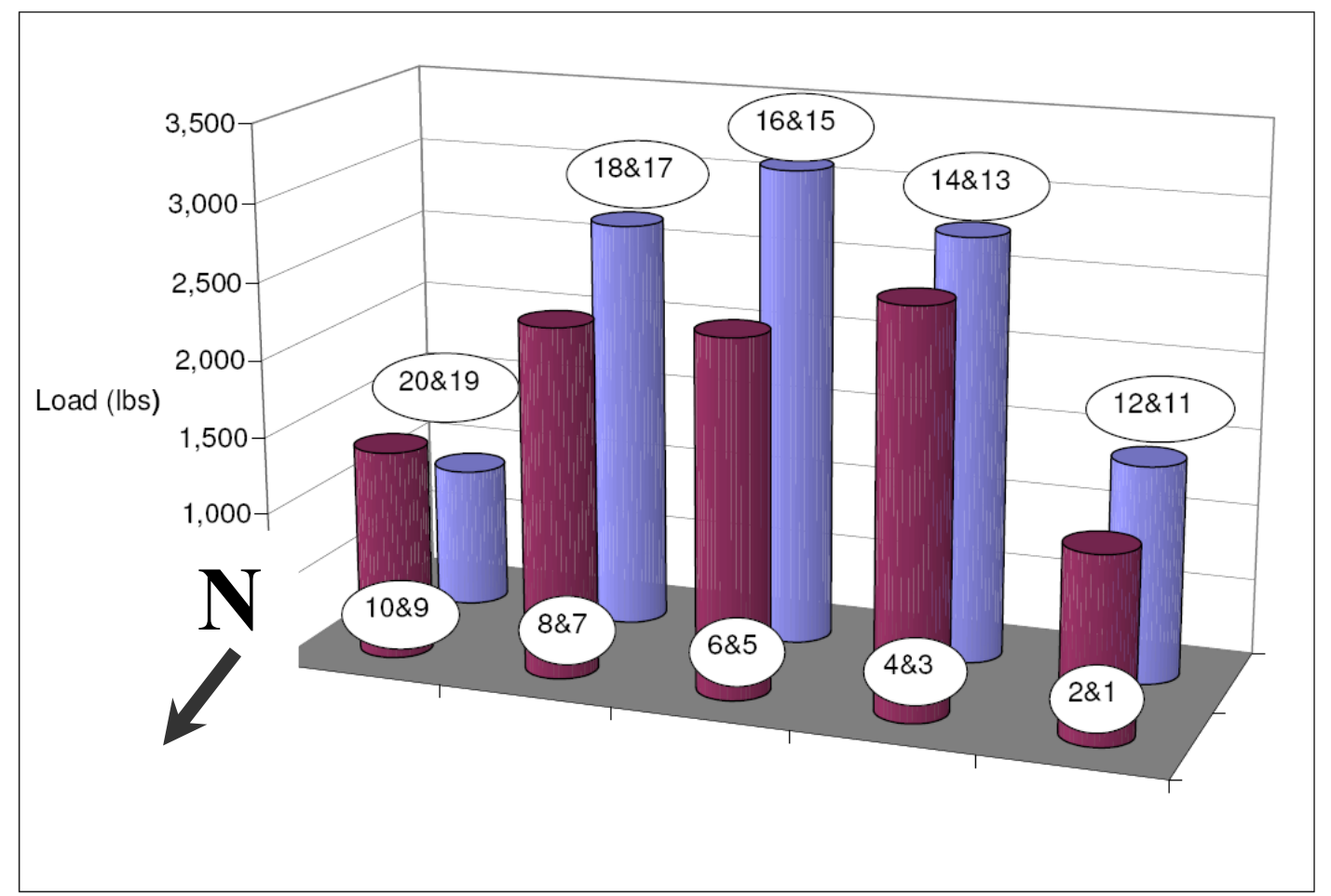

Figure 4.35: The Loads at Pairs of FRP Tie Connections at Initiation of Failure (Canbek, 2009)

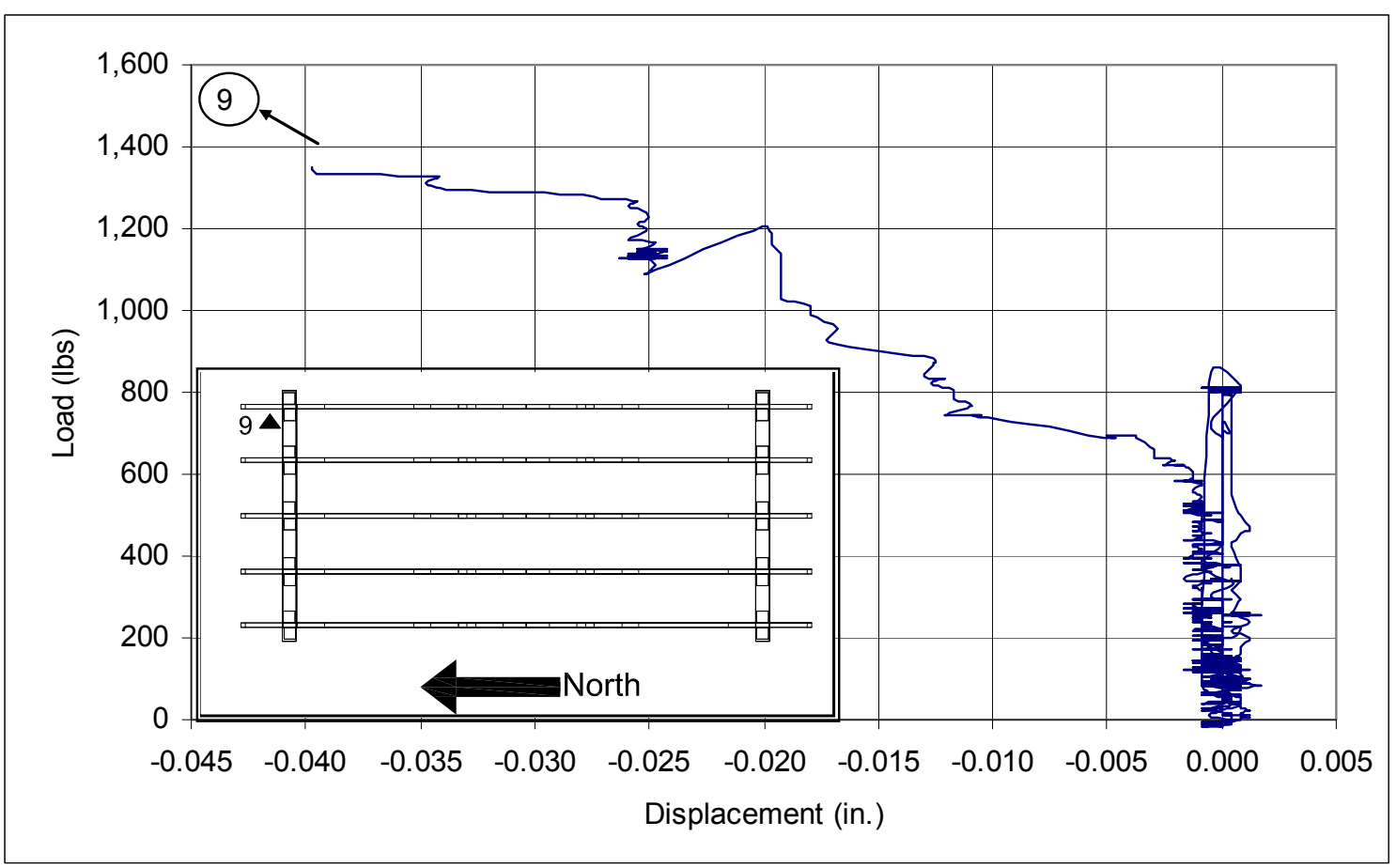

Figure 4.36: Load-Displacement for FRP Tie Connections 1 and 2 (Canbek, 2009) 


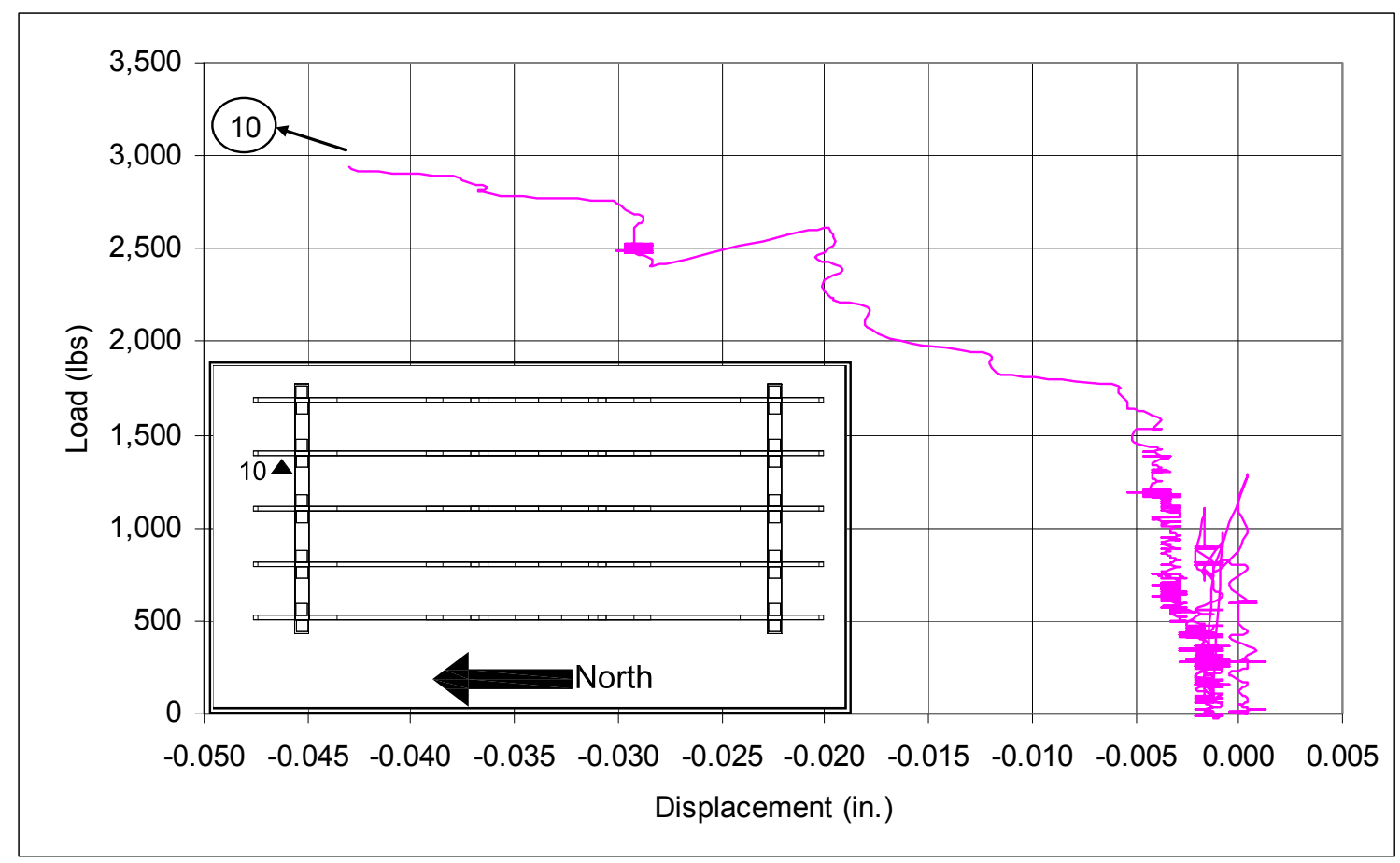

Figure 4.37: Load-Displacement for FRP Tie Connections 3 and 4 (Canbek, 2009)

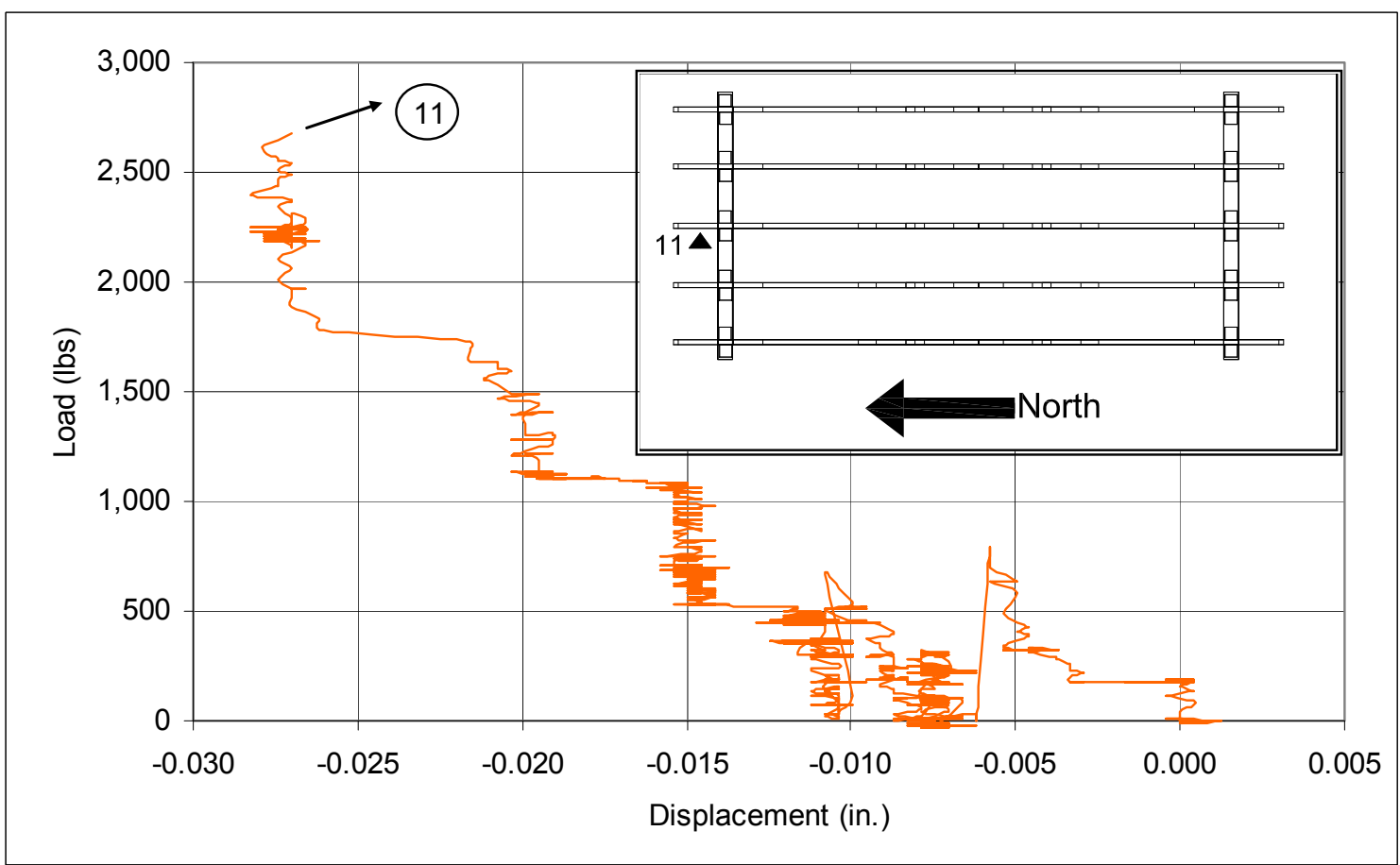

Figure 4.38: Load-Displacement for FRP Tie Connections 5 and 6 (Canbek, 2009) 


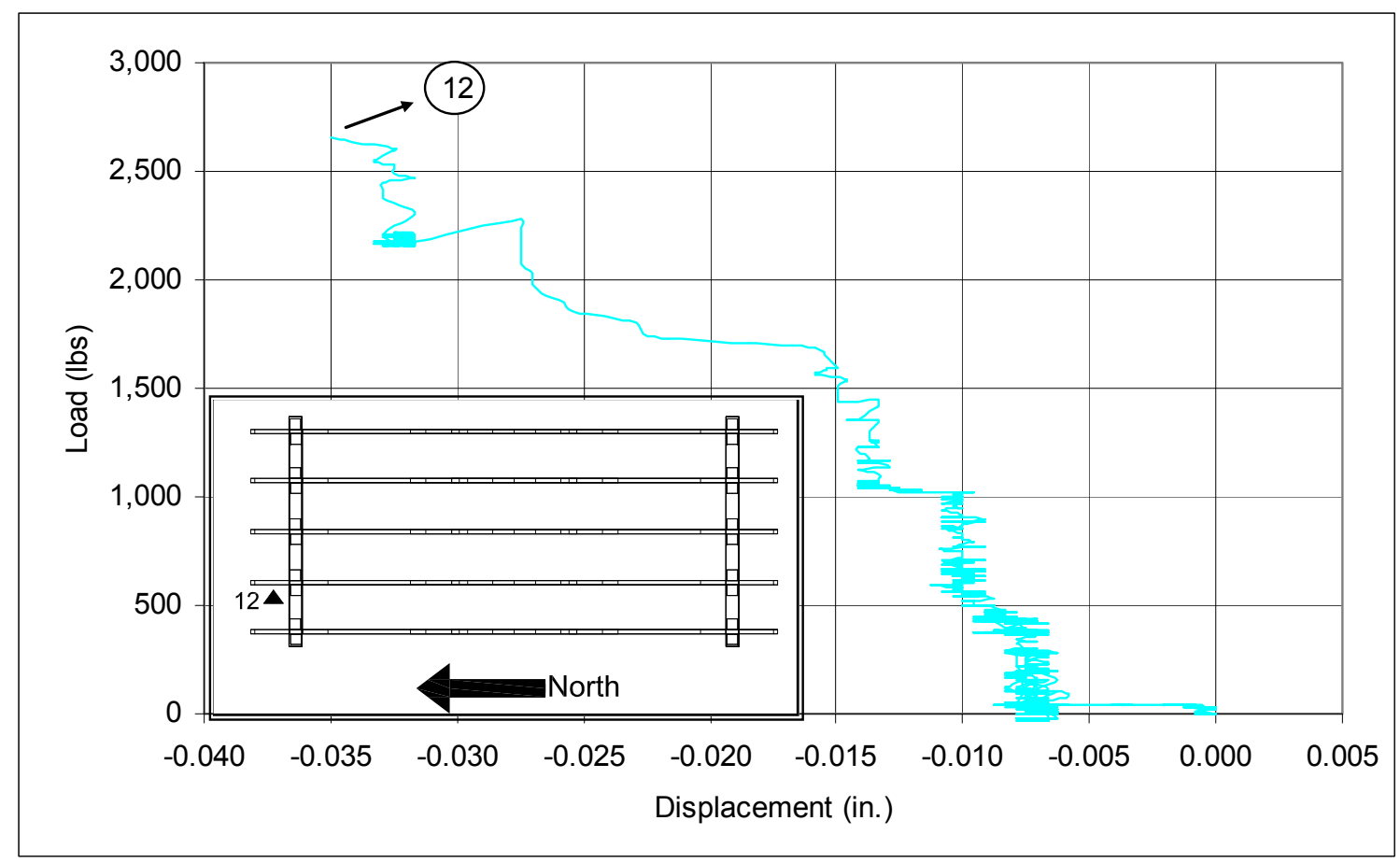

Figure 4.39: Load-Displacement for FRP Tie Connections 7 and 8 (Canbek, 2009)

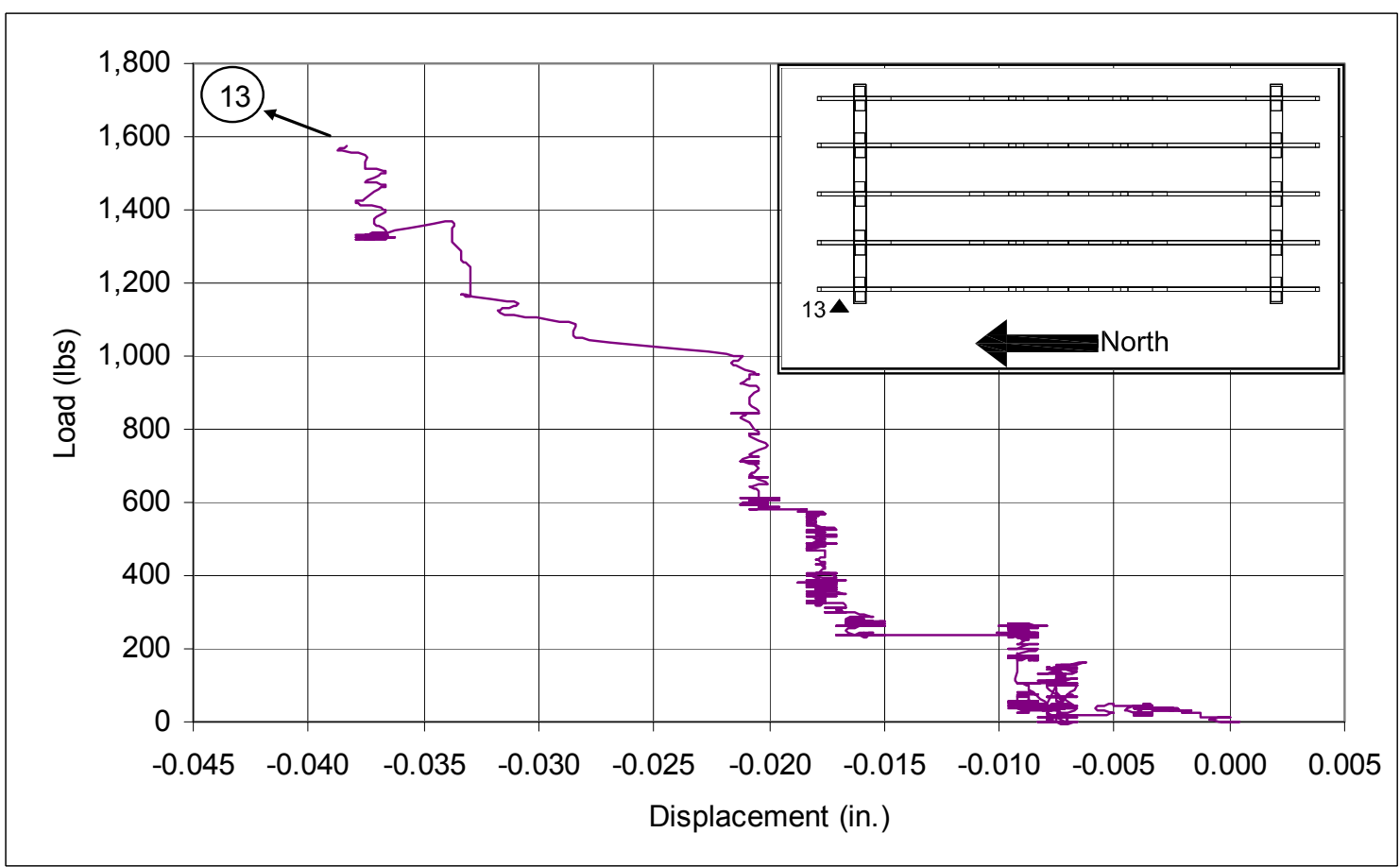

Figure 4.40: Load-Displacement for FRP Tie Connections 9 and 10 (Canbek, 2009) 


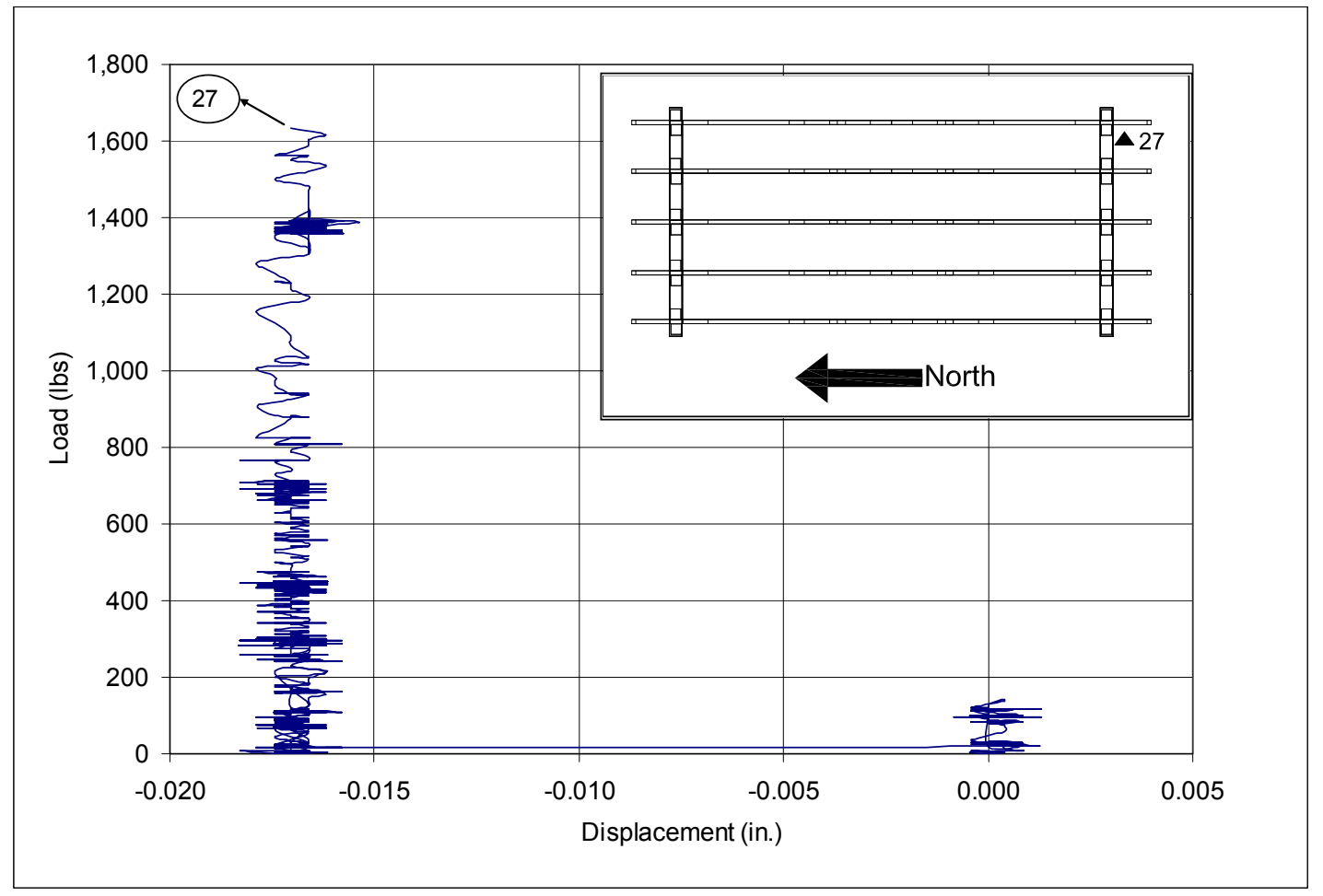

Figure 4.41: Load-Displacement for FRP Tie Connections 11 and 12 (Canbek, 2009)

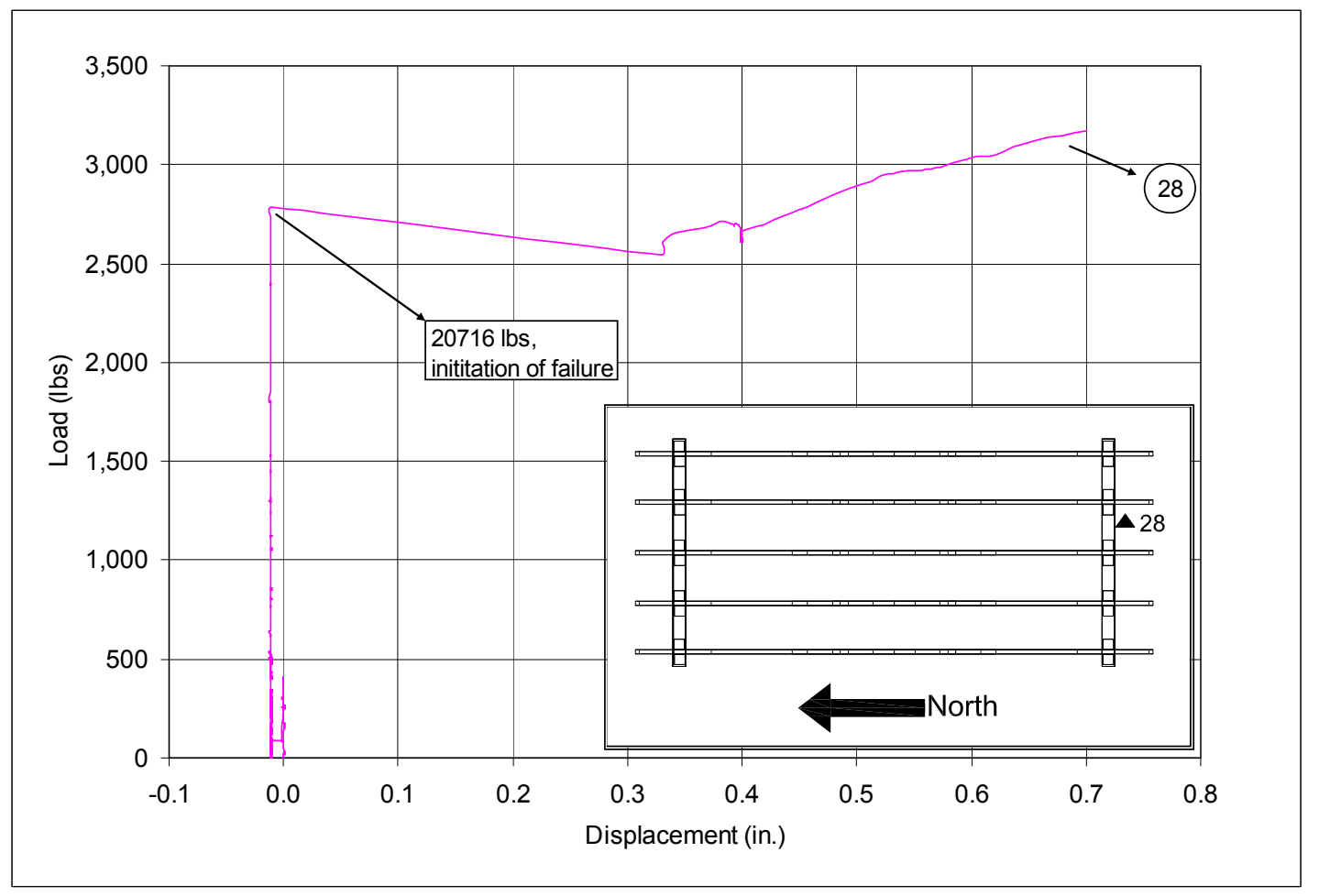

Figure 4.42: Load-Displacement for FRP Tie Connections 13 and 14 (Canbek, 2009) 


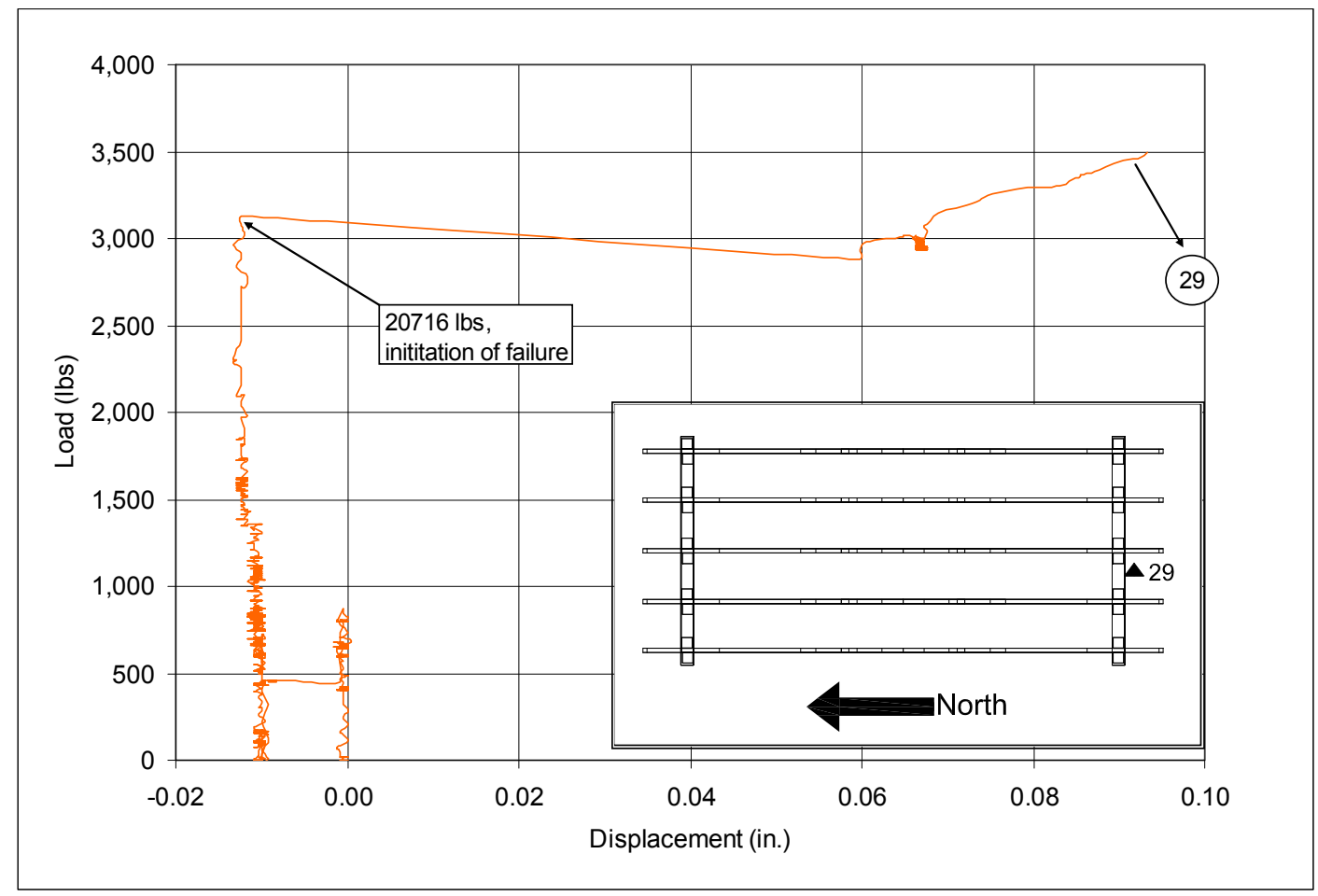

Figure 4.43: Load-Displacement for FRP Tie Connections 15 and 16 (Canbek, 2009)

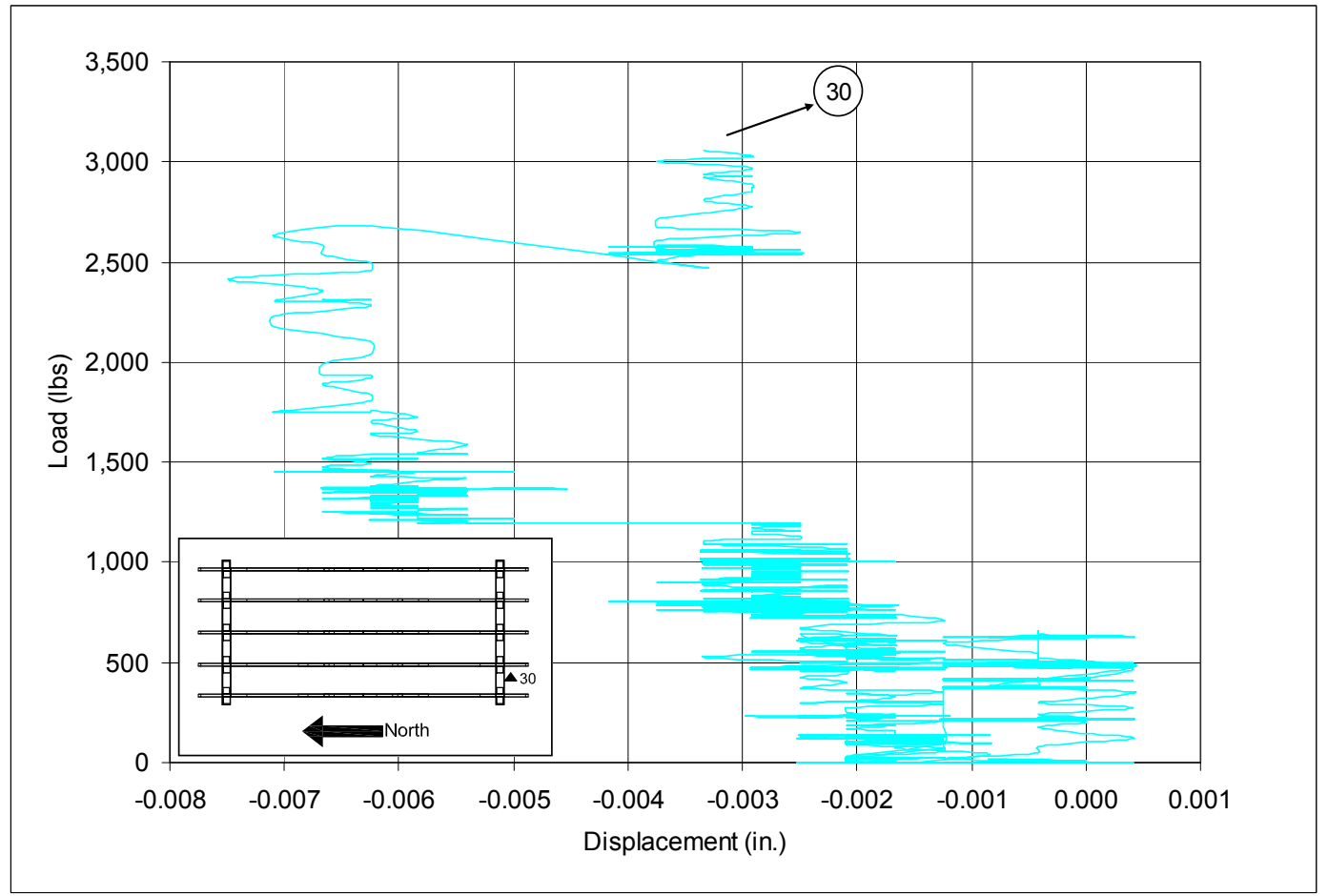

Figure 4.44: Load-Displacement for FRP Tie Connections 17 and 18 (Canbek, 2009) 


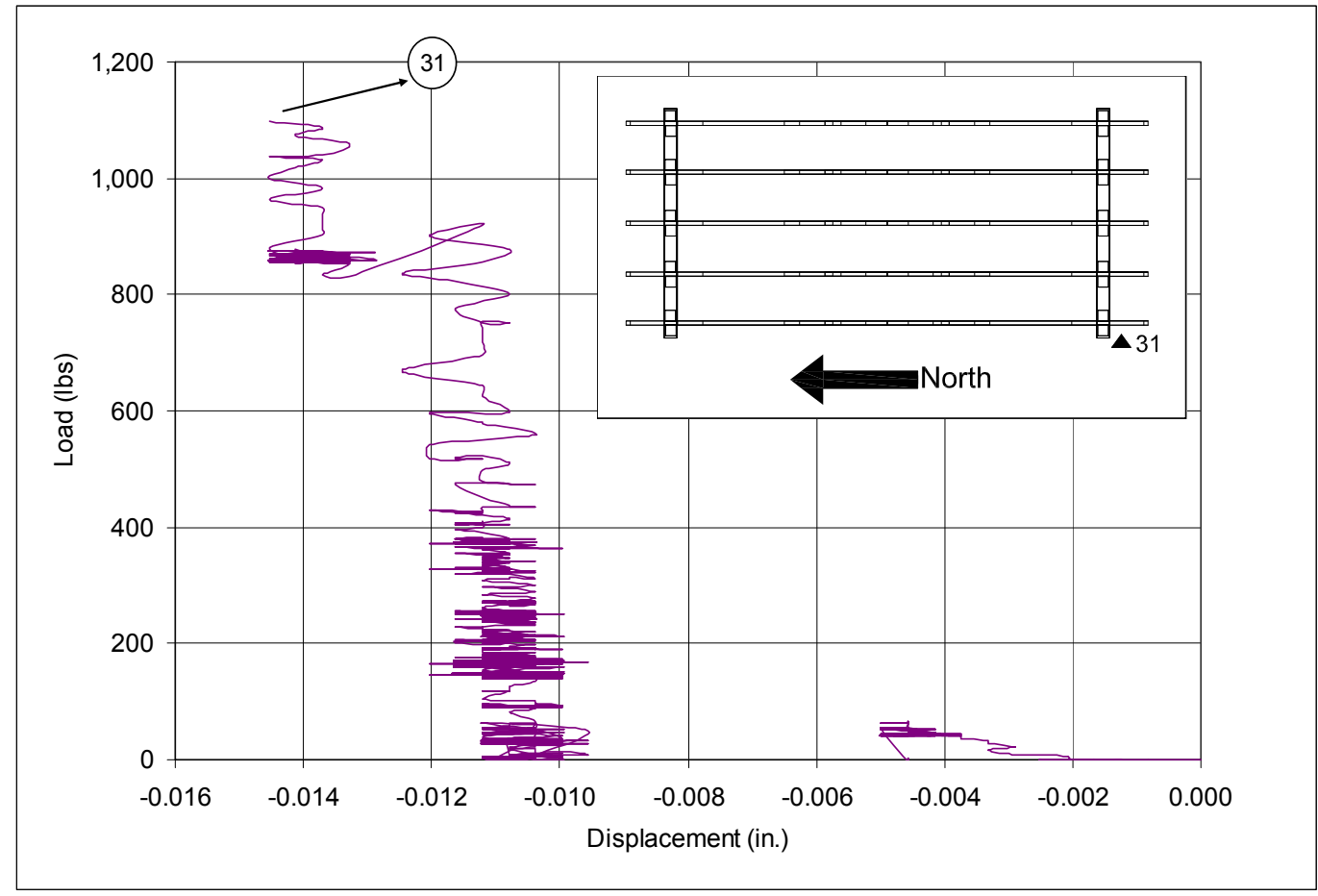

Figure 4.45: Load-Displacement for FRP Tie Connections 19 and 20 (Canbek, 2009)

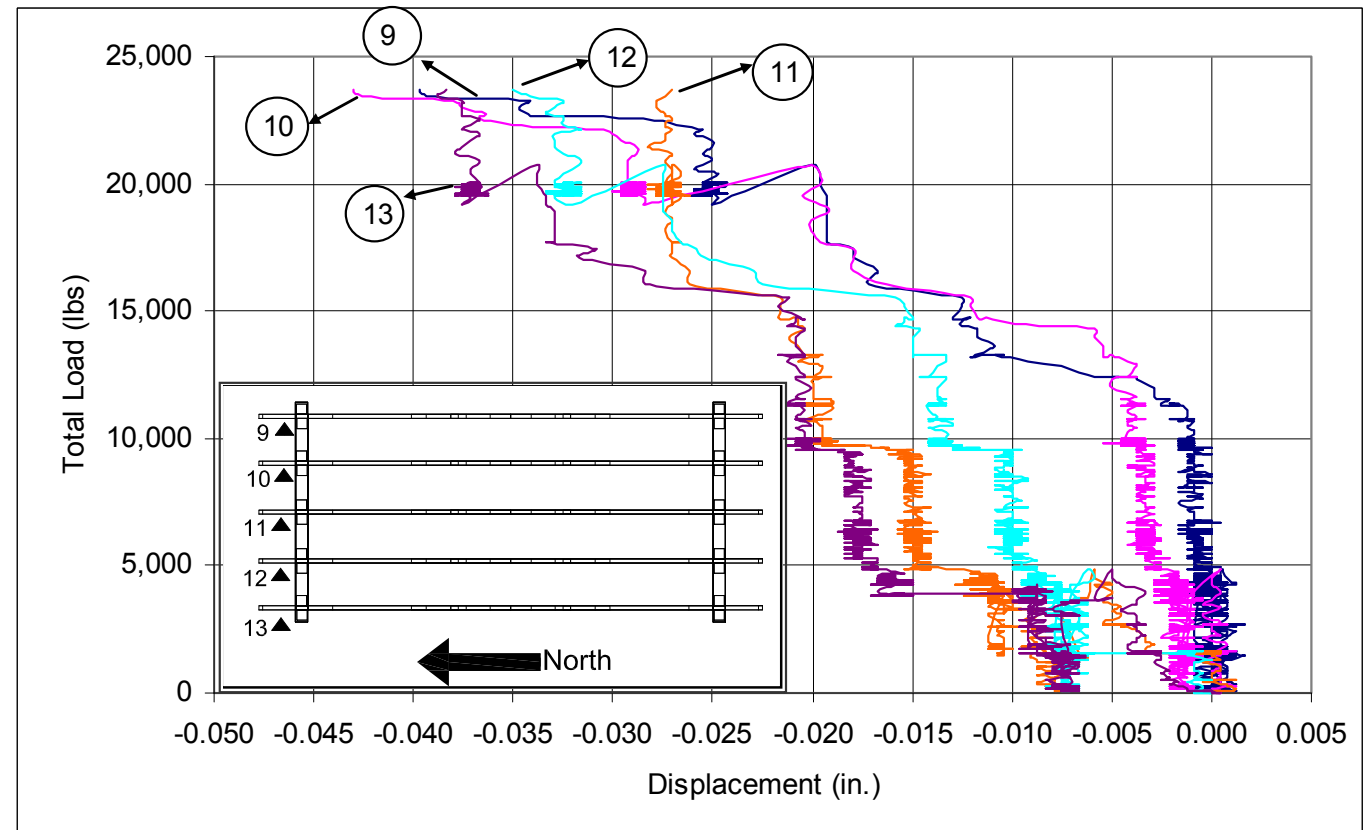

Figure 4.46: Total Load-Displacements on the North Side of the Truss vs. Total Load (Canbek, 2009) 


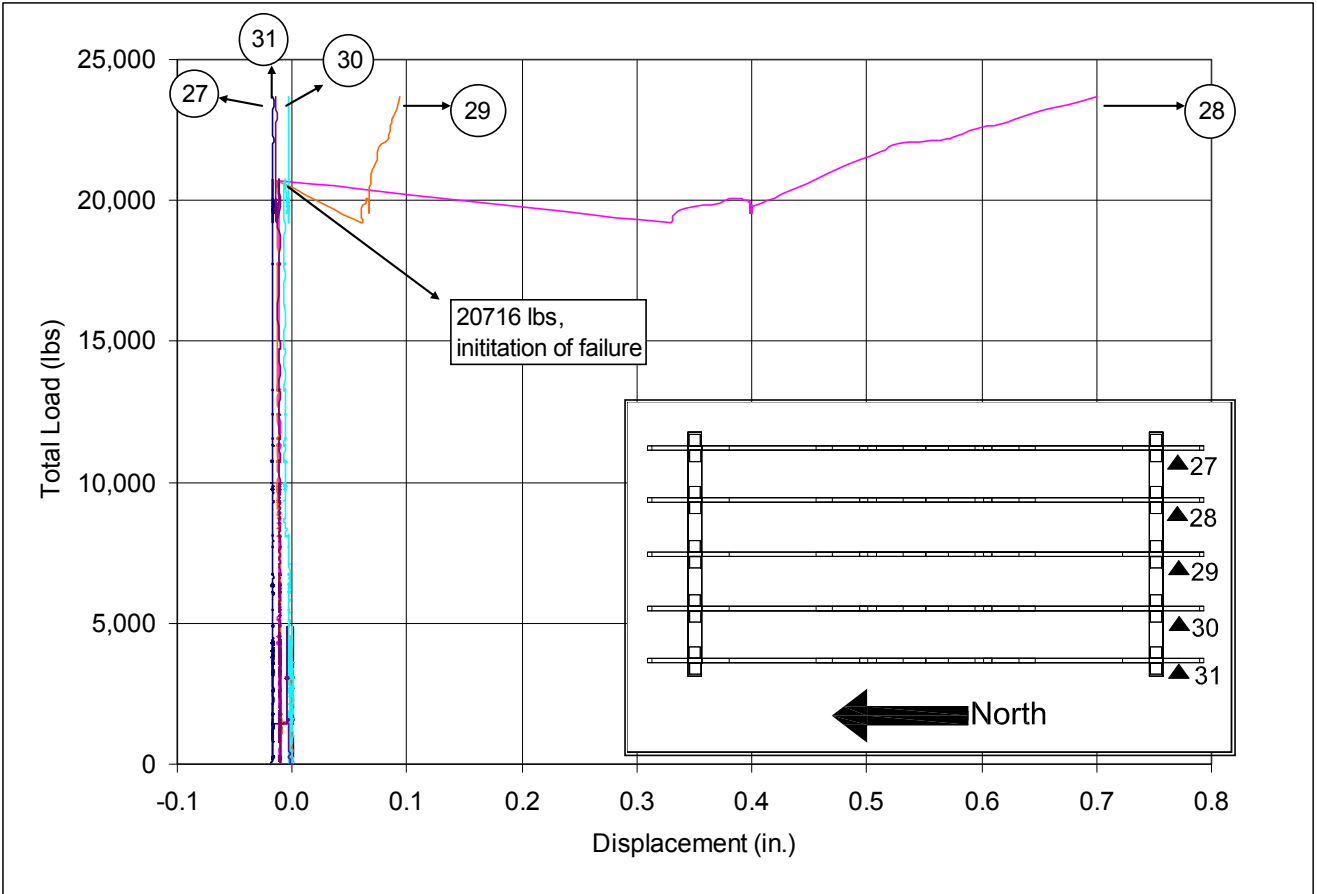

Figure 4.47: Total Load-Displacements on the South Side of the Truss vs. Total Load

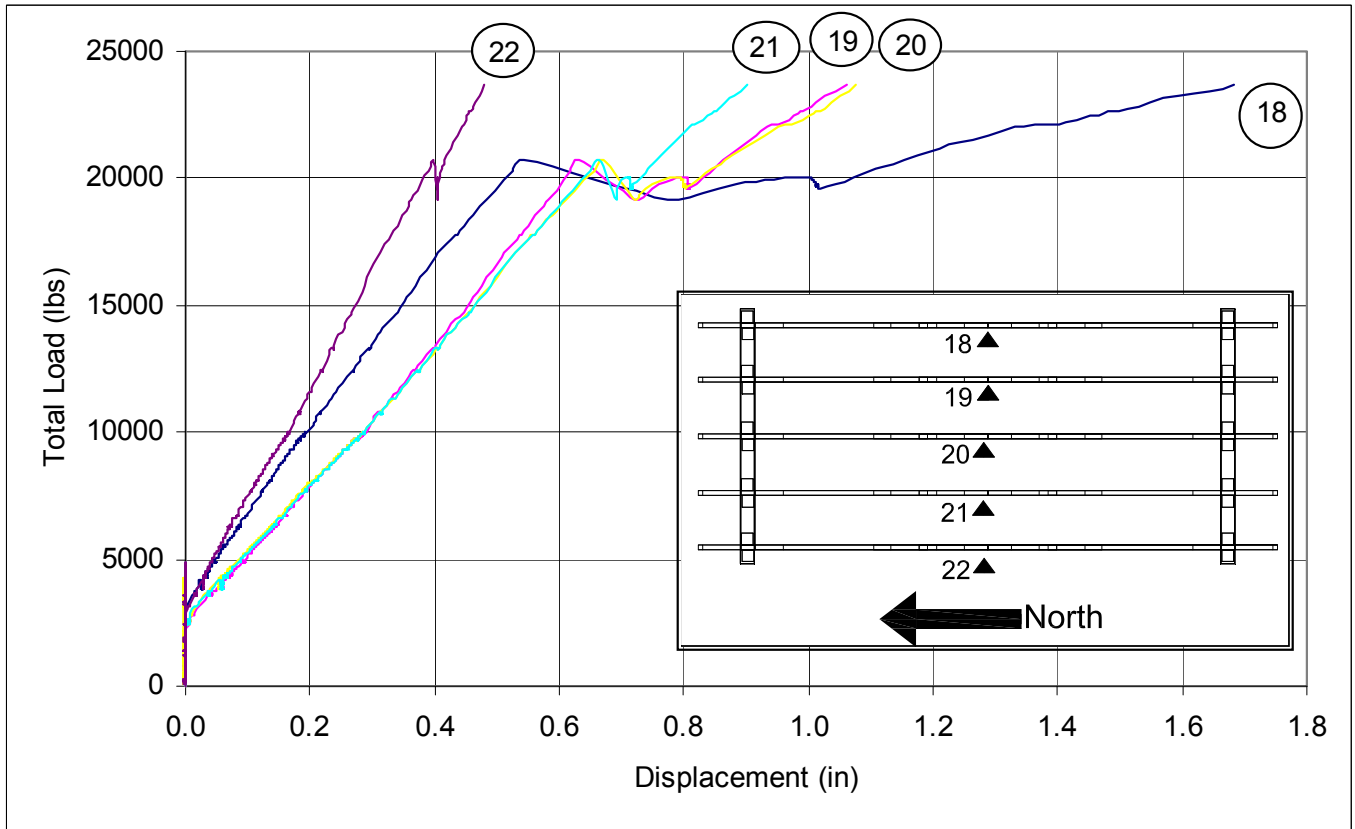

Figure 4.48: Total Load-Displacements at the Center of the Bottom Chord of the Truss (Canbek, 2009) 
In Figures 4.49 through 4.52, the strains at pairs of FRP tie connections at the corners are plotted versus the stress in vertical leg of FRP tie connections. It was assumed that the loads applied from each jack are equally shared between nearest pairs of FRP tie connections. The figures show that the ultimate stress values in the failed ties seem to be very close to the bond strengths calculated in component level tests (Canbek, 2009). The strains obtained from the strain gages placed on FRP tie connections at the corners are plotted versus time and versus total load in Figures 4.53 and 4.54 respectively. A maximum of 581 micro-strains was recorded at one of the failed connections. According to the manufacturer's specifications, the GFRP used has an elastic modulus of 3,790 ksi, a tensile strength of $87 \mathrm{ksi}$ and a maximum elongation of 0.023 inch (Canbek, 2009). Therefore, the average stress in the vertical leg of the FRP tie connection on the joist is about $2.2 \mathrm{ksi}$, less than its rupture strength. 


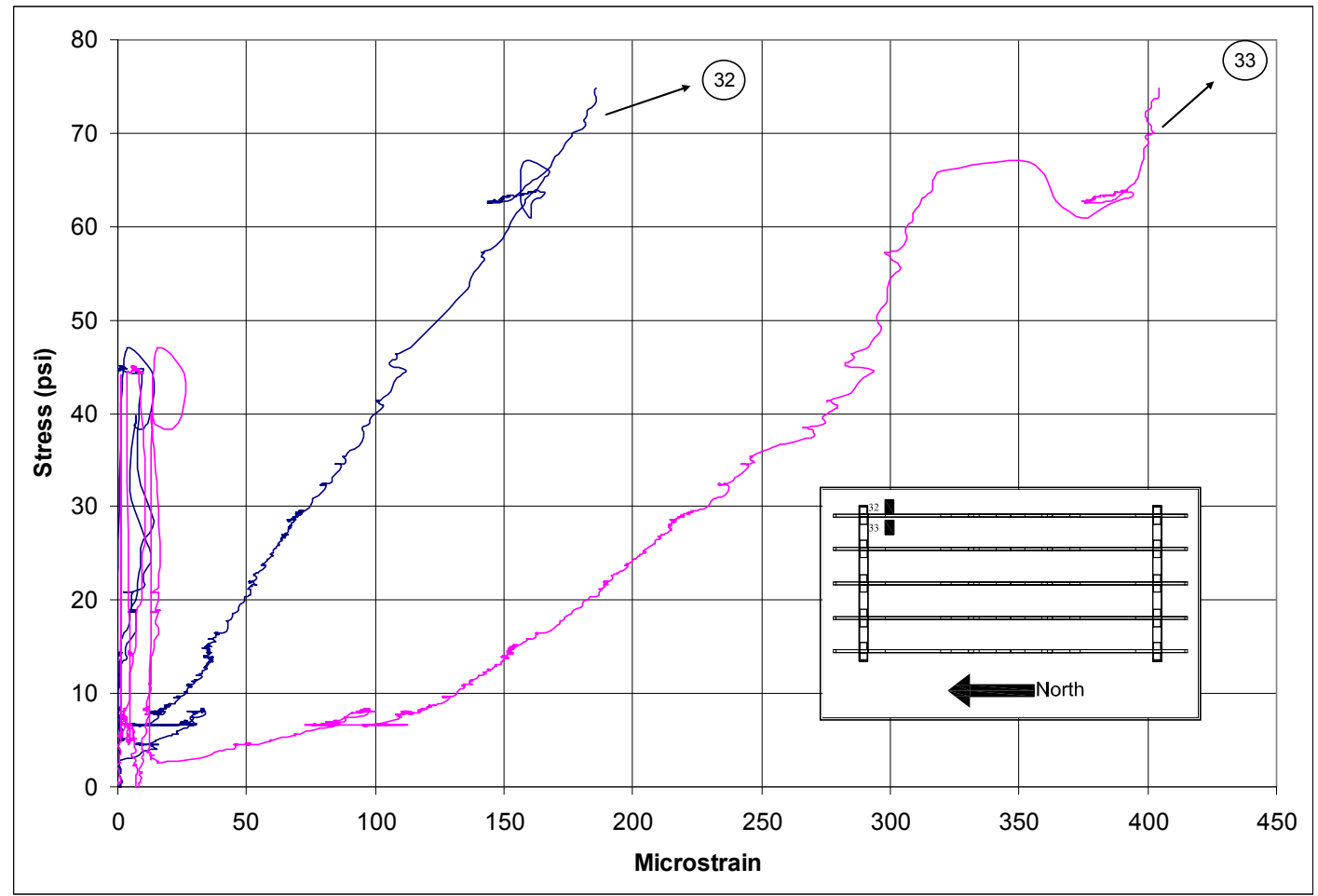

Figure 4.49: Stress-Strain for FRP Tie Connections 1 and 2 (Canbek, 2009)

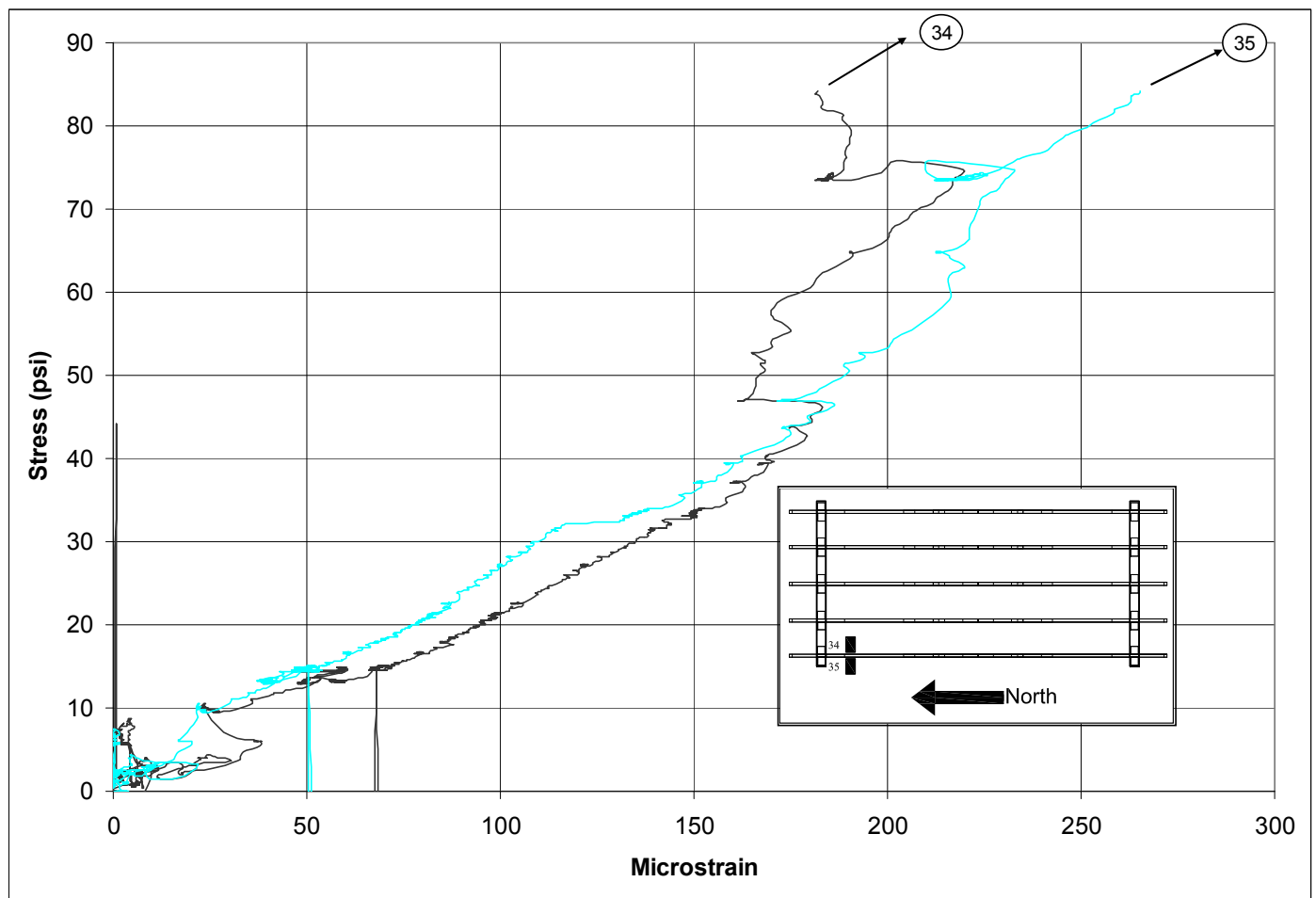

Figure 4.50: Stress-Strain for FRP Tie Connections 9 and 10 (Canbek, 2009) 


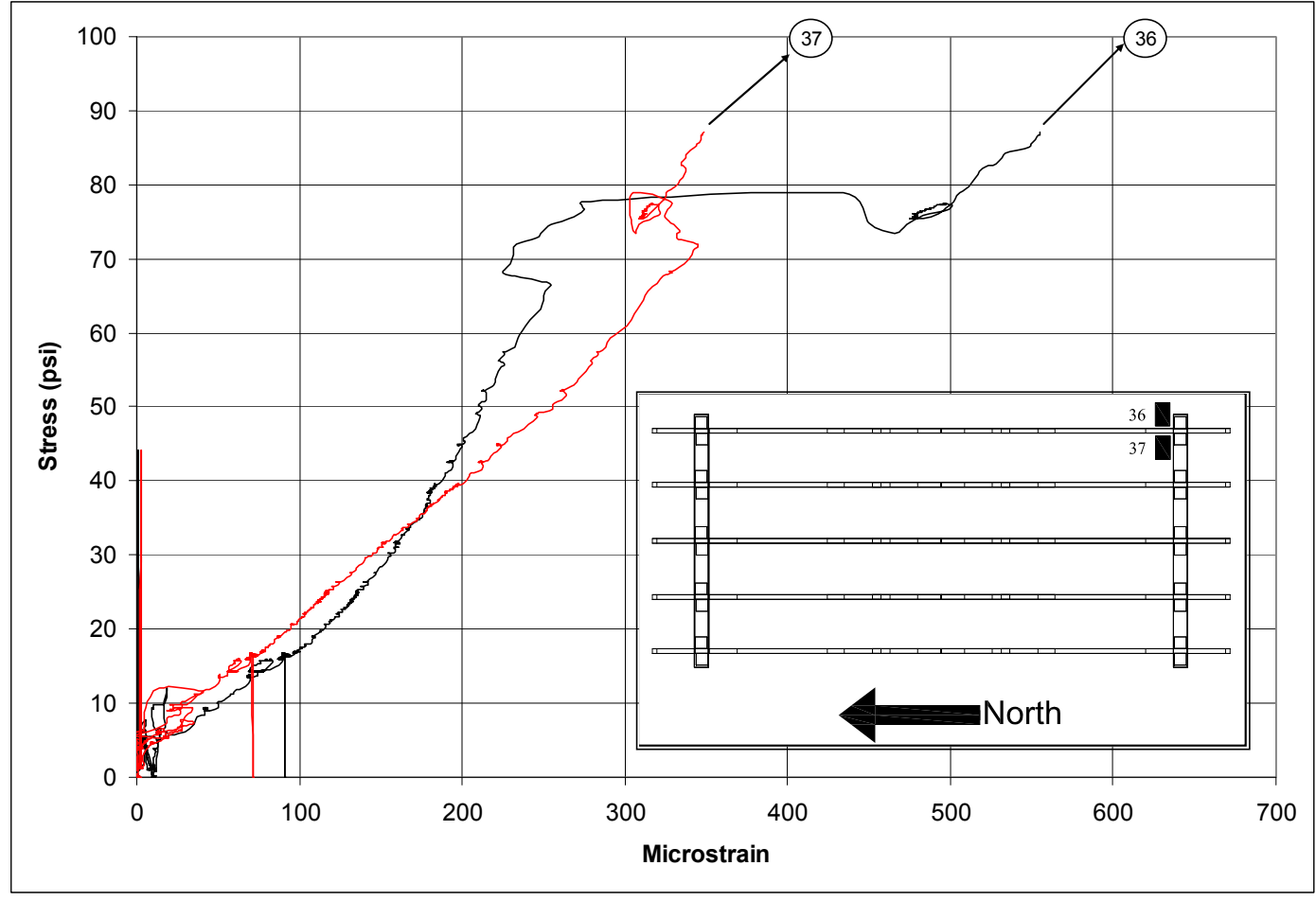

Figure 4.51: Stress-Strain for FRP Tie Connections 11 and 12 (Canbek, 2009)

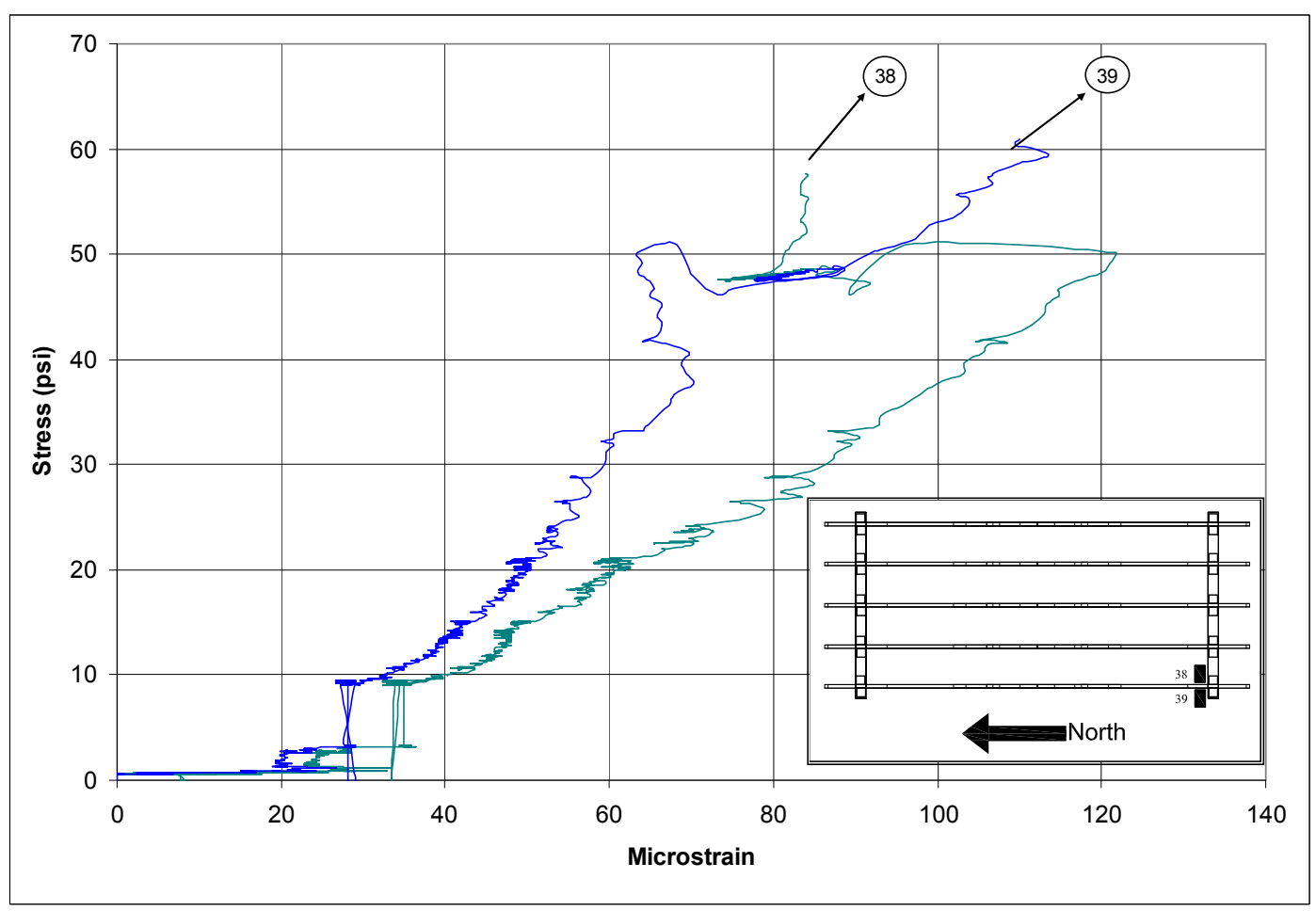

Figure 4.52: Stress-Strain for FRP Tie Connections 19 and 20 (Canbek, 2009) 


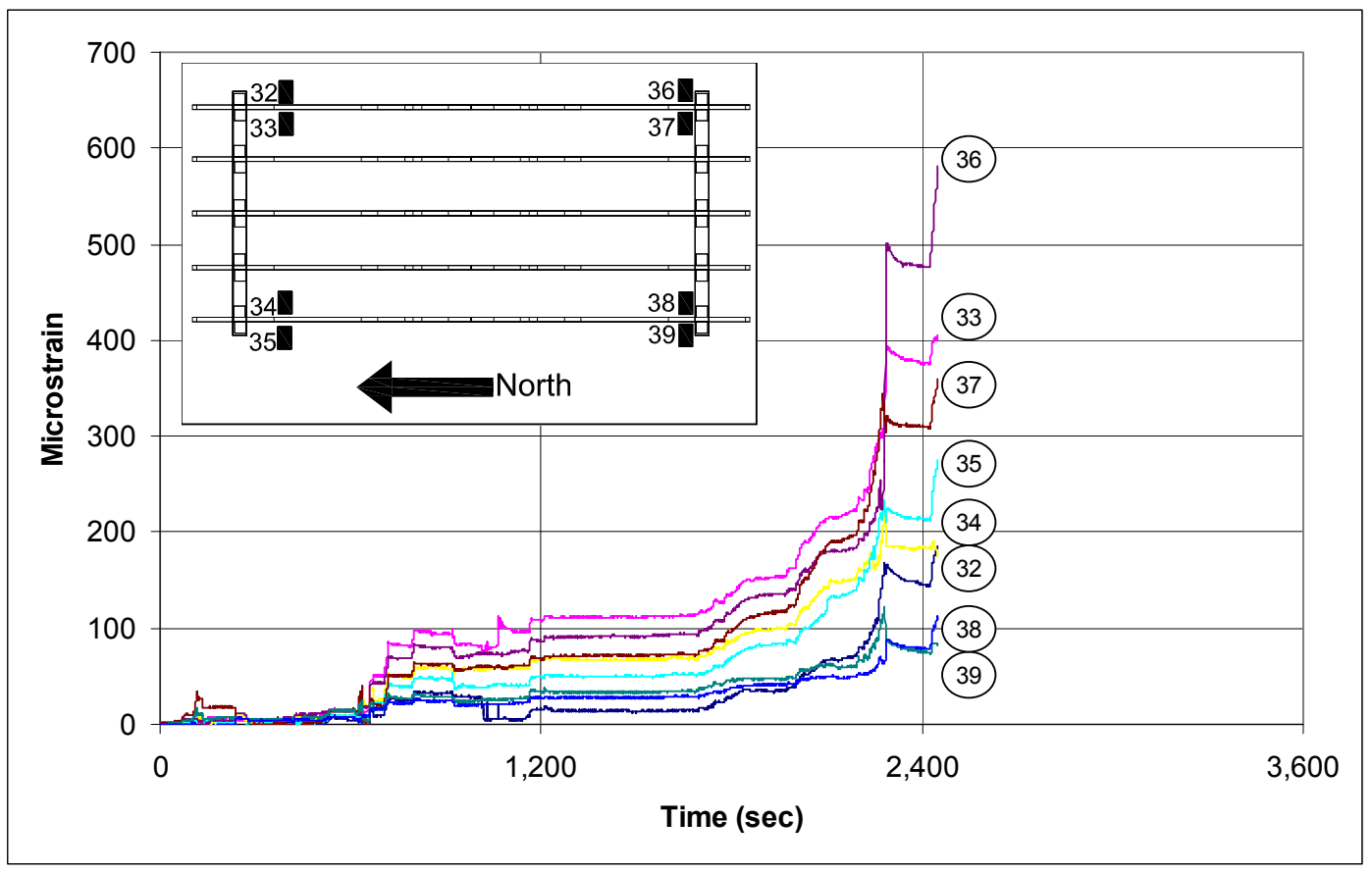

Figure 4.53: Strain Values of FRP Tie Connections Located at the Corners of the Truss (Canbek, 2009)

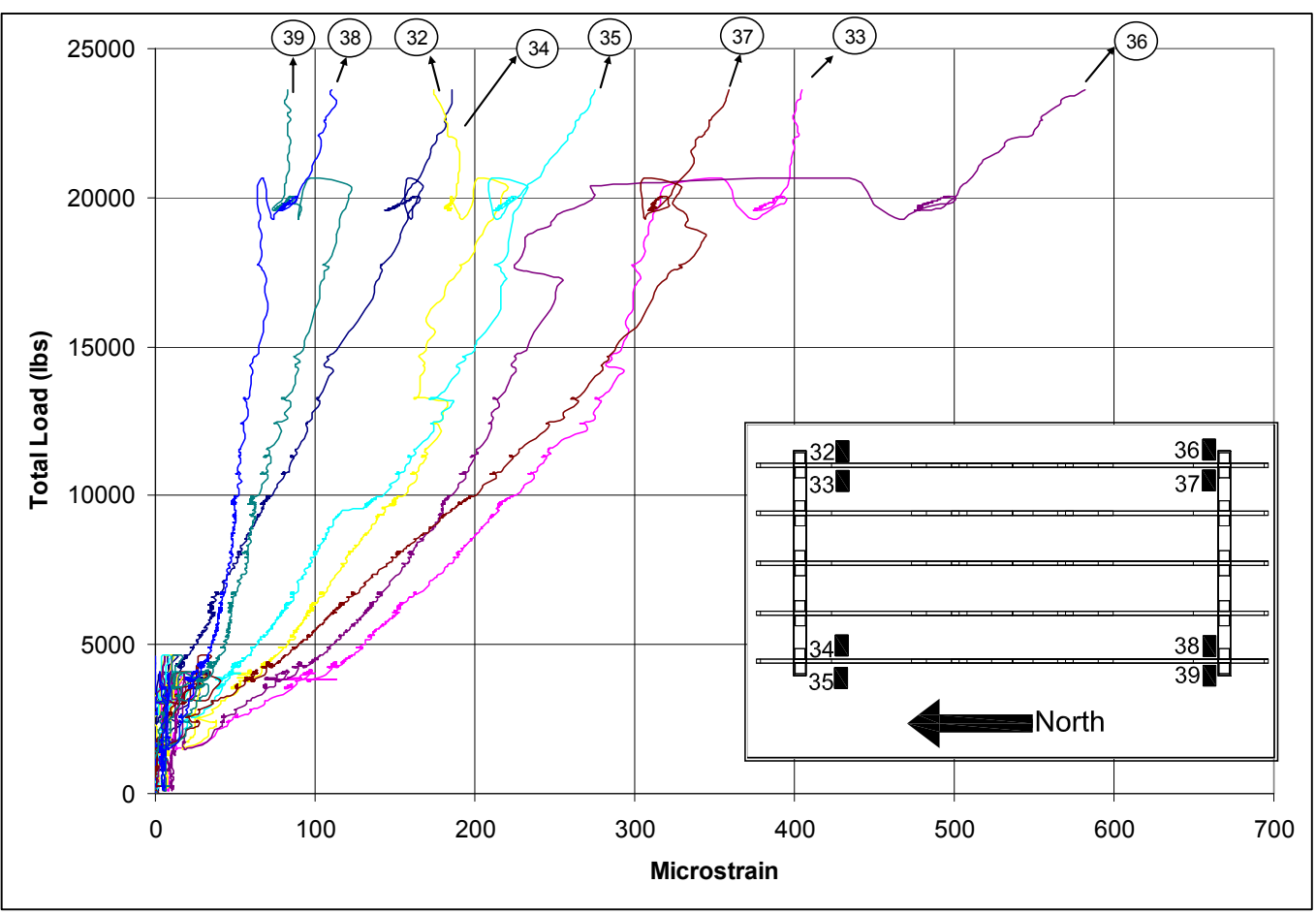

Figure 4.54: Total Load-Strain for FRP Tie Connections Located at the Corners (Canbek, 2009) 
The full-scale test has provided valuable information. Since there are ten connection points, the ultimate load per connection can be estimated as 2,365 lbs. Considering that the application of load from the jacks was not perfectly uniform and the system was able to take more loads even after failure of one connection, it may be concluded that the capacity of one tie is greater than this value (Canbek, 2009). This value exceeds the $\mathrm{FBC}$ requirement of $700 \mathrm{lbs}$ for $\mathrm{HVHZ}$ with a factor of safety of 3 as used by most of the hurricane clip manufacturers.

\subsection{Conclusions}

The component level tests showed that the FRP-timber bond strength is related to the size of the bonded area. The relation is not constant and beyond a threshold value, no more increase is observed in the FRP-timber Mode II bond strength. The component level tests and the full-scale test both suggest that the bond strengths of FRP-timber in Mode I and II seem to be very close to each other (Canbek, 2009). The full-scale and component level tests results, of the FRP connection, demonstrated similar load capacities and stiffness (Canbek, 2009).

The initial research on the FRP connection indicated that the new connection can be effective in transferring the vertical and lateral roof-to-wall loads. Furthermore, the connection is economically comparable to commercially available metal connectors and applicable to new construction or as a retrofit for existing structures (Canbek, 2009).

The FRP tie connection developed by Canbek (2009) provided the basis for further testing using hybridized experiments performed at the WoW and SCL. The hybridized testing, described in the following sections, was necessary to develop 
performance based design details to ascertain the performance of the new connection under tropical cyclone wind effects (including high winds, wind-driven-rain and windborne debris impacts). 


\section{Wall of Wind Testing of the FRP Roof-to-Wall Connections}

\section{$5.1 \quad$ Introduction}

The FRP tie connection developed by Canbek (2009) and described in Chapter 4 provided the basis for further testing and development of the GFRP connection. As part of the hybridized experiments, the WoW was employed to test the behavior of the roofto-wall connections as part of a test building subjected to simulated hurricane effects. These findings helped to evaluate the performance of the connections and aerodynamic and aero-hydrodynamic loading on them from wind and wind-driven rain effects for various angles of attack, enclosed and partially enclosed conditions, and various turbulence characteristics. Thus the performance of the connections were evaluated under high winds with and without wind-driven rain conditions and simulated high internal pressure that may occur due to the breach of building envelope from wind-borne debris.

A one-story gable-roof structure instrumented with sensors to measure the wind induced effects on the roof-to-wall connections underwent high wind tests for five different angles of attack, two internal pressure conditions, two kinds of wind flow (with and without low frequency fluctuations), and with and without simulated wind-driven rain.

\subsection{Rationale for Testing GFRP Connection at the WoW}

Using the GFRP tie connections developed at the SCL, the WoW was employed to tests, in a more realistic manner, the behaviors of the connection. Using the results of 
these aerodynamic and aero-hydrodynamic tests, resultant wind-induced forces were developed from the load cells data on the uplift loads, lateral loads parallel to the wall and lateral loads perpendicular to the wall. These resultant forces were used to test the GFRP connection to failure in the SCL as detailed in chapter 6. Therefore, the resultant loads are dependent on ratios of uplift to lateral loads for various cases of angles of attack, internal pressure conditions, wind turbulence, and rain conditions. From the failure load equivalent wind speed causing failure can then be estimated using the following equation:

$$
v_{\text {failure }}=\sqrt{\frac{2 F_{\text {failure }}}{C_{F} A \rho}}
$$

Where,

- $\quad v_{\text {failure }}$ is the equivalent wind speed at which the connection fails

- $\quad F_{\text {failure }}$ is the resultant load at which the connection fails (obtained from SCL tests)

- $\quad \rho$ is the air density

- $A$ is the tributary area for the connection

- $\quad C_{F}$ is the aerodynamic load coefficient for the connection

\subsection{Test Specimen and Setup}

The test specimen used in the WoW tests was built in house by research personnel (see Figure 5.1). It consisted of two separate entities, the base structure and the roof. 


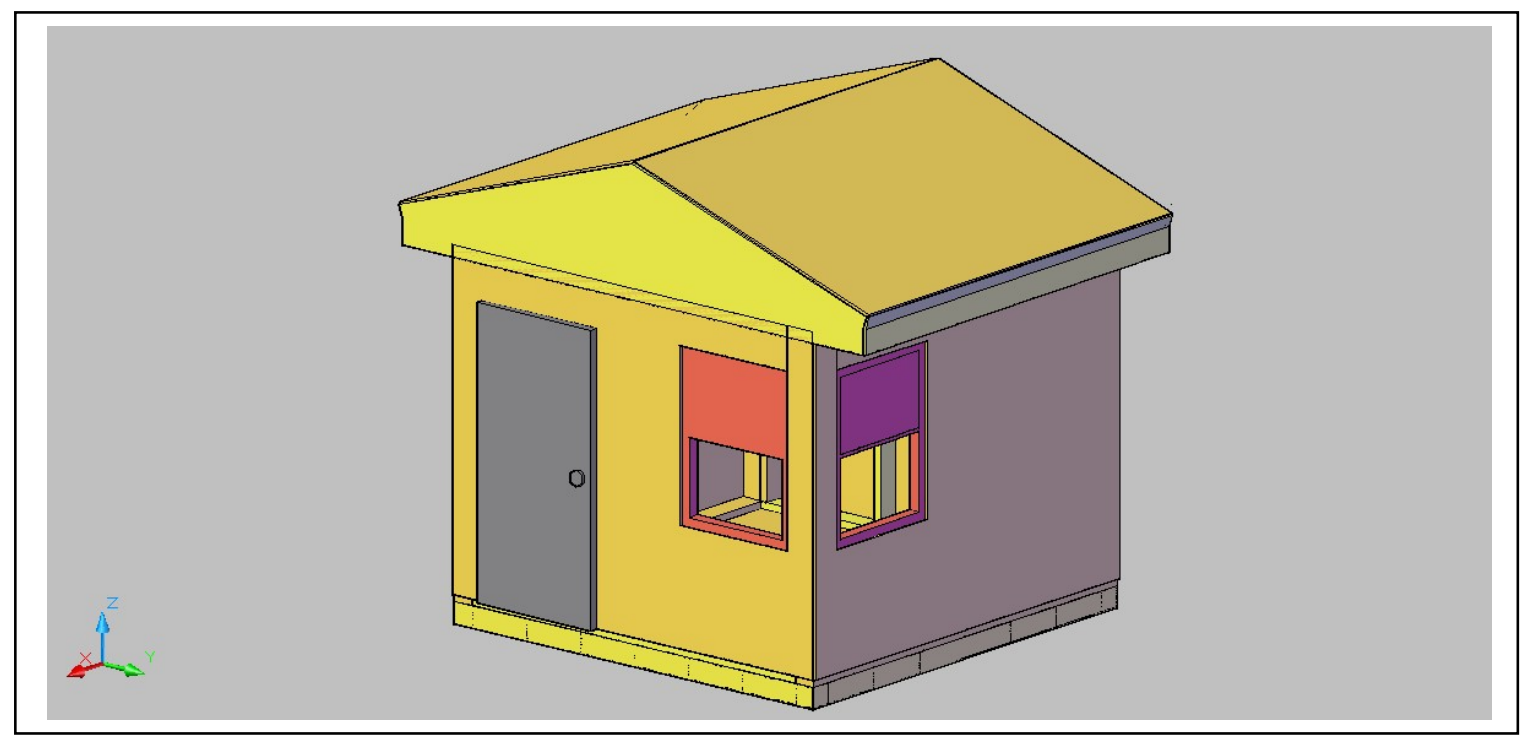

Figure 5.1: Wall of Wind Test Specimen

Since the load cells were placed in between the roof and the top-plate it was imperative for the two systems, the base structure and roof, to be built separately. The base structure and roof were purposely built to be very sturdy to prevent damage during testing, since the failure (if any) was to be limited to the roof-to-wall connection.

A $10 \times 10 \times 8$ (eave height) feet base structure was built using Spruce Pine Fir (SPF) No. $2-2 \times 6$ inch dimensional lumber to be consistent with the lumber utilized in the connection development stage in SCL (Chapter 4). The bottom structure was composed of a 5 inch high timber floor (Figure 5.2), 8 feet walls with 2 x 2 feet windows and one door (Figure 5.3). The floor consisted of 6-2 x 6 inch 10 feet long members spaced every 2 feet. Members 2 feet in length were installed in the perpendicular direction of the floor to create a foundation membrane (Figure 5.2). The wall studs were spaced 14 inches apart to prevent wall failure. Metal clips were installed at the top-plate to top of the stud and on the bottom plate to the bottom of the studs (Figure 5.4). The 


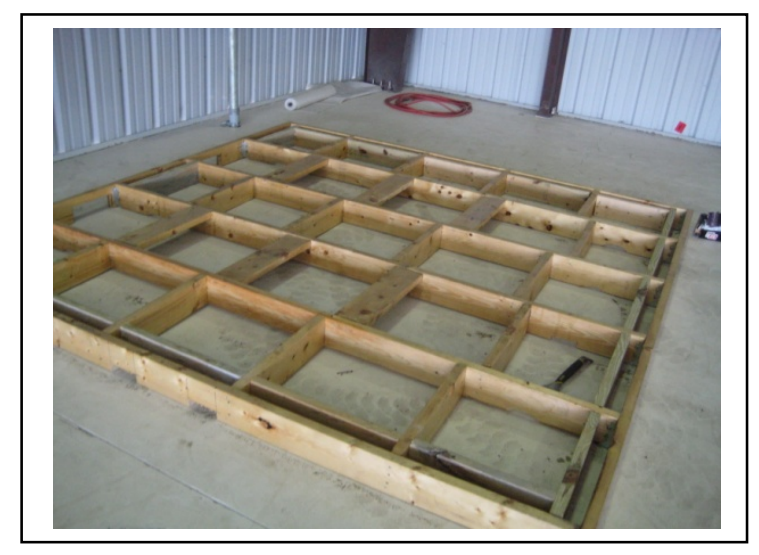

Figure 5.2: Floor Membrane

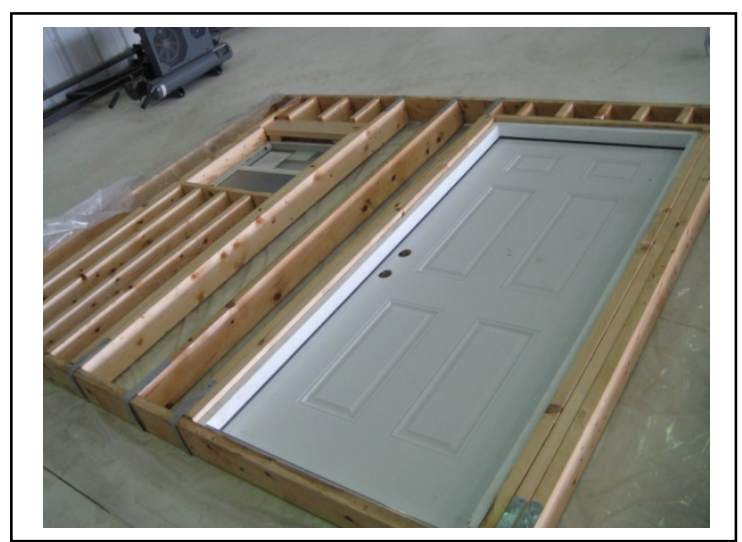

Figure 5.3: Wall with Door \& Window

outside and the inside sheathing used was 5/8 inch APA plywood nailed every 6 to 4 inches to the wall studs, bottom-plate and double top-plate. The entire structure was painted with polyurethane to slow down the weathering effects on the structure.

The gable roof was built using SPF No. $2-2 \times 4$ inch dimensional lumber and $1 / 2$ inch sheathing nailed every 4 inches. The roof consisted of three 10 feet trusses spaced 5 feet apart (see Figure 5.5), with a 1.5 feet overhang on each side. The trusses were connected to a $10 \times 10$ feet mitered single top-plate using the GFRP tie connection (Figure 5.6). The top-plate was later cut between the connections to determine if the load cells recorded any load sharing; no major difference was observed. The GFRP connection shown in Figure 5.7 is a typical example of the $3 \times 1$ inch GFRP used as the roof-to-wall connection for each roof. A total of 8 GFRP tie connections were utilized, 2 on the gable end trusses and 4 on the middle truss. Six 6-degrees of freedom (DOF) load cells were installed and sandwiched between aluminum plates bolted to the top plate underneath the trusses and the double top plate of the base structure (see Figure 5.8). Thus all the 
loading from the roof-to-wall connections were transferred through the load cells. A vented soffit was installed between the walls and overhang, but not connected to the bottom structure (see Figure 5.9). The soffit was screwed to the overhangs of the trusses and flashing was installed along the overhang, ridge and gable ends (see Figure 5.10). Sub-fascia was nailed to the trusses and no purlins or horizontal members were used between the trusses.

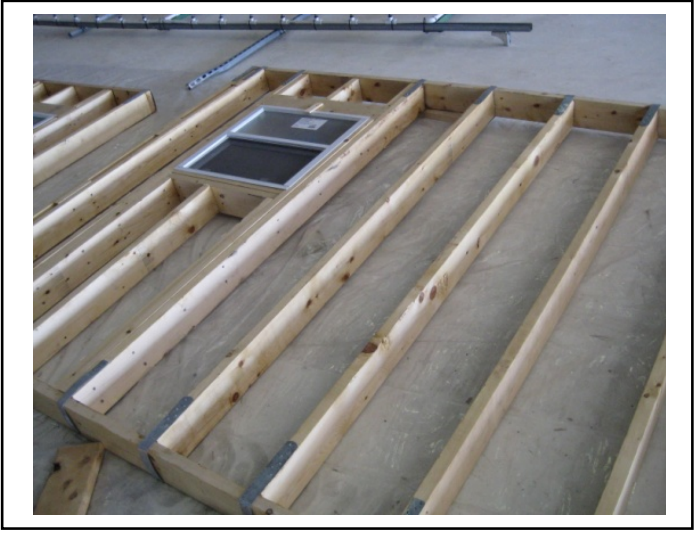

Figure 5.4: Metal Clips at the Stud to Top \& Bottom Plate

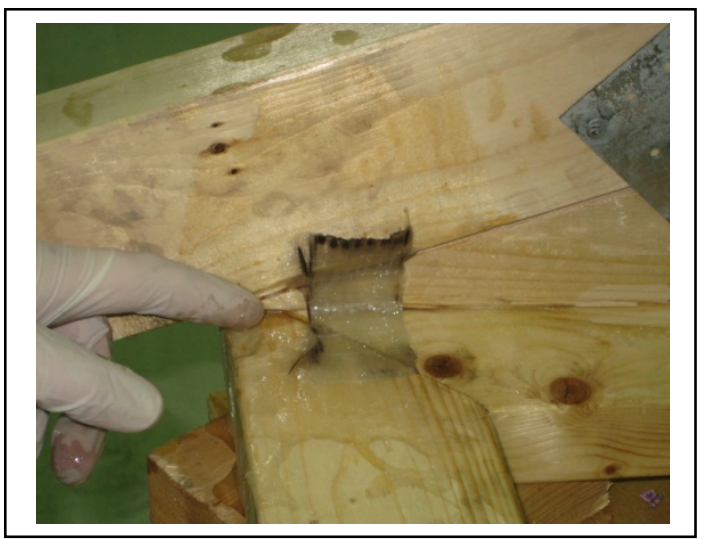

Figure 5.6: Mitered Top-Plate \& GFRP Connection

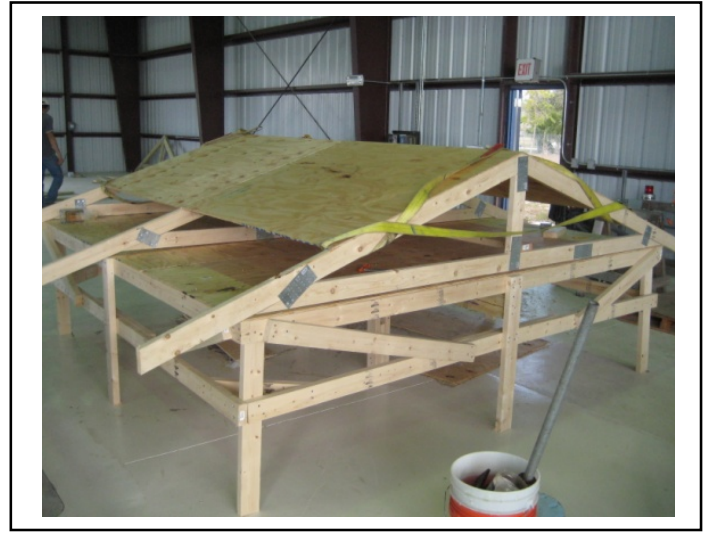

Figure 5.5: Roof Trusses

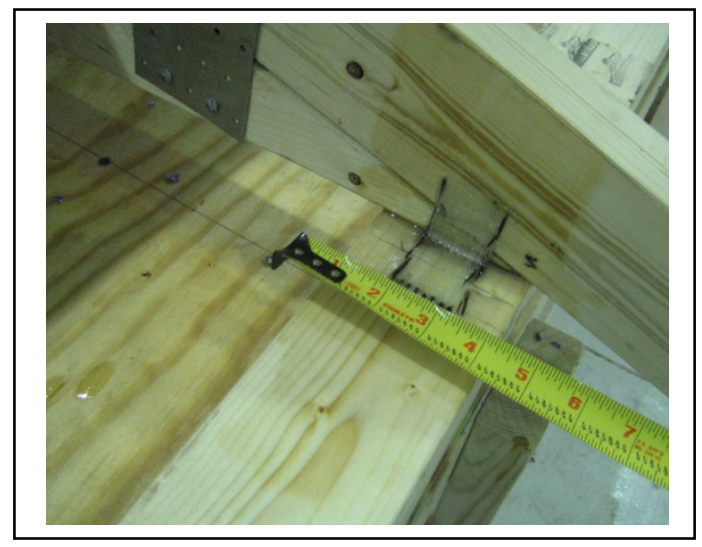

Figure 5.7: Typical 3 x 1 inch GFRP 

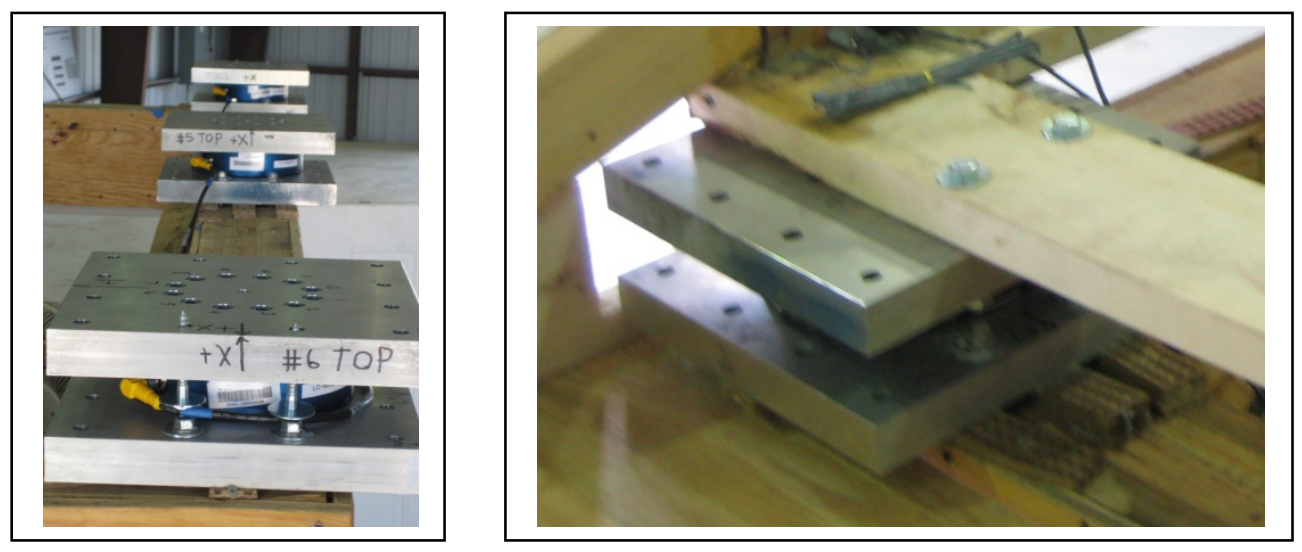

Figure 5.8: Roof \& Bottom structure Aluminum Plate Connection

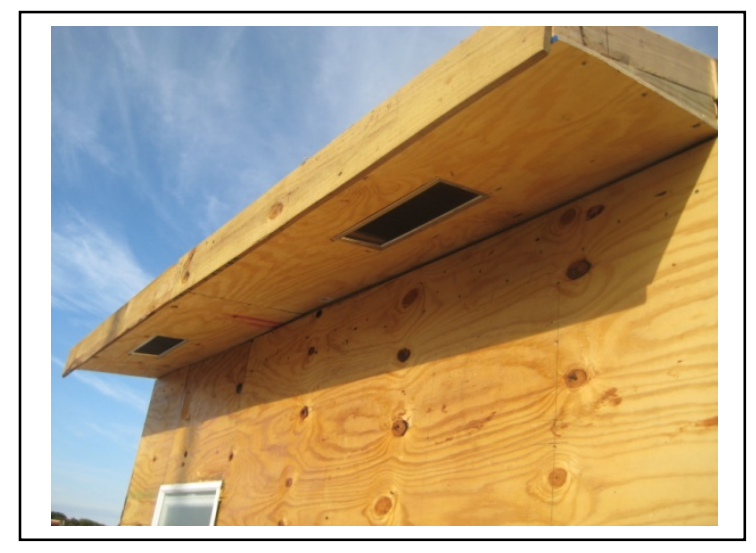

Figure 5.9: Vented Soffit

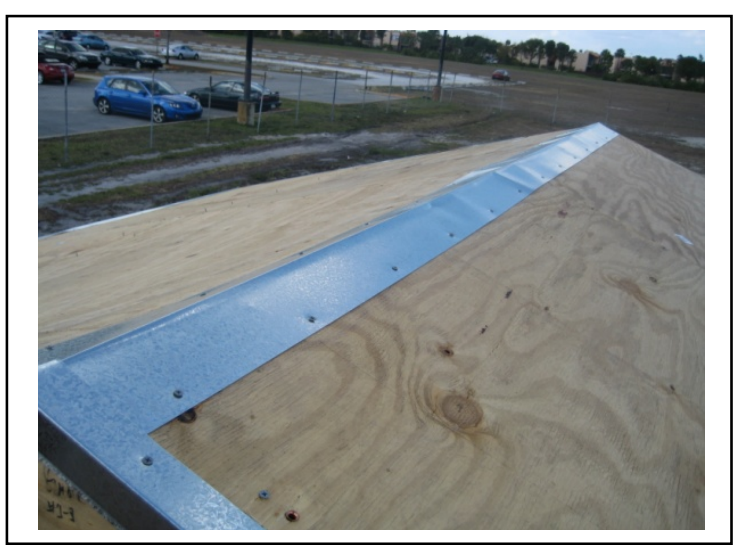

Figure 5.10: Roof Flashing 


\section{$5.4 \quad$ Test Specimen Instrumentation}

The test specimen was instrumented with the following sensors in all connections (see Figure 5.11 and 5.12):

- 6 Load Cells (each with 6 degrees of freedom) under the trusses; sandwiched between double top plate of walls and single top plate of roof (see Figure 5.13). The recorded forces are $\mathrm{F}_{\mathrm{X}}, \mathrm{F}_{\mathrm{Y}}$, and $\mathrm{F}_{\mathrm{Z}}$ corresponding to the in-plane shear (parallel to the side walls), out-of-plane shear (perpendicular to the side walls), and uplift, respectively. Three orthogonal moments $\left(\mathrm{M}_{\mathrm{X}}, \mathrm{M}_{\mathrm{Y}}\right.$, and $\left.\mathrm{M}_{\mathrm{Z}}\right)$ were also recorded.

- 6 Linear Voltage Differential Transformers (LVDT) to measure horizontal displacements of GFRP truss connection (parallel to the side walls); placed on roof single top-plate (see Figure 5.13)

- 12 String Potentiometers (Sting Pots) to measure vertical deflection and horizontal deflection (perpendicular to the side walls) of the connections; placed on roof single top-plate (see Figure 5.14)

- 8 Strain Gauges to measure strain in the vertical portion of each GFRP connection (see Figure 5.15)

- 2 Compact-Rios were used for all data acquisition, installed on the inside of the walls of the test specimen and controlled using a common laptop through an Ethernet connection (see Figure 5.16). 


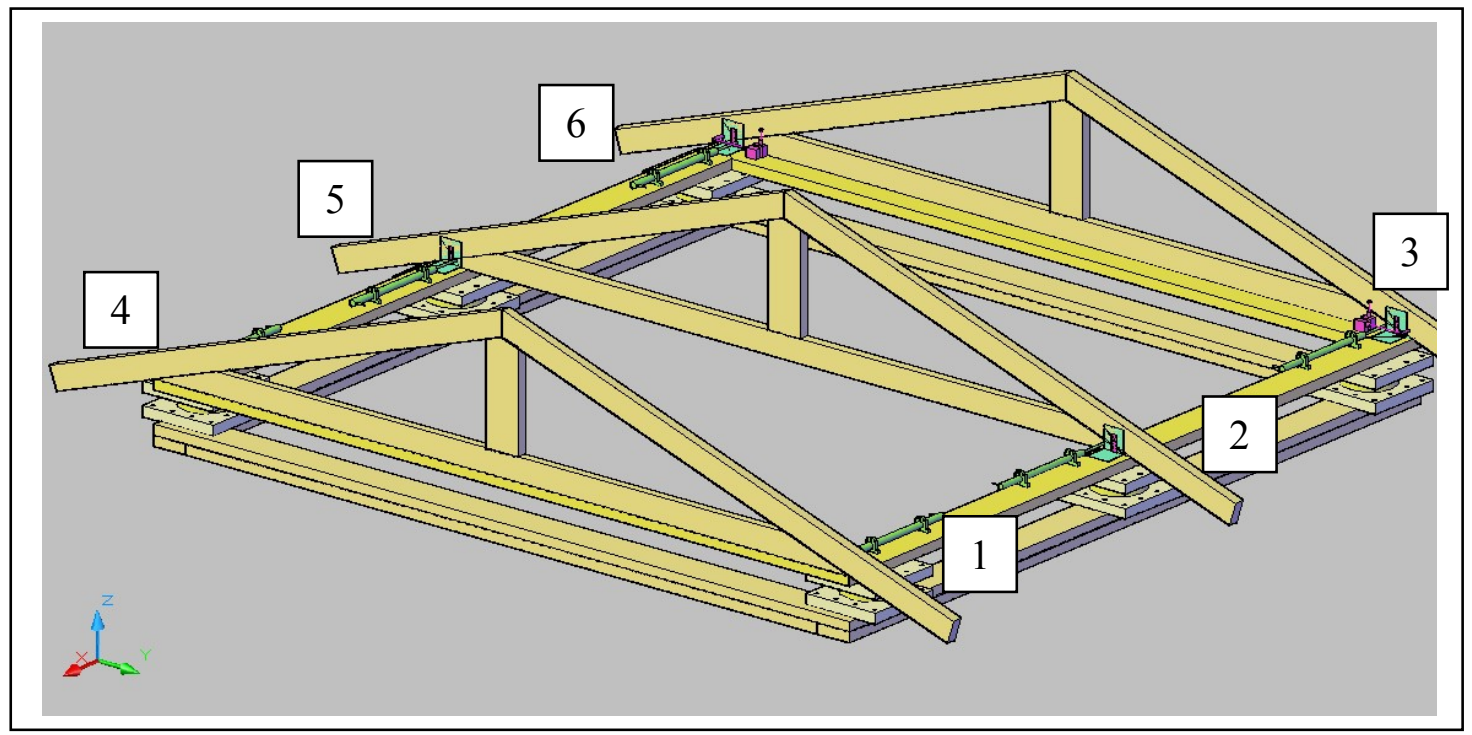

Figure 5.11: WoW Test Specimen Instrumentation; and Connection Numbers

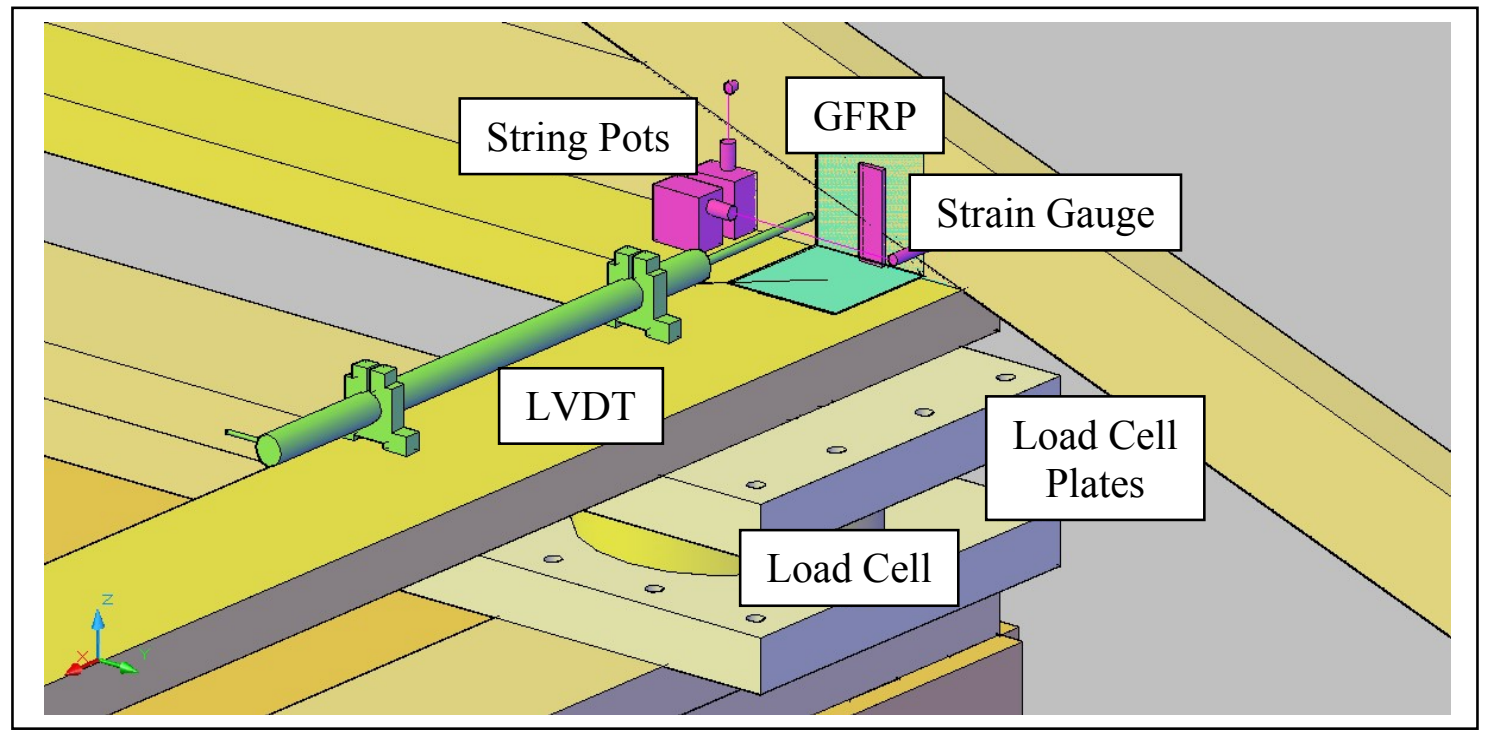

Figure 5.12: Typical Connection Instruments 


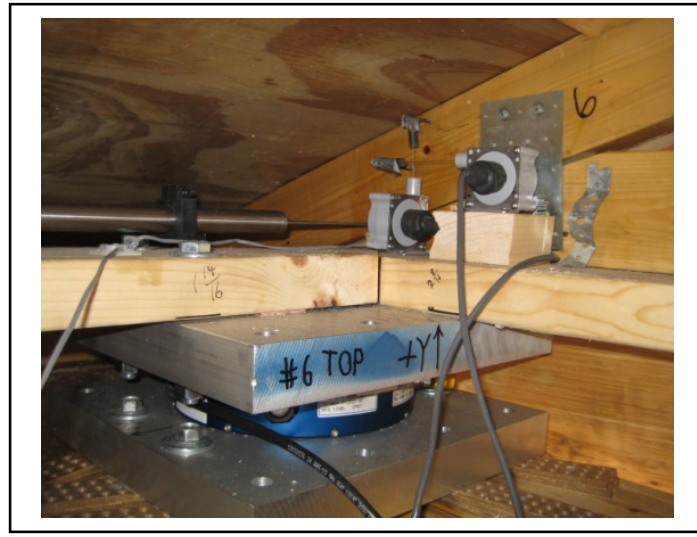

Figure 5.13: Load Cell \& LVDT

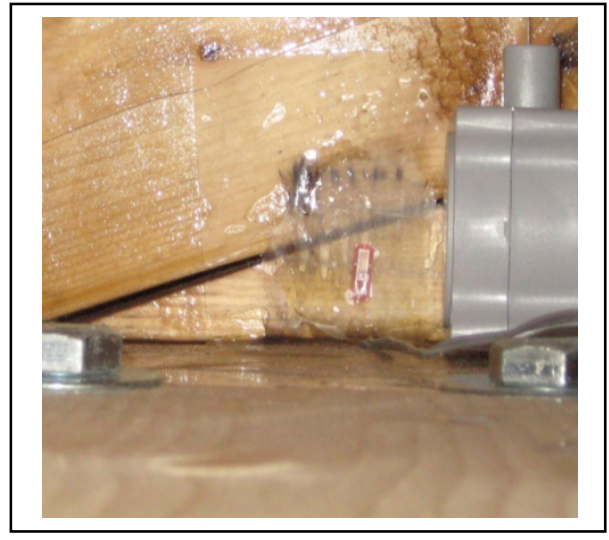

Figure 5.15: Strain Gauges

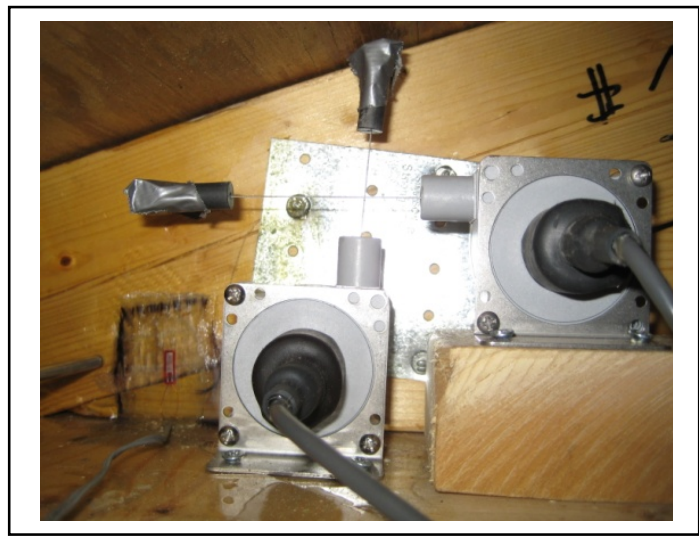

Figure 5.14: String Potentiometers

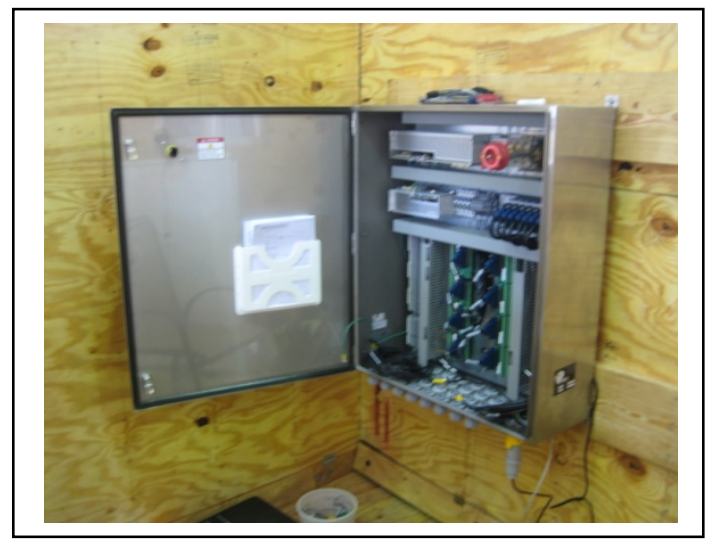

Figure 5.16: Compact Rios 


\subsubsection{Load Cell Loads Transferred to the GFRP Connection}

Due to the eccentricities between the trusses and the 6-DOF load cell used during the WoW tests, the recorded loads were transferred from the load cells to the truss-GFRP connection points (see Figure 5.17). The recorded data from the 6-DOF load cells employed during the WoW test was converted to tri-axial resultant forces using the equations below. The equations for carrying moments to any desired location:

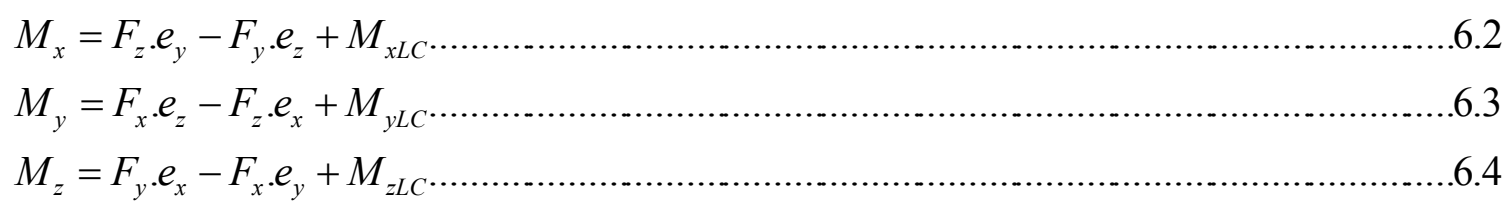

In order to find the point where the moments are zero, these three equations should be solved for $\mathrm{e}_{\mathrm{x}}, \mathrm{e}_{\mathrm{y}}, \mathrm{e}_{\mathrm{z}}$ for $\mathrm{M}_{\mathrm{x}}=\mathrm{M}_{\mathrm{y}}=\mathrm{M}_{\mathrm{z}}=0$

Solving equation 1 for $\mathrm{e}_{\mathrm{z}}$,

$e_{z}=\frac{F_{z} \cdot e_{y}-M_{x L C}}{F_{y}}$.

Solving equation 2 for $\mathrm{e}_{\mathrm{x}}$,

$e_{x}=\frac{F_{x} \cdot e_{z}-M_{y L C}}{F_{z}}$.

Insert $\mathrm{e}_{\mathrm{z}}$ into equation 5:

$e_{x}=\frac{\left(\frac{F_{z} \cdot e_{y}-M_{x L C}}{F_{y}}\right) \cdot F_{x}-M_{y L C}}{F_{z}}$

Now, insert $\mathrm{e}_{\mathrm{x}}$ found in equation 6 into equation 3 : 


$$
\left(\frac{\left(\frac{F_{z} \cdot e_{y}-M_{x L C}}{F_{y}}\right) \cdot F_{x}-M_{y L C}}{F_{z}}\right) F_{y}-F_{x} \cdot e_{y}+M_{z L C}=0 \ldots \ldots \ldots \ldots \ldots \ldots \ldots \ldots \ldots \ldots \ldots .6
$$

this equation is independent of ey. The only unknown in equation 7 is $e_{y}$, now solve for $\boldsymbol{e}_{\boldsymbol{y}}$. After $\mathrm{e}_{\mathrm{y}}$ is found, insert it into equation 4 and solve for $\boldsymbol{e}_{\boldsymbol{z}}$. After $\mathrm{e}_{\mathrm{z}}$ is found, insert it into equation 5 and solve for $\boldsymbol{e}_{\boldsymbol{x}}$.

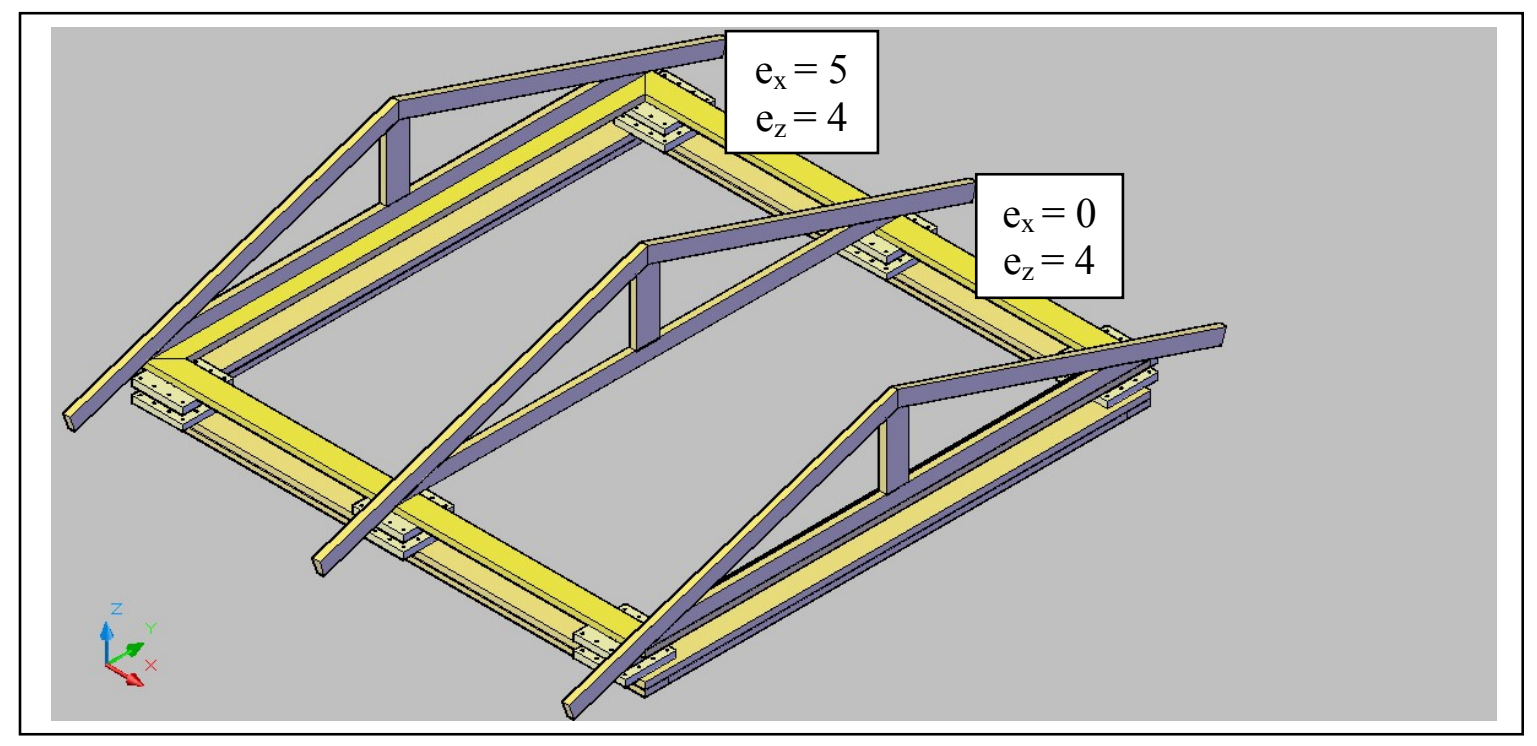

Figure 5.17: Load Cell and Truss Connection Points Eccentricities 


\subsection{WoW Testing Protocol for GFRP Roof-to-Wall Connections}

A total of 30 tests were performed during the WoW experiments under various parameters including: 5 angles of attack (AOA) (see Figures 18-22), enclosed and partially-enclosed building conditions, wind without rain condition, and wind-driven rain (WDR) condition. Each test was performed using a 1 minute flat waveform (at maximum rpm of the WoW engines and generating high frequency turbulence only) and 3 minutes quasi-periodic waveform (generating low frequency turbulence in addition to high frequency turbulence). The wind characteristics of the full-scale WoW are given in Table 3.2.

The various testing phases are described below.

\subsubsection{Phase I Test Protocol}

The first set of tests was performed with a wind angle of attack of 0 degrees with the gable ends being perpendicular to wind flow (see Figure 18). A total of six, 1-3 minutes tests were conducted in Phase I with:

- an enclosed building for 1 minute, at $4000 \mathrm{rpm}$ (WoW engine rpm)

- $\quad$ an enclosed building for 3 minutes, using a Quasi-Periodic waveform

- $\quad$ an enclosed building with WDR for 1 minute, at $4000 \mathrm{rpm}$

- $\quad$ an enclosed building with WDR for 3 minutes, using a Quasi-Periodic waveform

- a partially-enclosed building (1 window and the door removed) for 1 minute, at $4000 \mathrm{rpm}$

- a partially-enclosed building (1 window and the door removed) for 3 minutes, using a Quasi-Periodic waveform 


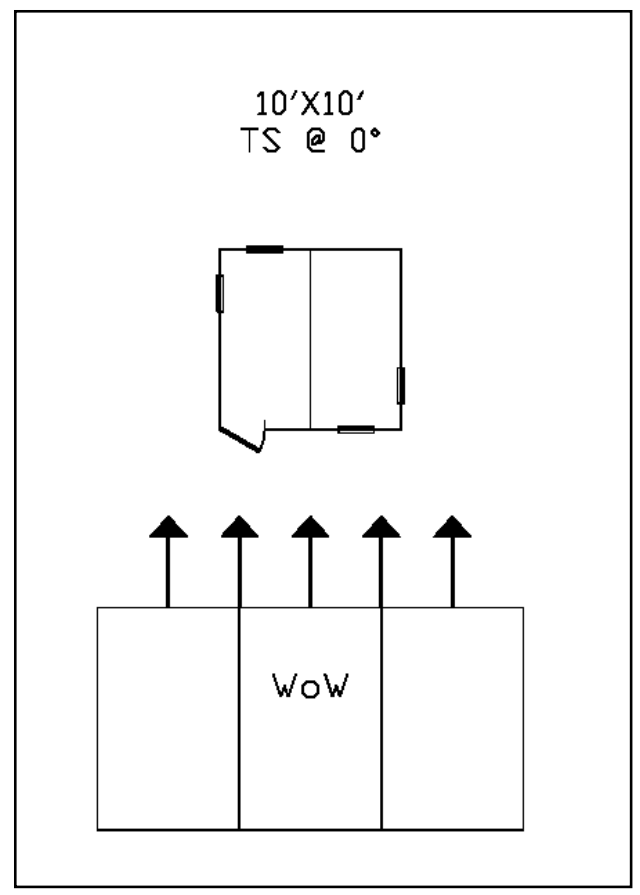

Figure 5.18: Wind AOA of 0 Degrees

\subsubsection{Phase II Test Protocol}

The second set of tests was performed with a wind angle of attack of 90 degrees with the gable ends being perpendicular to wind flow (see Figure 19). A total of six, 1-3 minutes tests were conducted in Phase II with:

- $\quad$ an enclosed building for 1 minute, at $4000 \mathrm{rpm}$

- $\quad$ an enclosed building for 3 minutes, using a Quasi-Periodic waveform

- $\quad$ an enclosed building with WDR for 1 minute, at $4000 \mathrm{rpm}$

- $\quad$ an enclosed building with WDR for 3 minutes, using a Quasi-Periodic waveform

- a partially-enclosed building (1 window removed) for 1 minute, at $4000 \mathrm{rpm}$

- a partially-enclosed building (1 window removed) for 3 minutes, using a Quasi-

Periodic waveform 


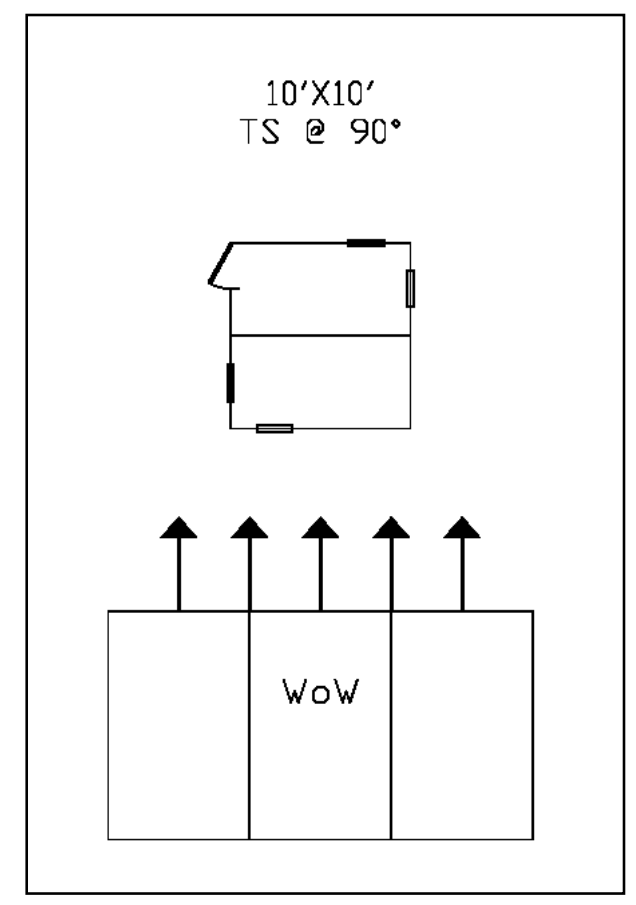

Figure 5.19: Wind AOA of 90 Degrees

\subsubsection{Phase III Test Protocol}

The third set of tests was performed with a wind angle of attack of 45 degrees (see

Figure 20). A total of eight, 1-3 minutes tests were conducted in Phase III with:

- $\quad$ an enclosed building for 1 minute, at $4000 \mathrm{rpm}$

- $\quad$ an enclosed building for 3 minutes, using a Quasi-Periodic waveform

- $\quad$ an enclosed building with WDR for 1 minute, at $4000 \mathrm{rpm}$

- $\quad$ an enclosed building with WDR for 3 minutes, using a Quasi-Periodic waveform

- a partially-enclosed building (2 windows removed) for 1 minute, at $4000 \mathrm{rpm}$

- a partially-enclosed building (2 windows removed) for 3 minutes, using a Quasi-

Periodic waveform 
- a partially-enclosed building (2 windows and the door removed) for 1 minute, at $4000 \mathrm{rpm}$

- a partially-enclosed building (2 windows and the door removed) for 3 minutes, using a Quasi-Periodic waveform

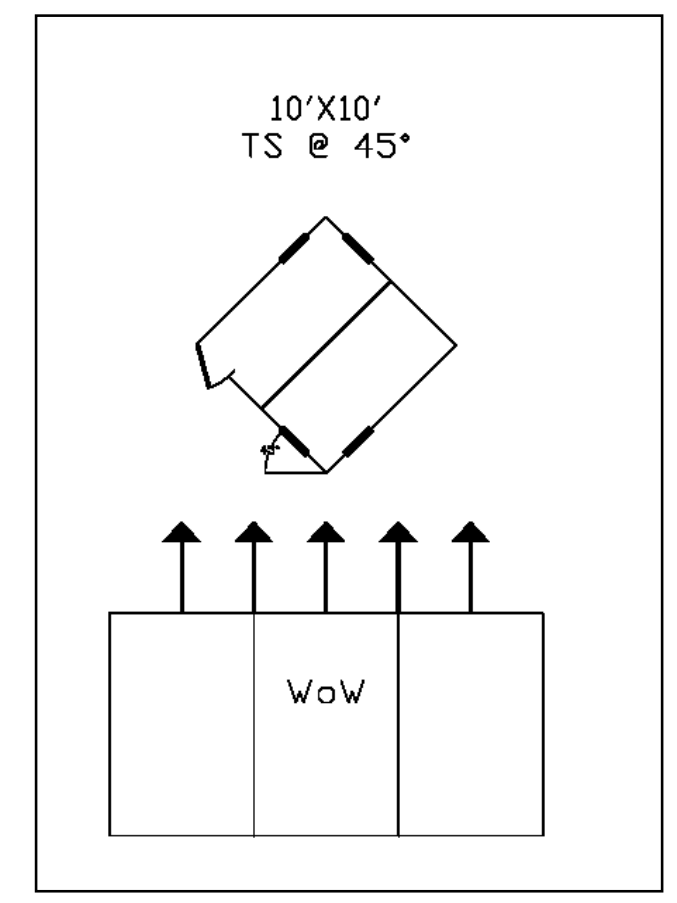

Figure 5.20: Wind AOA of 45 Degrees

\subsubsection{Phase IV Test Protocol}

The fourth set of tests was performed with a wind angle of attack of 30 degrees (see Figure 21). A total of four, 1-3 minutes tests were conducted in Phase IV with:

- $\quad$ an enclosed building for 1 minute, at $4000 \mathrm{rpm}$

- $\quad$ an enclosed building for 3 minutes, using a Quasi-Periodic waveform

- $\quad$ an enclosed building with WDR for 1 minute, at $4000 \mathrm{rpm}$

- $\quad$ an enclosed building with WDR for 3 minutes, using a Quasi-Periodic waveform 


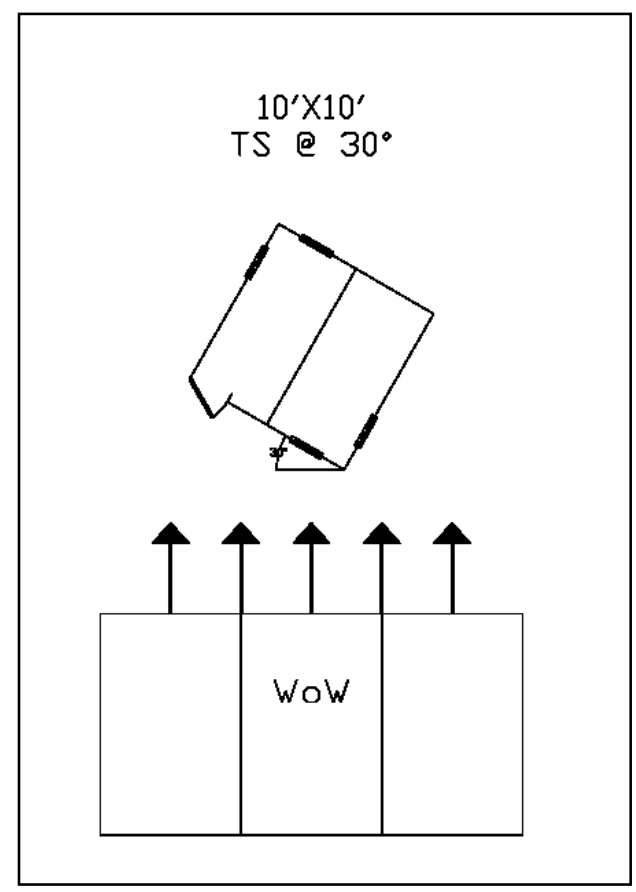

Figure 5.21: Wind AOA of 30 Degrees

\subsubsection{Phase V Test Protocol}

The last set of tests was performed with a wind angle of attack of 60 degrees (see

Figure 22). A total of six, 1-3 minutes tests were conducted in Phase V with:

- $\quad$ an enclosed building for 1 minute, at $4000 \mathrm{rpm}$

- $\quad$ an enclosed building for 3 minutes, using a Quasi-Periodic waveform

- a partially-enclosed building (2 windows removed) for 1 minute, at $4000 \mathrm{rpm}$

- a partially-enclosed building (2 windows removed) for 3 minutes, using a Quasi-

Periodic waveform

- a partially-enclosed building (2 windows and the door removed) for 1 minute, at 4000 rpm 
- a partially-enclosed building (2 windows and the door removed) for 3 minutes, using a Quasi-Periodic waveform

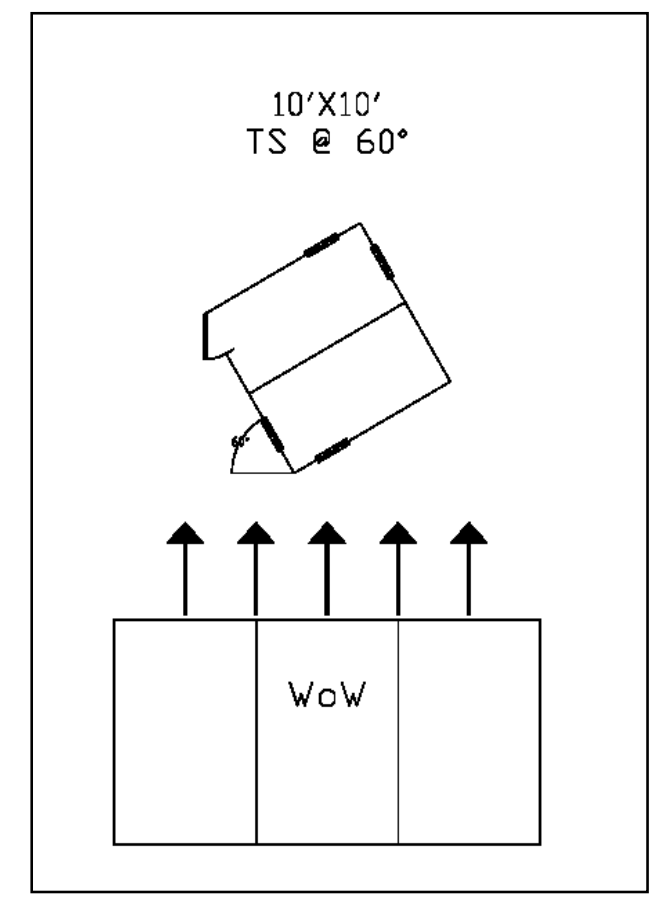

Figure 5.22: Wind AOA of 60 Degrees

\subsection{WoW Test Results for GFRP Roof-to-Wall Connections}

This section reports the WoW testing results. Graphs of the 3-second time averaged histories of individual load cells and load direction, bar graphs with mean results of all the conditions per load cell and the dot graphs with mean force results of individual load cells are presented here.

The nomenclature used to determine the type of test runs in the graphs is as follows:

1- E_FT: corresponds to an enclosed condition and wind speeds at full-throttle (4000 RPM) (Figure 5.23). 
2- $\mathbf{E}(\mathbf{W}) \_$FT: corresponds to an enclosed condition with wind driven rain and wind speeds at full-throttle (4000 RPM) (Figure 5.24).

3- PE_FT: corresponds to a partially enclosed condition where 1 (for AOA $90^{\circ}$ test) or 2 (for $\mathrm{AOA} 45^{\circ}$ test) windows have been removed and 1 window and the door (for $\mathrm{AOA} 0^{\circ}$ test) and wind speeds at full-throttle (4000 RPM) (Figure 5.25, 5.26 $\& 5.27)$

4- PE'_FT: corresponds to a partially enclosed condition, where the windows and the test specimen door have been removed and wind speeds are at full-throttle (4000 RPM) (for AOA $45^{\circ} \& 60^{\circ}$ tests).

5- E_QP: corresponds to an enclosed condition and wind speeds that correspond to a quasi-periodic ramp function.

6- E (W)_QP: corresponds to an enclosed condition with wind driven rain and wind speeds that correspond to a quasi-periodic ramp function.

7- PE_QP: corresponds to a partially enclosed condition where 1 (for AOA $0^{\circ} \& 90^{\circ}$ tests) or 2 (for $\mathrm{AOA} 45^{\circ}$ test) windows have been removed and wind speeds that correspond to a quasi-periodic ramp function.

8- PE'_QP: corresponds to a partially enclosed condition where 2 (for AOA $45^{\circ}$ \& $60^{\circ}$ tests) windows and the test specimen door have been removed and wind speeds that correspond to a quasi-periodic ramp function. 


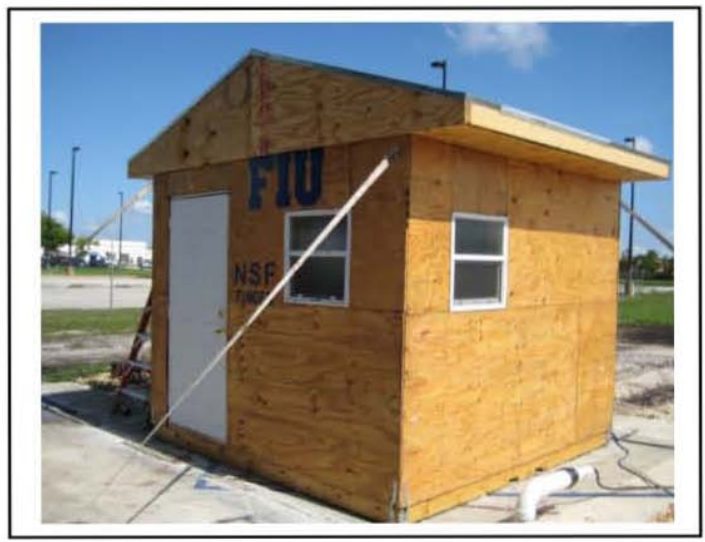

Figure 5.23: Enclosed 0 ${ }^{\circ}$

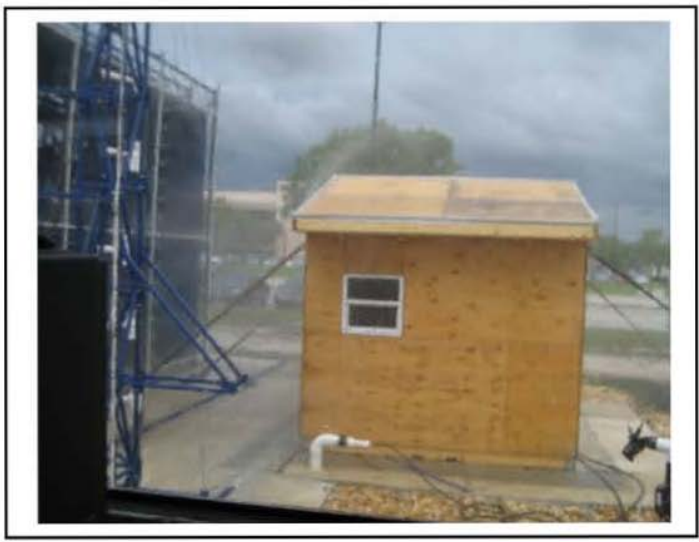

Figure 5.25: Enclosed \& Wind Driven Rain $0^{\circ}$

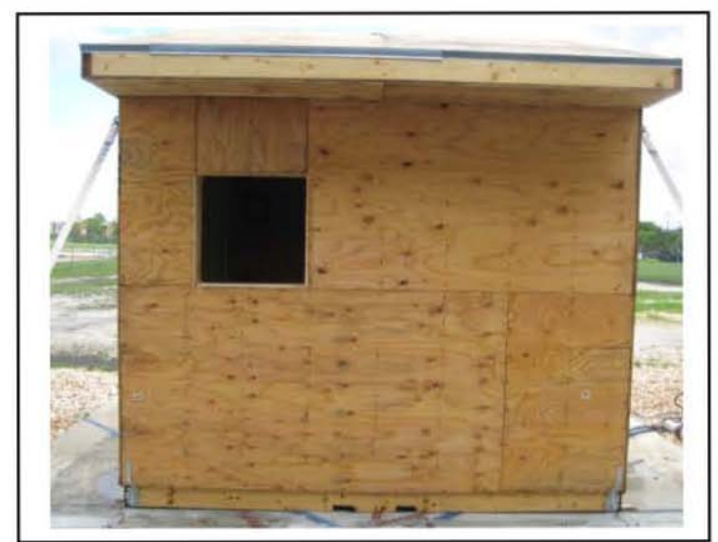

Figure 5.24: Partially Enclosed One Window Removed $90^{\circ}$

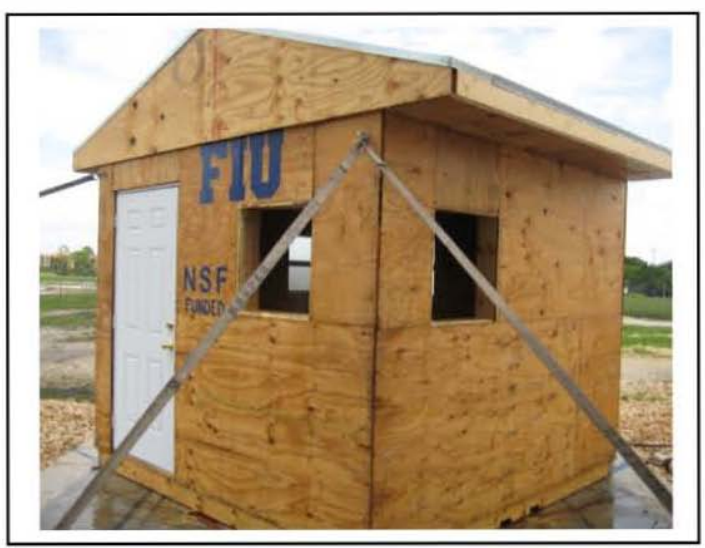

Figure 5.26: Partially Enclosed Two Windows Removed $45^{\circ}$

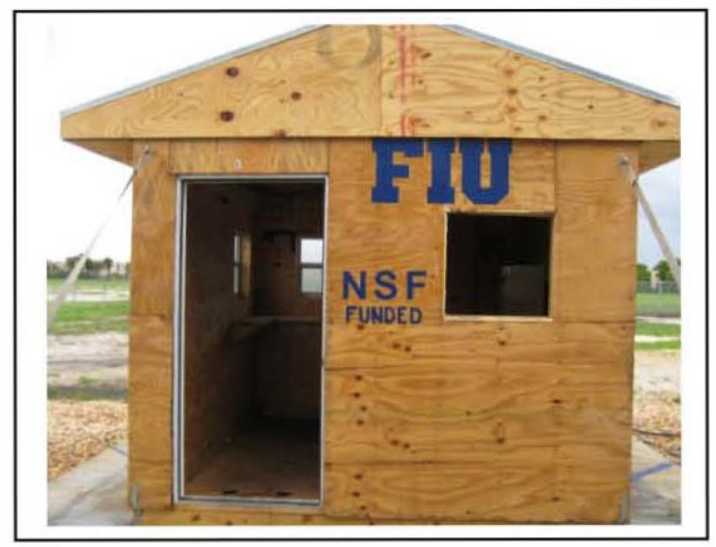

Figure 5.27: Partially Enclosed One Window \& Door Removed 0 


\subsubsection{Load Cell Results from Phase I Testing}

The load cell results plotted as graphs for all the tests under Phase I are shown below.

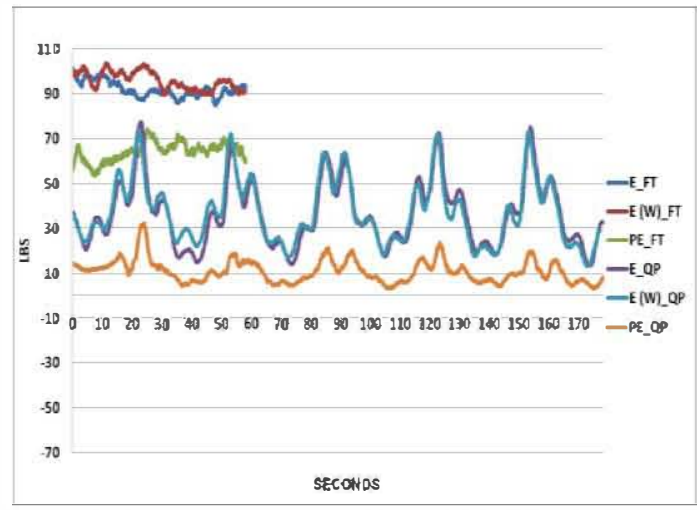

Graph 5.1: Load Cell 1 Fx 0

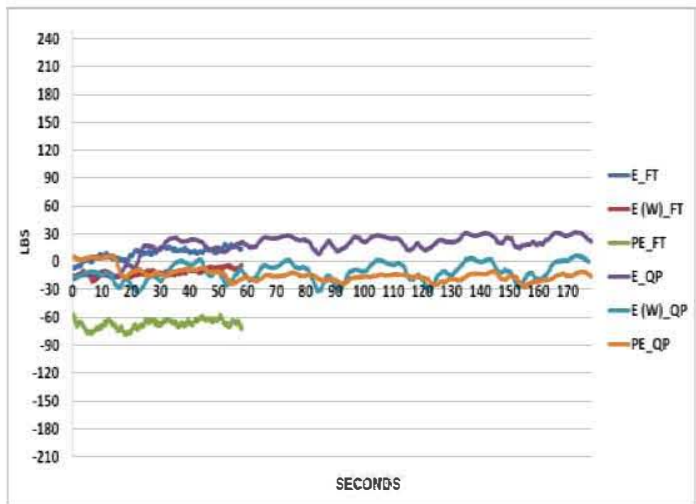

Graph 5.2: Load Cell 1 Fy 0

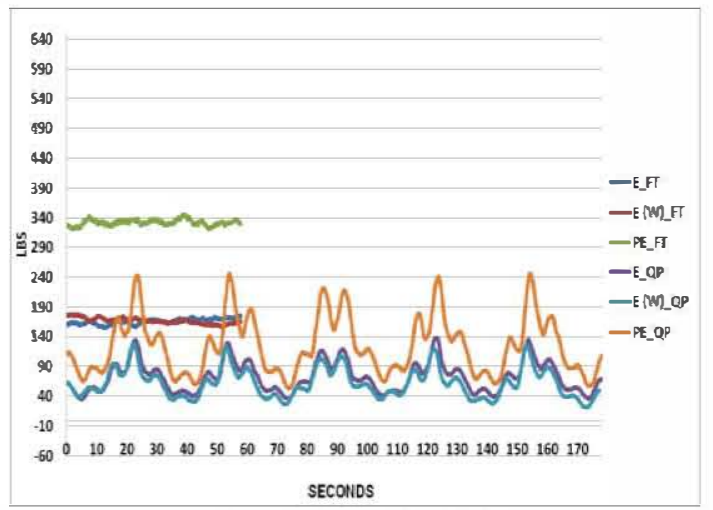

Graph 5.3: Load Cell 1 Fz O

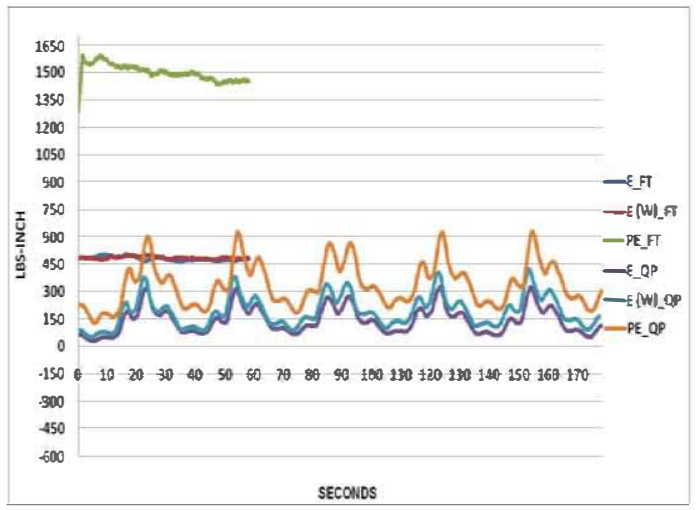

Graph 5.4: Load Cell 1 Mx 0

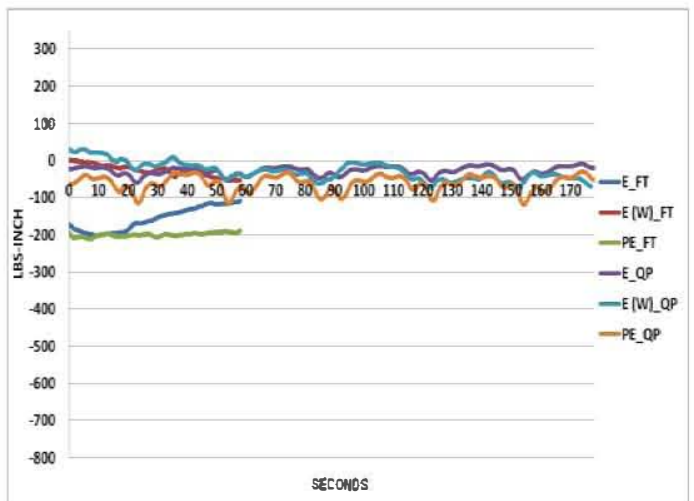

\section{Graph 5.5: Load Cell 1 My 0}

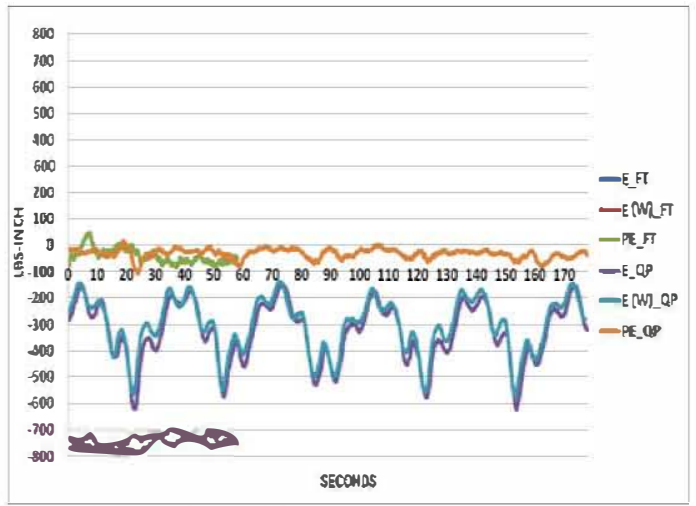

Graph 5.6: Load Cell $1 \mathrm{Mz} 0^{\circ}$ 


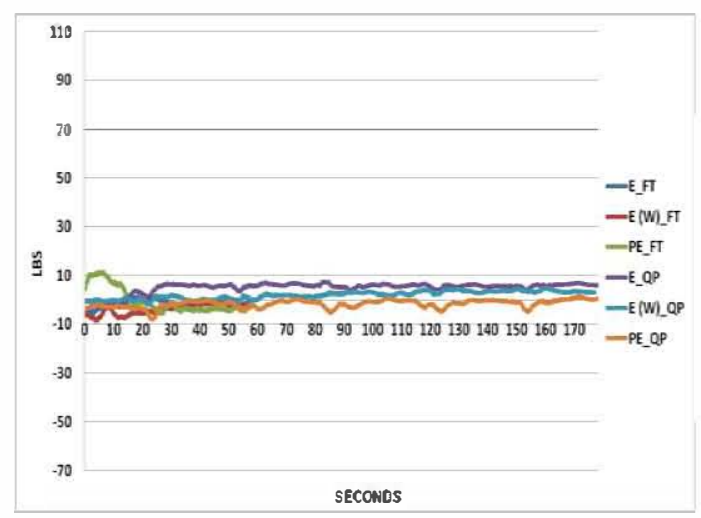

Graph 5.7: Load Cell 2 Fx $0^{\circ}$

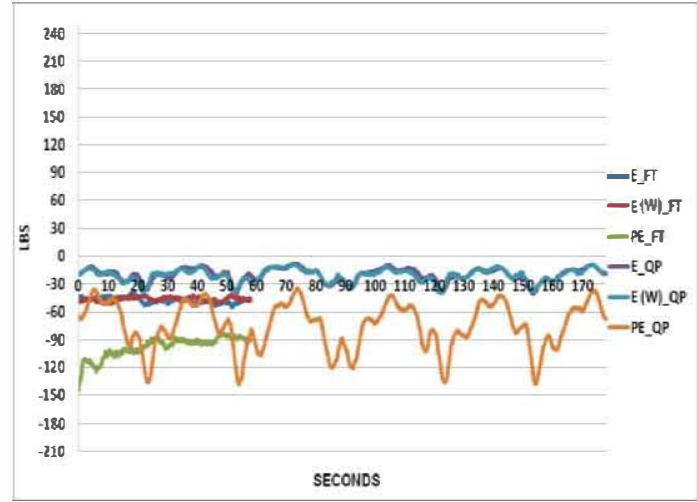

Graph 5.8: Load Cell 2 Fy $0^{\circ}$

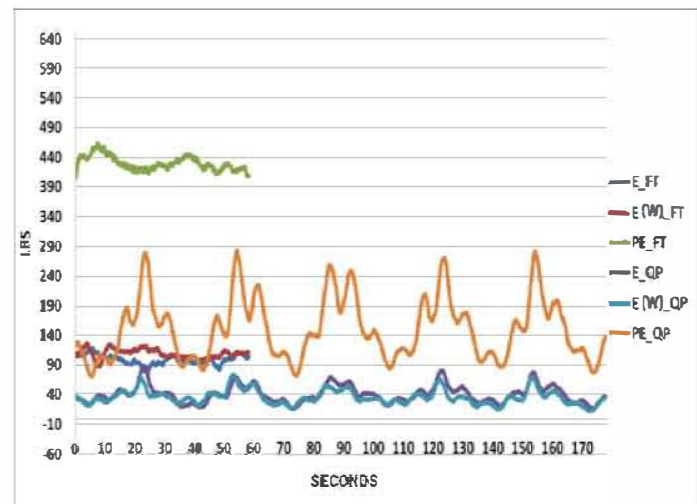

Graph 5.9: Load Cell $2 \mathrm{Fz} 0^{\circ}$

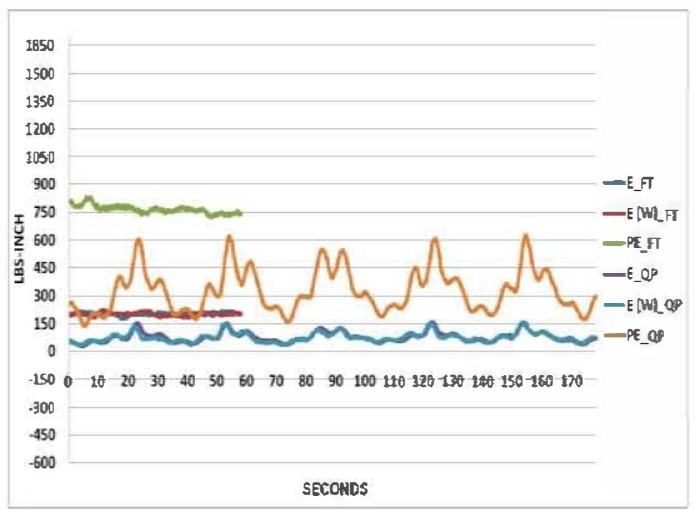

Graph 5.10: Load Cell $2 \mathrm{Mx} 0^{\circ}$

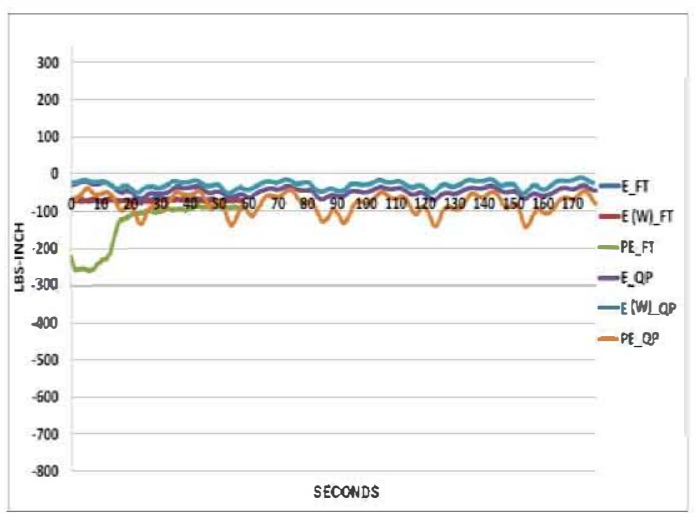

Graph 5.11: Load Cell 2 My $0^{\circ}$

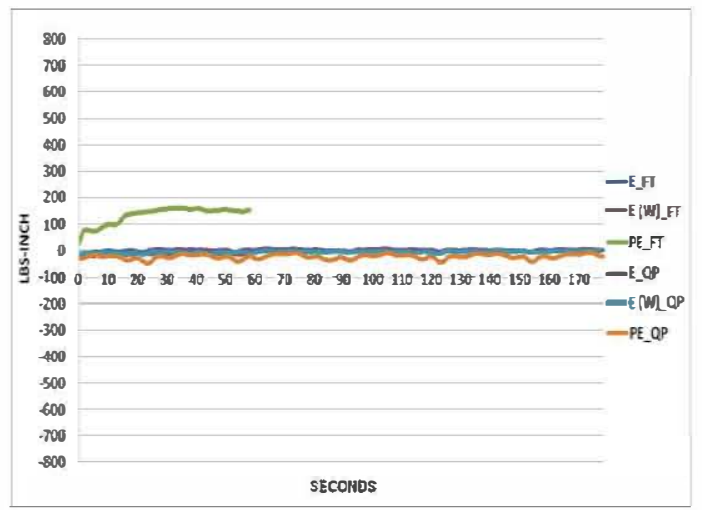

Graph 5.12: Load Cell $2 \mathrm{Mz} 0^{\circ}$ 


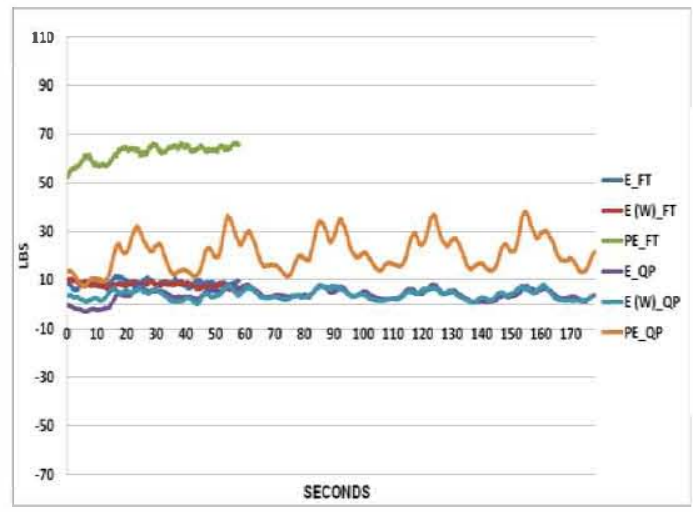

Graph 5.13: Load Cell 3 Fx $0^{\circ}$

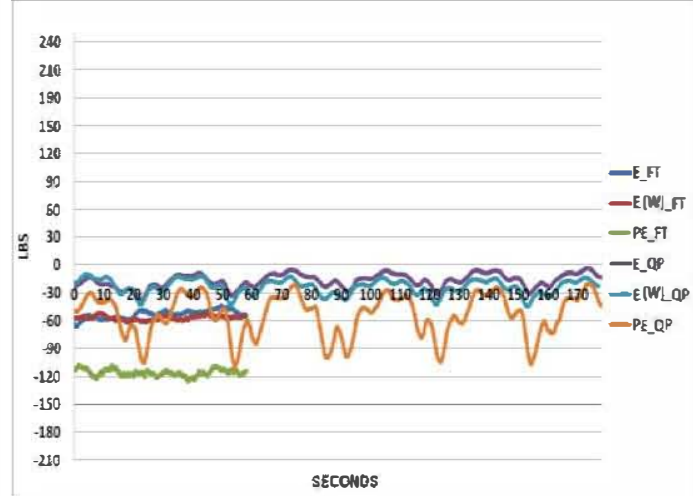

Graph 5.14: Load Cell 3 Fy $0^{\circ}$

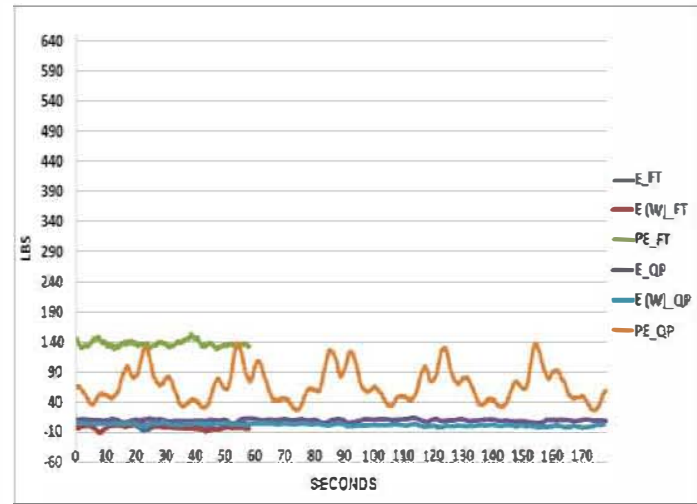

Graph 5.15: Load Cell 3 Fz $0^{\circ}$

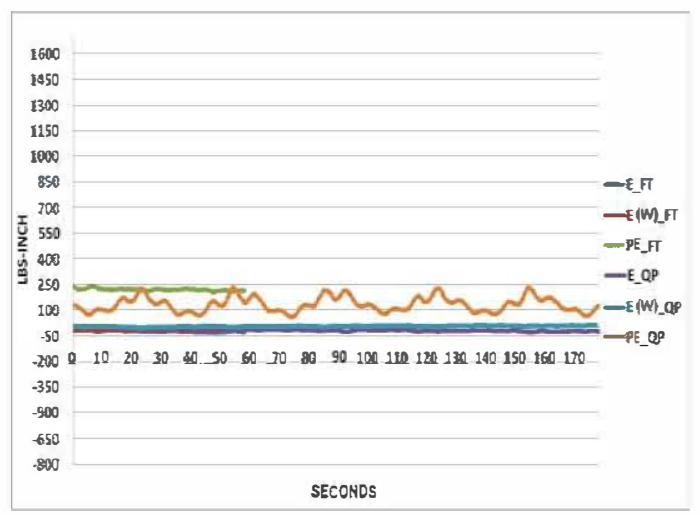

Graph 5.16: Load Cell 3 Mx 0

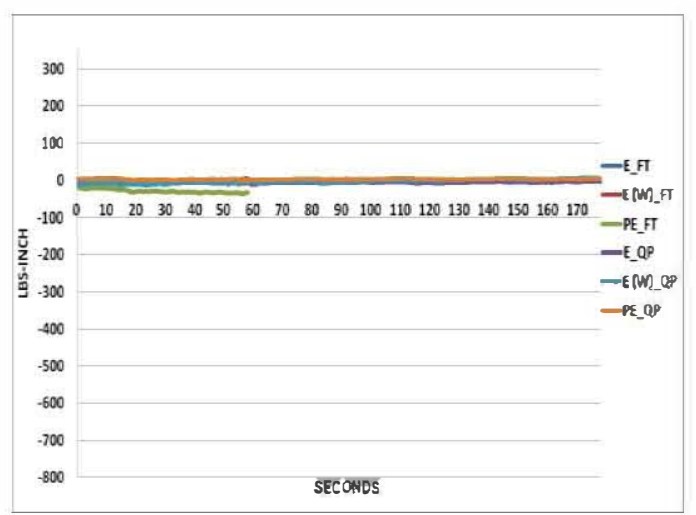

Graph 5.17: Load Cell 3 My 0

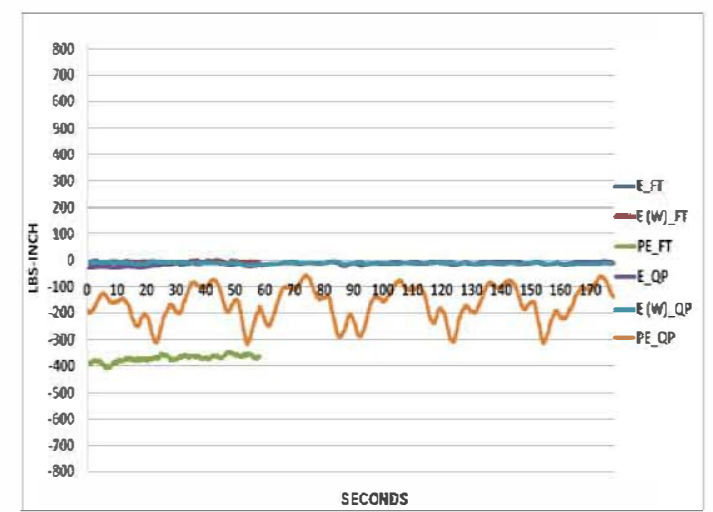

Graph 5.18: Load Cell 3 Mz 0 


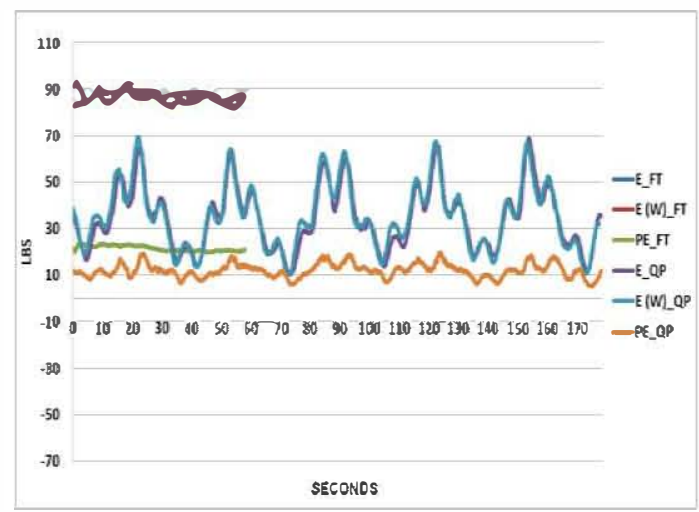

Graph 5.19: Load Cell 4 Fx $0^{\circ}$

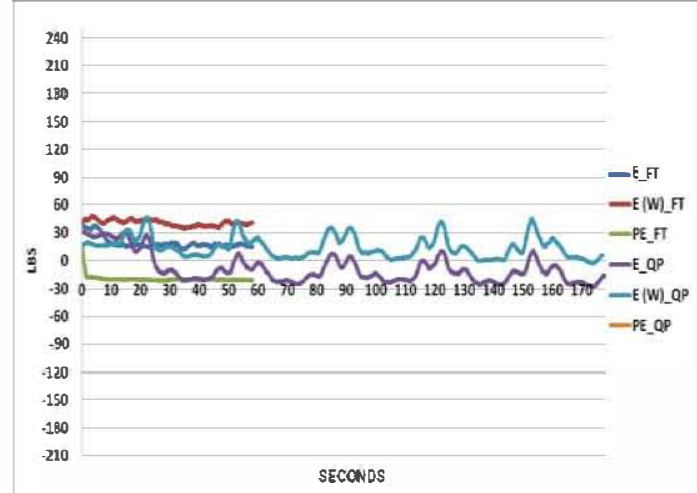

Graph 5.20: Load Cell 4 Fy $0^{\circ}$

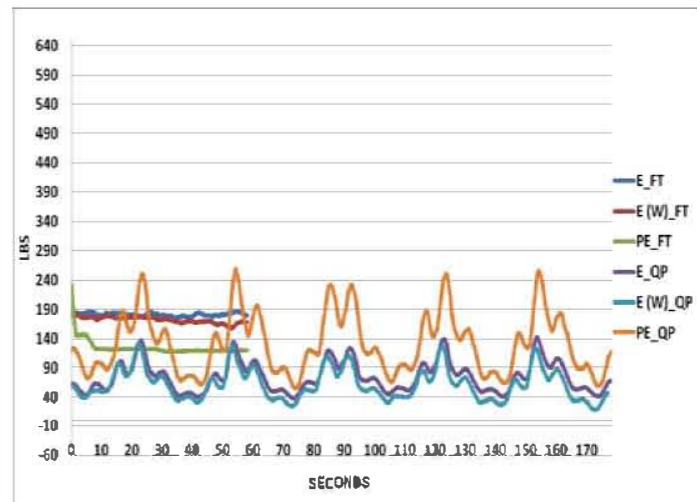

Graph 5.21: Load Cell 4 Fz 0

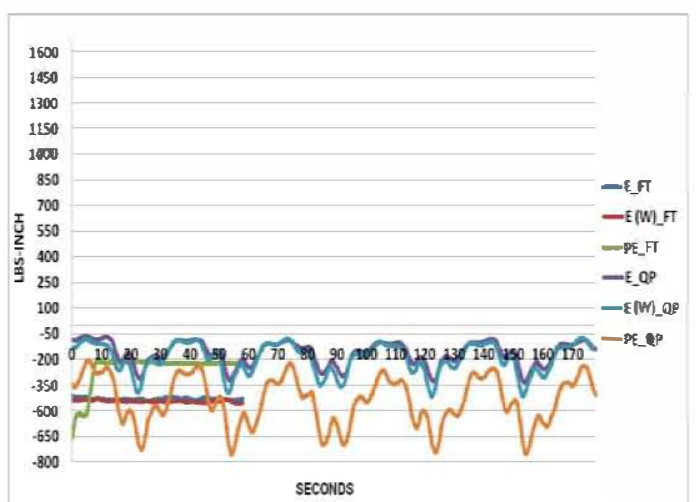

Graph 5.22: Load Cell 4 Mx 0

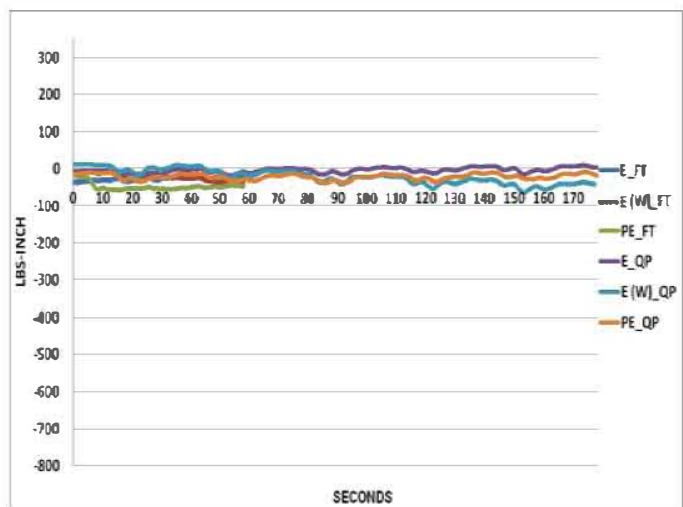

Graph 5.23: Load Cell 4 My 0

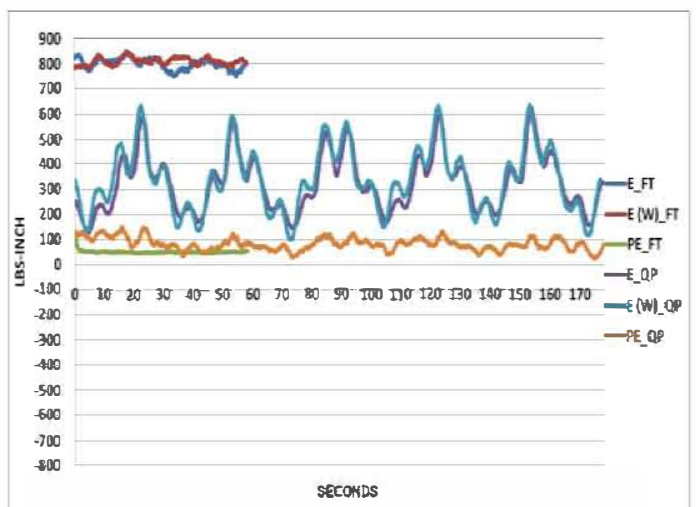

Graph 5.24: Load Cell $4 \mathrm{Mz} \mathrm{0^{ \circ }}$ 


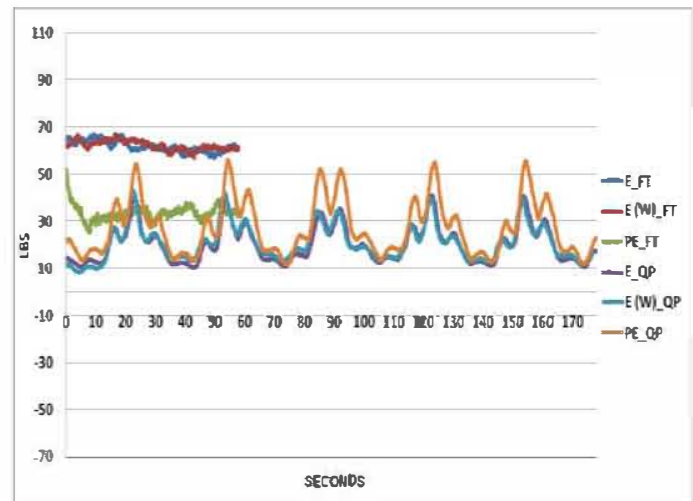

Graph 5.25: Load Cell 5 Fx $0^{\circ}$

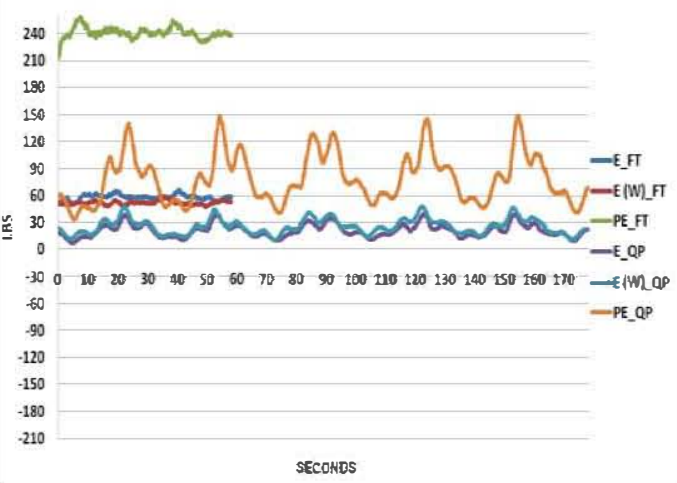

Graph 5.26: Load Cell 5 Fy $0^{\circ}$

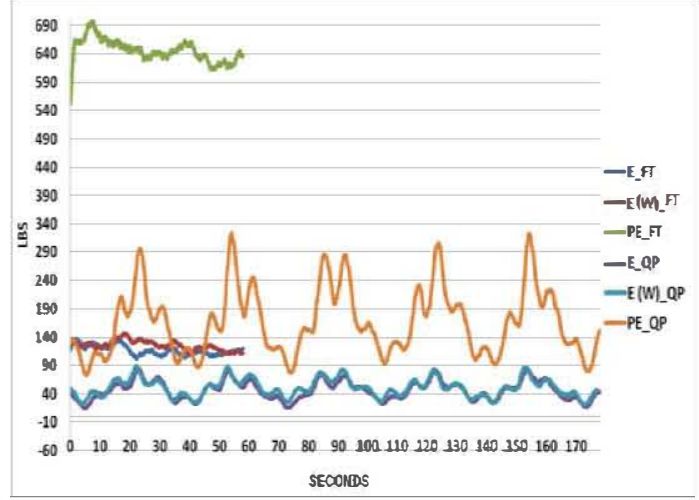

Graph 5.27: Load Cell 5 Fz $0^{\circ}$

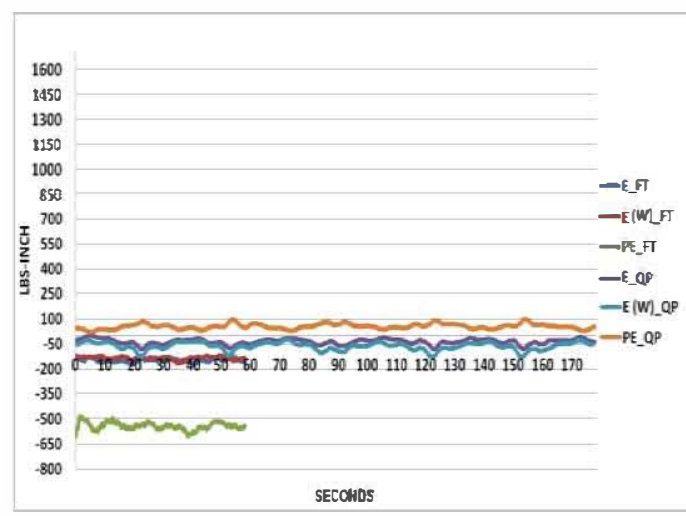

Graph 5.28: Load Cell 5 Mx $0^{\circ}$

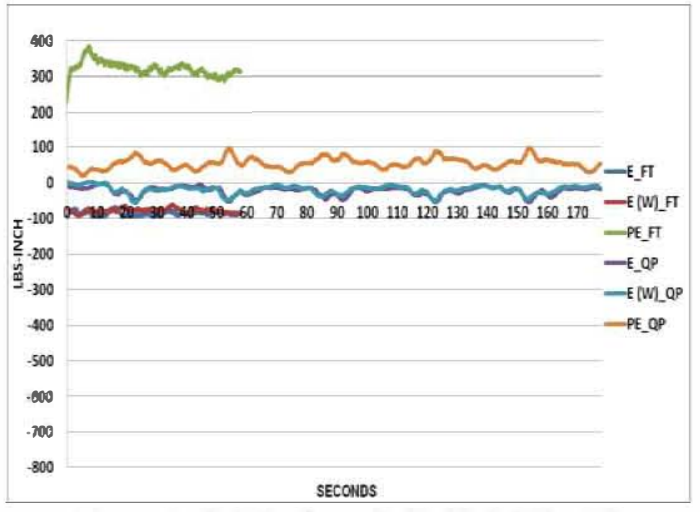

Graph 5.29: Load Cell 5 My 0

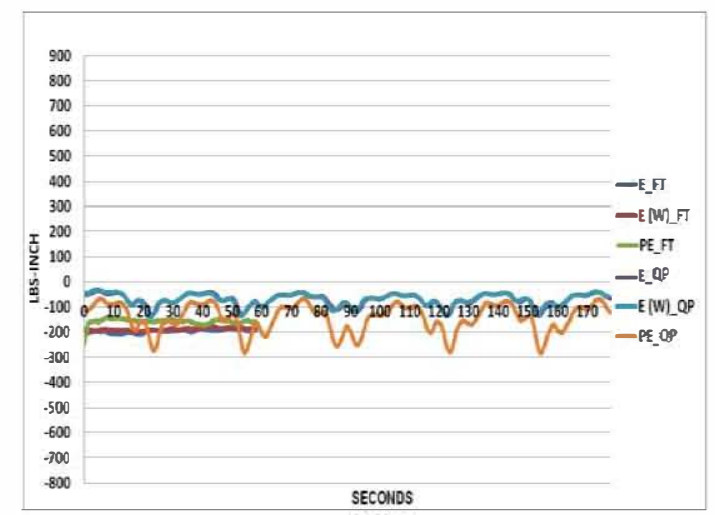

Graph 5.30: Load Cell 5 Mz $0^{\circ}$ 


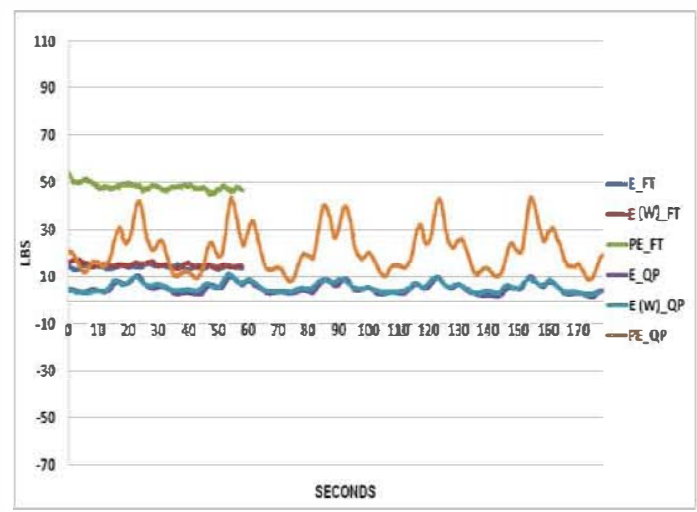

Graph 5.31: Load Cell 6 Fx $0^{\circ}$

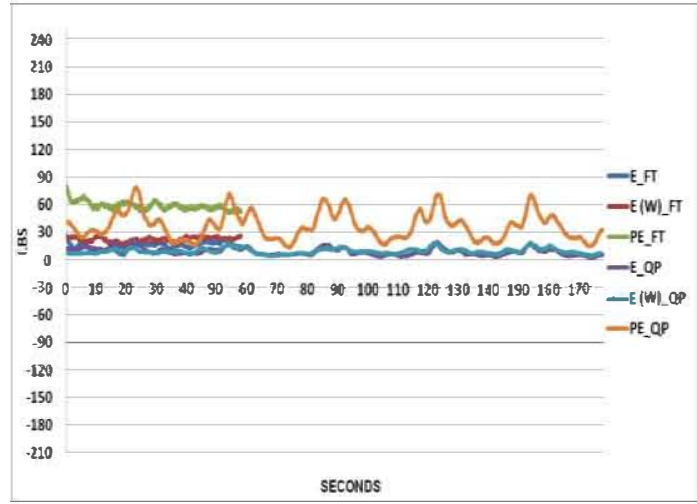

Graph 5.32: Load Cell 6 Fy $0^{\circ}$

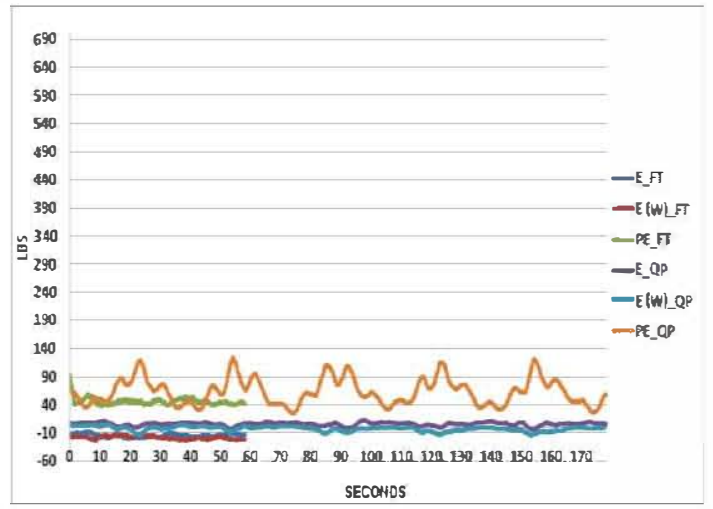

Graph 5.33: Load Cell 6 Fz $0^{\circ}$

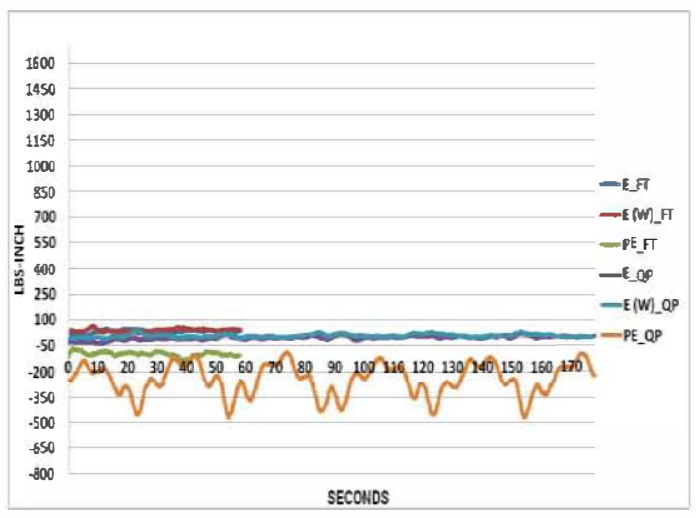

Graph 5.34: Load Cell $6 \mathrm{Mx} 0^{\circ}$

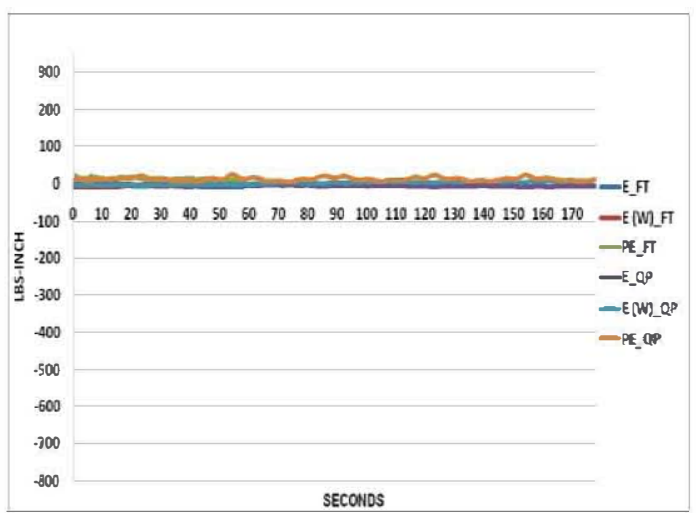

Graph 5.35: Load Cell 6 My $0^{\circ}$

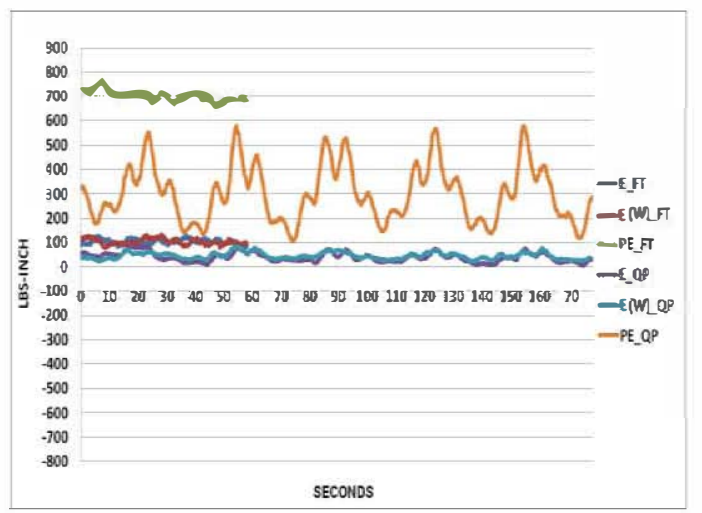

Graph 5.36: Load Cell $6 \mathrm{Mz} 0^{\circ}$ 


\subsubsection{Load Cell Results from Phase II Testing}

The load cell results plotted as graphs for all the tests under Phase II are shown below.

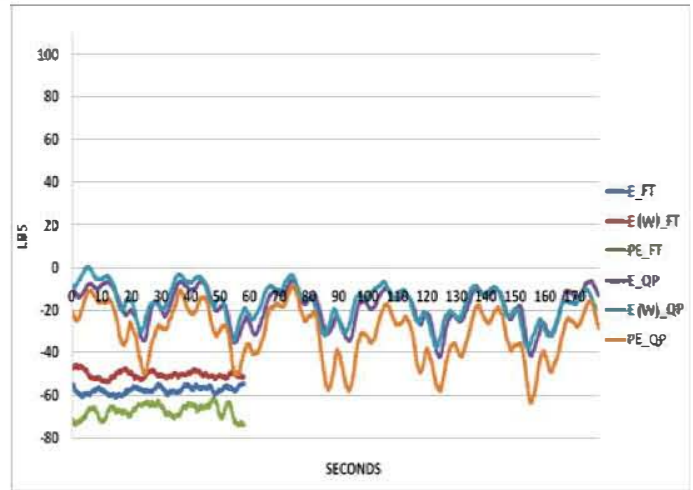

Graph 5.37: Load Cell 1 Fx 90

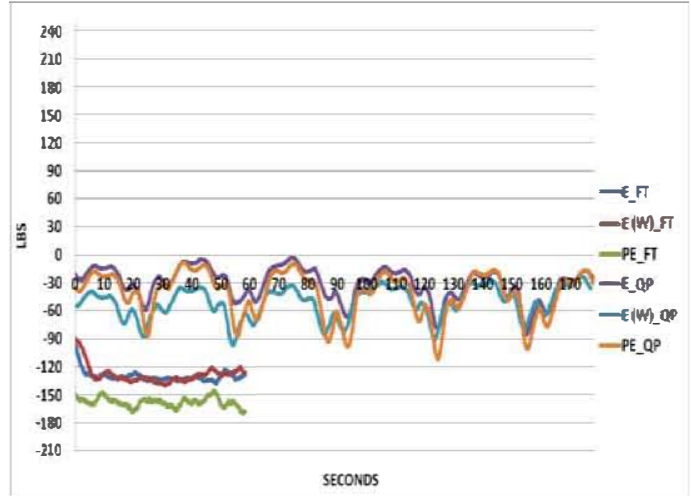

Graph 5.38: Load Cell 1 Fy $90^{\circ}$

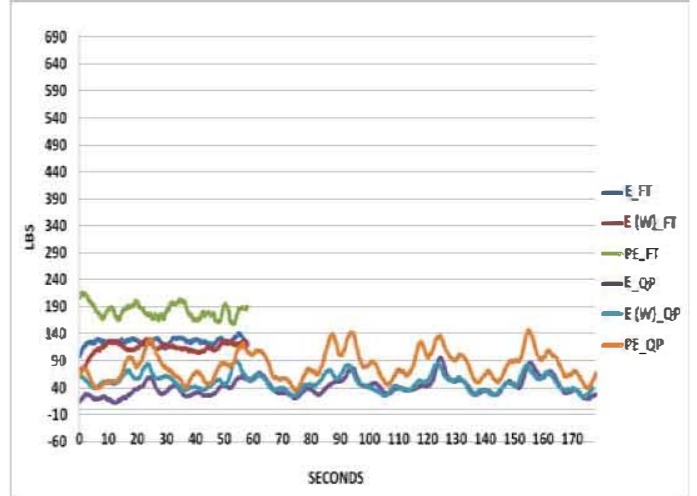

Graph 5.39: Load Cell $1 \mathrm{Fz} \mathrm{90}$

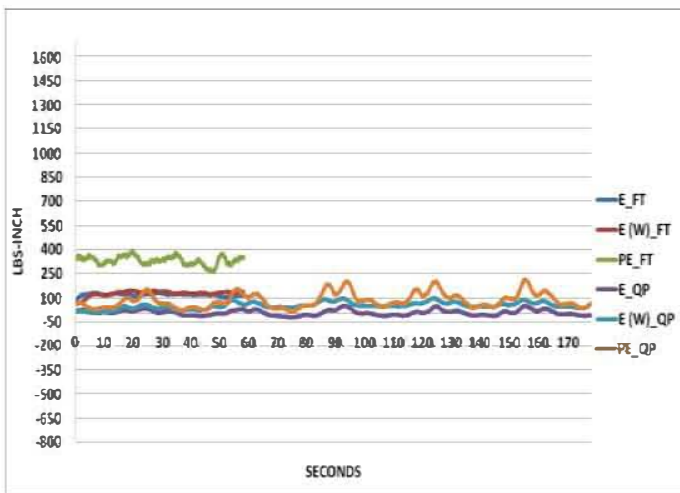

Graph 5.40: Load Cell $1 \mathrm{Mx} 90^{\circ}$

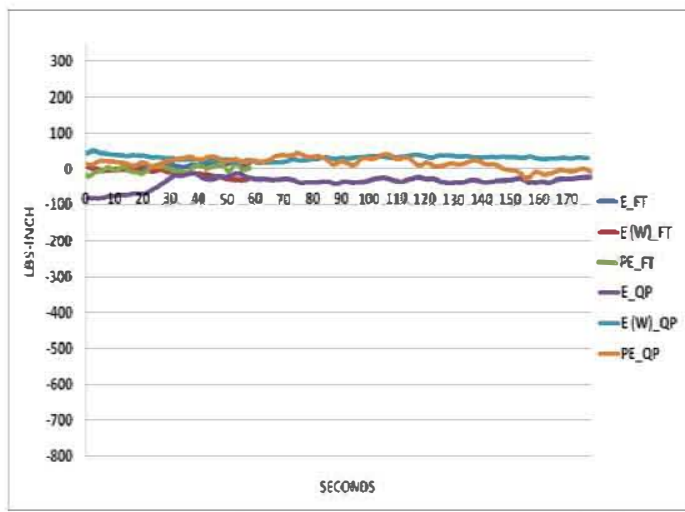

Graph 5.41: Load Cell 1 My $90^{\circ}$

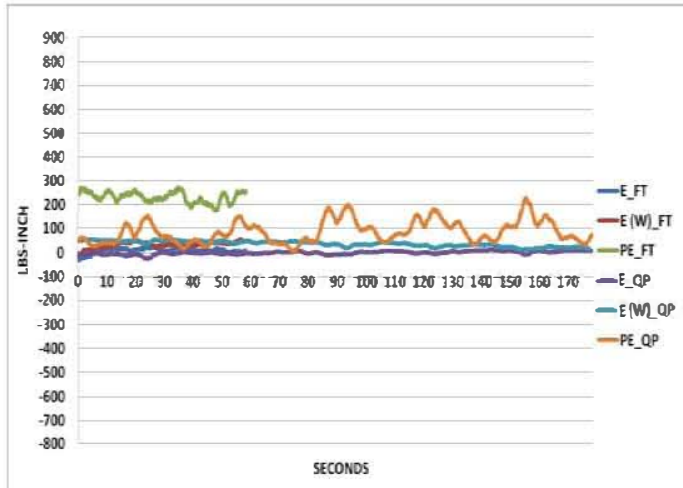

Graph 5.42: Load Cell $1 \mathrm{Mz} 90^{\circ}$ 


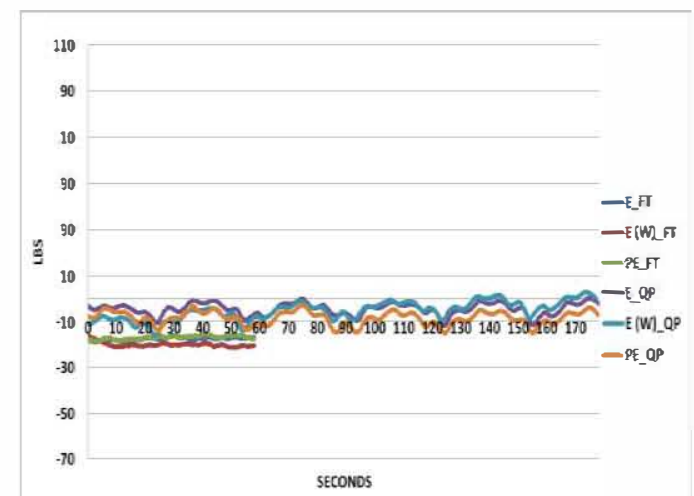

Graph 5.43: Load Cell 2 Fx $90^{\circ}$

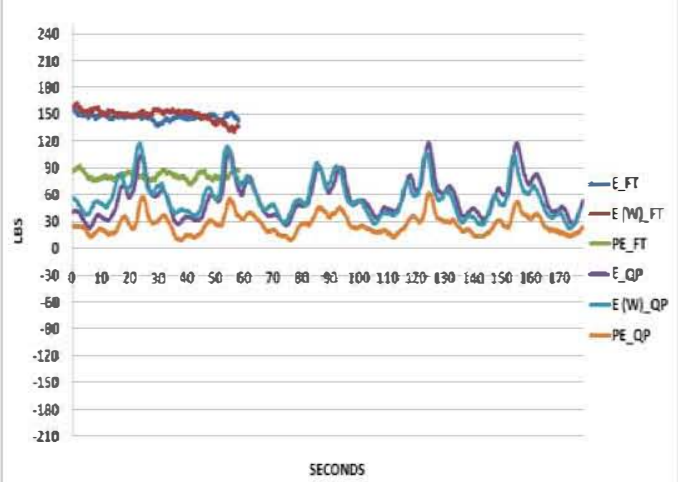

Graph 5.44: Load Cell 2 Fy 90

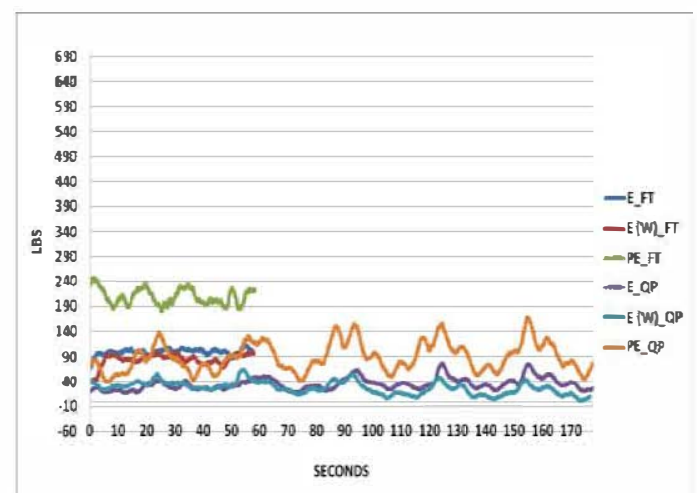

Graph 5.45: Load Cell 2 Fz $90^{\circ}$

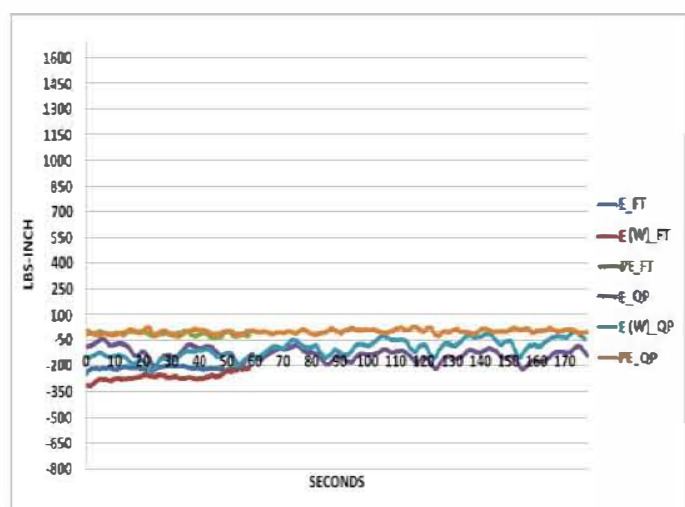

Graph 5.46: Load Cell $2 \mathrm{Mx} 90^{\circ}$

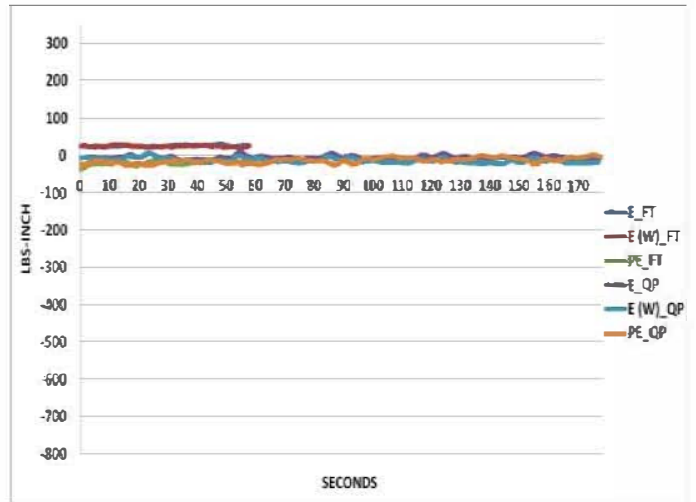

Graph 5.47: Load Cell 2 My $90^{\circ}$

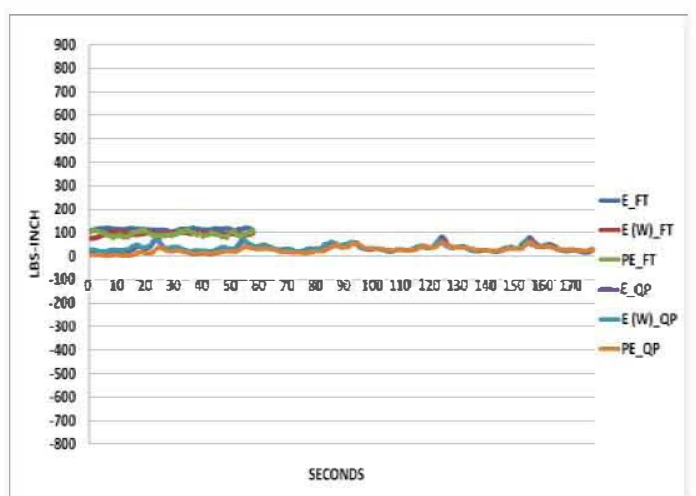

Graph 5.48: Load Cell 2 Mz 90 


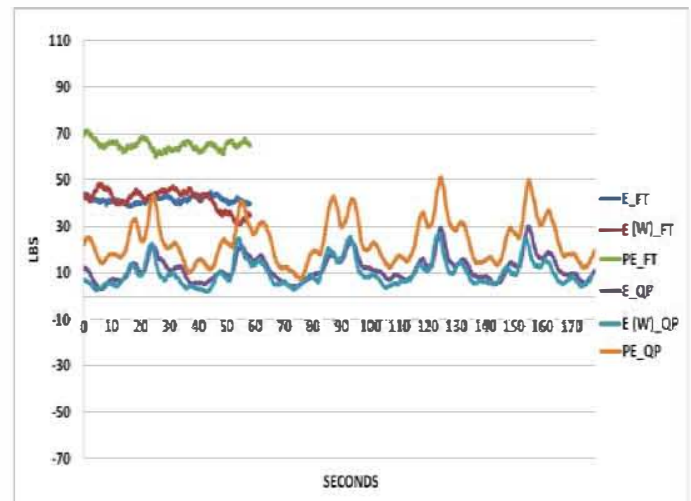

Graph 5.49: Load Cell 3 Fx $90^{\circ}$

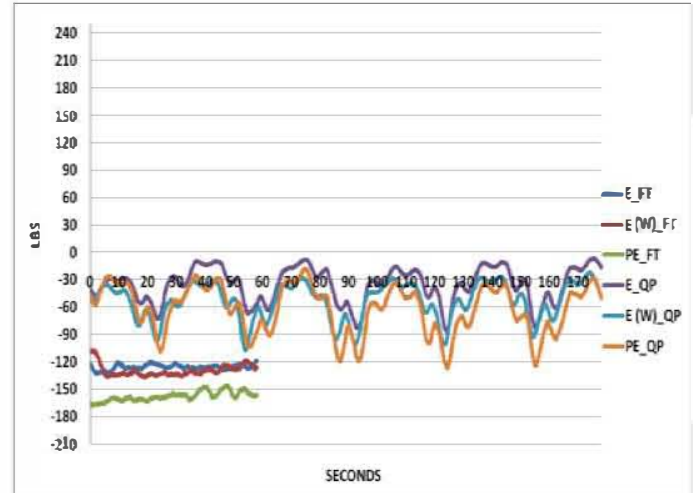

Graph 5.50: Load Cell 3 Fy 90

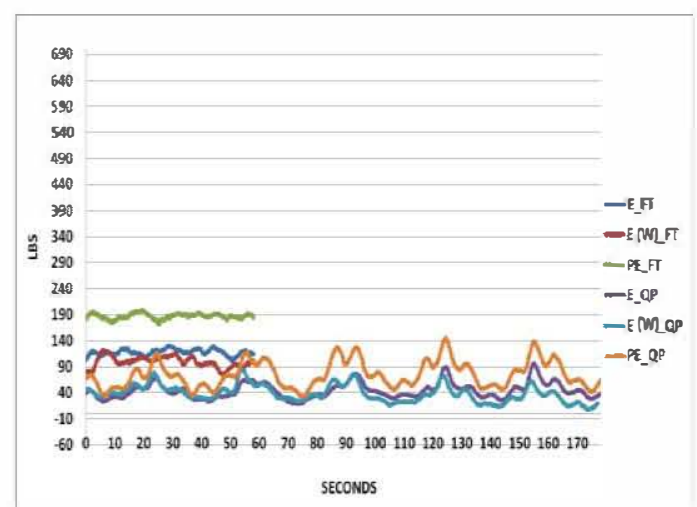

Graph 5.51: Load Cell 3 Fz $90^{\circ}$

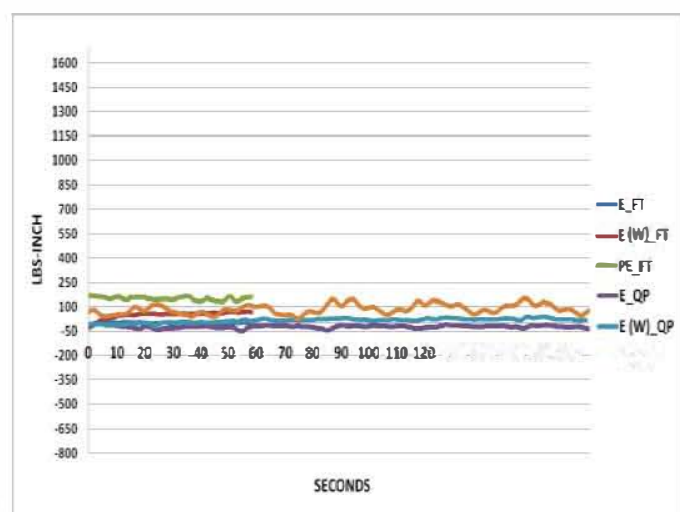

Graph 5.52: Load Cell 3 Mx $90^{\circ}$

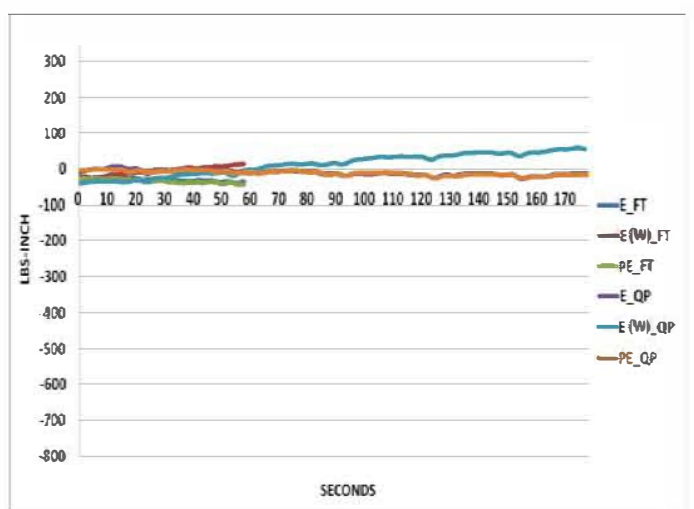

Graph 5.53: Load Cell 3 My $90^{\circ}$

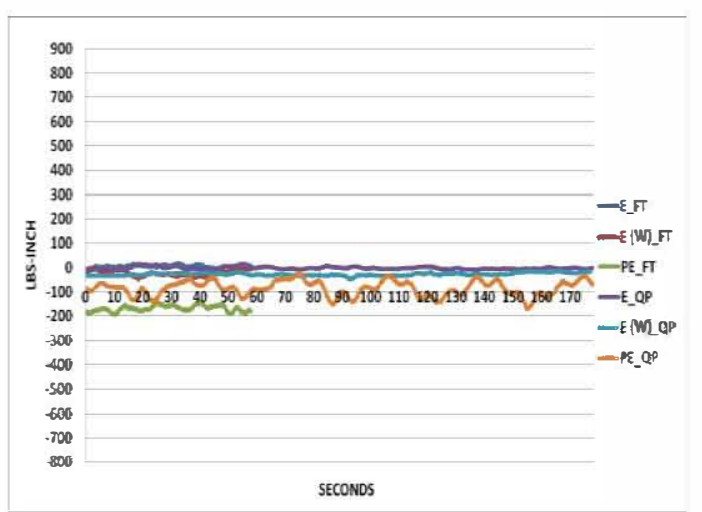

Graph 5.54: Load Cell $3 \mathrm{Mz} 90^{\circ}$ 


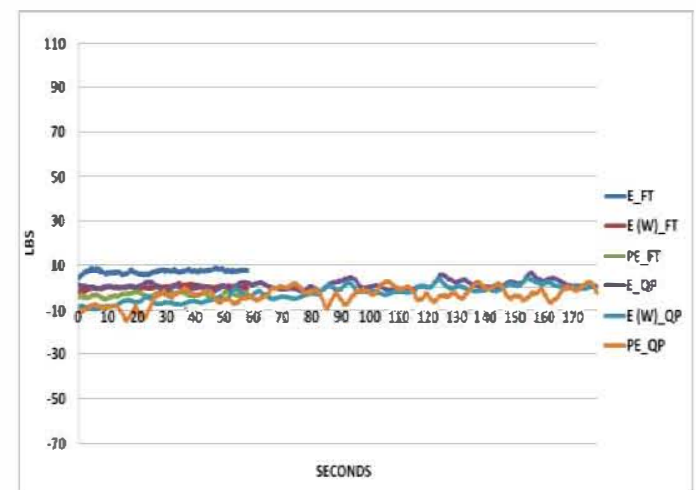

Graph 5.55: Load Cell 4 Fx $90^{\circ}$

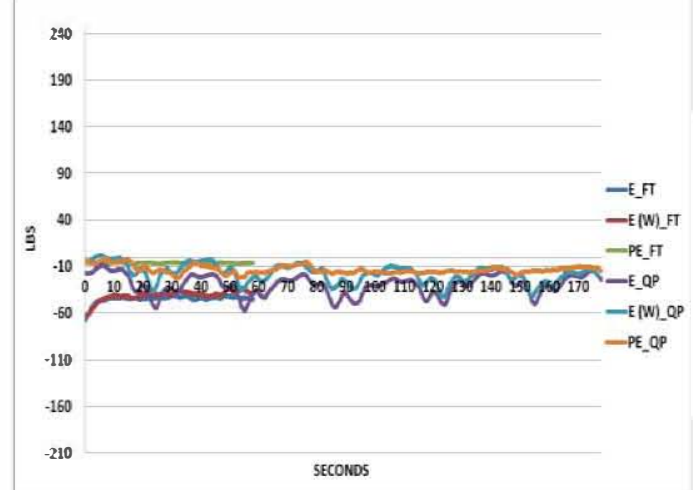

Graph 5.56: Load Cell 4 Fy 90

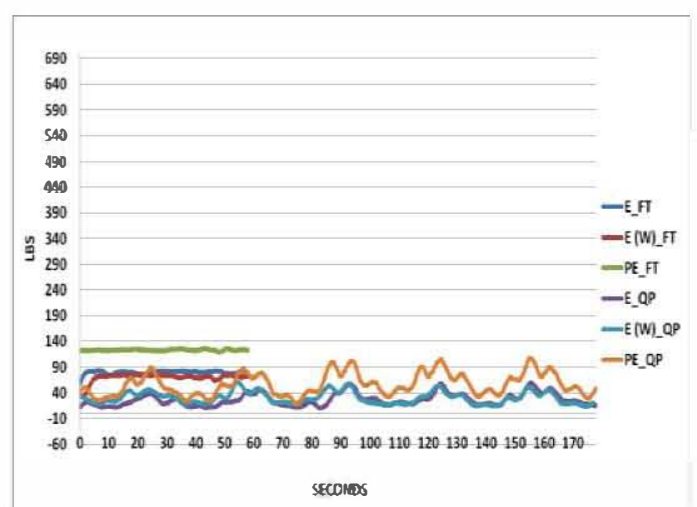

Graph 5.57: Load Cell 4 Fz 90

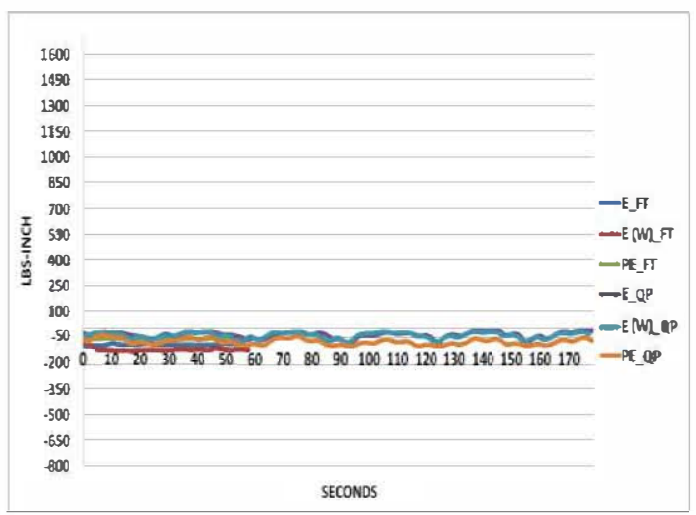

Graph 5.58: Load Cell $4 \mathrm{Mx} 90^{\circ}$

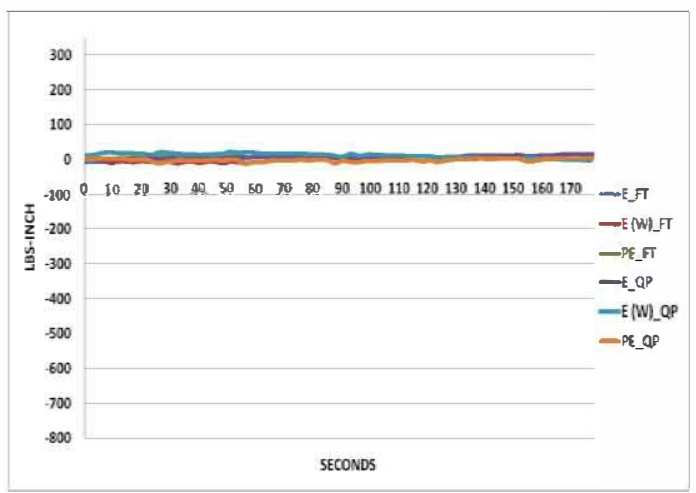

Graph 5.69: Load Cell 4 My $90^{\circ}$

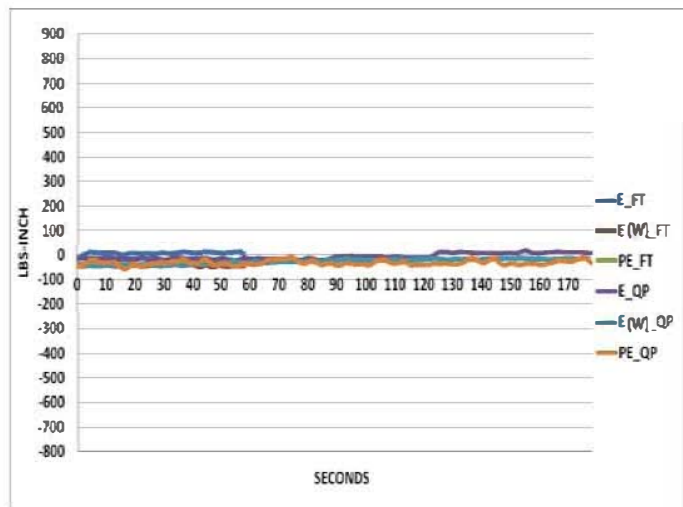

Graph 5.60: Load Cell 4 Mz 90 


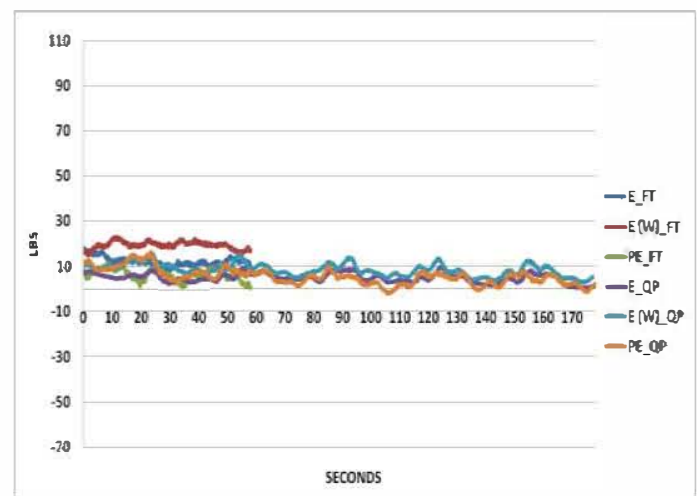

Graph 5.61: Load Cell 5 Fx $90^{\circ}$

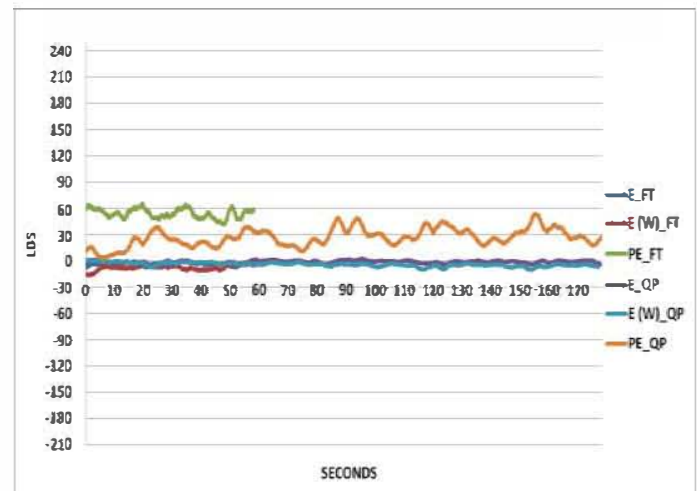

Graph 5.62: Load Cell 5 Fy 90

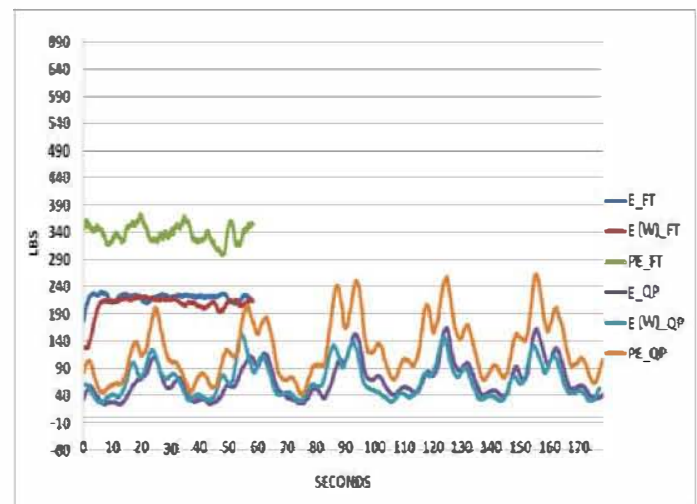

Graph 5.63: Load Cell 5 Fz 90

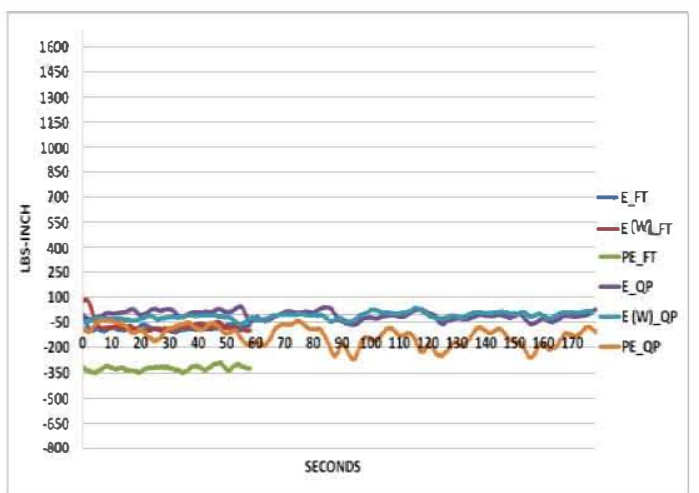

Graph 5.64: Load Cell 5 Mx 90

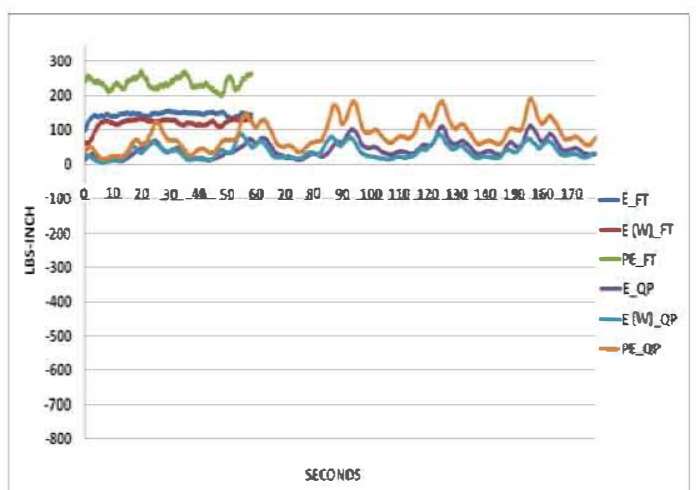

Graph 5.65: Load Cell 5 My $90^{\circ}$

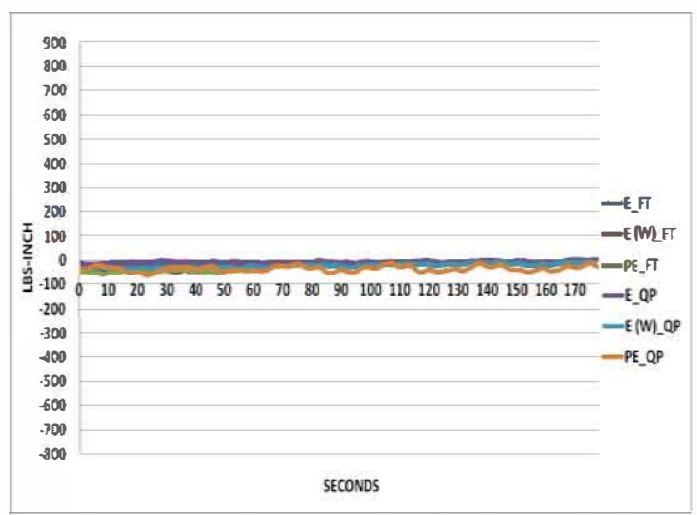

Graph 5.66: Load Cell $5 \mathrm{Mz} 90^{\circ}$ 


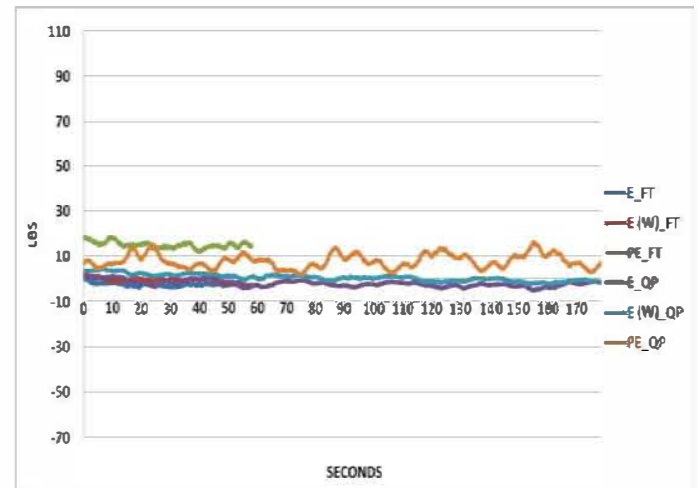

Graph 5.67: Load Cell 6 Fx 90

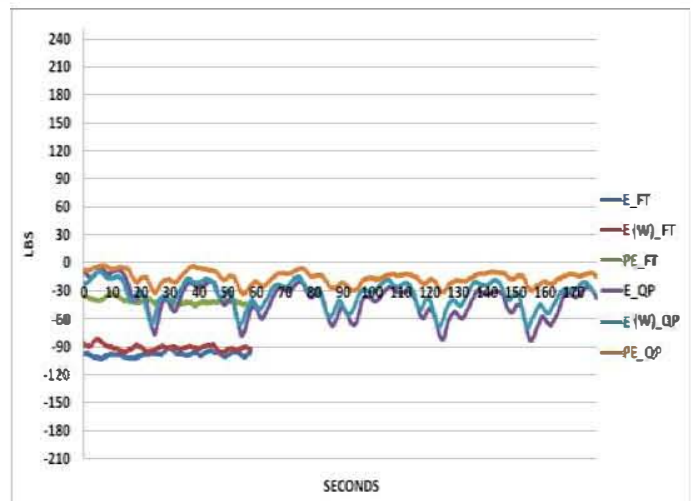

Graph 5.68: Load Cell 6 Fy $90^{\circ}$

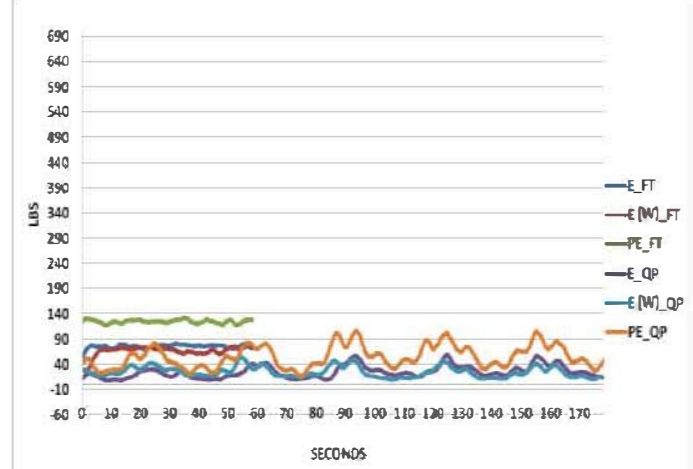

Graph 5.69: Load Cell 6 Fz 90

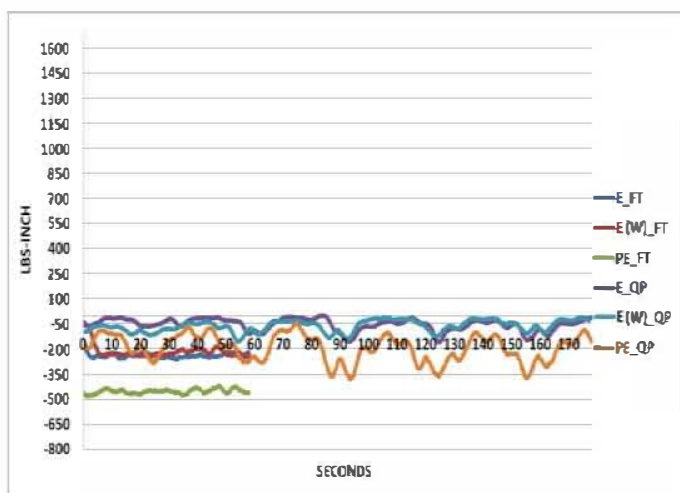

Graph 5.70: Load Cell 6 Mx 90

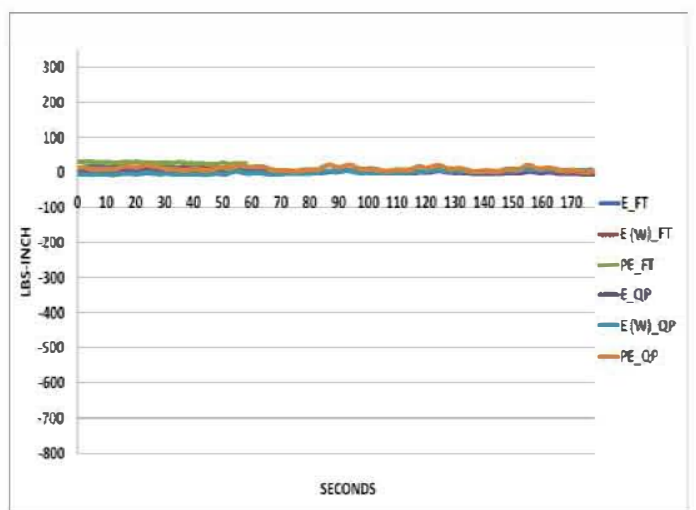

Graph 5.71: Load Cell 6 My 90

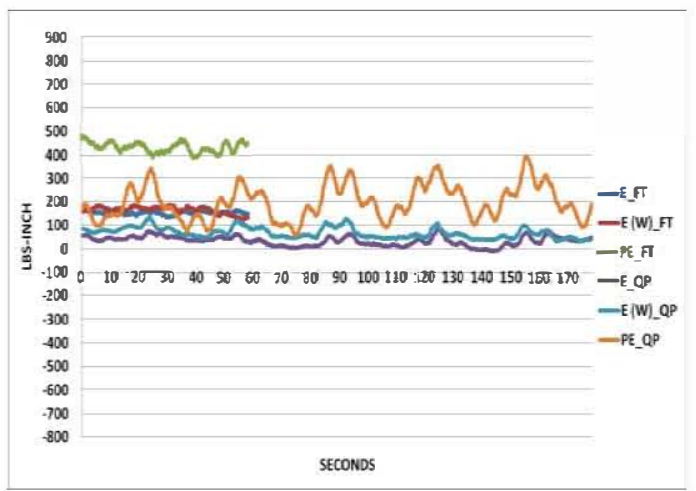

Graph 5.72: Load Cell 6 Mz 90 


\subsubsection{Load Cell Results from Phase III Testing}

The load cell results plotted as graphs for all the tests under Phase III are shown below.

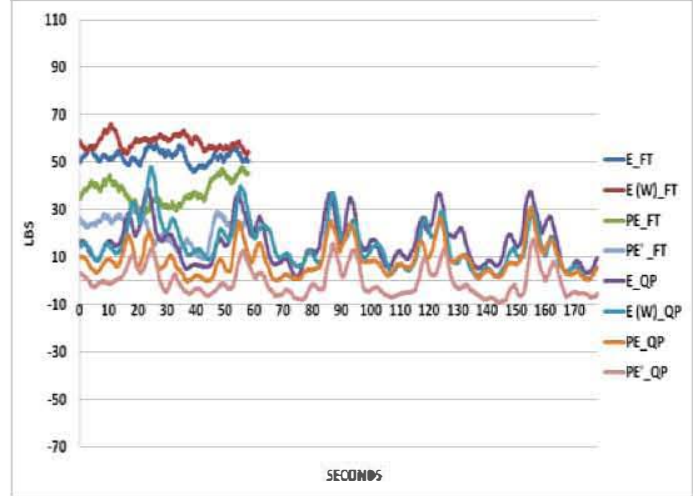

Graph 5.73: Load Cell 1 Fx $45^{\circ}$

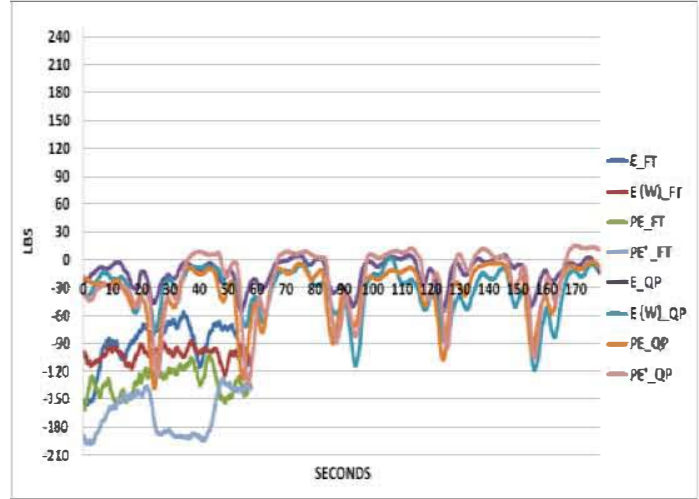

Graph 5.74: Load Cell 1 Fy $45^{\circ}$

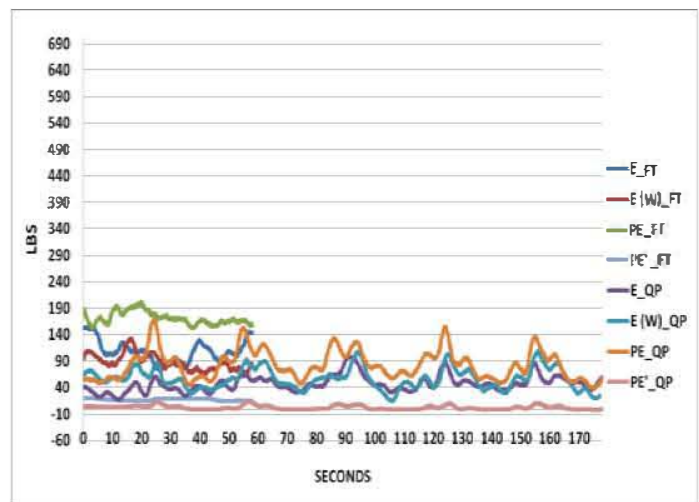

Graph 5.75: Load Cell 1 Fz 45

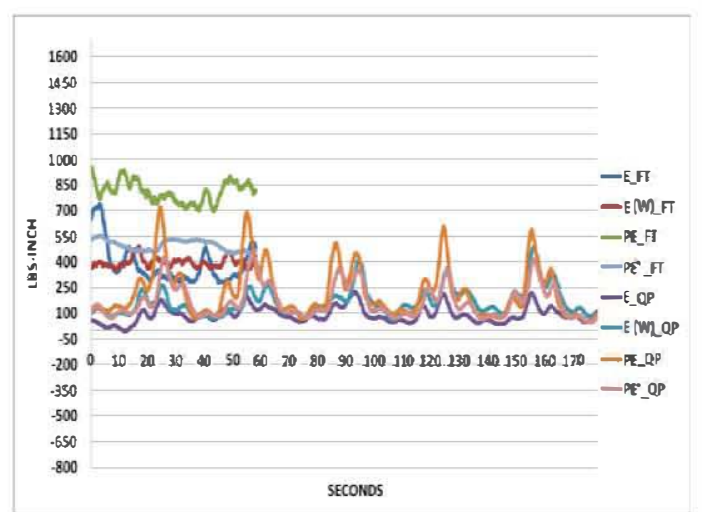

Graph 5.76: Load Cell $1 \mathrm{Mx} \mathbf{4 5}^{\circ}$

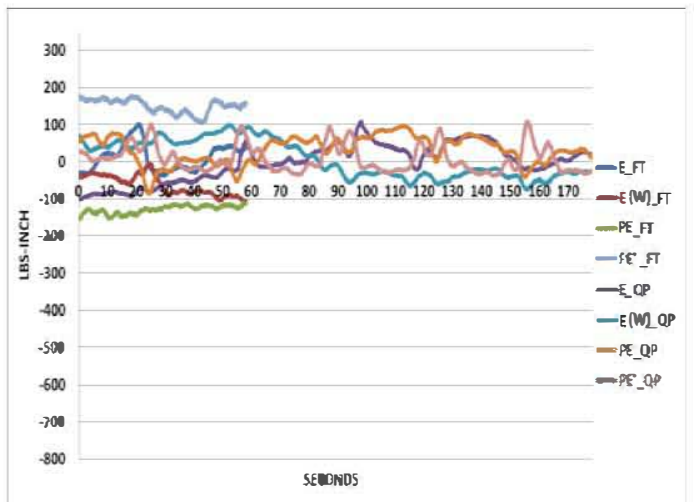

Graph 5.77: Load Cell 1 My $45^{\circ}$

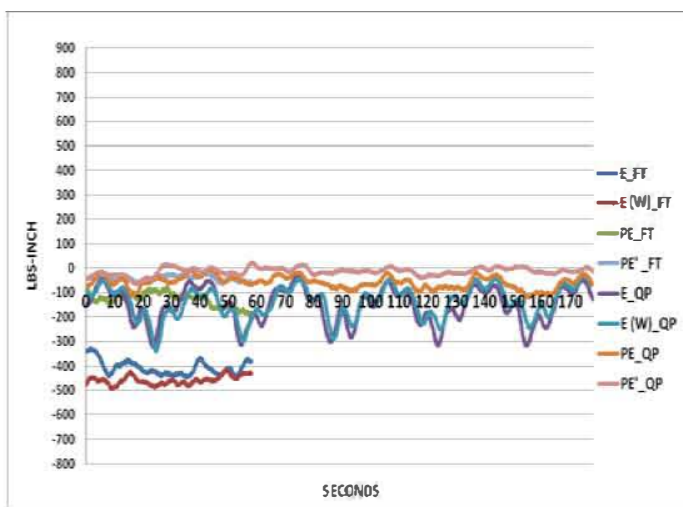

Graph 5.78: Load Cell $1 \mathrm{Mz} 45^{\circ}$ 


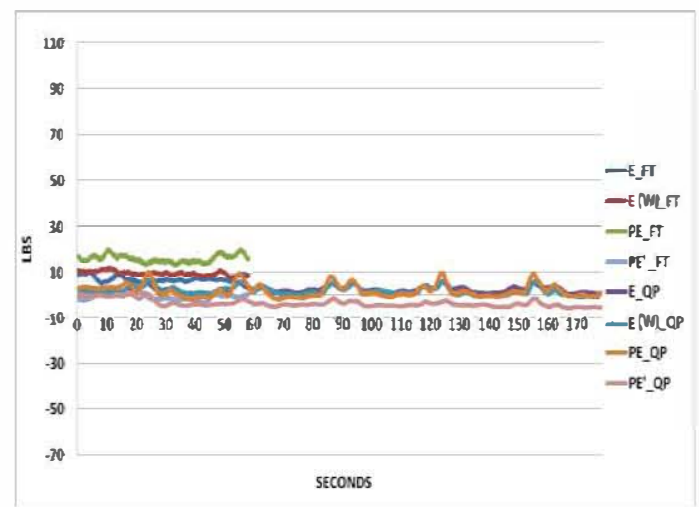

Graph 5.79: Load Cell 2 Fx $45^{\circ}$

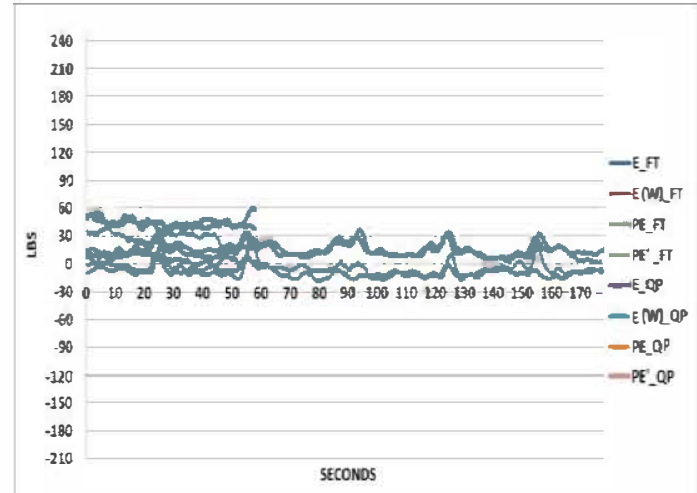

Graph 5.80: Load Cell 2 Fy $45^{\circ}$

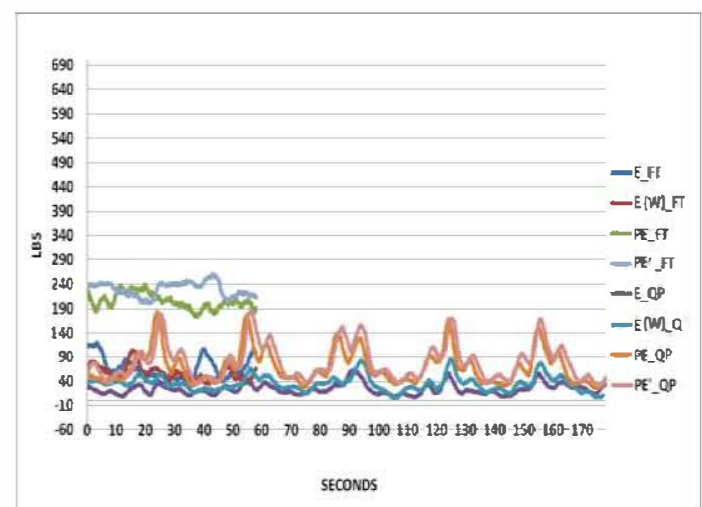

Graph 5.81: Load Cell 2 Fz $45^{\circ}$

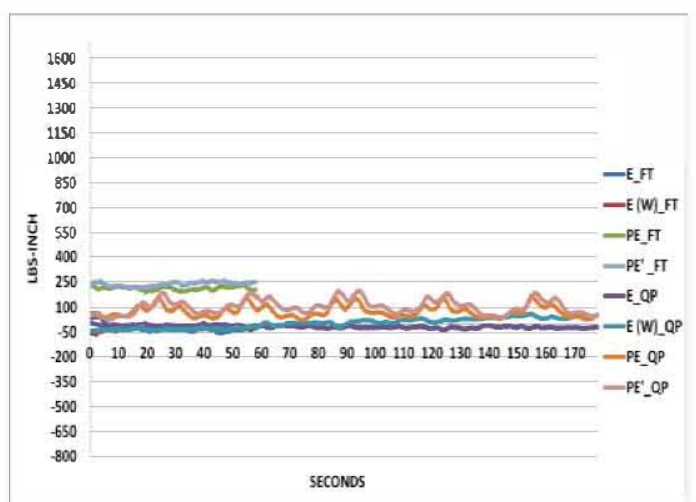

Graph 5.82: Load Cell $2 \mathrm{Mx} 45^{\circ}$

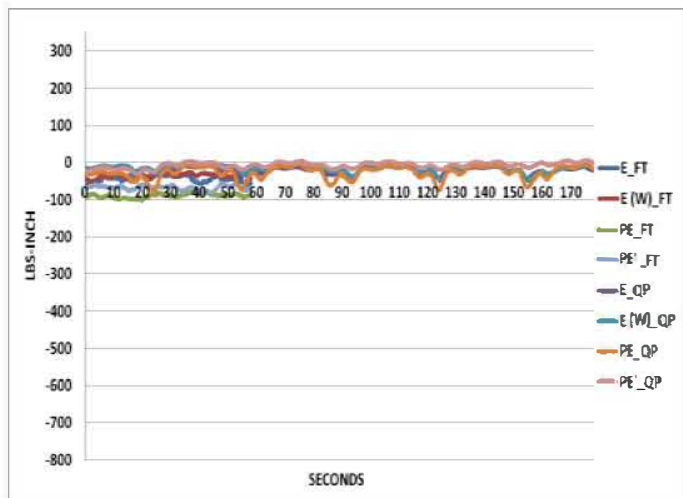

\section{Graph 5.83: Load Cell $2 \mathrm{My} \mathbf{4 5}^{\circ}$}

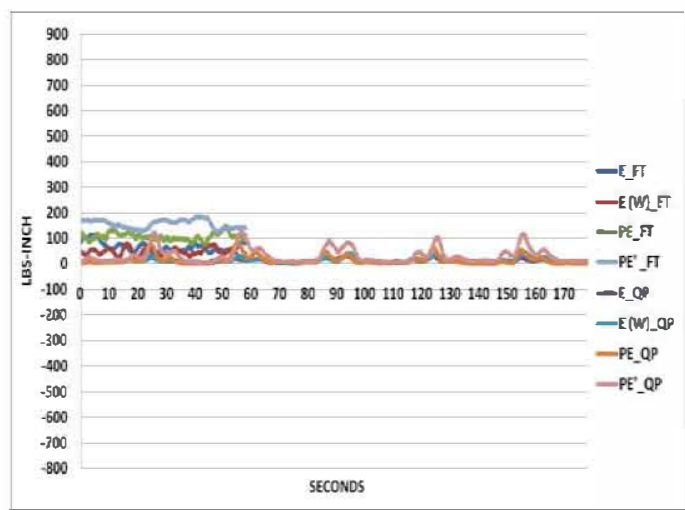

Graph 5.84: Load Cell $2 \mathrm{Mz} 45^{\circ}$ 


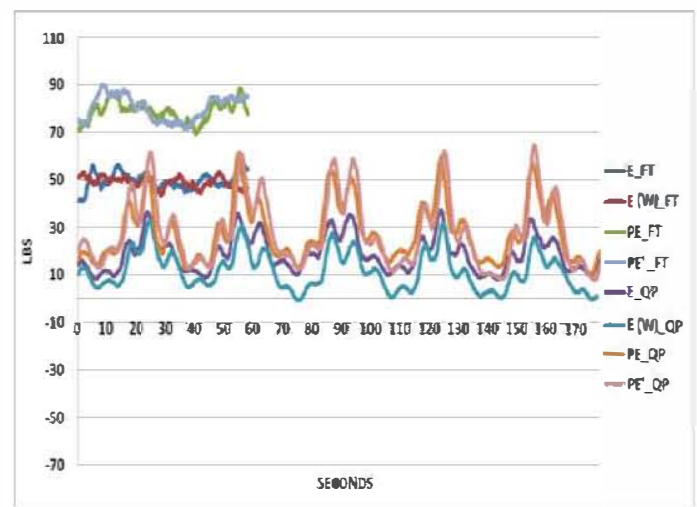

Graph 5.85: Load Cell 3 Fx $45^{\circ}$

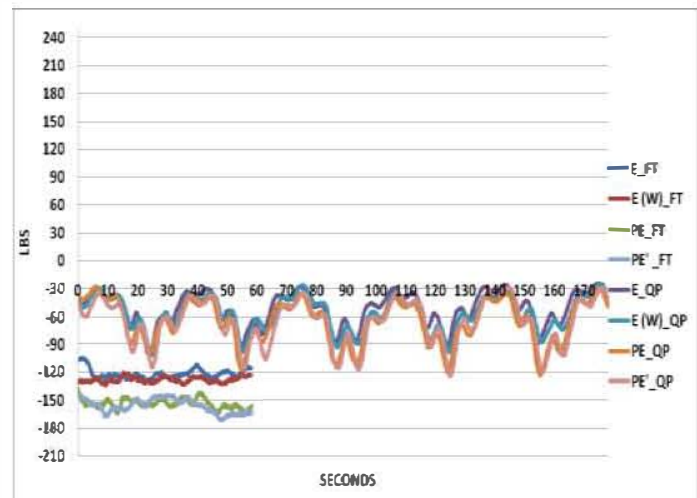

Graph 5.86: Load Cell 3 Fy $45^{\circ}$

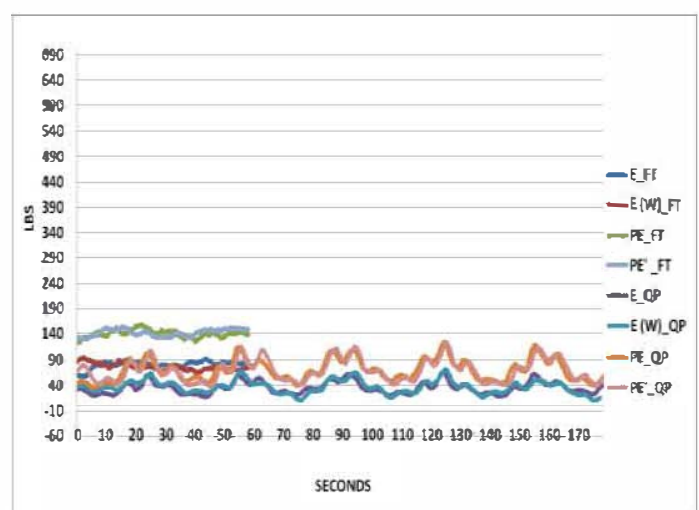

Graph 5.87: Load Cell 3 Fz 45

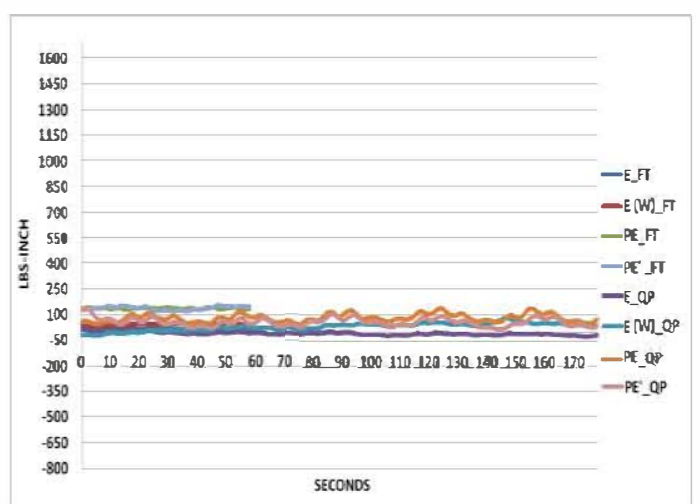

Graph 5.88: Load Cell 3 Mx $4^{\circ}$

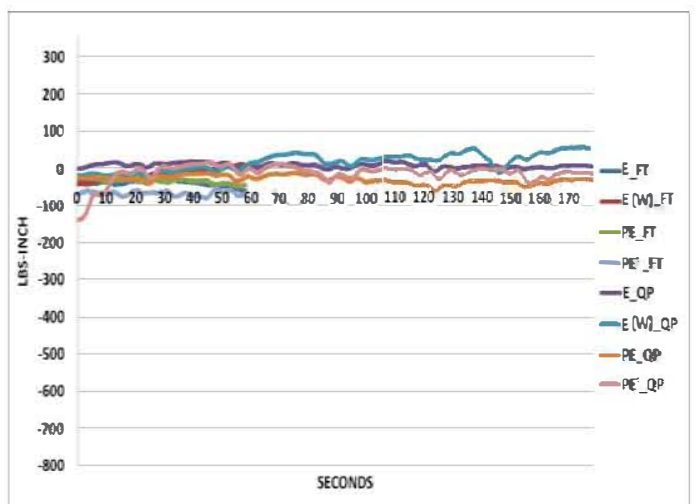

Graph 5.89: Load Cell 3 My $45^{\circ}$

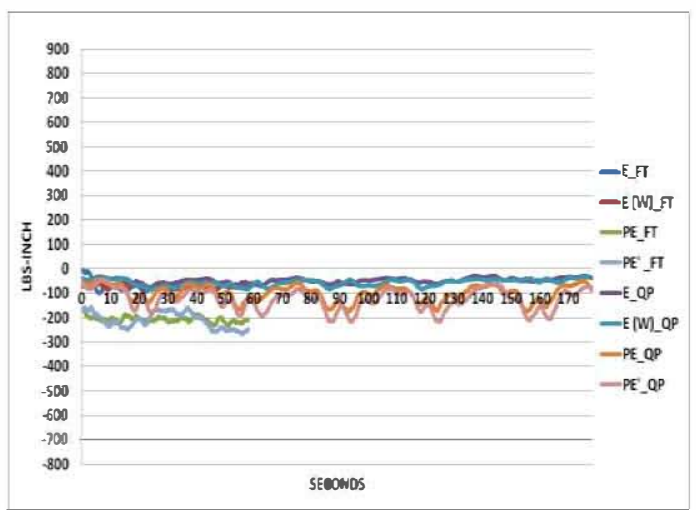

Graph 5.90: Load Cell $3 \mathrm{Mz} 45^{\circ}$ 


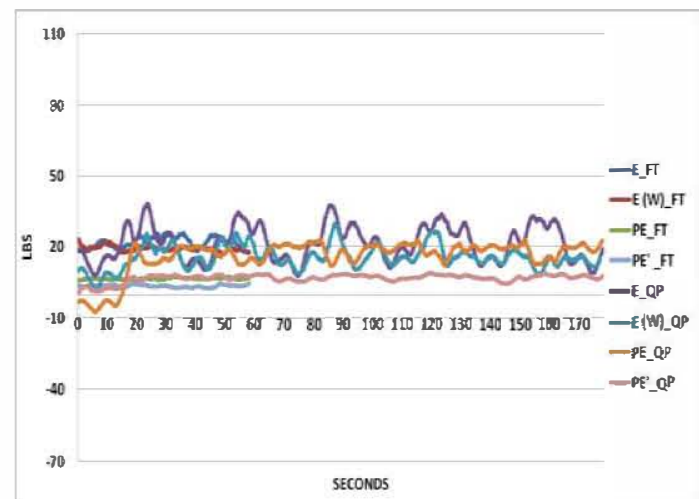

Graph 5.91: Load Cell 4 Fx $45^{\circ}$

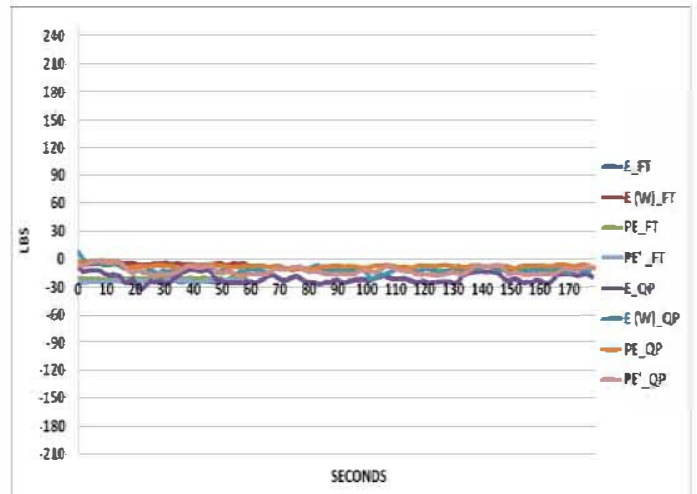

Graph 5.92: Load Cell 4 Fy $45^{\circ}$

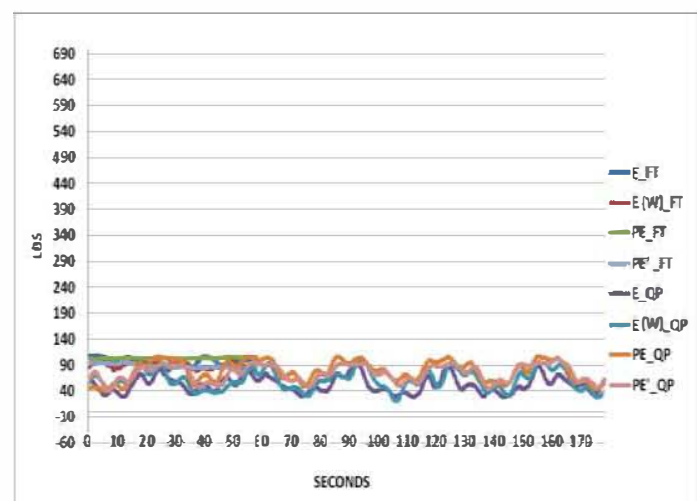

Graph 5.93: Load Cell 4 Fz $45^{\circ}$

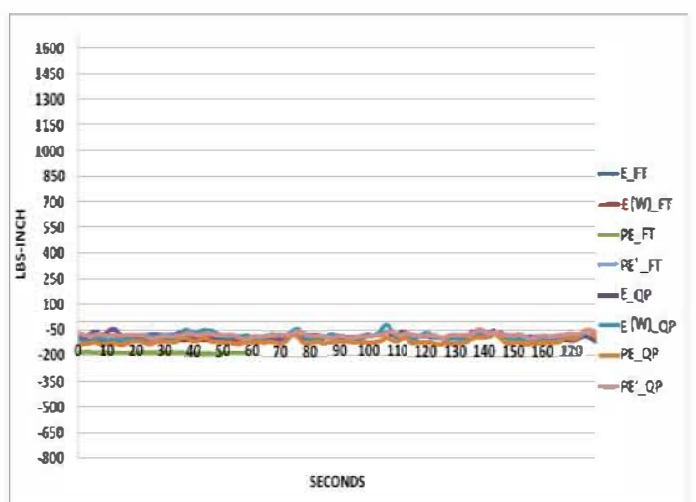

Graph 5.94: Load Cell $4 \mathrm{Mx} 45^{\circ}$

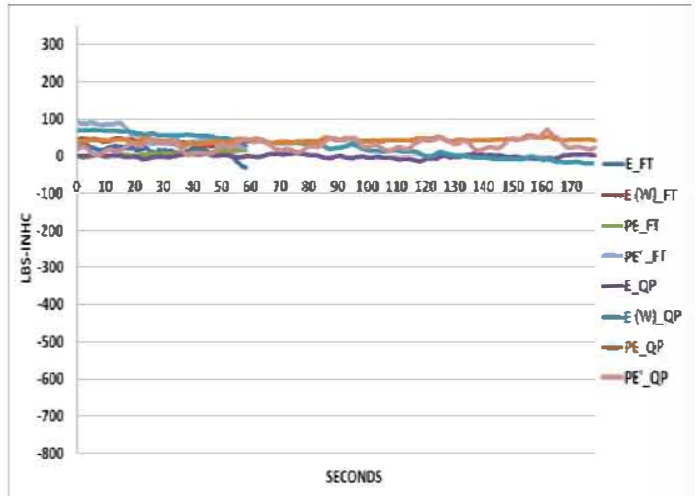

Graph 5.95: Load Cell 4 My $45^{\circ}$

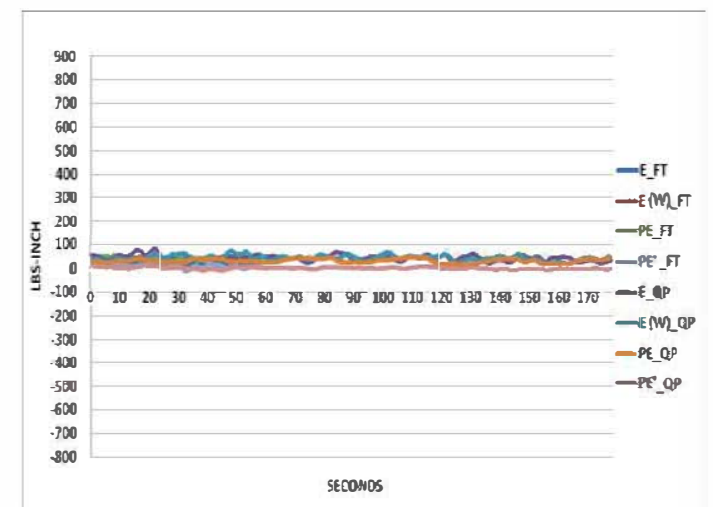

Graph 5.96: Load Cell $4 \mathrm{Mz} 45^{\circ}$ 


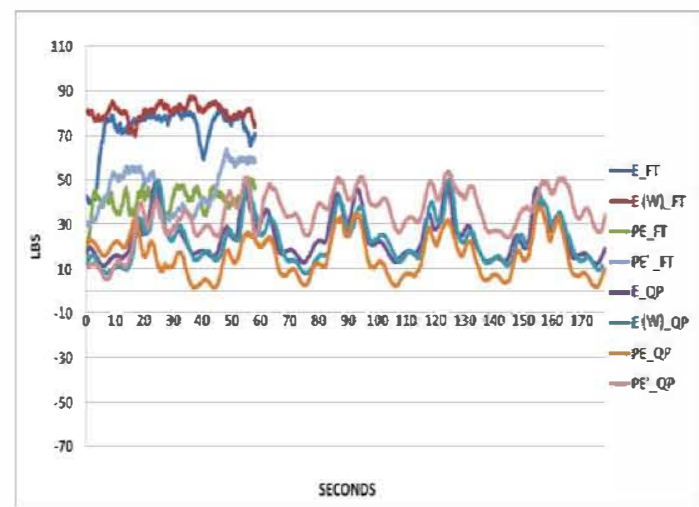

Graph 5.97: Load Cell 5 Fx 45

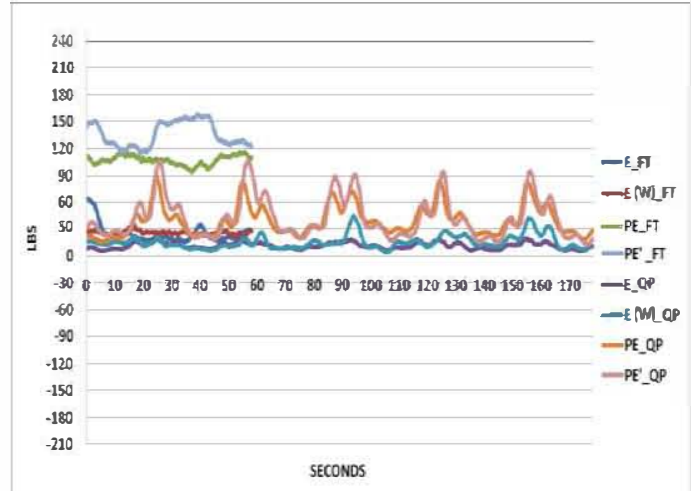

Graph 5.98: Load Cell 5 Fy $\mathbf{4 5}^{\circ}$

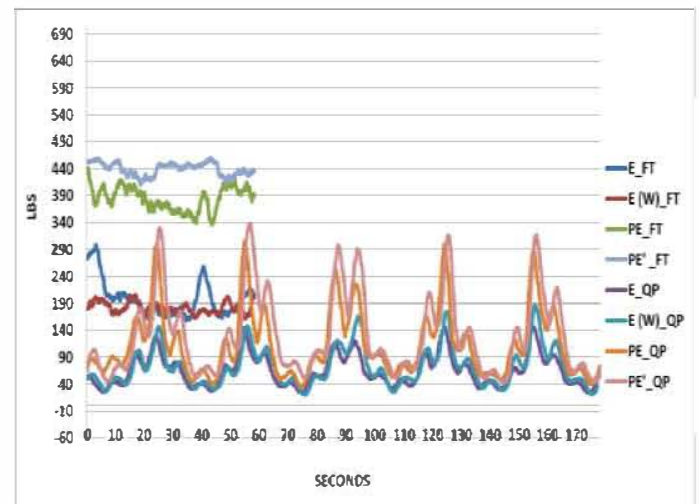

Graph 5.99: Load Cell 5 Fz 45

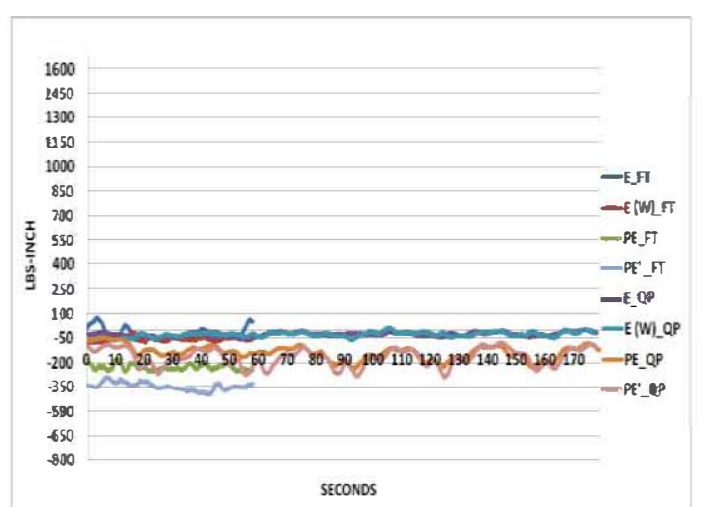

Graph 5.100: Load Cell 5 Mx 45

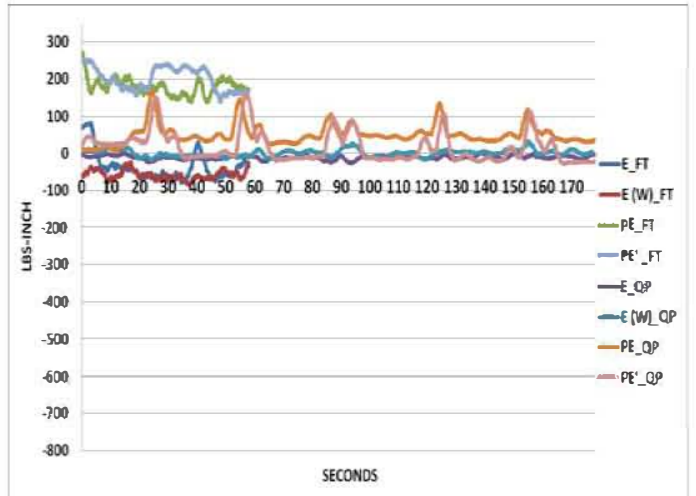

Graph 5.101: Load Cell 5 My 45

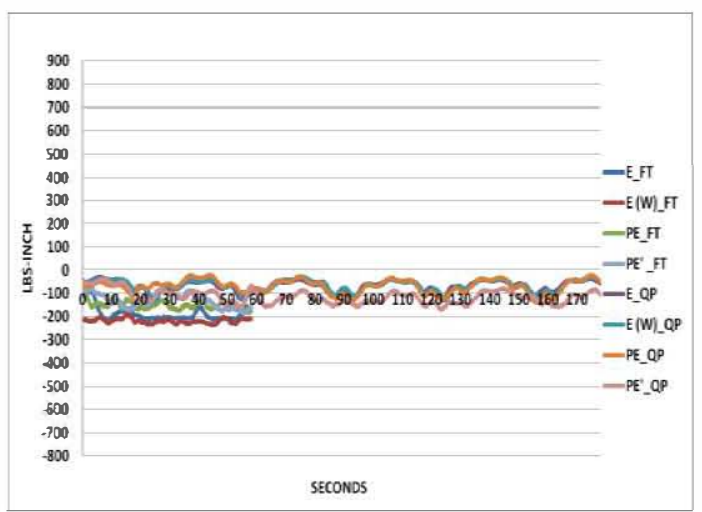

Graph 5.102: Load Cell $5 \mathrm{Mz}$ 45 $^{\circ}$ 


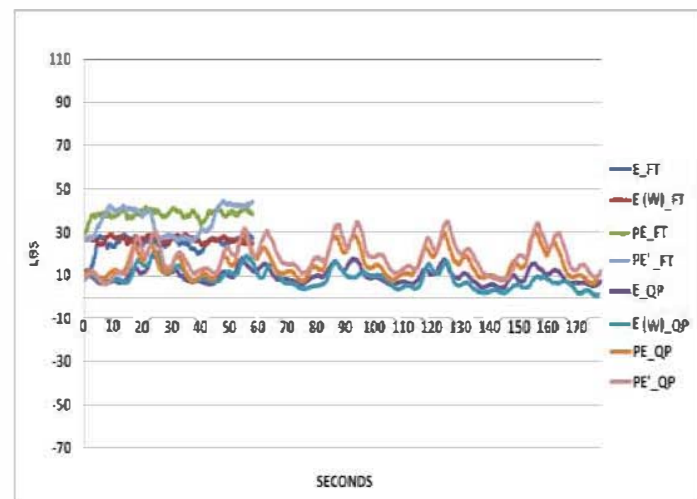

Graph 5.103: Load Cell 6 Fx 45

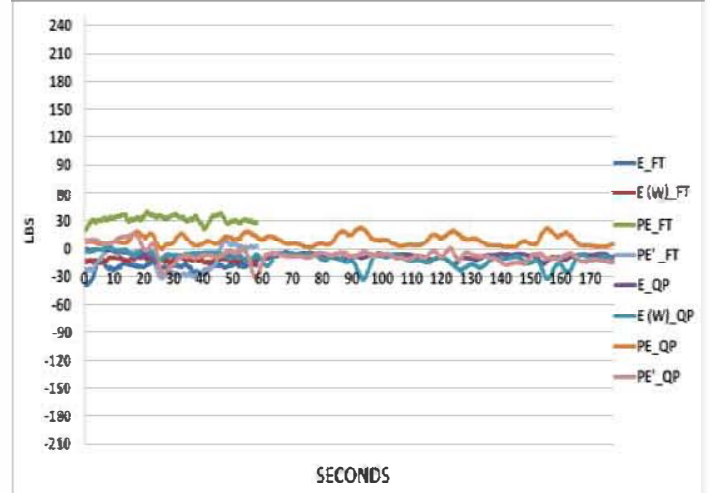

Graph 5.104: Load Cell 6 Fy $45^{\circ}$

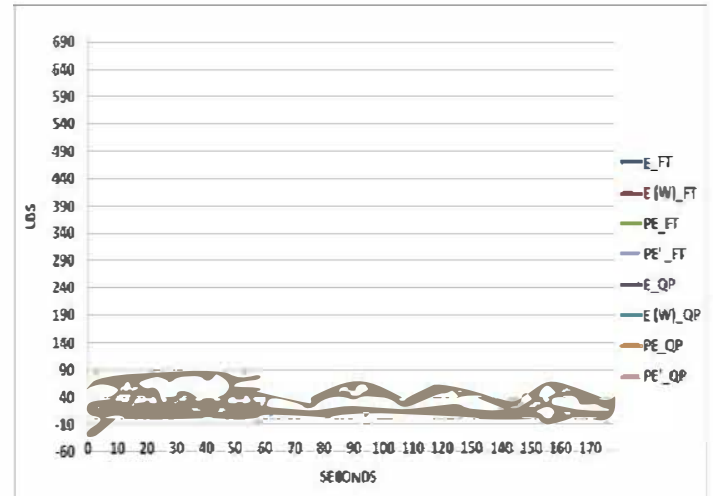

Graph 5.105: Load Cell 6 Fz 45

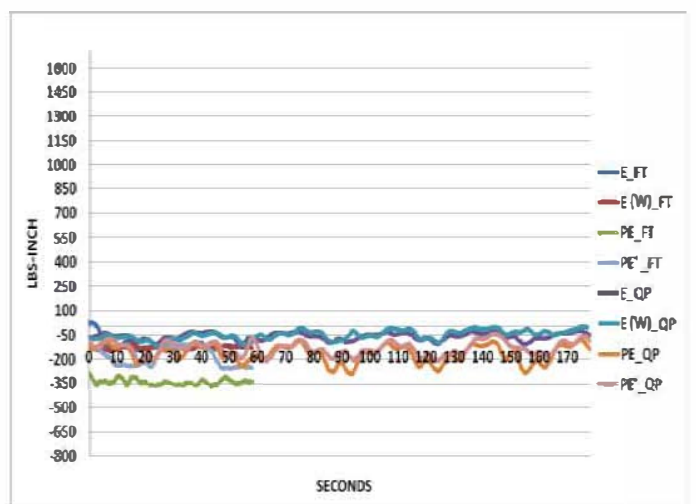

Graph 5.106: Load Cell $6 \mathrm{Mx} 45^{\circ}$

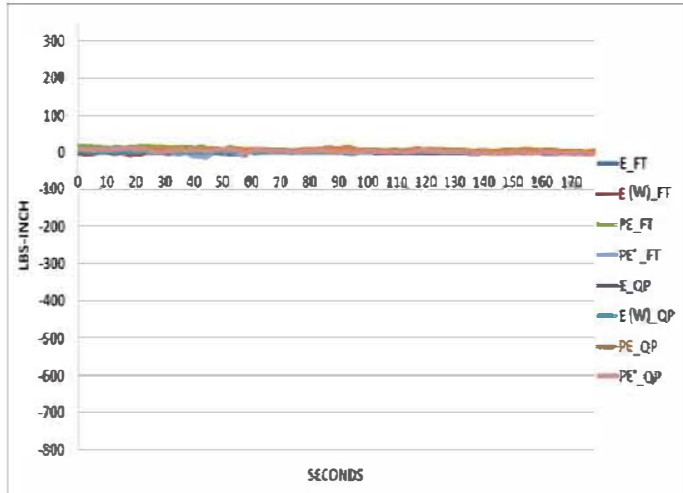

\section{Graph 5.107: Load Cell 6 My 45}

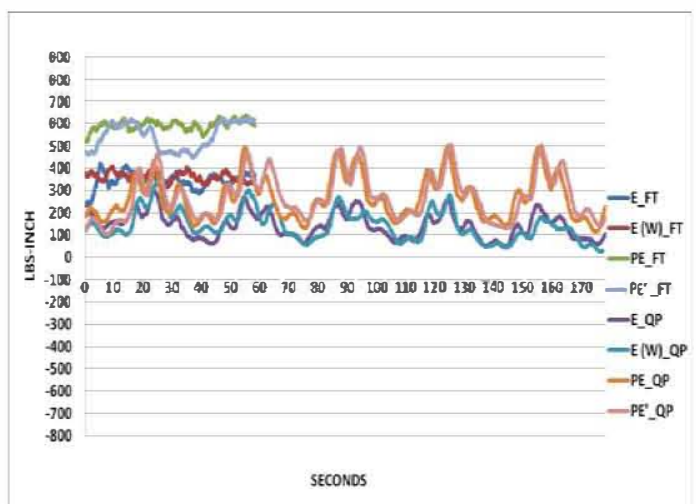

Graph 5.108: Load Cell $6 \mathrm{Mz}$ 45 $^{\circ}$ 


\subsubsection{Load Cell Results from Phase IV Testing}

The load cell results plotted as graphs for all the tests under Phase IV are shown below.

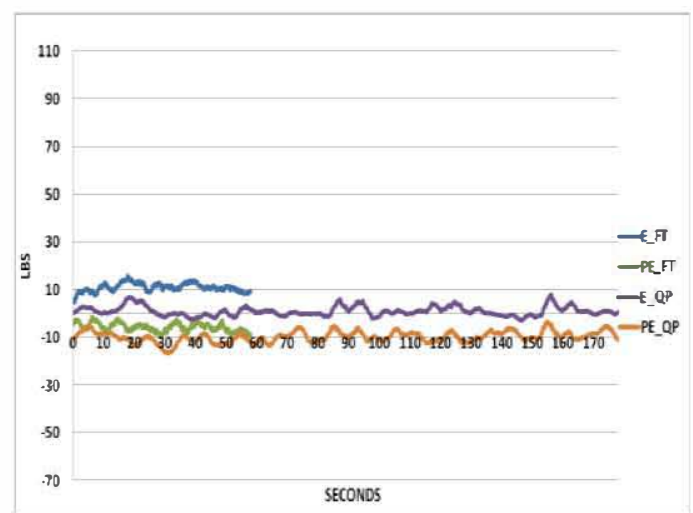

Graph 5.109: Load Cell 1 Fx 30

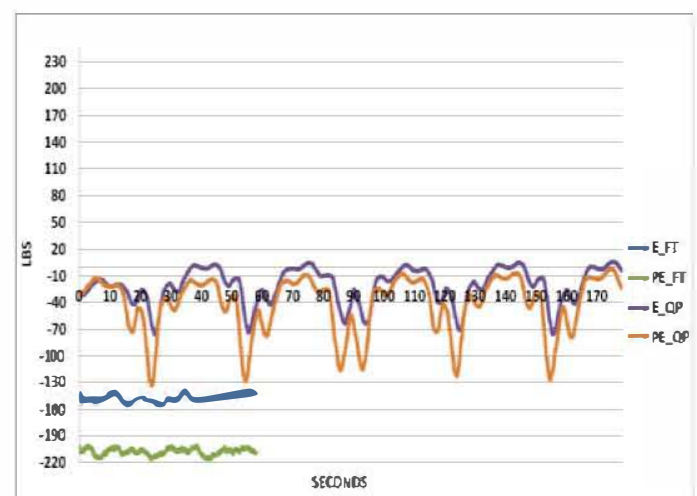

\section{Graph 5.110: Load Cell 1 Fy 30}

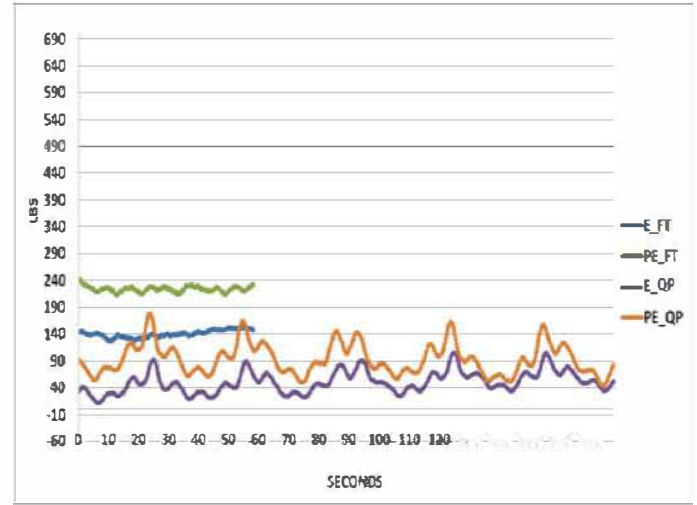

Graph 5.111: Load Cell 1 Fz 30

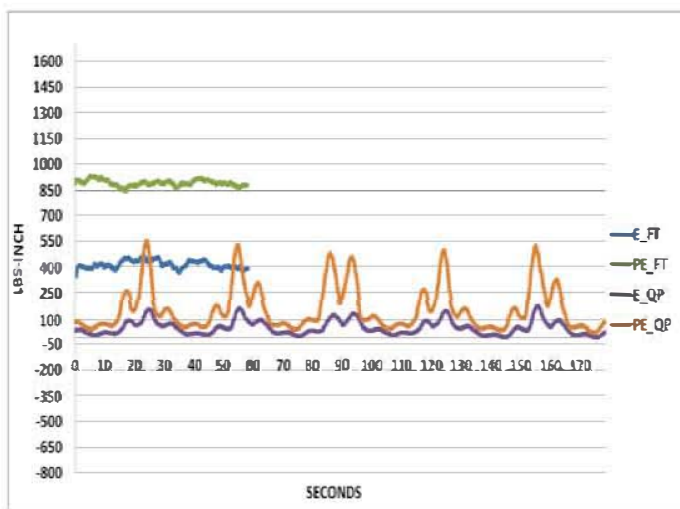

\section{Graph 5.1 12: Load Cell $1 \mathrm{Mx} \mathrm{30^{ \circ }}$}

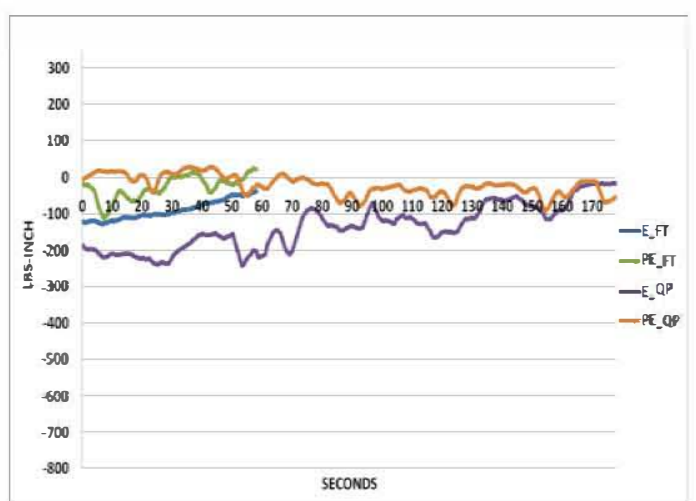

\section{Graph 5.113: Load Cell 1 My 30}

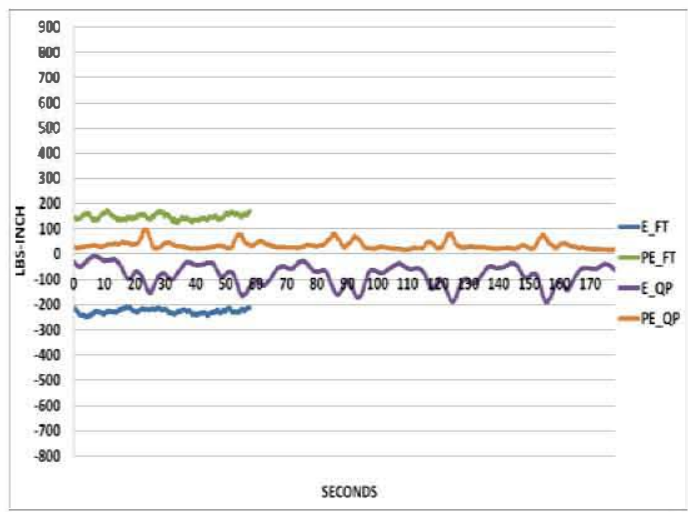

Graph 5.114: Load Cell $1 \mathrm{Mz} 3^{\circ}$ 


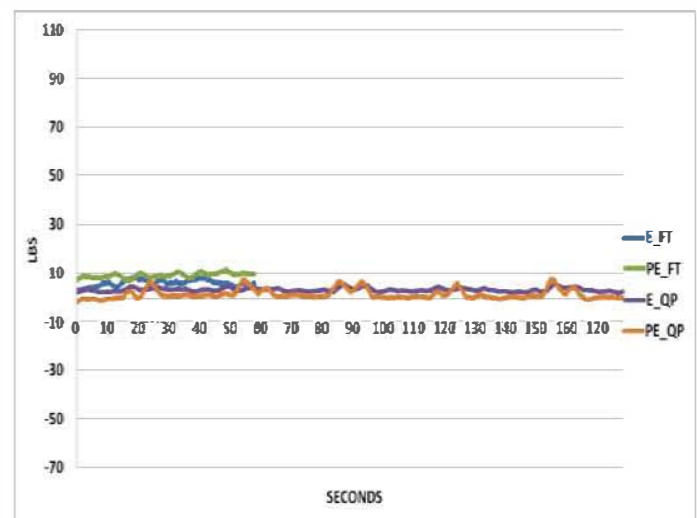

Graph 5.115: Load Cell 2 Fx 30

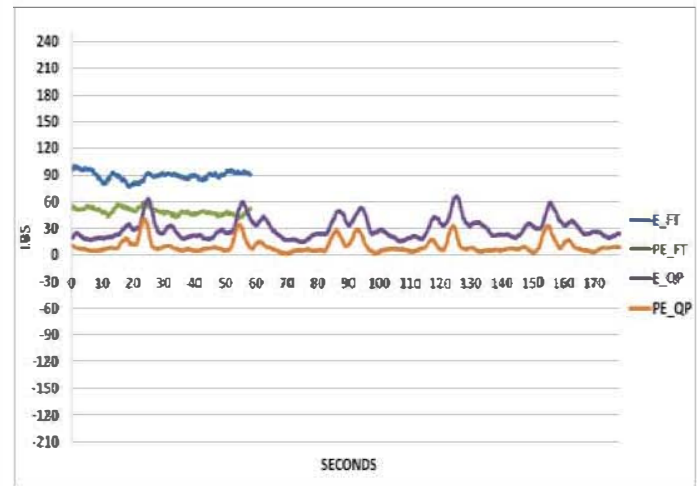

Graph 5.116: Load Cell 2 Fy 30

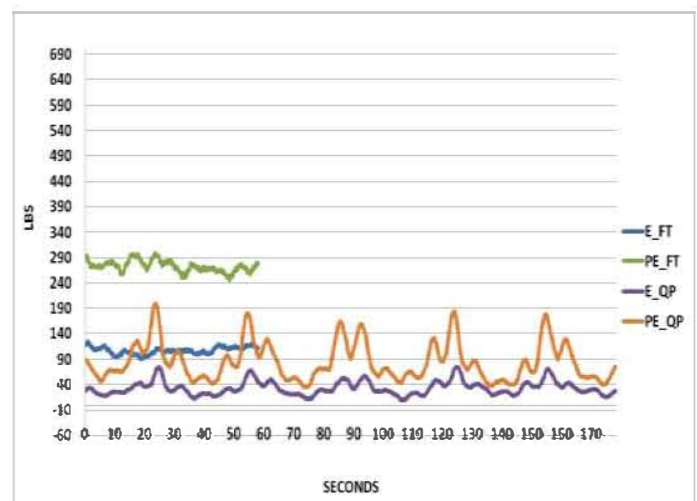

Graph 5.1 17: Load Cell 2 Fz 30

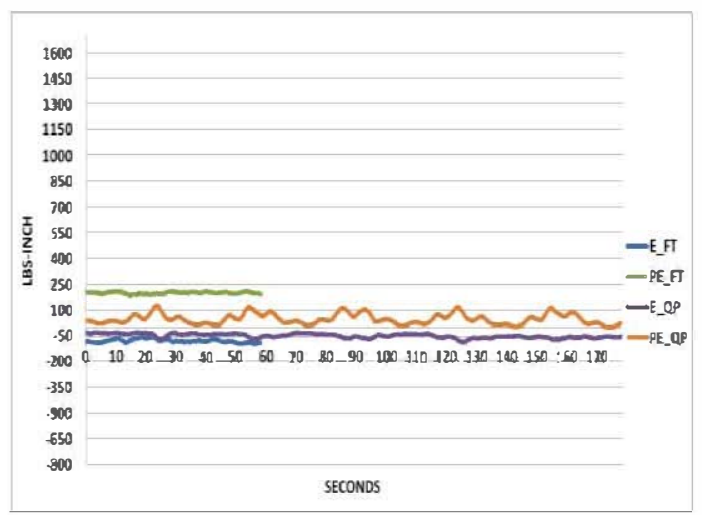

Graph 5.1 18: Load Cell 2 Mx 30

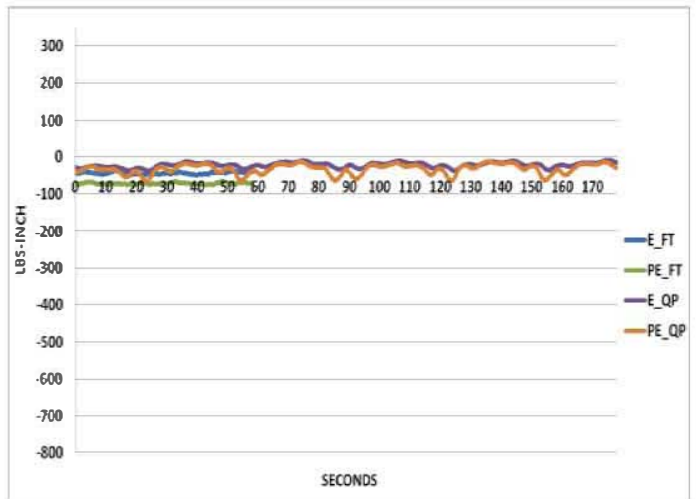

Graph 5.119: Load Cell 2 My 30

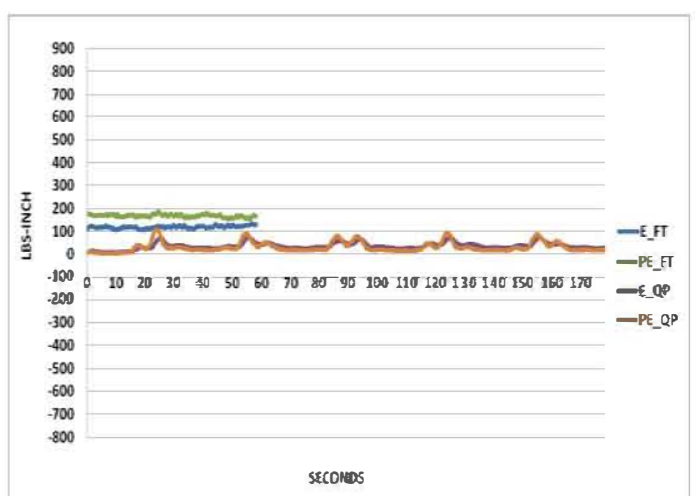

Graph 5.120: Load Cell $2 \mathrm{Mz} \mathrm{30}$ 


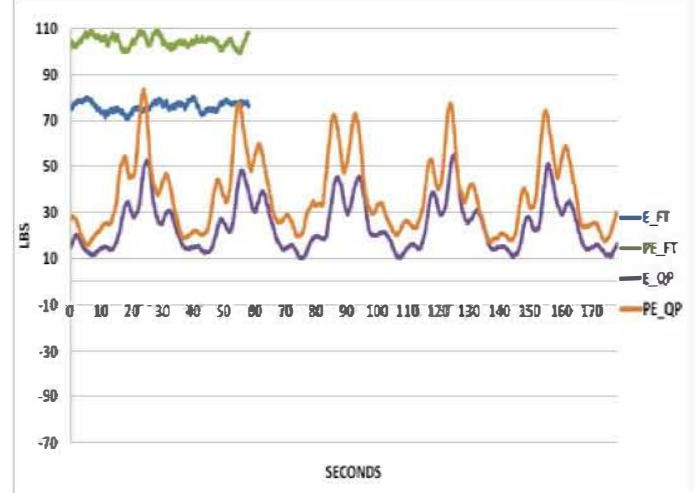

Graph 5.121: Load Cell 3 Fx 30

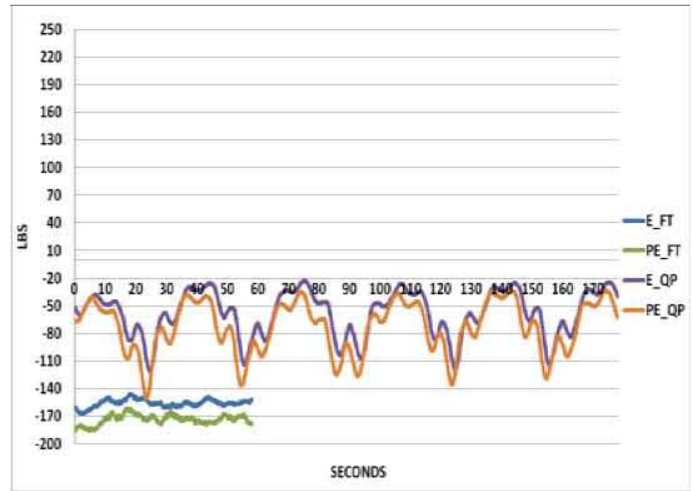

Graph 5.122: Load Cell 3 Fy 30

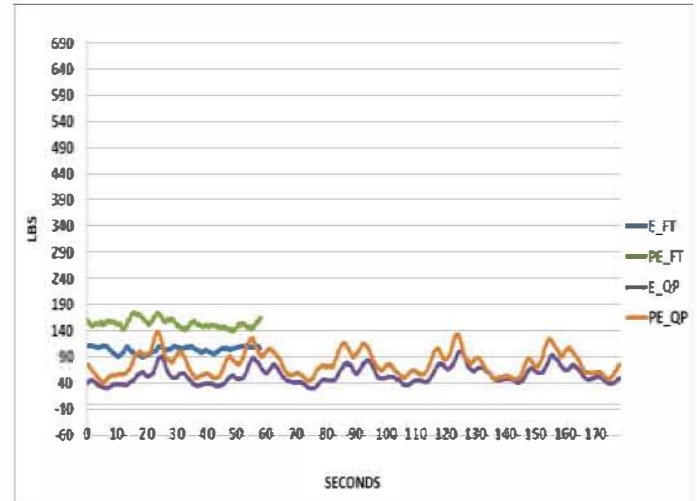

Graph 5.123: Load Cell 3 Fz 30

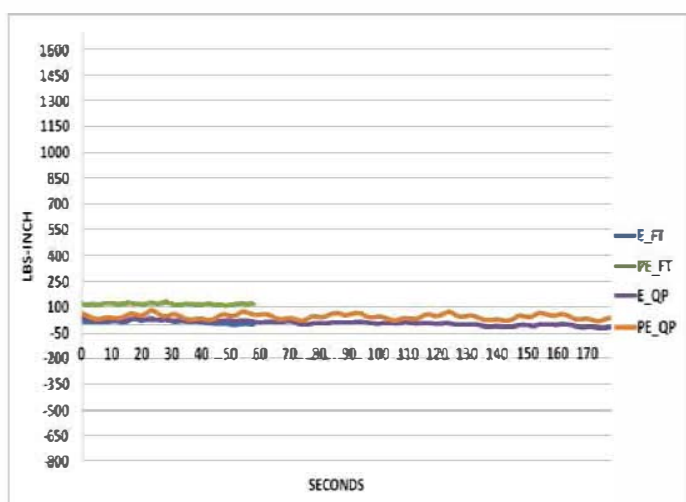

Graph 5.124: Load Cell 3 Mx 30

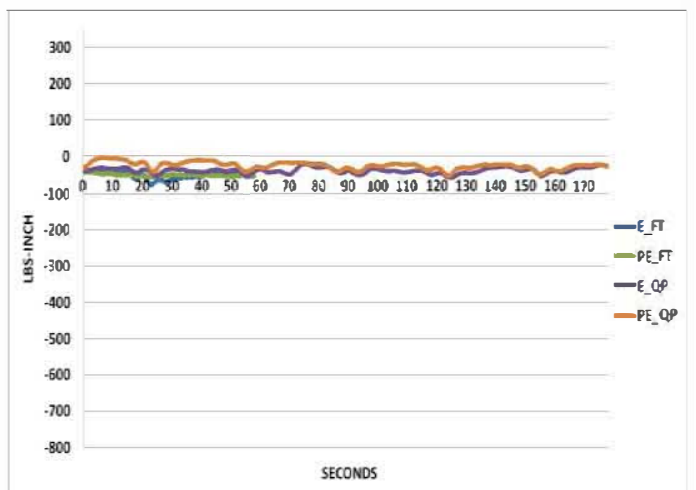

Graph 5.125: Load Cell 3 My 30

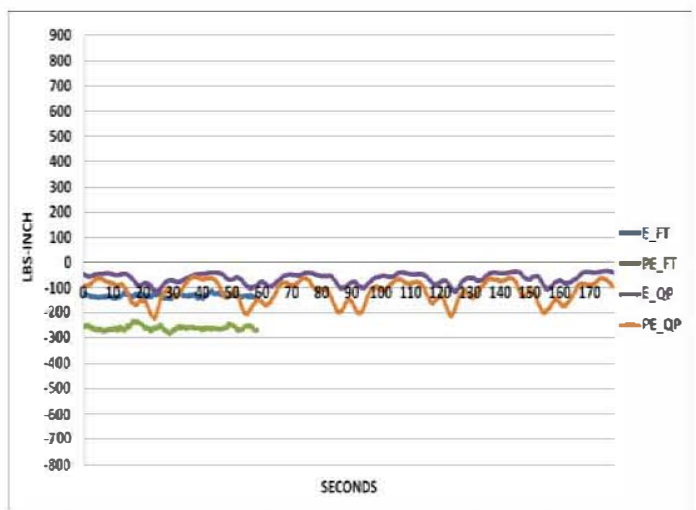

Graph 5.126: Load Cell $3 \mathrm{Mz} \mathrm{30}{ }^{\circ}$ 


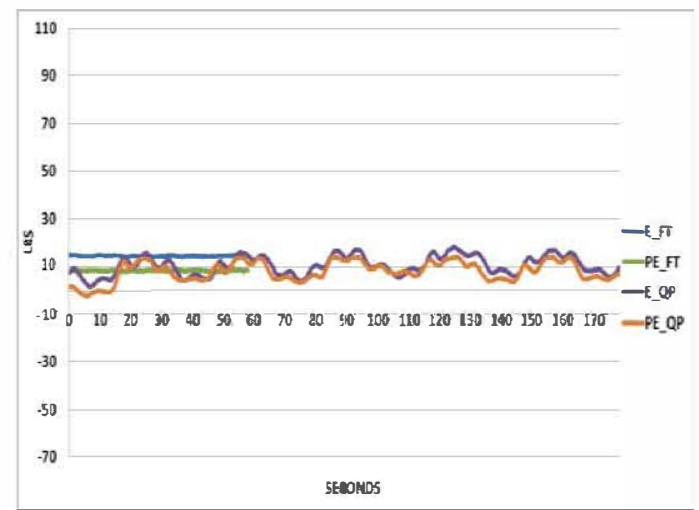

Graph 5.127: Load Cell 4 Fx 30

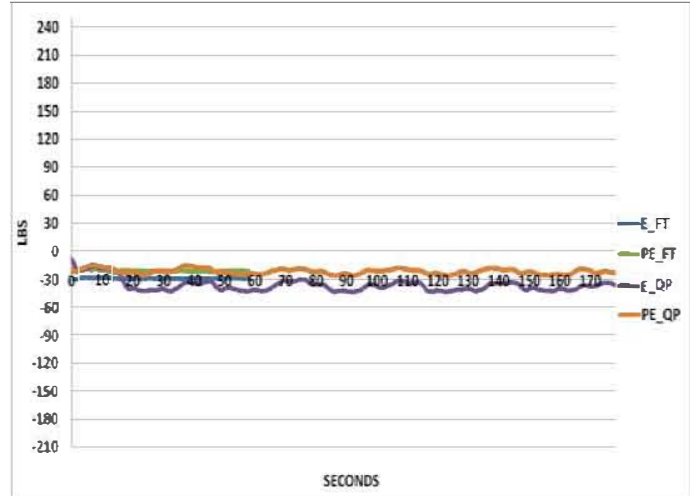

Graph 5.128: Load Cell 4 Fy $30^{\circ}$

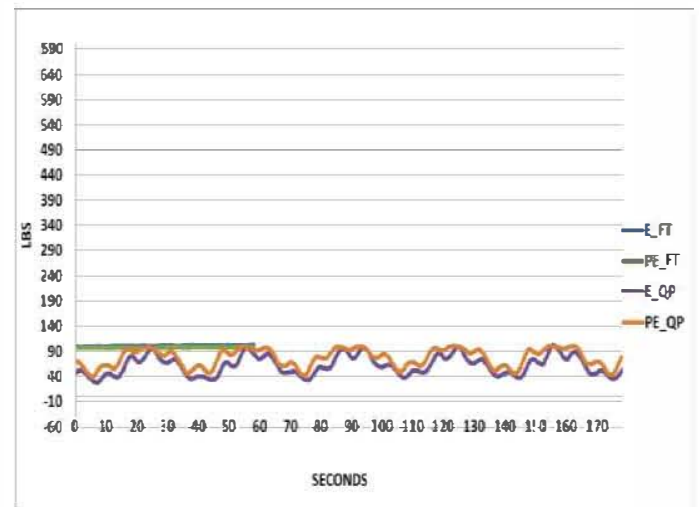

Graph 5.129: Load Cell 4 Fz 30

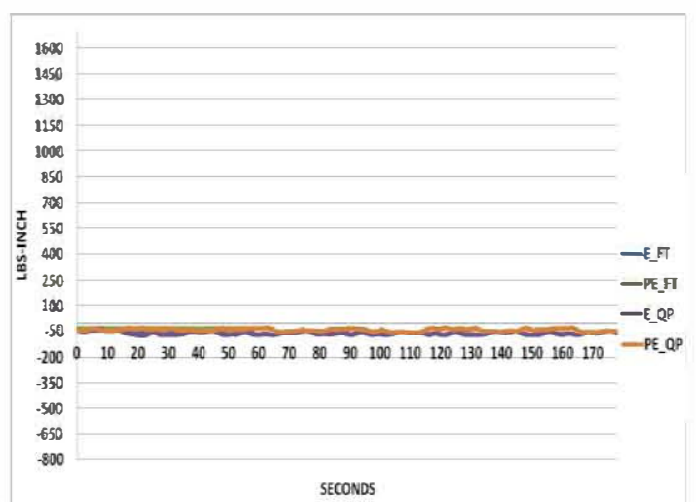

Graph 5.130: Load Cell 4 Mx 30

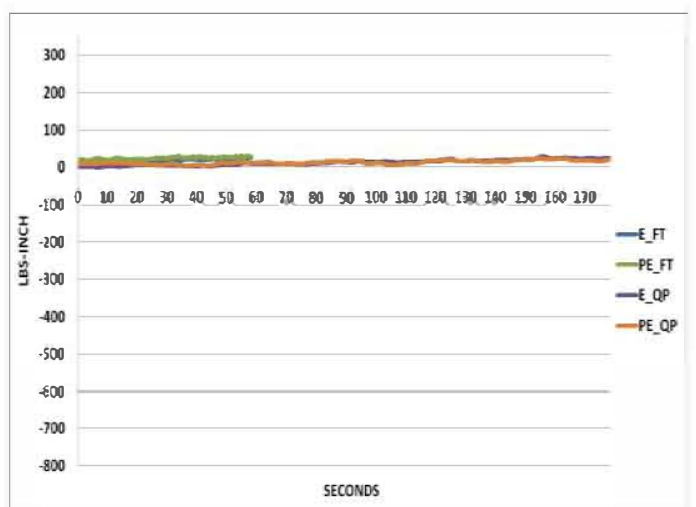

Graph 5.131: Load Cell 4 My 30

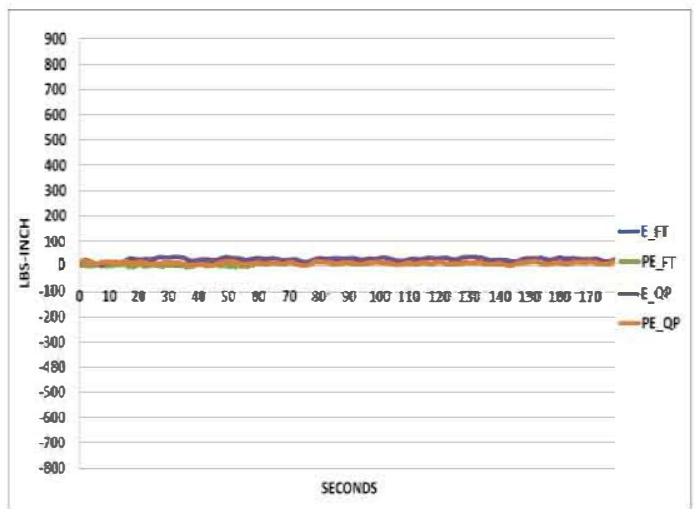

Graph 5.132: Load Cell $4 \mathrm{Mz} 30^{\circ}$ 


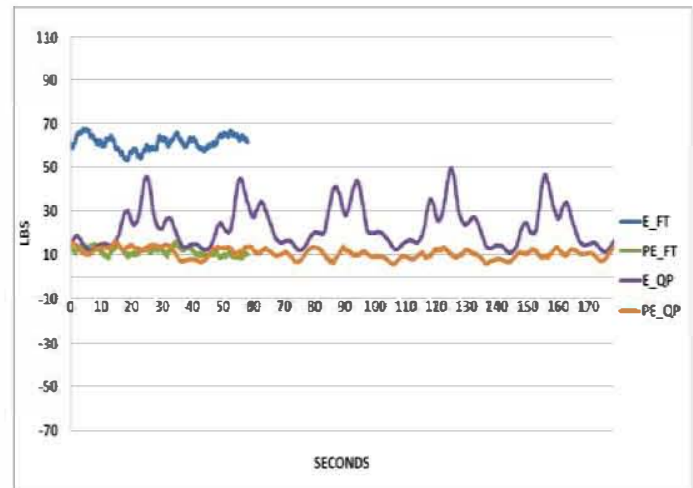

Graph 5.133: Load Cell 5 Fx 30

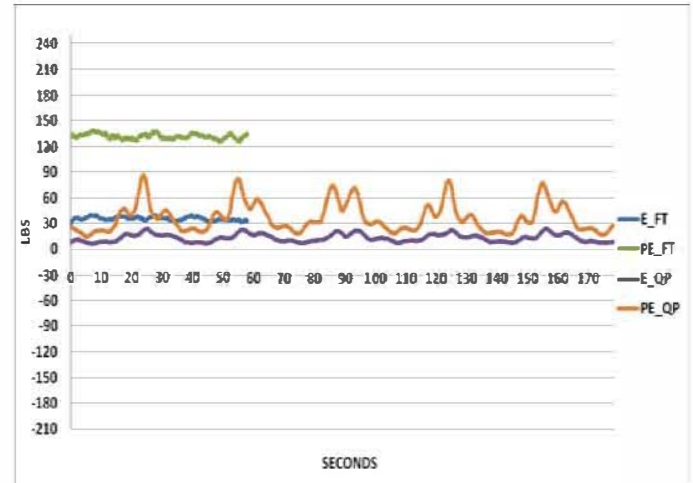

Graph 5.134: Load Cell 5 Fy 30

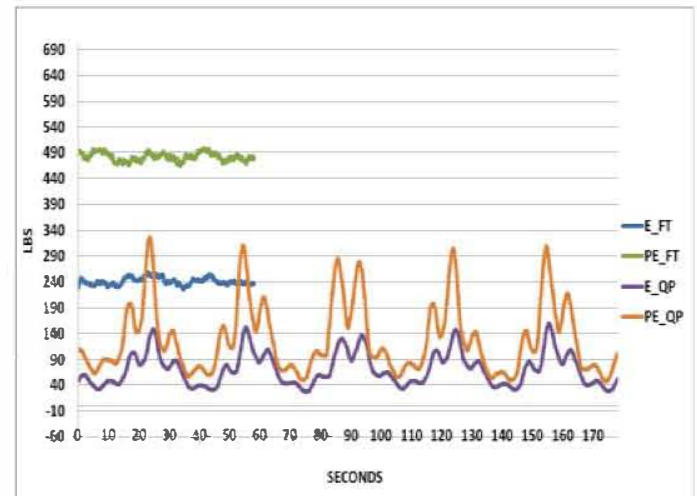

Graph 5.135: Load Cell $5 \mathrm{Fz} \mathrm{30}$

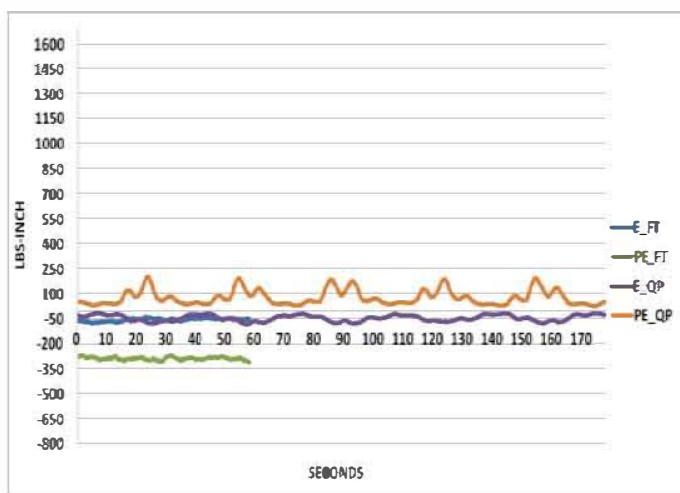

Graph 5.136: Load Cell 5 Mx 30

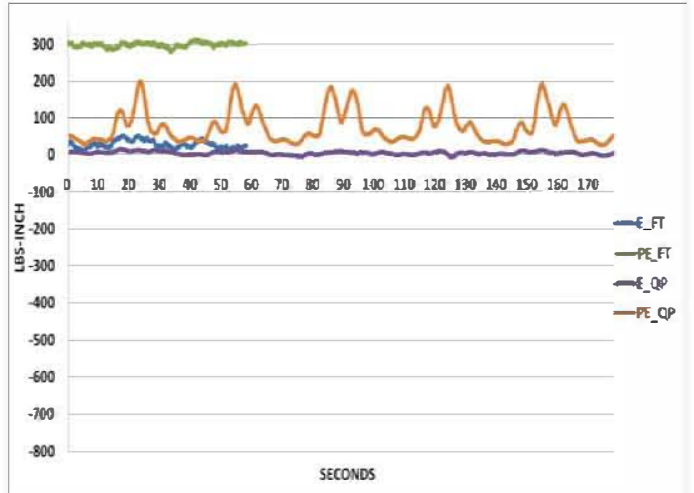

Graph 5.137: Load Cell 5 My 30

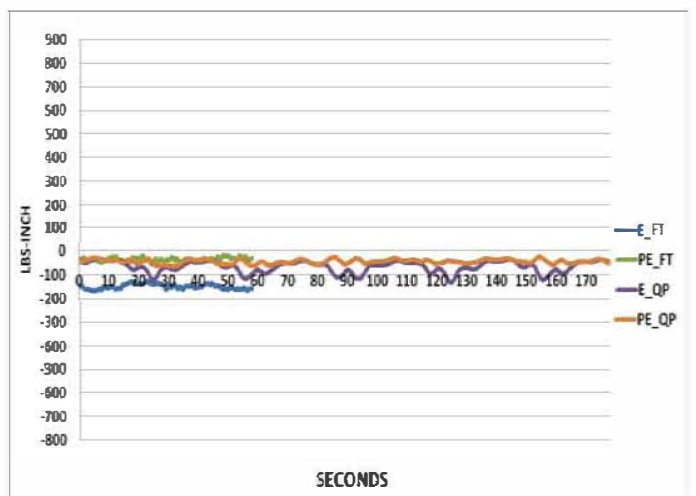

Graph 5.138: Load Cell 5 Mz 30 


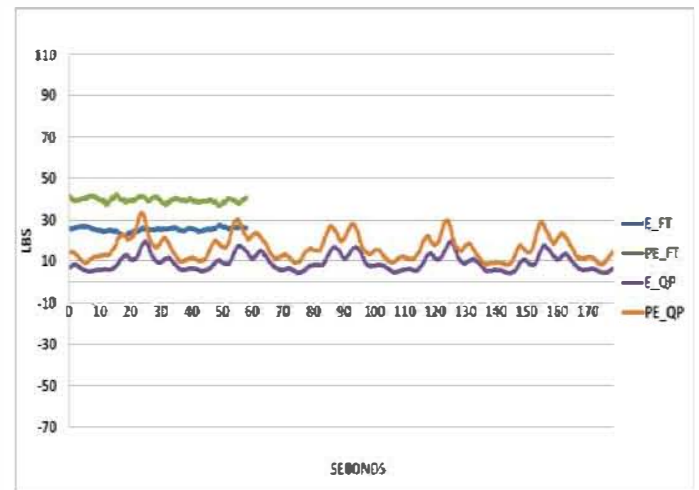

Graph 5.139: Load Cell 6 Fx 30

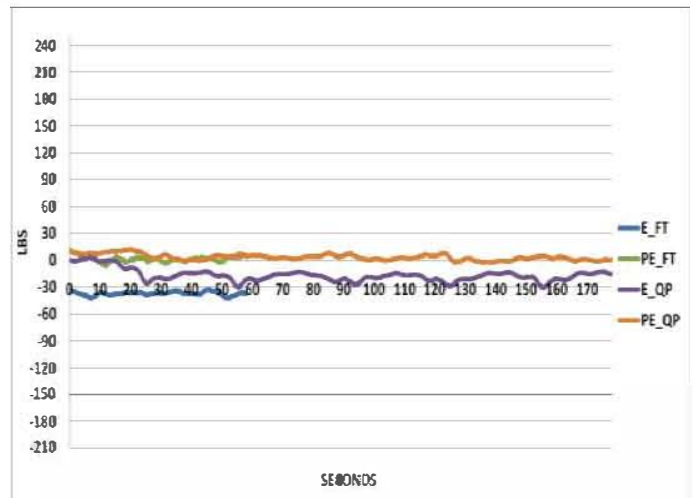

Graph 5.140: Load Cell 6 Fy 30

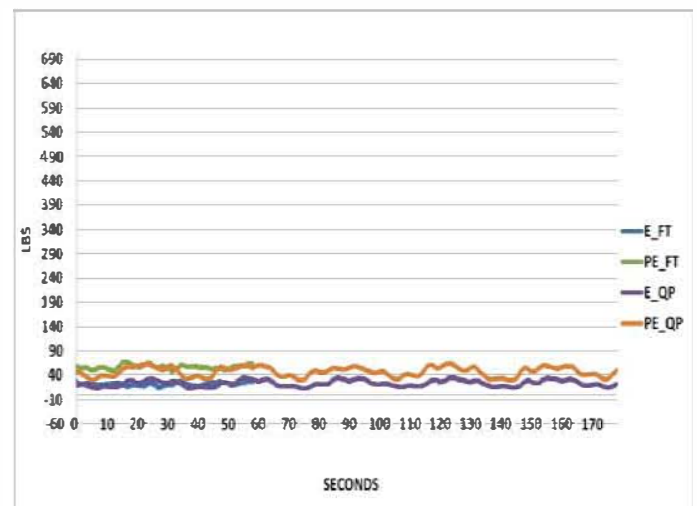

Graph 5.141: Load Cell 6 Fz 30

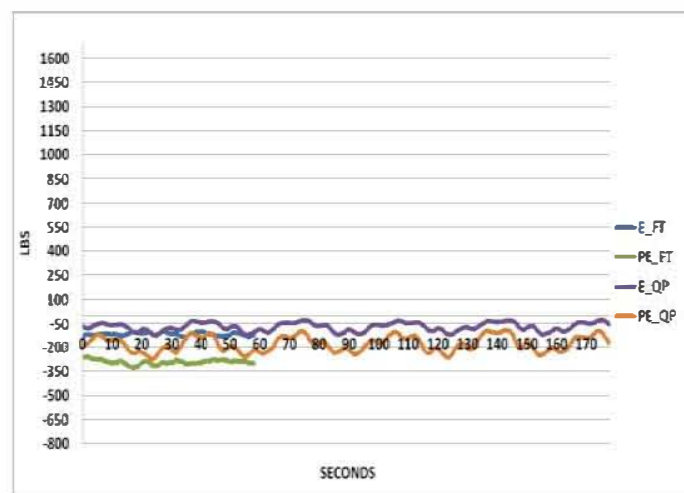

Graph 5.142: Load Cell $6 \mathrm{Mx} \mathrm{30^{ \circ }}$

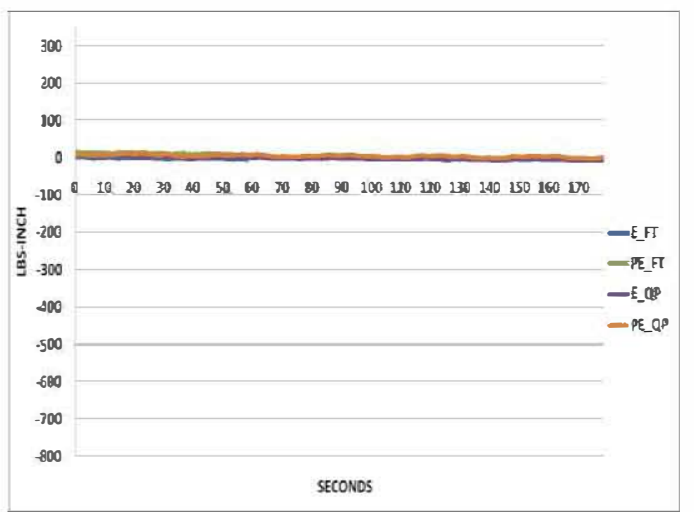

Graph 5.143: Load Cell 6 My 30

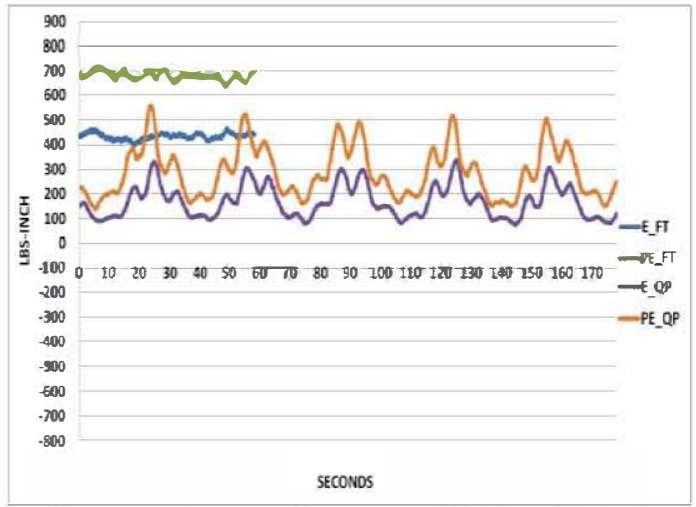

Graph 5.144: Load Cell $6 \mathrm{Mz} 30^{\circ}$ 


\subsubsection{Load Cell Results from Phase V Testing}

The load cell results plotted as graphs for all the tests under Phase $\mathrm{V}$ are shown below.

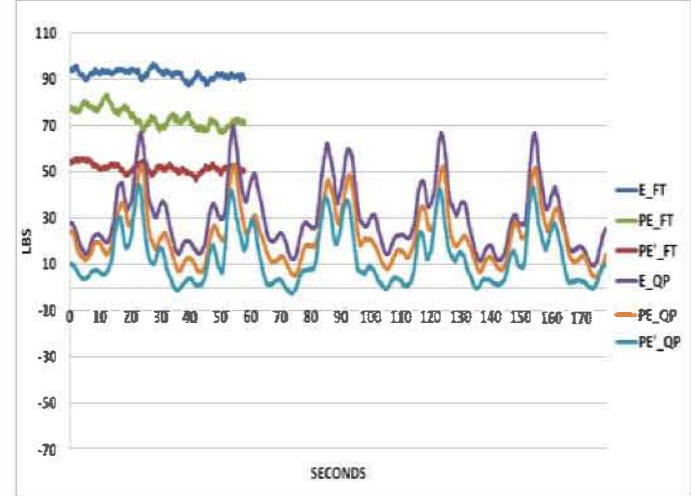

Graph 5.145: Load Cell 1 Fx $60^{\circ}$

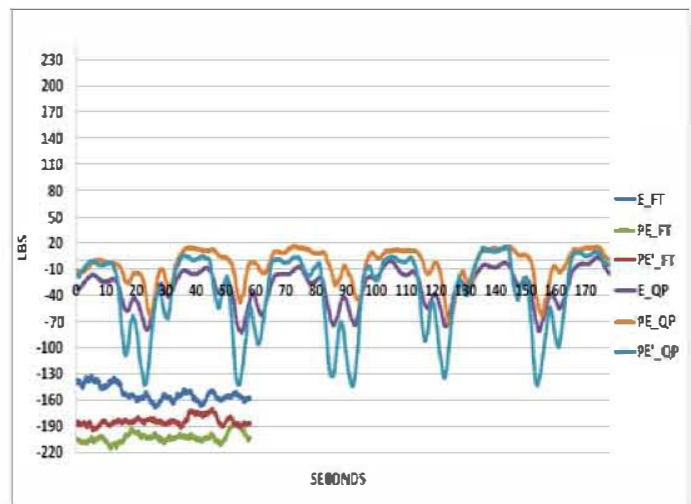

Graph 5.146: Load Cell 1 Fy 60

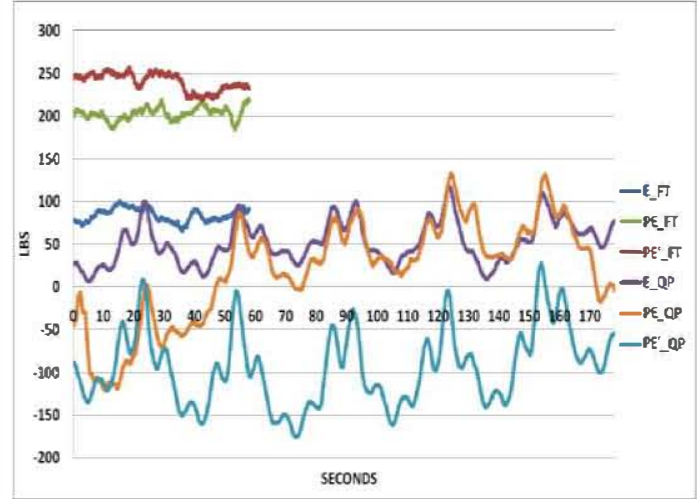

Graph 5.147: Load Cell 1 Fz 60

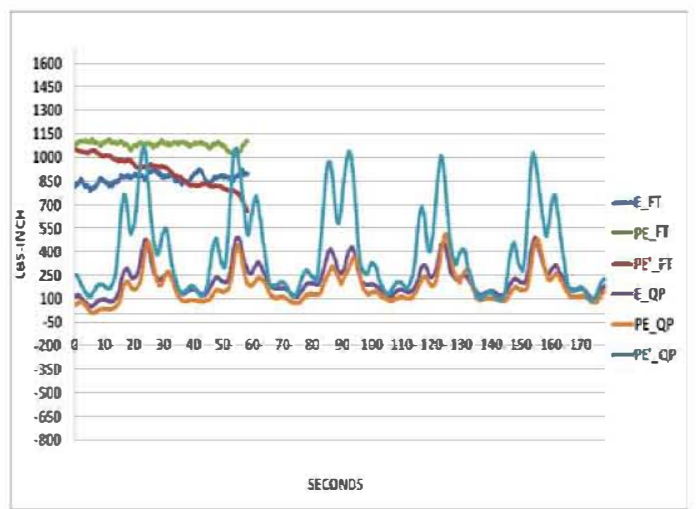

Graph 5.148: Load Cell $1 \mathrm{Mx} \mathrm{60^{ \circ }}$

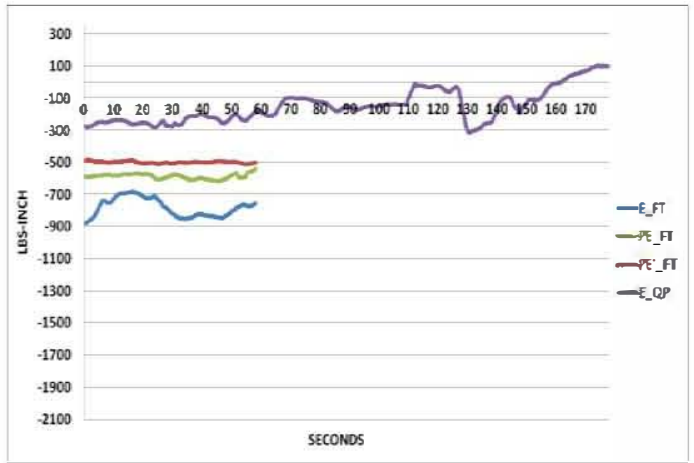

Graph 5.149: Load Cell $1 \mathrm{My} \mathrm{60}$ NOTE: PE_QP \& PE'_QP Data Error

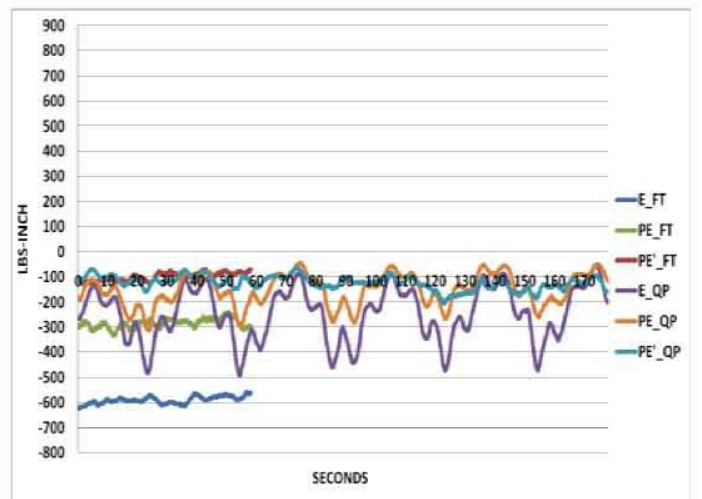

Graph 5.150: Load Cell $1 \mathrm{Mz} 60^{\circ}$ 


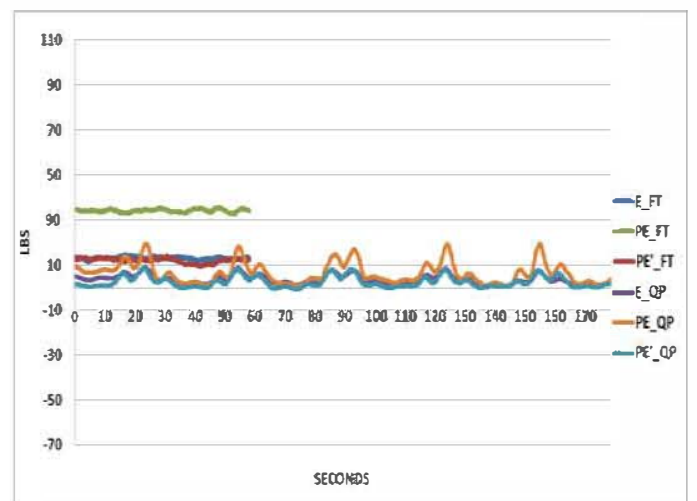

Graph 5.151: Load Cell 2 Fx 60

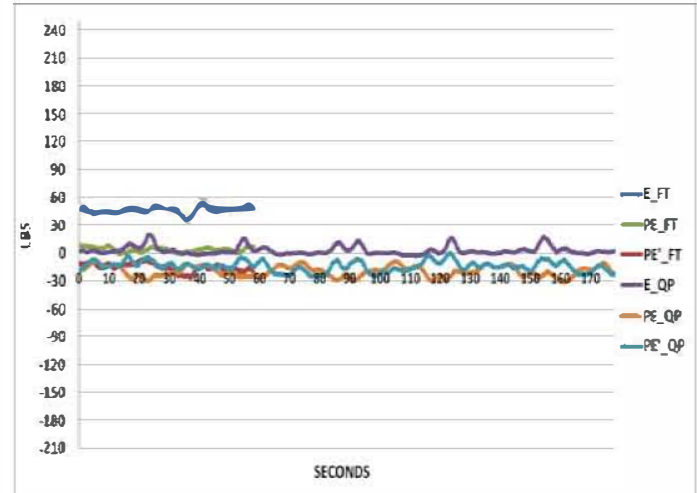

Graph 5.152: Load Cell 2 Fy $60^{\circ}$

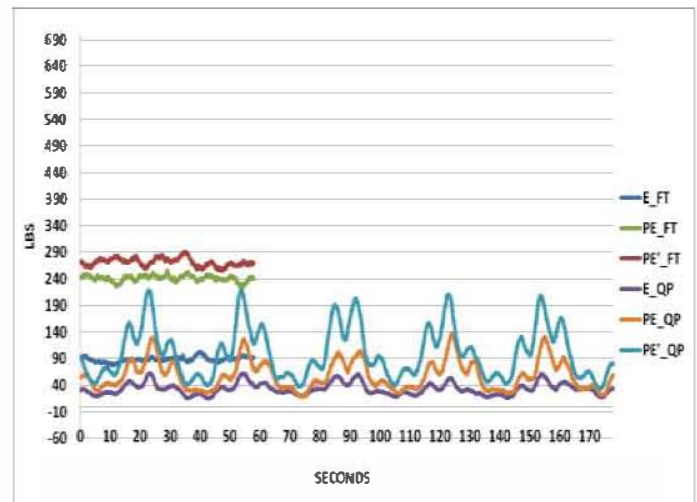

Graph 5.153: Load Cell 2 Fz 60

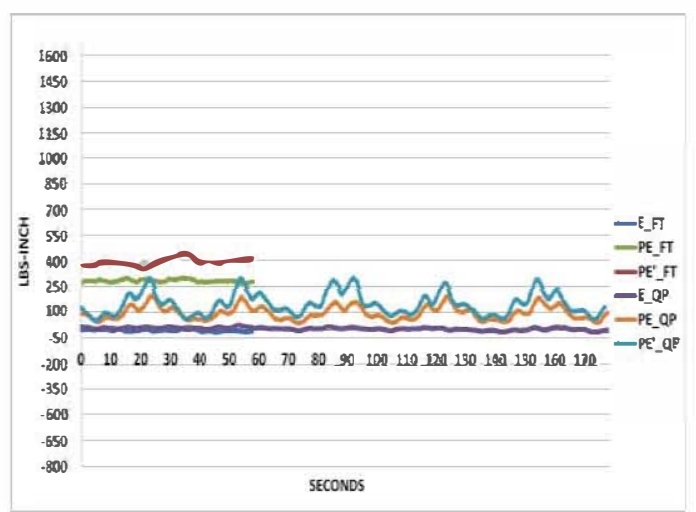

Graph 5.154: Load Cell 2 Mx 60

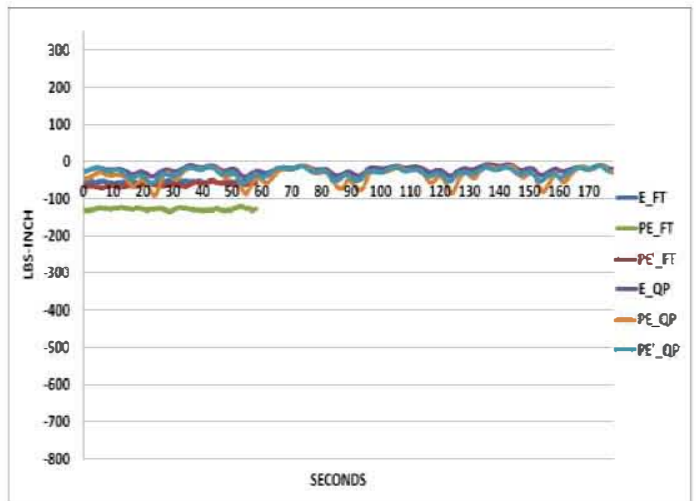

Graph 5.155: Load Cell 2 My 60

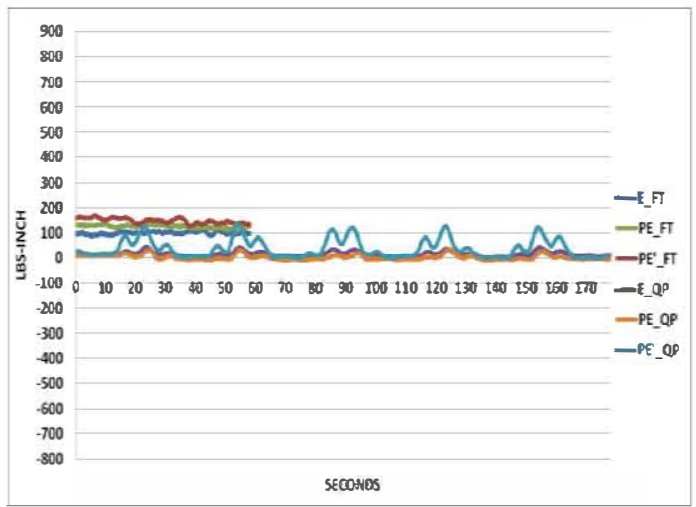

Graph 5.156: Load Cell $2 \mathrm{Mz} 60^{\circ}$ 


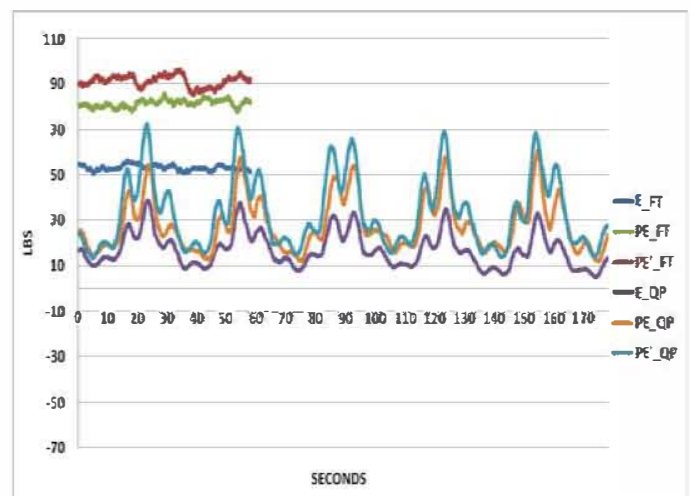

Graph 5.157: Load Cell 3 Fx 60

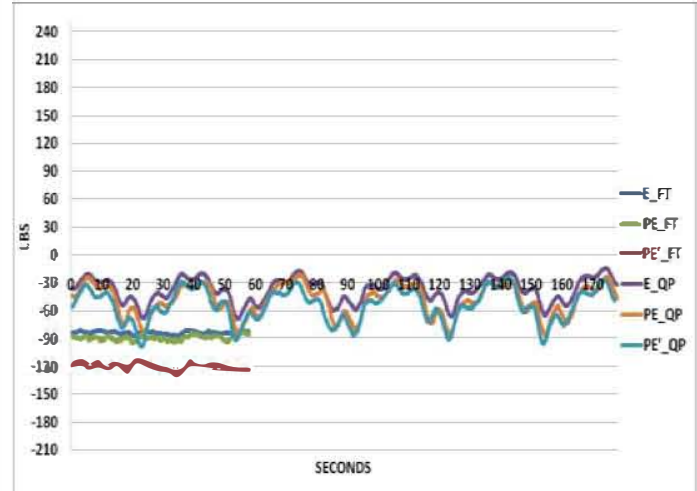

Graph 5.158: Load Cell 3 Fy 60 $^{\circ}$

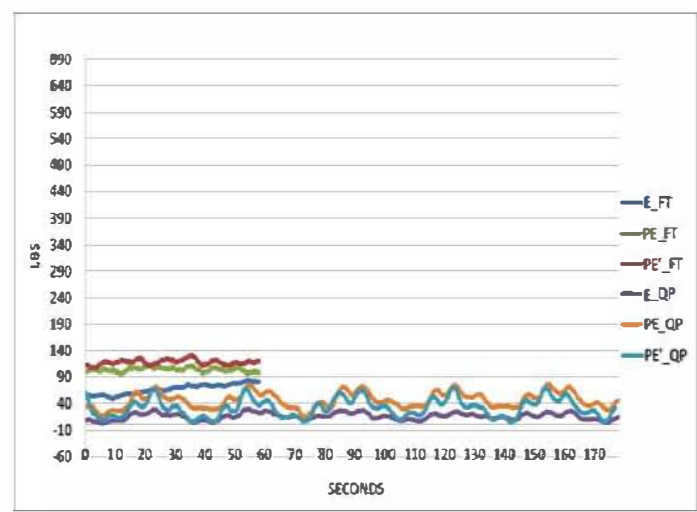

Graph 5.159: Load Cell 3 Fz 60 ${ }^{\circ}$

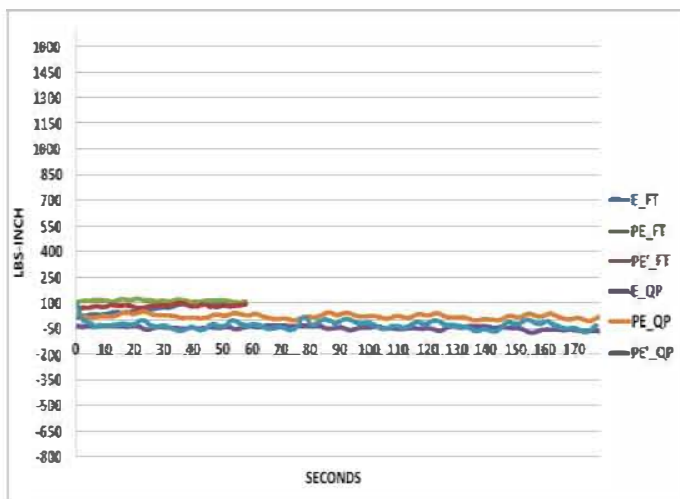

Graph 5.160: Load Cell 3 Mx 60

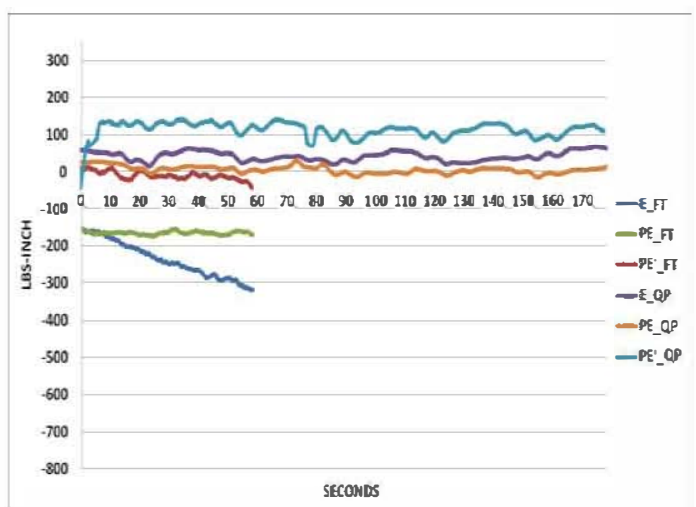

Graph 5.161: Load Cell 3 My 60

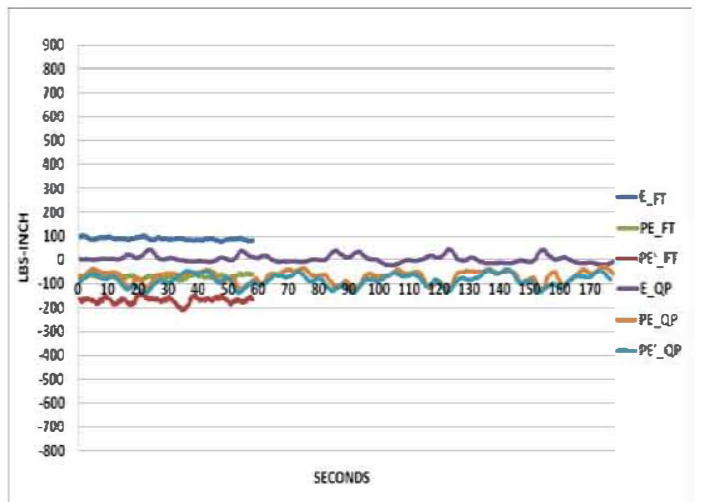

Graph 5.162: Load Cell $3 \mathrm{Mz} 60^{\circ}$ 


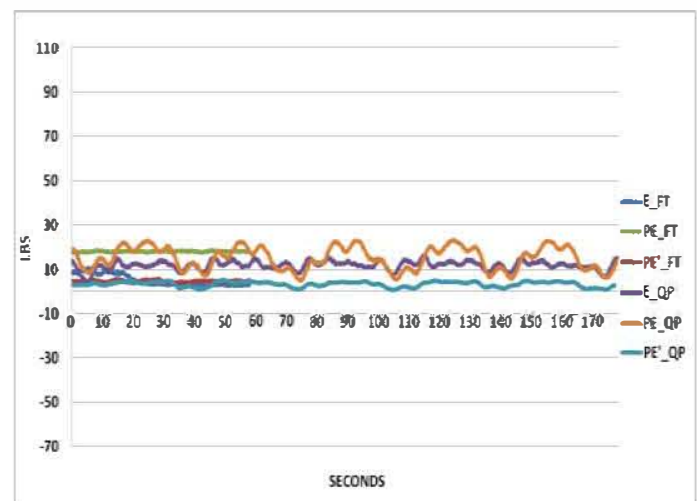

Graph 5.163: Load Cell 4 Fx 60

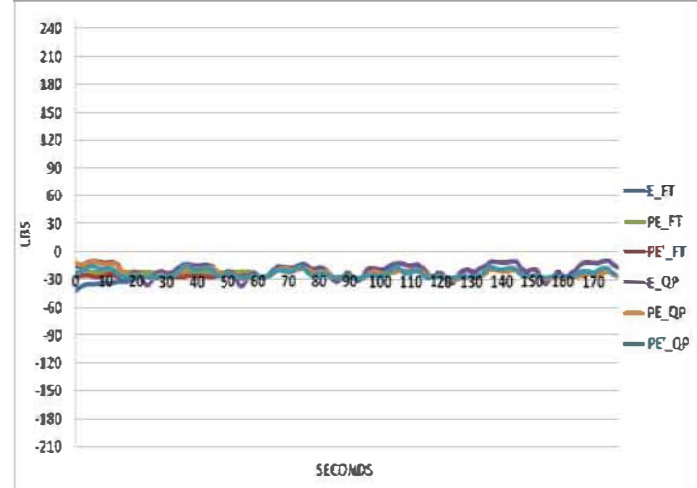

Graph 5.164: Load Cell 4 Fy $60^{\circ}$

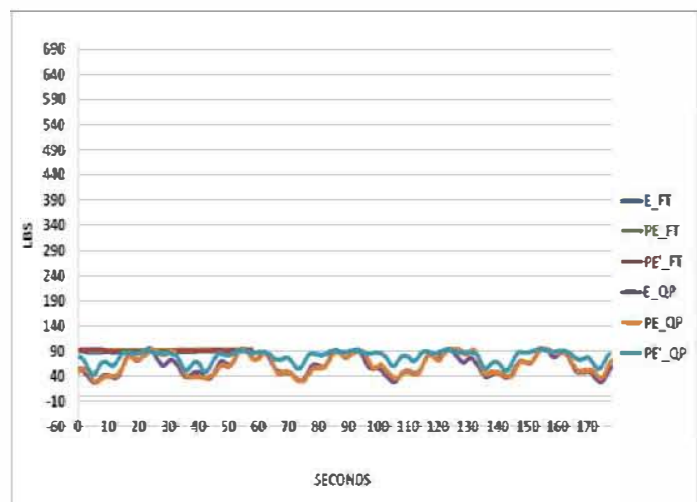

Graph 5.165: Load Cell 4 Fz 60 ${ }^{\circ}$

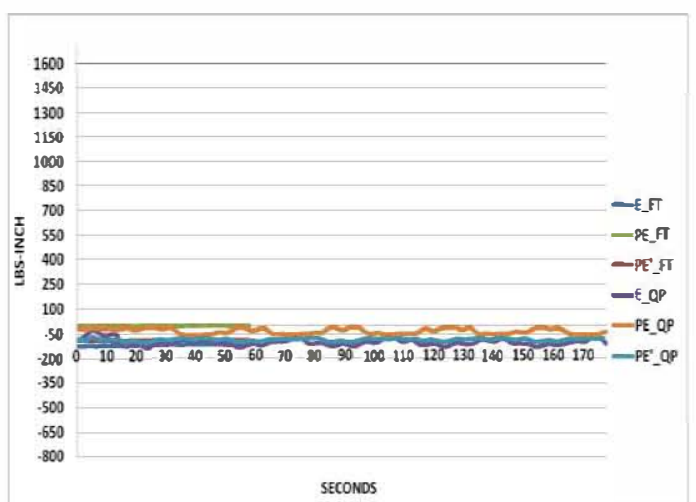

Graph 5.166: Load Cell $4 \mathrm{Mx}$ 60 $^{\circ}$

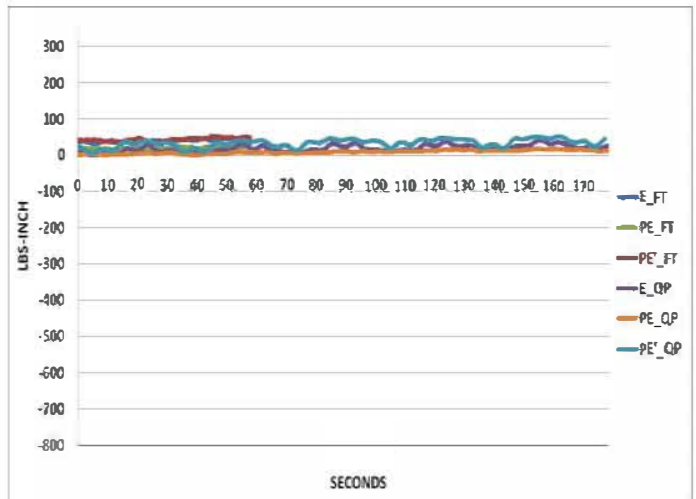

Graph 5.167: Load Cell 4 My 60

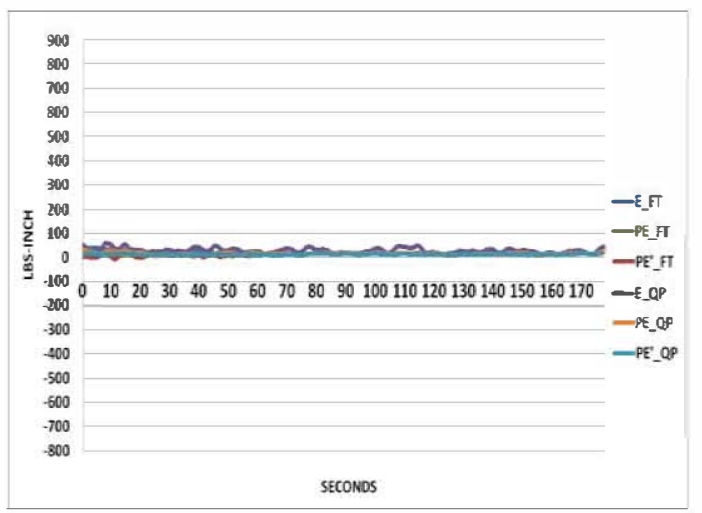

Graph 5.168: Load Cell $4 \mathrm{Mz} \mathrm{60}^{\circ}$ 


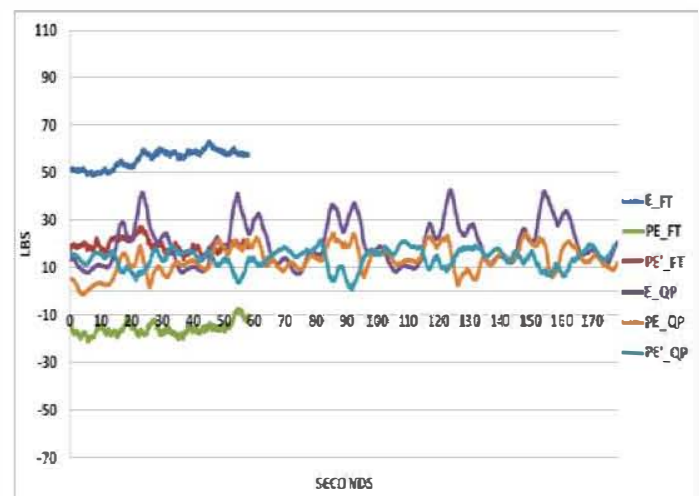

Graph 5.169: Load Cell 5 Fx 60

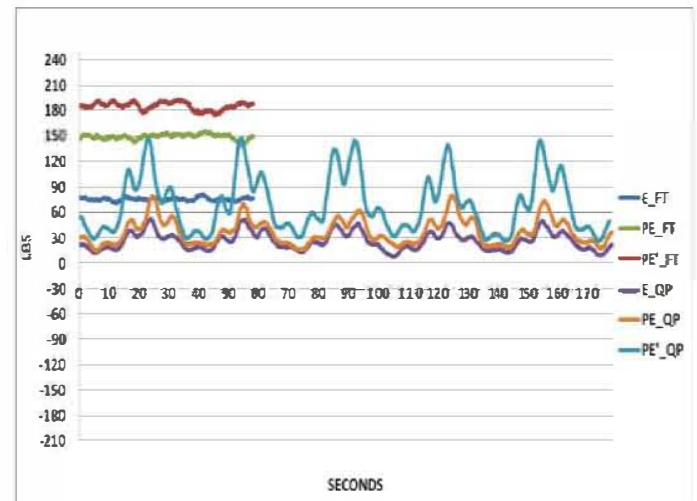

Graph 5.170: Load Cell 5 Fy $6^{\circ}$

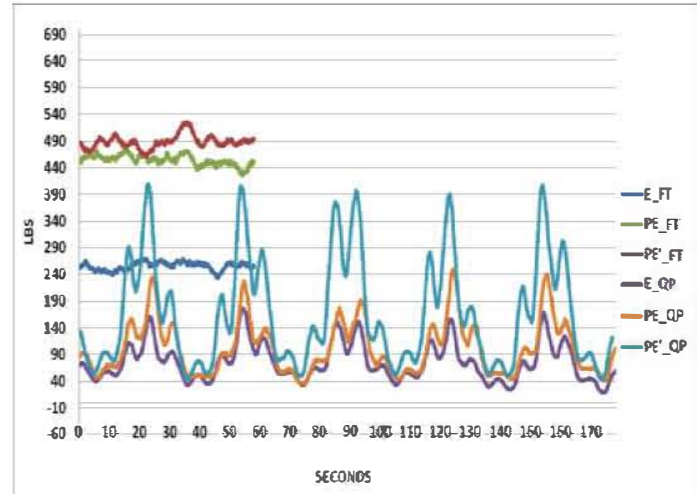

Graph 5.171: Load Cell 5 Fz 60

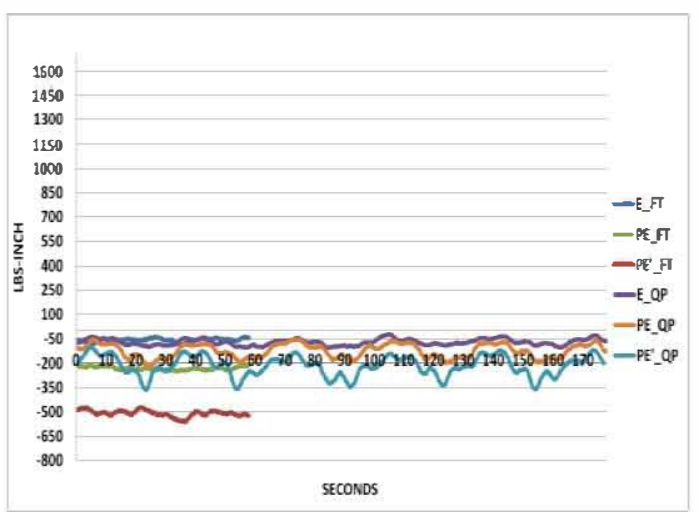

Graph 5.172: Load Cell 5 Mx 60

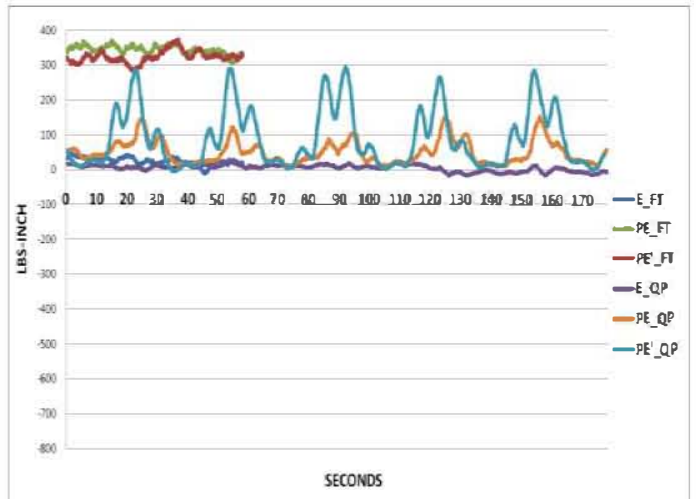

Graph 5.173: Load Cell 5 My 60

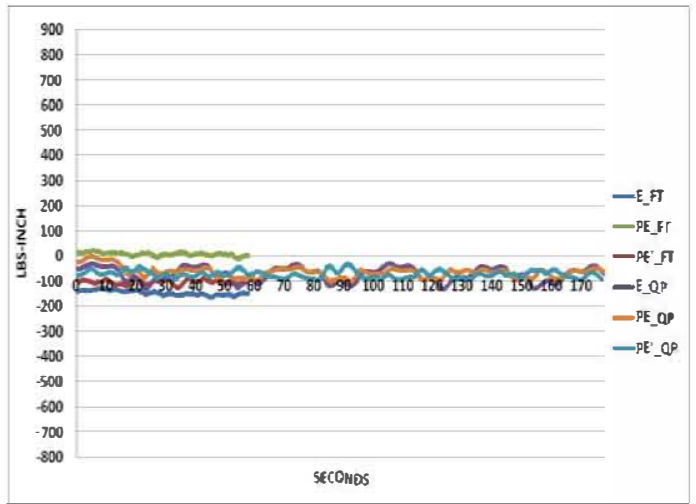

Graph 5.174: Load Cell 5 Mz 60 


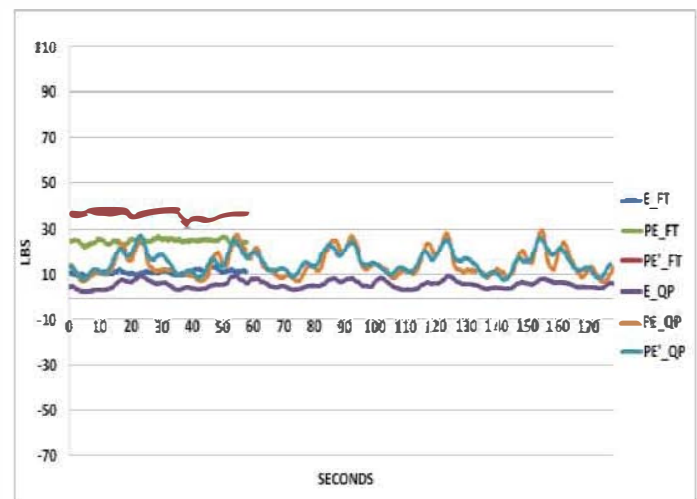

Graph 5.175: Load Cell 6 Fx 60

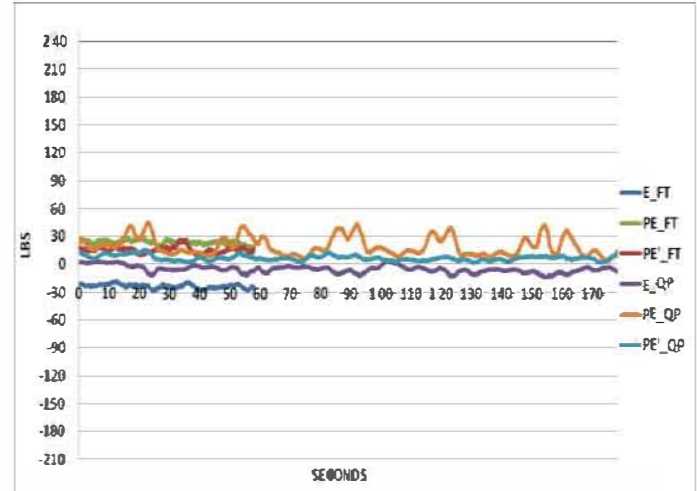

Graph 5.176: Load Cell 6 Fy 60

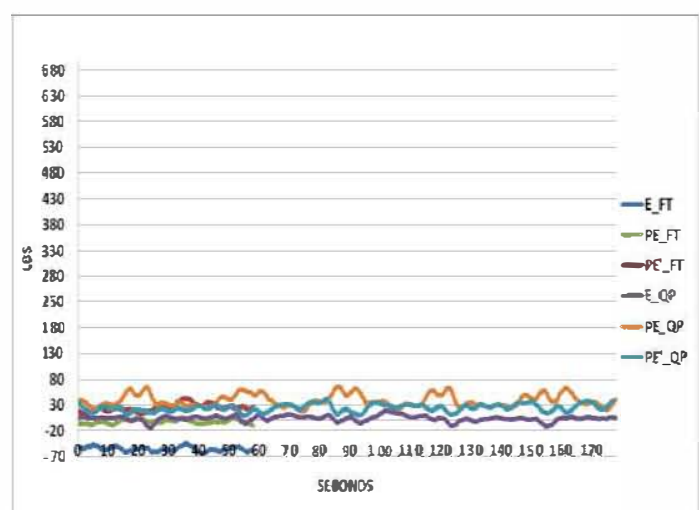

Graph 5.177: Load Cell 6 Fz 60

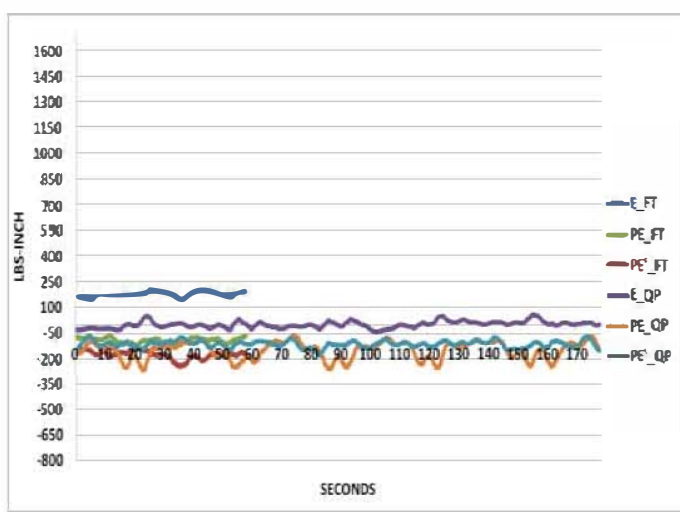

Graph 5.178: Load Cell $6 \mathrm{Mx} \mathrm{60^{ \circ }}$

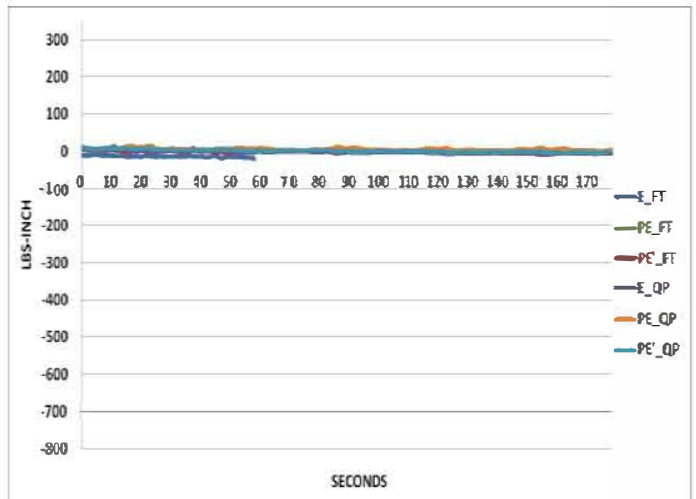

Graph 5.179: Load Cell 6 My 60

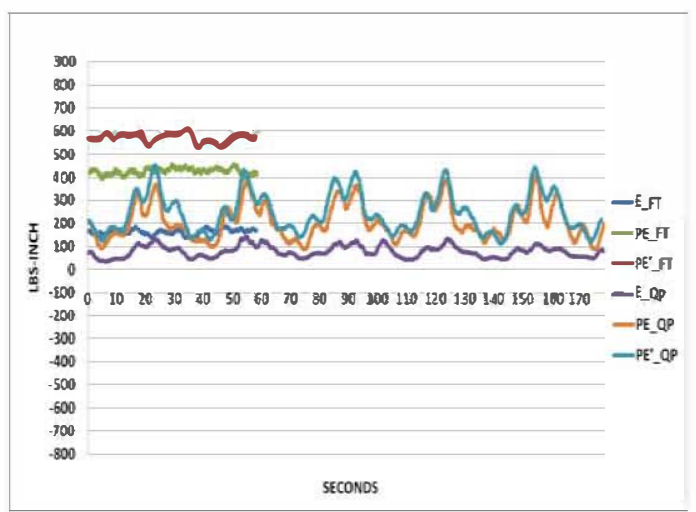

Graph 5.180: Load Cell $6 \mathrm{Mz} \mathrm{60}^{\circ}$ 


\subsubsection{Bar Graphs with Mean Results of All Conditions in Load Cell I}

Based on the loading time histories mean forces and moments were calculated and plotted as bar graphs as shown below.

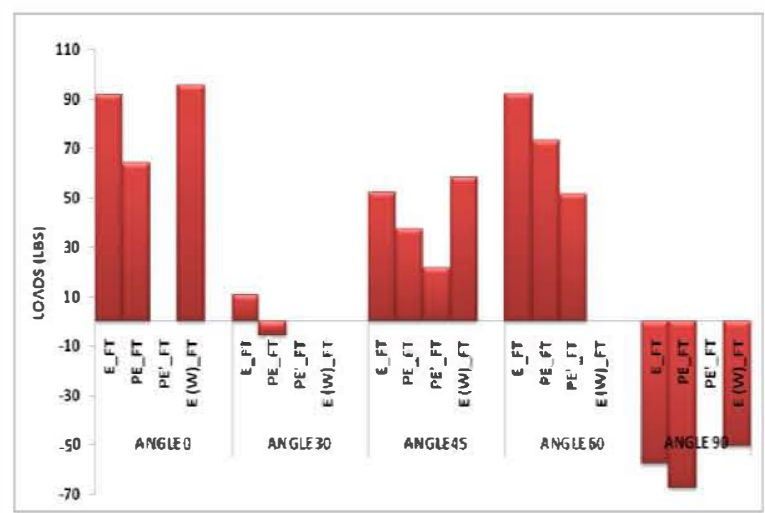

Graph 5.181: Load Cell 1 All Angles and Conditions Fx_FT

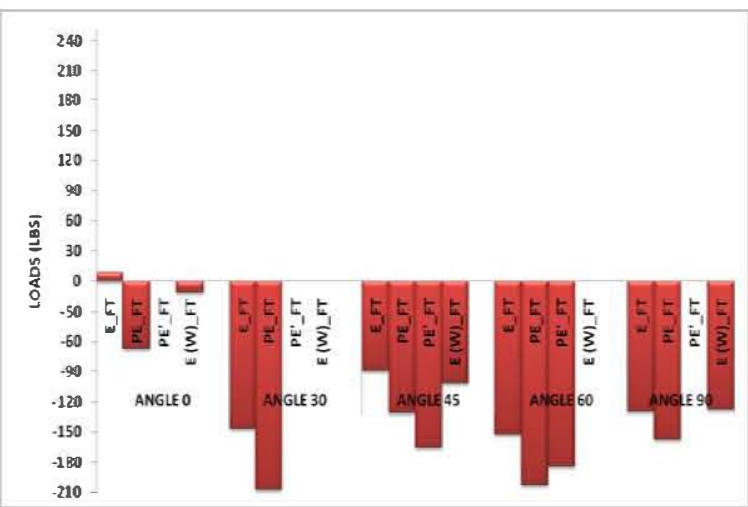

Graph 5.182: Load Cell 1 All Angles and Conditions Fy_FT

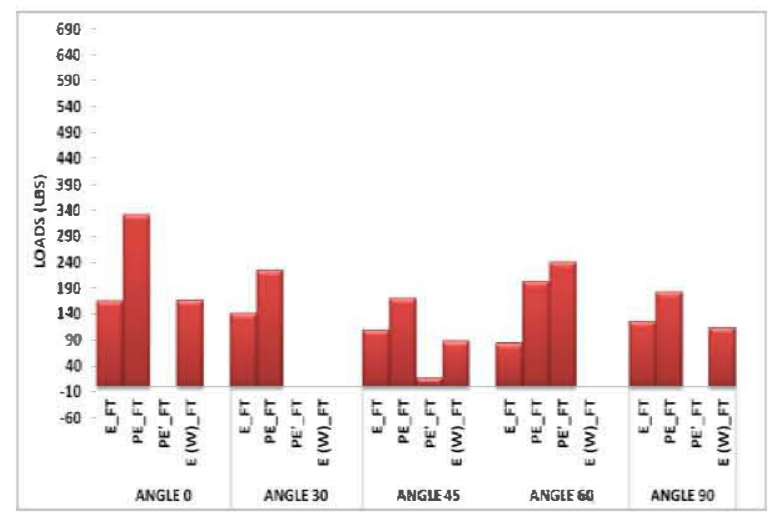

Graph 5.183: Load Cell 1 All Angles and Conditions Fz_FT 


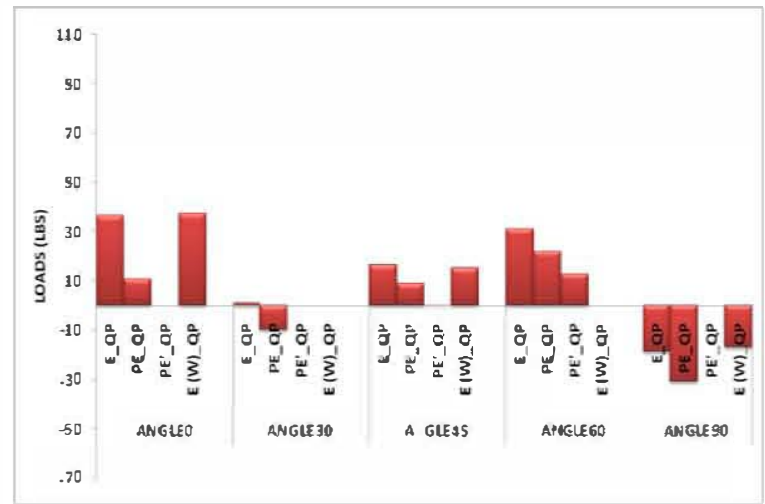

Graph 5.184: Load Cell 1 All Angles and Conditions Fx_QP

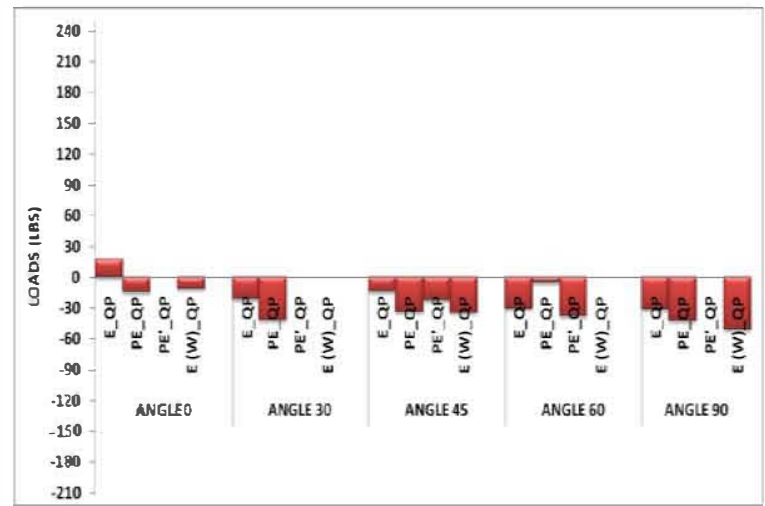

Graph 5.185: Load Cell 1 All Angles and Conditions Fy_QP

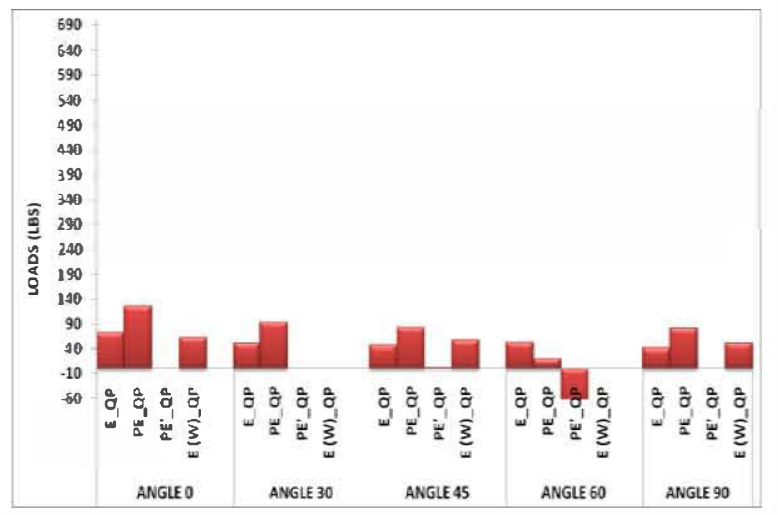

Graph 5.186: Load Cell 1 All Angles and Conditions Fz_QP 


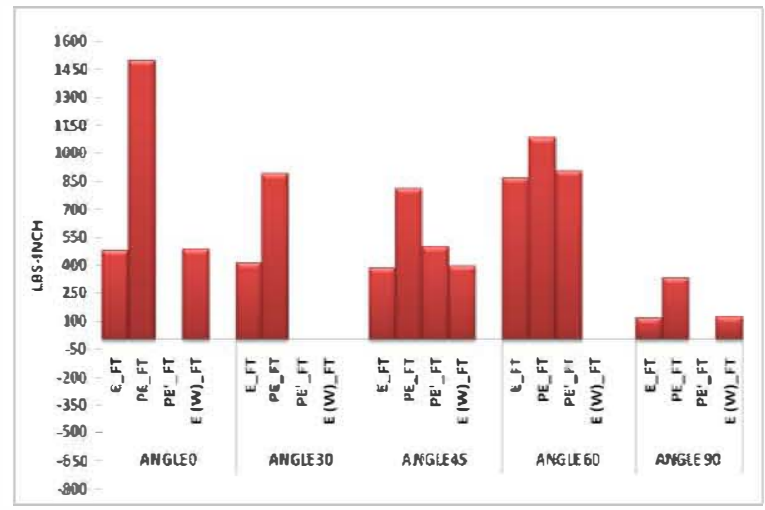

Graph 5.187: Load Cell 1 All Angles and Conditions Mx_FT

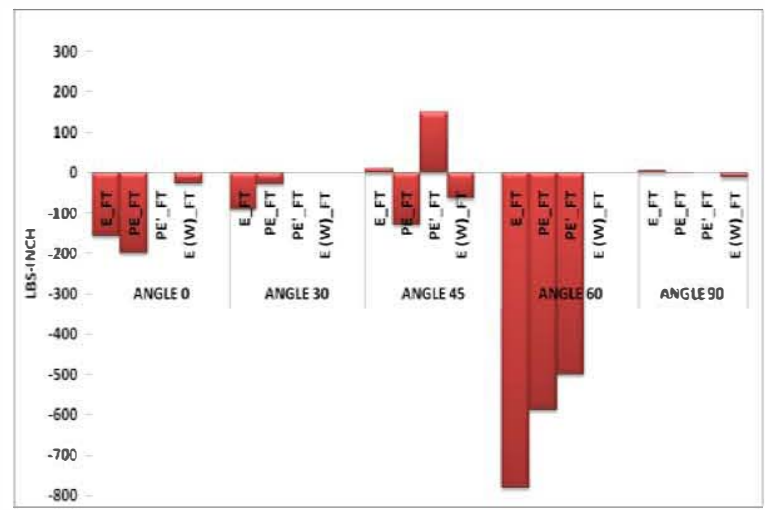

Graph 5.188: Load Cell 1 All Angles and Conditions My_FT

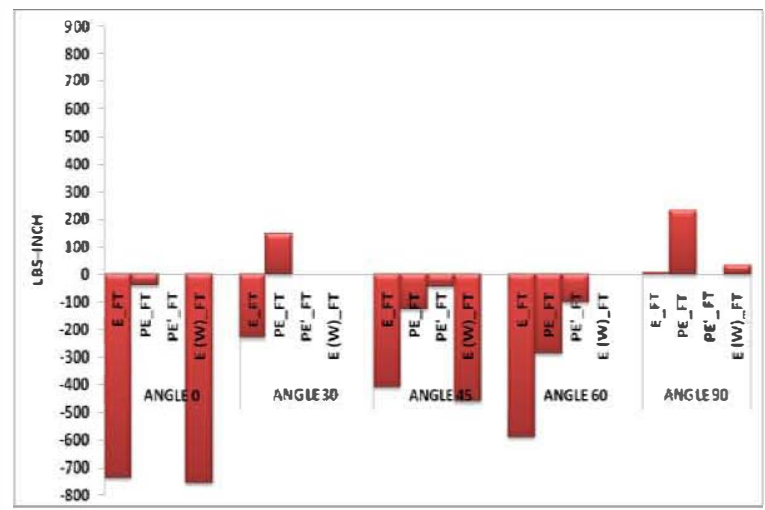

Graph 5.189: Load Cell 1 All Angles and Conditions Mz_FT 


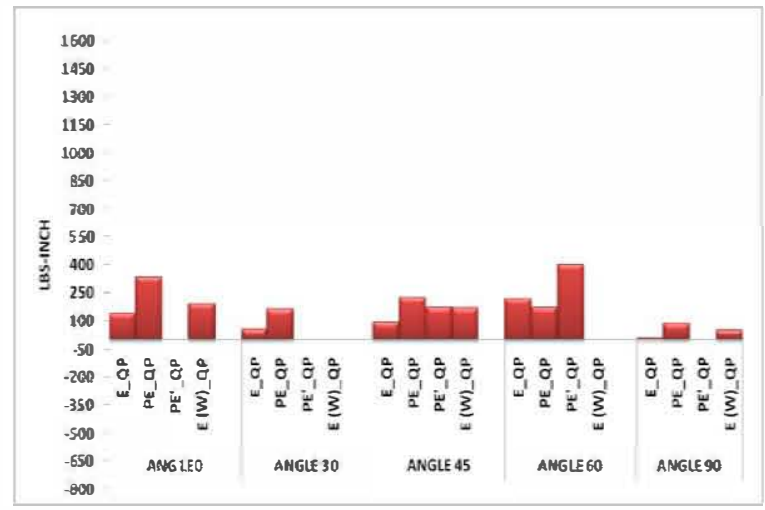

Graph 5.190: Load Cell 1 All Angles and Conditions Mx_QP

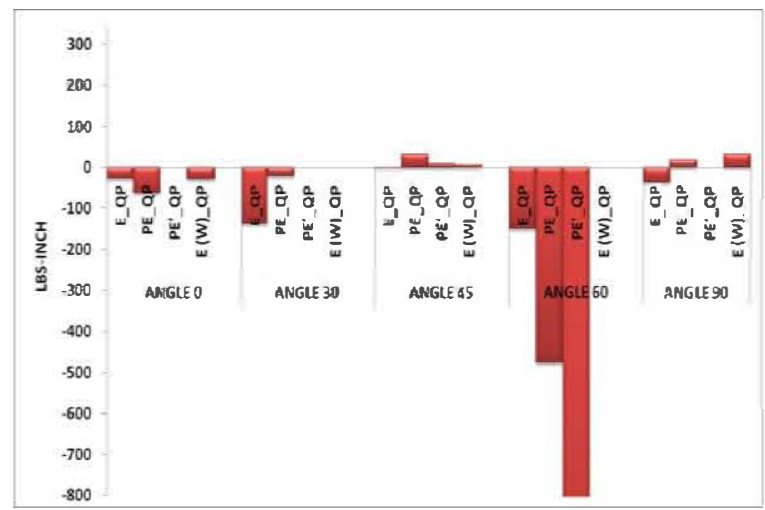

Graph 5.191: Load Cell 1 All Angles and Conditions My_QP

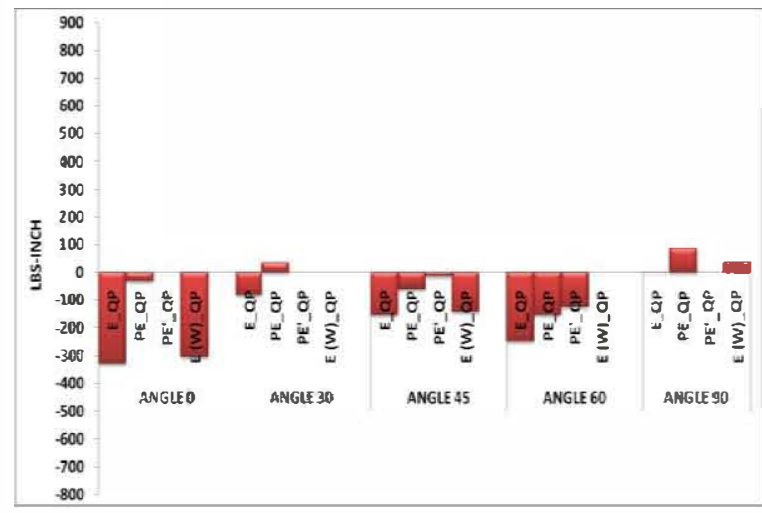

Graph 5.192: Load Cell 1 All Angles and Conditions Mz_QP 


\subsubsection{Bar Graphs with Mean Results of All Conditions in Load Cell 2}

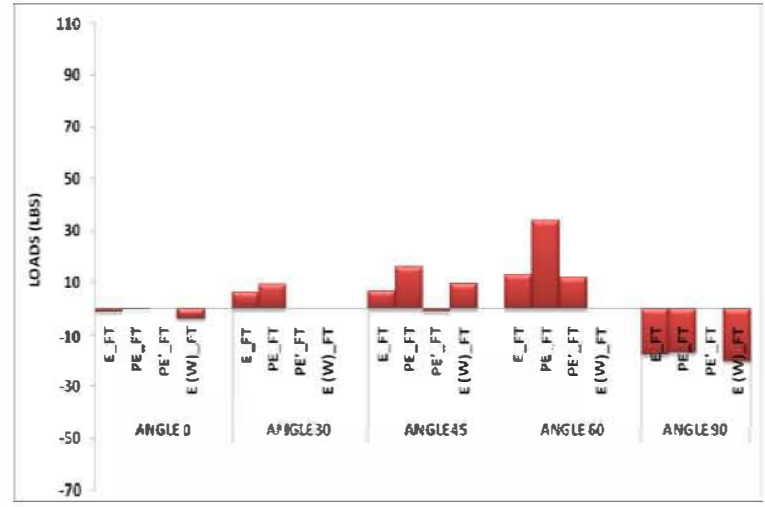

Graph 5.193: Load Cell 2 All Angles and Conditions Fx_FT

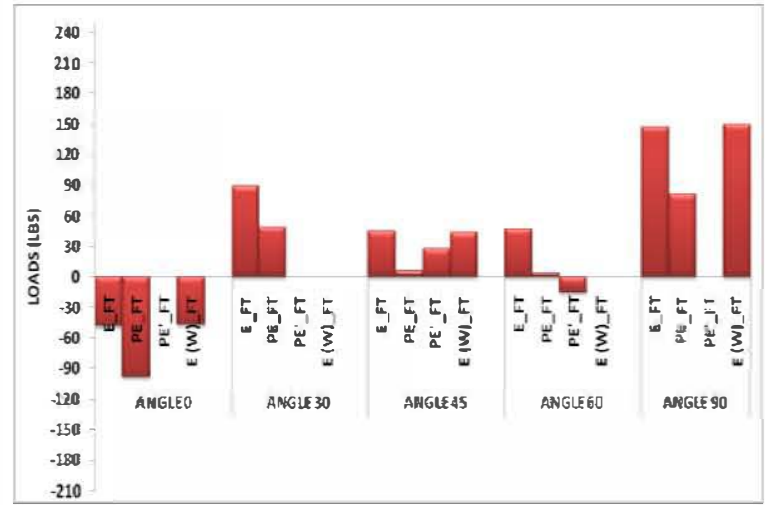

Graph 5.194: Load Cell 2 All Angles and Conditions Fy_FT

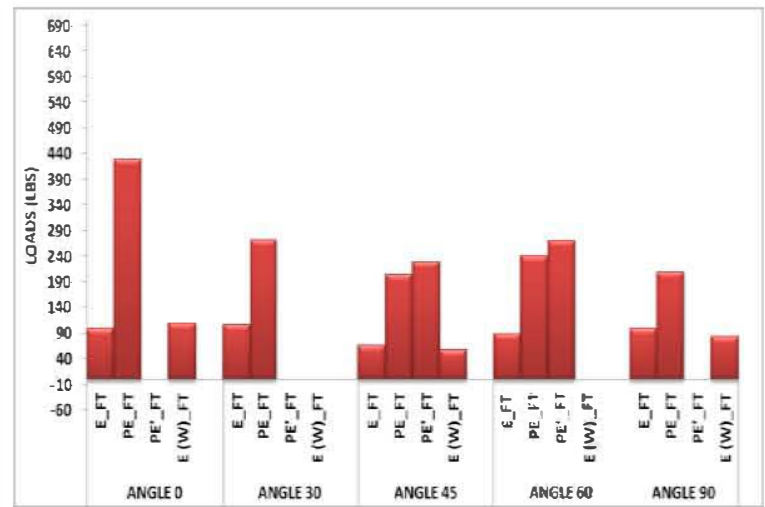

Graph 5.195: Load Cell 2 All Angles and Conditions Fz_FT 


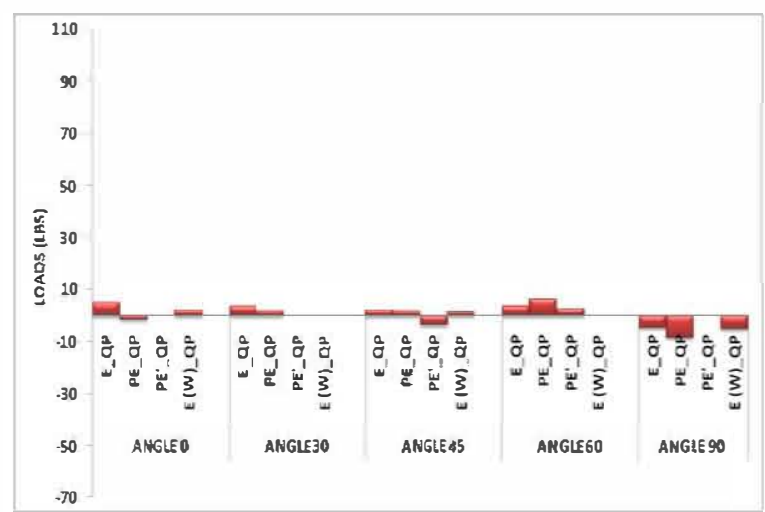

Graph 5.196: Load Cell 2 All Angles and Conditions Fx_QP

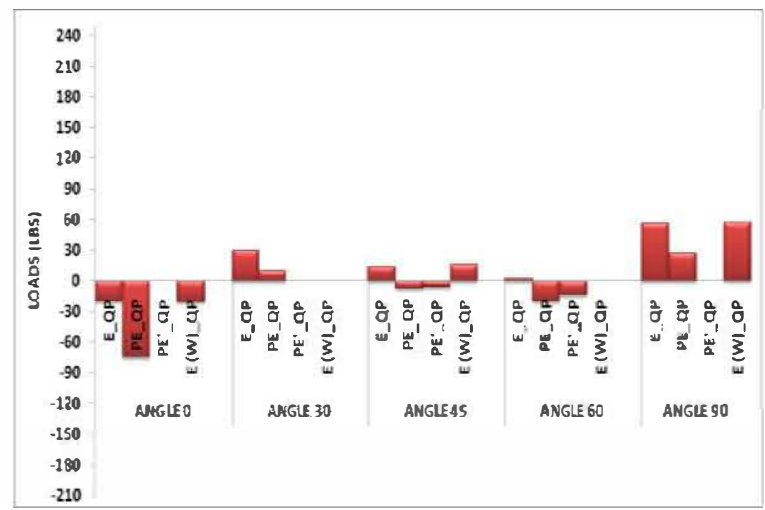

Graph 5.197: Load Cell 2 All Angles and Conditions Fy_QP

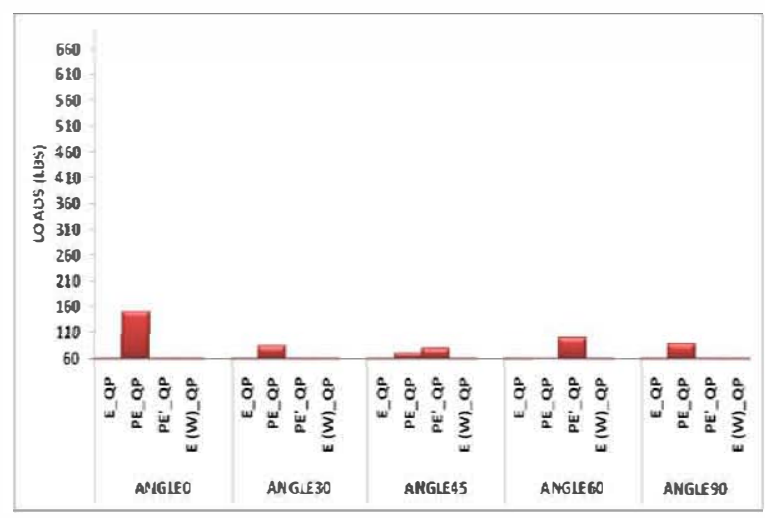

Graph 5.198: Load Cell 2 All Angles and Conditions Fz_QP 


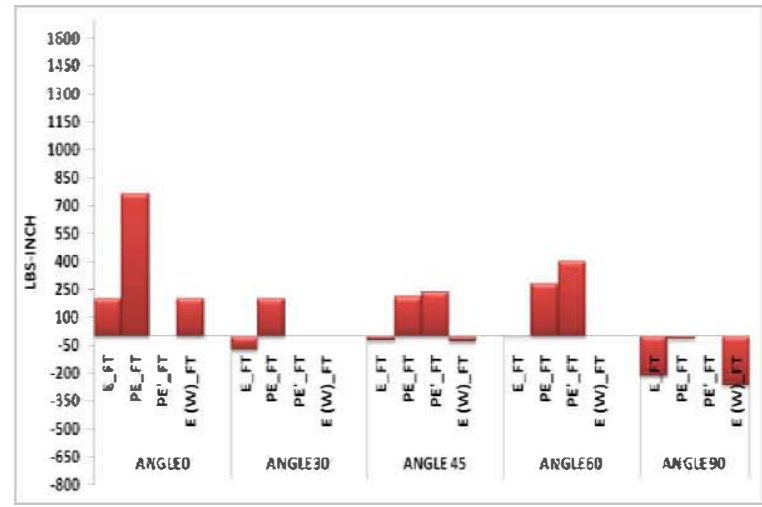

Graph 5.199: Load Cell 2 All Angles and Conditions Mx_FT

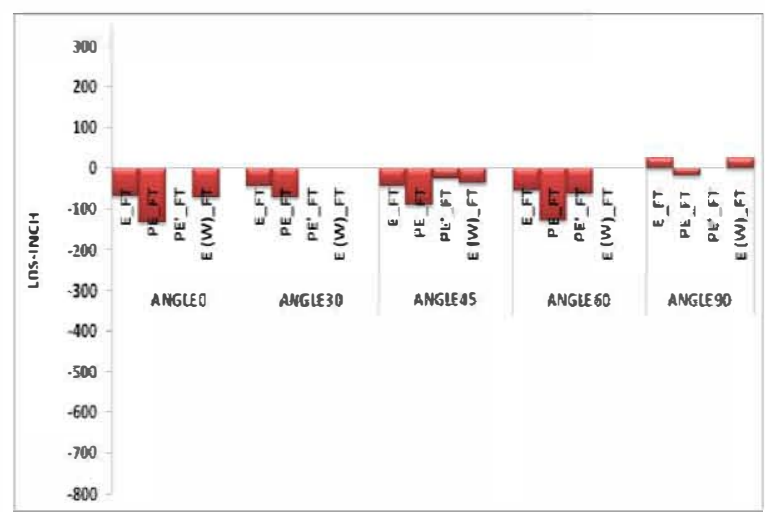

Graph 5.200: Load Cell 2 All Angles and Conditions My_FT

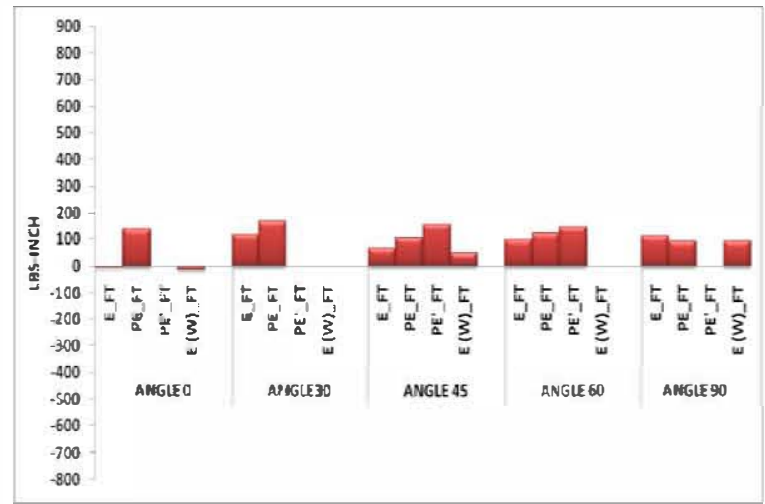

Graph 5.201: Load Cell 2 All Angles and Conditions Mz_FT 


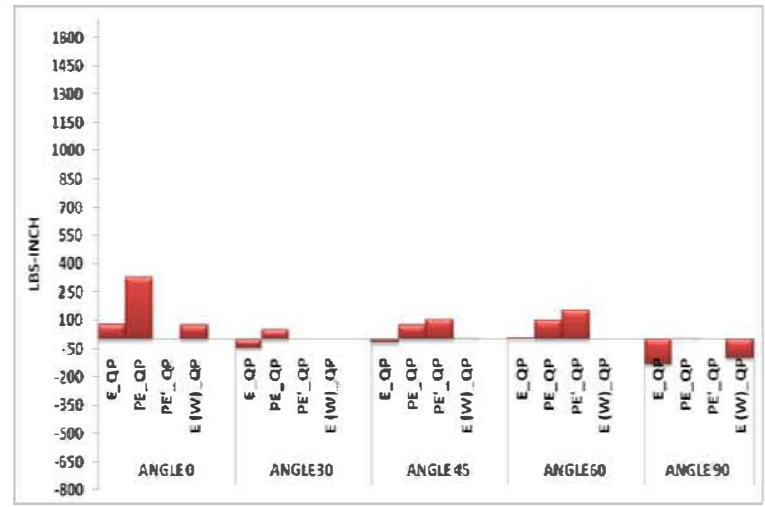

Graph 5.202: Load Cell 2 All Angles and Conditions Mx_QP

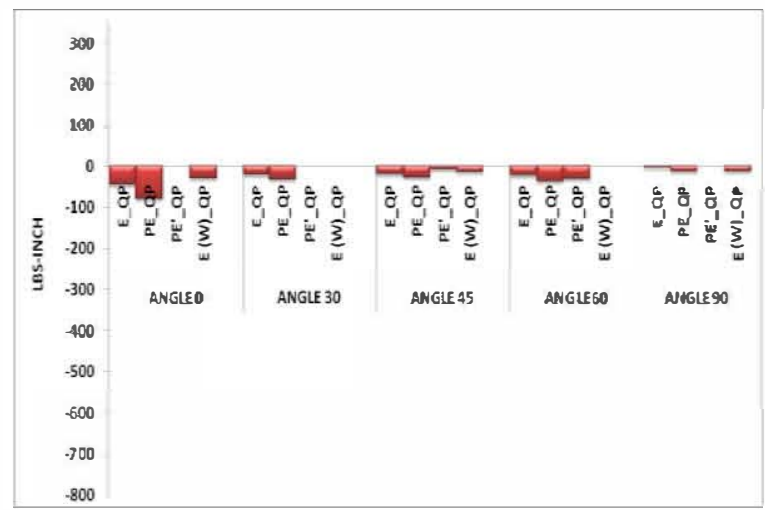

Graph 5.203: Load Cell 2 All Angles and Conditions My_QP

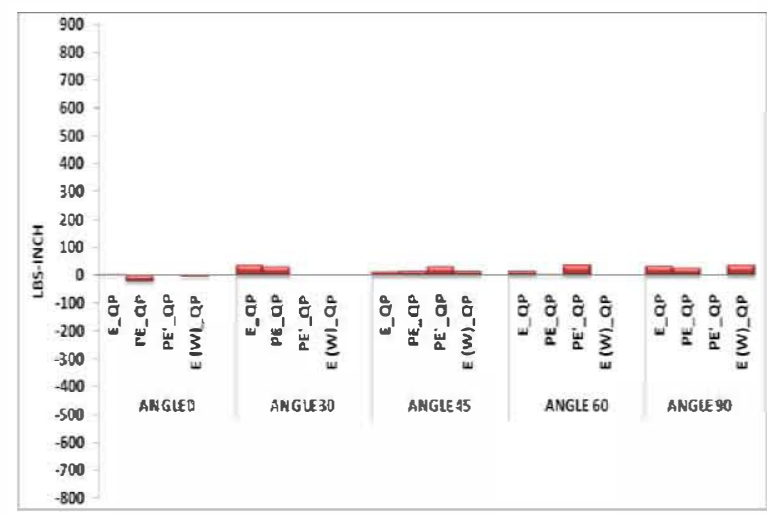

Graph 5.204: Load Cell 2 All Angles and Conditions Mz_QP 
5.6.8 Bar Graphs with Mean Results of All Conditions in Load Cell 3

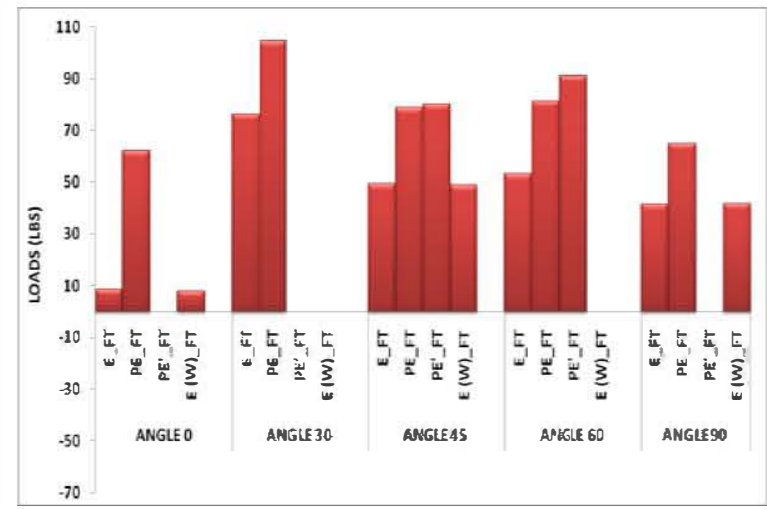

Graph 5.205: Load Cell 3 All Angles and Conditions Fx_FT

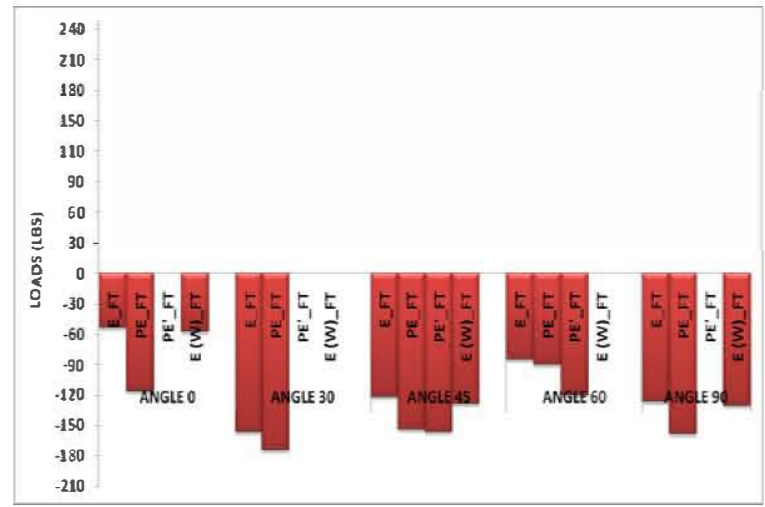

Graph 5.206: Load Cell 3 All Angles and Conditions Fy_FT

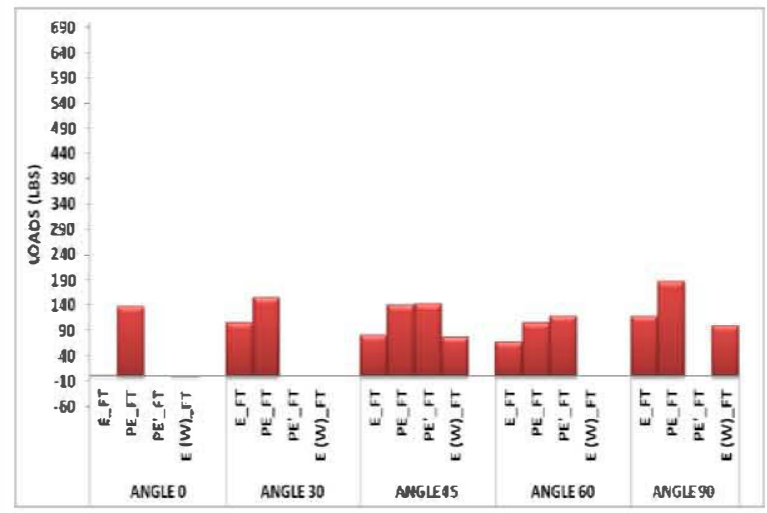

Graph 5.207: Load Cell 3 All Angles and Conditions Fz_FT 


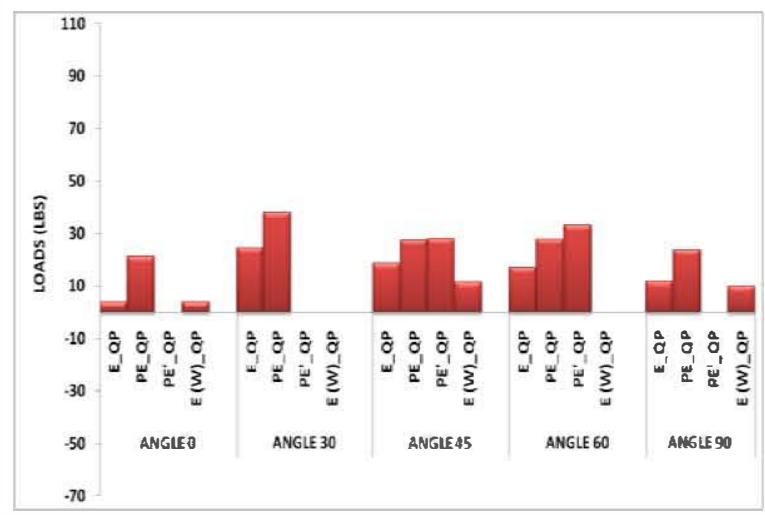

Graph 5.208: Load Cell 3 All Angles and Conditions Fx_QP

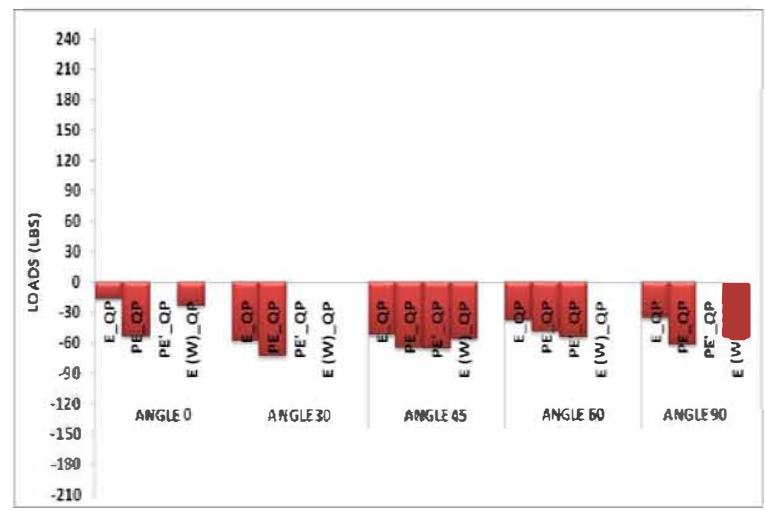

Graph 5.209: Load Cell 3 All Angles and Conditions Fy_QP

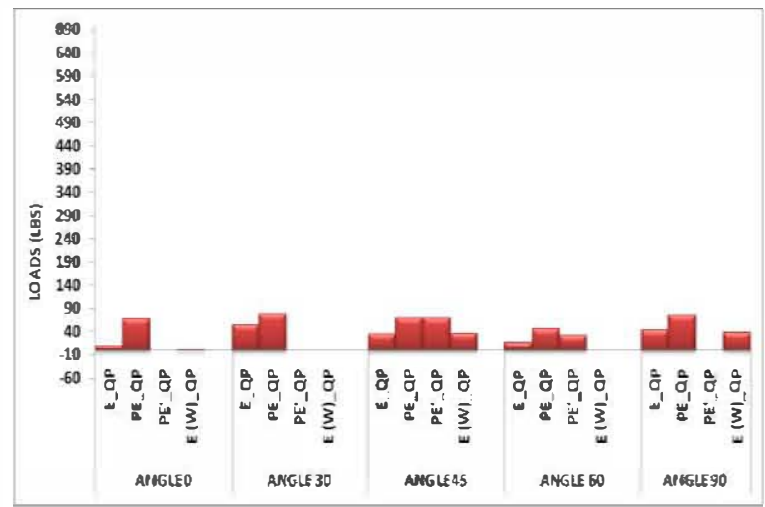

Graph 5.210: Load Cell 3 All Angles and Conditions Fz_QP 


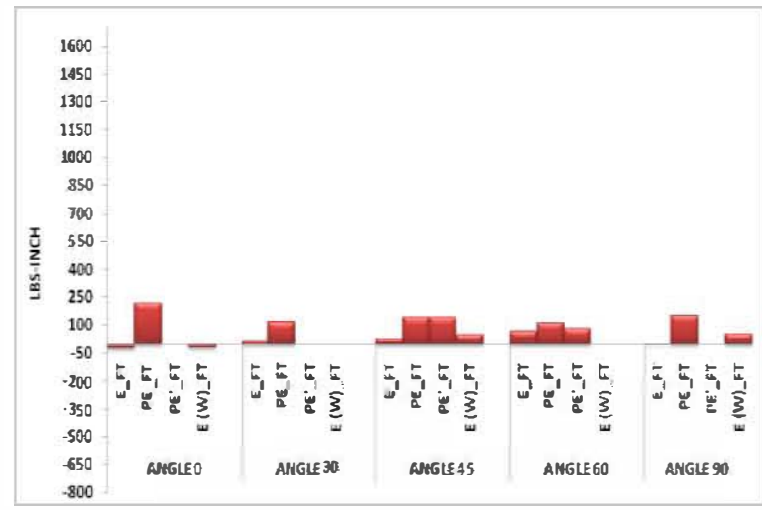

Graph 5.211: Load Cell 3 All Angles and Conditions Mx_FT

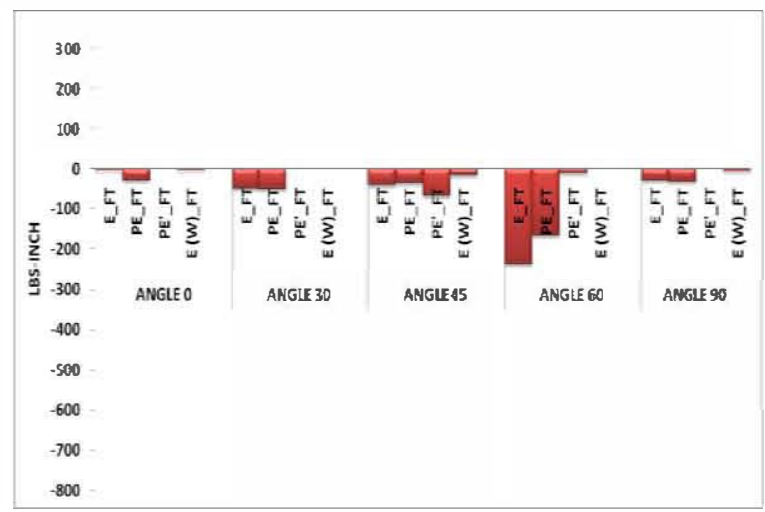

Graph 5.212: Load Cell 3 All Angles and Conditions My_FT

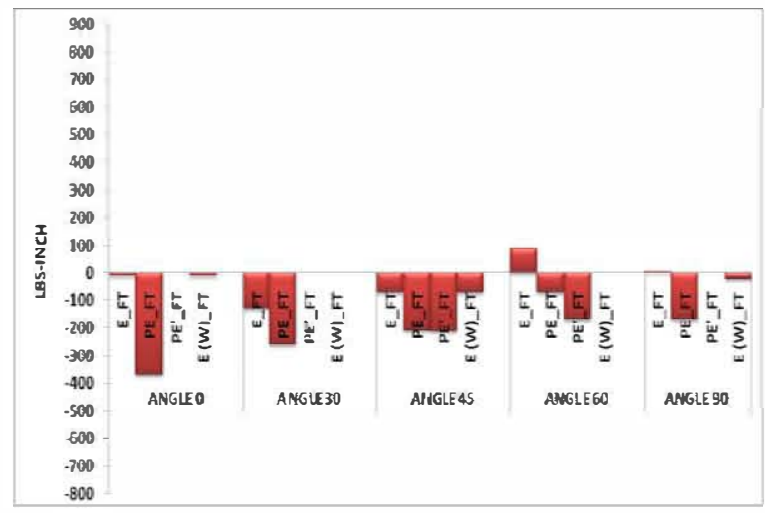

Graph 5.213: Load Cell 3 All Angles and Conditions Mz_FT 


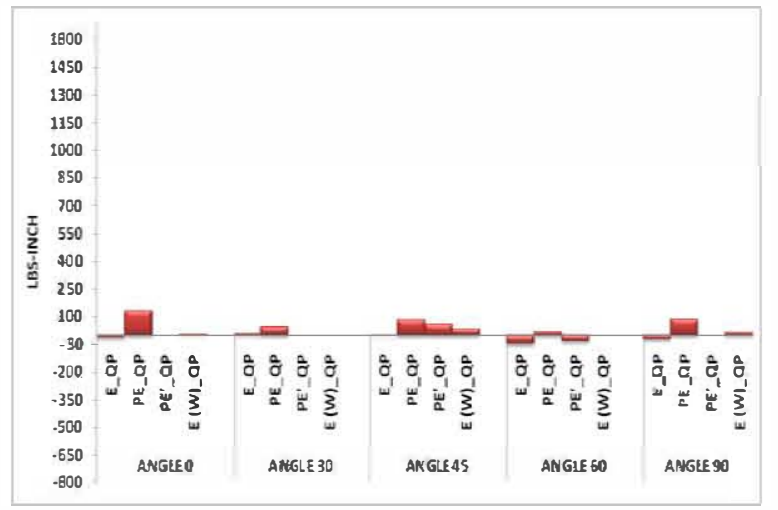

Graph 5.214: Load Cell 3 All Angles and Conditions Mx_QP

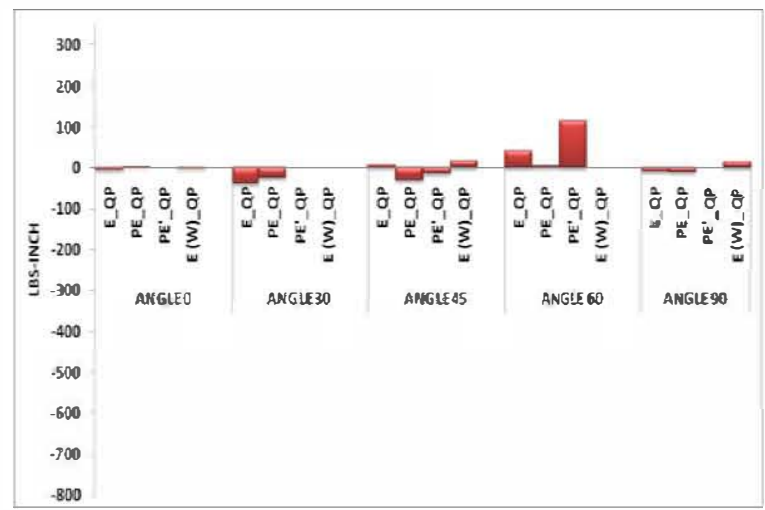

Graph 5.215: Load Cell 3 All Angles and Conditions My_QP

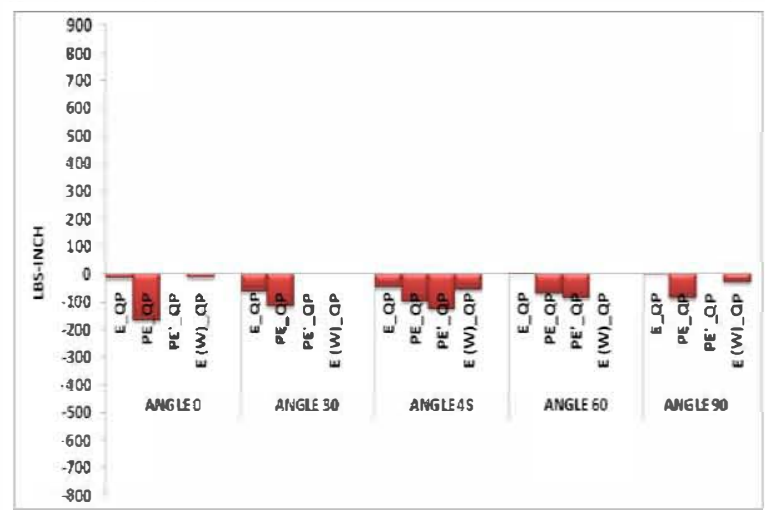

Graph 5.216: Load Cell 3 All Angles and Conditions Mz_QP 
5.6.9 Bar Graphs with Mean Results of All Conditions in Load Cell 4

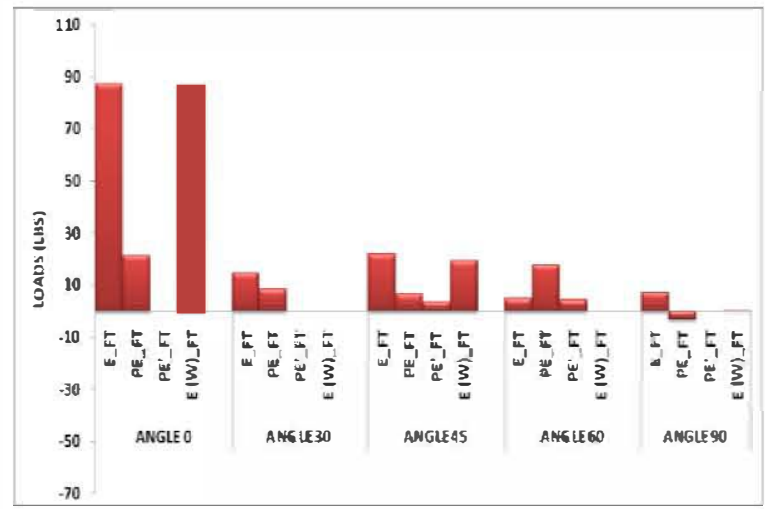

Graph 5.217: Load Cell 4 All Angles and Conditions Fx_FT

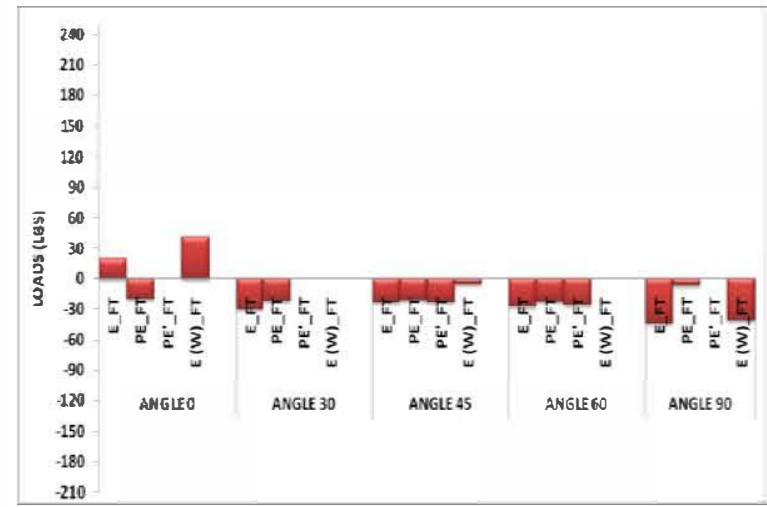

Graph 5.218: Load Cell 4 All Angles and Conditions Fy_FT

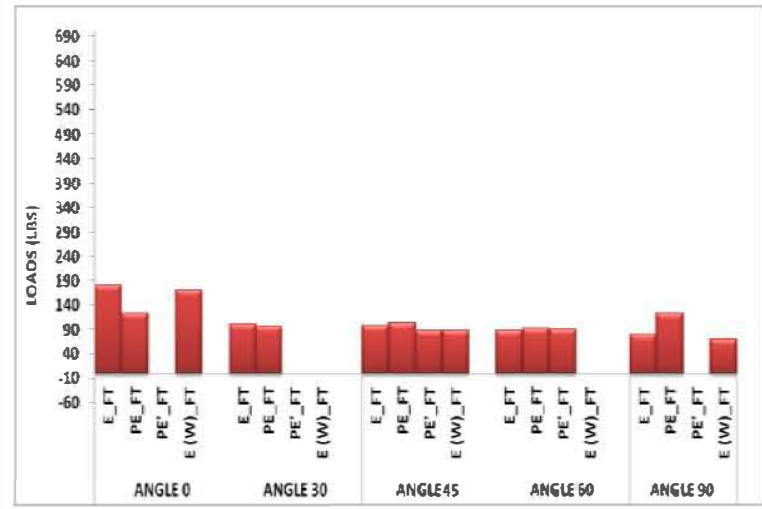

Graph 5.219: Load Cell 4 All Angles and Conditions Fz_FT 


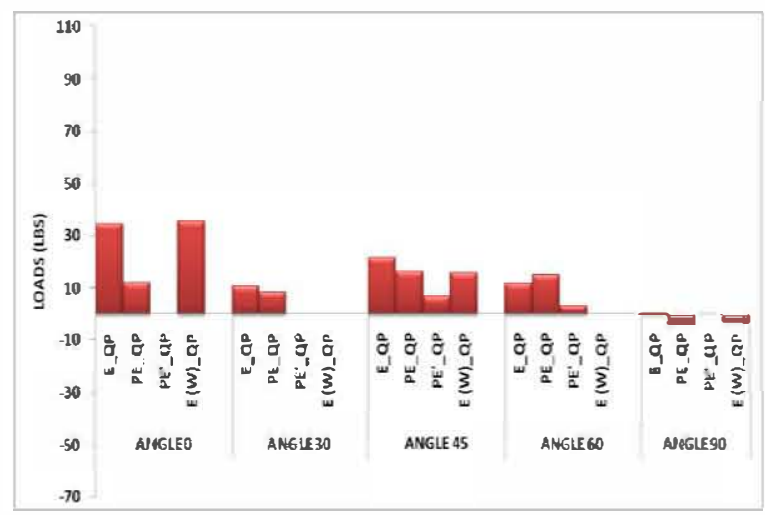

Graph 5.220: Load Cell 4 All Angles and Conditions Fx_QP

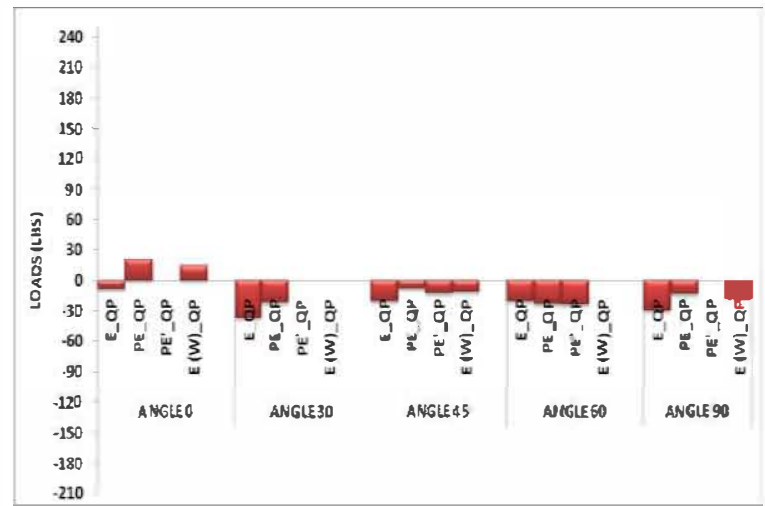

Graph 5.221: Load Cell 4 All Angles and Conditions Fy_QP

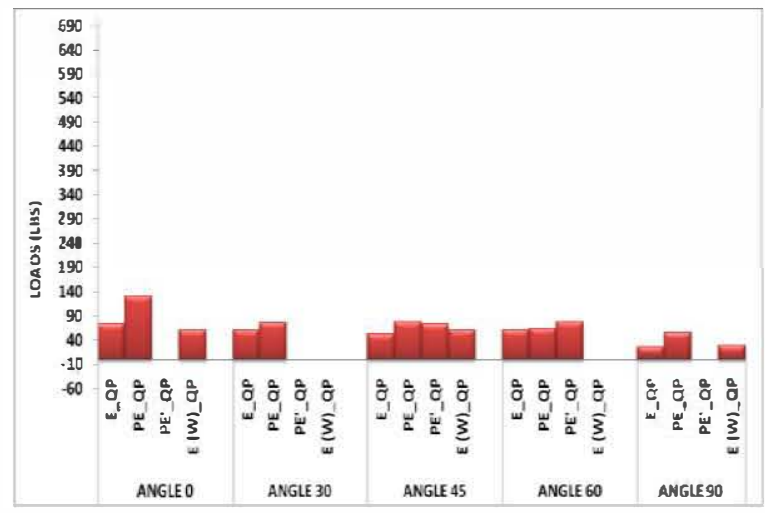

Graph 5.222: Load Cell 4 All Angles and Conditions Fz_QP 


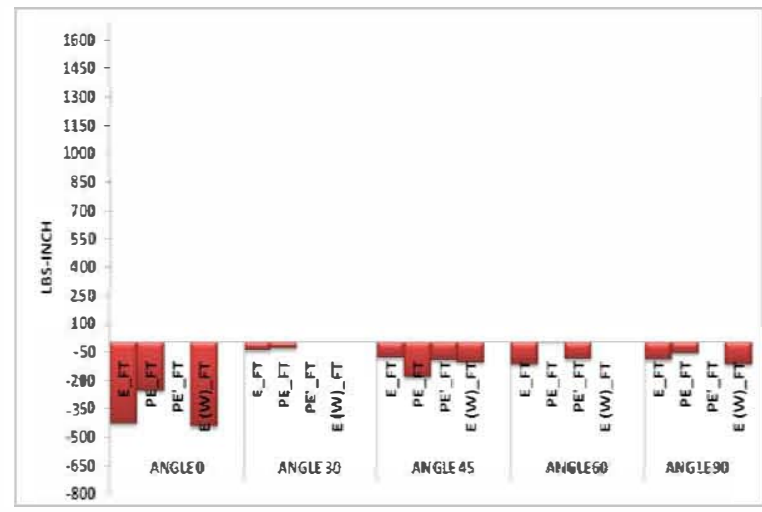

Graph 5.223: Load Cell 4 All Angles and Conditions Mx_FT

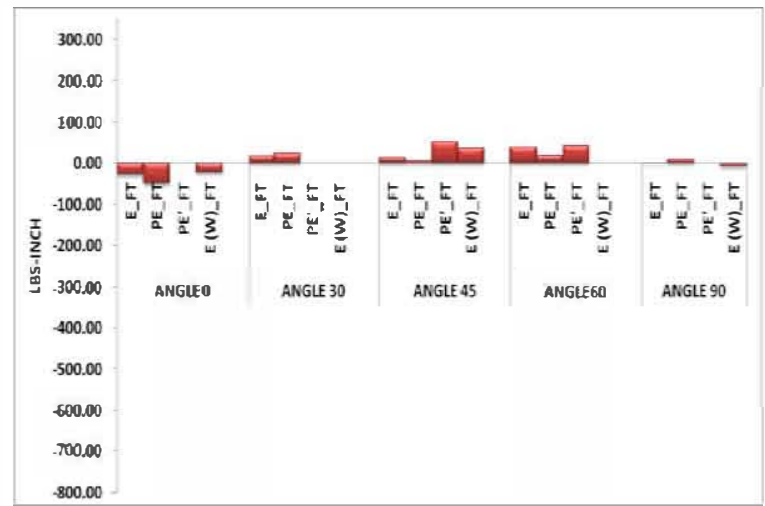

Graph 5.224: Load Cell 4 All Angles and Conditions My_FT

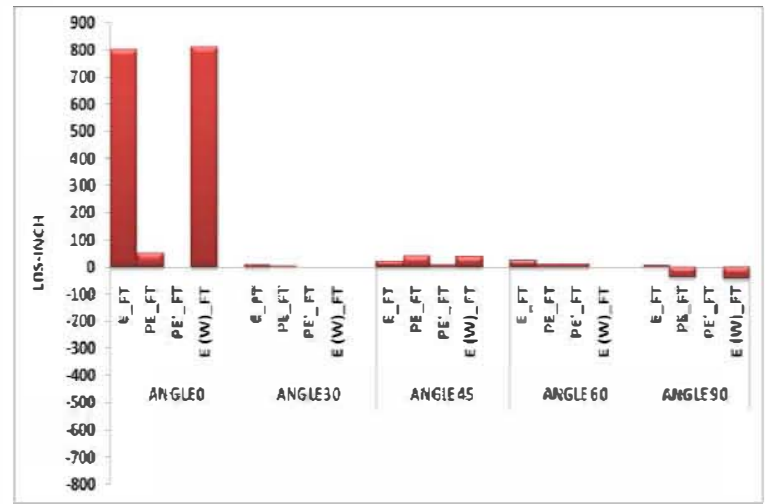

Graph 5.225: Load Cell 4 All Angles and Conditions Mz_FT 


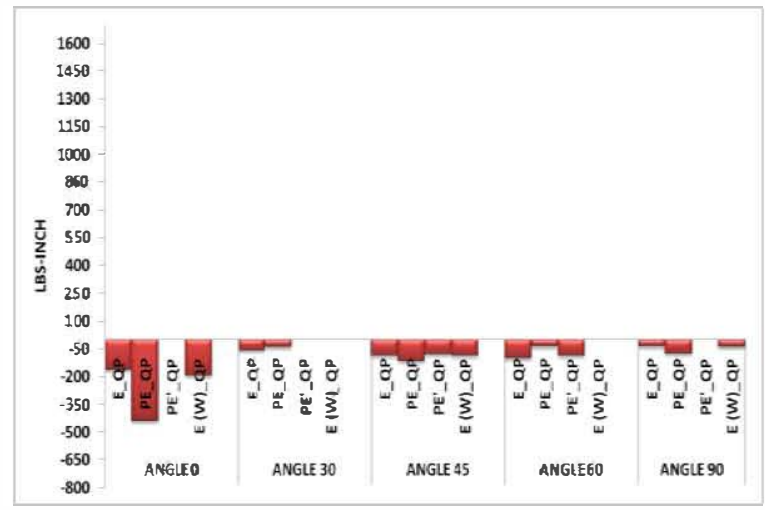

Graph 5.226: Load Cell 4 All Angles and Conditions Mx_QP

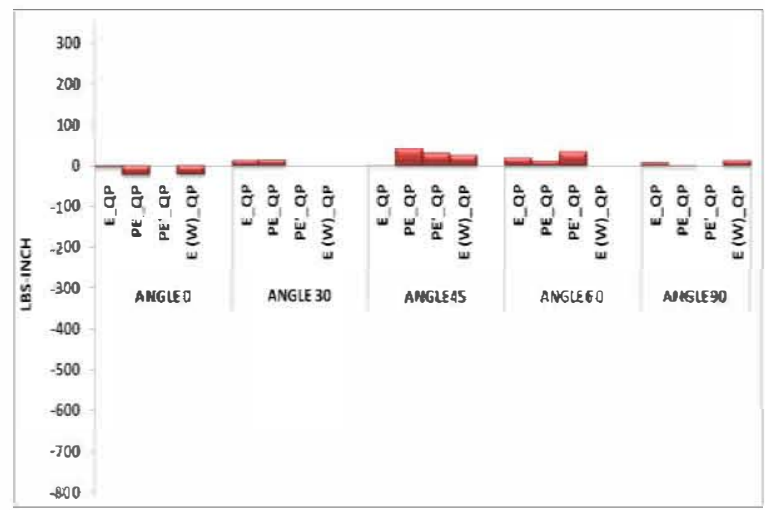

Graph 5.227: Load Cell 4 All Angles and Conditions My_QP

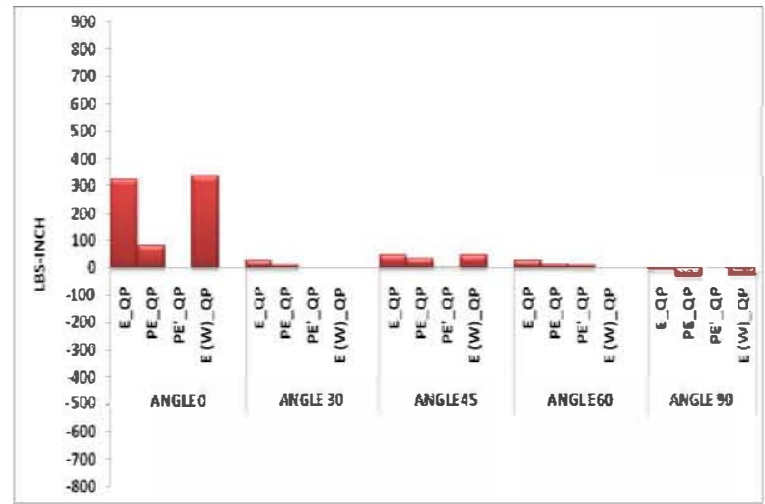

Graph 5.228: Load Cell 4 All Angles and Conditions Mz_QP 
5.6.10 Bar Graphs with Mean Results of All Conditions in Load Cell 5

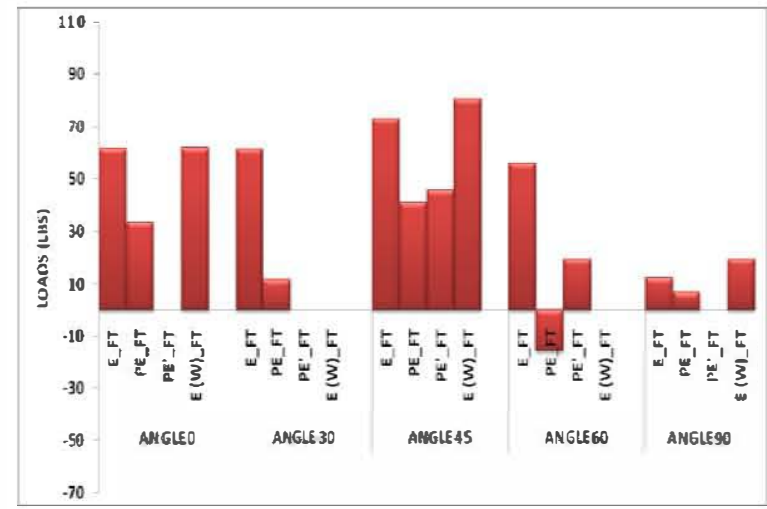

Graph 5.229: Load Cell 5 All Angles and Conditions Fx_FT

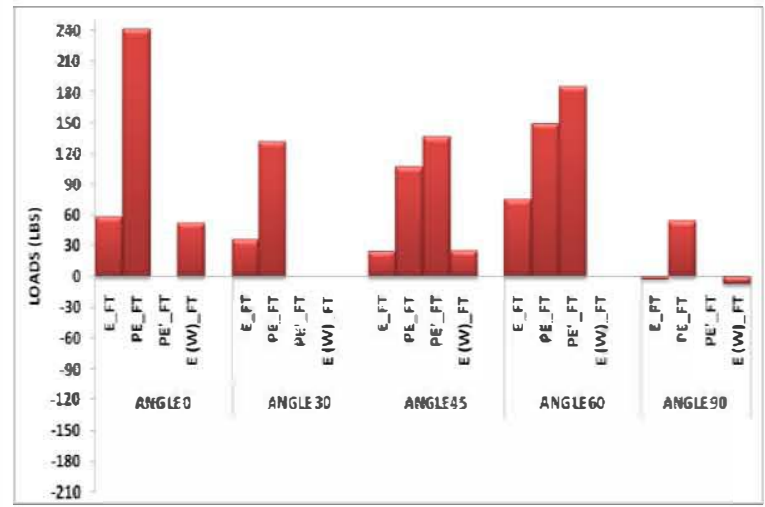

Graph 5.230: Load Cell 5 All Angles and Conditions Fy_FT

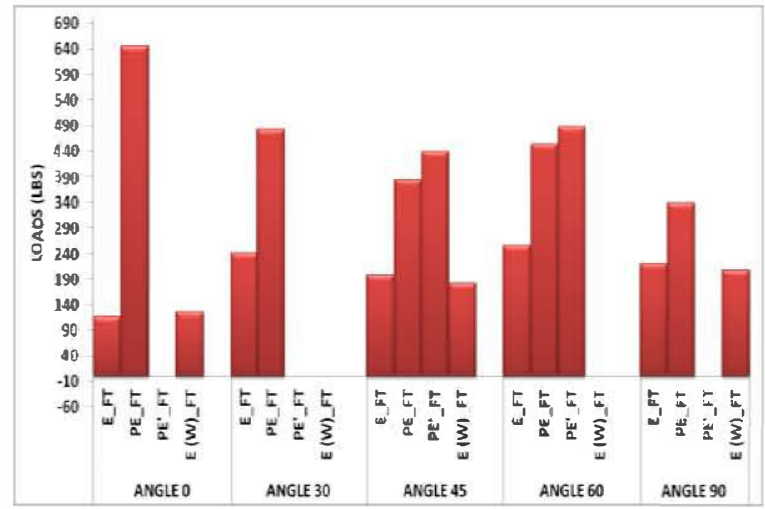

Graph 5.231: Load Cell 5 All Angles and Conditions Fz_FT 


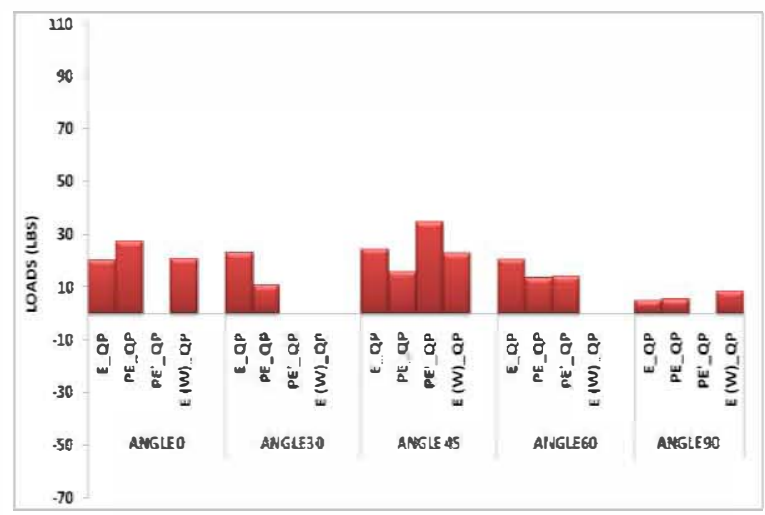

Graph 5.232: Load Cell 5 All Angles and Conditions Fx_QP

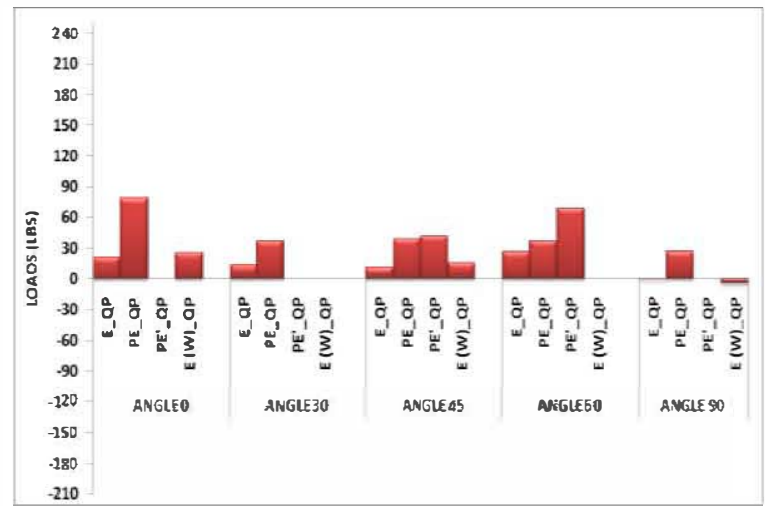

Graph 5.233: Load Cell 5 All Angles and Conditions Fy_QP

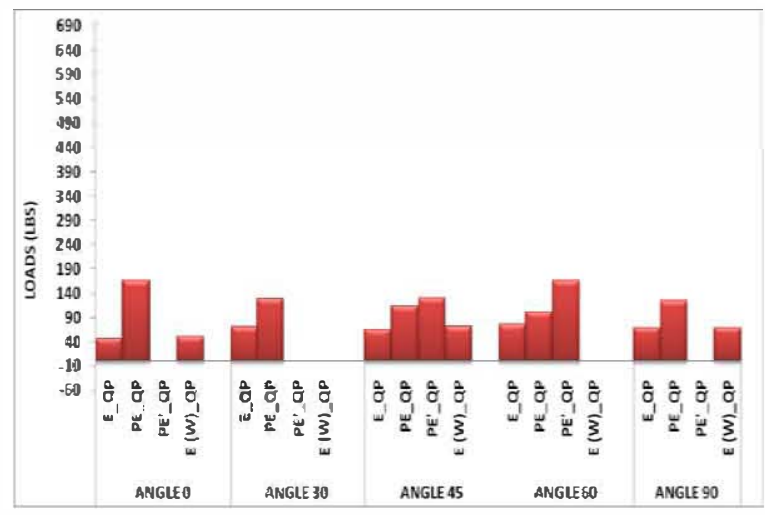

Graph 5.234: Load Cell 5 All Angles and Conditions Fz_QP 


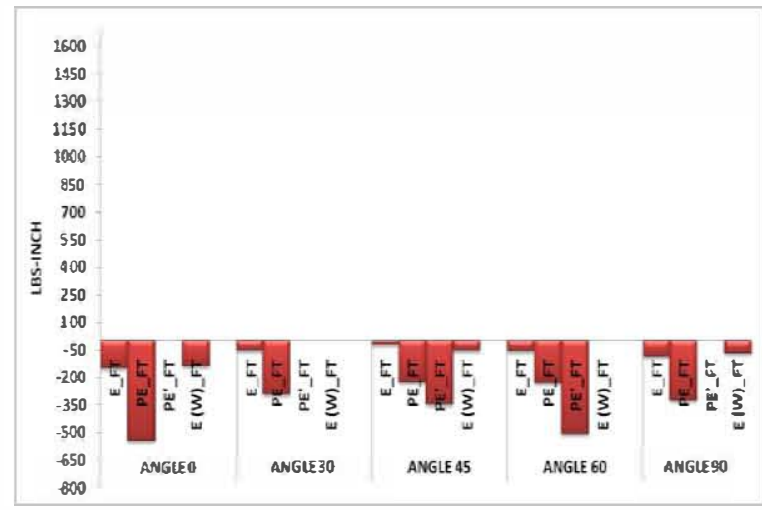

Graph 5.235: Load Cell 5 All Angles and Conditions Mx_FT

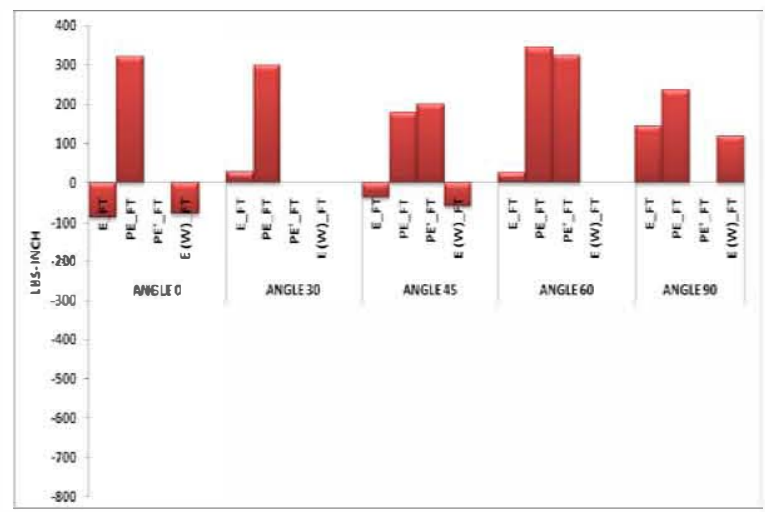

Graph 5.236: Load Cell 5 All Angles and Conditions My_FT

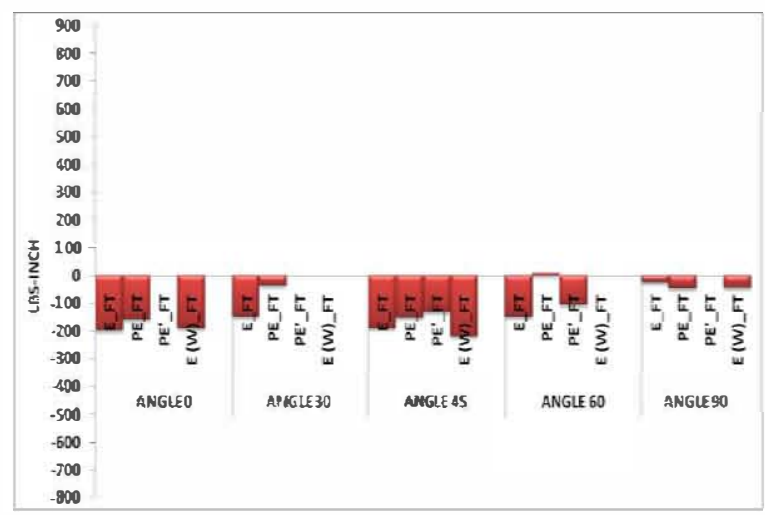

Graph 5.237: Load Cell 5 All Angles and Conditions Mz_FT 


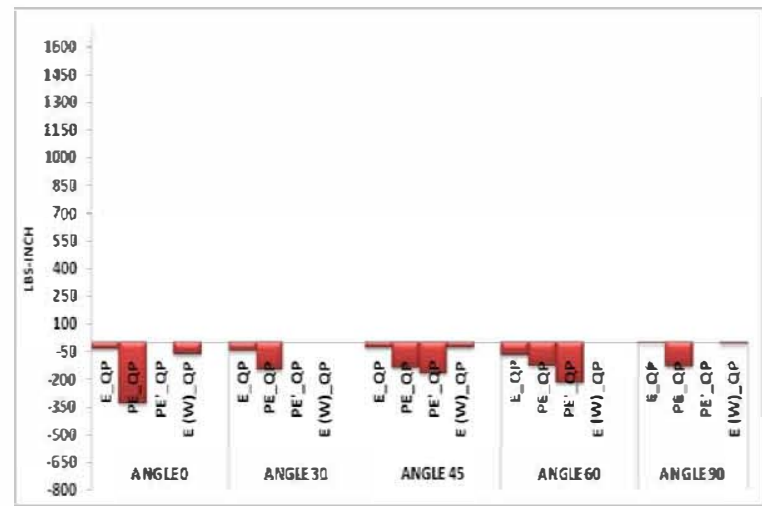

Graph 5.238: Load Cell 5 All Angles and Conditions Mx_QP

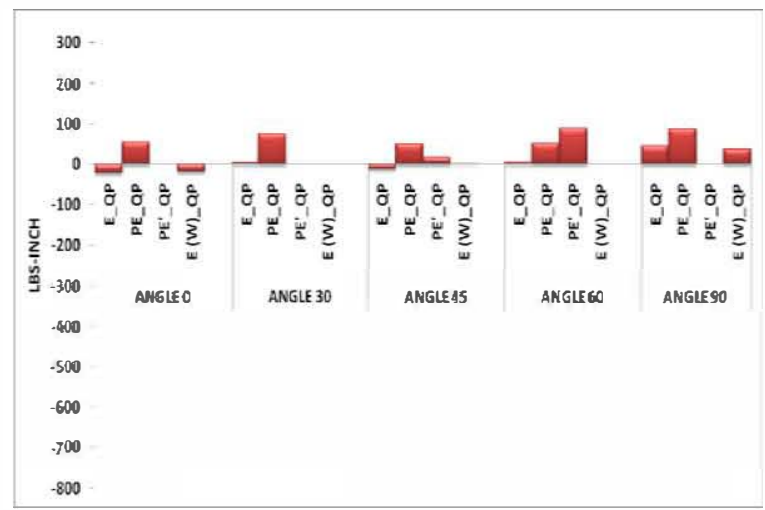

Graph 5.239: Load Cell 5 All Angles and Conditions My_QP

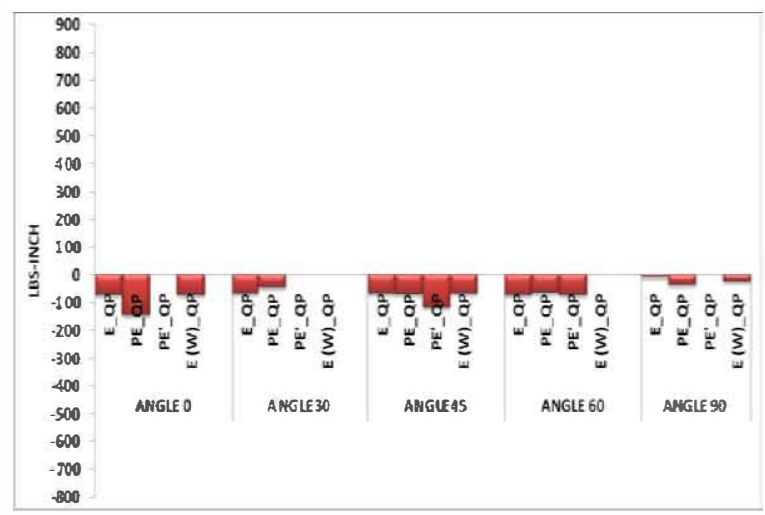

Graph 5.240: Load Cell 5 All Angles and Conditions Mz_QP 
5.6.11 Bar Graphs with Mean Results of All Conditions in Load Cell 6

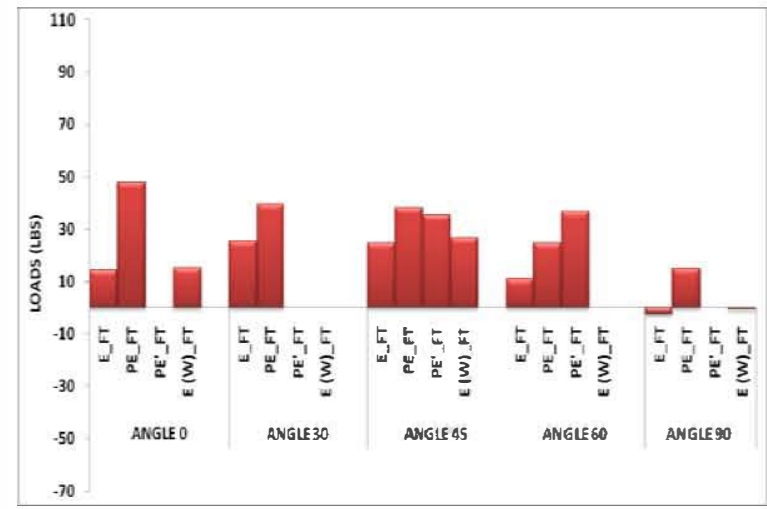

Graph 5.241: Load Cell 6 All Angles and Conditions Fx_FT

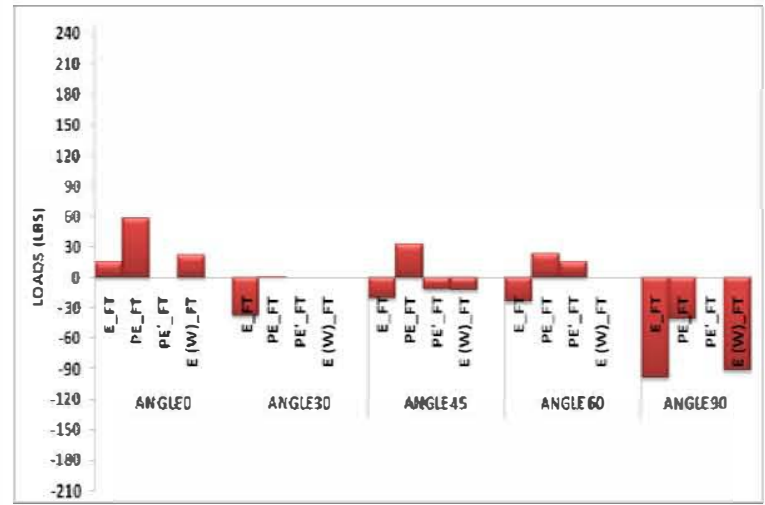

Graph 5.242: Load Cell 6 All Angles and Conditions Fy_FT

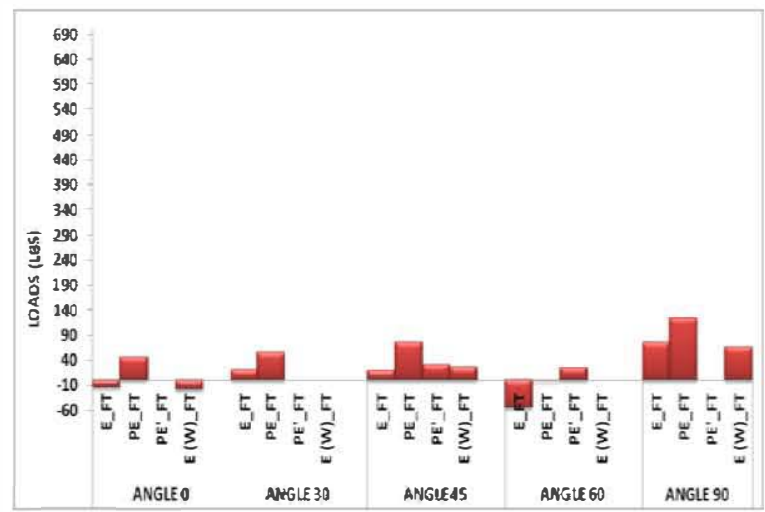

Graph 5.243: Load Cell 6 All Angles and Conditions Fz_FT 


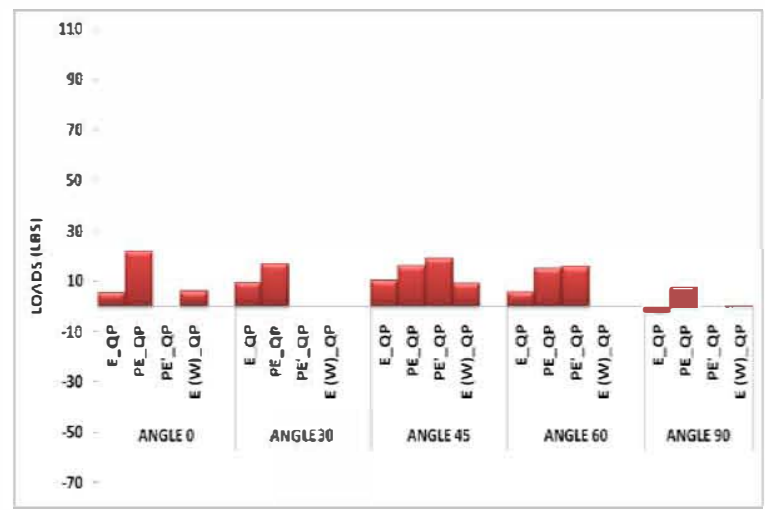

Graph 5.232: Load Cell 6 All Angles and Conditions Fx_QP

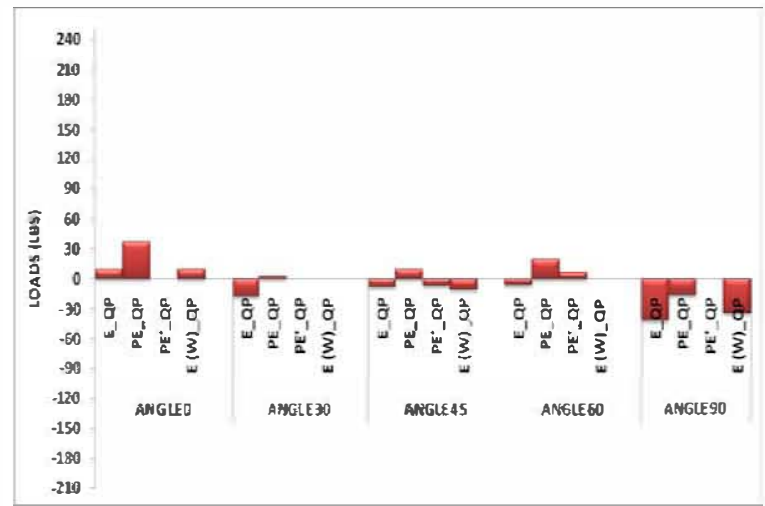

Graph 5.233: Load Cell 6 All Angles and Conditions Fy_QP

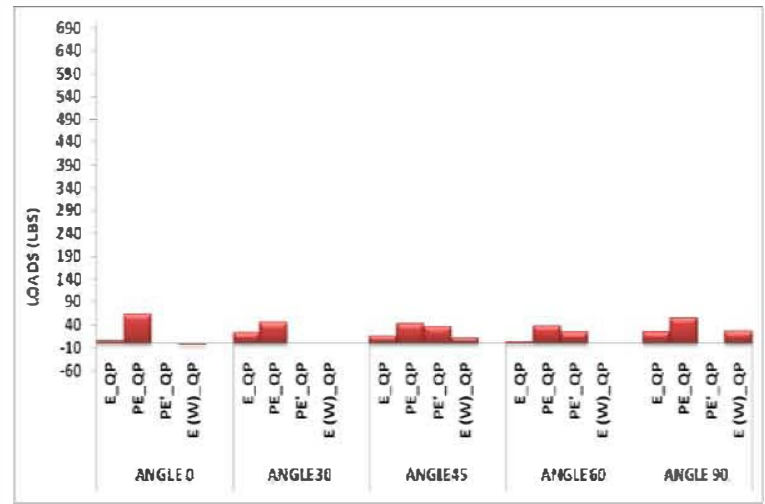

Graph 5.234: Load Cell 6 All Angles and Conditions Fz_QP 


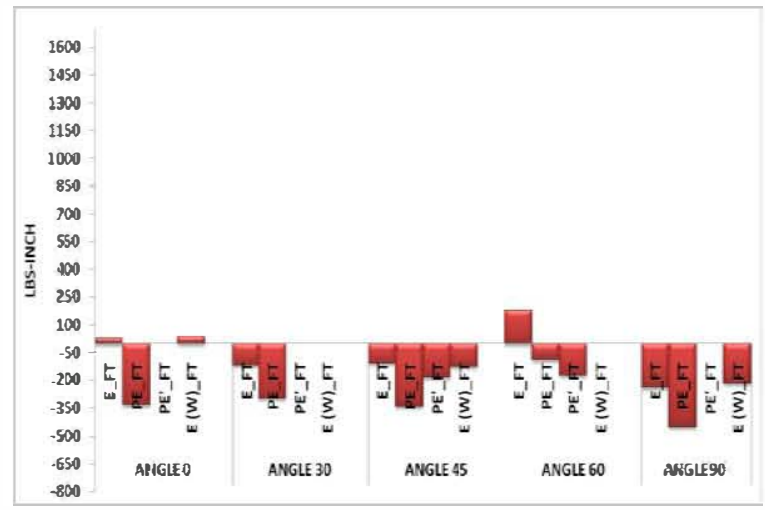

Graph 5.235: Load Cell 6 All Angles and Conditions Mx_FT

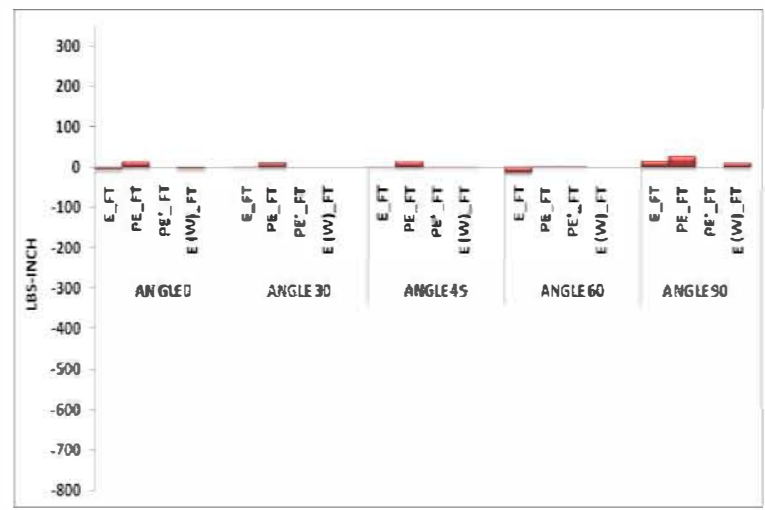

Graph 5.236: Load Cell 6 All Angles and Conditions My_FT

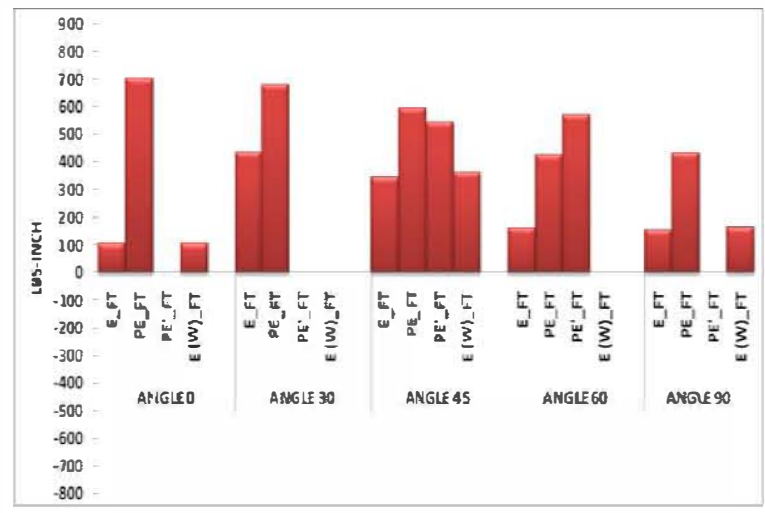

Graph 5.237: Load Cell 6 All Angles and Conditions Mz_FT 


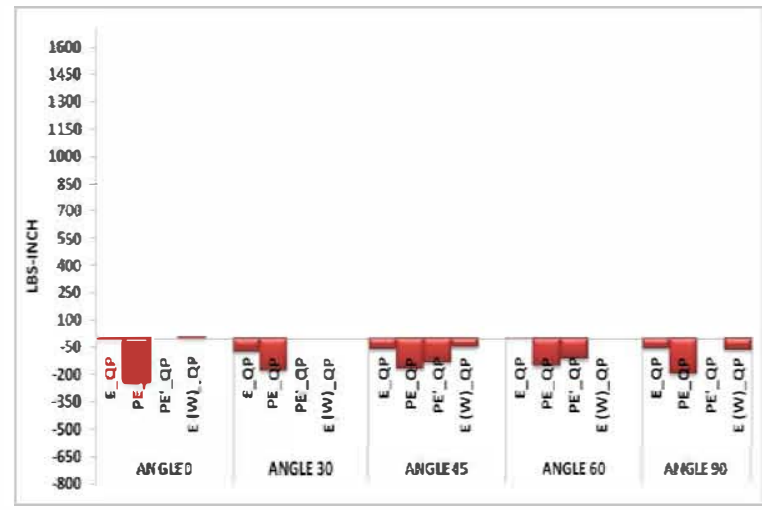

Graph 5.238: Load Cell 6 All Angles and Conditions Mx_QP

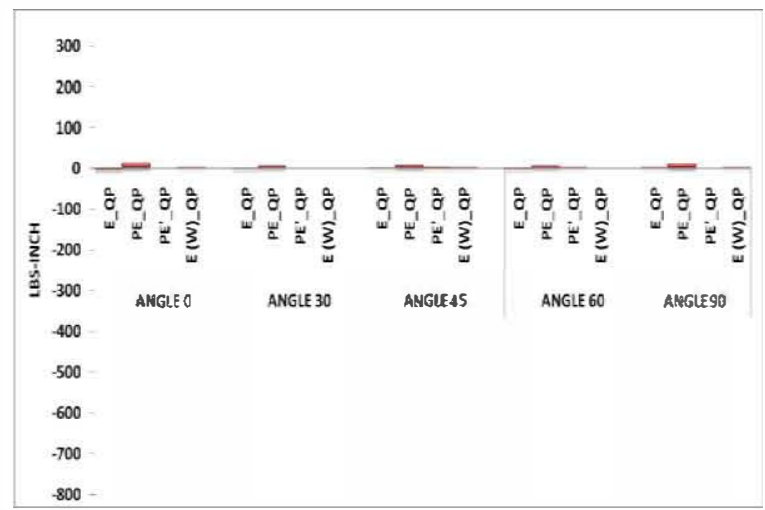

Graph 5.239: Load Cell 6 All Angles and Conditions My_ QP

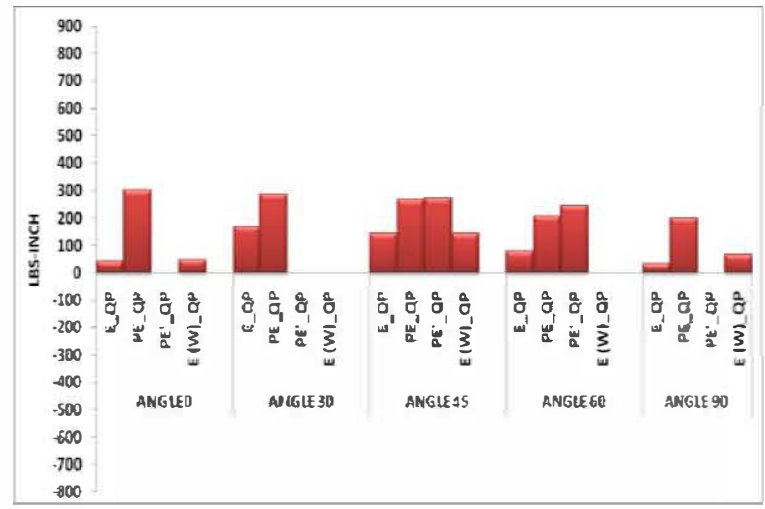

Graph 5.240: Load Cell 6 All Angles and Conditions Mz_QP 


\subsubsection{Scatter Plots of Mean Fx, Fy and Fz in Load Cell I}

Based on the mean Fx, Fy, and Fz values scatter plots are given below to show the proportionalities between the uplift and the lateral (in-plane shear and out-of-plane shear) forces.

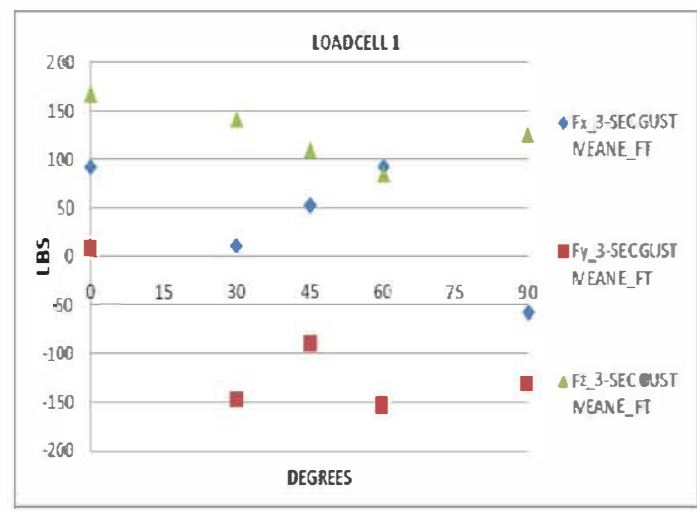

Graph 5.241: Mean Forces, Enclosed at Full Throttle

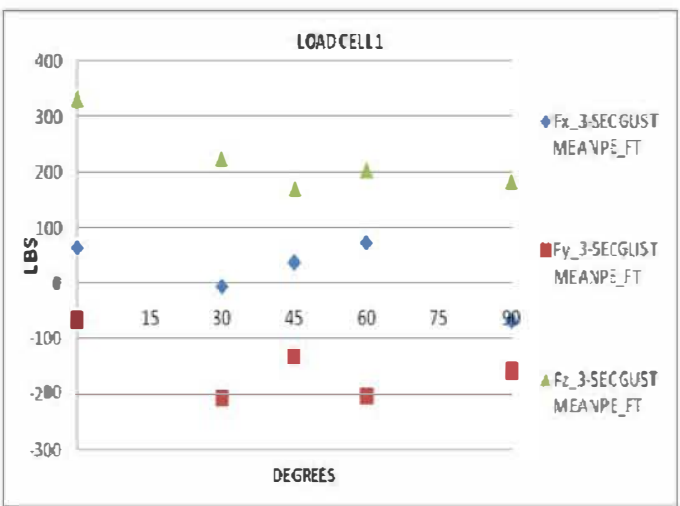

Graph 5.242: Mean Forces, Partially Enclosed at Full Throttle

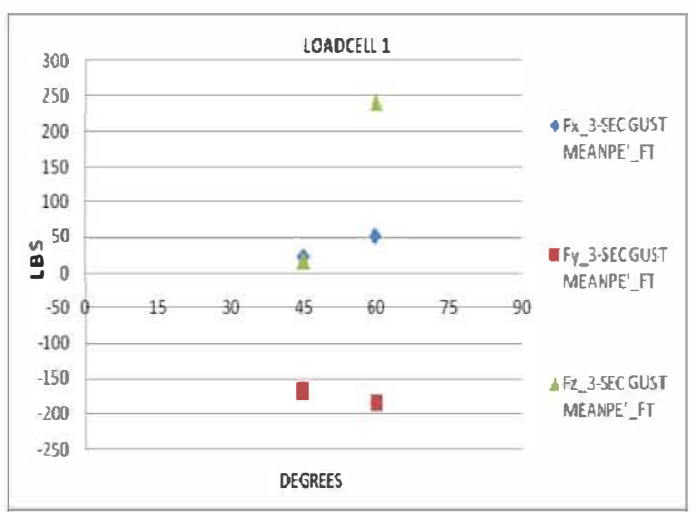

Graph 5.243: Mean Forces, Partially Enclosed' at Full Throttle

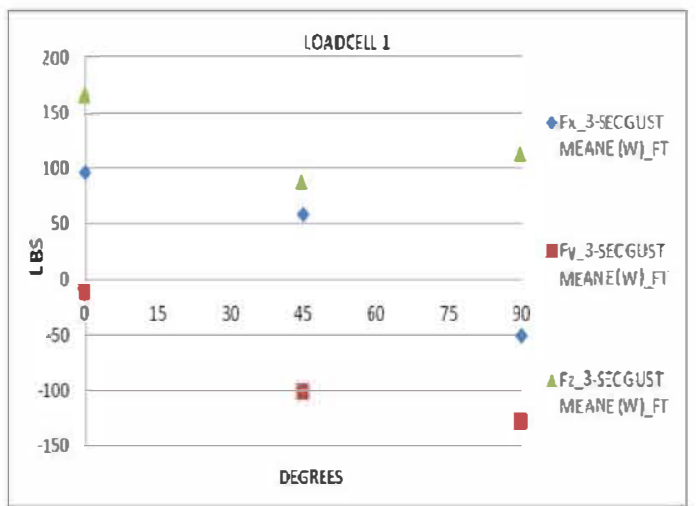

Graph 5.244: Mean Forces, Enclosed with Water at Full Throttle 


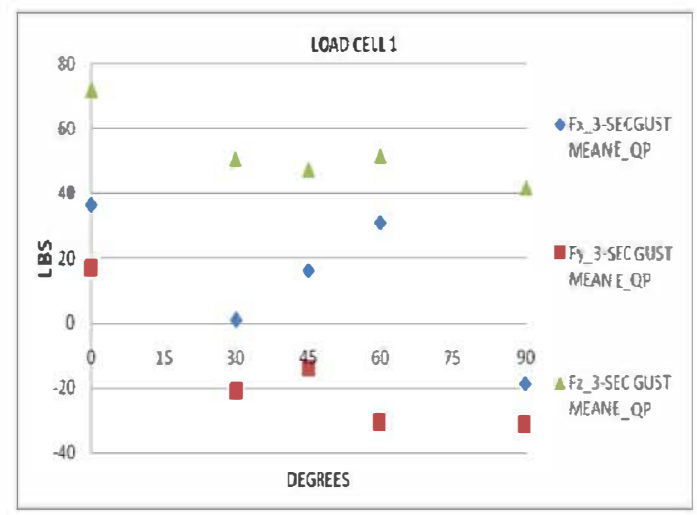

Graph 5.245: Mean Forces, Enclosed at Quasi-Periodical

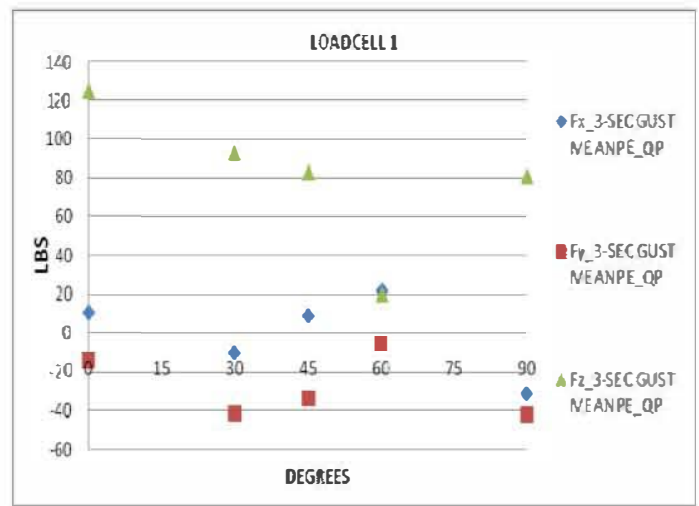

Graph 5.246: Mean Forces, Partially Enclosed at Quasi-Periodical

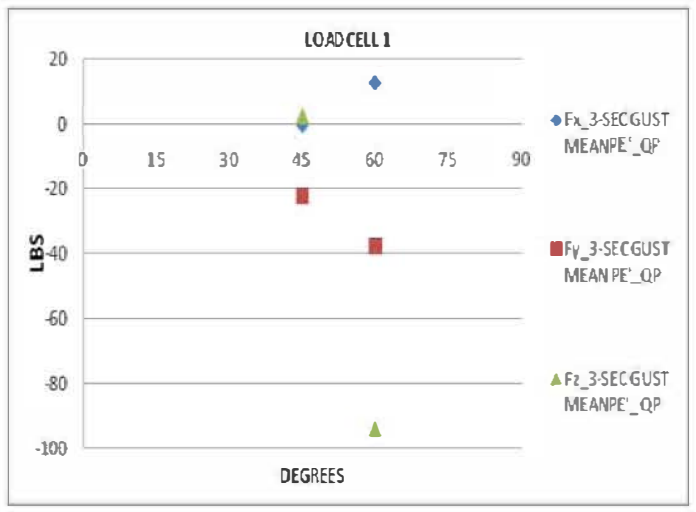

Graph 5.247: Mean Forces,

Partially Enclosed' at Quasi-

Periodical

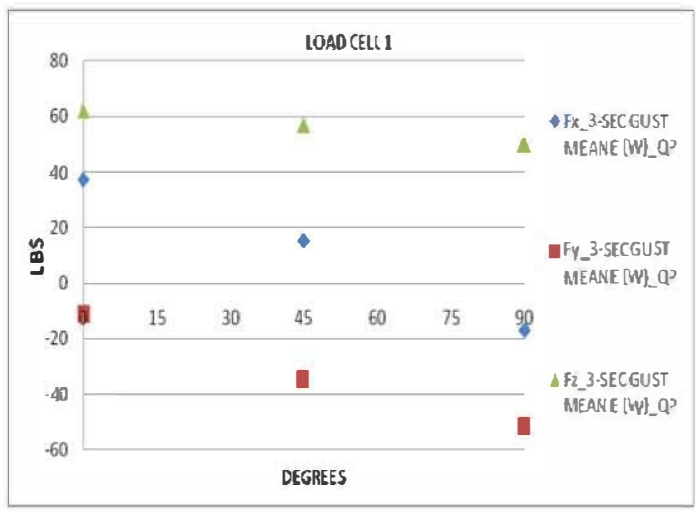

Graph 5.248: Mean Forces, Enclosed with Water at QuasiPeriodical 
5.6.13 Scatter Plots of Mean Fx, Fy and Fz in Load Cell 2

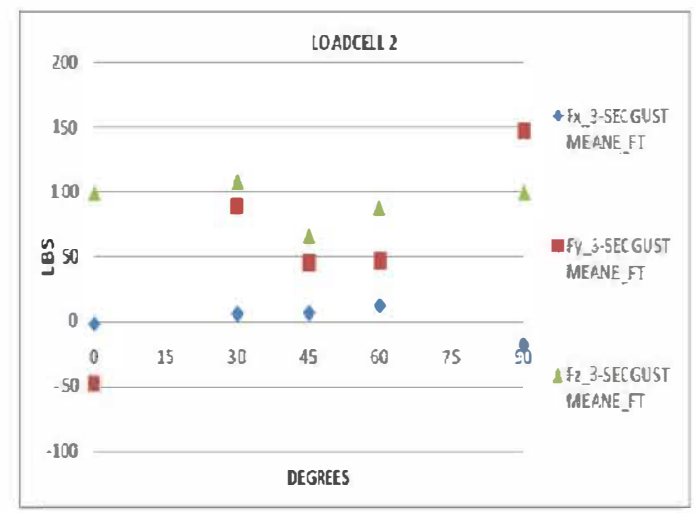

Graph 5.249: Mean Forces, Enclosed at Full Throttle

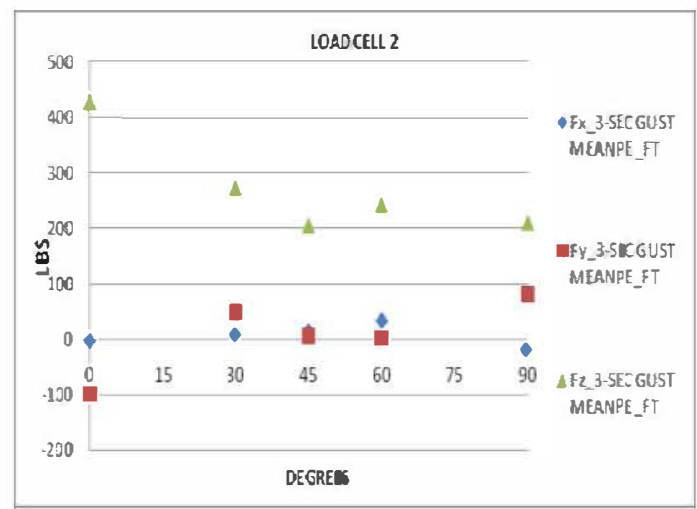

Graph 5.250: Mean Forces, Partially Enclosed at Full Throttle

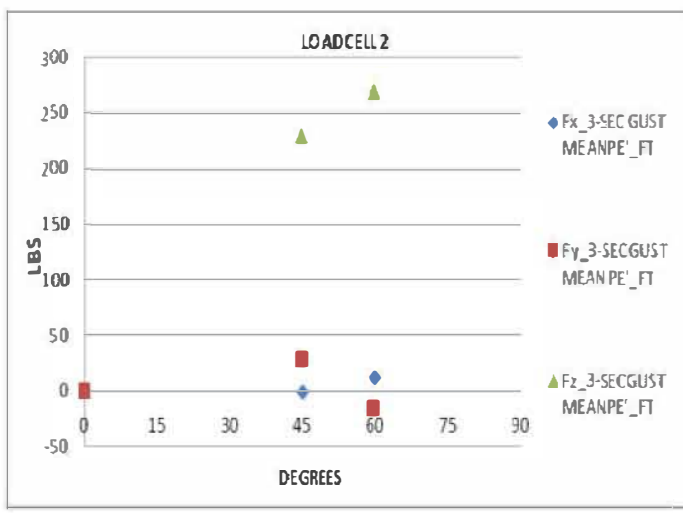

Graph 5.251: Mean Forces, Partially Enclosed' at Full Throttle

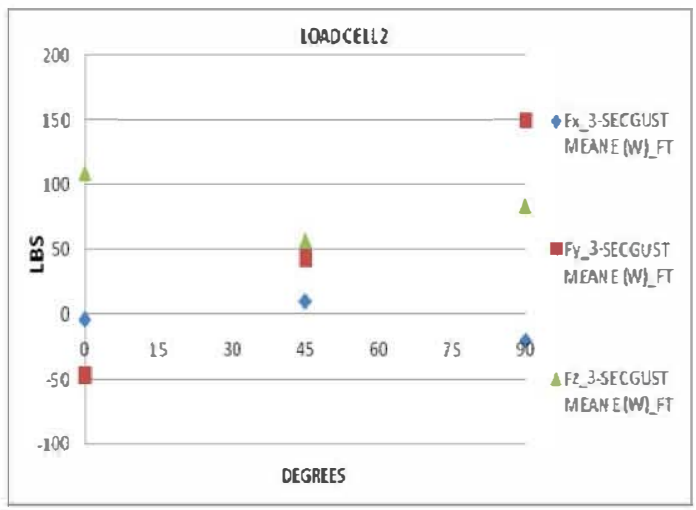

Graph 5.252: Mean Forces, Enclosed with Water at Full Throttle 


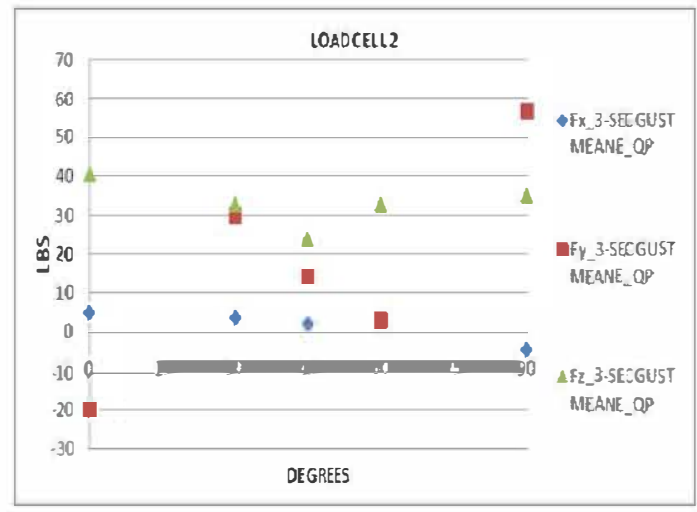

Graph 5.253: Mean Forces, Enclosed at Quasi-Periodical

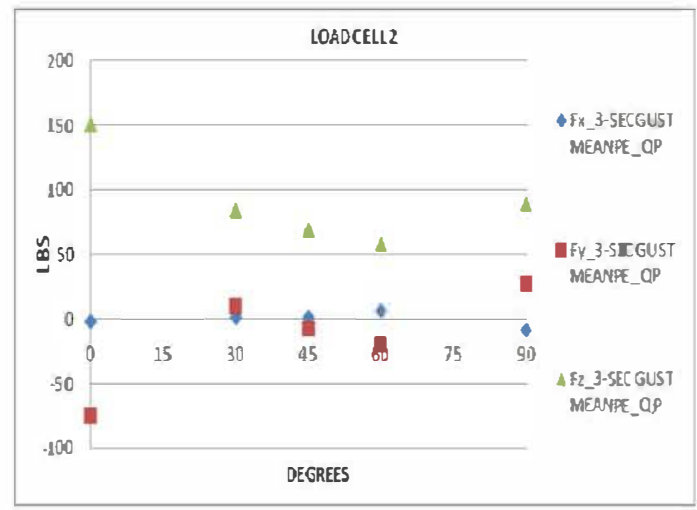

Graph 5.254: Mean Forces, Partially Enclosed at Quasi-Periodical

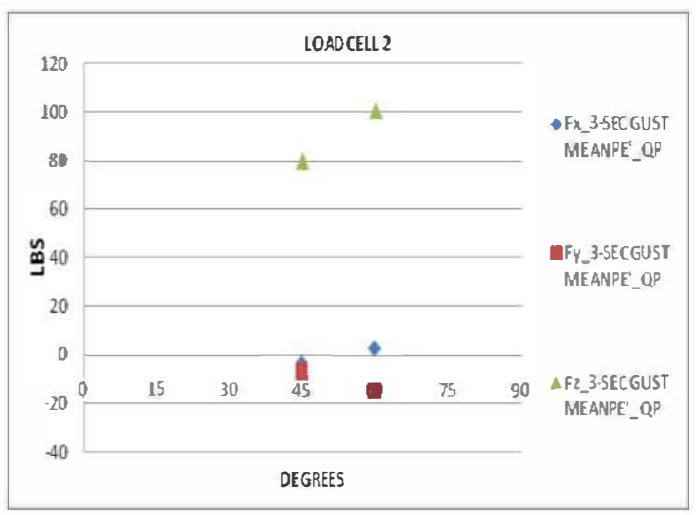

Graph 5.255: Mean Forces,

Partially Enclosed' at Quasi-

\section{Periodical}

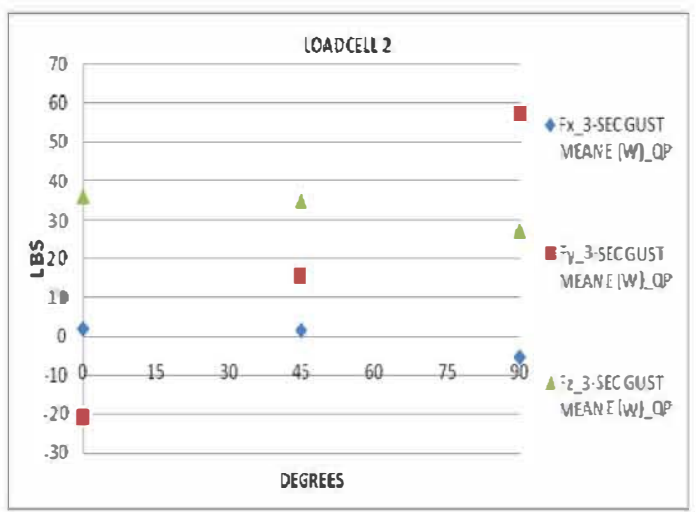

Graph 5.256: Mean Forces, Enclosed with Water at QuasiPeriodical 
5.6.14 Scatter Plots of Mean Fx, Fy and Fz in Load Cell 3

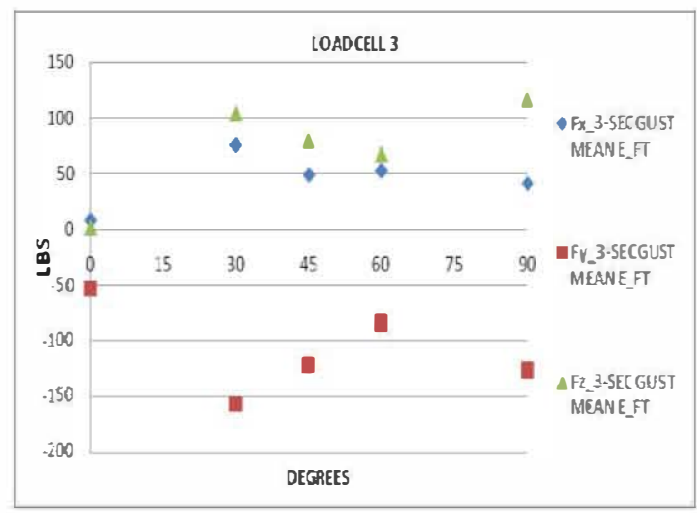

Graph 5.257: Mean Forces, Enclosed at Full Throttle

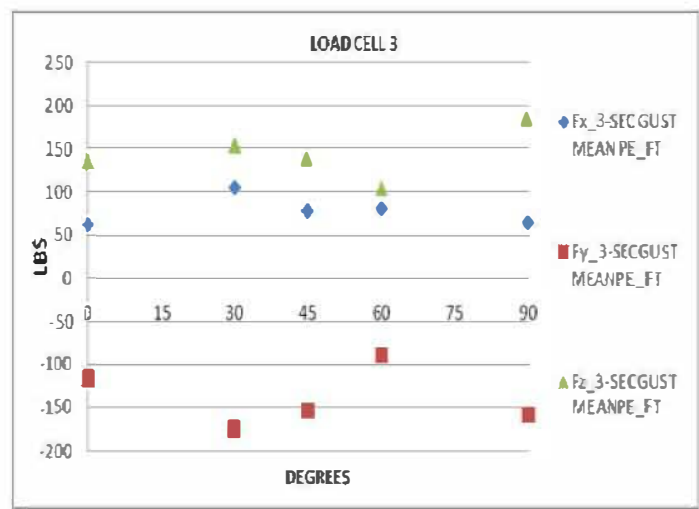

Graph 5.258: Mean Forces, Partially Enclosed at Full Throttle

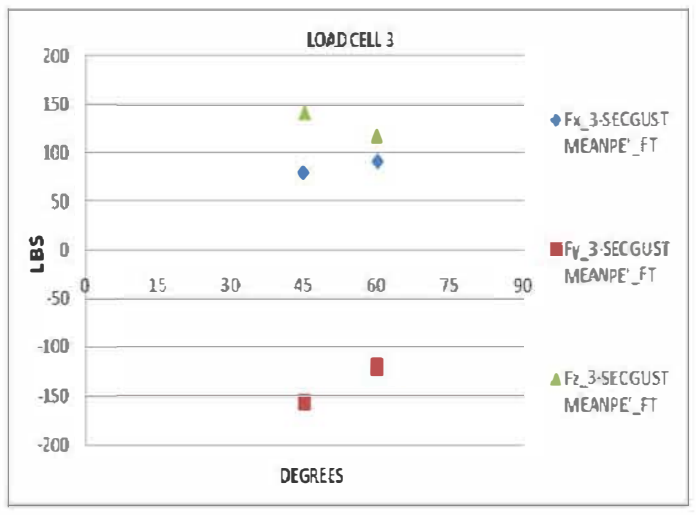

Graph 5.259: Mean Forces, Partially Enclosed' at Full Throttle

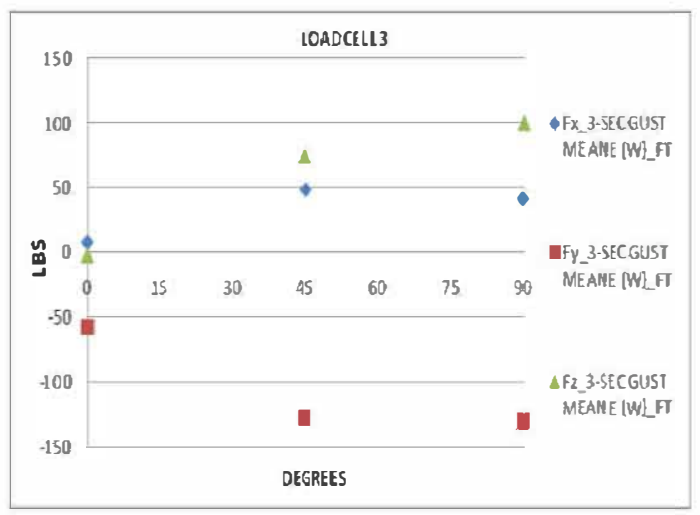

Graph 5.260: Mean Forces, Enclosed with Water at Full Throttle 


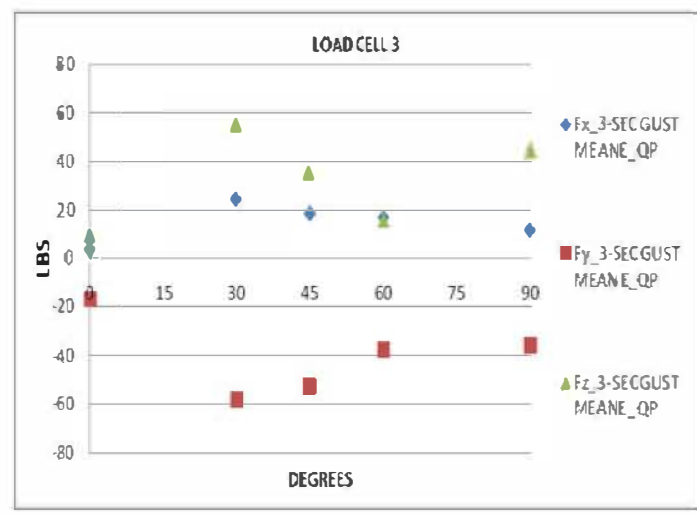

Graph 5.261: Mean Forces, Enclosed at Quasi-Periodical

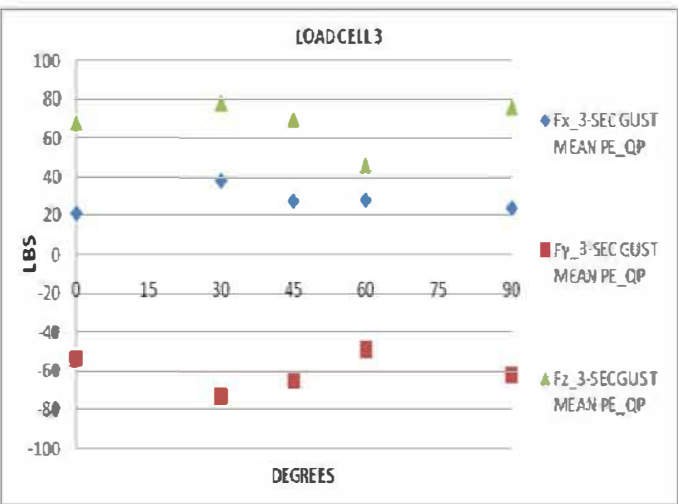

Graph 5.262: Mean Forces, Partially Enclosed at Quasi-Periodical

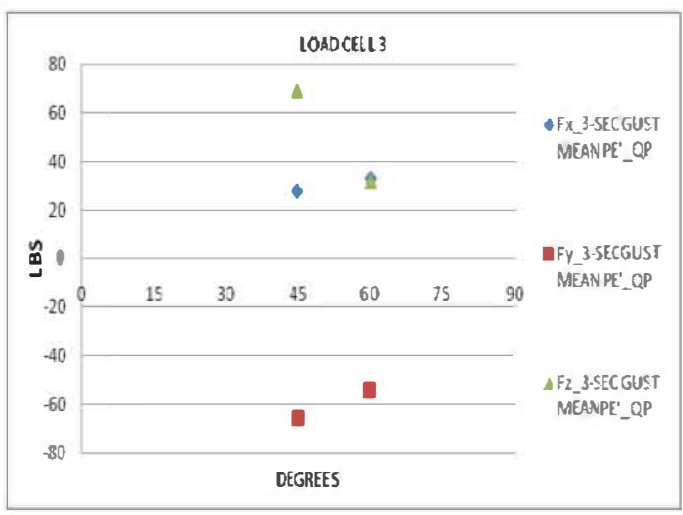

Graph 5.263: Mean Forces,

Partially Enclosed' at Quasi-

Periodical

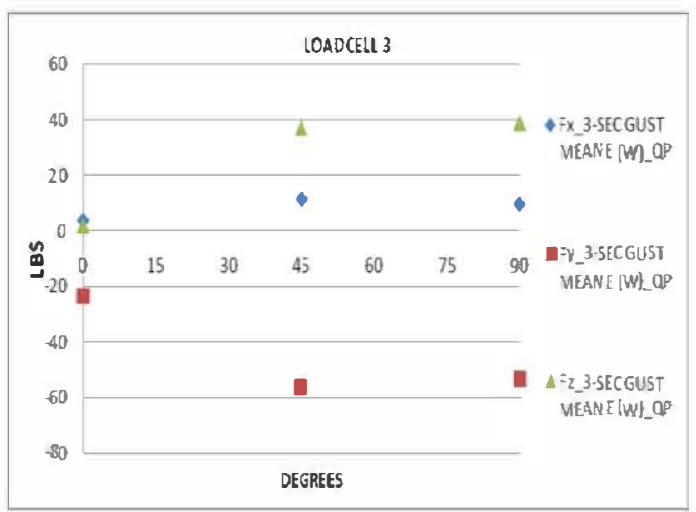

Graph 5.264: Mean Forces, Enclosed with Water at QuasiPeriodical 


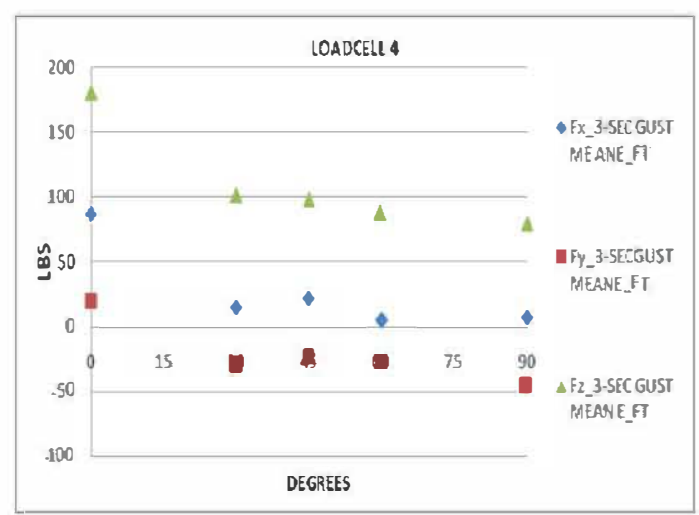

Graph 5.265: Mean Forces, Enclosed at Full Throttle

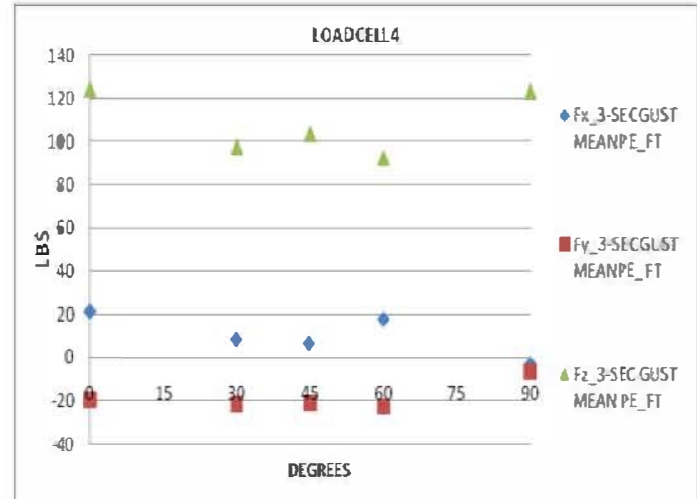

Graph 5.266: Mean Forces, Partially Enclosed at Full Throttle

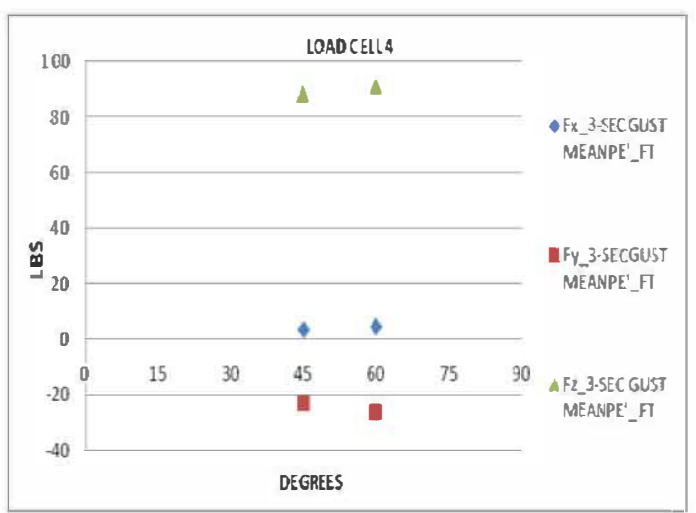

Graph 5.267: Mean Forces, Partially Enclosed' at Full Throttle

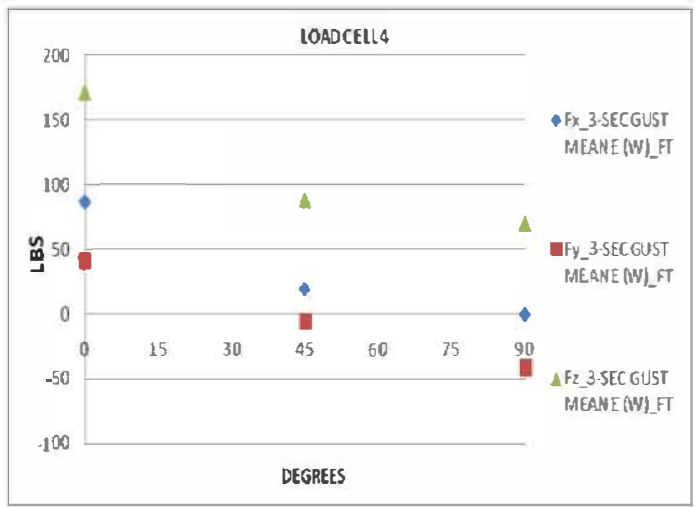

Graph 5.268: Mean Forces, Enclosed with Water at Full Throttle 


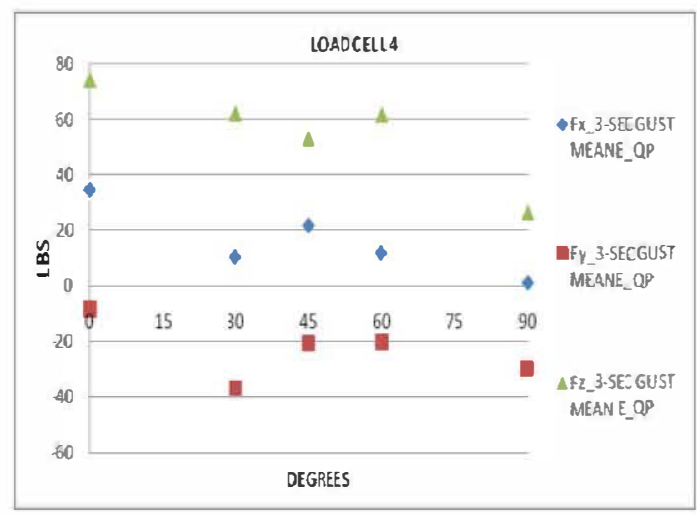

Graph 5.269: Mean Forces, Enclosed at Quasi-Periodical

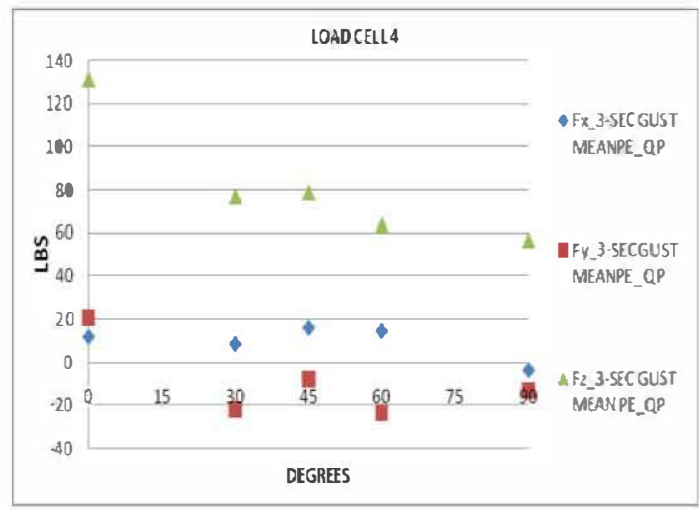

Graph 5.270: Mean Forces, Partially Enclosed at Quasi-Periodical

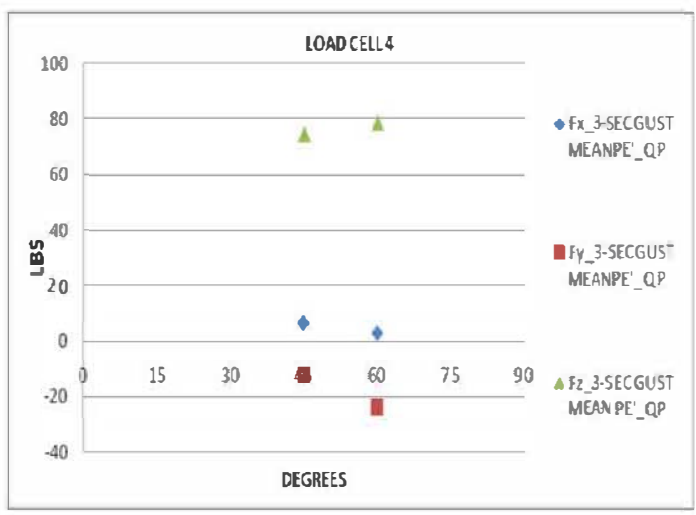

Graph 5.271: Mean Forces,

Partially Enclosed' at Quasi-

Periodical

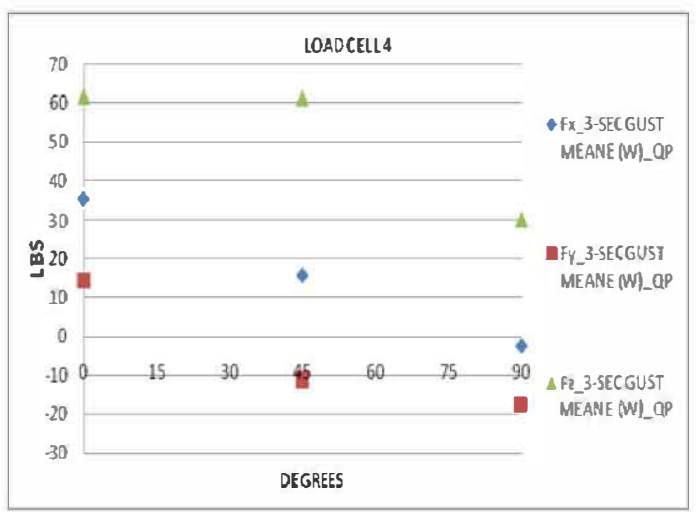

Graph 5.272: Mean Forces, Enclosed with Water at QuasiPeriodical 


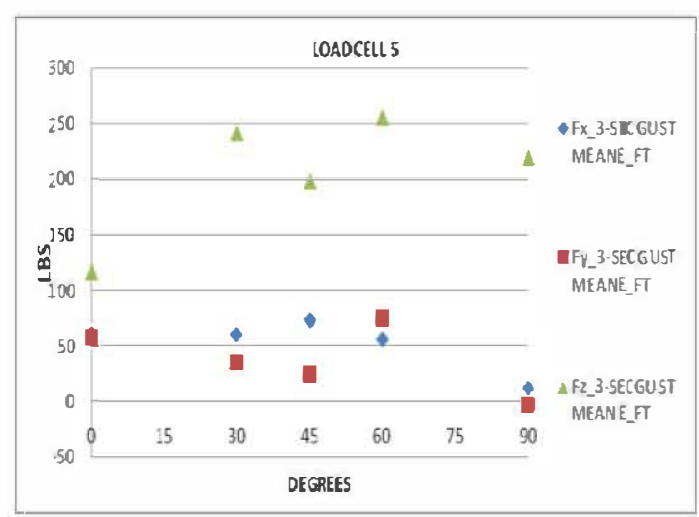

Graph 5.273: Mean Forces, Enclosed at Full Throttle

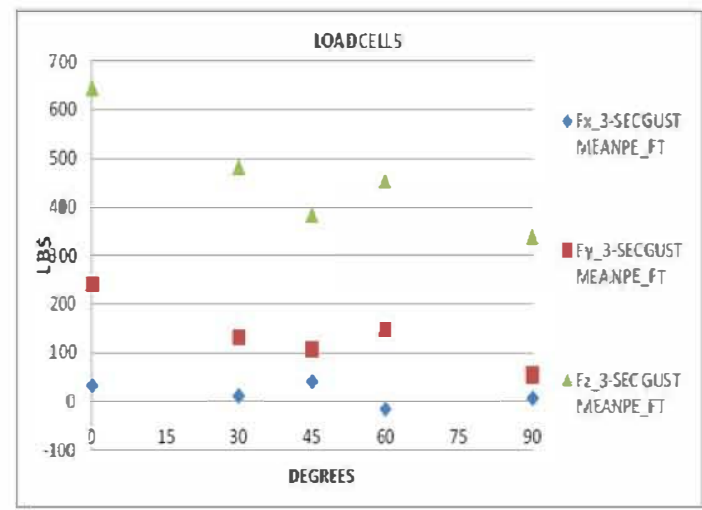

Graph 5.274: Mean Forces, Partially Enclosed at Full Throttle

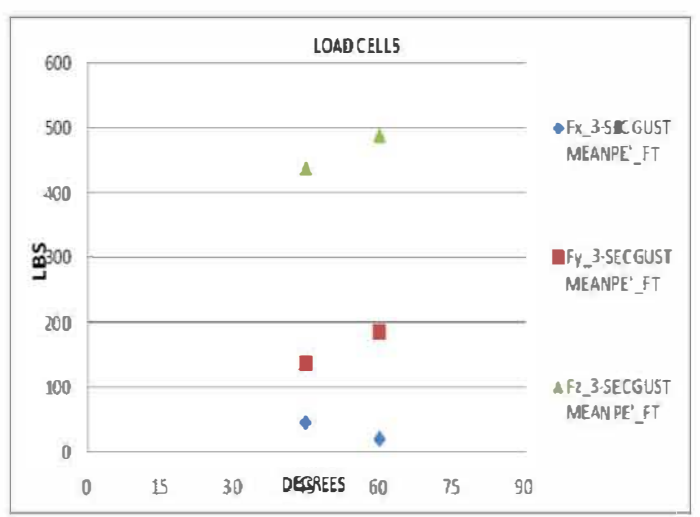

Graph 5.275: Mean Forces, Partially Enclosed' at Full Throttle

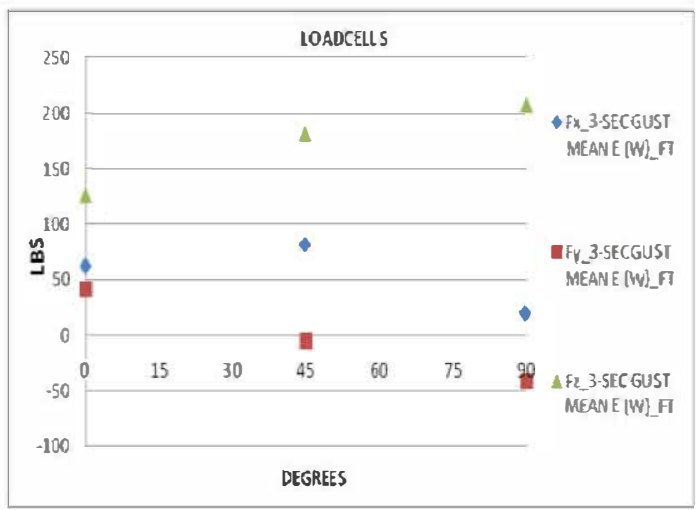

Graph 5.276: Mean Forces, Enclosed with Water at Full Throttle 


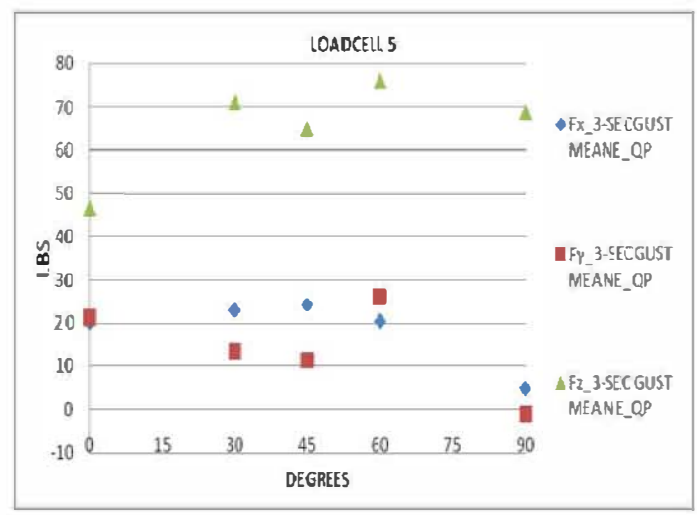

Graph 5.277: Mean Forces, Enclosed at Quasi-Periodical

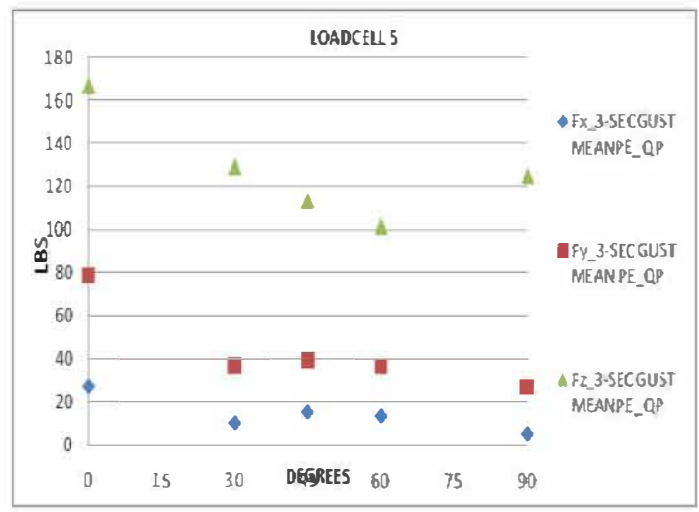

Graph 5.278: Mean Forces, Partially Enclosed at Quasi-Periodical

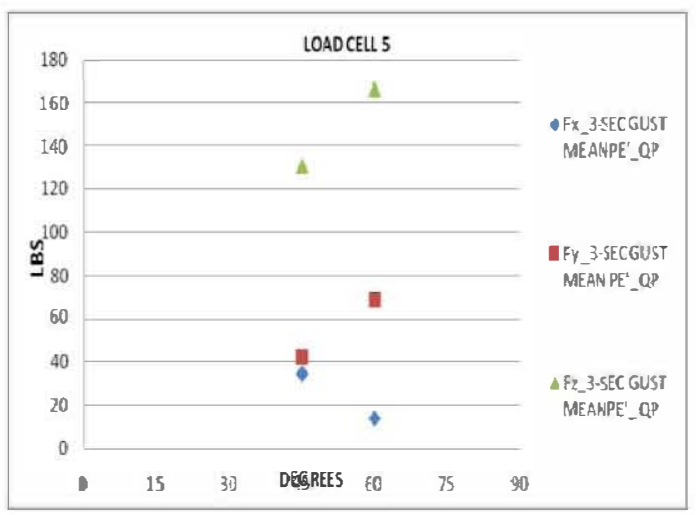

Graph 5.279: Mean Forces,

Partially Enclosed' at Quasi-

Periodical

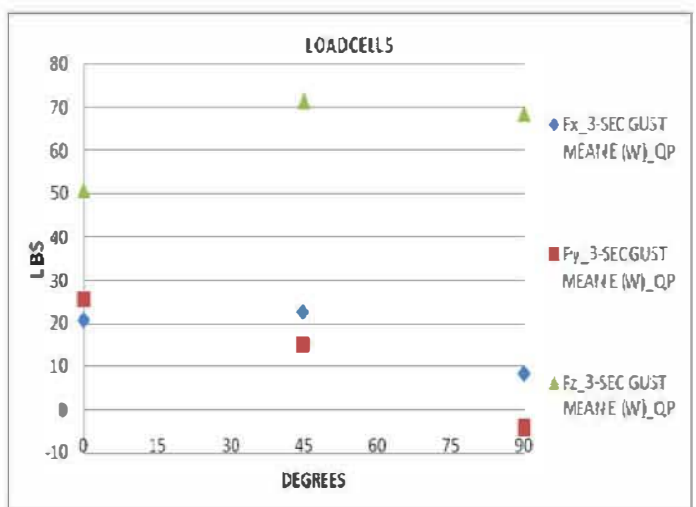

Graph 5.280: Mean Forces, Enclosed with Water at QuasiPeriodical 


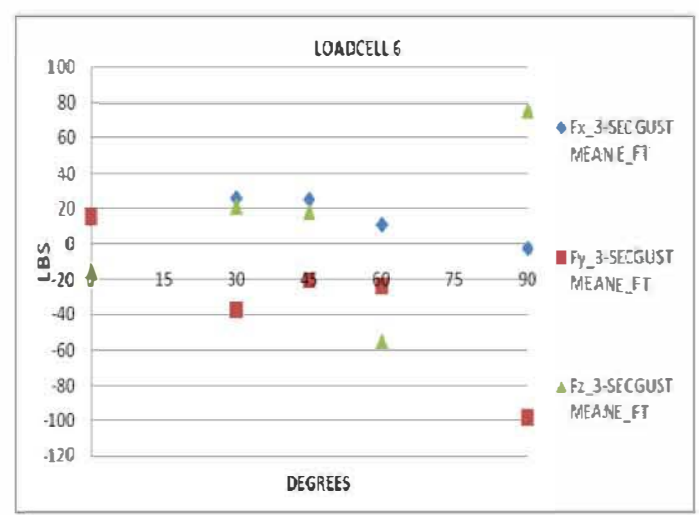

Graph 5.281: Mean Forces, Enclosed at Full Throttle

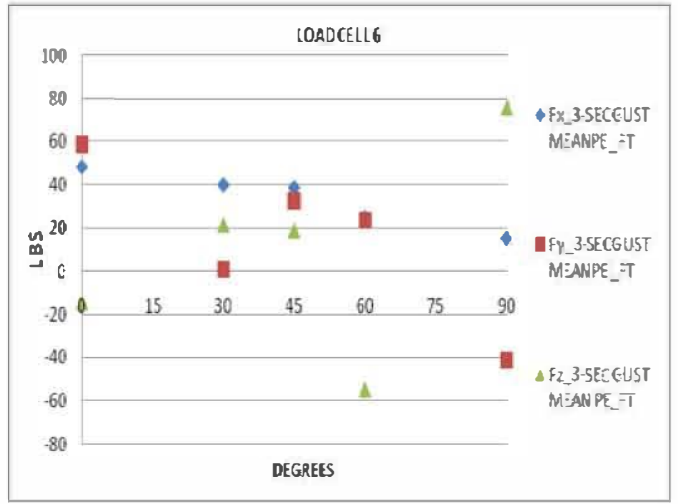

Graph 5.282: Mean Forces, Partially Enclosed at Full Throttle

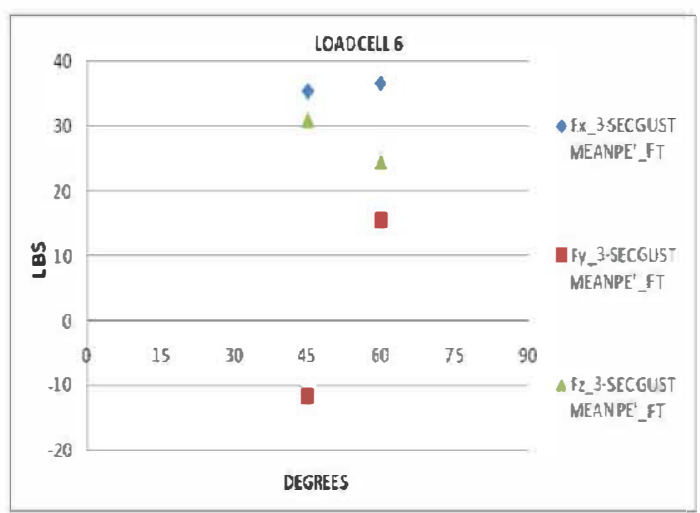

Graph 5.283: Mean Forces, Partially Enclosed' at Full Throttle

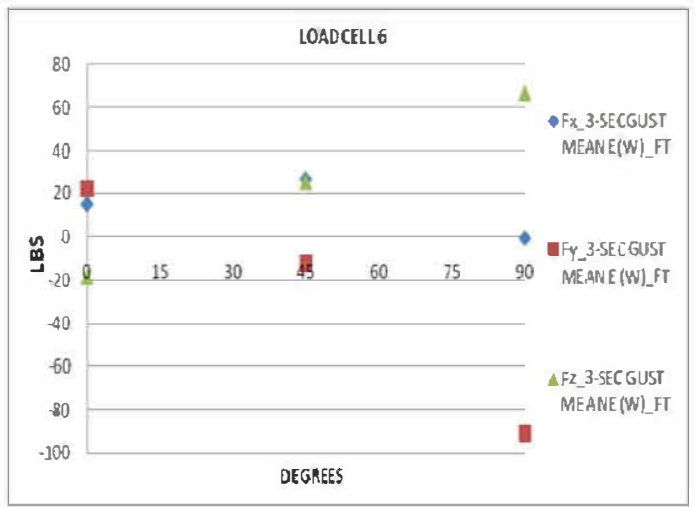

Graph 5.284: Mean Forces, Enclosed with Water at Full Throttle 


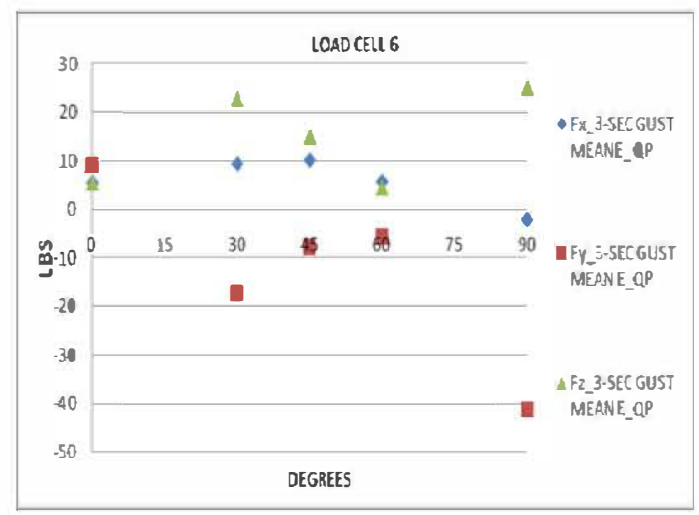

Graph 5.285: Mean Forces, Enclosed at Quasi-Periodical

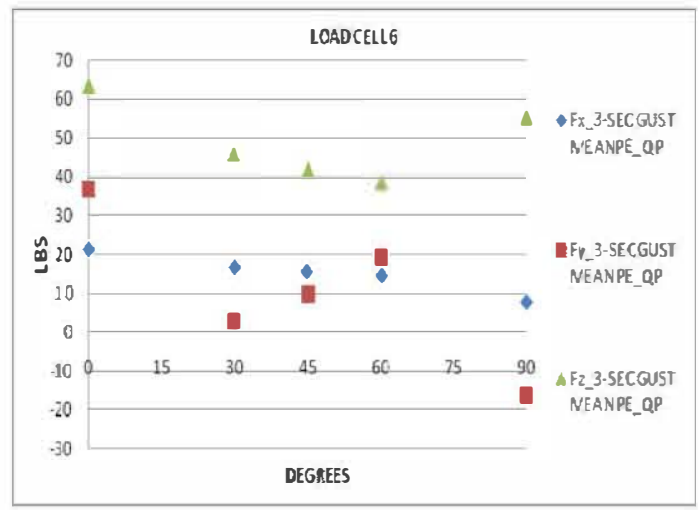

Graph 5.286: Mean Forces, Partially Enclosed at Quasi-Periodical

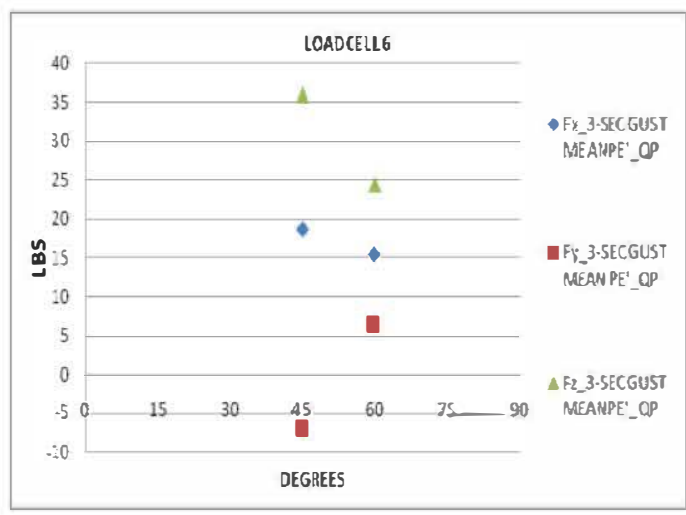

Graph 5.287: Mean Forces,

Partially Enclosed' at Quasi-

Periodical

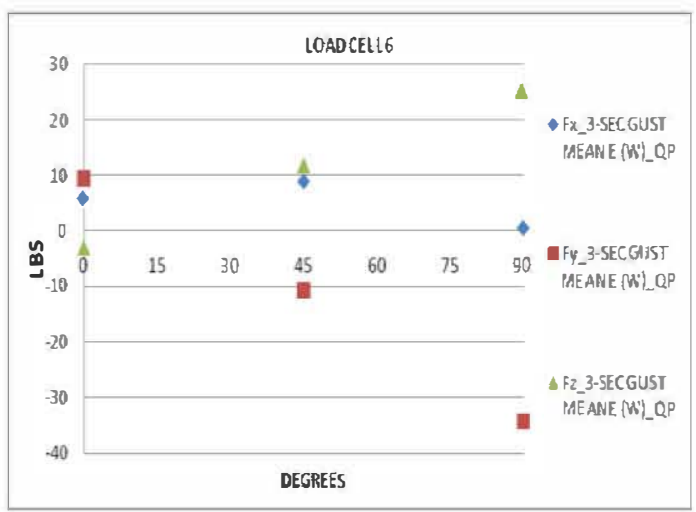

Graph 5.288: Mean Forces, Enclosed with Water at QuasiPeriodical 


\subsubsection{Strain Time Histories}

The data obtained from the strain gages provided an indication of the amount of strain induced in the vertical lap of each GFRP connection during the WoW testing. The data showed that minimal strains were induced. Sample plots (for connection 5) are shown.

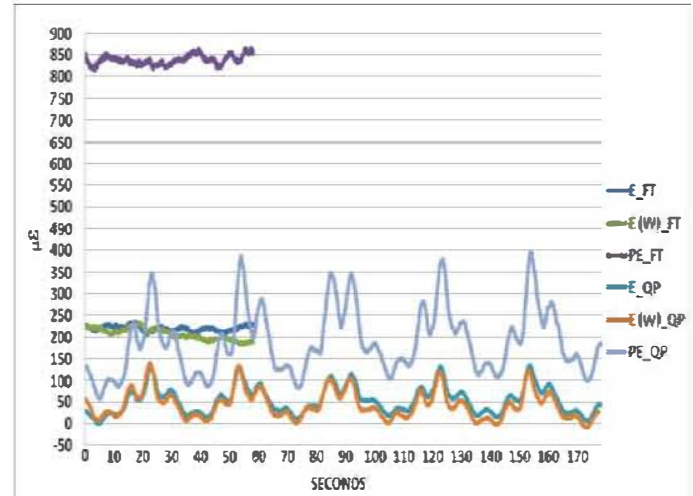

Graph 5.289: Strain for $0^{\circ}$ Test

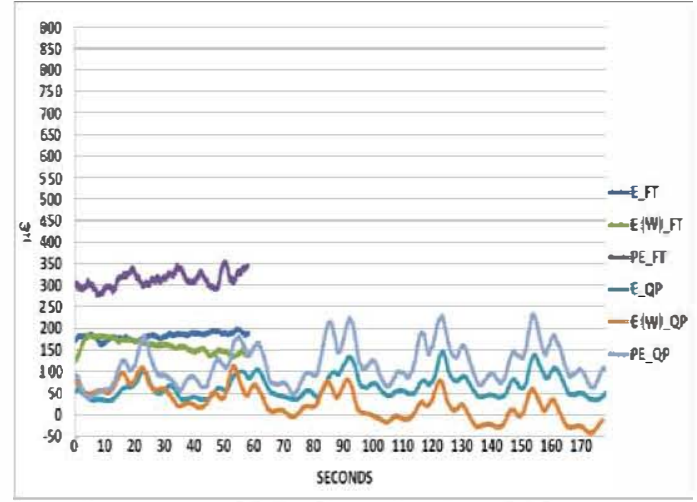

Graph 5.290: Strain for $90^{\circ}$ Test

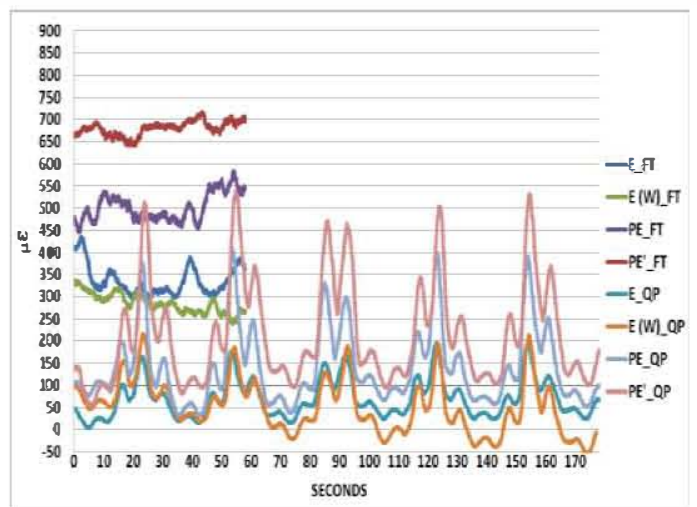

Graph 5.291: Strain for $45^{\circ}$ Test

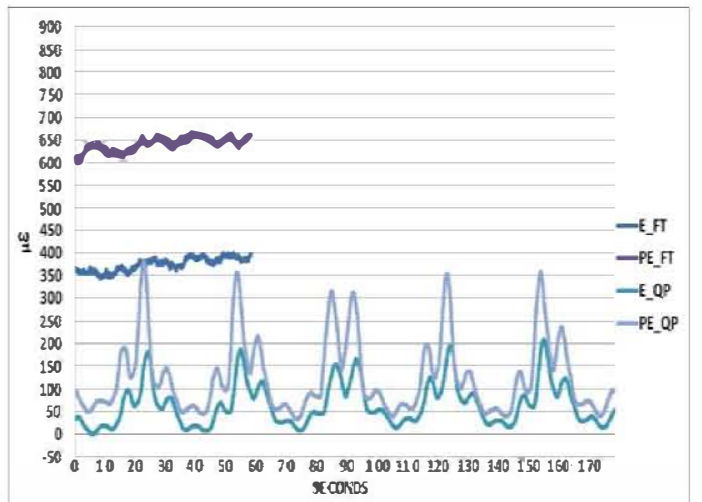

Graph 5.292: Strain for $30^{\circ}$ Test

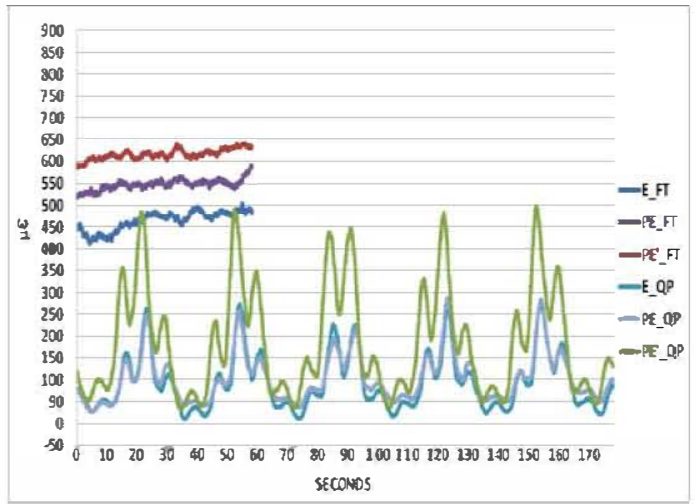

Graph 5.293: Strain for $60^{\circ}$ Test 


\subsubsection{Horizontal Displacement (Parallel to the Side Walls) Time Histories}

The data obtained from the LVDTs provided an indication of the horizontal deflections (parallel to the side walls) of the connections during the WoW testing. The data showed that minimal displacements were induced. Sample plots (for connection 5) are shown.

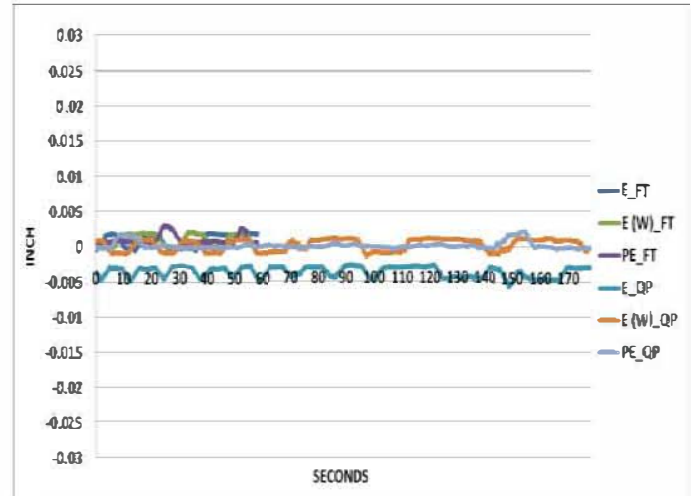

Graph 5.294: Displacement: $0^{\circ}$ Test

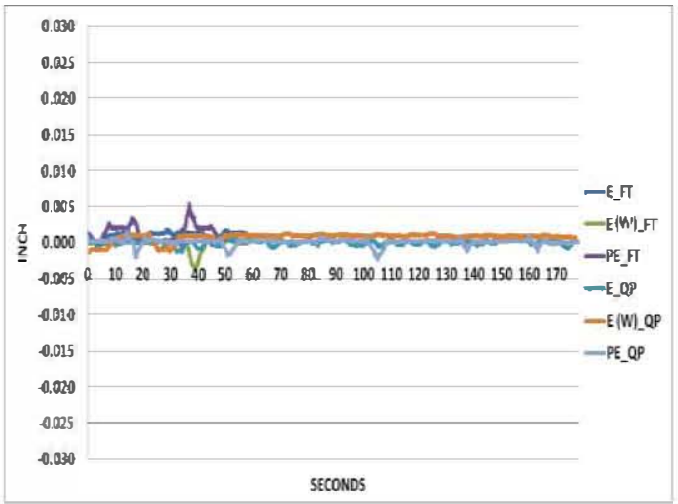

Graph 5.295: Displacement: $90^{\circ}$ Test

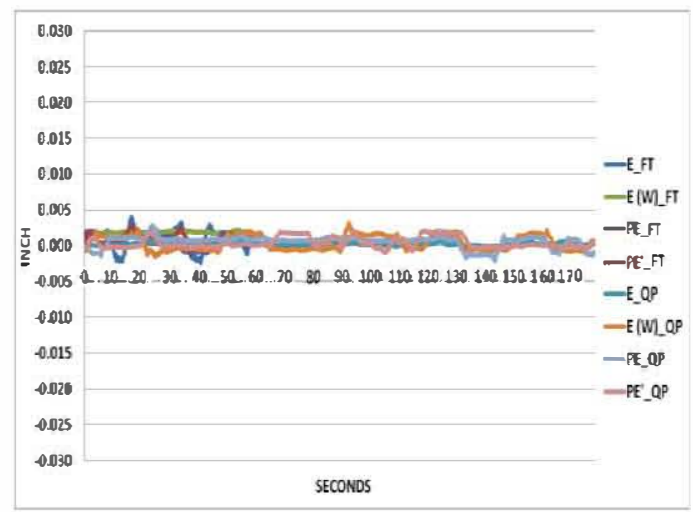

Graph 5.296: Displacement: $45^{\circ}$ Test

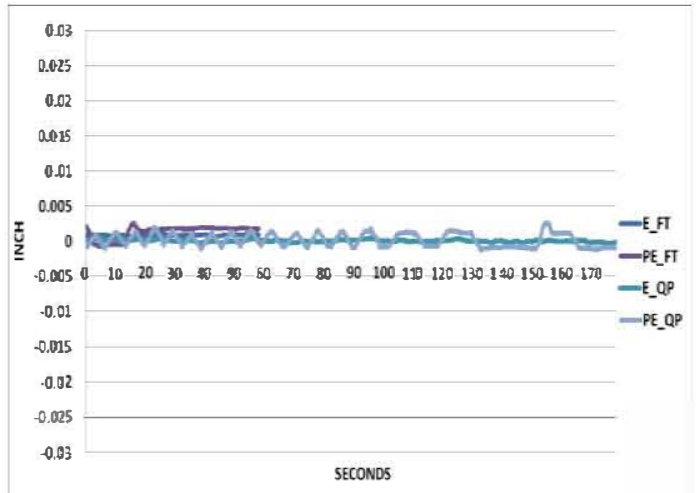

Graph 5.297: Displacement: $30^{\circ}$ Test

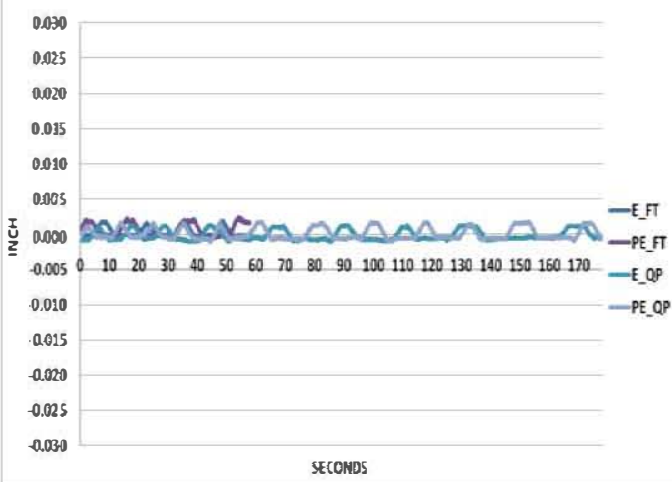

Graph 5.298: Displacement: $60^{\circ}$ Test 


\subsubsection{1) Horizontal Deflection (Perpendicular to the Side Walls) Time Histories}

The data obtained from the string pots provided an indication of the horizontal deflection (perpendicular to the side walls) of the connections during the WoW testing. The data showed that minimal deflections were induced. Sample plots (connection 1) are shown.

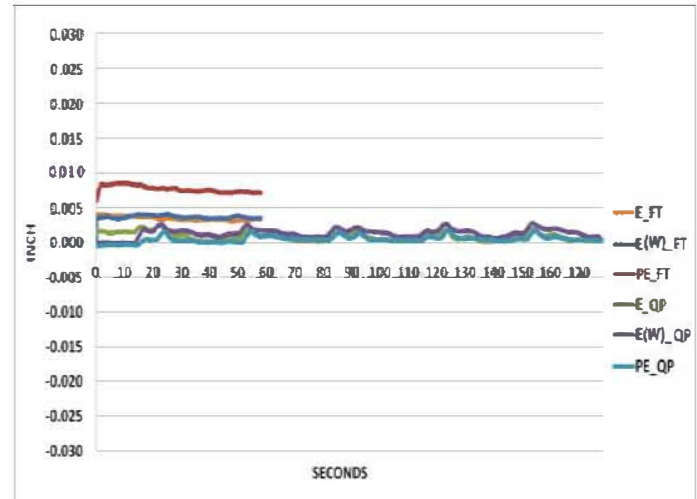

Graph 5.299: Deflection: $0^{\circ}$ Test

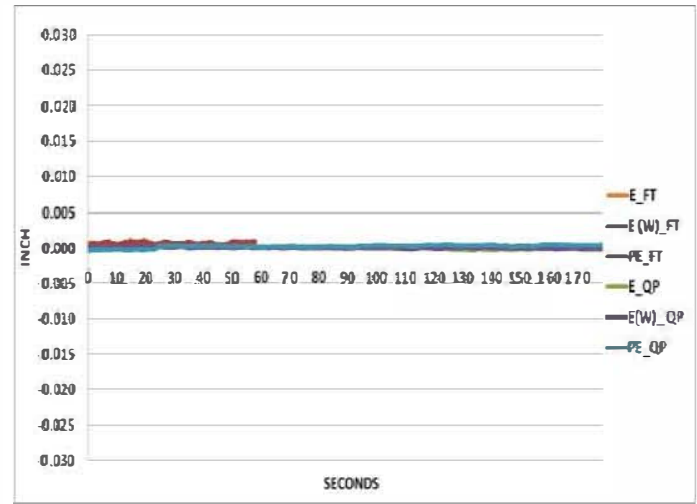

Graph 5.300: Deflection: $90^{\circ}$ Test

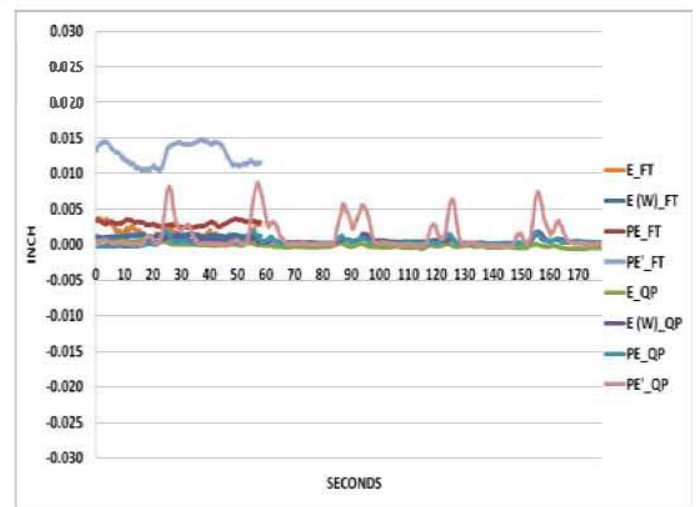

Graph 5.301: Deflection: $45^{\circ}$ Test

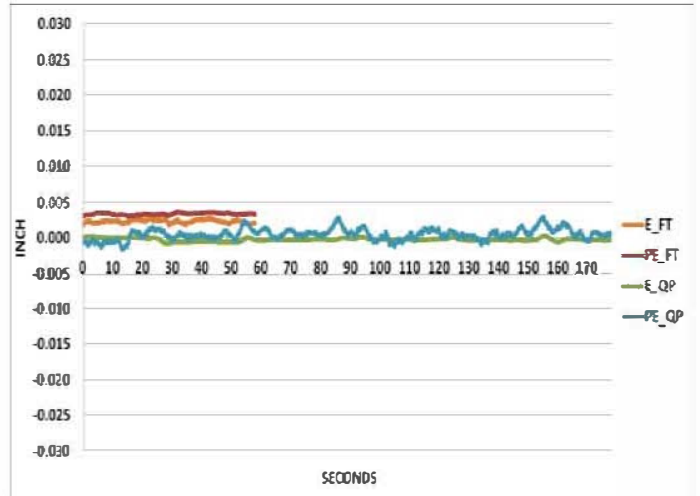

Graph 5.302: Deflection: $30^{\circ}$ Test

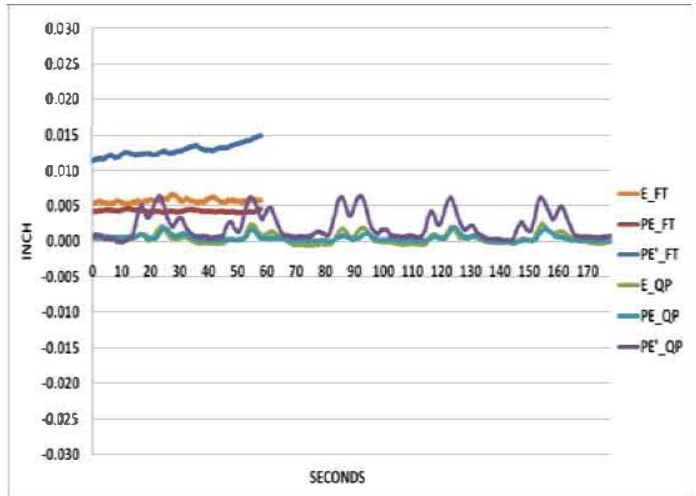

Graph 5.303: Deflection: $6^{\circ}$ Test 


\subsubsection{Vertical Deflection Time Histories}

The data obtained from the string pots provided an indication of the vertical deflection of the connections during the WoW testing. The data showed that minimal deflections were induced. Sample plots are shown below for connection 1 for various angles of attack.

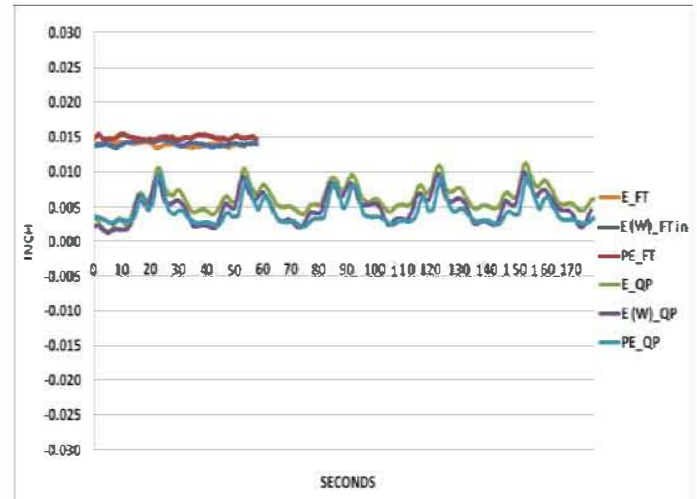

Graph 5.304: Deflection: $0^{\circ}$ Test

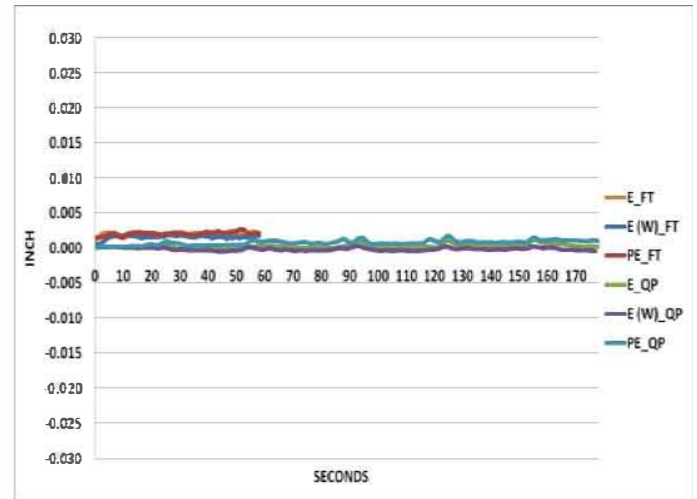

Graph 5.305: Deflection: $90^{\circ}$ Test

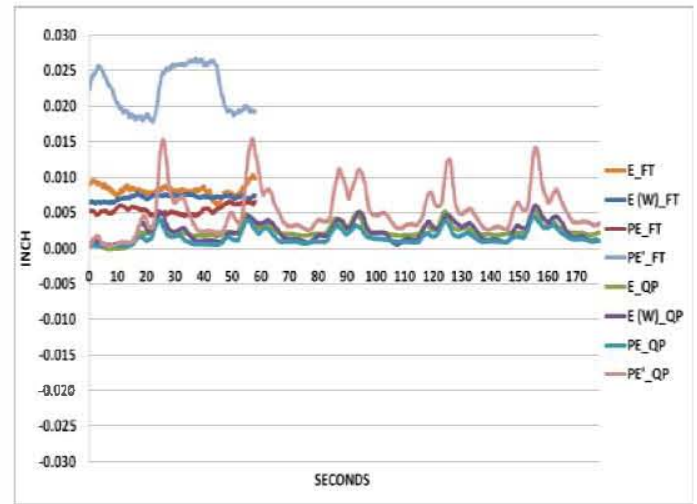

Graph 5.306: Deflection: $45^{\circ}$ Test

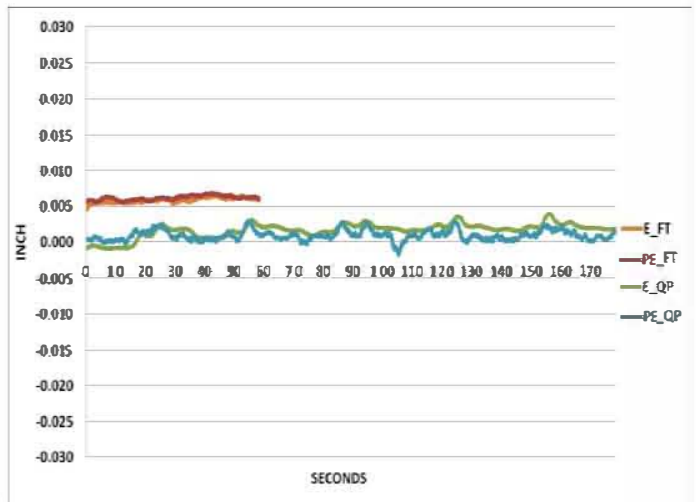

Graph 5.307: Deflection: $30^{\circ}$ Test

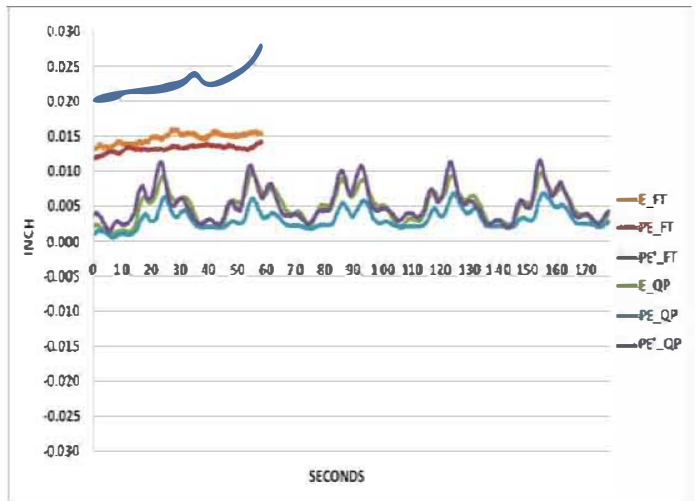

Graph 5.308: Deflection: $6^{\circ}$ Test 


\subsubsection{Internal Pressure Time Histories}

The data obtained from the pressure transducers helped to estimate the internal pressure generated by simulating breach of the building envelope. The maximum difference, related to the uplift loading on a connection (\#5), between enclosed and partiallyenclosed conditions was observed for $0^{\circ} \mathrm{AOA}$. The uplift force time histories and corresponding mean uplift forces for connection 5 for enclosed and partially-enclosed conditions for $0^{\circ} \mathrm{AOA}$ and full throttle testing are shown in Graphs 5.309, 5.310.

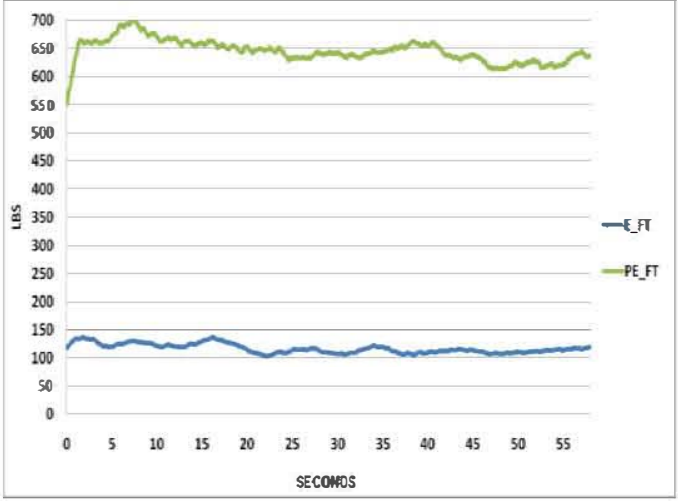

Graph 5.309: Uplift Load Time Histories for Connection \#5

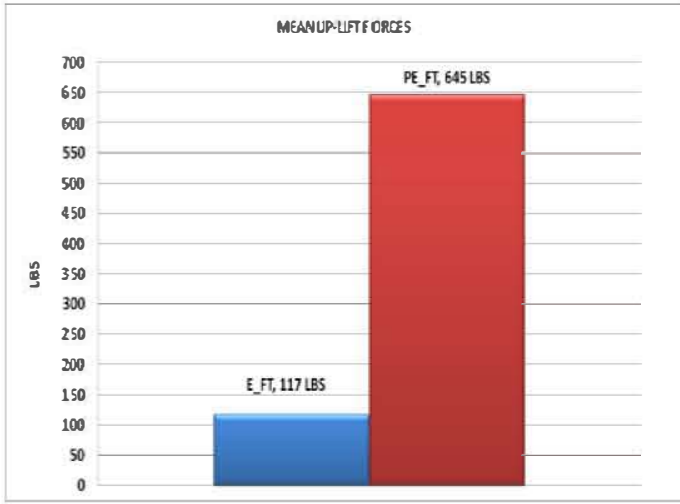

Graph 5.310: Mean Up-Lift Loads of for Connection \#5

The partially-enclosed condition was simulated by removing the windward window and opening the door. The corresponding internal pressure time histories obtained by pressure transducers 3, 4, and 5 (near connection 5) and the mean internal pressure values are shown in Graphs 5.311 to 5.315 . 


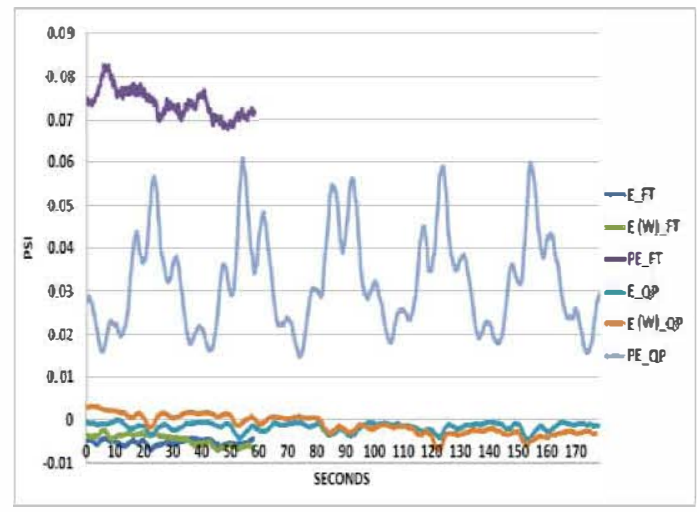

Graph 5.311: Internal Pressure: Transducer \#3

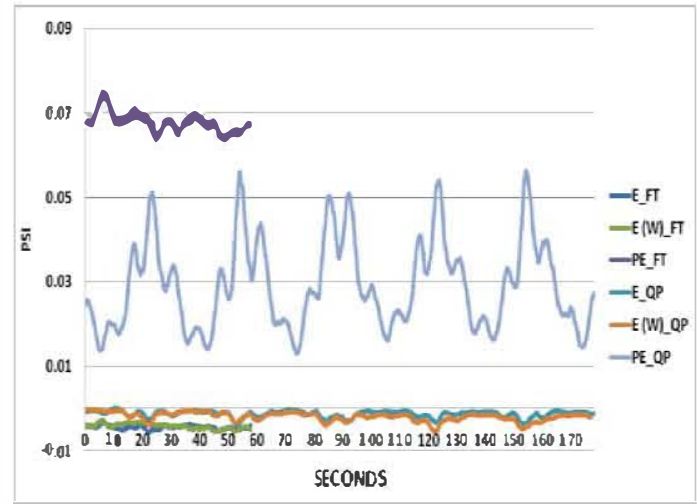

Graph 5.312: Internal Pressure Transducer \#4

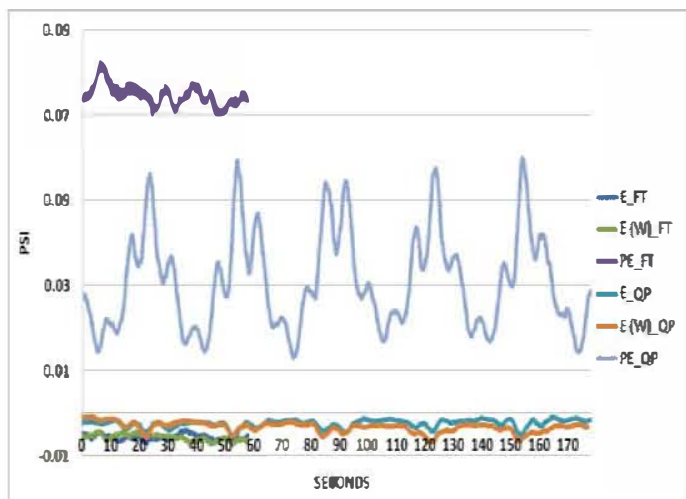

Graph 5.313: Internal Pressure: Transducer \#5

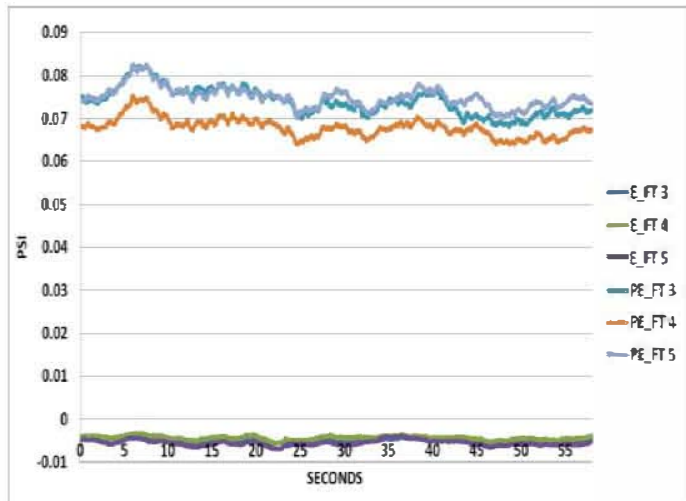

Graph 5.314: Internal Pressure: Transducers \# 3, 4 \& 5 (E \& PE at FT)

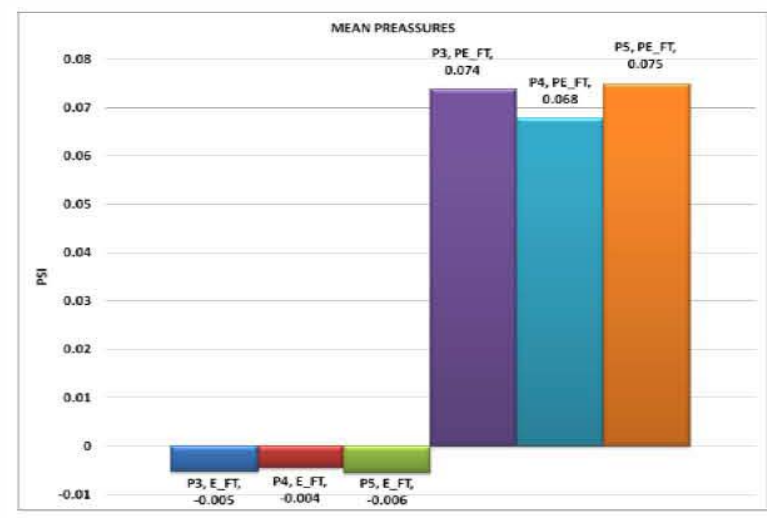

Graph 5.315: Mean Internal Pressures: Transducers \#3, 4, \& 5 (E \& PE at FT) 


\subsection{Discussion of Results}

The previous section, 5.6 illustrated by graphical representations all of the results obtained from the thirty WoW tests. In sections 5.6.1.1 to 5.6.1.5 the time histories of the load cells in the five phases $\left(0^{\circ}, 90^{\circ}, 45^{\circ}, 30^{\circ}\right.$ and $\left.60^{\circ}\right)$ of the experiments were graphically represented. The graphs were separated into individual load (Fx, Fy, Fz) and moment (Mx, My and Mz) components for all the six load cells installed underneath the GFRP roof-to-wall connections. The graphs contained the results of all the different conditions tested:

- Enclosed condition tested using full-throttle and quasi-periodic waveforms for all angles of attack $\left(0^{\circ}, 90^{\circ}, 45^{\circ}, 30^{\circ}\right.$ and $\left.60^{\circ}\right)$

- Enclosed condition tested under simulated wind-driven rain using full-throttle and quasi-periodic waveforms for $0^{\circ}, 45^{\circ} \& 90^{\circ}$ angles of attack

- Partially enclosed (PE) condition tested using full-throttle and quasi-periodic waveforms for all angles of attack $\left(0^{\circ}, 90^{\circ}, 45^{\circ}, 30^{\circ}\right.$ and $\left.60^{\circ}\right)$

- Partially enclosed (PE') condition tested using full-throttle and quasi-periodic waveforms for $45^{\circ} \& 60^{\circ}$ angles of attack.

Each test was performed using a 1 minute flat waveform (full-throttle; at maximum rpm of the WoW engines and generating high frequency turbulence only) and 3 minutes quasi-periodic waveform (generating low frequency turbulence components with $0.03,0.13$ and $0.3 \mathrm{~Hz}$, in addition to high frequency turbulence) (Huang et. at, 2008). Thus turbulence intensities for the flat waveform and the quasi-periodic waveform generated wind flows are shown in Table 3.2 as $4.6 \%$ and $23.8 \%$, respectively. The difference is due to the presence of low frequency fluctuations associated with the 
quasi-periodic waveform generated wind flow. Though the peak 3-sec gusts wind speeds are comparable for the two different waveform generated flows the mean wind speeds for the flat waveform case is considerably higher than the quasi-periodic waveform case. As such the loads recorded on the roof-to-wall connections for the flat-waveform (or full throttle) cases are higher than those for the quasi-periodic waveform cases. However the proportionalities between the mean uplift, in-plane, and out-of-plane forces are very similar for both waveforms as depicted by the plots. This emphasizes that the higher turbulence generated by the low frequency fluctuations of the wind does not affect the proportionalities between the mean uplift and lateral forces induced on the connections. Thus for further testing of the GFRP connections to failure under tri-axial loading in SCL, only the data obtained for the flat waveform tests are used.

Hurricane winds are accompanied by wind-driven rain. Aerodynamic loading on buildings and their components and connections, due to wind effects only, can differ from aero-hydrodynamic loading induced by the combined effect of wind and impinging rain. Generally wind tunnels cannot be used for comprehensive research into this phenomenon. This limitation can affect standard provisions, whose adequacy needs therefore to be assessed. For differences between aerodynamic and aero-hydrodynamic loading to be determined it is necessary to perform repeatable, controlled full-scale tests simulating hurricane winds and rain. WoW was used to determine if there is any significant difference between aerodynamic and aero-hydrodynamic loading induced on the GFRP connections by testing under simulated hurricane wind and wind-induced rain, respectively. Based on the results no significant increase in load was observed during the 
wind-driven rain tests as compared to wind with no rain. Thus the data used for failure testing in SCL were obtained from the wind tests.

Design wind loads on building components and connections are a combination of external and internal pressures. Internal pressures can contribute to a significant portion of the design wind load (Irwin and Sifton, 1998), depending on opening size and location. This is especially true in the event that windborne debris suddenly breach the building envelope creating sizeable openings. While significant work has been undertaken in boundary layer wind tunnels (BLWT) to assess external pressures on a building facade, research into internal pressures has been less extensive, and has typically been limited to a few building opening scenarios. Aynsley et al. (1977) investigated the impact of wall porosity on internal pressures. Stathopoulos et al. (1979) carried out BLWT experiments in order to examine the impact of various opening configurations on internal pressures for different background leakage values, wall openings and exposures. A state-of-the- art review was undertaken by Oh et al. (2007). Recently Karava (2008) studied internal pressures at model scale for a dominant opening in the building facade for ventilation purposes. For the current study on roof-to-wall connections full-scale testing was performed to determine the effects of internal pressure changes on the connections due to breach of building envelope. The testing included two conditions pertaining to internal pressures: enclosed and partially-enclosed (simulating breach of envelope) conditions as specified in ASCE 7-05. The test specimen was provided with operable panels (representing windows and doors) which were removed to simulate the breach of the envelope effects. Internal pressure data were collected by pressure transducers installed inside the test specimen. The change in the internal pressure was correlated with the 
change in the loading on the connections. The maximum difference in uplift loading between enclosed and partially-enclosed conditions was observed for connection \#5 for $0^{\circ}$ AOA. The mean uplift forces for connection 5 for enclosed and partially-enclosed conditions for $0^{\circ} \mathrm{AOA}$ and full-throttle testing were $117 \mathrm{lbs}$ and $645 \mathrm{lbs}$, respectively the difference being $528 \mathrm{lbs}$. The difference in the mean internal pressures between enclosed and partially-enclosed conditions was 0.08 psi. The tributary area for connection 5 was 35 sq. ft. which gives an additional load of about $400 \mathrm{lbs}$ on the connection due to the change in the internal pressure. Though the measured increase in loading on the connection is higher than the estimated increase based on internal pressure (which is based on approximation of tributary area and uniformity of internal pressure throughout the area), the experiments indicate how severe can be the effects of breach of building envelope on connections as the loading may increase several times (5.5 times in this case).

No significant movement of the roof structure or deformation/failure of the connections was observed under the highest wind generated by the WoW. In order to illustrate the minimal strains and deflections, two connections (connections 1 and 5) were selected and the time histories graphed for the strains and displacements. The strain for the vertical lap of the GFRP connection was limited 900 micro-strains. The horizontal and vertical deflections were limited to 0.015 inch and 0.03 inch, respectively.

The maximum recorded up-lift loads sustained by a single GFRP angle piece were observed at connection \#1 (332 lbs with a maximum recorded vertical GFRP strain of $185 \mu$ ) at $\mathrm{AOA} 0^{\circ}$ with a partially enclosed condition (see Graph 5.183 for the 3 -sec mean loads of load cell \#1). The maximum recorded in plane (parallel to side wall) load 
sustained by a single GFRP angle piece were observed at connection \#3 (105 lbs; strain was not recorded in the in plane direction of the GFRP connections), at AOA $30^{\circ}$ with a partially enclosed condition (see Graph 5.205 for the 3-sec mean loads of load cell \#3). Table 5.1 shows the ultimate load and strain results of the uni-axial component tests of the 3" x 1" GFRP connection used in the WoW tests. From the component and WoW test results it can be seen why the WoW tests could not achieve failure of the connection. The maximum ultimate up-lift load recorded at the component level test was more than double than that of the WoW results (666 lbs vs. $322 \mathrm{lbs}$, respectively); furthermore, the ultimate in-plane load was almost 26 times higher in the component tests vs. the WoW tests results (2760 lbs vs. $105 \mathrm{lbs}$, respectively). The up-lift strain at the component level was also more than double than the WoW strain results observed in connection \#1 (375 $\mu \quad$ vs. $185 \mu \quad)$.

\begin{tabular}{|c|c|c|c|c|c|}
\hline Component Test & $\begin{array}{l}\text { Test } \\
\text { No. }\end{array}$ & $\begin{array}{c}\text { Ultimate } \\
\text { Load/GFRP } \\
\text { Connection } \\
\quad(\text { lbs })\end{array}$ & $\begin{array}{c}\text { Ultimate } \\
\text { Strain/GFRP } \\
\text { Connection } \\
(\mu \quad)\end{array}$ & $\begin{array}{c}\text { Average } \\
\text { Load of } \\
\text { GFRP } \\
\text { Connection } \\
\text { (lbs)* }\end{array}$ & $\begin{array}{c}\text { Average } \\
\text { Strain of } \\
\text { GFRP } \\
\text { Connection } \\
(\mu \quad)^{*}\end{array}$ \\
\hline \multirow{3}{*}{ Up-Lift Test } & 1 & 762 & 357 & \multirow{3}{*}{666} & \multirow{3}{*}{375} \\
\hline & 2 & 450 & 340 & & \\
\hline & 3 & 785 & 428 & & \\
\hline \multirow{3}{*}{$\begin{array}{l}\text { Lateral In-Plane } \\
\text { (L1 or Parallel to } \\
\text { Side Walls) Tests }\end{array}$} & 1 & 2375 & $\mathrm{~N} / \mathrm{A}$ & \multirow{3}{*}{2760} & \multirow{3}{*}{ N/A } \\
\hline & 2 & 2630 & N/A & & \\
\hline & 3 & 3275 & N/A & & \\
\hline
\end{tabular}

* Un-Factored Results (i.e., FS=3)

Table 5.1: Uni-Axial Component Tests of 3" x 1" GFRP used in WoW Tests (Canbek, 2008) 
As mentioned earlier, the load cells measured uplift, in-plane (parallel to the side walls), and out-of-plane (perpendicular to the side walls) loads experienced by each GFRP connection. These combinations of loads were used in the next phase of the research, i.e., tri-axial loading of the GFRP connection in SCL till failure at the component level. For each test the three force components were converted to a resultant mean load in order to test the GFRP connections more realistically using aerodynamic loading obtained from WoW tests. A total of 36 resultant forces were obtained from the loads recorded at the WoW and were used to test the newly developed GFRP connections and metal hurricane clips. Hurricane clips were tested to provide a comparison of performance between FRP and metal connections subjected to simultaneous tri-axial loading. 


\section{Tri-Axial Component Testing of the GFRP Connections to Failure}

\subsection{Introduction}

The WoW tests were vital in understanding the wind induced loads on a connection and the corresponding failure modes necessary for an effective investigation of the performance of connection systems in high wind events. This knowledge was utilized to develop an innovative testing method, tri-axial testing, to determine if a fastener can withstand extreme wind forces.

The WoW testing performed using GFRP connections on a one-story gable-roof timber structure instrumented with the six load cells (each with 6-DOF) at the roof-towall connections, recorded the aerodynamic and aero-hydrodynamic loads effects at five angles of attack $\left(0^{\circ}, 30^{\circ}, 45^{\circ}, 60^{\circ}, \& 90^{\circ}\right)$ and two internal pressure conditions (enclosed and partially enclosed). The load cells measured uplift, in-plane (parallel to the side walls), and out-of-plane (perpendicular to the side walls) loads experienced by each GFRP connection. The three component forces (tri-axial mean loads), based on the aerodynamic loading obtained from WoW tests, were combined into a series of resultant

mean forces that were then used to test GFRP component connections in the SCL up to failure in a more realistic manner.

A total of 23 resultant forces were obtained from the loads recorded at the WoW. Because of testing set-up limitations, 23 of the 36 resultant forces were used to test the newly developed GFRP connections and hurricane clips. Hurricane clips were tested to 
provide a comparison of performance between GFRP and metal connections subjected to simultaneous tri-axial loading.

\subsection{Rationale for Tri-Axial Testing of GFRP Connection}

Research conducted at FIU on the performance of mechanical fasteners; seem to indicate a propensity to incorrectly report a mechanical fastener load capacity in the product manufacturers' literature (Ahmed et al., 2009). Research results showed that the increase of allowable load capacity in a timber connection joint with two or four metal fasteners is not linear in nature and the failure modes were highly dependent on the number of fasteners per joint. Therefore, the addition of multiple metal fasteners does not necessary increase the connection capacity, as is currently and incorrectly indicated in product manufacturers' literature (Ahmed et al., 2009). Also the general procedure for fastener testing is to test the connector under uni-axial loading - uplift or in-plane shear or out-of-plane shear. The tests are not usually performed using simultaneous tri-axial loading which can produce different results when compared to those obtained from testing under individual axial or shear loading. However under real storms a fastener will experience simultaneous uplift, in-plane, and out-of-plane loading which will have specific ratios based on several factors (e.g., location of the connection, type of the roof, etc). Thus the current procedure can lead to incorrect specifications of the allowable capacity of a mechanical fastener.

To circumvent the above limitations the current testing approach is based on simultaneous loading (uplift, in-plane or parallel to the side walls, and out-of-plane or perpendicular to the side walls) with proportionalities obtained from realistic wind 
testing. Such testing method is more realistic than the traditional unidirectional testing method as it takes into account the behavior of a connection under simultaneous aerodynamic tri-axes loads present during a high wind event, as observed in the results of the WoW GFRP tests (see Chapter 5). Therefore, new tri-axial test protocol was established and connections tested to failure at the SCL using ratios of uplift to in-plane lateral and out-of-plane lateral loads. Each test in SCL represented a particular tri-axial aerodynamic loading obtained at the WoW for specific parameters: connection location, angle of attack, and internal pressure condition (enclosed or partially enclosed condition). The results were compared with those from testing using individual loading.

\subsection{Test Specimen, Setup and Instrumentation}

The component test specimens used in the tri-axial tests were built by research personnel. A total of 23 GFRP and 23 metal connector specimens were tested. Each specimen composed of a 24 inch double top-plate and a 14 inch perpendicular member, which simulated the bottom chord of the truss. Each specimen was built using SPF No. 2 -2 x 6 inch lumber with two separate connection systems, GFRP (Figure 6.1) or metal connectors (Figure 6.2). The test system was composed of a double acting 10,000 lbs hydraulic jack that could pull on the component specimen using a cable and pulley (Figure 6.3). A load cell between the specimen and pulley recorded the ultimate failure load, via a DAQ computer. Each specimen was bolted to an I-beam that in turn was attached to two channels bolted to the SCL tie-downs. By moving the specimen NorthSouth and East-West the resultant loading could be simulated (Figure 6.4). 


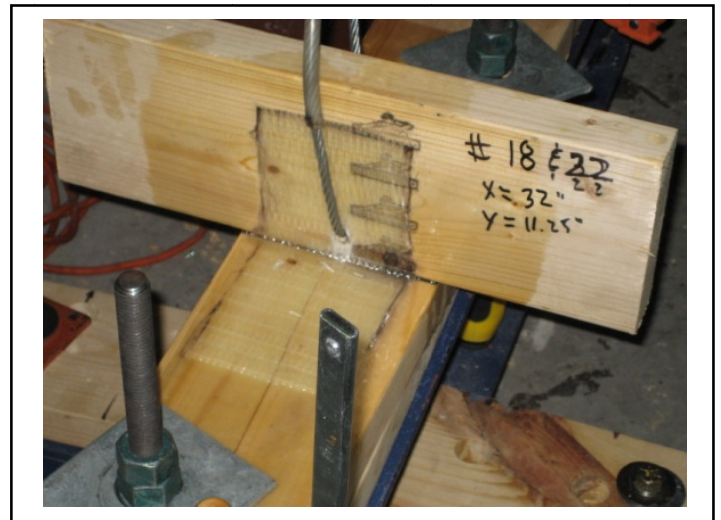

Figure 6.1: GFRP Specimen

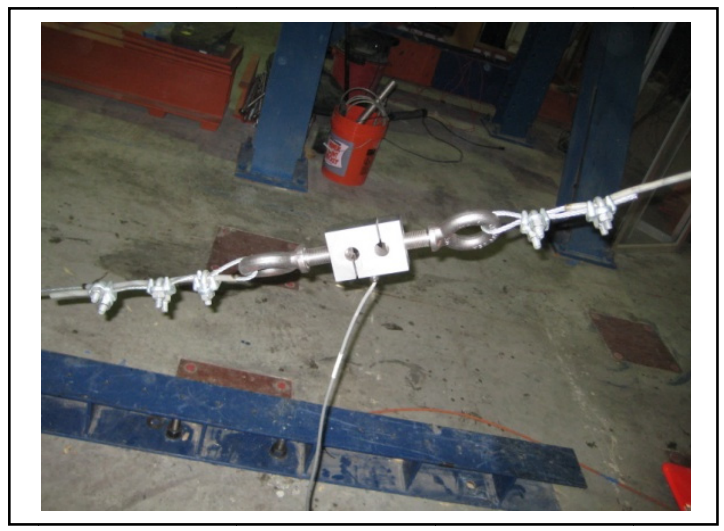

Figure 6.3: Load Cell Figure

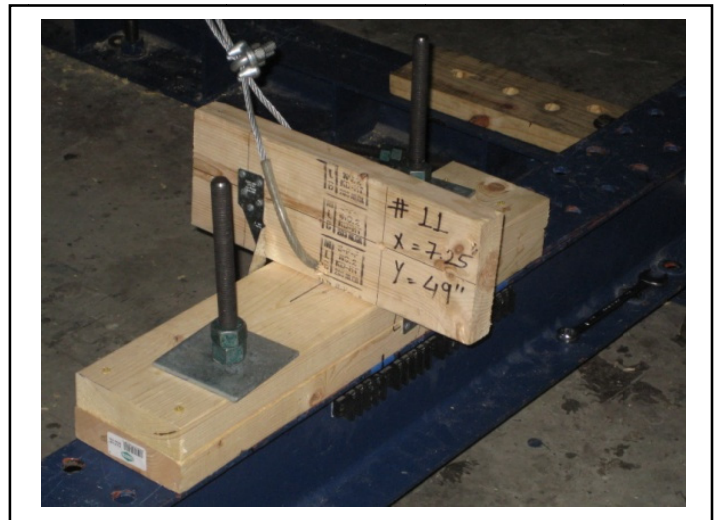

Figure 6.2: Metal Fastener Specimen

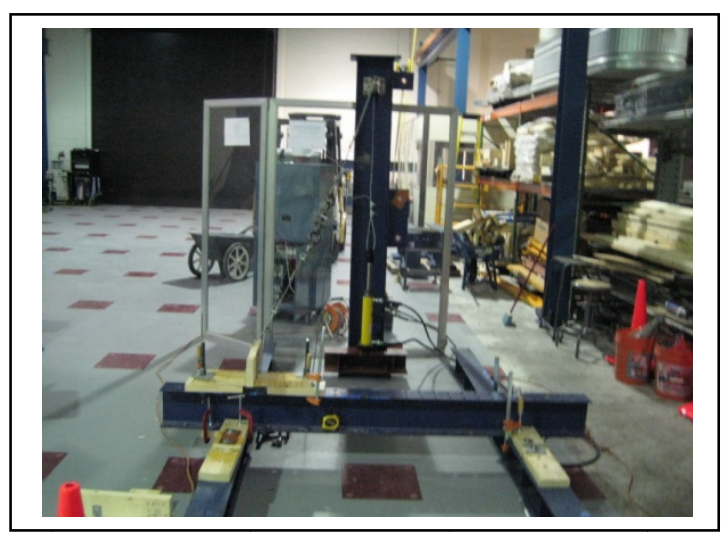

Figure 6.4a: SCL Test System

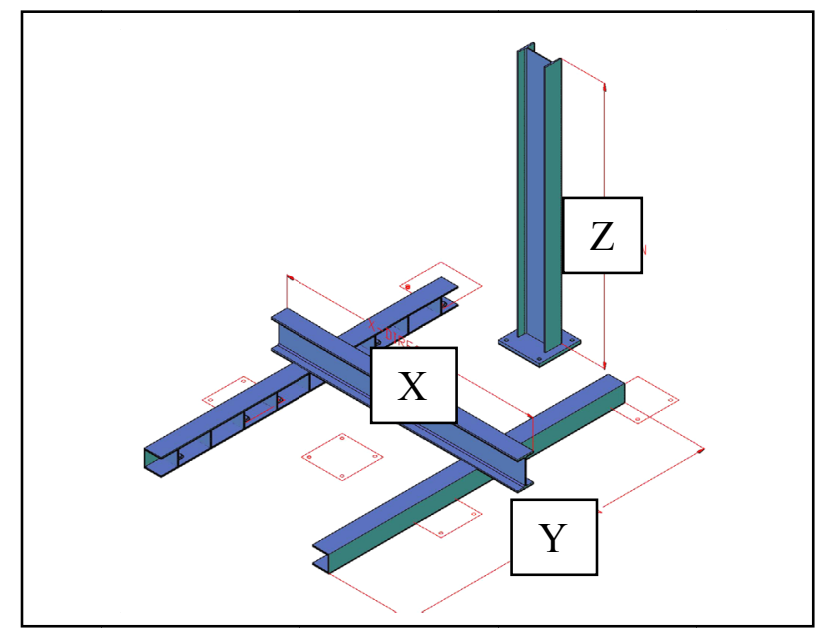

Figure 6.4b: Tri-Axial System, X, Y \& Z Directional Illustration 


\subsection{SCL Testing Protocol of Tri-Axial Component Specimens}

A total of 46 tri-axial tests were performed at the SCL (23 tests for GFRP connections and 23 tests for metal connectors). The tests were performed at 23 locations, each location simulating a particular tri-axial aerodynamic loading scenario as obtained from WoW testing. As explained in Chapter 5 the simulated rain didn't produce any significant loading difference when compared to the wind-only test condition. Also the ratios of the mean uplift loading to the lateral loading were similar for the flat and quasiperiodic waveform testing. The modified partially enclosed condition (PE') condition also didn't produce much different results when compared to those produced under the partially enclosed condition (PE). Thus the WoW results used for SCL testing were those obtained for the wind-only condition tested using the flat waveform (Full-Throttle) with "Enclosed" and "Partially Enclosed" building conditions. Also, for the current SCL testing the aerodynamics moments were neglected because of the difficulty in simulating tri-axial moments with the current test set up in SCL. Tri-axial moment testing is recommended as future work. The specimens, one set with the GFRP connections (one connection - 2 - 9 × 5.5 inch GFRP pieces-- per specimen) and one set with metal connectors (two diagonally placed connectors per specimen) were tested at each of the 23 specified locations.

The locations were established using Tables 6.1 through 6.6 - which show the mean tri-axial aerodynamic forces obtained from WoW testing, their ratios and the locations of the specimens based on those ratios (the locations are compared using case numbers). The locations were determined using ratios of the two lateral forces divided 
by the up-lift force (i.e. $\mathrm{F}_{\mathrm{X}} / \mathrm{F}_{\mathrm{Z}}$ and $\mathrm{F}_{\mathrm{Y}} / \mathrm{F}_{\mathrm{Z}}$ ). Therefore, the vertical component of the 3-D coordinate system was constant. Moving the I-beam further away from the jack and pulley (i.e, in the North to South direction) simulated the $F_{Y}$-component (or the force perpendicular to the side walls in the WoW test specimen) (Figure 6.4). In a similar manner by moving the specimens on the I-beam from East to West simulated the $F_{X}$ component (or the force parallel to the side walls in the WoW test specimen (Figures 6.4 $a \& b)$.

\subsubsection{SCL Tri-Axial Test Cases}

The following, Tables 6.1 to 6.6 , were used to calculate the tri-axial component test locations, using the mean forces obtained from the WoW tests for enclosed and partially enclosed conditions tested at full-throttle for all five angles of attack $\left(0^{\circ}, 30^{\circ}\right.$, $45^{\circ}, 60^{\circ}$ and $90^{\circ}$ ). Since the height of the pulley used remained constant, ratios of the lateral forces parallel to the side walls $\left(\mathrm{F}_{\mathrm{X}}\right)$ and lateral forces perpendicular to the side walls $\left(\mathrm{F}_{\mathrm{Y}}\right)$ were divided by the up-lift forces $\left(\mathrm{F}_{\mathrm{Z}}\right)$, in order to calculate the distance $\mathrm{X}$ and $\mathrm{Y}$ used in the SCL tests. The following tables give the specimen locations for the tri-axial positions. The following tables give the specimen locations for the tri-axial positions. 


\begin{tabular}{|c|c|c|c|c|c|c|c|c|c|}
\hline \multicolumn{7}{|c|}{ Connection \#1 } & \multicolumn{3}{|c|}{ Location of the Specimen } \\
\hline Enclosed & $F_{x}($ lbs $)$ & $F_{y}(l b s)$ & $F_{z}($ lbs $)$ & $\begin{array}{l}\text { Total Load } \\
\text { (Ibs) }\end{array}$ & Fx/Fz & Fy/Fz & $X$ (in.) & $Y$ (in.) & $Z$ (in.) \\
\hline AOA 0 & 91.8 & 8.9 & 166.1 & 190.0 & 0.6 & 0.1 & 35.9 & 3.5 & 65.0 \\
\hline AOA 30 & 10.9 & -146.8 & 140.4 & 203.4 & 0.1 & -1.0 & 5.0 & -68.0 & 65.0 \\
\hline AOA 45 & 52.3 & -89.4 & 108.6 & 150.1 & 0.5 & -0.8 & 31.3 & -53.5 & 65.0 \\
\hline AOA 60 & 92.2 & -152.6 & 84.0 & 197.1 & 1.1 & -1.8 & 71.3 & -118.0 & 65.0 \\
\hline AOA 90 & -57.7 & -130.2 & 125.6 & 189.9 & -0.5 & -1.0 & -29.8 & -67.4 & 65.0 \\
\hline Part. Enclosed & $F_{x}($ lbs) & $F_{y}(l b s)$ & $F_{z}($ lbs $)$ & $\begin{array}{l}\text { Total Load } \\
\text { (Ibs) }\end{array}$ & Fx/Fz & $\mathrm{Fy} / \mathrm{Fz}$ & $X$ (in.) & $Y$ (in.) & $Z$ (in.) \\
\hline AOA 0 & 64.1 & -67.2 & 331.9 & 344.6 & 0.2 & -0.2 & 12.6 & -13.2 & 65.0 \\
\hline AOA 30 & -5.8 & -207.6 & 223.9 & 305.4 & 0.0 & -0.9 & -1.7 & -60.2 & 65.0 \\
\hline AOA 45 & 37.6 & -131.3 & 171.3 & 219.1 & 0.2 & -0.8 & 14.3 & -49.8 & 65.0 \\
\hline AOA 60 & 73.4 & -203.1 & 202.8 & 296.3 & 0.4 & -1.0 & 23.5 & -65.1 & 65.0 \\
\hline AOA 90 & -67.4 & -157.5 & 182.4 & 250.2 & -0.4 & -0.9 & -24.0 & -56.1 & 65.0 \\
\hline
\end{tabular}

Table 6.1: Specimen Locations for Connection \#1 


\begin{tabular}{|c|c|c|c|c|c|c|c|c|c|}
\hline \multicolumn{7}{|c|}{ Connection \#2 } & \multicolumn{3}{|c|}{ Location of the Specimen } \\
\hline Enclosed & $\mathbf{F}_{\mathbf{x}}(\mathrm{lbs})$ & $F_{y}($ lbs $)$ & $F_{z}($ lbs $)$ & $\begin{array}{l}\text { Total Load } \\
\text { (Ibs) }\end{array}$ & $F x / F z$ & $\mathrm{Fy} / \mathrm{Fz}$ & $X$ (in.) & $Y$ (in.) & $Z$ (in.) \\
\hline AOA 0 & -1.1 & -47.8 & 99.0 & 109.9 & 0.0 & -0.5 & -0.8 & -31.4 & 65.0 \\
\hline AOA 30 & 6.3 & 89.0 & 107.5 & 139.7 & 0.1 & 0.8 & 3.8 & 53.8 & 65.0 \\
\hline AOA 45 & 7.0 & 45.1 & 66.4 & 80.6 & 0.1 & 0.7 & 6.8 & 44.1 & 65.0 \\
\hline AOA 60 & 13.0 & 46.9 & 88.5 & 101.0 & 0.1 & 0.5 & 9.6 & 34.5 & 65.0 \\
\hline AOA 90 & -17.6 & 146.8 & 99.3 & 178.1 & -0.2 & 1.5 & -11.5 & 96.1 & 65.0 \\
\hline Part. Enclosed & $\mathbf{F}_{\mathbf{x}}(\mathrm{lbs})$ & $F_{y}($ lbs $)$ & $F_{\mathrm{z}}(\mathrm{lbs})$ & $\begin{array}{c}\text { Total Load } \\
\text { (Ibs) }\end{array}$ & $\mathrm{Fx} / \mathrm{Fz}$ & $\mathrm{Fy} / \mathrm{Fz}$ & $X$ (in.) & $Y$ (in.) & $Z$ (in.) \\
\hline AOA 0 & -0.4 & -97.9 & 429.8 & 440.8 & 0.0 & -0.2 & -0.1 & -14.8 & 65.0 \\
\hline AOA 30 & 9.4 & 49.1 & 272.4 & 276.9 & 0.0 & 0.2 & 2.2 & 11.7 & 65.0 \\
\hline AOA 45 & 16.0 & 5.8 & 204.5 & 205.2 & 0.1 & 0.0 & 5.1 & 1.9 & 65.0 \\
\hline AOA 60 & 34.0 & 3.8 & 241.3 & 243.7 & 0.1 & 0.0 & 9.1 & 1.0 & 65.0 \\
\hline AOA 90 & -17.0 & 81.1 & 209.5 & 225.3 & -0.1 & 0.4 & -5.3 & 25.2 & 65.0 \\
\hline
\end{tabular}

Table 6.2: Specimen Locations for Connection \#2 


\begin{tabular}{|c|c|c|c|c|c|c|c|c|c|}
\hline \multicolumn{7}{|c|}{ Connection \#3 } & \multicolumn{3}{|c|}{ Location of the Specimen } \\
\hline Enclosed & $F_{x}($ lbs $)$ & $F_{y}($ lbs $)$ & $F_{z}($ lbs $)$ & $\begin{array}{l}\text { Total Load } \\
\text { (Ibs) }\end{array}$ & Fx/Fz & Fy/Fz & $X$ (in.) & $Y$ (in.) & $Z$ (in.) \\
\hline AOA 0 & 8.8 & -52.9 & 1.4 & 53.6 & 6.3 & -38.2 & 410.2 & -2479.9 & 65.0 \\
\hline AOA 30 & 76.2 & -156.1 & 104.2 & 202.5 & 0.7 & -1.5 & 47.5 & -97.4 & 65.0 \\
\hline AOA 45 & 49.3 & -121.8 & 80.0 & 153.8 & 0.6 & -1.5 & 40.0 & -98.9 & 65.0 \\
\hline AOA 60 & 53.2 & -84.2 & 67.5 & 120.3 & 0.8 & -1.2 & 51.2 & -81.0 & 65.0 \\
\hline AOA 90 & 41.4 & -126.1 & 117.9 & 177.5 & 0.4 & -1.1 & 22.8 & -69.5 & 65.0 \\
\hline Part. Enclosed & $F_{x}($ lbs $)$ & $F_{y}($ lbs $)$ & $F_{z}($ lbs $)$ & $\begin{array}{c}\text { Total Load } \\
\text { (lbs) }\end{array}$ & Fx/Fz & $\mathrm{Fy} / \mathrm{Fz}$ & $X$ (in.) & $Y$ (in.) & $Z$ (in.) \\
\hline AOA 0 & 62.2 & -116.0 & 136.8 & 189.8 & 0.5 & -0.8 & 29.6 & -55.1 & 65.0 \\
\hline AOA 30 & 104.6 & -173.7 & 154.1 & 254.7 & 0.7 & -1.1 & 44.1 & -73.3 & 65.0 \\
\hline AOA 45 & 78.7 & -153.3 & 139.8 & 221.9 & 0.6 & -1.1 & 36.6 & -71.3 & 65.0 \\
\hline AOA 60 & 81.4 & -89.4 & 104.2 & 159.7 & 0.8 & -0.9 & 50.8 & -55.8 & 65.0 \\
\hline AOA 90 & 64.9 & -158.0 & 187.2 & 253.4 & 0.3 & -0.8 & 22.5 & -54.9 & 65.0 \\
\hline
\end{tabular}

Table 6.3: Specimen Locations for Connection \#3 


\begin{tabular}{|c|c|c|c|c|c|c|c|c|c|}
\hline \multicolumn{7}{|c|}{ Connection \#4 } & \multicolumn{3}{|c|}{ Location of the Specimen } \\
\hline Enclosed & $F_{x}($ lbs $)$ & $F_{y}($ lbs $)$ & $F_{\mathrm{z}}(\mathrm{lbs})$ & $\begin{array}{l}\text { Total Load } \\
\text { (Ibs) }\end{array}$ & Fx/Fz & $\mathrm{Fy} / \mathrm{Fz}$ & $X$ (in.) & $Y$ (in.) & $Z$ (in.) \\
\hline AOA 0 & 87.1 & 19.4 & 180.9 & 201.7 & 0.5 & 0.1 & 31.3 & 7.0 & 65.0 \\
\hline AOA 30 & 14.6 & -29.5 & 101.3 & 106.6 & 0.1 & -0.3 & 9.4 & -18.9 & 65.0 \\
\hline AOA 45 & 21.8 & -23.1 & 98.0 & 103.1 & 0.2 & -0.2 & 14.5 & -15.3 & 65.0 \\
\hline AOA 60 & 4.9 & -27.1 & 88.9 & 93.0 & 0.1 & -0.3 & 3.6 & -19.9 & 65.0 \\
\hline AOA 90 & 7.3 & -44.4 & 79.6 & 91.5 & 0.1 & -0.6 & 5.9 & -36.3 & 65.0 \\
\hline Part. Enclosed & $F_{x}($ lbs $)$ & $F_{y}($ lbs $)$ & $F_{z}($ lbs $)$ & $\begin{array}{l}\text { Total Load } \\
\text { (Ibs) }\end{array}$ & $\mathrm{Fx} / \mathrm{Fz}$ & $\mathrm{Fy} / \mathrm{Fz}$ & $X$ (in.) & $Y$ (in.) & Z (in.) \\
\hline AOA 0 & 21.3 & -19.6 & 124.1 & 127.5 & 0.2 & -0.2 & 11.2 & -10.3 & 65.0 \\
\hline AOA 30 & 8.5 & -21.6 & 97.6 & 100.4 & 0.1 & -0.2 & 5.6 & -14.4 & 65.0 \\
\hline AOA 45 & 6.6 & -21.1 & 103.4 & 105.7 & 0.1 & -0.2 & 4.1 & -13.2 & 65.0 \\
\hline AOA 60 & 17.9 & -22.7 & 92.7 & 97.1 & 0.2 & -0.2 & 12.5 & -15.9 & 65.0 \\
\hline AOA 90 & -3.1 & -6.5 & 123.2 & 123.4 & 0.0 & -0.1 & -1.7 & -3.4 & 65.0 \\
\hline
\end{tabular}

Table 6.4: Specimen Locations for Connection \#4 


\begin{tabular}{|c|c|c|c|c|c|c|c|c|c|}
\hline \multicolumn{7}{|c|}{ Connection \#5 } & \multicolumn{3}{|c|}{ Location of the Specimen } \\
\hline Enclosed & $F_{x}($ lbs) & $F_{y}($ lbs $)$ & $F_{\mathbf{z}}($ lbs) & $\begin{array}{l}\text { Total Load } \\
\text { (Ibs) }\end{array}$ & $F x / F z$ & $\mathrm{Fy} / \mathrm{Fz}$ & $X$ (in.) & $Y$ (in.) & $Z$ (in.) \\
\hline AOA 0 & 61.7 & 58.1 & 116.9 & 144.4 & 0.5 & 0.5 & 34.3 & 32.3 & 65.0 \\
\hline AOA 30 & 61.5 & 35.7 & 241.4 & 251.7 & 0.3 & 0.1 & 16.5 & 9.6 & 65.0 \\
\hline AOA 45 & 72.9 & 24.6 & 198.4 & 212.8 & 0.4 & 0.1 & 23.9 & 8.1 & 65.0 \\
\hline AOA 60 & 55.8 & 75.3 & 255.6 & 272.2 & 0.2 & 0.3 & 14.2 & 19.2 & 65.0 \\
\hline AOA 90 & 12.3 & -3.2 & 220.9 & 221.2 & 0.1 & 0.0 & 3.6 & -0.9 & 65.0 \\
\hline Part. Enclosed & $F_{x}($ lbs) & $F_{y}($ lbs $)$ & $F_{z}($ lbs $)$ & $\begin{array}{c}\text { Total Load } \\
\text { (lbs) }\end{array}$ & $\mathrm{Fx} / \mathrm{Fz}$ & $\mathrm{Fy} / \mathrm{Fz}$ & $X$ (in.) & $Y$ (in.) & $Z$ (in.) \\
\hline AOA 0 & 33.4 & 240.9 & 645.4 & 689.7 & 0.1 & 0.4 & 3.4 & 24.3 & 65.0 \\
\hline AOA 30 & 11.6 & 131.4 & 482.2 & 499.9 & 0.0 & 0.3 & 1.6 & 17.7 & 65.0 \\
\hline AOA 45 & 40.9 & 106.7 & 384.5 & 401.2 & 0.1 & 0.3 & 6.9 & 18.0 & 65.0 \\
\hline AOA 60 & -15.8 & 149.2 & 454.2 & 478.4 & 0.0 & 0.3 & -2.3 & 21.4 & 65.0 \\
\hline AOA 90 & 6.7 & 54.2 & 338.1 & 342.4 & 0.0 & 0.2 & 1.3 & 10.4 & 65.0 \\
\hline
\end{tabular}

Table 6.5: Specimen Locations for Connection \#5 


\begin{tabular}{|c|c|c|c|c|c|c|c|c|c|}
\hline \multicolumn{7}{|c|}{ Connection \#6 } & \multicolumn{3}{|c|}{ Location of the Specimen } \\
\hline Enclosed & $F_{x}(l b s)$ & $F_{y}($ lbs $)$ & $\mathbf{F}_{\mathbf{z}}(\mathrm{lbs})$ & $\begin{array}{l}\text { Total Load } \\
\text { (Ibs) }\end{array}$ & $F x / F z$ & $\mathrm{Fy} / \mathrm{Fz}$ & $X$ (in.) & $Y($ in.) & $Z$ (in.) \\
\hline AOA 0 & 14.3 & 15.3 & -14.6 & 25.5 & -1.0 & -1.0 & -63.8 & -68.1 & 65.0 \\
\hline AOA 30 & 25.5 & -37.3 & 21.2 & 49.9 & 1.2 & -1.8 & 78.1 & -114.4 & 65.0 \\
\hline AOA 45 & 24.8 & -20.3 & 18.6 & 37.0 & 1.3 & -1.1 & 86.7 & -71.1 & 65.0 \\
\hline AOA 60 & 11.0 & -23.6 & -54.9 & 60.7 & -0.2 & 0.4 & -13.1 & 27.9 & 65.0 \\
\hline AOA 90 & -2.5 & -98.4 & 75.6 & 124.1 & 0.0 & -1.3 & -2.1 & -84.6 & 65.0 \\
\hline Part. Enclosed & $F_{x}($ lbs $)$ & $F_{y}(l b s)$ & $F_{\mathrm{z}}(\mathrm{lbs})$ & $\begin{array}{l}\text { Total Load } \\
\text { (Ibs) }\end{array}$ & Fx/Fz & $\mathrm{Fy} / \mathrm{Fz}$ & $X$ (in.) & $Y$ (in.) & Z (in.) \\
\hline AOA 0 & 48.0 & 58.6 & 45.9 & 88.6 & 1.0 & 1.3 & 68.0 & 83.0 & 65.0 \\
\hline AOA 30 & 39.6 & 1.0 & 55.4 & 68.1 & 0.7 & 0.0 & 46.4 & 1.2 & 65.0 \\
\hline AOA 45 & 38.3 & 32.4 & 75.3 & 90.5 & 0.5 & 0.4 & 33.0 & 27.9 & 65.0 \\
\hline AOA 60 & 24.7 & 23.6 & -1.7 & 34.2 & -14.4 & -13.8 & -938.8 & -897.3 & 65.0 \\
\hline AOA 90 & 15.0 & -41.1 & 124.5 & 132.0 & 0.1 & -0.3 & 7.8 & -21.4 & 65.0 \\
\hline
\end{tabular}

Table 6.6: Specimen Locations for Connection \#6 
6.5 SCL Tri-Axial Tests Results

All the results recorded from the tri-axial tests are shown in Tables 6.7 through 6.11.
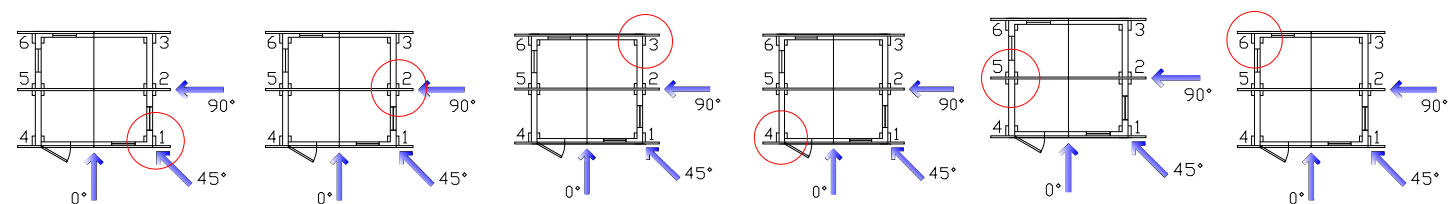

\begin{tabular}{|c|c|c|c|c|c|c|c|c|c|c|c|c|}
\hline \multicolumn{2}{|c|}{ Tri-Axial Load Testing Results } & \multicolumn{11}{|c|}{ AOA 0} \\
\hline $\begin{array}{l}\text { Connection } \\
\text { Number }\end{array}$ & CONDITION & Case & $\mathbf{F x} / \mathbf{F z}$ & $\mathbf{F y} / \mathbf{F z}$ & $\begin{array}{l}\text { FRP } \\
\text { (lbs) }\end{array}$ & $\begin{array}{c}\mathbf{F x} \\
(\mathbf{l b s})\end{array}$ & $\begin{array}{c}\text { Fy } \\
(\mathbf{l b s})\end{array}$ & $\begin{array}{c}\text { Fz } \\
(\mathbf{l b s})\end{array}$ & $\begin{array}{c}\text { CLIP } \\
\text { (lbs) }\end{array}$ & $\begin{array}{c}\text { Fx } \\
(\mathrm{lbs})\end{array}$ & $\begin{array}{c}\text { Fy } \\
\text { (lbs) }\end{array}$ & $\begin{array}{c}\text { Fz } \\
(\mathbf{l b s})\end{array}$ \\
\hline \multirow{2}{*}{ No. 1} & Enclosed & 1 & 0.6 & 0.1 & 1424* & 688 & 86 & 1244 & $642 *$ & 310 & 39 & 561 \\
\hline & Partially Enclosed & 5 & 0.2 & -0.2 & 1944 & 362 & 379 & 1872 & 1393 & 259 & 271 & 1342 \\
\hline \multirow{2}{*}{ No. 2} & Enclosed & 7 & $\mathbf{0 . 0}$ & -0.5 & 2658 & 28 & 1155 & 2394 & 899 & 9 & 391 & 810 \\
\hline & Partially Enclosed & 10 & $\mathbf{0 . 0}$ & -0.2 & 2492 & 2 & 553 & 2430 & 1474 & 1 & 327 & 1437 \\
\hline \multirow{2}{*}{ No. 3} & Enclosed & N/A & 6.3 & -38.2 & \multicolumn{8}{|c|}{ Lateral $(\mathrm{X})$ direction $>3$ Feet } \\
\hline & Partially Enclosed & 11 & 0.5 & -0.8 & 1197 & 392 & 731 & 863 & 1015 & 333 & 620 & 731 \\
\hline \multirow{2}{*}{ No. 4} & Enclosed & 13 & 0.5 & 0.1 & 1538 & 664 & 148 & 1379 & 818 & 353 & 79 & 734 \\
\hline & Partially Enclosed & 14 & 0.2 & -0.2 & 1734 & 290 & 267 & 1689 & 1299 & 217 & 100 & 1265 \\
\hline \multirow{2}{*}{ No. 5} & Enclosed & 16 & 0.5 & $\mathbf{0 . 5}$ & 1350 & 577 & 544 & 1093 & 1117 & 478 & 450 & 904 \\
\hline & Partially Enclosed & 20 & $\mathbf{0 . 1}$ & $\mathbf{0 . 4}$ & 2131 & 103 & 744 & 1994 & 1609 & 78 & 562 & 1506 \\
\hline \multirow{2}{*}{ No. 6} & Enclosed & $\mathbf{N} / \mathbf{A}$ & -1.0 & -1.0 & \multicolumn{8}{|c|}{ Lateral $(\mathrm{X})$ direction $>3$ Feet } \\
\hline & Partially Enclosed & N/A & 1.0 & 1.3 & \multicolumn{8}{|c|}{ Lateral $(\mathrm{X})$ direction $>3$ Feet } \\
\hline
\end{tabular}

Table 6.7: Tri-Axial Test Results AOA $0^{\circ}$ (* Y-distance is 4.5”) 

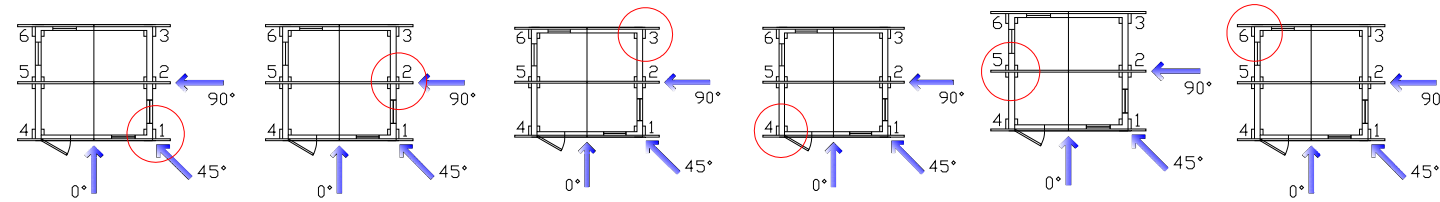

\begin{tabular}{|c|c|c|c|c|c|c|c|c|c|c|c|c|}
\hline \multicolumn{2}{|c|}{ Tri-Axial Load Testing Results } & \multicolumn{11}{|c|}{ AOA 30} \\
\hline $\begin{array}{l}\text { Connection } \\
\text { Number }\end{array}$ & CONDITION & Case & $\mathbf{F x} / \mathbf{F z}$ & $\mathbf{F y} / \mathbf{F z}$ & $\begin{array}{l}\text { FRP } \\
\text { (lbs) }\end{array}$ & $\begin{array}{c}\mathbf{F x} \\
(\mathrm{lbs})\end{array}$ & $\begin{array}{l}\text { Fy } \\
(\text { lbs) }\end{array}$ & $\begin{array}{c}\mathbf{F z} \\
(\mathbf{l b s})\end{array}$ & $\begin{array}{c}\text { CLIP } \\
\text { (lbs) }\end{array}$ & $\begin{array}{c}\text { Fx } \\
\text { (lbs) }\end{array}$ & $\begin{array}{c}\text { Fy } \\
\text { (lbs) }\end{array}$ & $\begin{array}{c}\mathbf{F z} \\
(\mathbf{l b s})\end{array}$ \\
\hline \multirow{2}{*}{ No. 1} & Enclosed & 3 & $\mathbf{0 . 1}$ & -1.0 & 2915 & 156 & 2104 & 2012 & 1172 & 63 & 846 & 809 \\
\hline & Partially Enclosed & 3 & $\mathbf{0 . 0}$ & -0.9 & 2915 & 55 & 1981 & 2138 & 1172 & 22 & 797 & 859 \\
\hline \multirow{2}{*}{ No. 2} & Enclosed & 8 & $\mathbf{0 . 1}$ & $\mathbf{0 . 8}$ & 1893 & 86 & 1206 & 1457 & 1070 & 49 & 682 & 823 \\
\hline & Partially Enclosed & 10 & $\mathbf{0 . 0}$ & 0.2 & 2492 & 85 & 442 & 2451 & 1474 & 50 & 261 & 1450 \\
\hline \multirow{2}{*}{ No. 3} & Enclosed & $\mathbf{N} / \mathbf{A}$ & 0.7 & -1.5 & \multicolumn{8}{|c|}{ Lateral $(\mathrm{X})$ direction $>3$ Feet } \\
\hline & Partially Enclosed & 12 & 0.7 & -1.1 & 1491 & 612 & 1017 & 902 & 1366 & 561 & 932 & 826 \\
\hline \multirow{2}{*}{ No. 4} & Enclosed & 14 & $\mathbf{0 . 1}$ & -0.3 & 1734 & 237 & 480 & 1649 & 1299 & 178 & 360 & 1235 \\
\hline & Partially Enclosed & 14 & $\mathbf{0 . 1}$ & -0.2 & 1734 & 146 & 374 & 1687 & 1299 & 110 & 280 & 1264 \\
\hline \multirow{2}{*}{ No. 5} & Enclosed & 17 & 0.3 & $\mathbf{0 . 1}$ & 1101 & 269 & 156 & 1056 & 1325 & 324 & 188 & 1271 \\
\hline & Partially Enclosed & 19 & $\mathbf{0 . 0}$ & $\mathbf{0 . 3}$ & 2228 & 52 & 586 & 2149 & 1157 & 27 & 304 & 1116 \\
\hline \multirow{2}{*}{ No. 6} & Enclosed & N/A & 1.2 & -1.8 & \multicolumn{8}{|c|}{ Lateral $(X)$ direction $>3$ Feet } \\
\hline & Partially Enclosed & $\mathbf{N} / \mathbf{A}$ & 0.7 & $\mathbf{0 . 0}$ & \multicolumn{8}{|c|}{ X or Y Too Small for current set-up. } \\
\hline
\end{tabular}

Table 6.8: Tri-Axial Test Results AOA 30 

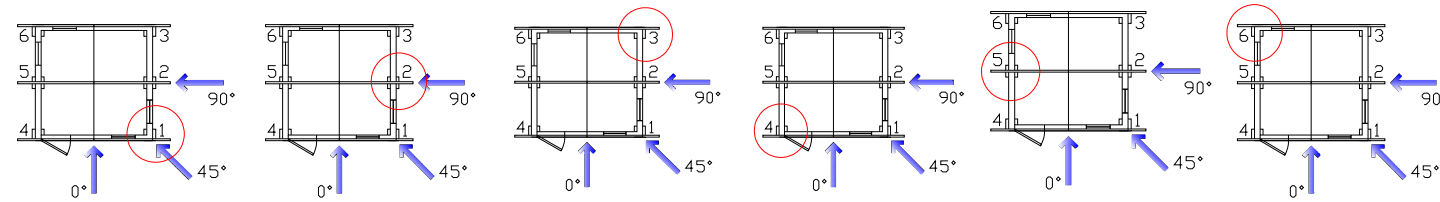

\begin{tabular}{|c|c|c|c|c|c|c|c|c|c|c|c|c|}
\hline \multicolumn{2}{|c|}{ Tri-Axial Load Testing Results } & \multicolumn{11}{|c|}{ AOA 45} \\
\hline $\begin{array}{c}\text { Connection } \\
\text { Number }\end{array}$ & CONDITION & Case & $\mathbf{F x} / \mathbf{F z}$ & $\mathbf{F y} / \mathbf{F z}$ & $\begin{array}{l}\text { FRP } \\
\text { (lbs) }\end{array}$ & $\begin{array}{c}\mathbf{F x} \\
(\mathrm{lbs})\end{array}$ & $\begin{array}{c}\text { Fy } \\
\text { (lbs) }\end{array}$ & $\begin{array}{c}\mathbf{F z} \\
(\mathbf{l b s})\end{array}$ & $\begin{array}{c}\text { CLIP } \\
\text { (lbs) }\end{array}$ & $\begin{array}{c}\text { Fx } \\
\text { (lbs) }\end{array}$ & $\begin{array}{c}\text { Fy } \\
(\mathbf{l b s})\end{array} \mid$ & $\begin{array}{c}\mathbf{F z} \\
(\mathbf{l b s})\end{array}$ \\
\hline \multirow{2}{*}{ No. 1} & Enclosed & 2 & 0.5 & -0.8 & 1565 & 546 & 933 & 1132 & 1352 & 471 & 806 & 978 \\
\hline & Partially Enclosed & 4 & $\mathbf{0 . 2}$ & -0.8 & 2043 & 351 & 1224 & 1597 & 1010 & 173 & 605 & 790 \\
\hline \multirow{2}{*}{ No. 2} & Enclosed & 8 & $\mathbf{0 . 1}$ & $\mathbf{0 . 7}$ & 1893 & 164 & 1059 & 1560 & 1070 & 93 & 599 & 882 \\
\hline & Partially Enclosed & 10 & 0.1 & $\mathbf{0 . 0}$ & $2492 *$ & 193 & 172 & 2479 & 1474 & 114 & 101 & 1466 \\
\hline \multirow{2}{*}{ No. 3} & Enclosed & $\mathbf{N} / \mathbf{A}$ & 0.6 & -1.5 & \multicolumn{8}{|c|}{ Lateral $(\mathrm{X})$ direction $>3$ Feet } \\
\hline & Partially Enclosed & 12 & 0.6 & -1.1 & 1491 & 529 & 1030 & 939 & 1366 & 484 & 944 & 861 \\
\hline \multirow{2}{*}{ No. 4} & Enclosed & 14 & 0.2 & -0.2 & 1734 & 367 & 389 & 1649 & 1299 & 275 & 291 & 1236 \\
\hline & Partially Enclosed & 14 & $\mathbf{0 . 1}$ & -0.2 & 1734 & 108 & 345 & 1696 & 1299 & 81 & 259 & 1270 \\
\hline \multirow{2}{*}{ No. 5} & Enclosed & 17 & 0.4 & $\mathbf{0 . 1}$ & 1101 & 377 & 127 & 1027 & 1325 & 454 & 153 & 1235 \\
\hline & Partially Enclosed & 20 & $\mathbf{0 . 1}$ & 0.3 & 2131 & 217 & 567 & 2043 & 1609 & 164 & 428 & 1542 \\
\hline \multirow{2}{*}{ No. 6} & Enclosed & $\mathbf{N} / \mathbf{A}$ & $\mathbf{1 . 3}$ & -1.1 & \multicolumn{8}{|c|}{ Lateral $(\mathrm{X})$ direction $>3$ Feet } \\
\hline & Partially Enclosed & 23 & 0.5 & 0.4 & 1110 & 470 & 397 & 924 & 803 & 340 & 287 & 668 \\
\hline
\end{tabular}

Table 6.9: Tri-Axial Test Results AOA $45^{\circ}$ (* Y-direction is 4.5") 

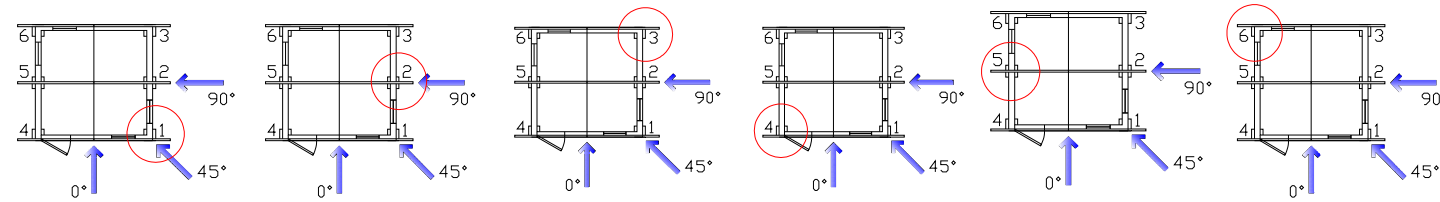

\begin{tabular}{|c|c|c|c|c|c|c|c|c|c|c|c|c|}
\hline \multicolumn{2}{|c|}{ Tri-Axial Load Testing Results } & \multicolumn{11}{|c|}{ AOA 60} \\
\hline $\begin{array}{c}\text { Connection } \\
\text { Number }\end{array}$ & CONDITION & Case & $\mathbf{F x} / \mathbf{F z}$ & $\mathbf{F y} / \mathbf{F z}$ & $\begin{array}{l}\text { FRP } \\
\text { (lbs) }\end{array}$ & $\begin{array}{c}\text { Fx } \\
\text { (lbs) }\end{array}$ & $\begin{array}{c}\text { Fy } \\
\text { (lbs) }\end{array}$ & $\begin{array}{c}\mathbf{F z} \\
(\mathrm{lbs})\end{array}$ & $\begin{array}{c}\text { CLIP } \\
\text { (lbs) }\end{array}$ & $\begin{array}{c}\text { Fx } \\
(\mathbf{l b s})\end{array}$ & $\begin{array}{c}\text { Fy } \\
\text { (lbs) }\end{array}$ & $\begin{array}{c}\mathbf{F z} \\
(\mathbf{l b s})\end{array}$ \\
\hline \multirow{2}{*}{ No. 1} & Enclosed & $\mathbf{N} / \mathbf{A}$ & 1.1 & -1.8 & \multicolumn{8}{|c|}{ Lateral $(\mathrm{X})$ direction $>3$ Feet } \\
\hline & Partially Enclosed & 6 & 0.4 & -1.0 & 2483 & 615 & 1703 & 1700 & 1076 & 267 & 738 & 736 \\
\hline \multirow{2}{*}{ No. 2} & Enclosed & 7 & 0.1 & 0.5 & 2658 & 343 & 1235 & 2328 & 899 & 116 & 418 & 787 \\
\hline & Partially Enclosed & 10 & 0.1 & $\mathbf{0 . 0}$ & $2492 *$ & 347 & 170 & 2462 & 1474 & 205 & 101 & 1456 \\
\hline \multirow{2}{*}{ No. 3} & Enclosed & $\mathbf{N} / \mathbf{A}$ & 0.8 & -1.2 & \multicolumn{8}{|c|}{ Lateral $(\mathrm{X})$ direction $>3$ Feet } \\
\hline & Partially Enclosed & $\mathbf{N} / \mathbf{A}$ & 0.8 & -0.9 & \multicolumn{8}{|c|}{ Lateral $(\mathrm{X})$ direction $>3$ Feet } \\
\hline \multirow{2}{*}{ No. 4} & Enclosed & 14 & $\mathbf{0 . 1}$ & -0.3 & 1734 & 92 & 506 & 1656 & 1299 & 69 & 379 & 1241 \\
\hline & Partially Enclosed & 14 & $\mathbf{0 . 2}$ & -0.2 & 1734 & 319 & 406 & 1655 & 1299 & 239 & 304 & 1240 \\
\hline \multirow{2}{*}{ No. 5} & Enclosed & 18 & $\mathbf{0 . 2}$ & 0.3 & 2011 & 413 & 557 & 1888 & 1358 & 279 & 376 & 1275 \\
\hline & Partially Enclosed & 19 & $\mathbf{0 . 0}$ & 0.3 & 2228 & 73 & 695 & 2116 & 1157 & 38 & 361 & 1099 \\
\hline \multirow{2}{*}{ No. 6} & Enclosed & 21 & -0.2 & 0.4 & 2558 & 464 & 993 & 2311 & 904 & 164 & 351 & 817 \\
\hline & Partially Enclosed & $\mathbf{N} / \mathbf{A}$ & -14.4 & -13.8 & \multicolumn{8}{|c|}{ X or Y Too big for current set-up. } \\
\hline
\end{tabular}

Table 6.10: Tri-Axial Test Results AOA 60 (* Y-direction is 4.5”) 

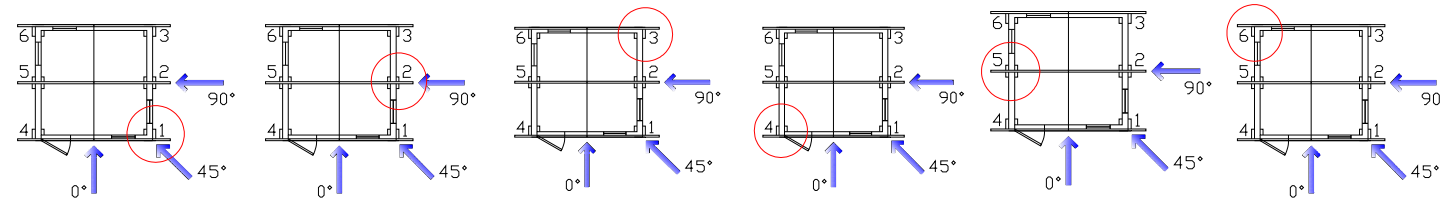

\begin{tabular}{|c|c|c|c|c|c|c|c|c|c|c|c|c|}
\hline \multicolumn{2}{|c|}{ Tri-Axial Load Testing Results } & \multicolumn{11}{|c|}{ AOA 90} \\
\hline $\begin{array}{l}\text { Connection } \\
\text { Number }\end{array}$ & CONDITION & Case & $\mathbf{F x} / \mathbf{F z}$ & $\mathbf{F y} / \mathbf{F z}$ & $\begin{array}{l}\text { FRP } \\
\text { (lbs) }\end{array}$ & $\begin{array}{c}\mathbf{F x} \\
(\mathbf{l b s})\end{array}$ & $\begin{array}{l}\text { Fy } \\
\text { (lbs) }\end{array}$ & $\begin{array}{c}\text { Fz } \\
(\mathbf{l b s})\end{array}$ & $\begin{array}{c}\text { CLIP } \\
\text { (lbs) }\end{array}$ & $\begin{array}{c}\text { Fx } \\
\text { (lbs) }\end{array}$ & $\begin{array}{c}\text { Fy } \\
(\mathbf{l b s})\end{array} \mid$ & $\begin{array}{c}\mathbf{F z} \\
(\mathbf{l b s})\end{array}$ \\
\hline \multirow{2}{*}{ No. 1} & Enclosed & 2 & -0.5 & -1.0 & 1565 & 475 & 1073 & 1035 & 1352 & 411 & 927 & 894 \\
\hline & Partially Enclosed & 6 & -0.4 & -0.9 & 2483 & 669 & 1563 & 1810 & 1076 & 290 & 677 & 784 \\
\hline \multirow{2}{*}{ No. 2} & Enclosed & 9 & -0.2 & 1.5 & 2209 & 218 & 1821 & 1232 & 823 & 81 & 678 & 459 \\
\hline & Partially Enclose & 7 & -0.1 & 0.4 & 2658 & 201 & 957 & 2471 & 899 & 68 & 324 & 836 \\
\hline \multirow{2}{*}{ No. 3} & Enclosed & 12 & 0.4 & -1.1 & 1491 & 348 & 1059 & 990 & 1366 & 319 & 970 & 907 \\
\hline & Partially Enclosed & 11 & 0.3 & -0.8 & 1197 & 307 & 746 & 884 & 1015 & 260 & 633 & 750 \\
\hline \multirow{2}{*}{ No. 4} & Enclosed & 15 & 0.1 & -0.6 & 2341 & 186 & 1138 & 2037 & 1158 & 92 & 563 & 1008 \\
\hline & Partially Enclosed & 14 & $\mathbf{0 . 0}$ & -0.1 & 1734 & 44 & 120 & 1729 & 1299 & 33 & 90 & 1295 \\
\hline \multirow{2}{*}{ No. 5} & Enclosed & 19 & 0.1 & $\mathbf{0 . 0}$ & $2228 *$ & 123 & 154 & 2219 & 1157 & 64 & 80 & 1155 \\
\hline & Partially Enclosed & 19 & $\mathbf{0 . 0}$ & 0.2 & 2228 & 44 & 352 & 2200 & 1157 & 23 & 183 & 1142 \\
\hline \multirow{2}{*}{ No. 6} & Enclosed & 22 & $\mathbf{0 . 0}$ & -1.3 & 2530 & 51 & 2006 & 1541 & 1028 & 21 & 815 & 626 \\
\hline & Partially Enclosed & 21 & 0.1 & -0.3 & 2558 & 291 & 796 & 2413 & 904 & 103 & 281 & 853 \\
\hline
\end{tabular}

Table 6.11: Tri-Axial Test Results AOA 90 (* Y-direction is 4.5”) 


\subsection{Tri-Axial Component Specimens Failure Modes}

The following Figures illustrate the different modes of failure for all the GRFP and metal connector experiments conducted in the SCL tri-axial tests.

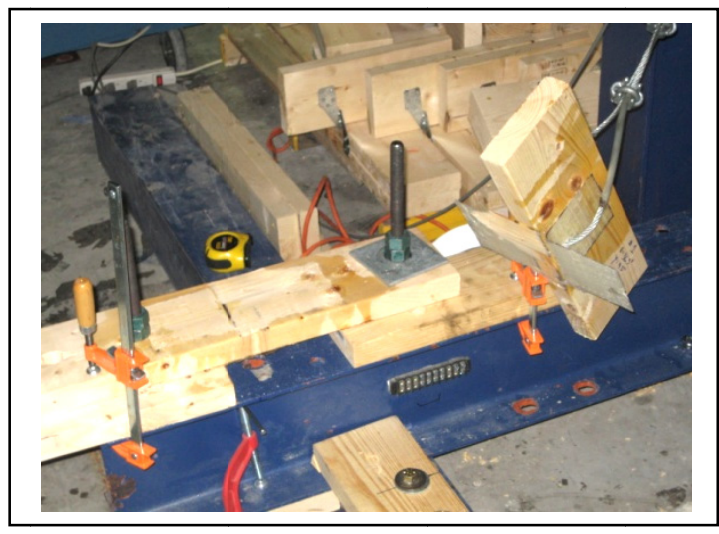

Figure 6.5: GRFP Connector Case 1

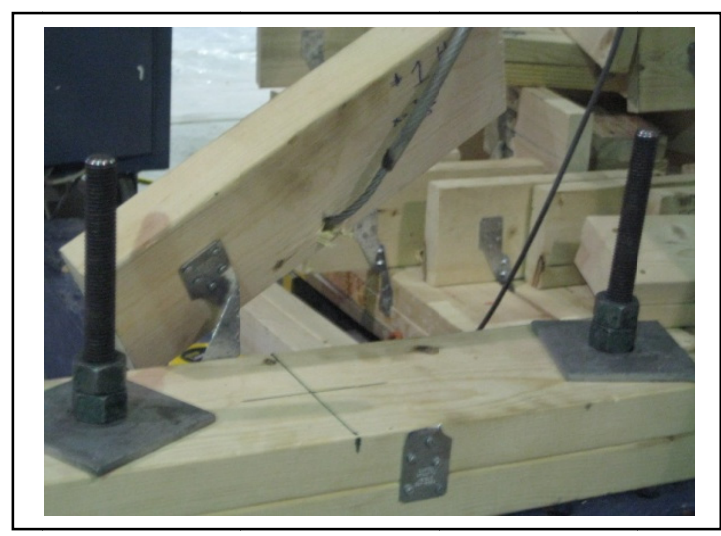

Figure 6.6: Metal Connector Case 1

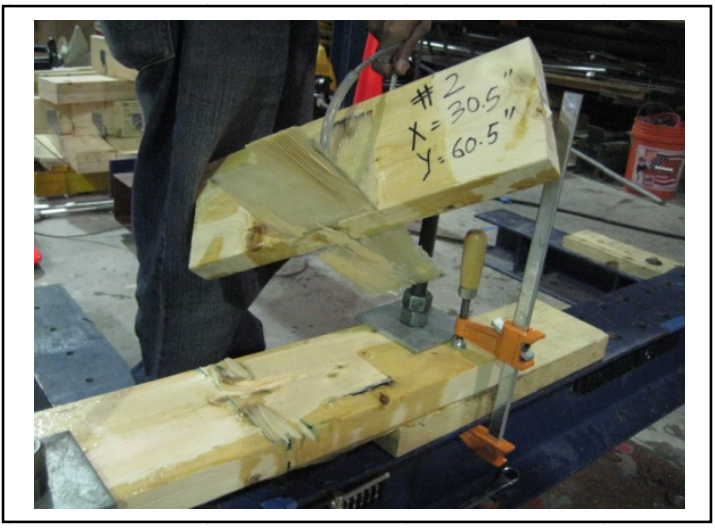

Figure 6.7: GRFP Connector Case 2

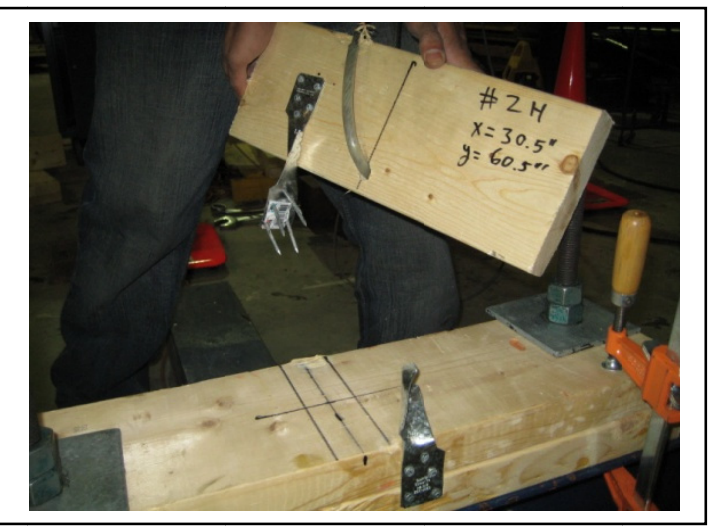

Figure 6.8: Metal Connector Case 2 


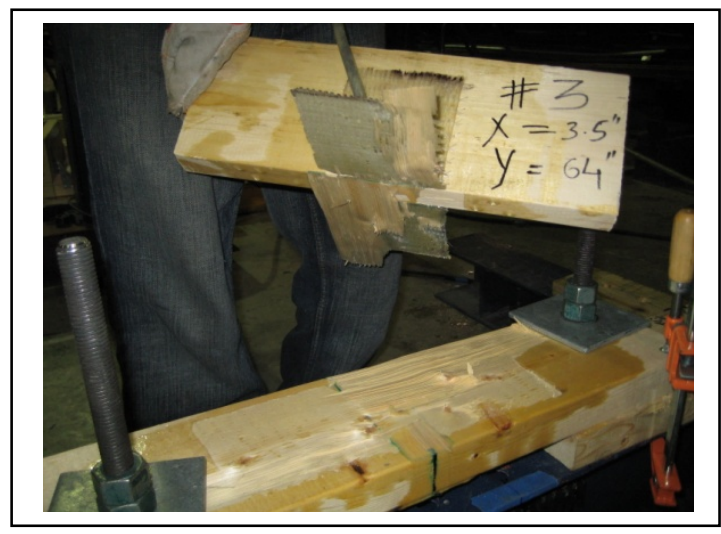

Figure 6.9: GRFP Connector Case 3

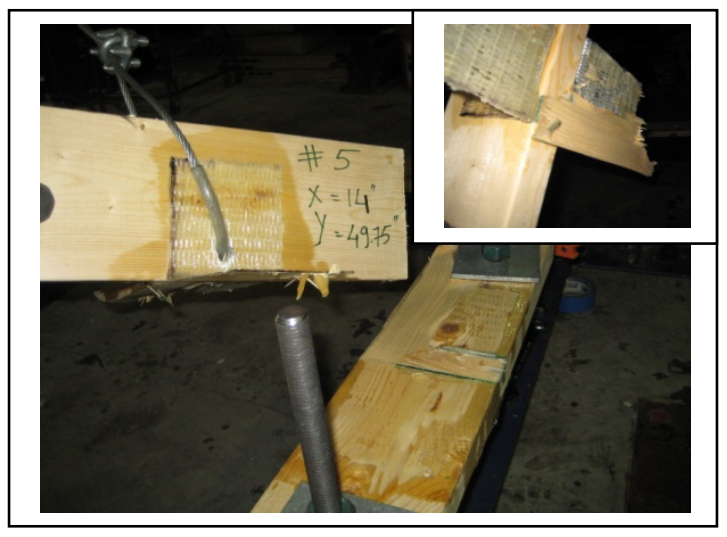

Figure 6.11: GRFP Connector Case 4

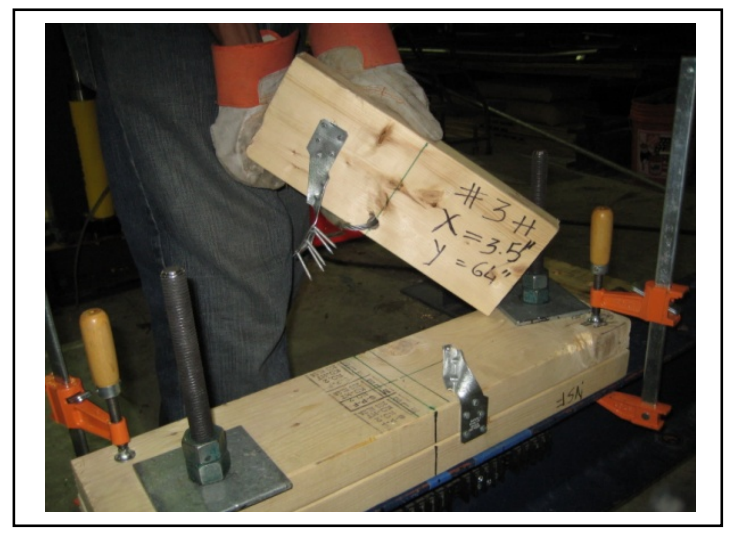

Figure 6.10: Metal Connector Case 3

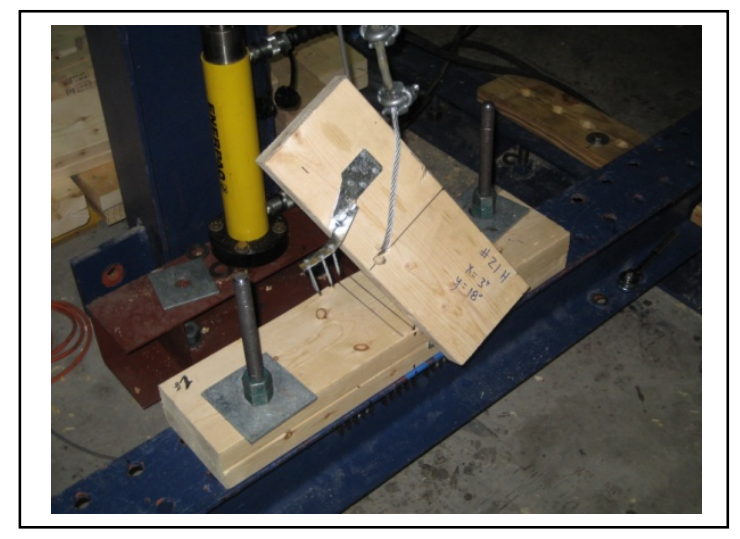

Figure 6.12: Metal Connector Case 4 


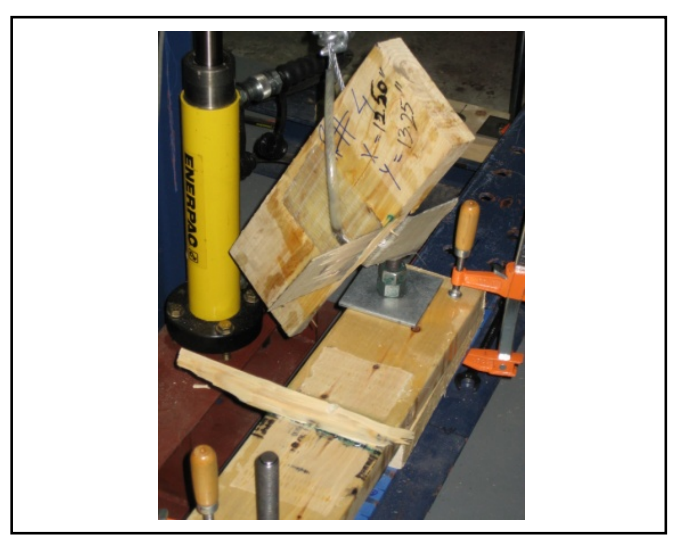

Figure 6.13: GRFP Connector Case 5

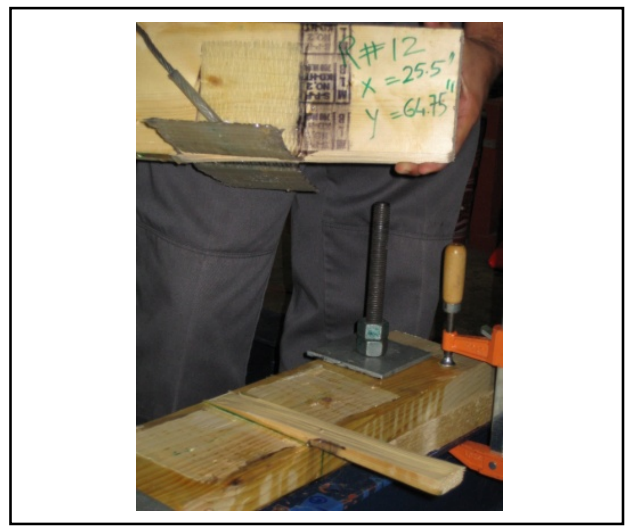

Figure 6.15: GRFP Connector Case 6

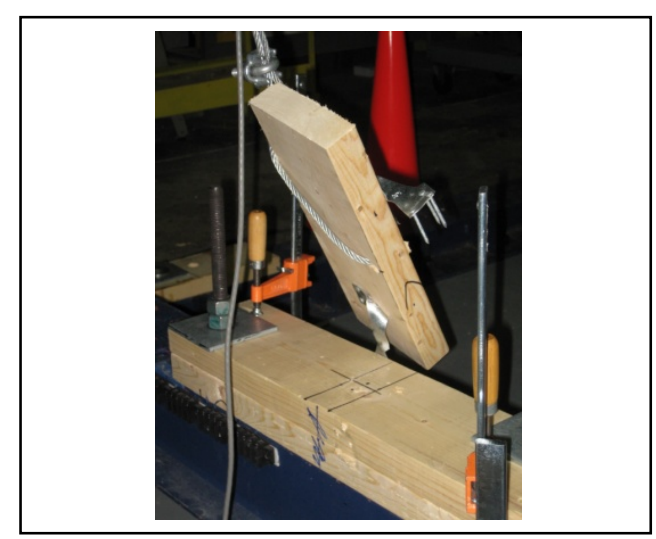

Figure 6.14: Metal Connector Case 5

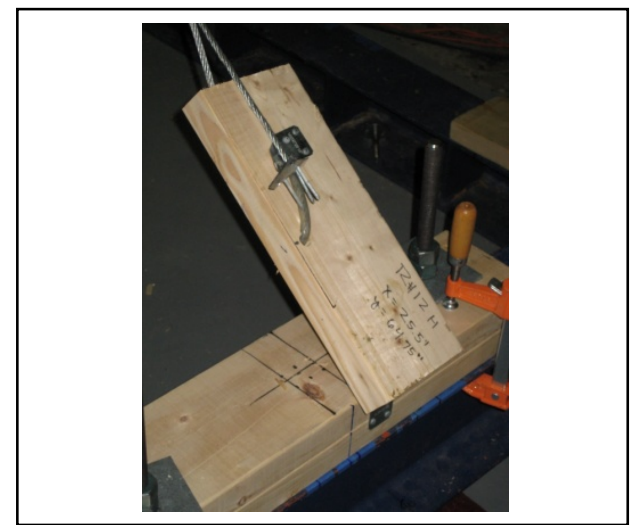

Figure 6.16: Metal Connector Case 6 


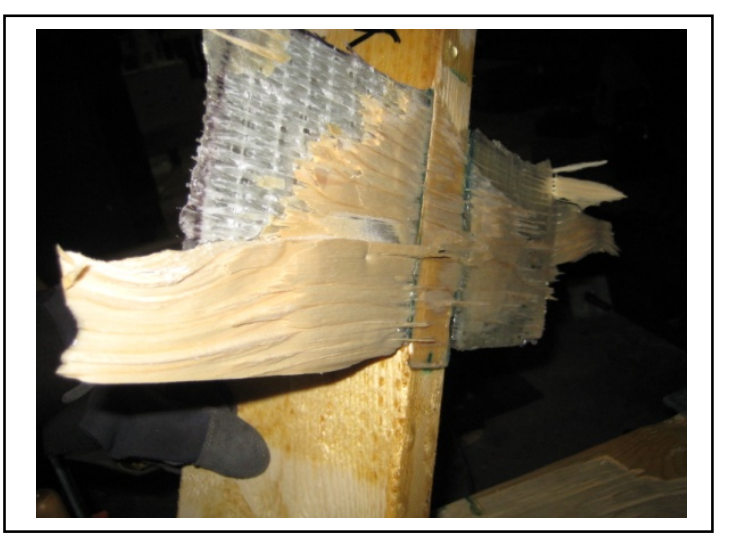

Figure 6.17: GRFP Connector Case 7

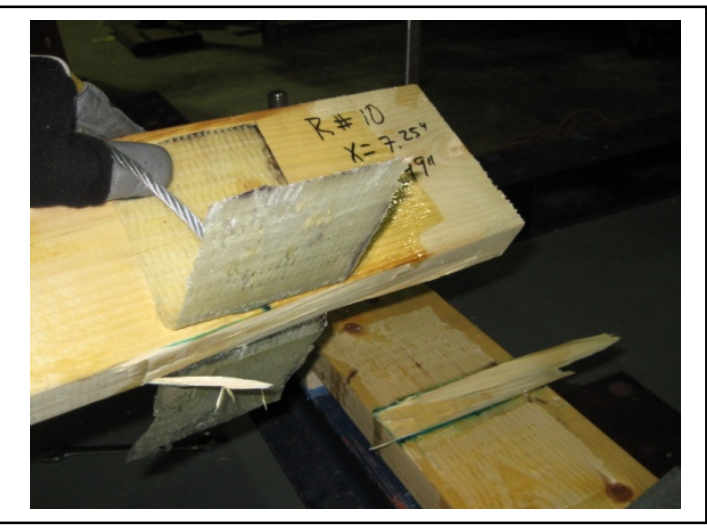

Figure 6.19: GRFP Connector Case 8

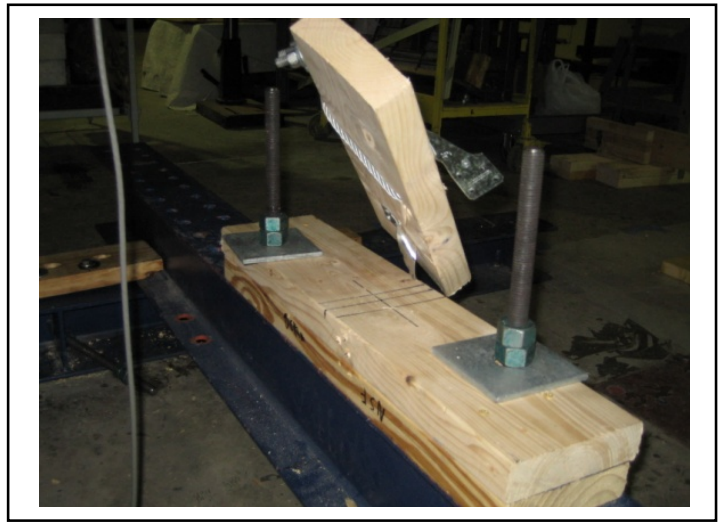

Figure 6.18: Metal Connector Case 7

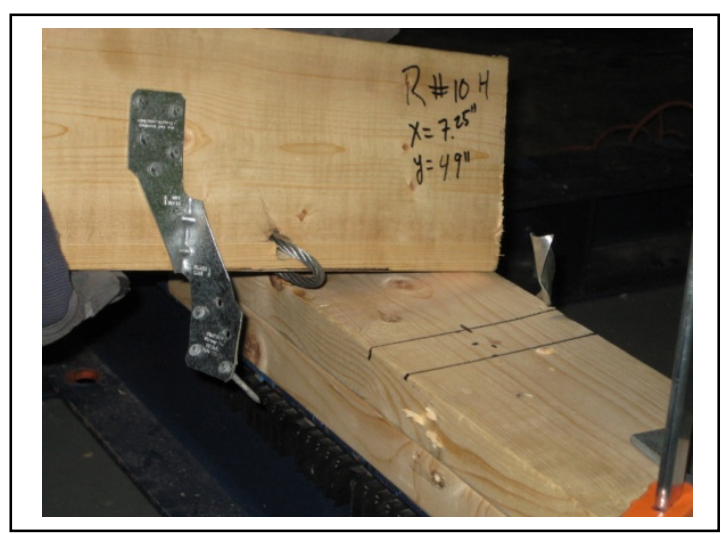

Figure 6.20: Metal Connector Case 8 


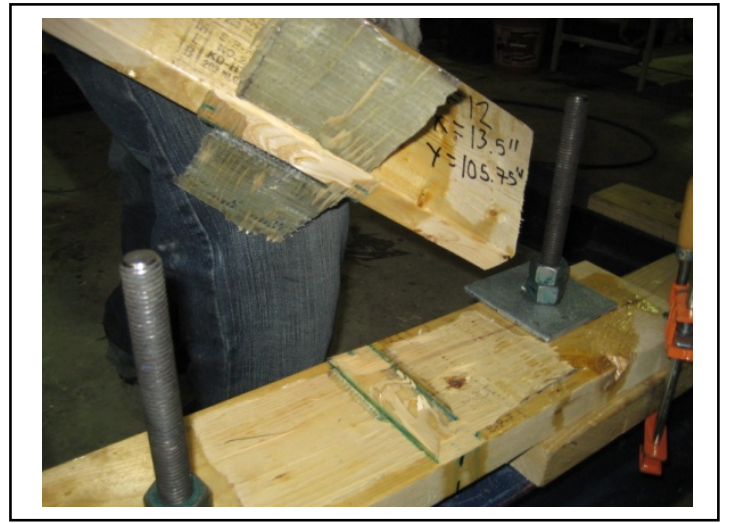

Figure 6.21: GFRP Connector Case 9

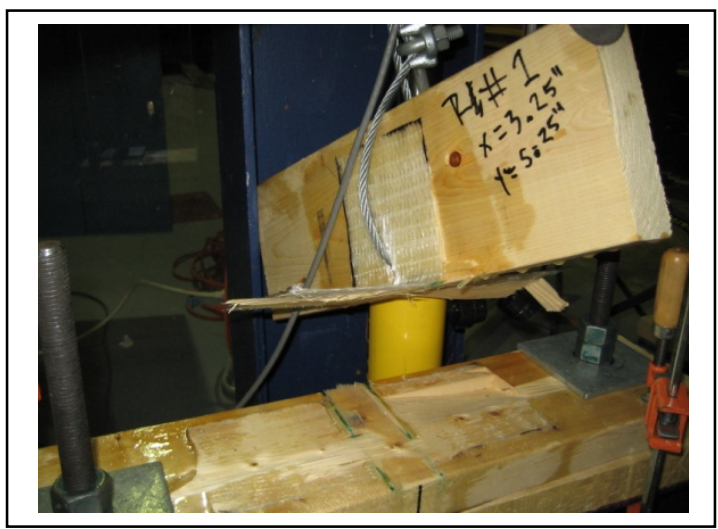

Figure 6.23: GRFP Connector Case 10

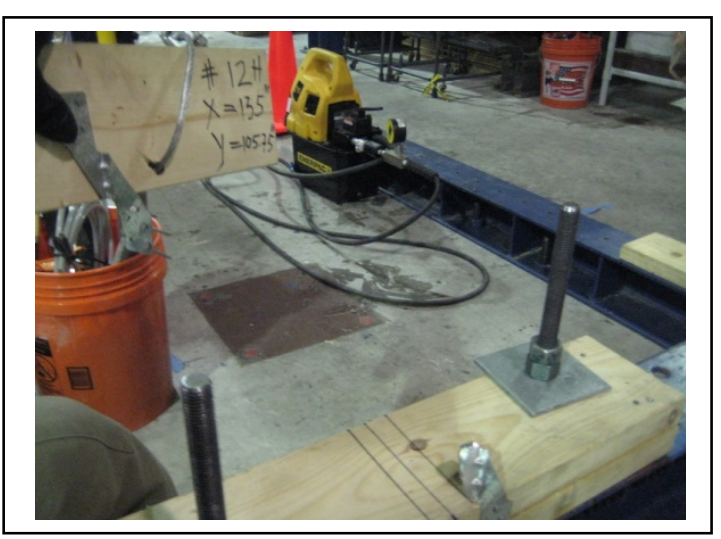

Figure 6.22: Metal Connector Case 9

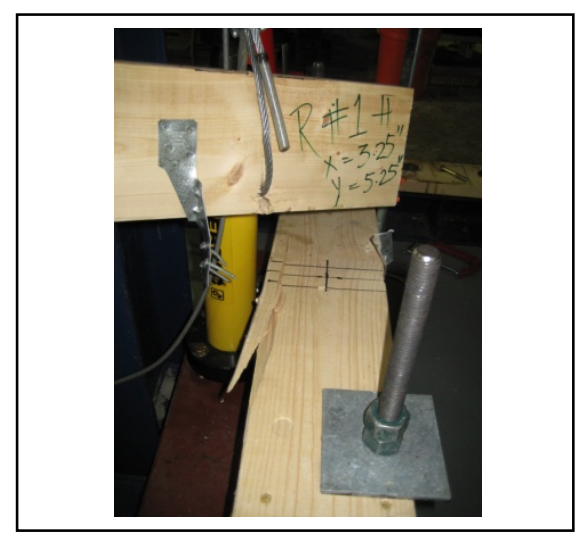

Figure 6.24: Metal Connector Case 10 


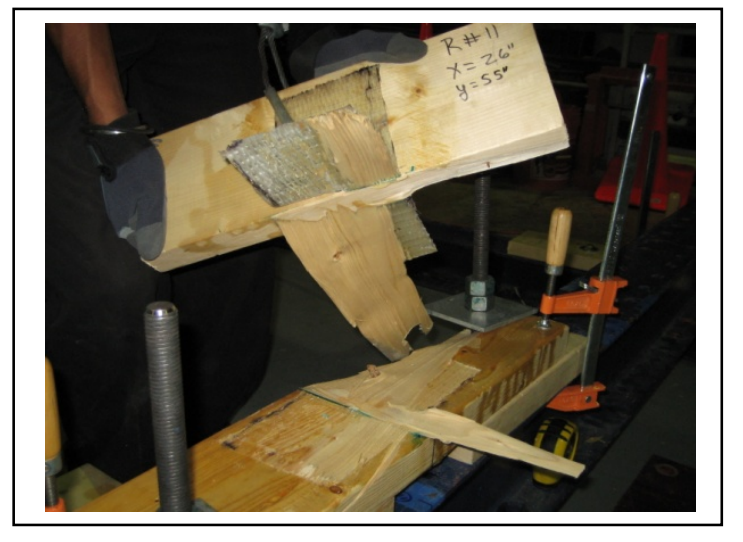

Figure 6.25: GRFP Connector Case 11

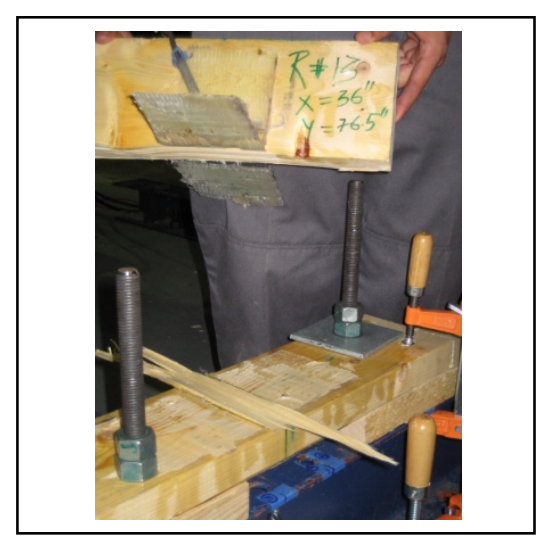

Figure 6.27: GRFP Connector Case 12

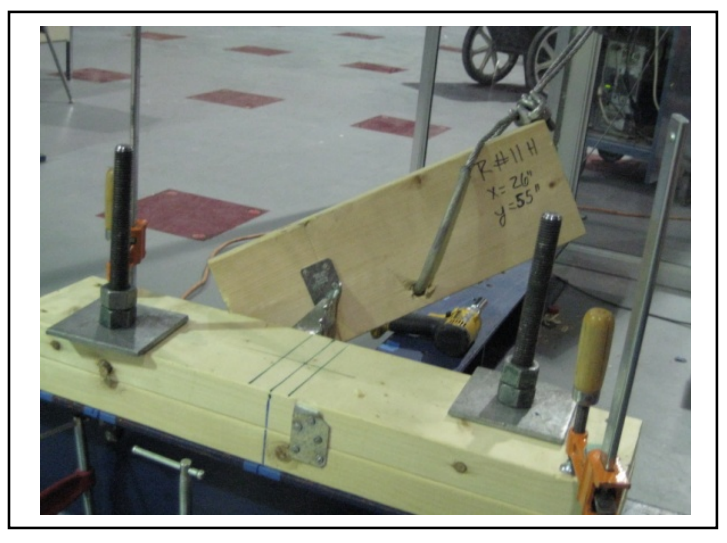

Figure 6.26: Metal Connector Case 11

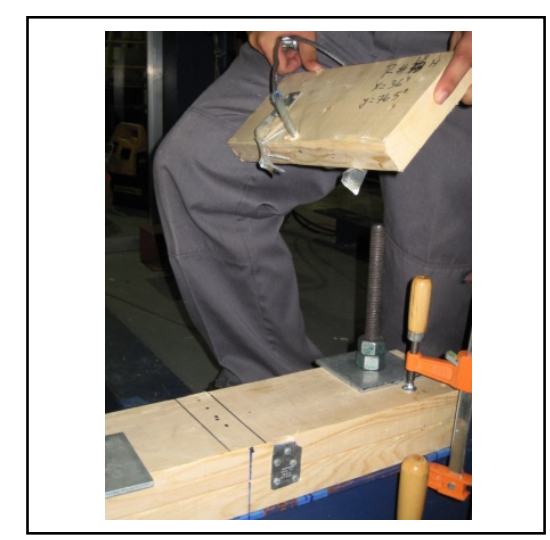

Figure 6.28: Metal Connector Case 12 


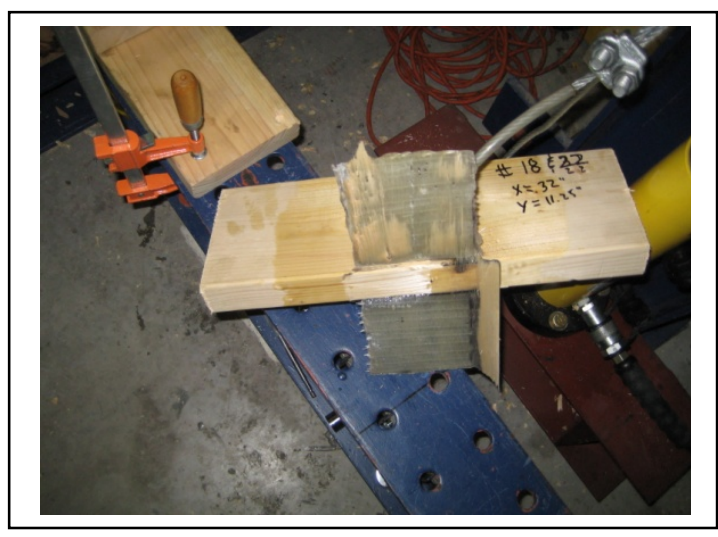

Figure 6.29: GRFP Connector Case 13

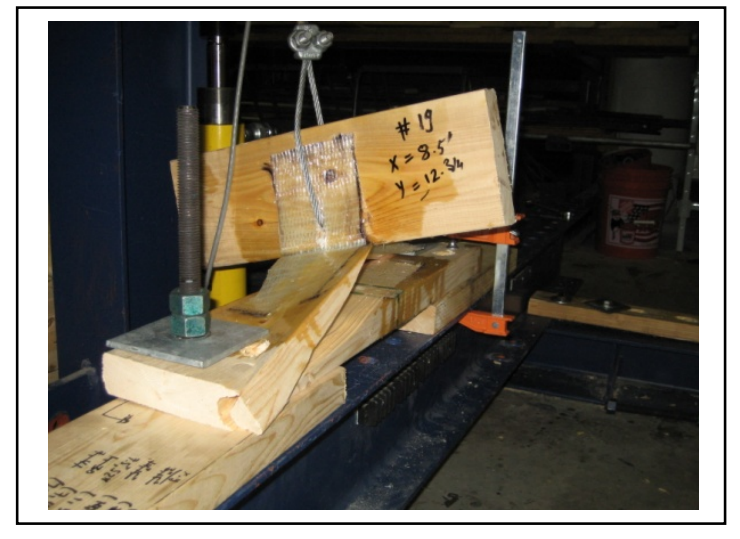

Figure 6.31: GRFP Connector Case 14

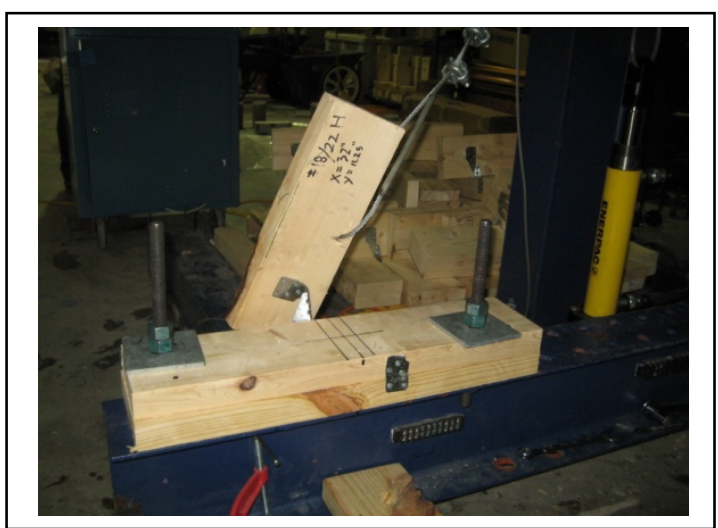

Figure 6.30: Metal Connector Case 13

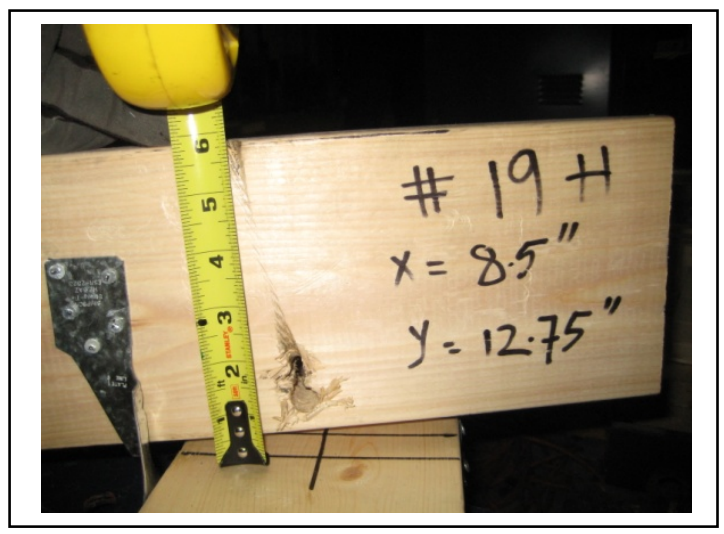

Figure 6.32: Metal Connector Case 14 


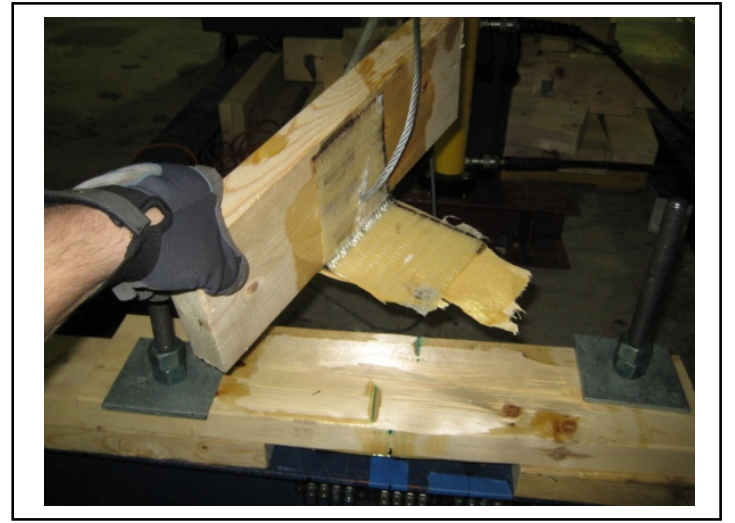

Figure 6.33: GRFP Connector Case 15

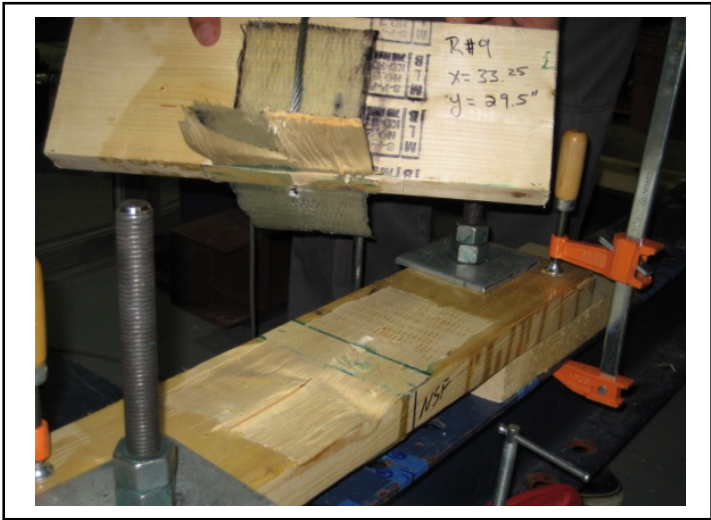

Figure 6.35: GRFP Connector Case 16

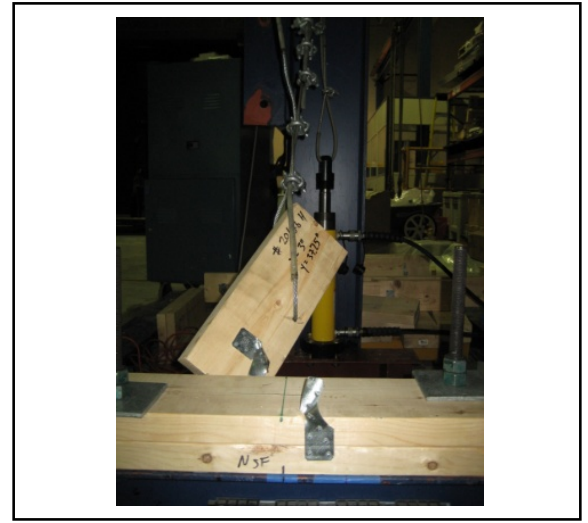

Figure 6.34: Metal Connector Case 15

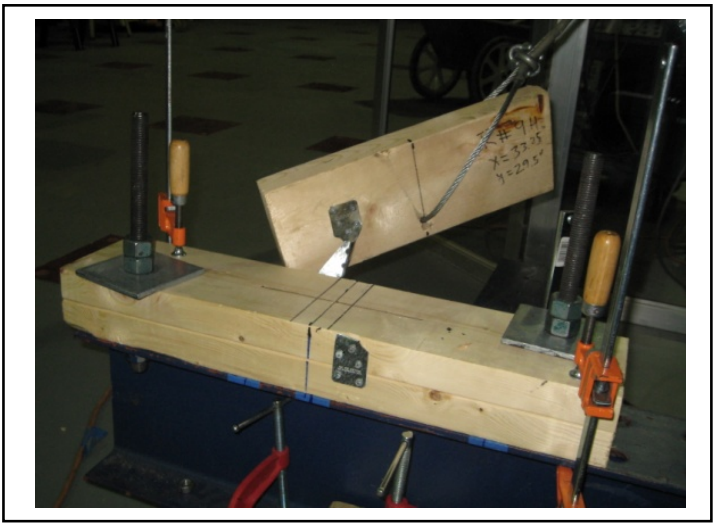

Figure 6.36: Metal Connector Case 16 


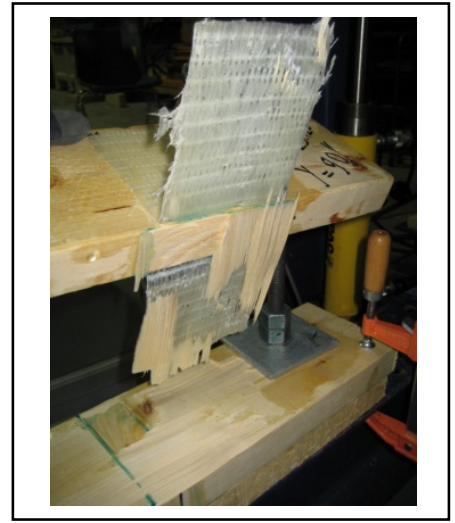

Figure 6.37: GRFP Connector Case 17

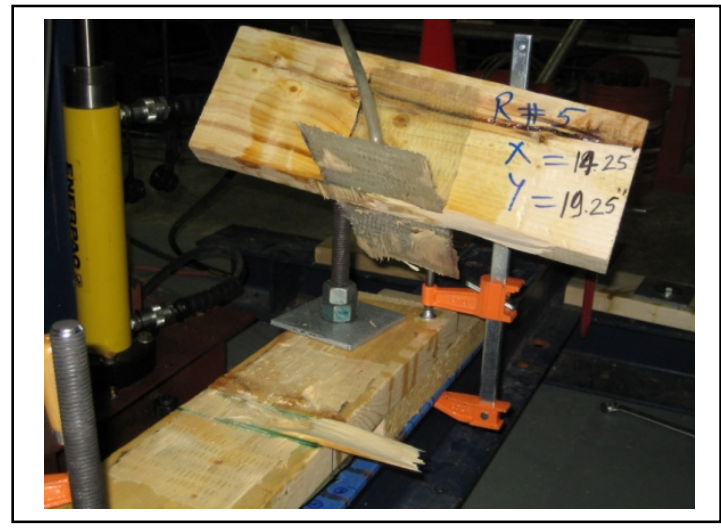

Figure 6.39: GRFP Connector Case 18

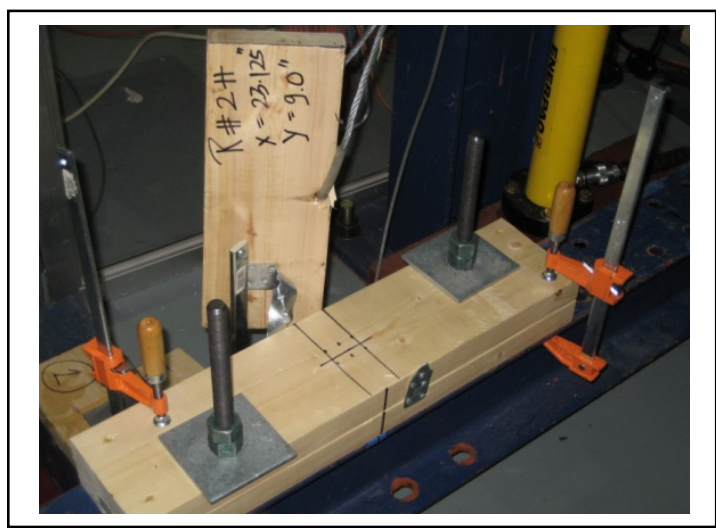

Figure 6.38: Metal Connector Case 17

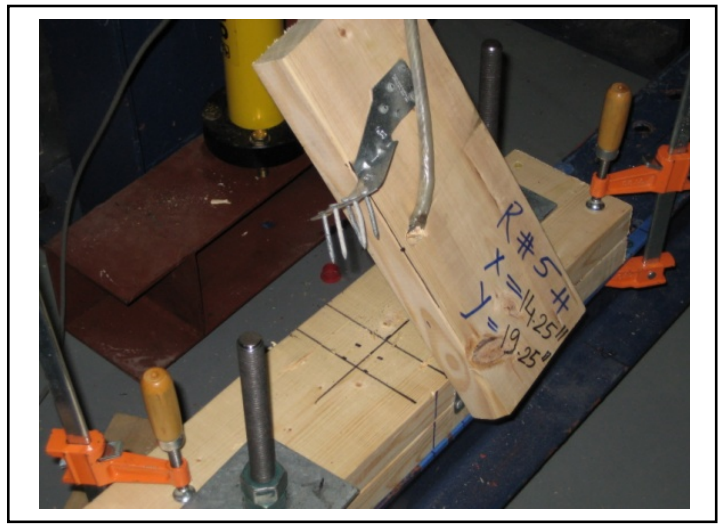

Figure 6.40: Metal Connector Case 18 


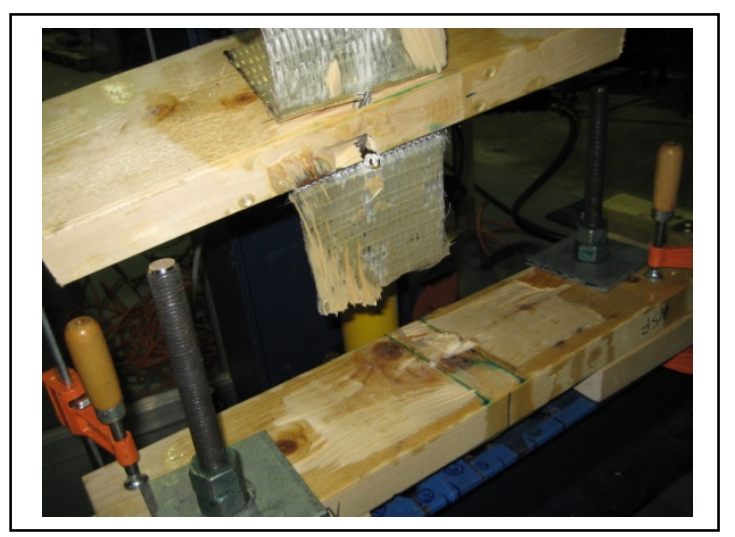

Figure 6.41: GFRP Connector Case 19

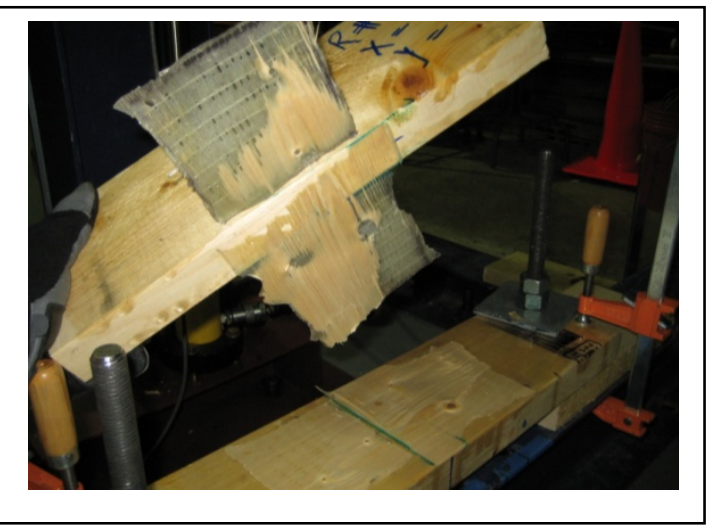

Figure 6.43: GRFP Connector Case 20

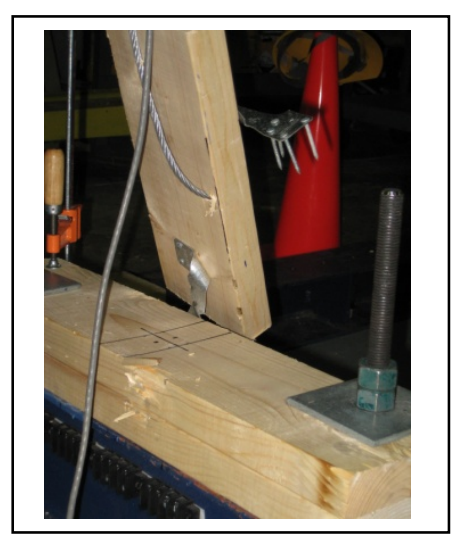

Figure 6.42: Metal Connector Case 19

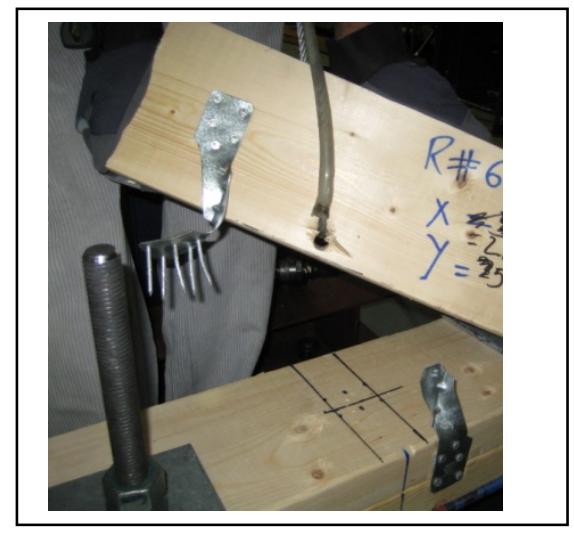

Figure 6.44: Metal Connector Case 20 


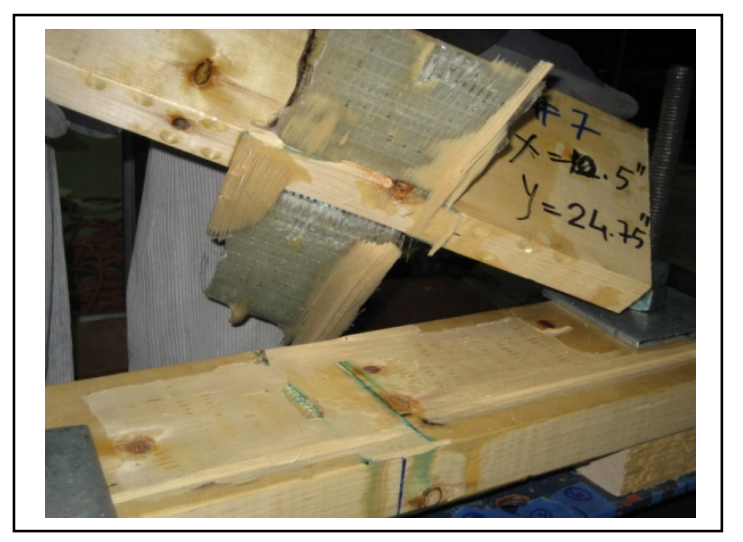

Figure 6.45: GFRP Connector Case 21

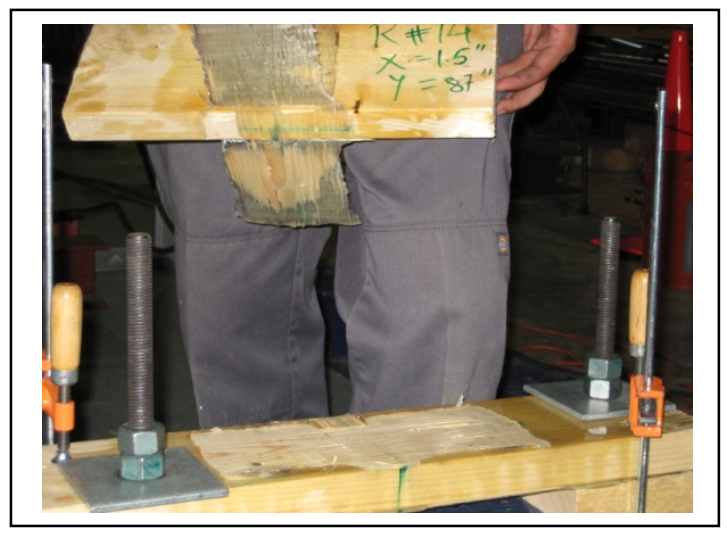

Figure 6.47: Metal Connector Case 22

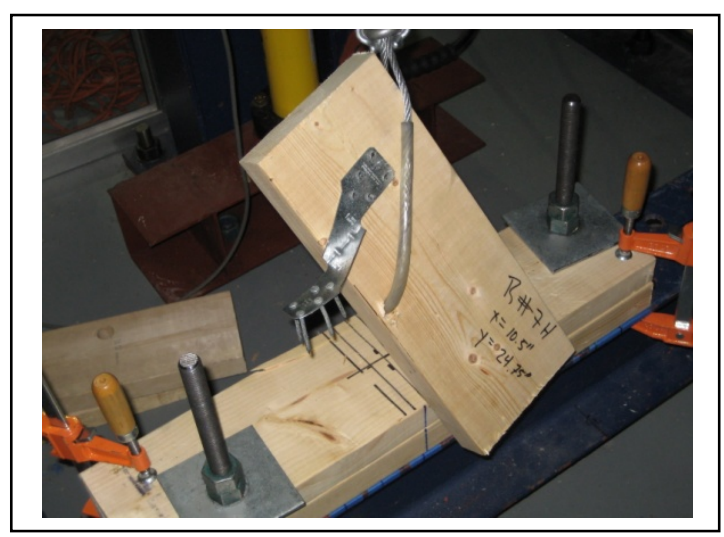

Figure 6.46: GRFP Connector Case 21

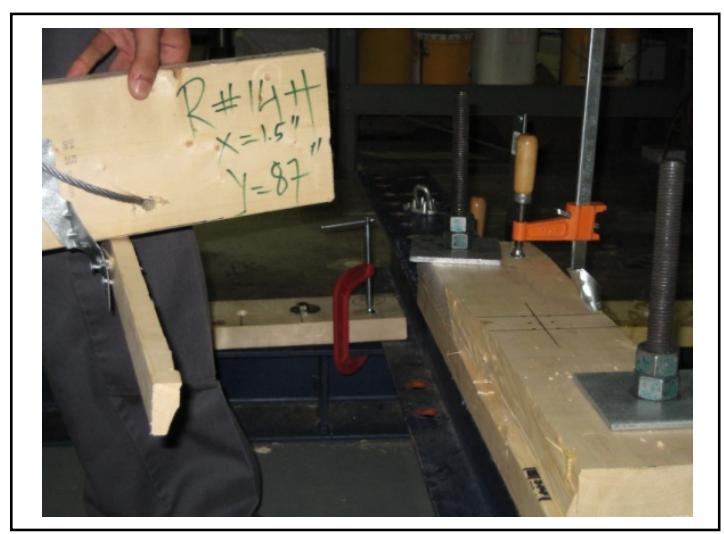

Figure 6.48: Metal Connector Case 22 


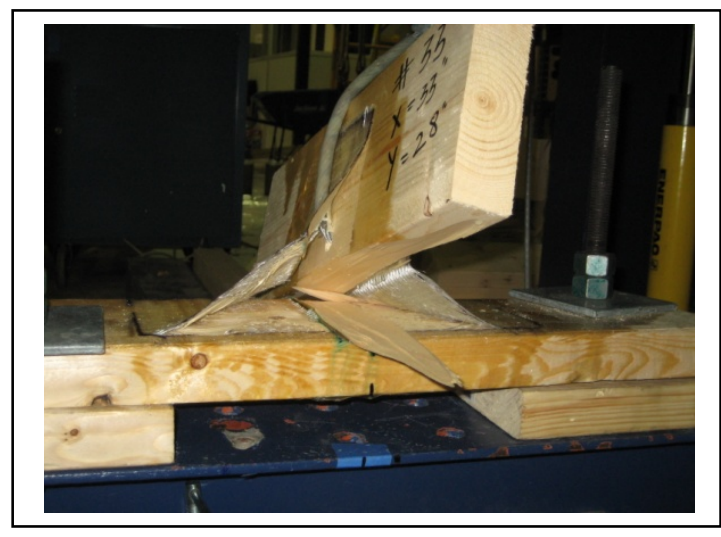

Figure 6.49: GFRP Connector Case 23

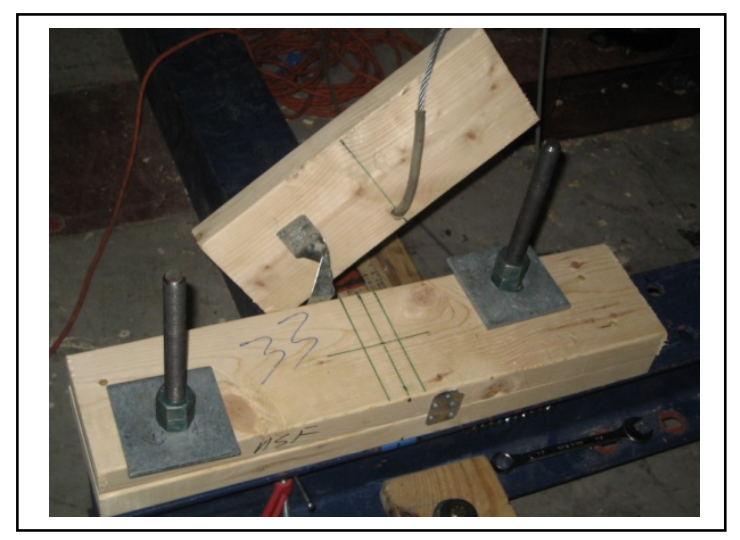

Figure 6.50: GRFP Connector Case 23

\subsection{Unidirectional Tests on Metal and GFRP Connections}

This section reports on the unidirectional tests performed at the SCL for metal and GFRP fasteners. These tests closely simulate the current testing methods used to determine the ultimate failure loads published by fasteners manufacturers. The up-lift capacity test method of the metal fasteners is first illustrated and the results tabulated in Figure 6.51 and Table 6.12, respectively. The L1 (parallel to the side wall) load capacity test method of the metal fasteners then illustrated and the results tabulated in Figure 6.52 and Table 6.13 respectively. The same methods to determine up-lift and L1 (parallel to the side wall) failure capacity are repeated for the GFRP connection in Figures 6.53 and 6.54 and the results are shown in Tables 6.14 and 6.15 . 

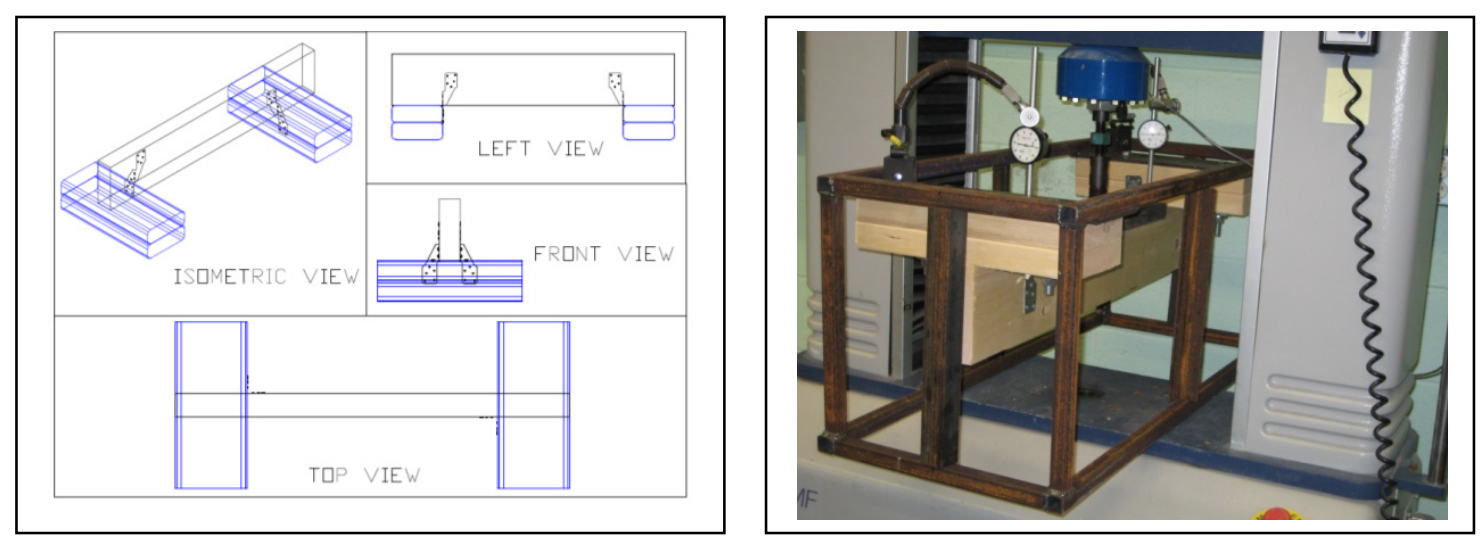

Figure 6.51: Metal Clip Connection Tested in Up-Lift

\begin{tabular}{|c|c|c|c|c|c|c|c|c|}
\hline \multirow{2}{*}{ Load Type } & Test 1 & Test 2 & Test 3 & Test 4 & Test 5 & Mean & STDV & \multirow{2}{*}{ cov } \\
\cline { 2 - 7 } & Ibs & Ibs & Ibs & lbs & lbs & Ibs & Ibs & \\
\hline 1/8" LOAD & 450 & 465 & 560 & 655 & 620 & \multirow{2}{*}{437} & \multirow{2}{*}{58.0} & \multirow{2}{*}{0.13} \\
\hline ULTIMATE & 478 & 385 & 420 & 385 & 515 & & & \\
\hline
\end{tabular}

Table 6.12: Measured Test Results and Sample Statistics of the Load capacity of Metal Clip Connectors Tested in Up-Lift 

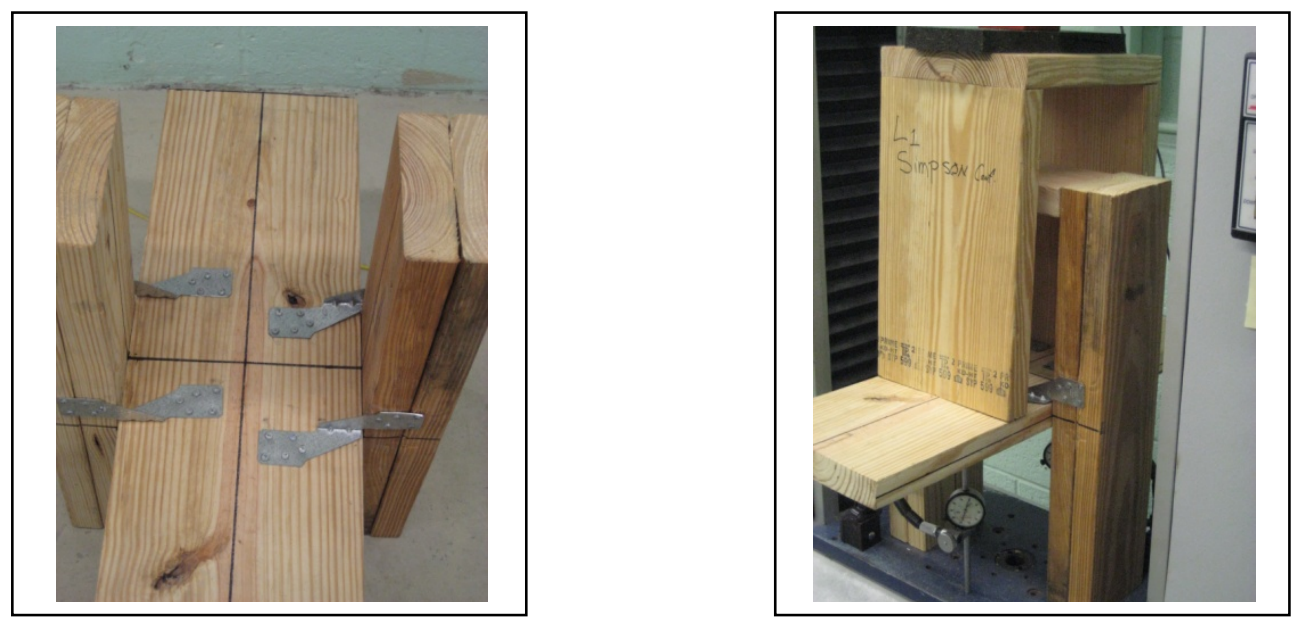

Figure 6.52: Metal Clip Connection Tests Set-Up in the L1 or Parallel to the Side Walls Direction

\begin{tabular}{|c|c|c|}
\hline Test & $\begin{array}{c}\text { Governing } \\
\text { L1 Load } \\
\text { /Clip }\end{array}$ & Mean \\
\hline No & lbs & Ibs \\
\hline 1 & 188 & \multirow{2}{*}{} \\
\hline 2 & 168 & \multirow{2}{*}{165} \\
\hline 3 & 125 & \\
\hline 4 & 124 & \\
\hline 5 & 220 & \\
\hline
\end{tabular}

Table 6.13: Metal Clip Connection Tests Results for L1 or Parallel to the Side Walls Direction 

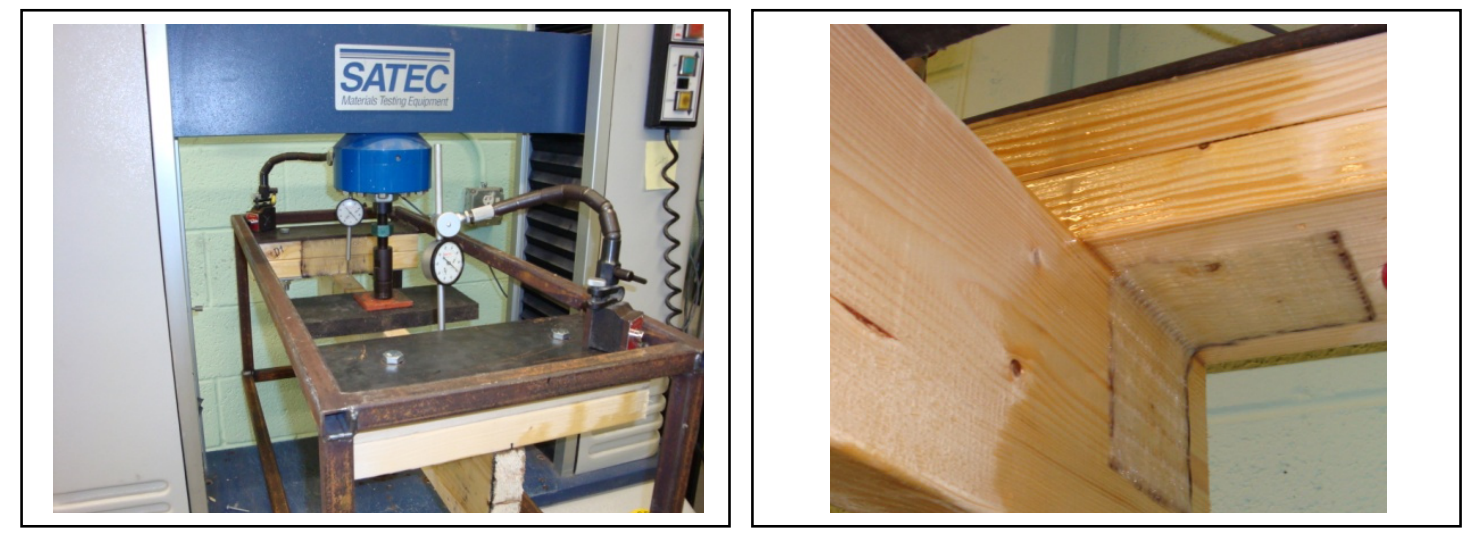

Figure 6.53: GFRP Connection Tested for Up-Lift (Canbek, 2009)

\begin{tabular}{|c|c|c|c|c|}
\hline Test No. & $\begin{array}{c}\text { Ultimate } \\
\text { Load (lbs) }\end{array}$ & $\begin{array}{c}\text { Average } \\
\text { Ultimate } \\
\text { Load (lbs) }\end{array}$ & $\begin{array}{c}\text { Governing } \\
\text { Up-Lift } \\
\text { Load/Clip }\end{array}$ & $\begin{array}{c}\text { Coefficient } \\
\text { of } \\
\text { Variation }\end{array}$ \\
\hline 1 & 4,650 & & 720 & 0.089 \\
\hline 2 & 3,900 & 4,320 & & \\
\hline 3 & 4,410 & & & \\
\hline
\end{tabular}

Table 6.14: GFRP Tests Results for Up-Lift (Canbek, 2009) 

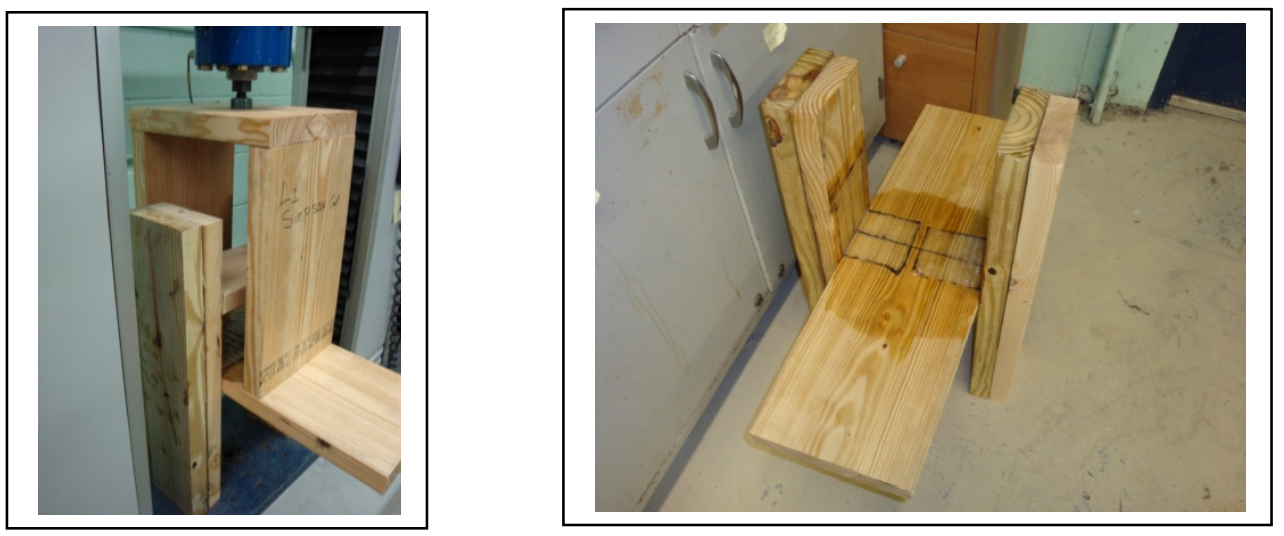

Figure 6.54: GFRP Connection Tested for $L 1$ or Parallel to the Side Walls (Canbek, 2009)

\begin{tabular}{|c|c|c|c|c|c|}
\hline $\begin{array}{c}\text { Wood } \\
\text { Type }\end{array}$ & $\begin{array}{c}\text { Specimen } \\
\text { No. }\end{array}$ & $\begin{array}{c}\text { Ultimate } \\
\text { Load } \\
\text { (lbs) }\end{array}$ & $\begin{array}{c}\text { Average } \\
\text { Ultimate } \\
\text { Load } \\
\text { (lbs) }\end{array}$ & $\begin{array}{c}\text { Governing } \\
\text { L1 Load } \\
\text { /Clip }\end{array}$ & $\begin{array}{c}\text { Coefficient } \\
\text { of } \\
\text { Variation }\end{array}$ \\
\hline \multirow{3}{*}{ SPF } & 1 & 3,480 & & & \\
\cline { 2 - 3 } & 2 & 3,530 & \multirow{2}{*}{3,313} & 552 & 0.100 \\
\cline { 2 - 3 } & 3 & 2,930 & & & \\
\hline
\end{tabular}

Table 6.15: GFRP Connection Tested for $L 1$ or Parallel to the Side Walls (Canbek, 2009) 


\subsection{Test Observations and Discussion}

From the SCL tri-axial test results three major findings can be noted. One is the GFRP connection load capacity compared to that of the metal connector tested. In many tests results, the ultimate failure load of the GFRP connection specimen was double of that for the hurricane clip. The second is the failure mode difference between the metal connectors versus the non-intrusive GRFP connection. The third is the reduction in ultimate uplift load capacities as compared to the manufacturer specified capacities of metal connectors or hurricane clips, when subjected to tri-axial loads simulating the aerodynamic forces that occur during a high wind event, versus unidirectional testing.

This research reports an investigation into the performance of GFRP and mechanical fasteners used in residential construction to withstand uplift forces, lateral forces parallel to the side walls and lateral forces perpendicular to the side walls occurring during high wind events. The capacity of both types (GFRP connection and metal fasteners) of roof-to-wall connection systems were evaluated by testing specimens under simultaneous tri-axial loads. The aim was to perform a series of tests on both types of connectors to evaluate and compare their failure load capacity under more realistic conditions. The results obtained from the SCL tri-axial tests, appear to indicate that the failure load capacity of the GFRP connection performed similar to and in most cases better than the metal fasteners test results; under tri-directional simultaneous loads obtained from aerodynamic tests at the WoW (see Tables 6.7 through 6.11). In some cases the ultimate failure resultant load for the GFRP connection was observed to be double of that for the metal fastener. The GFRP connection test results seem to demonstrate that it can be applicable to new construction as well as retrofitting of old 
residential buildings that require strengthening against extreme wind loads with minimally intrusive techniques.

The results show that the failure modes of connection joints are highly dependent on the type of the connection (GFRP versus metal). The failure modes difference observed during the tri-axial testing of the metal connector versus the non-intrusive GRFP connection are shown in Figures 6.5 through 6.24. In most cases the GFRP failed when the bond between the GFRP and the wood ruptured. It was noted that as GFRP is non-intrusive it doesn't weaken the wood members and crushing of wood is avoided. The failure mode observed was mostly detachment of GFRP from the wood surface and wood surface peeling. In the case of the hurricane clip the failure mode was observed as both nail withdraw or pull-out, clip rupture (Figures 6.5 through 6.24) and in some cases wood failure (Figure 6.48).

Currently, the allowable uplift loads for existing metal fasteners are established using unidirectional tests. As reported in Section 6.7, metal connector tests conducted in SCL illustrated that a variety of failure modes exist that included clip buckling, clip tearing, nail withdrawal and wood member splitting; with the predominant failure mode being wood splitting (Ahmed et al., 2009). The allowable loads are determined by the following formula: Allowable Load $=\min (\operatorname{Load}$ at failure / 3.0; Load at 1/8" deflection)/number of clips. There was no linear relationship between the failure load for the entire specimen and the number of clips used. The average uplift capacity for the clip (when tested using one clip per connection joint) (Figure 6.51) was calculated to be 437 pounds (see Table 6.12). A similar metal fastener tested unidirectional in the lateral direction (i.e. parallel to the side wall) (see Figure 6.52) (using four clips per specimen) 
showed a mean allowable capacity of 165 pounds per clip (see Table 6.13). Using similar test procedures Canbek (2008) tested GFRP connections as shown in Figures 6.53 and 6.54 also in Section 6.7. These unidirectional component tests resulted in mean load capacities of 720 pounds and 552 pounds for up-lift and lateral load respectively (see Tables 6.14 and 6.15); once the factor of safety had been applied (Canbek, 2008). The test results obtained from the uni-axial testing are overestimated, because the other force components are being neglected during the testing, which is not realistic as determined by the WoW test results (Chapter 5).

The failure loads for both connectors (GFRP and metal) decreased during the triaxial test, as expected (see Tables 6.7 through 6.11). Various aerodynamic force components ratios were simulated during the testing to failure which caused the resultant failure loads to vary depending on the specific test case. When the coefficients $F_{X} / F_{Z}$ and $\mathrm{F}_{\mathrm{Y}} / \mathrm{F}_{\mathrm{Z}}$ for the tri-axial testing were low the uplift capacity matched the uni-axial testing uplift capacity closely. However when the coefficients were high, reduced uplift capacity was observed compared to the uni-axial testing uplift capacity. This indicated that the lateral load components, if applied simultaneously with the uplift load component as experienced during real storms, the uplift load capacity of the connection is reduced - so that the uni-axial uplift test results are overestimated; even though a factor of three was applied to them. Similar overestimation may occur for uni-axial lateral load testing. As an example, in one of the most extreme cases where the tri-axial test was simulating a partially-enclosed condition at $90^{\circ}$ AOA, the uplift failure recorded loads were 295 (884/3FS) pounds and $250(750 / 3 \mathrm{FS})$ pounds as compared to the 720 pounds (see Table 6.14) and 437 pounds (see Table 6.12), obtained from uni-axial testing, for the GFRP and 
metal clip respectively; and the lateral (parallel to the walls) failure loads were 102 (307/3FS) pounds and $87(260 / 3 \mathrm{FS})$ pounds as compared to the 552 pounds (see Table 6.15) and 165 pounds (see Table 6.13) obtained from uni-axial testing for the GFRP and metal clip, respectively (see Table 6.11 for tri-axial results). Even though, the GFRP has more ultimate failure capacity, results clearly indicate the inappropriateness of the existing testing protocol used to test connectors. Thus the current design approach, based as it is on testing a fastener in one direction instead of simultaneous three dimensional loads, may lead to erroneous predictions of the allowable capacity. Design based on these erroneous allowable load capacities can cause inter-component connection failures during hurricanes. Improving upon current practice by taking into account the results reported herein and the suggested tri-axial testing will improve the performance of timber construction in high winds.

The wide-ranging variety of tri-axial test results in this research (23 cases) (see Tables 6.7 through 6.11), which are based on the extensive aerodynamic load configurations observed during the WoW test results, are not practical for industry product testing; therefore, a series of nine tri-axial critical configurations (covering the range of possible direction cosines) are suggested in order to find the ultimate capacity of a timber roof-to-wall connection in all three directions (see Table 6.16). The capacity of a connection depends upon the ratio between the vertical component $\mathrm{Fz}$ and the longitudinal component Fx of the demand and the ratio between the vertical component Fz and the lateral component Fy of the demand. Therefore, the test protocol must consist, for any one connection, of a set of tests covering the ratios $\mathrm{Fx} / \mathrm{Fz}$ and $\mathrm{Fy} / \mathrm{Fz}$ as shown in Table 6.16. It is the intent of this proposed testing method to simplify the work of a 
product testing engineer and still provide accurate results that consider the three dimensional forces that occur during a high wind event. Table 6.17 shows the results obtained from the tri-axial testing performed using the newly developed test protocol and test set up. The coefficients shown in Table 6.17 are obtained from the tri-axial tests performed in the SCL by approximating ratios $\mathrm{Fx} / \mathrm{Fz}$ and $\mathrm{Fy} / \mathrm{Fz}$ to the first decimal places. The tri-axial failure loads are given for corresponding cases as shown in Table 6.17 .

\begin{tabular}{|c|c|c|c|c|c|c|}
\hline \multicolumn{6}{|c|}{ Component Tri-Axial Tests Configuration } \\
\hline \multirow{2}{*}{ Test } & \multicolumn{3}{|c|}{ Coefficients } & \multicolumn{3}{|c|}{ Averaged Clip Results } \\
\hline & Fz & Fx & Fy & Fx (lbs) & Fy (lbs) & Fz (lbs) \\
\hline $\mathbf{1}$ & $\mathbf{1 . 0}$ & $\mathbf{1 . 0}$ & $\mathbf{1 . 0}$ & & & \\
\hline 2 & $\mathbf{1 . 0}$ & $\mathbf{1 . 0}$ & $\mathbf{0 . 5}$ & & & \\
\hline 3 & $\mathbf{1 . 0}$ & $\mathbf{1 . 0}$ & $\mathbf{0 . 0}$ & & & \\
\hline 4 & $\mathbf{1 . 0}$ & $\mathbf{0 . 5}$ & $\mathbf{1 . 0}$ & & & \\
\hline $\mathbf{5}$ & $\mathbf{1 . 0}$ & $\mathbf{0 . 0}$ & $\mathbf{1 . 0}$ & & & \\
\hline $\mathbf{6}$ & $\mathbf{1 . 0}$ & $\mathbf{0 . 5}$ & $\mathbf{0 . 5}$ & & & \\
\hline 7 & $\mathbf{1 . 0}$ & $\mathbf{0 . 5}$ & $\mathbf{0 . 0}$ & & & \\
\hline $\mathbf{8}$ & $\mathbf{1 . 0}$ & $\mathbf{0 . 0}$ & $\mathbf{0 . 5}$ & & & \\
\hline 9 & $\mathbf{1 . 0}$ & $\mathbf{0 . 0}$ & $\mathbf{0 . 0}$ & & & \\
\hline
\end{tabular}

* Test could not be performed due to testing system limitations.

Table 6.16: Component Tri-Axial Tests Configuration 


\begin{tabular}{|c|c|c|c|c|c|c|c|}
\hline \multicolumn{7}{|c|}{ Component Tri-Axial Tests Configuration -- Example } & \multirow{3}{*}{ Case } \\
\hline \multirow{2}{*}{ Test } & \multicolumn{3}{|c|}{ Coefficients } & \multicolumn{3}{|c|}{ Averaged Clip Results } & \\
\hline & $\mathbf{F z}$ & $\mathbf{F x}$ & Fy & Fx (lbs) & Fy (lbs) & Fz (lbs) & \\
\hline 1 & 1.0 & 1.0 & 1.0 & 455 & 949 & 865 & 12 \\
\hline 2 & 1.0 & 1.0 & 0.5 & * & $*$ & $*$ & $*$ \\
\hline 3 & 1.0 & 1.0 & $\mathbf{0 . 0}$ & * & * & * & * \\
\hline 4 & 1.0 & 0.5 & 1.0 & 441 & 867 & 936 & 2 \\
\hline 5 & 1.0 & 0.0 & 1.0 & 43 & 822 & 834 & 3 \\
\hline 6 & 1.0 & 0.5 & 0.5 & 478 & 450 & 904 & 16 \\
\hline 7 & 1.0 & 0.5 & $\mathbf{0 . 0}$ & 389 & 171 & 1253 & 17 \\
\hline 8 & 1.0 & 0.0 & 0.5 & 71 & 424 & 860 & $7 \& 15$ \\
\hline 9 & 1.0 & 0.0 & 0.0 & 65 & 215 & 1290 & $10 \& 19$ \\
\hline
\end{tabular}

* Test could not be performed due to testing system limitations.

Table 6.17: Tri-Axial Tests Example 


\section{Summary, Conclusions and Future Work}

\subsection{Summary of Research Activities and Findings}

A unique experimental facility called the Wall of Wind (WoW) capable of performing controlled and repeatable full-scale testing in wind flow that adequately replicate hurricane conditions was employed to develop mitigation techniques to prevent large damage caused to residential buildings in the coastal areas by hurricane induced winds and wind-driven rain. One of the most critical connections in wood frame construction, prone to hurricane wind induced failure, is that of the roof rafter and the top plate of the wall. These connections typically use mechanical fasteners, such as metal straps fastened with nails. However these connections are intrusive, have several failure modes, and suffer corrosion when used in coastal regions. Through full-scale testing under simulated hurricane conditions the current research focused on developing novel, cost effective, light, strong, ductile, corrosion-resistant, and no-intrusive roof-to-wall connection systems using high performance glass fiber reinforced polymer (GFRP) materials to strengthen new and existing residential buildings to improve their hurricane resiliency.

Testing of the GFRP connections in the WoW generated aerodynamic and aerohydrodynamic data pertaining to tri-axial loading and to corresponding displacements and strains at the connections. No significant movement of the roof structure or deformation/failure of the connections was observed under the highest wind generated by the WoW. The load cells recorded tri-axial loads and moments for various angles of attack. When the building specimen was tested under the partially enclosed condition, 
noticeable load increases were recorded at the connections. This allowed quantification of the increase in loads due to any possible breach of the building envelope and the corresponding increase in the internal pressures. No significant increase in load was observed during the wind-driven rain tests as compared to wind tests without rain. The WoW data were used to generate simultaneous tri-axial loading. The new GFRP connections (initially developed through component level and full-scale testing in the Structures and Construction Laboratory (SCL)) and existing metal fasteners were then tested to failure under such loading in SCL. The failure modes were detachment of GFRP from the wood for non-intrusive connections versus nails pull out and clip rupture for the metal fasteners. Results demonstrated that the newly developed GFRP connections had similar or, in most cases greater tri-axial load capacity as compared to metal fasteners. Furthermore, the GFRP connection is economically comparable to commercially available metal connectors $(\$ 0.73 /$ GFRP connection versus $\$ 0.55 /$ metal connector) (Canbek, 2009). In addition to the development of the new GFRP connection, a new test protocol was developed for testing inter-component connections under realistic tri-axial aerodynamic loading as opposed to the existing method of unidirectional testing. The following sections state the conclusions pertaining to the various components of the research.

\subsection{Initial GFRP Connection Development}

The initial research on the GFRP connection indicated that the GFRP connection can be effective in transferring the vertical and lateral roof-to-wall loads. However the tests were unidirectional and thus did not evaluate the performance of the connection 
under simulated tri-axial aerodynamic loading. The full-scale and component level tests results, of the GFRP connection, demonstrated similar uplift load capacities (Canbek, 2009). The GFRP tie connection thus developed provided the basis for further testing using hybridized experiments performed at the WoW and SCL. The hybridized testing, performed in this research, was necessary to ascertain and validate the performance of the new connection under closely simulated tropical cyclone wind effects (including high winds, wind-driven-rain and wind-borne debris impacts). The initially developed GFRP connection configuration when evaluated for cost effectiveness proved to be economically comparable to commercially available metal connector.

\subsection{Wall of Wind (WoW) Tropical Storm Simulator Experiments}

The WoW tests performed in this research helped to better understand the aerodynamic and hydro-aerodynamic loading on the roof-to-wall connections during an extreme wind event. The results obtained from the thirty WoW tests performed in five phases $\left(0^{\circ}, 90^{\circ}, 45^{\circ}, 30^{\circ}\right.$ and $\left.60^{\circ}\right)$ were graphically represented to demonstrate the peak and mean loads, deflections, and strains. The graphs contained the results of all the different conditions tested:

- $\quad$ Enclosed condition tested using full-throttle and quasi-periodic waveforms for all angles of attack $\left(0^{\circ}, 90^{\circ}, 45^{\circ}, 30^{\circ}\right.$ and $\left.60^{\circ}\right)$

- $\quad$ Enclosed condition tested under simulated wind-driven rain using full-throttle and quasi-periodic waveforms for $0^{\circ}, 45^{\circ} \& 90^{\circ}$ angles of attack

- $\quad$ Partially enclosed (PE) condition tested using full-throttle and quasi-periodic waveforms for all angles of attack $\left(0^{\circ}, 90^{\circ}, 45^{\circ}, 30^{\circ}\right.$ and $\left.60^{\circ}\right)$ 
- $\quad$ Modified partially enclosed (PE') condition tested using full-throttle and quasiperiodic waveforms for $45^{\circ} \& 60^{\circ}$ angles of attack.

Each test was performed using a 1 minute flat waveform (full-throttle; at maximum rpm of the WoW engines and generating high frequency turbulence only) and 3 minutes quasi-periodic waveform (generating low frequency turbulence in addition to high frequency turbulence). The difference was due to the presence of low frequency fluctuations associated with the quasi-periodic waveform generated wind flow. Though the peak 3-sec gusts wind speeds were comparable for the two different waveform generated flows the mean wind speeds for the flat waveform case was considerably higher than the quasi-periodic waveform case. As such the loads recorded on the roof-towall connections for the flat-waveform (or full throttle) cases were higher than those for the quasi-periodic waveform cases. However the proportionalities between the mean uplift, in-plane, and out-of-plane forces were very similar for both waveforms. This emphasized that the higher turbulence generated by the low frequency fluctuations of the wind did not affect the proportionalities between the mean uplift and lateral forces induced on the connections. Thus for further testing of the GFRP connections to failure under tri-axial loading in SCL, only the data obtained for the flat waveform tests were used.

Hurricane winds are accompanied by wind-driven rain (WDR). Aerodynamic loading on buildings and their components and connections, due to wind effects only, may differ from aero-hydrodynamic loading induced by the combined effect of wind and impinging rain. The WoW was used to determine if there is any significant difference between aerodynamic and aero-hydrodynamic loading induced on the GFRP connections 
by testing under simulated hurricane wind and wind-induced rain, respectively. Based on the results no significant increase in load was observed during the wind-driven rain tests as compared to wind tests without rain generation. Thus the data used for failure testing in SCL were obtained from the dry wind tests only. It should be noted that due to the lack of published WDR research, additional research is needed on drop size distribution and rainfall intensity during tropical cyclones. Such data are needed to attempt more realistic generation of WoW-WDR capabilities needed to realistically simulate tropical cyclone related rainfalls and their variability's.

Design wind pressures on building components and connections are combinations of external and internal pressures. Internal pressure contribution is significant especially in the event where windborne debris suddenly breach the building envelope creating sizeable openings. For the current study on roof-to-wall connections, full-scale testing was performed to determine the effects of internal pressure changes on the connections due to breach of building envelope. The testing included two conditions pertaining to internal pressures: enclosed and partially-enclosed (simulating breach of envelope) conditions as specified in ASCE 7-05. The test specimen windows and doors were removed to simulate breach of the envelope effect. The change in the internal pressure was correlated with the change in the loading on the connections. Since it had more tributary area, the maximum difference in uplift loading between enclosed and partiallyenclosed conditions was observed in the middle truss (connection $\# 5$ for $0^{\circ} \mathrm{AOA}$ and full-throttle testing). The mean uplift at connection \# 5, for enclosed and partiallyenclosed conditions were $117 \mathrm{lbs}$ and $645 \mathrm{lbs}$, respectively - the difference being $528 \mathrm{lbs}$. The difference in the mean internal pressures between enclosed and partially-enclosed 
conditions was 0.077 psi. The tributary area for connection \# 5 was 35 sq. ft., which would contribute to an additional load of about $390 \mathrm{lbs}$ on the connection due to the change in the internal pressure. The measured load increase on the connection was higher than the estimated increase based on internal pressure and tributary area. This might be caused by the approximation of tributary area and assumption of uniformity of internal pressure throughout the area. Nevertheless, the experiments indicated how severe the effects of a breach in the building envelope could be on connections, as the loading might increase several times (5.5 times in this case).

There was no significant movement of the roof structure or deformation/failure of the GFRP connections under the highest winds generated by the WoW, indicating that the connections were adequate at least under simulated moderate hurricane conditions. The tests provided a wealth of information on the aerodynamic tri-axial loads on roof-towall connections that might occur during an extreme wind event. Thus a database was developed on wind-induced uplift, in-plane (parallel to the side walls), and out-of-plane (perpendicular to the side walls) loads experienced by the GFRP connections. The database showed that there could be significant lateral load components acting simultaneously with the uplift load component-such load combination is generally not simulated in existing connection test methods. The combinations of loads were used in the next phase of the research, i.e., tri-axial loading of the GFRP connection in the SCL till failure at the component level. For each test the three force components were converted to a resultant mean load in order to test the GFRP connections more realistically using the aerodynamic loading obtained from WoW tests. Based on the SCL testing system capability a total of 23 out of 36 resultant forces obtained from the WoW 
testing were simulated in the SCL to test the newly developed GFRP connections and metal hurricane clips to failure. Hurricane clips were tested to provide a comparison of performance between GFRP and metal connections subjected to simultaneous tri-axial loading.

\subsection{Laboratory Tri-Axial Loading Experiments}

The capacity of both types (GFRP connection and metal fasteners) of roof-to-wall connection systems were evaluated by testing specimens under simultaneous tri-axial loads. The aim was to perform a series of tests on both types of connectors to evaluate and compare their failure load capacities under more realistic conditions.

The results obtained from the SCL tri-axial tests indicated that the GFRP connection performed similar to and in most cases better than the metal fasteners. . In some cases the ultimate failure resultant load for the GFRP connection was observed to be double of that for the metal fastener.

The results show that the failure modes of connection joints are highly dependent on the type of the connection (GFRP versus metal). It was noted that as GFRP is nonintrusive it didn't weaken the wood members and crushing of wood was avoided. The failure mode observed was mostly detachment of GFRP from the wood surface and wood surface peeling. In the case of the hurricane clip the failure mode was observed as nail withdrawal or pull-out, clip rupture, and in limited cases wood failure.

The test results on ultimate load capabilities and failure modes demonstrated that GFRP connection could be a viable alternative to metal fasteners. Such non-intrusive GFRP connection is applicable to new construction and will be especially useful as a 
retrofitting tool for old residential buildings that require strengthening against extreme wind loads with minimally intrusive techniques.

Currently, the allowable uplift loads for existing metal fasteners are established using unidirectional tests. The allowable load per clip is determined by the following formula: Allowable Load per Clip $=\min (\operatorname{Load}$ at failure $/ 3.0$; Load at $1 / 8$ " deflection)/number of clips used in the test specimen. The test results obtained from the unidirectional testing are often overestimated, because the other force components are neglected during the testing, which is not realistic as determined by the WoW and SCL test results. The unidirectional failure loads for both connectors (GFRP and metal) decreased during the tri-axial tests. Various aerodynamic force components ratios were simulated during the tri-axial testing to failure which caused the resultant failure loads to vary depending on the specific test case. When the coefficients $F_{X} / F_{Z}$ and $F_{Y} / F_{Z}$ for the tri-axial testing were low the uplift capacity matched the uni-axial testing uplift capacity closely. However when the coefficients were high, reduced uplift capacity was observed compared to the unidirectional testing uplift capacity. This indicated that when the lateral load components were comparable to and applied simultaneously with the uplift load component, as experienced during real storms, the uplift load capacity of the connection was reduced - implying that the unidirectional uplift test results were overestimated. Similar overestimation may occur for unidirectional lateral load testing. As an example, in one of the most extreme cases the tri-axial test recorded the uplift failure loads to be 295 pounds and 250 pounds as compared to the 720 pounds and 437 pounds, obtained from unidirectional testing, for the GFRP and metal clip respectively; and the lateral (parallel to the walls) failure loads were 102 pounds and 87 pounds as compared to the 
552 pounds and 165 pounds obtained from unidirectional testing for the GFRP and metal clip, respectively.

Thus, tri-axial aerodynamic loading investigation into the performance of GFRP and mechanical fasteners used in residential construction to withstand forces occurring during high wind events demonstrated a propensity to overestimate fastener capabilities while using unidirectional testing methods. Even though, the GFRP has more ultimate failure capacity, results clearly indicated the inappropriateness of the existing testing protocol used to test connectors. Thus the current design approach, based as it is on testing a fastener in one direction instead of simultaneous three dimensional loads, may lead to erroneous predictions of the allowable capacity. Design based on these erroneous allowable load capacities can cause inter-component connection failures during hurricanes. Improving upon current practice by using the suggested tri-axial testing protocol with nine test configurations should allow the designer to have proper understanding of the simultaneous load capacities of a connection and thus help to improve the performance of timber construction in high winds.

\subsection{Project Contributions}

The project helped in the development of WoW research infrastructure and instrumentation at FIU, which is facilitating testing of entire structures and promoting research focusing on the complex interaction between hurricanes and the built environment. This is necessary to develop a cohesive and systemic approach to building hurricane resilient communities. The WoW provides testing capabilities for investigating real building structure and component performance against hurricanes and for developing 
advanced mitigation techniques and products, filling a significant technological gap. Three different types of tests are feasible: (i) Aerodynamic (pressure/load tests for low rise buildings), (ii) Hydro-aerodynamic (wind-driven rain tests), and (iii) Destructive (failure-mode testing). WoW research activities and findings would have important and sometimes immediate economic and social impact in the coastal states, as well as inland states.

In addition, a component level testing setup has been developed in SCL to test connections to failure under the influence of simultaneous tri-axial loading. The test system is composed of a double acting hydraulic jack that can pull on the component specimen using a cable and pulley. A load cell between the specimen and pulley records the ultimate failure load. The specimen is bolted to an I-beam that in turn is attached to two channels bolted to the SCL tie-downs. By moving the specimen North-South and East-West the resultant loading can be simulated.

Based on WoW testing a database has been developed on aerodynamic and aerohydrodynamic loading on roof-to-wall connections tested under several parameters: angles of attack, wind-turbulence content, enclosed and partially-enclosed building conditions, with and without effects of rain. This database can be used by other researchers and industry professionals to test roof-to-wall connections under realistic combined loading (based on 'holistic' testing under wind) simulated in structural laboratories.

A database has been developed on the uni-axial and tri-axial load capacity of the GFRP connections and of a particular type of metal fastener. To the researcher's knowledge the simultaneous application of tri-axial loading to roof-to-wall connections in 
SCL is one of the first attempts to mimic realistic aerodynamic loads obtained from fullscale wind testing.

The research's findings demonstrated that a GFRP connection system is a viable option for use in a timber roof-to-wall connection system. In most cases the GFRP connection was able to achieve double the resultant load capacity of a typical metal fastener. Findings also indicated that current testing methods for mechanical fasteners tend to overestimate the actual load capacity of a connector, because of improper testing methods. The research proposed a new testing protocol to test connection fasteners using simultaneous tri-directional forces that closely resemble actual aerodynamic forces on a roof-to-wall connection experienced during an extreme wind event.

The work reported in this paper is intended to draw the attention of practitioners and code writers to current inappropriate and incorrect testing methods for evaluating the capacity of connectors, and to suggest that tests such as those reported in this dissertation can contribute significantly to improving the performance of roof-to-wall connections and enhance the resilience of communities subjected to strong winds. This research presents the first step into the understanding of tri-axial connection loads and the connector capacities that are representative of the loads that a single story residential timber framed structure undergoes during a high wind event.

\subsection{Future Work Recommendations}

Although this dissertation encompassed a broad range of research activities, some aspects of the GFRP connection behavior and proposed tri-axial testing method need to be further researched. The GFRP connection has yet to be tested aerodynamically under 
very strong hurricane conditions. This performance can be simulated in the 12 -fan WoW system which is presently under development. Also, a series of timber structures, within tropical cyclone prone coastal areas, could be retrofitted with the new GFRP roof-to-wall connections. Building performance under possible future storms can then provide validation of the connections -- there is no better test method than subjecting the connections to actual tropical cyclone conditions. Such retrofitting can also be used to study the long term weather effects of moisture, heat and rain on the GFRP connections, which are not yet completely understood. Also, the impacts of fatigue and creep in the GFRP connections have yet to be examined. Studies on creep and fatigue are warranted for the GFRP connections as they are for existing metal fasteners. The tri-axial testing method and system used in this research could be improved to test all 36 resultant aerodynamic forces obtained from the WoW tests. This could be done by enhancing the current testing system by enlarging the size of the system and implementing a pulley swivel system that can allow more lateral locations to be tested. Also, performing more than one test per resultant location would give a better statistical representation of the triaxial component test results reported in this research. Finally, the simulation of simultaneous tri-axial moments in addition to the tri-axial loads is recommended as future work as such loading would more closely replicate the aerodynamic loading on a roof-towall connection occurring during an extreme wind event. 


\section{REFERENCES}

Adams, A. D. (1989). "Structural Framing Considerations for Wind Resistance of Buildings." Jamaican Institute of Engineers Seminar on Effects of "Hurricane Gilbert" on Buildings and Engineering Facilities in Jamaica, Jamaican Institute of Engineers, Jamaica.

AF\&PA. (2007). National Design Specification for Wood Construction (NDS), American Forest and Paper Association, Washington, D.C.

Allen, D. E. (1989). "Hurricane Gilbert: Building Damage in Jamaica." Jamaican Institute of Engineers Seminar on Effects of "Hurricane Gilbert" on Buildings and Engineering Facilities in Jamaica, Jamaican Institute of Engineers, Jamaica.

Ahmed, S., Canino, I., Gan Chowdhury, A., Mirmiran, A., Suksuwang, N., (2009), “A Study into the Capability of Multiple Mechanical Fasteners in Roof-To-Wall Connections of Timber Residential Buildings," Editorial Manager (tm) for Practice Periodical on Structural Design and Construction, Manuscript Draft.

Alvarez, R. (2000). Proceedings of the National Hurricane Hazard Reduction Act Meeting, International Hurricane Center, Florida International University, Miami, FL.

American Wood Council Council (AWC). 2007. National Design Specifications (NDS) for Wood Construction. Am. Wood Council of the Am. Forest \& Paper Assoc., Washington, DC.

ASTM, "Standard Test Methods for Mechanical Fasteners in Wood,” 2006

ASTM, "Standard Test Method for Strength Properties of Adhesive Bonds in Shear by Compression Loading," 2008

ASTM, "Standard Specification for Adhesives for Structural Laminated Wood Products for Use Under Exterior (Wet Use) Exposure Conditions," 2004

Bitsuamlak, G., Gan Chowdhury, A., Sambare, D. (2009), “Application of a full-scale testing facility for assessing wind-driven-rain intrusion," Building and Environment, 44-12, 2430-2441.

Canbek, C. (2009). "Development of a Hurricane-Resistant Roof-to-Wall Connection Using High-Performance Fiber Composites," Master Thesis, Florida International University, Miami, FL.

Cermak, J.E., Leighton, S.C., and Leffler, R.D. (1995). "Wind-Tunnel Modeling of the Atmospheric Surface Layer.” J. Wind Eng. Indust. Aerodyn., 54-55, 505-513. 
Cheng, J. (2004), "Testing and Analysis of the Toe-Nailed Connection in the Residential Roof-to-Wall System”, Forrest Product Journal, 54(4), p. 58-65.

Coastal Contractor. (http://www.coastalcontractor.net)

Davenport, A. G. (2002). "Past, present and future of wind engineering." Journal of Wind Engineering and Industrial Aerodynamics, 90(12-15), 1371-1380.

Dantin, P. (2007). "Wind Up-Lift Reactions at Roof-to-Wall Connections of a WoodFramed Gable Roof Assembly", M.S., Clemson University, Clemson, SC.

Davalos, J. F., Qiao, P. Z., and Trimble, B.S., "Fiber-Reinforced Composite and Wood Bonded Interfaces: Part 1. Durability and Shear Strength," Journal of Composites Technology and Research, Vol. 22, No. 4, pp. 224-231, 2000.

DCCA (Department of Commerce and Community Affairs) Loss mitigation Grant Program, "Wind Resistive Devices Technical Specifications" (2006), State of Hawaii.

Dikkers, R. D., Marshall, R. D., and Thom, H. C. S. (1970). "Hurricane Camille August1969: A Survey of Structural Damage Along the Mississippi Gulf Coast." National Bureau of Standards.

Eaton, K.J. and Mayne, J.R. (1975). "The Measurement of Wind Pressures on Two Storey Houses at Aylesbury." J. Wind Eng. Indust. Aerodyn., 1, 67-109.

Federal Building and Fire Safety Investigation of the World Trade Center Disaster (2005). National. Inst. Standards \& Techn., Table 4-4, 80 (http://wtc.nist.gov/NISTNCSTAR1-2A.pdf).

FEMA. (1992). "Building Performance: Hurricane Andrew in Florida - Observations, Recommendations, and Technical Guidance." Federal Emergency Management Agency.

FEMA. (1993). "Building Performance: Hurricane Iniki in Hawaii - Observations, Recommendations, and Technical Guidance." Federal Emergency Mangement Agency.

FEMA. (1999). "Building Performance Assessment Report: Hurricane Georges...In the Gulf Coast...Building on Success - Observations, Recommendations, and Technical Guidance." FEMA 338, Federal Emergency Management Agency.

FEMA. (2005a). "Mitigation Assessment Team Report: Hurricane Charley in Florida Observations,Recommendations, and Technical Guidance." FEMA 488, Federal Emergency Management Agency. 
FEMA. (2005b). "Mitigation Assessment Team Report: Hurricane Iván in Alabama and Florida - Observations, Recommendations, and Technical Guidance." FEMA 489, Federal Emergency Management Agency.

FEMA. (2005c). "Summary Report on Building Performance: 2004 Hurricane Season."FEMA 490, Federal Emergency Management Agency. FEMA. (2006). "Hurricane Katrina in the Gulf Coast: Mitigation Assessment Team Report -Building Performance Observations, Recommendations, and Technical Guidance." FEMA 549, Federal Emergency Management Agency.

Florida Coastal Monitoring Program (FCMP) (http://users.ce.ufl.edu/ fcmp/overview/house.htm).

Florida Building Code (FBC, 2007). Building. FL

Florida Division of Emergency Management, (2007). "Florida Hurricane Loss Mitigation Program; Report to the Florida Legislature.” Florida.

Gan Chowdhury, A., Huang, P., Bitsuamlak, G. (2008). "Wind Flow Simulation and Testing for Mitigating Coastal Disaster under Hurricanes.” Disaster Advances Journal, 1 (4), pp. 9-19.

Gan Chowdhury, A., Huang, P., Erwin, J. (2009). "Aerodynamic Testing Application of a Full-Scale Facility for Mitigating Hurricane-Induced Coastal Disasters.” Far East Journal of Ocean Research, 2 (1), pp. 1-27.

Gan Chowdhury, A., Simiu, E., Leatherman, S.P. (2009). "Destructive Testing under Simulated Hurricane Effects to Promote Hazard Mitigation.” ASCE Natural Hazards Review Journal, 10 (1), pp. 1-10.

Goldenburg, S.B., Landsea, C.W., Mestas-Nunez, A.M., Gray, W.M., 2001. "The Recent Increase in Atlantic Hurricane Activity: Causes and Implications." Science, Vol. 293, pp. 474-479.

Groom, K.M., Leichti, R.J. (1991), "Finite-Element Model of a Nonlinear InterComponent Connection in Light-Framed Structures," Proceedings of the 1991 International Timber Engineering Conference, London, England, 4, p. 4.346-4.353.

Groom, K.M., Leichti, R.J. (1994), "Transforming a Corner of a Light-Frame Wood Structure to a Set of Nonlinear Springs," Wood and Fiber Science, Society of Wood Science and Technology, 26(1), p. 28-35.

Gupta, R. (2005). "System behavior of wood truss assemblies." Progress in Structural Engineering and Materials, 7(4), 183-193. 
Hoxey, R.P., Richards, P.J. (1993), "Flow Patterns and Pressure Fields Around a FullScale Building," Journal of Wind Engineering and Industrial Aerodynamics, 50(1/3), p. 203-212.

Holmes, J.D. (2001). Wind Loading of Structures, Spon Press, New York.

Holmes, J.D., Letchford, C.W., and Lin, N. (2006). "Investigations of Plate-Type Windborne Debris - Part II: Computed Trajectories.” J. Wind Eng. Indust. Aerodyn., 94, 21-39.

Huang, P., Liu, R., Gan Chowdhury, A., Bitsuamlak, G., Erwin, J., and Ahmed, S.S. (2008), "Turbulence Simulation of Small-Scale Wall of Wind Flows," 4th International Conference on Advances in Wind and Structures", AWAS08, Jeju, Korea, pp. 1559-1578, (CD-ROM).

Huang, P., Gan Chowdhury, A., Bitsuamlak, G., Liu, R. (2009). "Development of Devices and Methods for Simulation of Hurricane Winds in a Full-Scale Testing Facility", Wind and Structures, 12 (2), pp. 151-177.

International Building Code, (2000). (http://www.iccsafe.org/Pages/default.aspx).

Jia, J., and Davalos, J.F., "Study of Load Ratio for Mode-I Fatigue Fracture of WoodFRP-bonded Interfaces," Journal of Composite Materials, Vol. 38, No. 14, pp. 12111230, 2004.

Jones, N.P., Reed, D.A., Cermak, J.E. (1995), "National Wind Hazards Reduction Program," Journal of Professional Issues in Engineering Education and Practice, 121(1), p. 41-46.

Kennedy, C. (1999). "Feasibility Study for a Full-Scale Wind Test Facility," Master Thesis, Clemson University, Clemson, SC.

Kareem, A., and Cermak, J.E. (1979). "Wind-Tunnel Simulation of Wind Structure Interactions." ISA Transactions, 18, 23-41.

Kareem, A. (1985). "Structural Performance and Wind Speed-Damage Correlation in Hurricane Alicia." Journal of Structural Engineering, 111(12), 2596-2610.

Leatherman, S.P., Gan Chowdhury, A., Robertson, C. J., (2007). "Wall of Wind FullScale, Destructive Testing of Coastal Houses and Hurricane Damage Mitigation." Journal of Coastal Research, 23 (5), pp. 1211-1217.

Levitan, M.L., Mehta, K.C., (1992a), “Texas Tech Field Experiments for Wind Loads. Part I: Buildings and Pressure Measurement System," Journal of Wind Engineering and Industrial Aerodynamics, 41-44, p. 1565-1576. 
Li, Q.S., and Melbourne, W.H., (1995). "An Experimental Investigation of the Effects of Free-Stream Turbulence on Streamwise Surface Pressures in Separated and Reattaching Flows." J. Wind Eng. Ind.. Aerodyn., 54-55, 313-323.

Li, Y., (2005). "Fragility Methodology for Performance-Based Engineering of WoodFrame Residential Construction," Ph.D. Dissertation, Georgia Institute of Technology, Atlanta, GA.

Liu, R. (2008). "Wall of Wind Flow Characterization and Active Control of Turbulence ," Master Thesis, Florida International University, Miami, FL.

Long, F., Smith, D.A., Zhu, H., and Gilliam, K. (2006). "Uncertainties Associated with the Full-Scale to Wind Tunnel Pressure Coefficient Extrapolation." Texas Tech University Report submitted to National Institute of Standards and Technology (NIST).

Lott, N., \& Ross, T., 2006. "Tracking and Evaluating U.S. Billion Dollar Weather Disasters. 1980-2005.” NOAA National Climatic Data Center, Asheville, N.C.

Mani, S. (1997). "Influence Functions for Evaluating Design Loads on Roof-Truss to Wall Connections in Low-Rise Buildings," M.S. Thesis, Clemson University, Clemson, SC.

Marshall, R.D. (1977). The Measurement of Wind Loads on a Full-Scale Mobile Home. National Bureau of Standards (NBS), Washington DC, NBS Internal Report No. 771289.

Masters, F.J., Reinhold, T.A., Gurley, K.R., and Aponte-Bermudez, L.D. (2005). "InField Measurement and Stochastic-Modeling of Tropical Cyclone Winds." Proc., Fourth European and African Conf. on Wind Eng. (EACWE4), Prague, Czech Republic, Paper 129 (CD-ROM).

NAHB (National Association of Home Builders) Research Center (2002), "Roof Framing Connections in Conventional Residential Construction," Contract No. H-21172CA, p. $1-48$

National Science Board (2007), "Hurricane Warning: The Critical Need for a National Hurricane Research Initiative," Draft Paper for Public Comment, NSB-06-104, p. 127.

Nishi, A., and Miyagi, H. (1995). "Computer-Controlled Wind Tunnel for WindEngineering Applications." J. Wind Eng.. Indust. Aerodyn., 54-55, 493-504.

Plevris, N., and Triantafillou, T. C., "Creep Behavior of FRP-Reinforced Wood Members,” Journal of Structural Engineering, Vol. 121, No. 2, pp. 174-186, 1995. 
Polensek, A., Schimel, B., 1986. "Rotational Restraint of Wood-Stud Wall

Supports," Journal of Structural Engineering, 112(6):1247-1262.

Polensek, A., Schimel, B., 1988. " Analysis of Nonlinear Connection Systems in Wood Dwellings,". Comp. in Civ. Engrg. Volume 2, Issue 4, pp. 365-379

Reed, T. D., Rosowsky, D. V., and Schiff, S. D. (1997). "Uplift capacity of light-frame rafter to top plate connections." Journal of Architectural Engineering, 3(4), 156-163.

Reed, T.D., Rosowsky, D.V., Schiff, S.D. (1996), "Roof Rafter-Top Plate Connection in Coastal Residential Construction," Proceedings: International Wood Engineering Conference, IWEC'96, New Orleans, LA.

Richardson, G.M., Hoxey, R.P., Robertson, A.P., and Short, J.L. (1997), "The Silsoe Structures Building: Comparisons of Pressures Measured at Full Scale and in Two Wind Tunnels," J. Wind Eng. Ind.. Aerodyn., 72, 187-197.

Riley, M.A., Sadek, F. (2003), "Experimental Testing of Roof To Wall Connections in Wood Frame Houses," Technical Report NISTIR 6938, National Institute of Standards and Technology. Gaithersburg, MD.

Rosowsky, D.V., Reed, T.D., Tyner, K.G. (1998), "Establishing Design Values for Uplift Connections in Light-Frame Construction," Journal of Testing and Evaluation, ASTM, 26(4), p. 426-433.

Simiu, E., and Scanlan, R.H. (1996). "Wind Effects on Structures.” Wiley, NY.

Simpson Strong Tie (1999). (www.SimpsonStrongTie.com).

Sparks, P. R. (1990). "Performance of structures in Hurricane Hugo 1989. The Carolinas." NIST Special Publication (796), 445-457.

Three Little Pigs" facility, University of Western Ontario, (http://www.eng.uwo.ca/research/ttlpp/default.htm)

Tascioglu, C., Goodell, B., and Lopez-Anido, R., "Bond Durability Characterization of Preservative Treated Wood and E-glass/phenolic Composite Interfaces," Composites Science and Technology, Vol. 63, pp. 978-991, 2003.

Triantafillou, T. C., "Shear Reinforcement of Wood Using FRP Materials," Journal of Materials in Civil Engineering, Vol. 9, No. 2, pp 65-69, 1997

Yancey, C.W., Cheok, G.S., Sadek, F., Mohraz, B. (1998), "A Summary of the Structural Performance of Single-Family, Wood-Frame Housing," Technical Report NISTIR 6224, National Institute of Standards and Technology. 
Yu, B. (2007), "Surface Mean Flow and Turbulence Structure in Tropical Cyclone Winds," Ph.D. Dissertation, Florida International University, Miami, FL.

Yu, B., Gan Chowdhury, A. (2009). "Gust Factors and Turbulence Intensities for the Tropical Cyclone Environment." Journal of Applied Meteorology and Climatology, 48 (3), pp. 534-552.

Yu, B., Gan Chowdhury, A., Masters, F.J. (2008) "Hurricane Power Spectra, Co-Spectra, and Integral Length Scales.” Boundary Layer Meteorology, 129, pp. 411-430.

Whitbread, R.E. (1980), "The Influence of Shielding on the Wind Forces Experienced by Arrays of Lattice frames," Wind Engineering, Proc. Fifth Intern. Conf., Ft Collins, J.E. Cermak (ed)., Vol. 1, Pergamon Press, NY.

Wind Simulator, University of Florida, (http://news.ufl.edu/2007/08/29/tropical cyclonewind-machine/).

Wolfe, R. W., and McCarthy, M. (1989). "Structural Performance of Light-Frame Roof Assemblies I. Truss Assemblies With High Truss Stiffness Variability." FPL-RP-492, Forest Products Laboratory. 
VITA

IVAN R. CANINO-VAZQUEZ

May 19, 1976

2000-2002

2002

2005-2007

2007

2007-2008

2008-2009
Born, San Juan, Puerto Rico

B.S., Civil and Environmental Engineering

Florida International University

Miami, Florida

M.S., Civil Engineering

Florida International University

Miami, Florida

Graduate Assistant

Construction Research Laboratory

Florida International University

Miami, FL

National Deans List Award

Academic Excellence Commendation

Florida International University

Miami, Florida

Teaching Assistant, CAD Instructor

Florida International University

Miami, Florida

GTA, Excellence in Teaching Award

Graduate Students Association

Florida International University

Miami, Florida

Graduate Research Assistant

Laboratory for Wind Engineering

International Hurricane Research Center

Florida International University

Miami, Florida

Research Assistant, NSF Grant

Florida International University

Miami, Florida 


\title{
PUBLICATIONS AND PRESENTATIONS
}

Ahmad, I., Azhar, S., and Canino, I., (2002) "Causes of Lumps and Balls in High Slump Truck-Mixed Concrete: An Experimental Investigation," Advances in Building Technology, Vol. 1, 2002, p. 671-678.

Canino, I., Masters, F., (2006), Presenter, "Wall of Wind Project"

Latin American and Caribbean Consortium of Engineering Institutions (LACCEI), Universidad de Puerto Rico, Mayaguez, P.R.

\begin{abstract}
Ahmed, S., Canino, I., Gan Chowdhury, A., Mirmiran, A., Suksuwang, N., (2009), "A Study into the Capability of Multiple Mechanical Fasteners in RoofTo-Wall Connections of Timber Residential Buildings," Editorial Manager (tm) for Practice Periodical on Structural Design and Construction, Manuscript Draft.
\end{abstract}

